University of South Florida

DIGITAL COMMONS

@ UNIVERSITY OF SOUTH FLORIDA
Digital Commons @ University of

South Florida

$12-1-2001$

\title{
Assessment of Operational Barriers and Impediments to Transit Use
}

CUTR

Follow this and additional works at: https://digitalcommons.usf.edu/cutr_nctr

\section{Scholar Commons Citation}

CUTR, "Assessment of Operational Barriers and Impediments to Transit Use" (2001). Research Reports. 194.

https://digitalcommons.usf.edu/cutr_nctr/194

This Technical Report is brought to you for free and open access by the National Center for Transit Research (NCTR) Archive (2000-2020) at Digital Commons @ University of South Florida. It has been accepted for inclusion in Research Reports by an authorized administrator of Digital Commons @ University of South Florida. For more information, please contact digitalcommons@usf.edu. 


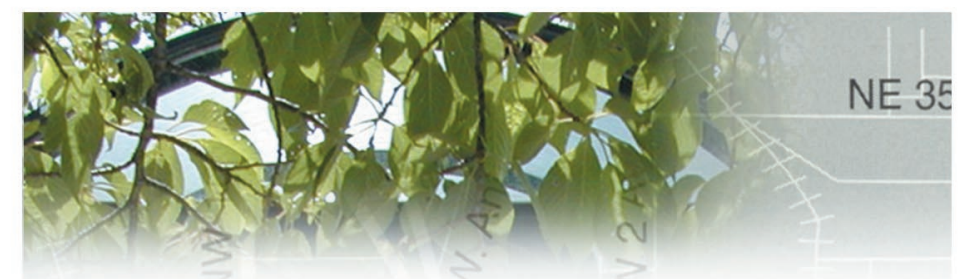

\section{Assessment of Operational Barriers and Impediments to Transit Use: \\ Transit Information and Scheduling for Major Activity Centers}

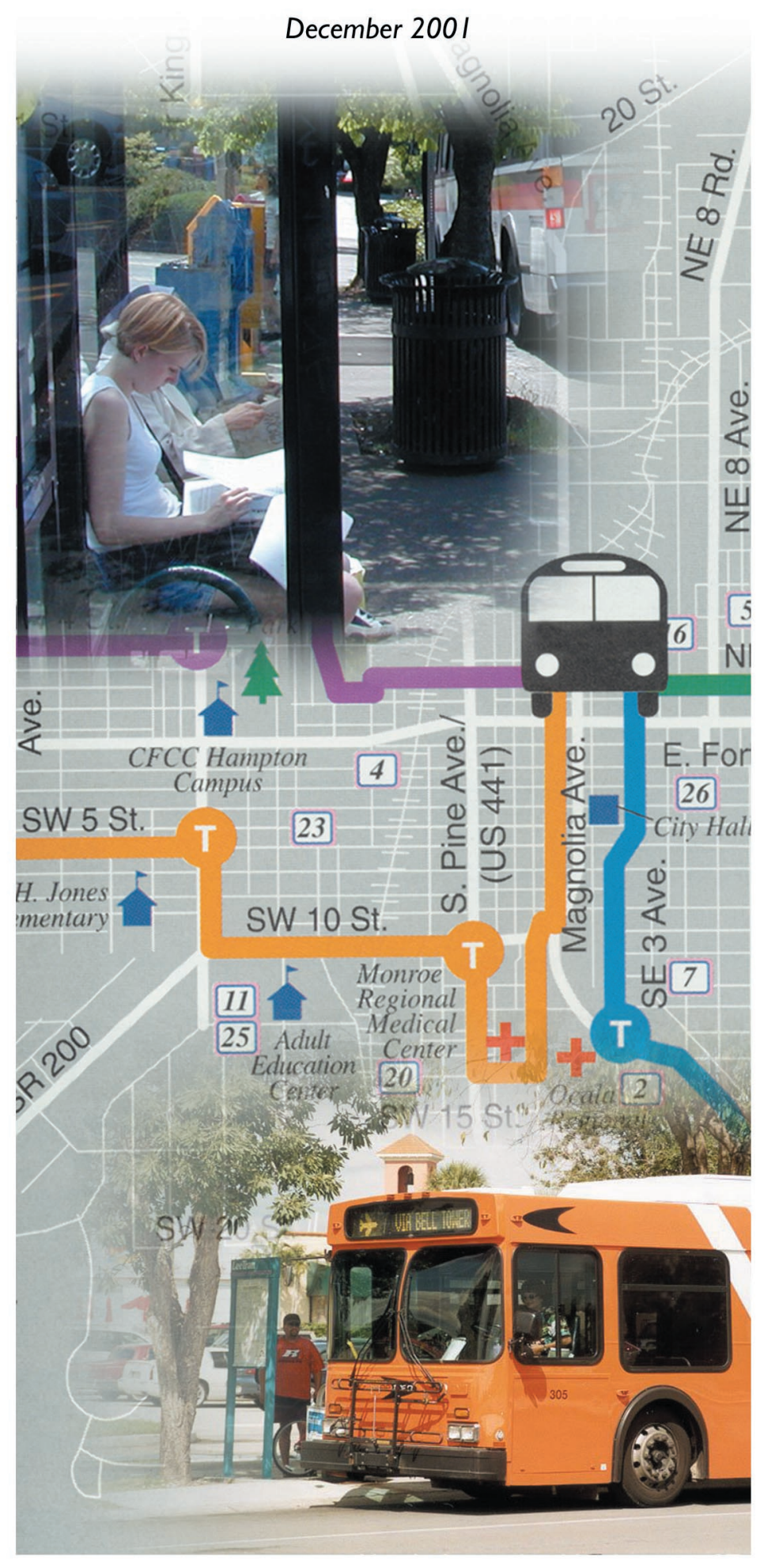




\begin{tabular}{|c|c|c|}
\hline $\begin{array}{l}\text { 1. Report No. } \\
392-11\end{array}$ & 2. Government Accession No. & 3. Recipient's Catalog No. \\
\hline \multirow{2}{*}{\multicolumn{2}{|c|}{$\begin{array}{l}\text { 4. Title and Subtitle } \\
\text { Assessment of Operational Barriers and Impediments to Transit Use: Transit } \\
\text { Information and Scheduling for Major Activity Centers }\end{array}$}} & $\begin{array}{l}\text { 5. Report Date } \\
\text { December } 2001\end{array}$ \\
\hline & & 6. Performing Organization Code \\
\hline $\begin{array}{l}\text { 7. Author(s) } \\
\text { Hardin, Jennifer, Tucker, Lisa, and Calleja }\end{array}$ & AS, Linda & 8. Performing Organization Report No. \\
\hline \multirow{2}{*}{\multicolumn{2}{|c|}{$\begin{array}{l}\text { 9. Performing Organization Name and Address } \\
\text { National Center For Transit Research (NCTR) } \\
\text { University of South Florida CUT } 100 \\
4202 \text { East Fowler Avenue, Tampa, FL } 33620\end{array}$}} & 10. Work Unit No. \\
\hline & & $\begin{array}{l}\text { 11. Contract or Grant No. } \\
\text { DTRS98-G-0032 }\end{array}$ \\
\hline \multirow[t]{2}{*}{$\begin{array}{l}\text { 12. Sponsoring Agency Name and Address } \\
\text { Office of Research and Special Programs } \\
\text { U.S. Department of Transportation } \\
\text { Washington, DC } 20590\end{array}$} & \multirow[t]{2}{*}{$\begin{array}{l}\text { Florida DOT } \\
605 \text { Suwannee } \\
\text { Tallahassee, Florida } 32399\end{array}$} & 13. Type of Report and Period Coverec \\
\hline & & 14. Sponsoring Agency Code \\
\hline
\end{tabular}

15. Supplementary Notes

Supported by a Grant from the USDOT Research and Special Programs Administration, and the Florida Department of Transportation

16. Abstract

The decision to use public transit as a means of alternative transportation is a somewhat complex process. The potential rider must know that a public transportation system is available, how to contact the public transportation system for information on how to use the system for each desired trip, where to go to catch a bus, how to recognize bus stops, which side of the street to stand on to catch a bus going to his destination, how to make transfers, the fare and fare media accepted for each trip, as well as how to read and understand bus system maps and schedules. If the individual must wait for a bus, the final decision to ride may also be impacted by the safety and comfort of the bus stop environment. The on-board experience, which includes passenger comfort and driver courtesy and assistance, will also be important to the rider's overall impression and opinion of public transit. Problems encountered in any of the transit experience elements described above can result in a decision to find alternative means of transport. Many barriers encountered in the transit experience may be rectified by transit agencies with relatively little expense. This project provided a preliminary assessment of the issues or problems encountered by existing and potential transit users in the overall transit experience that may become barriers to using transit. In addition, the project includes detailed analyses of two identified barriers with the potential to be overcome with a feasible level of effort and investment of resources by transit agencies: the user-friendliness of printed transit information materials and the level of transit service provided to major activity centers. Following the analyses, summary recommendations are offered to facilitate the elimination of these two identified barriers to transit use throughout Florida, as well as suggestions for future research.

17. Key Words

Transit Barriers, Bus Schedules, Route Maps, Transit Scheduling, Transit Literacy, Major Activity Centers, NonUsers
18. Distribution Statement

Available to the public through the National Technical Information Service (NTIS), 5285 Port Royal Road, Springfield, VA 22161, (703) 487-4650, and through the NCTR web site at http://www.nctr.usf.edu/
19. Security Classif. (of this report) Unclassified
20. Security Classif. (of this page) Unclassified
21. No. of pages
175 


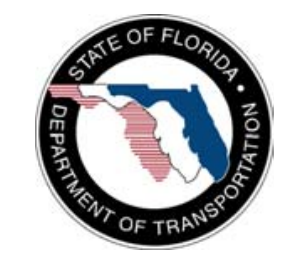

\author{
State of Florida Department of Transportation \\ Public Transit Office \\ 605 Suwannee Street \\ Tallahassee, FL 32399-0450 \\ (850) 414-4500 \\ Project Manager: \\ Tara Bartee \\ Planning Administrator
}

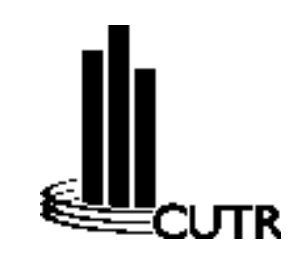

\title{
National Center for Transit Research Center for Urban Transportation Research \\ University of South Florida \\ 4202 E. Fowler Avenue, CUT 100 \\ Tampa, FL 33620-5375
}

(813) $974-3120$

Project Director: $\quad$ Dennis Hinebaugh, Transit Program Director

Project Manager: Jennifer A. Hardin, Research Associate

Project Staff: $\quad$ Lisa Tucker, Research Assistant

Linda Callejas, Research Assistant

The opinions, findings and conclusions expressed in this publication are those of the authors and not necessarily those of the U.S. Department of Transportation or the State of Florida Department of Transportation. 


\section{Introduction}

Currently, there are 22 fixed-route bus transit systems in operation within the state of Florida. These systems operate in a variety of environments, from large, densely populated urban areas such as Miami, Florida, to more rural environments such as those found in Ocala, Florida, and Indian River, Florida. The systems also vary in size, from those operating more than 200 buses to systems operating 1 to 9 vehicles. Despite all of this variation, the 22 fixed-route bus systems in Florida all share a common goal - to increase ridership and enhance community mobility. Increasing transit ridership is a complex task that may involve a multitude of important variables, including many that are actually external to the transit system, such as land use and density (i.e., location and concentration of residences, employment centers, and other commercial/recreational areas), income, and auto ownership rates. The external conditions, while having tremendous impact on ridership, are, in many ways, outside the control of individual transit systems. However, a number of the variables that may affect transit ridership can be influenced by public transit systems. By addressing these variables, transit systems may be able to accomplish the goals of both increasing ridership and enhancing community mobility, even in situations where the external variables mentioned previously are not particularly favorable for transit.

The individual decision to use public transit as a means of personal transportation is a somewhat multifaceted process. The decision requires that potential passengers have knowledge of available transit services, information on how to use the service, as well as information related to the cost and method of payment for the service. Potential passengers will also base their decision to ride on whether or not the transit service travels to the places they would like to go at times that they would like to travel. Individual riders must know where to go to catch a bus, how to recognize bus stops, and perhaps even how to transfer between vehicles. Passengers must also understand bus schedules and route maps in order to plan their trip. The decision to use transit will also be impacted by the level of safety and comfort associated with the bus stop environment, as well as the overall experience on board a transit vehicle. Each of these variables represents a potential barrier to using public transit. If potential passengers experience difficulties related to any of these variables, their decision to use public transit may be reversed. Many of the potential barriers described in relation to the transit experience may be rectified by transit systems with relatively little expense. The objective of the present project is to identify those issues or problems encountered by existing and potential transit users in the overall transit experience that may become barriers to using transit.

This document presents the results of these efforts. This report is divided into two parts with a total of four distinct chapters. Part One is dedicated to the identification of potential barriers to accessing transit experienced faced by non-users. Chapter One contains an extensive review of 
local, state, and national literature pertaining to potential barriers to using transit in the United States. Chapter Two presents the results of a review of the barriers identified by current transit on-board passenger surveys conducted by CUTR for transit systems throughout the state of Florida. The information presented herein is drawn primarily from comparable customer satisfaction data collected from nine transit systems of varying size in Florida. Part Two builds on the identification of potential barriers presented in Part One by selecting two of the potential barriers (transit information and scheduling for major activity centers) for further investigation in the field through various types of observational tests. Chapter Three, the first chapter included in Part Two, examines the potential for printed transit information materials to become a barrier to transit use by presenting the results of field tests designed to measure the understandability and effectiveness of existing printed transit information in Florida. The chapter closes with recommendations offered to improve the user-friendliness and usability of printed transit information materials. Chapter Four focuses on transit scheduling to serve major activity centers. The field tests conducted for this chapter compare transit access to identified major activity centers in 13 communities throughout Florida with the operating hours associated with each activity center and offers recommendations for further assessment of transit scheduling practices. 


\section{Table of Contents}

Introduction

\section{PART ONE: IDENTIFICATION OF POTENTIAL BARRIERS \& IMPEDIMENTS TO TRANSIT USE}

Chapter One: Transit Barriers Literature Review ................................................ 2

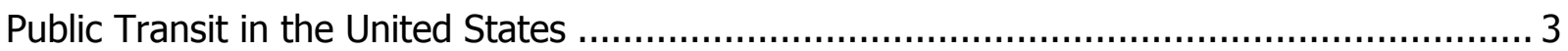

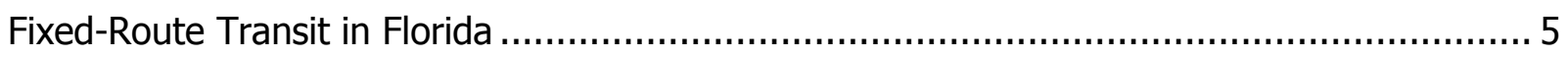

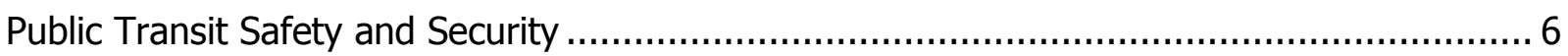

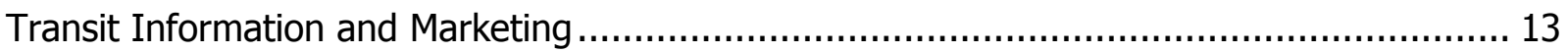

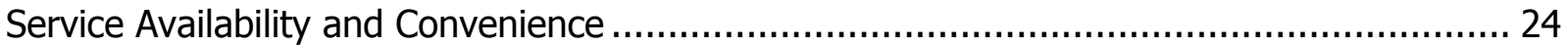

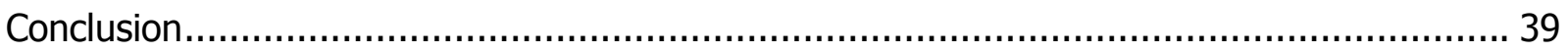

Chapter Two: Florida Transit Customer Satisfaction ........................................... 41

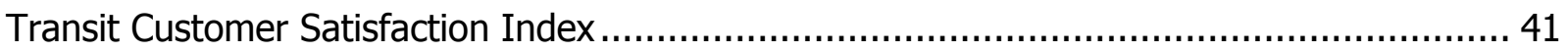

Selected Systems

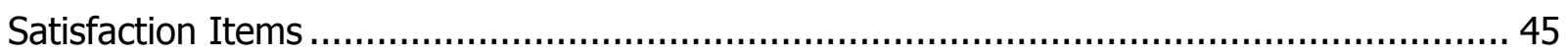

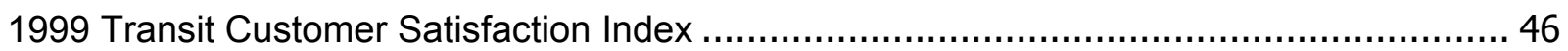

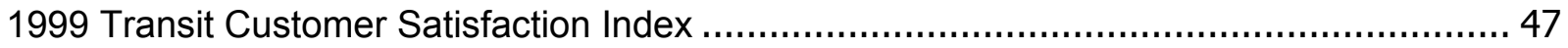

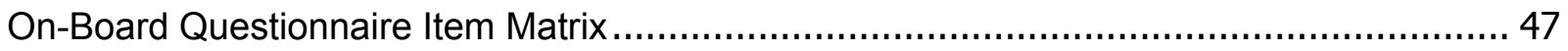

Results

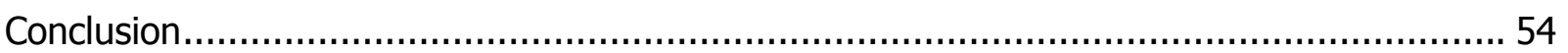

\section{PART TWO: INTRODUCTION TO THE BARRIERS TO TRANSIT USE FIELD TESTS}

Chapter Three: Transit Information \& Marketing: Efficacy Field Test .................... 57

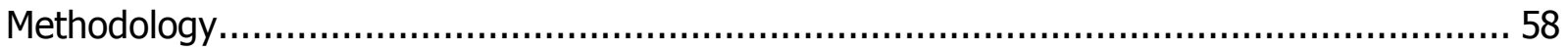

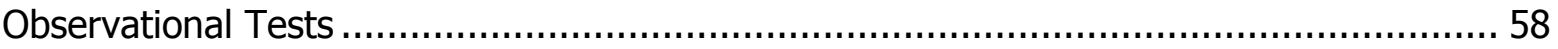

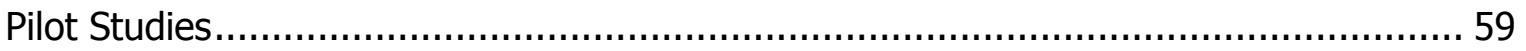

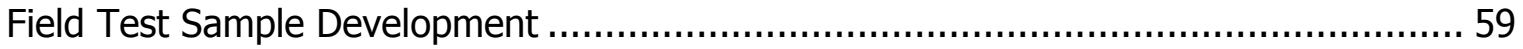

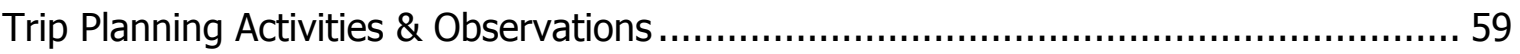

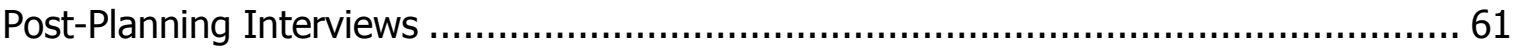

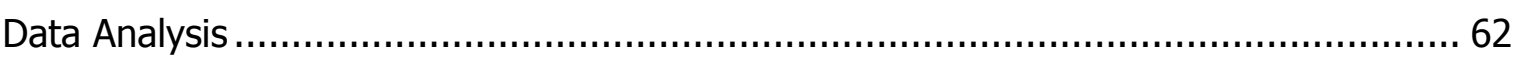

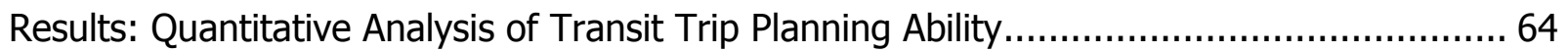

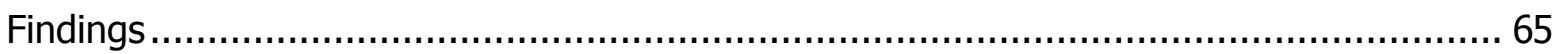

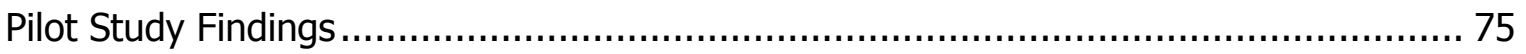

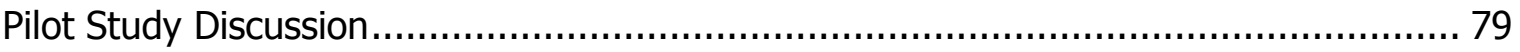

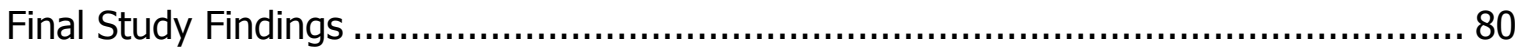


Statistical Analysis

Participants Who Quit One or Both Tasks or Were Unable to Complete in Allotted Time 92 Results: Qualitative Analysis of Participant Interviews .......................................... 95

Participant Reactions to Transit Trip Planning .............................................. 95

Transit Trip Planning - The Frustration Factor .............................................. 96

Positive Responses to Transit Trip Planning .................................................. 97

Difficulties Encountered Using Transit Information Materials .................................. 97

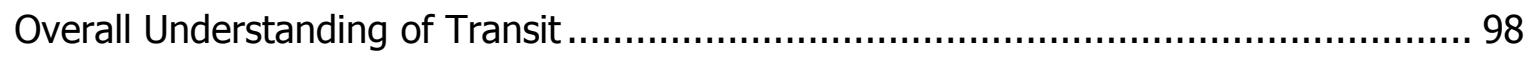

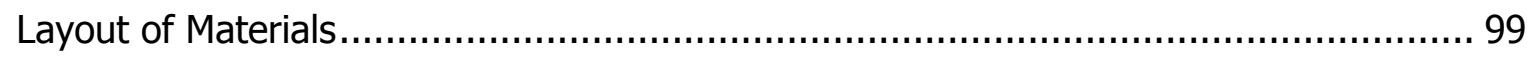

Using System Maps and Individual Route Maps .............................................. 100

Using Timetables................................................................................. 101

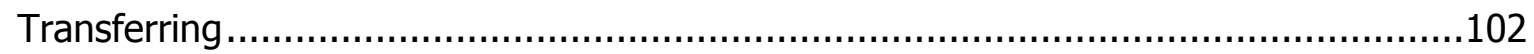

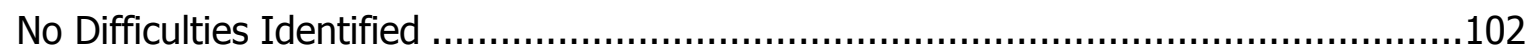

Perceptions of Useful Design Elements: What Worked ........................................ 103

Bus Route Identification: Using System Maps and Route Maps ...............................103

Points of Interest and the Map Legend ......................................................... 104

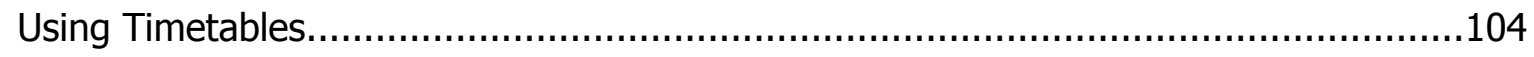

Nothing Was Understandable or Easy .......................................................

Major Findings of the Transit Information and Marketing Field Test ...........................106

Summary of Quantitative Transit Trip Planning Major Findings .................................106

Summary of Participant Interview Major Findings ................................................ 109

Recommendations: Making Transit Information Materials More User-Friendly ..................112

The Big Picture: Transit Knowledge is Not Common Knowledge...............................112

Recommendation 1: Conduct Additional Research on Most Effective Design Elements....114

Recommendation 2: Educate Potential Passengers about Transferring ........................115

Recommendation 3: Help Potential Passengers Use Transit Information Materials .........116

Consistency is Key.............................................................................116

Provide Explanation about the Meaning and Use of Information ..........................117

Materials Should Help Spatially Orient Passengers ...........................................117

Use Contrasting Colors Whenever Possible.....................................................118

Include Map Legends and Points of Interest Information ................................118

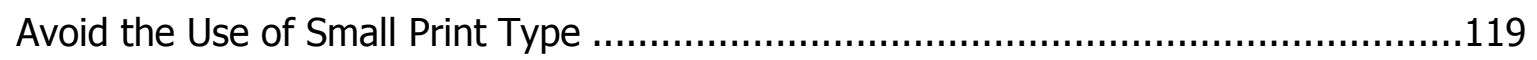

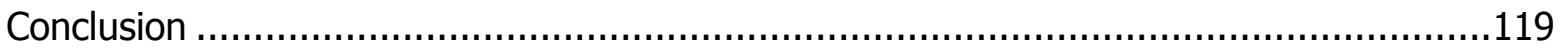

Chapter Four: Transit Scheduling for Major Activity Centers Field Test ................ 121

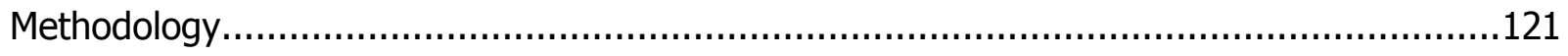

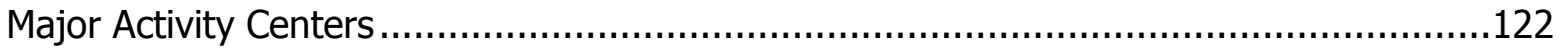

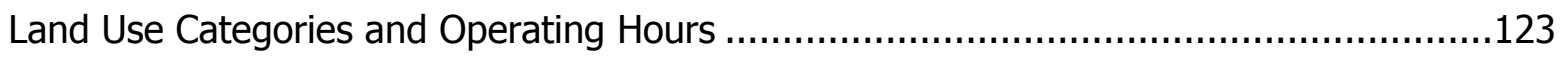

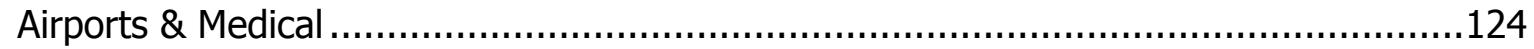

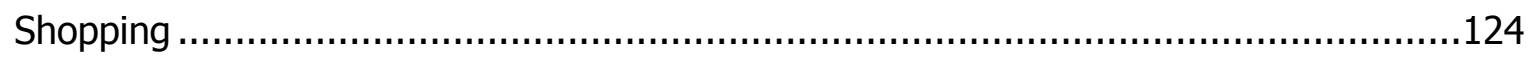

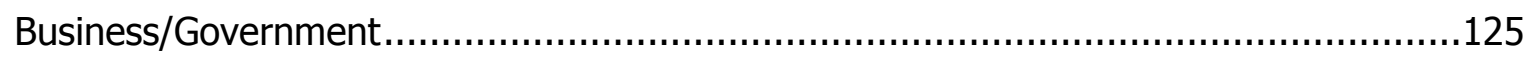




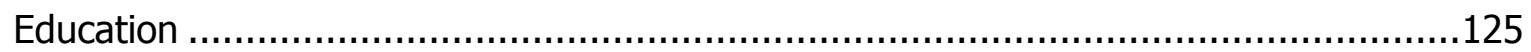

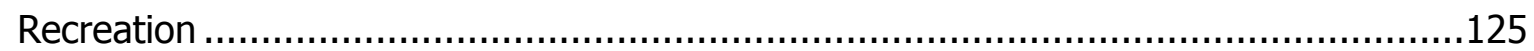

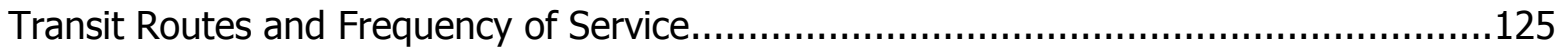

Transit Scheduling for Major Activity Centers Analysis.............................................127

Results: Existing Conditions of Transit Service to Major Activity Centers .........................129

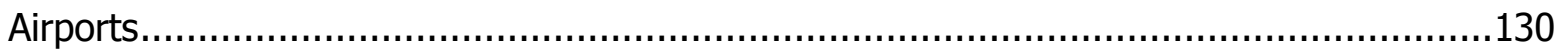

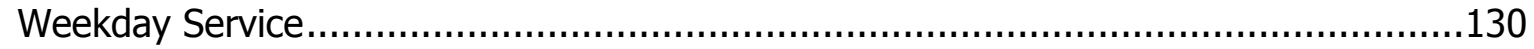

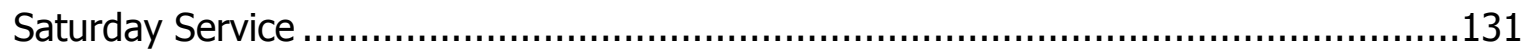

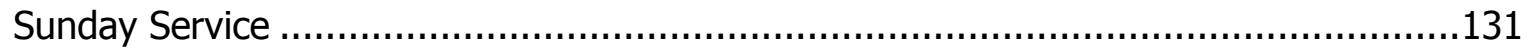

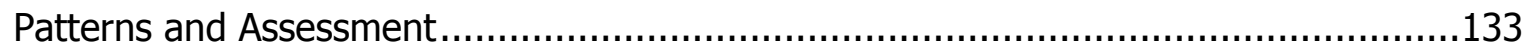

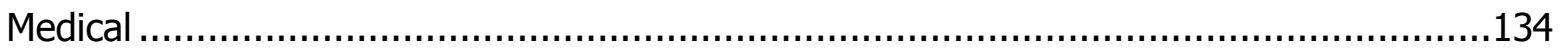

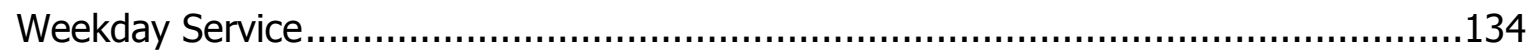

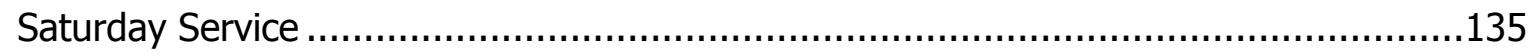

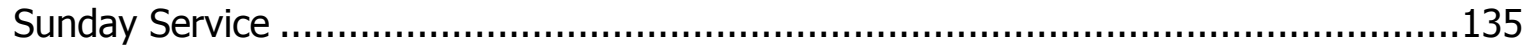

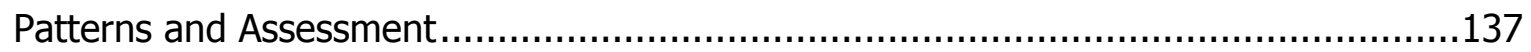

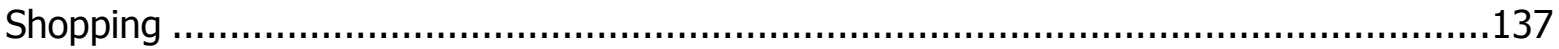

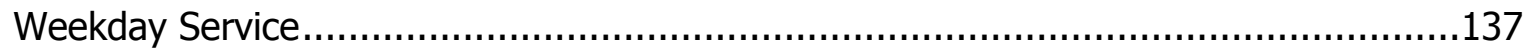

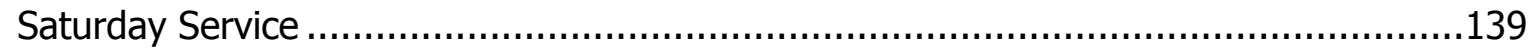

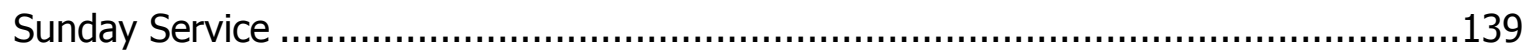

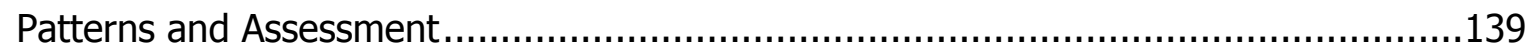

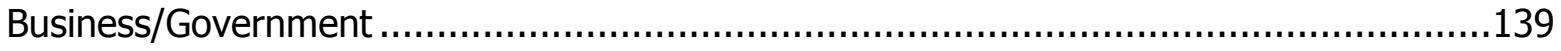

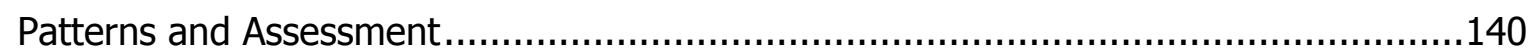

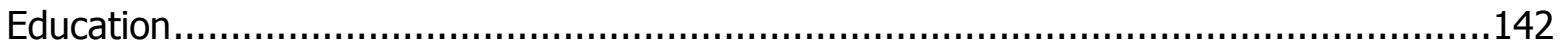

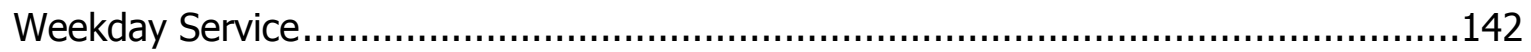

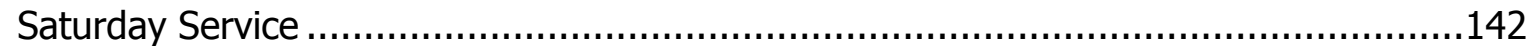

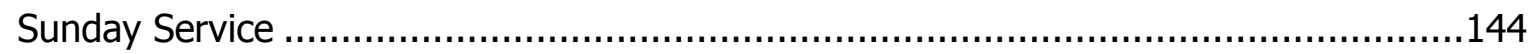

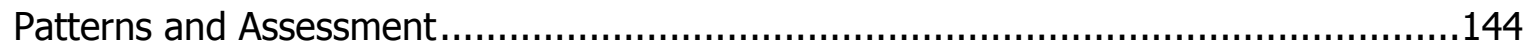

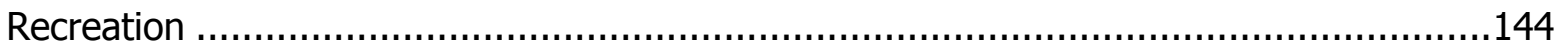

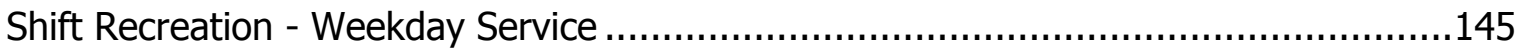

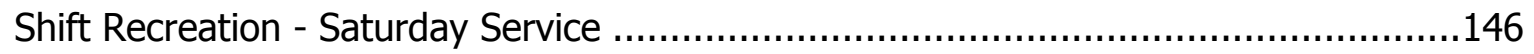

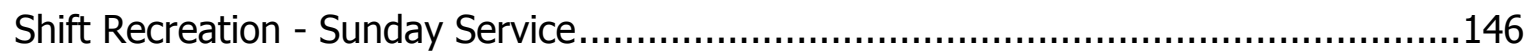

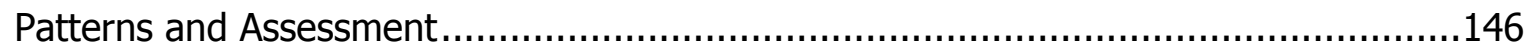

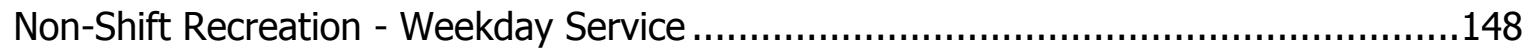

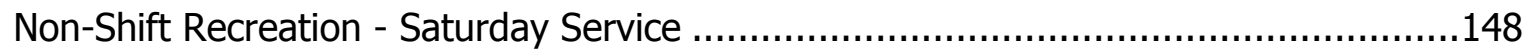

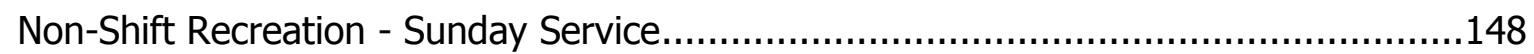

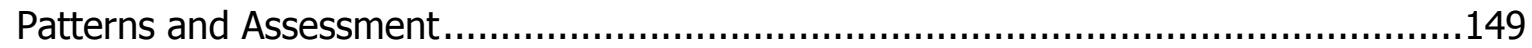

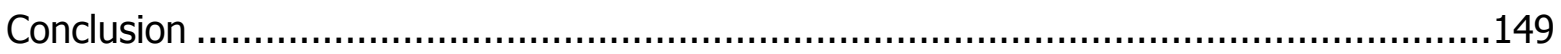

Results: Level of Transit Service Access to Major Activity Centers ….............................151

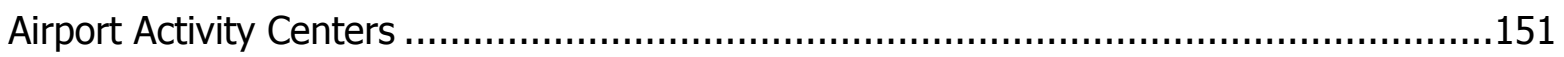

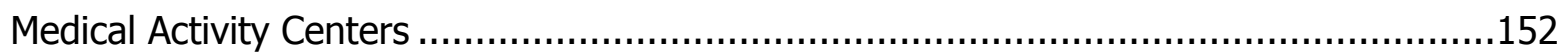


Shopping Activity Centers 153

Business/Government Activity Centers 154

Education Activity Centers 155

Recreation Activity Centers. 156

Major Findings of the Transit Scheduling for Major Activity Centers Field Test 158

Summary of Major Findings - Existing Conditions of Transit Service to Major Activity Centers 158

Summary of Major Findings - Level of Transit Service Access to Major Activity Centers ...160 Recommendations: Transit Scheduling for Major Activity Centers. 164

Recommendation 1: Conduct Assessment of Transit Service Access to Major Transit Attractors. 164

Recommendation 2: Evaluate Scheduling Process and Priorities 165

Recommendation 3: Develop Guidelines for Level of Transit Service Access Standards ..165 Recommendation 4: Assess the "Hub and Spoke" Configuration of Transit Services.......165

Recommendation 5: Consider Increasing Evening Span of Transit Service....................166

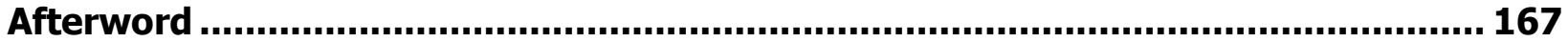

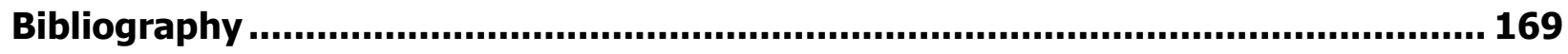

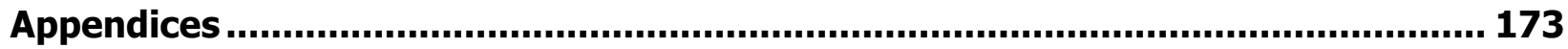




\section{PART ONE: Identification of Potential Barriers \& Impediments to Transit Use}

As noted in the Introduction to this report, the overall transit experience is a multitude of components, any of which could become a potential barrier to transit use. For instance, the overall transit travel time for an individual could be comparable to driving time; however, if that individual has no idea how to contact a transit agency for information, this fact may never be known. Part One draws upon available literature and data to identify as many of the issues and/or problems as possible that are encountered by existing and potential transit users as a basis for identifying barriers to transit use. Preliminary identification of potential barriers to transit use is accomplished through an extensive review of local, state, national, and international research and data, as well as a review of Florida on-board passenger survey data collected from transit systems throughout the state.

The literature review compiles information on barriers that are/were reported to restrict usage among current transit riders, as well as those barriers that inhibit use among the population of potential transit users. All identified barriers are included in the review that follows, without regard to the potential costs associated with the resolution of identified problems. The literature review is supplemented with information on barriers to transit use identified by current transit users in on-board passenger surveys conducted by CUTR for 9 transit systems throughout Florida. These data provide insight into the aspects of existing transit service in Florida that are the least satisfying to current riders and thus, are also potential barriers to transit use among the population of potential riders in Florida.

The results of Part One form the foundation for Part Two of the report, wherein two components of the transit experience identified as barriers are examined in greater detail. Specifically, the overall usefulness of transit information materials as a trip planning tool and scheduling at major activity centers are empirically tested and evaluated. The goal of this report is to provide professionals in the field with specific strategies and recommendations to address these barriers. For the research community, the report is designed to stimulate additional research on transit barriers. 


\section{Chapter One: \\ Transit Barriers Literature Review}

The results of the transit barriers literature review are presented in the following sections. Several extensive literature searches were conducted using the TRIS literature database made available from the Transportation Research Board (TRB) and CUTR's Resource Information Center (CRIC). Every attempt was made to obtain and review the most current literature available. All literature were reviewed for their relevancy to the topic and summarized. The literature reviewed addressed barriers that restrict usage among current transit riders, as well as those barriers that inhibit usage among potential transit patrons. Based on the results of this data collection effort, the results of the review have been synthesized into the three categories of potential barriers to using transit determined to be the most significant - personal safety, transit information and marketing, and service availability and convenience. It should be noted that the literature presented in this review does not include all data reviewed or all categories of potential barriers. Rather, the articles summarized herein were chosen for inclusion in order to represent the range of issues involved with each identified potential barrier. It is also important to note that none of the potential barriers addressed should be considered in a mutually exclusive fashion. Rather, all of the barriers are, in many ways, interconnected. For example, perceptions of personal safety and security are often shaped by such operational characteristics as wait time and overall knowledge of the system. All identified barriers have been considered without regard to potential costs associated with the resolution of each identified barrier. However, the barriers are presented in the literature review in the order of highest priority: those that appear to have the greatest relevance to Florida transit systems and the greatest potential for transit systems to address are presented first.

The review begins with a brief discussion of transit in the United States, based primarily on the document, Americans in Transit: A Profile of Public Transit Passengers, published in 1992 by the American Public Transit Administration. Next, a review of transit in Florida based on National Transit Database (NTD) performance evaluation data collected by CUTR for the completion of the Performance Evaluation of Florida's Public Transit Systems is provided. These overviews are followed by a discussion of potential transit barriers identified through a review of available literature. These data have been organized into the following sections: public transit safety and security, transit information and marketing, and service availability and convenience. As described previously, the potential barriers are presented in rank order: those that appear to be the most likely barriers, according to the literature reviewed and given the nature of Florida's transit systems, are presented first. 


\section{Public Transit in the United States}

In late 1992, the American Public Transit Association (APTA) published a special report written by Jim Linsalata and entitled, Americans in Transit: A Profile of Public Transit Passengers, which explores the socioeconomic characteristics of the transit-riding population in the United States. While the data presented in this report are almost 10 years old, the document remains the most comprehensive study of transit use in the United States. The report describes the "average public transit rider" in terms of gender, age, race, ethnicity, income, and trip purpose, as well as addressing future trends in transit. The ridership data presented in the report were collected from a survey of 136 transit systems of varying size within the United States. APTA reported that the size and diversity of the sample accounted for almost 60 percent of total transit ridership in 1992. U.S. Census data also were used in compiling the rider profiles.

Transit ridership in the United States has been experiencing a period of revitalization. An increase in the number of modes offered, the application of technologies, and the advent of innovative approaches to providing services have contributed to increasing growth of ridership. According the APTA Transit Ridership Report, more than 9 million trips were made on transit systems in 1999. This represents an increase of over 500,000 annual trips since the Americans in Transit report was published (1992).

According to that study, the majority of transit riders were female. In smaller cities, a distinct majority of riders were female. For example, in places with populations of less than one million, females made up approximately 60 percent of transit riders. In some cases, rural transit systems reported that over 75 percent of their riders were female.

At the national level almost seven percent of all transit riders were senior citizens, and smaller cities and rural areas had an even greater percentage of senior riders. In communities with populations of less than 50,000 persons, 18 percent of riders were 65 and older. APTA contends that this high percentage indicates that transit is an indispensable service for seniors for important trip purposes such as medical care, shopping, recreation, and other non-work travel. Further, it was not uncommon to find that many senior citizens in rural areas relied exclusively on transit for their transportation.

Within the U.S. transit market, ethnic and racial minorities were found to be another large and important ridership segment. In areas with populations of one million or more, approximately 49 percent of riders were African-Americans or Hispanic. In contrast, areas with populations of less than 50,000 reported an average of six percent of African-American riders and nine percent of Hispanic riders. Nationwide, 45 percent of riders were White, 31 percent were AfricanAmerican, 18 percent were Hispanic, and 6 percent were considered "Other." 
The study also revealed that minority groups use transit in disproportionate amounts compared to their population shares. African-Americans, Hispanics, and other minorities made up a larger percentage of transit riders in the more populous areas than did Whites. The proportion of White riders in areas with populations less than 50,000 was found to be 82 percent, but in areas with populations between 200,000 and 500,000 persons this share dropped to 48 percent, and Whites made up only 45 percent of transit riders in areas with populations with one million or more. It is also notable that many transit systems serving small cities and rural areas reported a relatively high percentage of Hispanic riders. The APTA report also forecasted an increased demand for transit services in the future, based on the growing non-White population and the fact that Hispanics have the highest birthrate in the United States.

While the 1992 APTA special report forecast that the Americans with Disabilities Act of 1990 (ADA) would result in a dramatic increase in the number of persons with disabilities who have access to public transportation, the author reports that at the time of writing, transit riders with disabilities comprised less than two percent of the total ridership nationally. However, when New York City was excluded, this percentage increased to just less than three percent. The authors also reported that, as the community size decreases, the percentage of riders with disabilities increases. According to the author, it was not uncommon for 10 to 15 percent of the transit riders in smaller areas to have disabilities. Much as with the senior population, people with disabilities often rely solely on public transportation for their mobility.

Transit holds great economic importance in the most populous areas of the country because approximately 70 percent of transit use is related to business and educational activities. More than half of all trips made using public transit in the United States are work trips. The APTA study also reported that approximately 15 percent of transit trips are made for school purposes and the remainder are trips taken for the purposes of shopping, medical, social, and recreation. The study found that trip purposes varied significantly in communities of different sizes. For example, in areas of less than 50,000 persons, almost 61 percent of transit trips were taken for medical, social, and recreational purposes, and 21 percent were for work trips. In those areas with populations of at least one million persons, almost 55 percent of transit trips were taken for work and approximately 15 percent were for medical, social, and recreational purposes.

With respect to income, almost 28 percent of transit riders at the national level have an annual income below $\$ 15,000$. Again, when New York City is excluded, this percentage increases to 38 percent. In areas with a population of less than one million, more than half of transit riders declared an annual income of less than $\$ 15,000$. In areas with populations less than 50,000, more than 61 percent of riders had annual incomes less than $\$ 15,000$. Although there were riders with higher incomes in areas of all population sizes, APTA demonstrates that it is those riders with lower incomes, often with few other transportation alternatives, who constitute the largest market of transit riders in the United States. Nationwide, 28 percent of transit riders 
earn incomes below $\$ 15,000$, but only 17 percent of the general population is in this income category. The author claims that this emphasizes the importance of public transit to lower income populations.

Finally, Linsalata draws several overall conclusions from the aforementioned data on public transit ridership in the United States. First, the results of this study indicate that minorities and low-income workers comprise a large proportion of public transit passengers nationally. Secondly, public transit does serve a very important function in the social system. Specifically, for many population segments, such as women, seniors, people with disabilities, minorities, people with low incomes, and students, public transit is the primary, or sole, means of transportation available to meet travel needs. Thirdly, public transit clearly performs a vital economic role by providing access to employment. The author also contends that the characteristics of transit riders vary from community to community. The average transit user in large urban areas appears to differ significantly from the average rider in rural areas. Finally, Linsalata forecast that transit demand will continue to grow into the $21^{\text {st }}$ century, alongside growth in the overall U.S. population and urbanization.

\section{Fixed-Route Transit in Florida}

The following analysis of the state of fixed-route transit in Florida is based on data collected as part of the FDOT-sponsored research entitled, Performance Evaluation of Florida's Public Transit Systems (1999). The information in this report is compiled from National Transit Database data submitted by the transit properties in Florida. All data presented are FY 1998 data, as this is the most recent, validated information available. While this research does provide excellent data related to the performance of Florida's transit systems, it does not include information on socioeconomic characteristics of transit users in the state. Unfortunately, no comprehensive document is currently available that provides the type of socioeconomic profile of transit riders in the state of Florida that was developed on a national level by APTA in 1992. While it would be possible to compile this information from passenger surveys conducted at the various transit systems, such an analysis is beyond the scope of the present project.

Florida has shown consistent growth in population for more than a decade. At the same time, Florida's commitment to public transit has also grown. Like the population in Florida, the transit systems operating in the state exhibit great variation and diversity. One transit system in South Florida operates more than 200 buses, while 7 systems operate between 1 and 9 buses. The 14 remaining transit systems in the state operate between 10 and 200 buses. Between 1984 and 1998, the state population increased by 467 percent. While federal funding for transit has declined as a percentage of total transit funding from 20 percent in 1984 to 9 percent in 1998, the state of Florida has increased its financial commitment to transit from 1 percent of total 


\section{OPERATIONAL BARRIERS \& IMPEDIMENTS TO TRANSIT USE-}

funding to nearly 12 percent in 1998 . Local financial commitments to transit also remain significant, with local governments contributing more than 51 percent of total transit funding in 1998.

The use of fixed-route transit continues to grow in Florida. Between 1984 and 1998, statewide fixed-route ridership increased by 39 percent. Between 1997 and 1998, ridership increased by nearly 3 percent from 171 million trips to approximately 176 million trips. In addition, total ridership has increased by almost 17 percent since 1992. Since 1984, the amount of service provided, as represented by service miles, by Florida's fixed-route bus and rail systems has increased by 63 percent. This measure has increased by a full 25 percent since 1992 . Although the operating cost per service mile has increased by 58 percent for all modes since 1984 , the costs associated with bus transportation reveal a more positive trend. Between 1984 and 1998, the cost per service mile for bus service increased by only 52 percent, which is a lower rate than inflation during this time period.

Despite the significant commitment to public transit in Florida and the favorable performance of Florida's transit systems, a great deal of mismatch exists between the hopes and expectations for public transportation and the role that these systems have been able to play in community mobility. As Polzin (2000) has noted, although ridership has grown at a rate that approximates population growth in the state, transit has not been able to retain its share of the travel market, as travel growth exceeds population growth. Use of a personal vehicle remains the most popular mode of travel in the state of Florida. According to the 1990 Census, approximately 77 percent of Florida's drivers reported driving alone as their primary means of travel to work. At the same time, traffic congestion in the state is growing at an alarming rate, population is increasing, and the environment is becoming more fragile (Polzin 2000). And while the number of public transit systems available in the state continues to grow, many potential barriers to using these systems exist, which may prevent new users from trying transit and/or inhibit use among current users. These potential barriers are discussed in the sections that follow.

\section{Public Transit Safety and Security}

Concerns related to personal safety are cited within the literature as a deterrent to the public's utilization of mass transit. The Federal Transit Administration (FTA) makes a distinction between transit safety and transit security. Safety refers primarily to programs designed to prevent or mitigate unintentional harm to people using transit. Thus, transit safety addresses issues of vehicle maintenance, alcohol and drug testing, and emergency management. Transit security refers to programs and procedures that are developed and implemented to reduce crime on transit. In the literature, issues of personal safety and the perception of safety are commonly referred to in relation to the reasons that people do not use transit or are anxious 
about using transit. Crime is perhaps most often cited as the primary personal safety issue, and several authors have examined the public's perception of, as well as the realities of, crime on buses and the areas served by buses. The premise held by most researchers is that the perception of crime significantly affects mode choice, and that the perception and degree of affectation vary according to the region and the level of urbanization, as well as individual passenger characteristics.

Reed et al. (1999) have examined passenger attitudes toward crime and crime reduction measures taken by transit authorities in the state of Michigan. Their findings indicate that transit patrons generally hold the following perceptions:

- passengers mostly feel safe when using transit;

- passengers feel less safe traveling after dark than during the day;

- those who use smaller transit agencies feel safer than those traveling in larger systems;

- passengers feel less secure waiting at bus stops than they do when on the bus; and,

- there is dissatisfaction with the limited availability of weekend and nighttime bus service, which could be related to safety if people must walk late at night.

The authors further contend that wait times are indirectly a safety issue because the longer the wait at the bus stop, the higher the perceived level of possible crime.

Of those passengers surveyed, 88 percent claimed that they rarely or never skip or alter their bus trip because of personal safety concerns. However, several of those who made such claims did admit to regularly taking more inconvenient routes to avoid what they perceive to be unsafe areas or "unseemly riders." Of further note, the ratings of perceived safety are lower for females than for males.

The data also revealed that most perceived crime-related experiences are classified as "quality of life" offenses, such as obscene language/verbal abuse, public drunkenness, vandalism, and disorderly conduct. Property crimes and violent crimes are ranked second and third, but poor statistics from law enforcement and transit agencies make accounting for actual incident difficult.

The security improvements most desired by the transit riding public were found to be emergency phones at bus stops and increased lighting at bus stops. Further, Reed et al. (1999) assert that there should be improvements in frequency and timeliness of buses so that wait times at bus stops are lessened. Based upon this study, the authors conclude that the greater is one's perceived exposure to crimes, the greater the appreciation of transit crime prevention measures. 
It should be noted that this survey was conducted among those who already utilize transit services rather than the general public. Therefore, no conclusions can be drawn from this study in relation to the effect of transit-related crime perceptions on non-transit users.

According to Ingalls et al. (1994), although most transit crime studies are focused upon large urban centers, smaller areas also have safety issues with which they must contend. This study considers Greensboro, North Carolina, as a typical mid-sized southern city and examines the role of the public's fear of crime in relation to use of the city's transit system.

Similar to the studies conducted in Michigan (Reed et al. 1999), safety is cited as one reason for not using the bus in Greensboro; however, both residents in areas where bus service is available and bus riders considered crime to be a citywide problem, rather than a transit issue. In fact, the bus system was generally perceived as being safer than the community as a whole. However, the authors note that many areas served by the transit system, such as Downtown Greensboro, were considered to be unsafe by users and nonusers.

The authors also note that one's level of experience with the transit system appears to have an effect upon feelings of personal safety. Those residents who do not utilize the bus system, but live in proximity to bus service, were found to be two to five times more concerned about personal safety on the buses than were those classified as riders. The public perception of crime is, therefore, not necessarily based upon firsthand experience. For those who do have personal experience with transit-related crime, the two primary problems reported were obscene language/disorderly conduct and public drunkenness.

This study also found that non-user residents were two to three times more likely than transit riders to take precautionary measures for their personal safety. More than 80 percent of nonuser residents claimed to avoid drunk or "strange-looking" people. In addition, more than half of these respondents avoid groups of teenagers, traveling after dark, and traveling alone. Transit riders also reported the tendency to avoid traveling after dark and "strange-looking" people. Women were found to be more likely to take precautionary measures than were men.

In addition to concerns related to transit crime, those factors cited as deterrents to riding the bus include, in order of importance:

- having a car;

- inconvenience;

- no need for using a bus;

- unavailability of bus service near the home;

- lack of information about buses; and, 
- time inefficiency.

Although Ingalls et al. (1994) found that fear for personal safety does affect bus ridership at some level in Greensboro, all of the factors listed above, when considered together, resulted in the authors' contention that the availability of basic service and information may be more important than personal safety for the focus of policy makers.

Benjamin and Hartgen (1994) give further consideration of perceptions of public transit safety in Greensboro, North Carolina. This research provides an assessment of public perception of crime and the actual incidence of crimes on buses in the Greensboro area. Studies to determine public perceptions of safety included surveys of residents along the bus system routes, surveys of bus riders, and bus operator surveys. This research indicated that almost one-half of the residents surveyed perceived crime on transit to be a problem, including a general fear of transit and/or the downtown area. Conversely, passengers and drivers indicated little or no serious or violent crime on buses. However, offenses such as obscene language and disorderly conduct were considered problems by both of these groups.

At the request of the authors, the Greensboro Police Department produced a report on the offenses that occurred on or near public transit in the preceding year. The authors' analysis of this report indicated that the "true" level of transit-related crime is actually lower than the perceived level of crime. However, the authors report that there is a low confidence level in the statistics reported by the police department because locations are typically identified by intersections, making it difficult to determine crimes that occurred "near" transit routes or stops.

Experience again appears to be a determining factor in the public perception of crime on transit. Passengers and bus drivers each have a more positive view of personal safety on and near transit than do resident non-users. These differences were cross-tabulated by race and gender and, although varied by proportion of responses, these variables were not found to be statistically significant in the explanation of the perception of crime. However, women were noted to be generally more cautious than men.

The authors also questioned resident non-users regarding how a variety of service changes, safety actions, and other improvements might affect ridership. The results indicated that, although safety related measures might lead to substantial ridership increases, the most effective ways to increase ridership actually related directly to service frequency, bus stop locations, and schedule information. The responses to the question regarding the one thing that should be done to encourage non-users to utilize the bus system are listed below in rank order:

- nothing; 
- change location of routes/stops/extensions;

- improve frequency/schedule;

- provide information, telephone, maps, publicity;

- offer free service for cultural events;

- provide better mass transit;

- provide disabled/medical and services;

- make service more convenient/easier;

- lack of car;

- reduce cost of riding/fares; and,

- improve bus stops (benches, shelters, etc).

Benjamin and Hartgen (1994) recommended the following safety-related measures to increase ridership on the bus system in Greensboro:

- create environments on/near transit that provide the perception of safety;

- implement campaign to educate the public about the safety of public transit; and,

- implement economic incentives and system performance levels that will entice people to experience the level of safety on transit firsthand.

Wallace et al. (1999) conducted a study of the public's perceived safety of transit following safety enhancements in Ann Arbor, Michigan. The safety improvements implemented by the Ann Arbor Transportation Authority included the following programs and equipment:

- comprehensive new driver and refresher training related to safety and security;

- formal review and evaluation of accidents and incidents;

- security cameras at the two transit centers;

- security lighting at the two transit centers;

- security phones at the two transit centers;

- police mini-station at the primary downtown transit center; and,

- a security station located at the secondary downtown transit center and maintained by student security officers from a local university.

The authors conducted a survey of transit riders following these improvements to determine the visibility of each component among the transit riding population. Several factors were revealed that might relate to the perception of safety on city buses, including age, sex, and ridership patterns. With regard to age, approximately 45 percent of the riders surveyed were between the ages of 18 and 35, while only seven percent were over the age of 65 . The authors found that each 10-year increase in age was associated with a 12 percent lower probability of noticing the phones and security cameras that had been installed in the transit centers. 


\section{OPERATIONAL BARRIERS \& IMPEDIMENTS TO TRANSIT USE}

In general, women felt less safe than did men, but also were more likely to notice security precautions that were undertaken by the transit authority, specifically increased lighting. Thirty-three percent of female respondents reported taking note of the increased lighting in transit centers.

Although not explicitly stated, the authors noted that income might be a factor in ridership patterns and even in perceptions of safety. Thirty-five percent of the respondents reported a household income of less than $\$ 15,000$ and another 30 percent declared a household income between $\$ 15,000$ and $\$ 30,000$. Only 5.7 percent reported a household income of more than $\$ 75,000$. The authors noted that the higher the income of respondents, the less likely they were to notice increased police, increased lighting, and security cameras.

Those measures that were found to be most effective in promoting perceptions of safety were a stronger police presence and increased lighting. Emergency phones and video cameras also were cited as having a positive effect on feelings of safety. Further, the authors hypothesized that the more often passengers use transit, the higher the perception of transit safety.

Loukaitou-Sideris and Liggett (2000) provide information about how the physical environment at and near transit bus stops can impact the level of perceived and actual passenger safety. The authors discuss bus stop crime in Los Angeles in terms of how the surrounding physical environment of the bus stop contributes to the transit crime rate. The concentration of bus stop crime in Los Angeles occurs at specific stops within a 13-square mile area of the city and the authors contend that there is a significant spatial concentration of crime within the downtown and inner city region. Buses along these routes serve some of the poorest and most neglected, crime-ridden areas of the city, and it is the authors' assertion that this surrounding environment directly affects transit ridership and passengers' perception of personal safety while they wait for the bus.

Loukaitou-Sideris and Liggett (2000) claim that it is "astonishing" that bus stops within a small area along the same route could have such varying crime rates. While some stops seem immune to crime, others are consistently "hot spots" of criminal activity. The authors cite criminological research and their own observations as evidence that environmental attributes around the bus stop can play a vital role in the stop's safety and susceptibility to crime.

The authors examined the physical and social environments of the 10 most dangerous bus stops in Los Angeles in 1994 and 1995, which were determined from data obtained from transit police. Next, they conducted a survey among 212 riders waiting at the 10 bus stops and found that almost one-third of the respondents had been victims of crime on the bus or at the bus stop within the previous five years. In addition, one-half of those surveyed claimed to feel 
unsafe and "always on guard" at the bus stop. These unsafe feelings were more prominent among women than among men.

Loukaitou-Sideris and Liggett's data indicate that most crimes occur in isolated situations where there are numerous hiding places and escape paths for potential criminals, such as alleys and empty lots. Of the 10 bus stops that were studied, none were found to have any of the elements that would mark the bus stop as "defensible:"

- all were located in seedy and litter-filled commercial areas;

- the surrounding environment was derelict and forbidding;

- most stops were not visible from surrounding shops and lacked adequate lighting;

- many of the stops were next to empty lots and vacant, dilapidated buildings; and,

- the desolate settings lacked either formal or informal surveillance.

Further, the authors found evidence to support criminologists' contention that specific land uses are more likely to generate, or at least allow, crime than others. These negative land uses surrounding the 10 bus stops include:

- bars and liquor stores located close to eight of the 10 stops;

- check-cashing facilities and pawn shops were located near high-crime bus stops; and

- "hot sheet" motels and adult bookstores and theaters also were common.

To understand how particular features of the physical environment relate to bus stop crime the authors also studied 60 high- and low-crime bus stops in Downtown Los Angeles. They examined the urban-form characteristics of the surrounding area, the bus stop characteristics, and the street characteristics. Their analysis of these data led the authors to conclude that certain urban-form and bus stop characteristics seem compatible with crime. For example, crime rates were higher at bus stops in areas with alleys and mid-block passages, near multifamily housing, liquor stores, check-cashing facilities, vacant buildings, and buildings marked by graffiti and litter. They determined that check-cashing establishments near bus stops have the strongest correlation with higher crime rates, followed by the presence of alleys.

With regard to street characteristics, Loukaitou-Sideris and Liggett found that intersections with on-street parking have higher crime rates and those with heavy vehicular traffic are associated with lower crime rates. Those factors that positively affect the rates of crime are good visibility from the surrounding establishments and the presence of bus shelters. The authors conclude that their data provide evidence that environmental attributes affect crime at bus stops and that it is the "microenvironments that matter." 
The authors assert that, because bus stops are not permanently fixed, they may be moved up or down a street in accordance with passenger safety and the surrounding environment. Further, the general upkeep and cleanliness of the immediate public environment of the bus stop indicates to transit passengers that "someone cares." Loukaitou-Sideris and Liggett also suggest the retrofit of bus stops with shelters and lighting to make the passenger's wait more comfortable, less anxious, and safer. They also contend that transit agencies must recognize that bus stops are part of the overall transit system, and that agencies should focus their resources on the safety of their riders through the improvement and maintenance of the bus stop environment.

\section{Transit Information and Marketing}

Transit information and marketing represent two of the most fundamental means of "getting the word out" to the transit public. However, they are also often two of the least successful areas involved in transit operations. The completion of a transit trip is dependent on a passenger having enough knowledge and information to know that the service exists, where the service travels, where and how to catch a bus, what time the bus arrives and departs, and where to disembark. Without any piece of this information, the trip may not be made or, if it is made, may be accompanied by anxiety and frustration on the part of the passenger. Therefore, it is critical that transit passengers have access to easily available, up-to-date, and user-friendly transit information. This information also needs to provide geographic information to passengers that will assist in orientation and illustrate how to make transfers or connections. In addition, transit information should be prepared in such a way as to be understood by customers from a wide variety of demographic, socioeconomic, and/or educational backgrounds. As the following discussion illustrates, the lack of user-friendly, reliable, and readily available transit information continues to pose a significant barrier to transit use in the United States.

Everett et al. (1977) examined the effectiveness of transit pamphlets as a means of disseminating information about public transit systems. These authors acknowledge the importance of quality information systems and recognize that transit information "could certainly be one of the salient determinants of attracting riders to the system and/or increasing the effective use of the route network by existing riders."

According to Everett et al. (1977), there has not been adequate study of what passengers perceive to be quality information systems. They contend that studies have focused upon existing information systems or merely upon those that transit officials believe to be appropriate. The authors assert that passenger insight is crucial to the improvement of 
information services, and cite previous studies as examples that have sought the consumer's opinion.

From 1964 to 1969, a telephone survey was conducted in Washington, D.C., regarding transit information. The respondents were asked how they would navigate from one location to another; how they would obtain further information about transit within the city; and what type of bus information they would like that was not being provided at that time. The results of this survey led to new bus stop markers, bus route indicators, and timetable folders. Despite these improvements, survey respondents did not make fewer errors in trip planning or feel the need for less transit information following the additions. Furthermore, there was no noticeable effect on ridership.

Everett et al. also described the results of a study completed by Liff (1971). This research is cited as another attempt to make transit improvements based upon public needs. Although this research also found that improvements in information systems did not necessarily affect ridership, other information was gathered from this study that may assist transit professionals in designing transit information. As cited by Everett et al. (1977), Liff discovered that relatively equal numbers of people preferred to obtain their transit information via the telephone, transit map, asking bus drivers or ticket agents, or asking friends/relatives. Very few people reported asking strangers on or near the bus for transit information.

This study also reported consumer preferences for transit information. These results are listed below in rank order:

- information on what route to take;

- information as to what station to disembark;

- information about headways;

- location of stops;

- time of arrival at destination; and,

- information on crowding in transit vehicles.

In addition, preferences related to transit information aids were found to be the following, in rank order:

- electronic route finder at transit station;

- telephone information;

- transit information sign;

- bus drivers;

- information booths;

- pocket schedules; 
- computer information at home; and,

- folding transit map.

It is notable that, although the folding transit map was the least preferred information aid, it is the one most commonly used.

The final study cited by the authors was based upon information obtained through an Urban Mass Transit Association (UMTA) study (1969) in several areas of Mexico, Canada, the United States, and Europe. The preferred information aids reported in this study, in rank order, were the following:

- pocket schedule;

- telephone information;

- bus stop information;

- other people at the bus stop;

- fold-out map;

- electronic route finder;

- bus driver; and,

- sign on the front of the bus.

The focus of the article by Everett et al. (1977) is those attributes of information aids that would serve to increase the accuracy of transit trip planning and trip-making. The authors are specifically concerned with route and system schedules and maps that are distributed to passengers by transit authorities. The authors found there to be considerable variability in the effectiveness of printed schedule information, both in terms of an individual's trip-making ability and the pamphlet's ease of use and adequacy, which may therefore affect the likelihood of a consumer to make a trip via transit.

A high degree of uncertainty or unpredictability in planning a transit trip also was implied through a lab experiment conducted by Everett et al. (1977). The subjects in the study were asked to plan a trip using pamphlets from various transit systems. The overall inability of the group to answer basic questions led the authors to conclude that the uncertainty involved in trip planning may serve as an important deterrent to the utilization of mass transit systems. The authors found that neither previous bus-riding experience nor the past use of route information was related to an individual's performance in the trip-making experiment. The information found to be most effective were single-route pamphlets, produced in two colors, with features such as bus stops clearly designated. The authors contend that such a study should be replicated in a field setting for comparative purposes and in order to draw further conclusions regarding the efficacy of pamphlets in trip planning. 
Abdel-Aty et al. (1996) present the results of a study designed to determine the propensity of commuters to utilize public transit in Santa Clara and Sacramento Counties in northern California. The authors conducted a telephone survey to determine users' levels of satisfaction with the transit system and with the information that was available. Non-transit users were questioned about their familiarity with transit, what types of information they would need to use transit, and their likelihood to do so.

Of the five percent of respondents who used transit at least once in the two weeks prior to the survey, 25 percent did so because a car was not available every day, and 15 percent used transit because they wanted to save money. Approximately 72 percent of the transit users surveyed reported being either satisfied or very satisfied with the transit information. With regard to specific items, 22 percent of surveyed transit users considered transit route maps as the most important, and 16 percent ranked information about waiting times the most important of information items. Those factors considered least among users were fare, walking time to transit stop, and seat availability.

Among surveyed non-transit users, approximately 41 percent indicated that the frequency of transit service was one of the most important information items. Waiting times at transit stops, transit route maps, and operating hours were considered important, as well. A small percentage declared walking time to transit stops, park-and-ride, and seat availability to be important elements of information. It is worth noting that 38 percent of non-transit users surveyed indicated that they might consider using transit if more information was available to them, and almost one-half stated that they were extremely likely to use transit if this condition was met.

Those socioeconomic characteristics affecting the propensity to use transit, as identified by Abdel-Aty et al. (1996), were found to be the following:

- women were found to be less likely to use transit, possibly because of safety concerns;

- those over 70 years of age were more likely to use transit if information was available;

- automobile owners were less likely to use transit; and

- those with lower incomes were more likely to use transit than those with high incomes.

Furthermore, the association between income and mode choice was found to be statistically significant. Approximately 53 percent of the respondents in this survey earned annual incomes of less than $\$ 30,000$, and 25 percent had incomes between $\$ 30,000$ and $\$ 50,000$. 
Abdel-Aty et al. (1996) also determined that those commuters who do not use transit but already receive traffic reports are among those most likely to utilize transit information when it is available, thereby potentially increasing their transit use. Despite these findings, the authors assert that their study was not designed to determine the effects of an integrated system that provided both transit and traffic information. However, they contend that "it would not be unrealistic in cases of substantial delays" for more drivers to obtain information on commute estimates and utilize the transit system.

According to Abdel-Aty and Jovanis' (1995) research, there is a paucity of studies relating transit information systems to travel behavior and mode choice. The effect of intelligent transportation systems (ITS) on public transit use is the topic of this article. Research was conducted in northern California to gather data about travel habits and public perceptions of transit.

Transit users were asked to rank the three aspects of transit information that most needed improvement. Twenty-two percent of respondents chose transit route map changes and 16 percent selected information on wait times. Those items least selected by the respondents were fare information, walking time to the transit stop, and seat availability.

In the attempt to assess the likelihood of automobile driving commuters to utilize public transit when provided with the necessary information, Abdel-Aty and Jovanis (1995) developed a model to measure these propensities. Their results show that travelers with longer distances are less likely to consider public transportation as an option. Factors that were noted to increase the likelihood of commuters using transit were income (earning less than $\$ 30,000$ annually); having one car in the household; and age (those under 20 years of age were more likely to consider using the transit system). It was found that drivers who already receive traffic information were likely to choose transit at least once per week, when given adequate transit information. Of the non-transit users who previously declared that they would use transit if adequate information was provided, approximately 49 percent indicated they would choose transit when they were provided a hypothetical customized scenario.

Based on their findings, Abdel-Aty and Jovanis (1995) contend that, if ITS were implemented to provide transit information, the number of commuters utilizing public transit could possibly be tripled. The following improvements were cited as having great potential in affecting commuter mode choice:

- electronic displays of actual bus and train arrival times;

- computerized maps and travel directions; and,

- real-time information on current delays and estimated travel times on alternate routes and competing modes. 
Southworth (1996) contends that, because of the diversity of transit users, the form of public transit information is just as important as the content of transit information. The author reports that too frequently information systems are difficult to use and often ignore the special needs of non-English speakers, children, the elderly, those who are not familiar with the area, the illiterate, the vision-impaired, the hearing-impaired, and those who are disabled in some other way. Transit information systems must be designed to accommodate the many groups who use transit if the benefits of the system are to be fully realized and if the public is to be adequately served.

Due to varying levels of English proficiency and prose, document, and quantitative literacy, transit information, in its typical format, may serve to overwhelm, rather than inform, potential transit users. Southworth asserts that the information should be presented in a palatable way to minimal literacy levels and diverse language backgrounds.

These considerations led Southworth to promote the use of electronic methods of communication in transit information centers because computer systems are able to provide an individually tailored plan of travel based on the user's needs. The author recommends the following design guidelines to achieve a successful transit information system:

- several levels of on-screen help for different skill levels;

- interactive systems that allow users to make specific requests;

- maps and aerial views denoting the organization of streets and paths;

- maps with recognizable images of landmarks;

- sequentially arranged walk-through images of routes with an overview of the environment; and,

- graphically-presented route information accompanied by written and spoken descriptions of the route.

Whelan (1988) contends that automated vehicle location and control (AVLC) technology is a superior method of schedule information to printed materials or other automated scheduling systems. This assertion is based on OC Transpo (Ottawa, Canada) customer perceptions of what constitutes good service and the timeliness and level of detail that automated vehicle locator information can provide in comparison to these other methods.

Based on the total calls to an automated telephone information system called Telerider, and a live telephone call center, Whelan determined that approximately 58 percent of callers to the Telerider system and 7 in 10 callers to the center were actually seeking "assurance" rather than hard schedule information. Common perceptions of transit customers included: 
- there are frequent changes in service;

- there are frequent bus delays and schedule changes; and,

- the information provided is superior to the predictions made at the time of schedule printing.

Whelan states that these views indicate the level of confidence transit customers have regarding the Ottawa system.

When asked what type of information they would most like to see at a bus stop, transit users overwhelmingly responded that schedule information at the bus stop would be their preference. This could be achieved through combining AVLC with Telidon (videotex) technology so that changes in service are updated as they are determined and are displayed immediately at the bus stops.

Bakr and Robinson (1978) call for better application of the transit-marketing concept through the broadening of marketing ideas and the integrating of strategies in order to meet the needs of transit users. The authors contend that the success of a transit system is contingent upon adequate and appropriate bus stop signage. Further, assessing the public's preferences for information is essential to creating effective signage. According to their survey, Bakr and Robinson (1978) determined the most important elements of bus sign information to be the following:

- route number;

- hours of service;

- waiting time for the bus;

- route name and schedule;

- type of service; and,

- route map.

In the analysis of the study results, a substantial relationship between commuter and trip characteristics and the importance of the various components of transit information was revealed. The authors speculate as to the value of customizing travel information, designing it to appeal to various groups who travel along particular routes or segments of routes. Bakr and Robinson do admit, however, that there is a risk of "abridging uniformity" if such customized signage were implemented, which may result in confusion on the part of the general transitriding public.

Those effects considered on the value of bus stop sign information included commuters' education, ethnicity, sex, age, trip purpose, and transfer. Level of education was shown to affect commuters' rated importance of travel information. In general, there was a decline in the 
need for bus stop sign information with increased levels of education. The authors conclude that it is likely that the more educated commuter is less interested in sign information and turns to "more convenient sources" such as the telephone, direct inquiry of bus operators, or fellow commuters.

With regard to the effect of ethnicity on preferences for bus stop sign information, AfricanAmericans rated sign information of greater importance, while American Indians rated it less important than any other group. In addition, African-Americans and Spanish-speaking Americans considered waiting time information more important than information related to service hours.

The level of importance of different aspects of bus stop sign information was found to differ between the sexes. Route number, route name, type of service, hours of service, and route schedule information were all rated higher in importance among females than they were among males. According to the authors, "the value of sign information also increases with age."

The purpose of the commuter's trip has a significant effect on the importance of bus stop sign information. The importance of sign information is highest among those who use the bus for shopping or for multiple purposes. It is lowest in importance for those who utilize the bus for school, followed by those who use it for social and recreational purposes. Information related to service hours typically was found to be more important to those who would need bus service in the evening or early morning hours.

Transfers also seem to have an effect on the importance of bus stop sign information. In this study, those who normally transferred buses during their trips consistently ranked the elements of bus stop sign information higher than those commuters who did not transfer. The authors, therefore, suggest that transfer points may require "special treatment" in sign design.

Through surveys of rural public transportation managers, directors of area agencies on aging, and elderly residents in the state of Iowa, Foster et al. (1996) determined that there are several barriers that may prevent or restrict the rural elderly from using transit. Transit managers and agency directors cited information barriers as the most likely reason that the elderly in rural areas do not take advantage of the transit services that are available to them. A survey of the elderly residents in rural Iowa confirmed this assumption, with almost one half claiming to be unaware that there was a transit system available in their area.

In addition to the lack of information, other elements of concern were discovered through the survey. A large proportion of the elders indicated dissatisfaction with transit scheduling, booking, and ease of use. Forty-one percent stated that transit was limiting in that they may not necessarily be able to make desired trips at times when they would like to travel. The 
advance reservation requirement was cited by 27 percent as a problem in using the system. Twenty-two percent also reported difficulty in boarding the transit vehicles.

According to Foster et al. (1996), the rural elderly in Iowa may not use the available transit system because of the idea that the system is not intended for them or that others are more in need of the services. To test this hypothesis, the authors posited several trip-making scenarios to elderly transit users and non-users. Their answers revealed that most of those using transit disagreed that others were more in need of the system or that they would prefer to pay someone to drive them rather than use transit. The non-users were more likely to have no opinion on these topics, revealing more of a neutral attitude toward transit rather than the negative stance that is often presumed.

A study described by Winters et al. (1991) examines how the provision of transit information affects the decision of ridesharing program participants' choice to use transit. This study was conducted in the Richmond, Virginia, area to determine the effectiveness of providing public transit information to those registered with Ridefinders, the local ridesharing organization. The purpose of the study was to provide data that would complement information sources used by Ridefinders and the Greater Richmond Transit Company (GRTC).

The following data were gathered to assist in analyzing the market potential of Ridefinders transit information for the area served by the GRTC:

- 33 percent of Ridefinders' customers lived within the area served by GRTC;

- 19 percent of those who lived and worked in the service area worked in the central business district of Richmond;

- 57 percent of Ridefinders' customers worked in the downtown area;

- 25 percent of Ridefinders' customers who worked downtown used the bus for work trips; and,

- regardless of where they lived or worked, eight percent of Ridefinders' customers were already using the bus for work trips when they registered with Ridefinders.

In addition, travel and demographic characteristics were compiled so that Ridefinders' customers and GRTC peak-time customers could be compared. The authors' analysis revealed that the two groups differed in several ways. First, the customers who were registered with Ridefinders were almost equally split between women and men. The GRTC had a larger percentage of female patrons (approximately 68 percent) than they did male patrons (approximately 33 percent). Ridefinders' customers also held more white-collar jobs than did GRTC peak-time customers, and they lived in households with higher incomes. Ridefinders' customers also had a higher degree of automobile ownership (87 percent versus 66 percent of GRTC patrons). 
With regard to determining the information that is most effective in encouraging Ridefinders' customers to utilize the transit services of the GRTC, the authors considered the following in their analysis:

- $\quad$ the GRTC phone number;

- a detailed route map for the nearest route;

- a general description of the nearest route;

- the name of the nearest route;

- travel time;

- frequency of service; and,

- schedule.

However, Winters et al. (1991) concluded that the level of transit schedule information provided to Ridefinders' customers was insignificant in generating calls to GRTC or an increase in the use of GRTC's services. This conclusion resulted from the finding that only 10 percent of the respondents increased their perceived value rating between the GRTC phone number (the lowest rated piece of transit information) and the name of the nearest route with time schedule (the highest rated). Furthermore, providing more detailed information to Ridefinders' customers on ride match lists was found to be unlikely to generate an increase in calls to GRTC or use of its services.

Rather, those factors that were found to affect the decision whether to use GRTC, in order of importance, included:

- $\quad$ service availability;

- reasonable fare;

- courtesy of driver;

- comfort; and,

- other.

It should be noted that the majority of those who cited service availability as the primary factor in decision-making lived in areas that were not served by GRTC at the time of the survey.

Finally, a study completed by Texas Transportation Institute and NuStats (1999) for the Transportation Research Board serves as a guidebook for those who are designing information for the transit user. The guidebook includes, among other things, a compilation of principles for designing effective passenger information services. Rather than focusing on high-tech approaches to passenger information delivery systems, the guidebook is concerned with traditional transit information media (i.e., schedules, maps, and signage). 
In order to begin the process of creating adequate information sources, the authors present three sequential steps of "how people navigate." Knowledge of this psychological process can assist planners in developing the most effective method of information transmission for the transit user. This process involves:

- orientation via landmarks;

- development of route knowledge to travel between those landmarks; and,

- a survey knowledge of the transit system.

Transit information must be user-friendly and should convey the adequate elements of information that will assist the rider in successfully planning and completing a trip. According to the authors, these elements include geography, connections with other routes and systems, operations, and rules. Furthermore, information should be available to the passenger at every stage of a trip. Pre-trip information allows the rider to accurately plan his or her routes and connections. The authors state that pre-trip information should consist of the following:

- location of the nearest bus stop;

- routes that travel to the desired destination and transfer locations;

- fares; and,

- time of departure and approximate duration of the trip.

In-transit information represents the second stage of information availability. While in the process of using transit, these data will assist the rider at each decision point during the trip. The authors suggest that the following in-transit information should be provided at various points during the trip:

- at departure point-identification of the correct bus to board;

- on the bus-identification of the bus stops for transfers or disembarking;

- at transfer points-how to transfer to another route; the cost, time limits, and restrictions involved; and identification of the correct bus to board; and,

- at the destination-area geography (i.e., location of the final destination in relation to the bus stop) and return trip information (e.g., departure times and changes in route numbers).

Finally, supportive/confirming information should be provided to the transit user at any point during the trip when the rider may want to be reassured that he or she is progressing successfully to the desired destination. According to the authors, repeated information at points throughout the trip provides the rider with this confirmation. 


\section{Service Availability and Convenience}

The final areas addressed by this review are issues related to the availability and convenience of transit service. These areas include such considerations as system coverage, frequency of service, days and hours of service, wait times, and the need for transfers. When considering issues of availability and convenience, it is important to consider the two primary categories of transit ridership: "captive" riders (traditional customers) and "choice" users (potential customers). As discussed by Pratt et al. (2000), a person is considered to be a "captive" transit rider if she or he has few transportation alternatives other than public transit. When discussing the category of "captive" transit riders, it is often assumed that these persons do not have access to a personal automobile and, therefore, must use transit. These riders are contrasted with "choice" riders, people who have a personal vehicle available and are able to make a clear choice between the automobile and transit. Changes to transit service may have the result of improving service for "captive" riders or serve to attract additional "choice" riders. The articles discussed below represent some of the most salient issues related to the availability and convenience of transit service.

The role of wait times, comfort, and convenience as factors in mode choice are considered by Algers et al. (1975) for service in Stockholm, Sweden. According to the authors, most previous studies focused upon time-savings and estimates of time and cost elasticities. The roles of comfort and convenience in mode choice were considered important, but they were rarely incorporated as policy-oriented variables in economic models. The authors also suggest that socio-psychological studies have revealed that comfort and convenience do serve as determinants in decision making when travelers evaluate alternative means of travel.

Citing Gustafson, Curd, and Golob (1971), Algers et al. (1975) discuss those factors that are considered to be more important than fares in determining mode choice in Stockholm:

- vehicle arriving when planned;

- having a seat;

- no transfer trip required;

- calling without delay;

- having shelters at pickup;

- less waiting time; and,

- choosing pickup time.

In an attempt to determine the perceived service quality (PSQ) of public transportation in Gothenburg, Sweden, 200 complaints and more than 200 reports of negative critical incidents (NCIs) were analyzed by Friman et al. (1998). The authors found that most complaints related 
to employee behavior, punctuality, missing or inaccurate information, and inadequate planning. Passenger concerns from the complaints and from on-board interviews include:

- treatment and action (uncomfortable driving, unsafe driving, driver failed to stop, bad treatment by other employee);

- $\quad$ punctuality (early departure, late departure, cancelled trip without notice);

- information (arrival and departure times [including delays], destination, tickets and their validity);

- technical malfunctioning (vehicle, equipment);

- vehicle design and space (crowding, discomfort, embarking and disembarking);

- traffic planning (fare structure, scheduling); and,

- other (retailer, injury, bus stop).

The findings of Friman et al. (1998) indicate that most complaints and NCIs took issue with employee behavior, reliability of service, and insufficient information; however, the design and available space of the vehicles is also important.

Through a survey conducted in 17 urban areas, Mierzejewski and Ball (1990) confirmed that the major reason commuters are not utilizing the public transportation systems that are available in these areas is the "comparative attractiveness of the automobile." Those who reside in the suburbs are even more dependent upon their cars than those who live in the central city, although both groups rely on private cars as their primary means of transportation.

Respondents who were non-transit users were asked about their perceptions of the advantages of driving their own car. Forty-two percent cited schedule flexibility as an advantage, and 32 percent perceived a travel time savings. Twenty-two percent claimed they could not use public transportation for their daily commute because the transit system does not reach their place of employment. When asked about the advantages of public transit the most common answer was "no advantage." Despite this, other answers about the benefits of transit included lower cost than driving, congestion reduction, and no parking issues.

Those who reside in the central city and in the suburbs and travel to the city for work declared travel time to be the primary disadvantage to using public transportation. The second most commonly cited disadvantage was schedule inflexibility. However, those who travel to work in the suburbs reported schedule inflexibility to be the major disadvantage, and travel time was the second most cited obstacle to using public transportation.

When presented with a list of nine possible improvements, approximately 50 percent of drivers claimed they would not switch to public transportation even if these improvements were made. Suggested service improvements, such as elimination of transfers and express transit service, 
drew a more favorable response. Also, when presented with the possibility of minivan service at half-hour headways with pick-up/discharge points within a block of the destination, approximately 50 percent declared they would utilize such a service.

An in-home survey was conducted in the Atlanta area to determine if there were significant differences with regard to characteristics, attitudes, and perceptions about transit between users and non-users of the Metropolitan Atlanta Rapid Transit Authority (MARTA) (Byrd 1976). The issues of greatest concern revealed through the survey are presented as follows:

- more than 25 percent of non-users claimed to be very likely or somewhat likely to use the transit system if service were "sufficiently improved;"

- 9 out of 10 non-users and 99 percent of users believed that MARTA was necessary or valuable to the city;

- non-users generally held a favorable view of the quality of service;

- transit was considered less convenient by non-users than by regular users;

- both transit users and non-users believed transit to be more convenient for shopping or personal business trips than for trips to work;

- despite a widely-publicized campaign prior to the survey, only 55 percent of nonusers knew the correct, reduced fare when asked; 45 percent either stated an incorrect fare or declined to answer; and

- users and non-users cited greater frequency of bus service as the most needed improvement, and bus shelters were second.

Byrd (1976) contends that non-users may be attracted to transit if there was a positive change in the perception of convenience; however, there are limitations to this approach since 30 percent of non-users indicated that transit was very convenient or somewhat convenient in the in-home survey. Those improvements considered most significant in gaining new transit riders and raising the level of service to current patrons include:

- greater frequency of service;

- bus shelters;

- schedule reliability; and,

- schedule information.

Fielding et al. (1976) conducted six studies to examine the nature of public attitudes regarding transit. The studies focused on trip purpose, trip frequency, and demographic characteristics of the area. Fielding et al. (1976) recount their conclusions from these studies in summary form:

- cars are widely considered more satisfactory than public transit; 
- mode choice is determined by reliability, time, cost, method of payment, and physical and psychological comfort;

- those factors crucial to making transit more appealing to non-users include better transit accessibility, more frequent scheduling, demand-responsive routing, and lower cost;

- those factors crucial to making transit more appealing to users include maintaining schedules, decreasing distances between origins and routes and routes and destinations, and reducing trip-time expenditure;

- speed and punctuality are less important for nonwork trips than they are for work trips; other conveniences are important for both; and,

- the importance of transit attributes varies according to the survey instrument used, geographic location of the sample, and existing public transportation use.

Scheduling and frequency changes are some of the most common service changes made by transit systems in order to improve effectiveness of service and increase ridership. Pratt (2000), in the Transit Cooperative Research Program (TCRP) Traveler Response to Transportation System Changes Interim Handbook - Project B-12, addresses the effects of transit scheduling and frequency on transit ridership. The author examines the responses of riders to scheduling changes that have been applied to conventional fixed-route bus and rail service. The scheduling changes addressed in the report include frequency of service changes, changes to hours of service, the structure of schedules, and scheduling reliability.

Transit systems commonly institute such changes to service in order to decrease passenger trip time and increase overall convenience of the transit service, as well as passenger perception of service quality. In addition, schedule and frequency changes may also improve passenger comprehension of the system and make it easier for passengers to use transit. Also important are improving reliability of transit service and reducing wait times so that passengers experience less anxiety related to using transit. Pratt concludes that, ultimately, the result of schedule and frequency changes that accomplish the above mentioned objectives will be transit service that is attractive to potential users, thus increasing ridership and reducing the amount of automobile travel.

According to Pratt's conclusions, the highest priority concerns that have been consistently expressed by transit riders relate to the dependability of service and the frequency of transit service in the midday and evening. As would be expected, the effect of dependability of transit service is particularly acute - riders are much more sensitive to unpredictable delays of service than to predictable delays. Ridership is often negatively impacted when riders are uncertain about when and if the next scheduled vehicle will arrive. Pratt also found that departure times that are easy to remember and schedules that are readily available often result in improved user perceptions of wait times, especially in areas with low or medium frequency transit service. 
Finally, Pratt also found that ridership is particularly sensitive to frequency changes in areas that previously offered infrequent service (i.e., hourly or half-hourly) and in areas serving middle- to upper-income groups. Again, frequency changes are also related to wait times in that, by increasing the frequency of service, wait times are reduced and transit service is viewed as more attractive by potential "choice" users.

Robert Cervero (1997) addresses the issue of tracking regional accessibility, the ability to reach places across a region, as central to the goal of urban and transportation planners. According to Cervero, accessibility improvements should not be focused on the transportation system but on people, places, and social activities because people engage in travel only to reach a destination, not for the sake of travel itself.

Cervero (1997) conducted a study in the San Francisco Bay Area in which changes in regional accessibility to jobs between 1980 and 1990 were traced and used to determine whether these changes could assist in long-range transportation and land use planning. The author discovered that the area's more centralized neighborhoods were three to four times more accessible to jobs than those neighborhoods on the periphery. Also, despite increasing suburbanization, disparities increased during the 1980s. The most job-accessible areas had the greatest gains in accessibility, and those neighborhoods that were already the least jobaccessible experienced the greatest losses. In addition, wealthier neighborhoods were generally more accessible to jobs for which their residents were qualified than were poorer areas. According to Cervero (1997), accounting for all variables, income and race were strongly associated with accessibility. Cervero (1997) contends that utilizing accessibility as a performance measure, and keeping track of such data, will assist transportation planners in their tasks of making destinations easier to reach.

Loukaitou-Sideris (1994) traces the development and decline of downtown and inner-city transit corridors, with particular attention to those within the City of Los Angeles. The author asserts that many central transit corridors within Los Angeles are "unfriendly to transit" due to the lack of pedestrians, landscaping, benches, and bus stops. However, despite these shortcomings, these areas are still the primary transit routes in the city.

According to a survey conducted by the author, up to one-third of the respondents did not own a car and were, therefore, dependent upon transit, which served an "often hostile corridor environment." The majority of the respondents who did own cars stated that they would utilize transit if the system were more reliable, clean, and safe. Further, the car owners cited a more amiable environment surrounding the bus stops as an incentive to use transit. 
Loukaitou-Sideris (1994) contends that, although transit agencies do attempt to increase their ridership through such traditional means as lowering fares and improving frequency and reliability of service, transit officials must also consider the environment of waiting for a bus. They must attempt to make the streets "friendly" to pedestrians, thereby making those areas friendly to transit and transit users. The author concludes that the physical and economic retrofit of city transit corridors should be a priority for transit agencies in their attempts to attract and retain transit users.

In a report prepared for the Transit Cooperative Research Program (Report 27), Charles River Associates discusses the market share held by transit and examines the policies that have been found to affect transit use. Based on 1990 United States Census data, the authors assert that transit ridership levels are heavily dependent upon development densities and are, therefore, highest in urban centers with dense development. Further, the authors contend that transit ridership is influenced by the following factors:

- levels of travel-inducing activities;

- price and other characteristics of the service;

- availability and comparison of other transportation options;

- characteristics of the population served; and,

- other factors, such as variation in the weather and changes in public taste.

Using both revealed and stated transit preferences, the authors cite several generalizations related to traveler behavior:

- travel times are relatively important;

- not all time savings are equal;

- travel prices do influence consumer choices;

- demand is usually inelastic with respect to price; and,

- aspects of "comfort" and "convenience" that are quantified usually prove to be very important.

Although most mode choices are based primarily on lifestyle choices, the authors contend that public policies greatly affect individual travelers' decisions regarding transportation. The policies cited by the authors as being the most significant in mode choice included transportation investment policies, transportation pricing policies, environmental policies, energy policies, tax policies, and land use policies.

The authors conclude that, even with large improvements in service and public policies, transit most likely still will have a lower market share than private automobiles due to the perception of greater convenience and the low cost of automobiles. Further research should, therefore, 
focus upon strategies that directly influence the attributes of private vehicle travel and serve to make transit a more attractive transportation alternative (e.g., parking pricing).

TCRP Report 55 (Urbitran Associates 1999) addresses the dramatic impact of suburban development on the transit industry in the United States. The report presents guidelines for improving suburban mobility utilizing public transit. With the expansion of suburban development in the United States, transit's market share declined from 6.4 percent in 1980 to 5.3 percent in 1990 . Improving suburban mobility is particularly challenging considering that land use and settlement patterns are very different in suburban areas as compared to central cities: suburban environments contain multiple centers, lower densities, and multiple origin/destination pairs.

Three waves of suburban development have occurred that, according to the authors, resulted in a dependence upon the private automobile rather than public transit in these areas. The first, during the middle part of the 1900s, was the migration to the suburbs of middle- and upperincome households in search of more living space. This was followed by the relocation of retail businesses to the suburbs, positioning themselves closer to their clientele. The third wave of development was the decentralization of the job market from urban centers.

While average suburban residential and employment densities are much lower now than in previous decades, trip origins and destinations are also farther apart, contributing to the convenience of the private automobile. The suburban environment now has multiple center areas and multiple origin/destination pairs. According to the authors, suburban development patterns have provided transit planners with the following challenges:

- extremely low densities;

- dispersed trip patterns;

- abundant free parking; and,

- inhospitable walking environments.

In addition, buildings are set farther back from roadways, requiring more deviations from primary routes. The authors also explain that, because suburban areas have several uses, travel peaks occur at different times throughout the day, thereby creating the necessity of different route patterns and configurations throughout the day. Coordination among various parties also becomes an issue because there are frequently several agencies involved in the provision of transit services in suburban areas.

The attributes that contribute to the dominance of the private automobile are an important consideration in transportation planning, and are a particular concern in the initial stages of developing suburban transit service. The authors have identified the following elements of 
consumer appeal that must be assessed when offering mobility alternatives to the private automobile:

- directness and comparative travel time;

- comfort and service quality;

- scheduling for convenience (e.g., flexibility, minimized transferring, connectivity);

- pricing, including overall cost and simplification of payments; and,

- market coverage.

The authors contend that, without major investment in transit and policy changes toward transit-oriented suburban development, public transit will never achieve the usage level found in most central cities. The authors suggest that planning be based upon market segments, as no single service will be able to meet the full range of needs of suburban residents. Based on their own case study research, the authors present the common features of successful strategies, which include:

- develop services around focal points;

- operate along moderately dense suburban corridors;

- connect land-use mixes that consist of all-day trip generators;

- serve transit's more traditional markets such as lower income, blue-collar neighborhoods within the suburb;

- link suburban transit services, especially local circulators and shuttles, to the broader regional line-haul network;

- target markets appropriately;

- economize on expenses;

- adapt vehicle fleets to customer demand;

- creatively adapt transit service practices to the landscape;

- obtain private sector support;

- plan with the community;

- establish realistic goals, objectives, and standards; and,

- develop supportive policies, plans, and regulations.

The authors assert that suburban transit planners are faced with significant challenges, but that with appropriate planning, policy, and market focus, appealing transit options can be offered to the suburban, private automobile user.

Evans et al. (1997) are interested in enhancing the representation of transit accessibility and amenities in travel forecasting models. They present the transit friendliness factor (TFF), a method of rating transit access environments in travel forecasting models. The elements of transit friendliness that were selected for evaluation were sidewalks, street crossings, transit 
amenities, and proximity of destinations. Sidewalks were chosen because they affect transit attractiveness due to their importance as walking paths to access transit stops. The authors assert that roadways without curbs, shoulders, or sidewalks are the most hostile to pedestrians, and that few people will choose to travel by transit in these areas because of this fact. Conversely, wide sidewalks provide a level of comfort to transit patrons.

The difficulty of reaching transit stops due to street crossings also affects the attractiveness of transit. The authors identify the following factors of street crossings that may be negative elements, and offer suggestions for their mitigation:

- Facility width - wide facilities require larger gaps in traffic because they take longer to cross;

- through-traffic speed - high-speed traffic requires larger gaps than slower traffic to accommodate a pedestrian's crossing;

- turning traffic speed - pedestrians may become confused in areas where free-flowing or multiple lanes are in use; and,

- type of traffic control device - controls on all approaches to an intersection will assist pedestrians in making street crossings.

According to Evans et al. (1997), the least friendly element of street crossings for pedestrians is the location of transit stops along wide, free-flowing facilities that have no pedestrian crossing signals. The authors suggest transit stops that are located along low-speed facilities that are "easy-to-cross."

With regard to transit amenities, the authors promote the construction of transit "superstops," where other activities besides waiting for a bus would occur. In-vehicle time and out-of-vehicle time are differentiated in planning models, and patrons tend to place greater disutility on outof-vehicle wait time. To combat this, the physical environment of the waiting area should include construction amenities such as concrete pads, benches or seats, shelter, and lighting. Service amenities define how the time is actually spent and could include the presence of telephones, newspaper bins, and vending machines.

The proximity of one's destination certainly affects the choice to use transit. Because the distance a business is located from a transit stop tends to influence the rate of which its employees use transit, the authors conclude that it is logical to state that transit use at any particular stop is affected by the proximity of potential origins and destinations. With regard to the TFF, walking through parking lots to remote sites is the least desirable, and a cluster of activities near the stop (50-150 feet) is most desirable. 
Rosenbloom (1998), in TCRP Report 28, addresses the combination of complex industrial, demographic, and land use changes in the United States that have served to dramatically decrease transit usage throughout the country, even among patrons who have traditionally utilized transit systems. This study focuses on communities that have expanded their transit markets or even found new ones by focusing on user needs and their travel patterns. Based on this research, 11 groups, relatively independent of income or density of the metropolitan areas in which they lived, were identified as more likely than average to use transit for commute trips to work:

- workers with low incomes;

- workers with no household cars;

- workers with a college education;

- African-Americans;

- Hispanics;

- workers with graduate school experience;

- workers age 17 to 29 ;

- women;

- Asians;

- immigrants who have been in the United States less than ten years; and,

- workers with mobility or work limitations.

However, Rosenbloom found that even within these 11 groups were different markets, leading to the conclusion that it would be unlikely that all groups could be well served by the same services, routes, schedules, and marketing approaches.

According to Rosenbloom, there are five identifiable societal trends that affect current as well as emerging transit markets, typically to the detriment of public transportation. These five trends include those related to economics, demographics, land use, policy, and social trends. Rosenbloom (1998) notes that most of these factors work against transit use and actually detract potential and current patrons from utilizing transit systems.

Rosenbloom describes that these trends have created new and different travel patterns that are not well served by traditional transit. Today's varying schedules and destinations create the necessity for transit services that are targeted to the individual traveler's needs. Rosenbloom contends that, to ensure success, transit systems must recognize these factors and meet the requirements of their existing and potential markets by focusing on particular service concepts for the individual traveler. 
The first service concept Rosenbloom (1998) discusses is faster or more direct transit for the traveler. According to the author, transit systems must generally do one of the following to achieve this successfully:

- give priority to transit vehicles;

- significantly reduce the number of stops made by a transit vehicle;

- streamline the route;

- reduce boarding time;

- decrease overall travel time; or,

- reduce headways and increase frequency of service.

Convenience is the next service concept the author presents as one of great importance for transit agencies. The author contends that those service concepts that make transit more convenient typically include changes to existing services, such as changes to fixed-route scheduled services. However, these changes do not generally make non-transportation barriers, such as childcare needs, any more convenient for travelers. Transit convenience is typically increased in one of the following ways:

- method of easier payment for service is implemented;

- traditional service characteristics are changed to meet user needs;

- traditional services are adapted to changing situations;

- traditional services are brought closer to users;

- demand-responsive options are provided; or

- more alternatives for any given trip are provided to users.

Making transit more affordable is another service concept that transit agencies must consider. Rosenbloom (1998) states that this can be achieved in two ways: directly reducing the cost of traditional services or indirectly reducing the cost of less traditional services.

The final service concept that is mentioned relates to making transit more feasible and practical. This concept addresses the basic problems that many people have with using transit. According to Rosenbloom (1998), the majority of these problems fall into the following categories:

- people cannot travel on transit because it does not support the other decisions they have made, such as riding a bicycle;

- people cannot use transit because it does not serve their destination; and/or,

- people cannot use transit because they do not know enough (or anything) about how to use it. 
The author states that the service concepts related to feasibility and practicality are often mutually supportive. For example, a park-and-ride facility can be made more attractive to a commuter by providing childcare or concierge services on-site. Rosenbloom (1998) concludes that feasibility and practicality of transit may be achieved in the following ways:

- facilitating bicycle and park-and-ride use;

- working with employers to provide new transit services;

- addressing non-transportation barriers to transit use;

- providing information, education, and training on transit use; and,

- changing land use patterns so transit can or does serve more destinations.

Rosenbloom also discusses the implementation of effective service concepts and the markets that will most likely experience an increase in the number of trips or travelers affected. Those services most likely to result in an increase in ridership if offered include:

- reverse commute services;

- services to employers;

- vanpools;

- route restructuring;

- feeder services; and,

- special event service.

Those groups most likely to take advantage of these services and increase their transit use include:

- low income workers;

- immigrants;

- Asians;

- Hispanics;

- African-Americans;

- those with less than high school education;

- people age 17 to 29 ;

- women;

- workers with some high school education; and,

- workers with high school education.

Those services that target non-workers or non-work trips may affect the next greatest change in ridership. Those services considered in this group include:

- service routes/community buses; 
- fare incentives; and,

- travel training/transit familiarization.

Those groups most likely to be affected by these changes include:

- people over age 65;

- people with limitations;

- school children;

- non-work tripmakers; and,

- people with no household car.

Services such as community buses and travel training have reached groups that are not considered current transit markets, such as children and the elderly. Considering their high level of reliance on transit, immigrants also may find these service options favorable for their non-work trips. Although there are four times as many non-work trips as there are work trips, riders would most likely not use them routinely and frequently, thereby resulting in less effects than are seen with commuter options. Rosenbloom (1998) states, however, that, because one in five Americans will be over the age of 65 within a few years, capturing a small percentage of the trips taken by elderly passengers now may ensure their ridership for decades to come.

The final service concepts, and those with the smallest effect include:

- express buses;

- light rail;

- commuter rail; and,

- park-and-ride.

Those groups most likely to be affected by these concepts are high-income workers, highly educated workers, and men - groups not traditionally considered as likely to use transit. These workers constitute no more than 25 percent of the labor force, and although they may commute, it is very unlikely that they would depend upon transit every day. Light rail and commuter rail have had success in older, dense communities where they have been in use for decades, but the national effects are substantially smaller. Rosenbloom (1998) suggests that, if these transit options were to be considered as new concepts, their overall effects would be minimal.

Finally, Rosenbloom addresses concerns of equity and efficiency with regard to the implementation of the suggested service concepts. The author asserts that the more equitable an outcome, the greater the overall benefit to society. Efficiency is used here to refer to a measure of how well a transit system meets the goals it has established with its given amount 
of resources. Public policy decisions must be weighed against many factors and these factors may sometimes conflict, potentially making something efficient and not equitable or equitable without being efficient.

Rosenbloom suggests that when the goal of transportation planning is achieving equity as a measure of fairness, or conditioning service on income or need, or the equality of input or output, those service concepts that are expensive, serve fewer people, and are targeted at higher income people would not be an equitable way of spending public money. Providing all transit users with the same levels of service or routing resources so that all gain the same benefit from the service may be considered equitable regardless of input. Ascribing to these definitions, service concepts such as park-and-ride lots and new rail systems may not be seen as being equitable. In contrast, other views on equity may lead to different conclusions. Some may consider spending public money on services such as rail systems and park-and-ride lots equitable if they believe that higher-income users pay more taxes and fees that support public transit than do low-income users.

Rosenbloom (1998) cautions that these views remain sensitive to reported ridership and market effects, and various concepts may demonstrate different effects in different communities. Further, the author contends that, while equity cannot be the only issue in determining public spending, it does appear that, in consideration of ridership patterns and limited funding, there are particular service concepts that will likely have a greater overall societal effect than others. These beneficial services include:

- reverse commute;

- services targeted to employers;

- route restructuring;

- service routes;

- fare incentives; and,

- travel training.

Voters and policymakers do not typically view transit ridership as the overall goal of a system, but as a measure of attaining some other goal such as reduced traffic congestion, increased access to jobs for low-income workers, decreased environmental pollution, or increased mobility for the elderly or disabled. In general, those service concepts considered to provide the greatest overall societal benefit in terms of equity and efficiency include:

- reverse commute services;

- services to specific employers and universities;

- vanpool incentives;

- route restructuring; and, 
- feeder services.

Those services considered least equitable and efficient because they target the least amount of people, particularly those with higher incomes or who are highly educated, and are largely male include:

- express buses;

- light rail;

- commuter rail; and,

- park-and-ride.

Finally, Weber et al. (2000) detail a study designed to determine the characteristics of "switchers" -- those urban commuters who change from single occupant vehicle (SOV) commuting to some other mode of transportation to work. The authors conducted a survey of those in the commute trip reduction (CTR) program in Washington State, focusing on those who had switched from SOV during the six years prior to the survey.

A significant portion (13 percent) of respondents provided reasons for switching from non-SOV travel and resuming SOV use. These reasons included: the loss of an opportunity to rideshare conveniently; changes in their work schedules; and changes in their home or work location. Many committed SOV users cited that alternatives to driving alone were either non-existent or quite inadequate to meet their particular needs. A number of respondents mentioned that work schedules made carpooling or public transit "exceedingly difficult."

A considerable number of respondents felt that they needed to have their own car for family responsibilities or personal tasks during the day. However, several respondents indicated that this difficulty might be reduced if employers made company cars available for occasional uses, such as family emergencies or pressing medical appointments.

The authors also examined the commuters' reliance on individual transportation modes, including SOV, carpooling, vanpooling, public transportation, walking, bicycling. The primary considerations were related to issues of convenience and flexibility. Carpoolers and vanpoolers attached a relatively low importance to flexibility and convenience. Bus riders and other types of public transit users tended to regard public transportation as relatively convenient. Regular users of bus and other forms of transit were inclined to attach less importance to having an independent schedule, and tended to believe that other people attach considerable importance to having an independent schedule. Commuters who walked or bicycled regularly believed that other people attach considerable importance to time savings. According to the authors, this suggests that walkers and bicyclists attach relatively less importance to time savings. These 
findings point to the importance of convenience and scheduling considerations in shaping workplace-related personal transportation decisions.

Cost considerations were found to be relevant to a number of transportation behaviors. SOV commuters tended to attach less importance to cost considerations. Commuters who attached considerable importance to cost concerns were more likely to car/vanpool, use public transportation, or switch from SOV.

Switchers tended to attach relatively little importance to privacy, and walkers in particular believed that other people attach considerable importance to privacy. There also was a "scattering" of open-ended comments that pointed to the benefit of time spent with one or more other people as a positive feature of car/vanpooling or public transit.

This study concluded that the efforts to reduce SOV commuting will probably encounter considerable resistance unless the gap between the convenience and flexibility of SOV commuting and its reasonable alternatives can be narrowed by making non-SOV commuting more convenient and flexible.

\section{Conclusion}

This chapter has examined potential barriers to transit use. A review of relevant literature has been presented in order to illustrate the nature and extent of each barrier category. Three major categories of barriers have been offered as representative of the most pressing issues faced by transit systems in Florida. First, perceptions of public transit safety and security are regularly cited in the literature as impacting the level of transit use in the United States. The perceived threat of crime in relation to transit use appears to be the most striking safety and security barrier. Women, in particular, are cited as having the highest level of anxiety related to using public transit. Also of note is that non-users of transit are more likely to have the perception that transit is unsafe than are current transit users. This review has also described the impact of conditions surrounding the bus stop environment on perceptions of personal safety related to using public transit.

Transit information and marketing is the second major category of transit barriers addressed in the review. This section has addressed the importance of "getting the word out" about transit to the public through effective transit information and marketing. The literature indicates that the form that transit information takes is especially important to the overall efficacy of that information. Transit information needs to be presented in a manner that is understandable to customers from a wide variety of demographic and socioeconomic backgrounds. In addition, 
transit passengers feel less anxiety related to using transit when information is available throughout the riding experience.

The final category addressed in this review was service availability and convenience. The barriers presented in this section of the review also represent some of the most challenging to address. The literature on these topics make clear that the level of convenience associated with the personal automobile presents an overwhelming barrier to transit use. Passengers and potential users are particularly dissatisfied with long wait times and the perceived unreliability of transit service. In addition, transit users and potential users often desire greater flexibility and increased frequency of service. Finally, the literature also indicates that the automobile is the preferred mode of travel in today's suburban environment due to its comparative directness of travel and short travel time. 


\section{Chapter Two: \\ Florida Transit Customer Satisfaction}

Chapter Two presents the results of an analysis of on-board passenger survey data collected from riders in nine of Florida's transit systems. The purpose of this analysis is to examine potential barriers identified by current transit users in Florida. These data were collected and analyzed as part of the National Center for Transit Research research program project entitled, Customer Satisfaction Index for Florida Transit Properties. The analysis reported in this section refers specifically to customer satisfaction information offered by current users of transit in Florida. These data will provide some insight into the aspects of Florida transit systems that are the least satisfying for current users.

\section{Transit Customer Satisfaction Index}

As described previously, the data presented in this chapter are drawn from the NCTR research project Customer Satisfaction Index for Transit Properties. The objectives of the Transit Customer Satisfaction Index (CSI) project were to provide:

- a systematic evaluation of each participating transit authority's customer satisfaction;

- insight into which factors drive customer satisfaction;

- a comparison of customer satisfaction data from each system with data from other Florida transit systems and other systems in the nation, which will enhance understanding of each system's relative performance; and,

- recommendations for how to increase customer satisfaction.

\section{Selected Systems}

For this study, on-board survey customer satisfaction data that had been collected recently for nine Florida transit properties were analyzed. The nine transit properties included in the analysis were the following:

\begin{tabular}{|c|c|c|c|}
\hline System & Location & Date of Survey & $\begin{array}{l}\text { Total Surveys } \\
\text { Returned }\end{array}$ \\
\hline MCAT & Bradenton & 1994 & 736 \\
\hline MCAT & Bradenton & 1998 & 655 \\
\hline JTA & Jacksonville & 1999 & 4,733 \\
\hline City Transit & Key West & 1999 & 200 \\
\hline PalmTran & West Palm Beach & 1999 & 3,090 \\
\hline SCAT & Sarasota & 1999 & 1,250 \\
\hline SCAT (Brevard) & Cocoa & 1999 & 422 \\
\hline
\end{tabular}




$\begin{array}{llll}\text { VOTRAN } & \text { Daytona Beach } & 1999 & 1,972 \\ \text { RTS } & \text { Gainesville } & 1999 & 2,107 \\ \text { TALTRAN } & \text { Tallahassee } & 1999 & 1,446\end{array}$

\section{Handling of the Ridership Frequency Response Bias}

In Technical Memorandum Number Two of the 1996 Transit CSI project, a particular difficulty in sampling is described, where higher frequency riders are more likely to be surveyed in an onboard surveying effort than low frequency riders. CUTR's analysis of the on-board representation problem yields a simple method for creating a rough estimate of the proper weighting for each response. The problem can be illustrated with the following example.

Suppose bus ridership for a particular route has frequency of use characteristics as described in Table 2-1 below. If we assume equal trips per day for each category of use, the percentage of all system trips by each category of use can be calculated with the following formula:

(Equation 1): $\quad \%$ of trips by users in category $I=$

(\% of riders in category $I) *($ frequency of use by category $I)$

$\Sigma((\%$ of riders in category $I) *$ (frequency of use by category $I))$

for all $I$

For those who use the system once per week, the formula would yield the result from Equation 1: $((35$ percent $) *(1$ day/week $)) /(.35 * 5+.1 * 4+.1 * 3+.1 * 2+.35 * 1)=(.35 / 3)=11.7 \%$

Application of the formula to each category yields the results in the right hand column of Table 2-1 below.

\begin{tabular}{|ccc|}
\hline \multicolumn{2}{c|}{ Table 2-1 } \\
Relationship of Rider Use Frequency to Percentage of Trips Taken \\
Frequency of Use & Percentage of Riders & Percentage of Trips \\
5/week & $35 \%$ & $58 \%$ \\
4/week & $10 \%$ & $13 \%$ \\
3/week & $10 \%$ & $10 \%$ \\
2/week & $10 \%$ & $7 \%$ \\
1/week & $35 \%$ & $12 \%$ \\
\hline
\end{tabular}

Any sampling plan that distributes surveys randomly to riders on a bus (or people waiting for a bus) will necessarily result in survey returns that are proportional to the trips taken by each 
category of rider, rather than to the percentage of the overall system ridership. In this admittedly extreme example, it is clear that the ridership would not be properly represented.

To minimize this problem, CUTR utilized a weighting scheme based on the respondents' selfassessment of frequency of bus ridership. Respondents were asked to note on which of the last seven days (Monday through Sunday) they had ridden the bus. Using the answers to these questions, CUTR determined the probability that each frequency category would have been surveyed and, from that probability and the total number of responses for each category, estimated the distribution of riders in each frequency category. Weights were assigned by dividing the estimated number of riders by the actual percentage of responses for each frequency category.

The exact formula for estimating the total distribution of weekday riders is then determined with the following formula:

\author{
$\%$ of riders in category $I=$ \\ $\%$ of surveys returned by category $I /$ Frequency of use by category $I$ \\ $\Sigma((\%$ of surveys returned by category $I) /($ Frequency of use by category $I)$ ) \\ for all $I$
}

These results were analyzed for the system as a whole only, since route-level results were not required for this project.

\title{
Ridership Frequencies
}

There are several different ways that ridership frequencies were recorded on these surveys. Since one of the initial steps in developing the Transit CSI was to account for different probabilities of sampling people who have different levels of frequency of use (see 1996 Transit CSI, Technical Memorandum No. 2), these differences had to be resolved in order to proceed.

The different recording methods arise from the response categories permitted for the question, "On average, how many days a week do you ride the bus?" The different response formats in the various surveys are:

Once per month to 7 days per week
TALTRAN, Key West Transit, VOTRAN, JTA 
Once per month to 6 days per week

Less than 1 day per week to 6 days per week

$1,2-3,4+$ days per week or once every

weeks
SCAT Sarasota, SCAT Brevard

RTS

MCAT, PalmTran, LYNX,

Okaloosa

The greatest difficulty rests with the systems where only "4+" days was recorded. Analysis of the data from systems where people were asked if they rode the bus 0 to 7 days per week provides the following data:

Percent Ride

System

$\underline{0 \text { days }} \underline{1 \text { day }} \underline{2 \text { days }} \underline{3 \text { days }} \underline{4 \text { days }} \underline{5 \text { days }} \underline{6 \text { days }} \underline{7 \text { days }}$

JTA

$2.5 \quad 3.4$

$6.1 \quad 7.8$

$\begin{array}{llll}9.2 & 40.4 & 16.9 & 13.8\end{array}$

Key West Transit

4.1

Comb. $11.8 \quad 13.3$

$\begin{array}{llll}10.7 & 24.0 & 10.7 & 19.4\end{array}$

TALTRAN

5.3

Comb. $10.1 \quad 7.7$

$\begin{array}{llll}9.6 & 40.6 & 12.6 & 14.1\end{array}$

VOTRAN

\section{0}

Comb. 8.6

7.9

$\begin{array}{lll}10.8 & 27.3 \quad 21.2\end{array}$

18.2

From these data, the best approximation for all riders in systems where anything over 4 days was not specified is approximately 5.5 days for all. Although this is not as precise as one might like, this will serve to provide appropriate probability sampling weights for ridership in those systems. The actual value of the weights only differs slightly in those ranges so the effects should be minimal. Certainly, it is not the objective of this project to dismiss data where the frequency of ridership does not match the ideal characteristics, where so much other valuable data are available with these minor adjustments.

\section{System weights}

To compare results across systems, a weighting scheme had to be developed to account for differences in number of responses across systems. Three weighting schemes were available:

1. No weighting

2. Weight by system ridership

3. Weight by area population 
Among these, it seemed most logical to weight by system ridership, thus allowing larger systems (such as JTA and Palmtran) to affect overall scores more than smaller systems, which, in turn, is more representative of attitudes among all Florida riders. Ridership data were drawn from CUTR's 1999 performance evaluation of all Florida systems.

Weighting by ridership is accomplished by creating a "weight" for each survey response. The weight is calculated in the following manner, using JTA as an example: a proportion is calculated as the combined riders in all 10 systems divided by the riders in the JTA system, as drawn from NTD data. This proportion is multiplied by the proportion of survey responses in the JTA system divided by the number of survey responses in all 10 systems. The table below summarizes the weights:

Table 2-2

Ridership Weights, by Transit System

\begin{tabular}{lrrrrr} 
System & Observations & Ridership (NTD) & Ridership weight & & Year of survey \\
${$\cline { 2 - 3 }$} }$ & 200 & 334,980 & 0.984282621 & 1999 \\
JTA & 4733 & $8,491,986$ & 1.054395878 & 1998 \\
PALMTRAN & 3090 & $4,312,442$ & 0.820154594 & 1999 \\
MCAT & 736 & 657,588 & 0.525057661 & 1994 \\
MCAT & 655 & 638,709 & 0.573050202 & 1998 \\
SCAT & 1250 & $1,656,654$ & 0.778848046 & 1999 \\
SCAT - Brevard & 422 & 251,834 & 0.350697643 & 1999 \\
RTS/GAIN & 1300 & $2,948,150$ & 1.332714609 & 1999 \\
TALTRAN & 1446 & $3,925,743$ & 1.595454805 & 1999 \\
VOTRAN & 1972 & $3,674,718$ & 1.09508553 & 1999 \\
& & & &
\end{tabular}

\section{Satisfaction Items}

The differences in satisfaction items on the surveys provided a potentially much more serious impact on the process of developing the index. The surveys do not contain an identical set of questions, so it is vital to distinguish which questions appear in which surveys and the extent to which non-identical surveys can be used to create the index. Table 2-3 summarizes the questions asked on the surveys. 
Table 2-3

On-Board Survey Questions

\begin{tabular}{|c|c|c|c|c|c|c|c|c|c|c|}
\hline \multicolumn{11}{|c|}{$\begin{array}{c}1999 \text { Transit Customer Satisfaction Index } \\
\text { On-Board Questionnaire Item Matrix }\end{array}$} \\
\hline Question & SCAT & TALTRAN & JTA & $\begin{array}{l}\text { Palm } \\
\text { Tran }\end{array}$ & $\begin{array}{l}\text { Key } \\
\text { West }\end{array}$ & VOTRAN & RTS & $\begin{array}{l}\text { MCAT } \\
94\end{array}$ & $\begin{array}{l}\text { MCAT } \\
98\end{array}$ & SCATBrev \\
\hline $\begin{array}{l}\text { satisfaction } \\
@ \text { beginning }\end{array}$ & & & $x$ & & $x$ & $x$ & $x$ & & & \\
\hline $\begin{array}{l}\text { satisfaction } \\
@ \text { end }\end{array}$ & $x$ & $x$ & & $x$ & & & & $x$ & $x$ & $x$ \\
\hline $\begin{array}{l}\text { days of } \\
\text { service }\end{array}$ & $x$ & $x$ & & & & & & $x$ & $x$ & $x$ \\
\hline $\begin{array}{l}\text { hours of } \\
\text { service }\end{array}$ & $x$ & $x$ & & & & & & $x$ & $x$ & $x$ \\
\hline $\begin{array}{l}\text { time of day } \\
\text { the earliest } \\
\text { buses run on } \\
\text { weekdays }\end{array}$ & & & $x$ & $x$ & $x$ & $x$ & $x$ & & & \\
\hline $\begin{array}{l}\text { time of day } \\
\text { the latest } \\
\text { buses run on } \\
\text { weekdays }\end{array}$ & & & $x$ & $x$ & $x$ & $x$ & $x$ & & & \\
\hline $\begin{array}{l}\text { time of day } \\
\text { the earliest } \\
\text { buses run on } \\
\text { weekends }\end{array}$ & & & $x$ & $x$ & $x$ & $x$ & $x$ & & & \\
\hline $\begin{array}{l}\text { time of day } \\
\text { the latest } \\
\text { buses run on } \\
\text { weekends }\end{array}$ & & & $x$ & $x$ & $x$ & $x$ & $x$ & & & \\
\hline $\begin{array}{l}\text { frequency of } \\
\text { service }\end{array}$ & $x$ & $x$ & $x$ & $x$ & $x$ & $x$ & $x$ & $x$ & $x$ & $x$ \\
\hline $\begin{array}{l}\text { convenience } \\
\text { of routes }\end{array}$ & $x$ & $x$ & & & & & & $x$ & $x$ & $x$ \\
\hline $\begin{array}{l}\text { your ability } \\
\text { to get where } \\
\text { you want to } \\
\text { go }\end{array}$ & & & $x$ & $x$ & $x$ & $x$ & $x$ & & & \\
\hline
\end{tabular}


Table 2-3 (continued)

On-Board Survey Questions

1999 Transit Customer Satisfaction Index

On-Board Questionnaire Item Matrix

\begin{tabular}{|c|c|c|c|c|c|c|c|c|c|c|}
\hline Question & SCAT & TALTRAN & JTA & $\begin{array}{l}\text { Palm } \\
\text { Tran }\end{array}$ & $\begin{array}{l}\text { Key } \\
\text { West }\end{array}$ & VOTRAN & RTS & $\begin{array}{l}\text { MCAT } \\
94\end{array}$ & $\begin{array}{l}\text { MCAT } \\
98\end{array}$ & SCATBrev \\
\hline $\begin{array}{l}\text { dependability of } \\
\text { buses (on time) }\end{array}$ & $x$ & $x$ & & & & & & $x$ & $x$ & $x$ \\
\hline $\begin{array}{l}\text { How regularly } \\
\text { buses arrive on } \\
\text { time }\end{array}$ & & & $x$ & $x$ & $x$ & $x$ & $x$ & & & \\
\hline $\begin{array}{l}\text { travel time on } \\
\text { buses }\end{array}$ & $x$ & $x$ & $x$ & $x$ & $x$ & $x$ & $x$ & $x$ & $x$ & $x$ \\
\hline $\begin{array}{l}\text { cost of riding the } \\
\text { bus }\end{array}$ & $x$ & $x$ & $x$ & $x$ & $x$ & $x$ & $x$ & $x$ & $x$ & $x$ \\
\hline $\begin{array}{l}\text { availability of } \\
\text { bus route } \\
\text { information/maps }\end{array}$ & $x$ & $x$ & & $x$ & $x$ & $x$ & $x$ & $x$ & $x$ & $x$ \\
\hline $\begin{array}{l}\text { usefulness of } \\
\text { bus route } \\
\text { info/maps }\end{array}$ & $x$ & $x$ & $x$ & $x$ & $x$ & $x$ & $x$ & & $x$ & $x$ \\
\hline $\begin{array}{l}\text { Vehicle } \\
\text { cleanliness \& } \\
\text { comfort } \\
\end{array}$ & $x$ & $x$ & & & & & & $x$ & $x$ & $x$ \\
\hline $\begin{array}{l}\text { temperature } \\
\text { inside the bus }\end{array}$ & & & $x$ & $x$ & $x$ & $x$ & $x$ & & & \\
\hline $\begin{array}{l}\text { how clean bus } \\
\text { stops \& buses } \\
\text { are }\end{array}$ & & & $x$ & $x$ & & $x$ & $x$ & & & \\
\hline $\begin{array}{l}\text { availability of } \\
\text { seats on the } \\
\text { buses }\end{array}$ & & & $x$ & $x$ & $x$ & $x$ & $x$ & & & \\
\hline $\begin{array}{l}\text { operator } \\
\text { courtesy }\end{array}$ & $x$ & $x$ & $x$ & $x$ & $x$ & $x$ & $x$ & $x$ & $x$ & $x$ \\
\hline $\begin{array}{l}\text { safety on bus \& } \\
\text { at bus stops }\end{array}$ & $x$ & $x$ & $x$ & $x$ & $x$ & $x$ & $x$ & $x$ & $x$ & $x$ \\
\hline $\begin{array}{l}\text { safety after } \\
\text { getting off bus }\end{array}$ & & & $x$ & $x$ & $x$ & $x$ & $x$ & & & \\
\hline $\begin{array}{l}\text { transferring b/t } \\
\text { buses }\end{array}$ & $x$ & $x$ & $x$ & $x$ & $x$ & $x$ & $x$ & & $x$ & $x$ \\
\hline $\begin{array}{l}\text { bus operator's } \\
\text { ability to drive } \\
\text { the bus }\end{array}$ & & & $x$ & $x$ & $x$ & $x$ & $x$ & & & \\
\hline
\end{tabular}


Many of the differences between the surveys amount to the level of detail for the topic in question. For instance, where some surveys contain questions where the customer responds by indicating satisfaction with "days of service" and "hours of service," others require customers to rate their satisfaction with the time of day buses leave earliest and latest on weekdays and weekends, creating four separate ratings instead of two. Another example of this is the question rating 'vehicle cleanliness and comfort' compared to separate questions on temperature inside the bus, how clean buses and bus stops are, and availability of seats on buses.

Other sources of differences are minor wording changes. So where one set of surveys has questions about "convenience of routes," others have questions rating the customers' satisfaction with "your ability to get where you want to go." Another example is "dependability of buses (on time)" versus "how regularly buses arrive on time."

Finally, some surveys have additional questions on similar topics. One set of surveys has a question about "safety on bus and at bus stops." Another set has both that question and one about "safety after getting off bus."

A factor analysis, conducting parallel analyses between the systems using one type of survey format and the set of systems using the second type, indicates that the safety issues are treated much the same way in the two surveys, as they load on to factors with comfort and driver. The span of service issues, however, are not so simple. The span of service when presented as earliest/latest weekday/weekend, is its own factor. When span of service is hours of service and days of service, it loads together with frequency of service as a kind of "system scheduling" factor. In the first instance, when we have earliest/latest weekday/weekend, the frequency loads on with items on convenience of routes and time to make trip. The differences in how these factors are constructed indicate that the two are not directly comparable, and that any comparison between the different forms of measuring span of service using the index could be very misleading. Hence comparison on those items should be limited to comparisons with other systems that used the same question format. 


\section{Results}

Data were analyzed related to 29 categories of customer satisfaction. Because of some of the differences in the ways that questions were asked for different systems, as noted in the preceding tables, some of the categories may appear repetitive. For instance, in some surveys three separate safety questions were asked (waiting for bus, on bus, after getting off bus) and in other systems only one safety question was asked (safety on bus and at stops). In order to handle these differences, five items (SQ31-35) are presented at the bottom of the table that combine the results from different questions. The results from each satisfaction category were further segmented into frequency of ridership of respondent. The three categories of ridership frequency examined were low ridership (less than once per week), medium (one to three days per week), and high (four or more days per week). Table 2-4 contains each of the satisfaction categories that were examined for the nine transit systems included and the satisfaction scale calculated for each item. 
Table 2-4

Transit Customer Satisfaction Categories

\begin{tabular}{|c|c|c|c|c|c|}
\hline & \multicolumn{5}{|c|}{ All Systems (JTA, MCAT, PalmTran, VOTRAN, TALTRAN, Key West, SCAT, SCAT Brevard, RTS) } \\
\hline & $\begin{array}{|llll|}\begin{array}{l}\text { Weighted by System Ridership } \\
\text { Ridership Frequency }\end{array} & & & \\
\end{array}$ & & & & \\
\hline & & & Ridership & & \\
\hline Indices & Satisfaction Categories & All & Low & Medium & High \\
\hline & & & $(<1$ week) & (1-3 days/wk) & (4+ days per week) \\
\hline SQ1 & Satisfaction (at beginning) & 3.84 & 4.15 & 3.84 & 3.68 \\
\hline SQ2 & Satisfaction (at end) & 4.02 & 4.05 & 4.07 & 3.96 \\
\hline SQ3 & Days of Service & 4.11 & 4.08 & 4.21 & 4.07 \\
\hline SQ4 & Hours of Service & 3.53 & 3.54 & 3.65 & 3.42 \\
\hline SQ5 & Frequency of Service & 3.30 & 3.51 & 3.32 & 3.14 \\
\hline SQ6 & Ability to get where you want to go & 3.85 & 4.03 & 3.83 & 3.76 \\
\hline SQ7 & Number of transfers & 3.50 & 3.63 & 3.48 & 3.44 \\
\hline SQ8 & Ease of transfer & 3.68 & 3.89 & 3.69 & 3.54 \\
\hline SQ9 & How regularly buses arrive on-time & 3.37 & 3.75 & 3.37 & 3.16 \\
\hline SQ10 & Time to make trip & 3.55 & 3.73 & 3.53 & 3.43 \\
\hline SQ11 & Value of fare/cost & 3.94 & 4.07 & 3.97 & 3.82 \\
\hline SQ12 & Ease to obtain schedule & 3.95 & 3.92 & 3.99 & 3.96 \\
\hline SQ13 & Ease to use schedule & 3.98 & 4.00 & 4.00 & 3.95 \\
\hline SQ14 & Time earliest bus leaves on weekdays & 3.65 & 3.72 & 3.69 & 3.58 \\
\hline SQ15 & Time latest bus leaves on weekdays & 3.02 & 3.26 & 3.05 & 2.86 \\
\hline SQ16 & Time earliest bus leaves on weekends & 3.29 & 3.60 & 3.33 & 3.08 \\
\hline SQ17 & Time latest bus leaves on weekends & 2.99 & 3.35 & 3.00 & 2.78 \\
\hline$S Q 18$ & Convenience of routes & 3.89 & 3.94 & 3.95 & 3.80 \\
\hline SQ19 & Dependability of buses & 3.67 & 3.74 & 3.73 & 3.57 \\
\hline SQ20 & Clean buses \& stop & 3.77 & 4.02 & 3.80 & 3.61 \\
\hline SQ21 & Cleanliness/comfort & 4.16 & 4.15 & 4.26 & 4.09 \\
\hline SQ22 & Safety at bus stop & 3.80 & 4.00 & 3.82 & 3.68 \\
\hline SQ23 & Safety on bus & 4.09 & 4.23 & 4.07 & 4.03 \\
\hline$\overline{S Q 24}$ & Safety after getting off bus & 3.96 & 4.13 & 3.94 & 3.88 \\
\hline$S Q 25$ & Safety on bus \& at stops & 4.17 & 4.10 & 4.27 & 4.17 \\
\hline SQ26 & Temperature in bus & 3.85 & 4.19 & 3.84 & 3.65 \\
\hline SQ27 & Availability of seats & 3.92 & 4.22 & 3.87 & 3.78 \\
\hline SQ28 & Drivers' ability to drive & 4.29 & 4.42 & 4.28 & 4.21 \\
\hline SQ29 & Driver courtesy & 4.23 & 4.32 & 4.25 & 4.14 \\
\hline SQ31 & Satisfaction (combined SQ 1 \& 2) & 3.92 & 4.10 & 3.94 & 3.77 \\
\hline SQ32 & Convenience of routes (combined SQ 6 \& 18) & 3.86 & 4.00 & 3.86 & 3.77 \\
\hline SQ33 & Dependability of buses (combined SQ $9 \& 19$ ) & 3.46 & 3.75 & 3.46 & 3.26 \\
\hline SQ34 & Cleanliness/comfort (combined SQ 20 \& 21) & 3.89 & 4.07 & 3.92 & 3.73 \\
\hline SQ35 & Combined Safety (SQ 22, 23, 24, \& 25) & 4.02 & 4.12 & 4.04 & 3.95 \\
\hline
\end{tabular}


The analysis of the data is simplified by removing the individual items that are used to make up the list of combined items. For convenience, the table of results is reproduced below without items SQ1 and SQ2, SQ6 and SQ18, SQ9 and SQ19, SQ20 and SQ21, and SQ22-SQ25.

Table 2-5

Revised Transit Customer Satisfaction Categories

\begin{tabular}{|c|c|c|c|c|c|}
\hline & \multicolumn{5}{|c|}{ All Systems (JTA, MCAT, PalmTran, VOTRAN, TALTRAN, Key West, SCAT, SCAT Brevard, RTS) } \\
\hline & $\begin{array}{l}\text { Weighted by System Ridership (NTD) and } \\
\text { Ridership Frequency }\end{array}$ & & & & \\
\hline & & & Ridership & & \\
\hline & & & & & \\
\hline Indices & Satisfaction Categories & All & Low & Medium & High \\
\hline & & & (<1 week) & $(1-3$ days/wk) & (4+ days per week) \\
\hline & & & & & \\
\hline SQ3 & Days of Service & 4.11 & 4.08 & 4.21 & 4.07 \\
\hline SQ4 & Hours of Service & 3.53 & 3.54 & 3.65 & 3.42 \\
\hline SQ5 & Frequency of Service & 3.30 & 3.51 & 3.32 & 3.14 \\
\hline SQ7 & Number of transfers & 3.50 & 3.63 & 3.48 & 3.44 \\
\hline SQ8 & Ease of transfer & 3.68 & 3.89 & 3.69 & 3.54 \\
\hline$S Q 10$ & Time to make trip & 3.55 & 3.73 & 3.53 & 3.43 \\
\hline$\overline{S Q 11}$ & Value of fare/cost & 3.94 & 4.07 & 3.97 & 3.82 \\
\hline$S Q 12$ & Ease to obtain schedule & 3.95 & 3.92 & 3.99 & 3.96 \\
\hline$\overline{S Q 13}$ & Ease to use schedule & 3.98 & 4.00 & 4.00 & 3.95 \\
\hline$S Q 14$ & Time earliest bus leaves on weekdays & 3.65 & 3.72 & 3.69 & 3.58 \\
\hline$\widehat{S Q 15}$ & Time latest bus leaves on weekdays & 3.02 & 3.26 & 3.05 & 2.86 \\
\hline SQ16 & Time earliest bus leaves on weekends & 3.29 & 3.60 & 3.33 & 3.08 \\
\hline SQ17 & Time latest bus leaves on weekends & 2.99 & 3.35 & 3.00 & 2.78 \\
\hline SQ26 & Temperature in bus & 3.85 & 4.19 & 3.84 & 3.65 \\
\hline SQ27 & Availability of seats & 3.92 & 4.22 & 3.87 & 3.78 \\
\hline$S Q 28$ & Drivers' ability to drive & 4.29 & 4.42 & 4.28 & 4.21 \\
\hline$S Q 29$ & Driver courtesy & 4.23 & 4.32 & 4.25 & 4.14 \\
\hline SQ31 & Satisfaction (combined SQ 1 \& 2) & 3.92 & 4.10 & 3.94 & 3.77 \\
\hline SQ32 & Convenience of routes (combined SQ $6 \& 18$ ) & 3.86 & 4.00 & 3.86 & 3.77 \\
\hline SQ33 & Dependability of buses (combined SQ 9 \& 19) & 3.46 & 3.75 & 3.46 & 3.26 \\
\hline$\overline{S Q 34}$ & Cleanliness/comfort (combined SQ 20 \& 21) & 3.89 & 4.07 & 3.92 & 3.73 \\
\hline$S Q 35$ & Combined Safety (SQ 22, 23, 24, \& 25) & 4.02 & 4.12 & 4.04 & 3.95 \\
\hline
\end{tabular}


Transit users who completed the on-board survey form were asked to rate each satisfaction item on a scale of 1 to 5 , with 1 representing the lowest level of satisfaction and 5 representing the highest level of satisfaction. As illustrated in the above table, the level of satisfaction of Florida transit users appears to decrease the more often one uses transit. For the purposes of analysis, it is assumed that satisfaction ratings above 3.50 represent fairly high satisfaction, whereas those ratings that fall below this benchmark reflect areas in need of improvement. A review of overall results indicates that the lowest customer satisfaction ratings were reported for the latest weekend hours of service (2.99), latest weekday hours of service (3.02), earliest weekend hours of service (3.29), and the frequency of transit service (3.30). The overall dependability of transit service also received a low satisfaction rating of 3.46 (includes dependability of buses and how regularly buses arrive on time). Overall, the highest satisfaction ratings were reported for driver ability (4.29), driver courtesy (4.23), and days of service (4.11).

As described in a previous section, the satisfaction results also were segmented by respondents' frequency of transit use. Three frequencies of transit use categories were developed: low frequency use (ride less than one day per week), medium frequency transit use (ride one to three days per week), and high frequency transit use (ride four or more days per week). Overall, high frequency users reported lower satisfaction with transit service than did infrequent riders and medium frequency users. However, the results were strikingly similar in terms of those customer satisfaction items that received the highest and lowest satisfaction ratings by each rider group. The results from each rider group are summarized briefly below.

\section{Low Frequency Transit Users (Ride less than once per week)}

The low frequency transit user group includes those passengers who reported using transit less than one day per week. It is assumed that this group includes many persons who would not be considered "captive" riders. Low frequency transit users reported lowest levels of satisfaction with the times that transit service ceases operation in the evening on both weekdays (3.26) and weekends (3.35). Low satisfaction ratings also were reported for the frequency of transit service (3.51) and overall hours of transit service (3.54). Low frequency transit users reported the highest level of customer satisfaction related to driver ability (4.42). These transit riders also appear to be highly satisfied with driver courtesy (4.32) and availability of seats on the bus (4.22). Overall, low frequency transit users appear to be relatively satisfied with the transit service provided, reporting no satisfaction ratings lower than 3.26 (latest weekday hours).

\section{Medium Frequency Transit Users (Ride one to three days per week)}

Passengers who reported using transit one to three days per week are included in the medium frequency transit user group. These transit users reported lower rates of satisfaction overall 
than did the low frequency riders; however, the categories receiving the three lowest ratings were identical to those reported by the low frequency riders: latest weekend hours (3.00), latest weekday hours (3.05), and frequency of transit service (3.32). Also rated low in terms of customer satisfaction were earliest weekend hours (3.33), the dependability of buses (3.46), and the number of transfers required to complete a trip (3.48). As with the low frequency riders, driver ability received the highest satisfaction rating (4.28) from medium frequency users. This group of transit users also rated driver courtesy (4.25) and days of service (4.21) quite highly. Finally, safety also received a high satisfaction rating (4.04) among these riders. This finding is particularly notable given that non-users of transit often cite safety at bus stops and on buses a barrier to transit use.

\section{High Frequency Transit Users (Ride four or more days per week)}

The final rider group examined is the group composed of high frequency transit users. The respondents in this group reported using transit four or more days per week. These riders are likely relying on transit for much of their personal travel, such as work trips, trips to the doctor or grocery, and/or recreational trips. This group of respondents reported the lowest levels of customer satisfaction, with ratings that ranged from 2.78 (latest weekend hours) to 4.21 (driver ability). This would be expected among transit users who rely on the service to meet their mobility needs and, thus, have the most experience using transit service. However, it must also be noted that these transit users reported the highest and lowest satisfaction ratings for the same categories as these reported by low and medium frequency transit users.

High frequency transit riders reported low satisfaction with latest hours of operation on weekend evenings (2.78) and weekday evenings (2.86). Similarly, these transit users also reported dissatisfaction with the earliest hours of service on weekends (3.08). Dissatisfaction also was expressed in relation to service availability and reliability. High frequency transit users rated the frequency of transit service low (3.14) and also expressed dissatisfaction with the overall dependability of transit service (3.26). High frequency transit users also reported low satisfaction with the hours of transit service (3.42), the time required to complete a transit trip (3.43), the number of transfers required (3.44), and the ease of transferring (3.54).

The highest satisfaction rating reported by high frequency transit users as for driver abilities (4.21). Riders with experience using the transit system also rated driver courtesy very high (4.14). Finally, high frequency transit users also reported high satisfaction with days of transit service (4.07) and overall transit system safety (4.02). 


\section{Conclusion}

This examination of current transit user satisfaction illustrates, in general, a fairly high level of satisfaction among current transit users in Florida. Overall, low frequency transit users, those who reported using transit less than one day per week, expressed the highest satisfaction ratings. Conversely, those respondents who reported using transit four or more times per week expressed the lowest level of satisfaction with transit service. This may be due to their greater experience with transit use and a higher level of dependency on transit to accomplish their mobility needs. The analysis demonstrates a high level of consistency between the overall ratings and ratings by user group. Driver ability and driver courtesy received high satisfaction ratings by each rider group, as well in the overall ratings. Similarly, medium and high frequency transit users gave high satisfaction marks to days of service and overall system safety. Without exception, the three lowest-rated satisfaction categories were latest weekend hours of service, latest weekday hours of service, and frequency of transit service. Medium and high frequency transit users also reported dissatisfaction with the dependability of transit service. 


\section{PART TWO: \\ Introduction to the \\ Barriers to Transit Use Field Tests}

The many individual barriers to transit use in the United States identified in Part One can be grouped into the following categories:

- Public Transit Safety and Security: perception of bus stop safety, gender-related concerns, impact of experience on perceptions of safety, etc.

- Transit Information and Marketing: importance of passenger feedback, customer preferences related to printed materials, ability to understand printed transit information, audience-oriented design (seniors, youth, people with disabilities), type of information provided to customers, accuracy of information, uncertainty and unpredictability in transit trip planning, etc.

- Service Availability and Convenience: long wait times, lack of dependability and reliability, lack of schedule flexibility, travel time, infrequent service, inconvenience when compared to the automobile, perceived low cost of auto travel, bus stop accessibility, lack of coverage, etc.

Given the unique geography and operating environments in the state, the project team identified two potential barriers to be field tested to assess the effect(s) of these potential barriers on transit ridership in Florida. The two categories of potential barriers within which CUTR has completed preliminary field test research are transit information and marketing and service availability and convenience. Each of these two categories contain several potential obstacles and barriers that could negatively impact transit usage and, therefore, merit in-depth field testing. However, the present project represents a starting point in stimulating future research. Therefore, the field tests included in this project focused on accomplishing baseline assessments of the two general, but extremely critical, pieces of the transit experience:

- Understanding and using printed transit information materials, and

- Scheduling transit services to match customer travel demands.

The two field test methodologies included in this research were chosen to represent two potential barriers to transit use in Florida that may be alleviated or rectified without major financial commitments from transit systems. It is important to note that they do not, however, 
represent the only potential barriers that would benefit from field test research. In fact, many additional methodologies were developed for consideration in this project that will likely yield very useful results for transit systems in Florida and throughout the United States. In addition, the results of the field tests that are the subject of Part Two suggest several additional avenues of research with great potential to provide further assistance to transit systems.

Overwhelmingly, the project team found that the two selected barriers are major obstacles to transit use in Florida. Field tests of transit information materials with non-users of transit revealed a high failure rate and considerable confusion and frustration associated with transit trip planning. Similarly, comparison of transit schedules to operating hours of major activity centers revealed considerable gaps in transit access based on transit operating hours. Therefore, each section includes a series of key findings and recommendations to address the barriers. Finally, the most useful aspect of this research is that it is the first time that transit information materials and transit agency scheduling practices have been compared among transit agencies throughout the State of Florida. 


\section{Chapter Three: Transit Information \& Marketing: Efficacy Field Test}

The availability and clarity of printed transit system information, such as bus schedules and route maps, play a paramount role in the decision to use public transit. Existing and potential transit passengers must often rely solely on such printed transit information materials to plan and complete trips in and through unfamiliar areas. While the importance of this information is widely recognized in the transit industry as a critical component of transit operations, transit literature indicates that existing and potential transit passengers often may experience anxiety related to planning and completing a transit trip when using printed transit materials such as bus schedules and route maps. Studies have indicated that the highest information hurdles for transit riders are encountered during the "planning" phase of a transit trip. Transit agencies are challenged to develop information that can be easily understood by passengers of all socioeconomic and demographic backgrounds. This information must be written in a manner that conveys enough information for a potential passenger to accurately plan their trip without inundating the reader with too much information that may confuse the planning process. As reported in Chapter One, uncertainty and/or unpredictability in planning a transit trip may pose a significant barrier to transit use.

In order to evaluate the extent to which printed transit information poses a barrier to transit use among current non-users in Florida, CUTR conducted a field test of the user-friendliness and clarity of printed information (bus schedules and route maps) developed by transit agencies throughout Florida. This field test focused specifically on materials currently being used by Florida transit properties in order to identify strengths of existing transit materials, as well as opportunities to strengthen the effectiveness of transit information in the state. The materials included in the field test were presented to a sample of test subjects who were asked to plan specific transit trips using only the transit information materials provided to them. The intent of the trip planning task was to evaluate the effectiveness of printed transit materials when presented to potential passengers with little to no transit experience, as well as to collect and analyze data related to the efficacy of particular design elements chosen for further evaluation in the study. This field test represented a preliminary, exploratory approach to the subject of transit literacy. Therefore, the primary focus was on the ability (or inability) of potential transit users to plan transit trips using available transit information materials. A secondary goal of the field tests was to evaluate a sample of design elements for their impact on the effectiveness of printed transit information. The methodology employed in this field test centered on the collection and analysis of both quantitative and qualitative data. However, particular attention is focused on passenger insight into the transit trip planning experience by requiring field test participants to complete trip planning activities as though they were planning an actual trip on fixed-route bus service and then gauging their responses to and impressions of the trip planning 
activities. This chapter details the activities and results of the transit information and marketing efficacy field test.

\section{Methodology}

In order to carry out the transit information and marketing field test, transit route, schedule, and system map materials were collected from each of the 22 transit properties in the state of Florida during March 2001. The materials provided to CUTR by the transit properties were dated between 1999 and 2001. Each piece of transit information was reviewed and a matrix was developed that categorized each according to the design elements included in the materials. The matrix contains information about all of the design elements included in each individual piece of transit information, such as alignment of timetables, route presentation, color scheme, and method of depicting transfer information. A copy of the matrix is included in Appendix $A$. The matrix was used to assess the content of the information provided as well as the design elements included, such as spatial representation, points of reference and the transit service area environment, use of color, use of maps, transfer locations, terminals, and bus stops. In addition, the matrix served as a starting point for the determination of specific design elements to be included in the field test for more detailed evaluation. The final decision regarding the design elements to include for additional analysis through the field test activities was based on those design elements most commonly included in Florida transit information materials. A total of three categories of design elements were included in this preliminary transit information and marketing field test: alignment of timetables (horizontal versus vertical), presentation of route and schedule information (All-in-One Ride Guide versus single route map/schedule), and presentation of transfer route information (depicted on timetable, on map, on both timetable and map, not depicted anywhere, or depicted elsewhere on the materials). Bus schedule and route map materials from a total of 18 transit agencies in Florida were included in the transit information and marketing field test.

\section{Observational Tests}

The transit information and marketing field test consisted of observation tests with a sample of participants who were asked to plan transit trips using the transit information materials presented. CUTR worked with the University of South Florida Department of Psychology to design, administer, and analyze the observational tests. The trip planning observations and assessments were designed to provide information on whether and how transit trip planning ability and efficiency may be related to socioeconomic and/or demographic characteristics such as age, gender, income, and education level, as well as the materials' design. The observational tests also were designed to provide results that attempt to address the ways in which design elements impact transit literacy and trip planning. Finally, the results of the observations sought to address the magnitude of the potential barrier to transit use posed by 
printed transit information materials, the effectiveness of specific design elements analyzed, and the overall effectiveness of the materials included in the analysis. Each observational test consisted of two trip planning tasks administered to a sample of participants coupled with observations made by the administrators of the tasks, post-planning interviews with participants following each trip planning task, the completion of a post-test questionnaire that collected demographic and socioeconomic information from each participant, and analysis of the quantitative and qualitative data collected from each participant. Each element of the observational tests is described in the following sections.

\section{$\underline{\text { Pilot Studies }}$}

Prior to developing the sample for the observational tests conducted in the transit information and marketing field test, CUTR conducted two pilot studies to test the usefulness of the trip planning tasks and materials. One pilot study was conducted with university students as part of their Psychology coursework and another pilot study was conducted with transportation professionals at the CUTR. A total of 17 individuals participated in the two pilot studies. The transit trip planning tasks and post planning interview guide (discussed below) were revised based on the results of the pilot studies. The results of the two pilot studies were analyzed separately from the final study sample and are discussed in a later section of this chapter.

\section{Field Test Sample Development}

The intent of the transit information and marketing field test was to assess the user-friendliness and effectiveness of transit information materials among individuals with little to no transit experience. Therefore, the primary aim of sample development in the field test was to identify participants who represent variations exhibited in the general public. Mall intercept recruitment methodology was used to identify field test participants. CUTR contracted with market research companies in four shopping malls in the Tampa Bay region to carry out participant recruitment. The four malls were chosen to represent a wide range of demographic characteristics. Three anthropologists from the University of South Florida traveled to each mall site where they were provided interview space. Staff from each market research firm recruited participants from the mall based on demographic requirements provided by CUTR. Each participant was provided a $\$ 5.00$ incentive as compensation for 30 to 40 minutes of his or her time. A total of 80 individuals were recruited for participation in the transit information and marketing field test.

\section{Trip Planning Activities \& Observations}

Two trip planning tasks were developed for each of the transit information materials included in the observational tests. The trip planning tasks developed included trip planning instructions for a simple transit trip and a complex transit trip, the presentation of transit information 
materials, and verbal explanation of the tasks, as well as an introduction to the transit information materials. In addition to the presentation of the trip planning tasks, verbal instructions introduced each participant to general elements of transit information materials including the concepts of systemwide route maps, bus routes, and timetables. In addition, the origins and destinations were marked on the materials for participants who received extensive and complex transit systems such as Miami-Dade Transit or LYNX in Orlando.

Each participant was presented two transit trip planning tasks: one simple trip and one complex trip. The presentations of trip planning tasks were randomized by complexity and transit information materials. For the purpose of the present study, a simple transit trip is defined as a trip that could be completed on a single bus route and a complex transit trip is one that requires the transfer from one bus route to a second bus route. The transit trip planning activities that were developed for the observational tests included information on the day of the week and the time of day of the intended transit trip. In addition, the instructions detailed the origin and the destination of the trip and the intended arrival time. An example of the instructions provided to participants for a simple transit trip follows:

You are on the corner of Grant St and Paper Dairy Rd on Sunday morning. You must get to the Downtown Bus Station by 8:30 AM. What is the most direct route(s) to take in order to get there on time? Please note any required transfers. Assume that you are on time if you arrive on or before the destination time. Please choose the arrival time that is closest to your required destination time and the listed bus stop that is nearest to your destination.

The instructions provided for a complex transit trip are illustrated in the following example:

You must get from University of Central Florida (UCF) to Apopka City Hall by 12:30 PM on Friday. What is the most direct route(s) to take in order to get there on time? Please note any required transfers. Assume that you are on time if you arrive on or before the destination time. Please choose the arrival time that is closest to your required destination time and the listed bus stop that is nearest to your destination.

Depending on the transit information materials presented, participants were required to use a systemwide bus route map to locate their origin and destination and route(s) necessary to complete the intended trip and then either turn to the individual route information contained in the system ride guides or choose the individual route information from a sample of single route information materials presented with the systemwide bus route map. In the cases of trips that were planned using systemwide route maps in conjunction with individual bus route schedules, the participants were presented from four to seven bus route schedules to choose from - one 
or two of which were necessary to complete the assigned transit trip plan and three to six unnecessary bus route schedules. All transit trip origins and destinations were clearly marked points of interest on the systemwide bus route maps presented to participants or, in the cases of extensive transit systems, were depicted on the materials using adhesive dots. Participants were asked to locate their origin and destination as defined in the trip planning instruction, determine the most direct bus route from their origin to their destination, the bus stop listed on the timetable closest to their origin and the best time to catch the origin bus in order to reach their destination by the intended time. Time points were used as bus stops in the assigned transit trip plans because the task of conceptualizing the location of an unlisted bus stop was considered to be too difficult for individuals with little to no transit experience. Participants also were instructed to choose the closest destination bus stop and disembarking time. For complex trips, participants also were required to identify the best transfer bus route, transfer bus stop and transfer time. The trip planning tasks were timed and participants were given eight minutes to plan a simple transit trip and ten minutes to plan a complex trip. The observers/interviewers noted the total time required to complete each task, including whether the participant was unable to complete the task in the allotted time or the participant "gave up" and refused to continue with the planning task. In addition, the observers/interviewers noted indications of emotional responses to the tasks, such as nervousness, frustration, anger, and/or any references to areas of apparent difficulty with the task. The incidence and content of any requests for assistance also were noted by observers/interviewers. A copy of the observation guide used by observers/interviewers is included in Appendix B.

\section{Post-Planning Interviews}

Each trip planning activity was followed by a post-planning interview wherein participants were queried about their experiences using the various information aids and any difficulties encountered. The post-planning interviews were conducted using an interview guide that consisted of close-ended and open-ended questions regarding participant impressions of the trip planning tasks and the transit information materials used in the trip planning tasks. The information obtained from the brief post-planning interviews was designed to provide supplemental data on the ease of use of the transit information materials and overall impressions of the task of planning a transit trip. Following each trip planning task, participants were asked to rank the task in terms of difficulty - from extremely difficult to extremely easy. Next, participants were queried about how they would feel in the event that they were actually planning to take a trip by bus and could only rely on the presented transit information materials to plan their trip. Participants also were asked to discuss their general impressions of the information materials, what they considered to be the most difficult or least understandable part of using the materials, and what they considered to be the least difficult or most understandable part of using the materials. Finally, participants were questioned regarding their familiarity with the area presented to them in the trip planning task. Following the 
completion of the second post-planning interview, each participant also was asked to rate several aspects of bus service, based on their general feelings and opinions about public bus service. Participants were asked to rate the following aspects of bus service:

- Convenience

- Comfort

- Dependability

- Personal Safety

- Transit Information

- Flexibility

- Availability

- Vehicle Safety

Next, participants were asked about how the trip planning task may have impacted their confidence in terms of planning a trip on the public bus and whether or not participation in the observational test would result in a greater likelihood of using public bus service. A copy of the interview guide is included in Appendix C. Following the post-planning interview, each participant completed a post-test questionnaire that collected information pertaining to the participant's gender, age, ethnicity, personal income, education level, automobile ownership, and experience with public transit. These data were coded with the participant number for later analysis in connection to trip planning results. A copy of the demographics questionnaire is included in Appendix D.

\section{$\underline{\text { Data Analysis }}$}

Each simple and complex trip planning task was scored according to the choices made by participants in relation to the following 10 data elements:

- Able to travel from origin to intended destination

- On-time arrival to destination

- Origin bus route

- Origin bus stop

- Origin time

- Transfer bus route (complex trip only)

- Transfer bus stop (complex trip only)

- Transfer time (complex trip only)

- Destination bus stop

- Destination time 
The quantitative assessment of participant responses to these data elements resulted in a composite score for each transit trip planning task attempted by participants. A detailed description of scoring methodology is provided in the Quantitative Results section of this chapter. Copies of the participant trip planning worksheet and score sheet are included in Appendix E. Statistical tests were applied to the quantitative data to determine the statistical significance of demographic characteristics, socioeconomic characteristics, and design elements on the final score associated with transit trip planning tasks. The statistical analysis is discussed in greater detail in later sections of Chapter Four.

In addition to the quantitative analysis presented for the transit trip planning data collected as part of the transit information and marketing field test, the results of the analysis of qualitative interview data collected from field test participants is also provided. These data were coded and analyzed according to the most salient themes emerging from participant responses to interview questions. Taken together, the results of the quantitative and qualitative data collected in the transit information and marketing field test provide tremendous insight into the effectiveness and user-friendliness of existing transit route and schedule information materials. 


\section{Results: Quantitative Analysis of Transit Trip Planning Ability}

As described previously, the transit trip planning portion of the field test was based upon a mixed model design, incorporating a "within subject" design element (each participant completed a simple session and a complex session with the randomized presentation order of simple and complex trip planning tasks) with "between subject" elements. The between subject elements included the materials used. There were 22 examples of transit information materials used for simple trip planning tasks and 20 examples of transit information materials used for complex trip planning tasks. Each information item also was categorized as varying on three dimensions of design elements:

\section{- Alignment of timetables}

1. Horizontal (see Figure 3-1)

2. Vertical (see Figure 3-2)

- Route information presentation

1. Single routes with systemwide map (see Figure 3-3)

2. All-in-One Ride Guide (see Figure 3-4), and

\section{- Transfer information presentation}

1. Listed on map and on timetable (see Figure 3-5)

2. Listed on map only, not on timetable (see Figure 3-6)

3. Not on map, listed on timetable only (see Figure 3-7)

4. Not listed (see Figure 3-8)

5. Listed elsewhere (e.g., front of route schedule pamphlet) (see Figure 3-9)

The materials used in the field test also were randomized, with a randomization matrix developed for each administration of the study so that no material was over sampled. There were three primary continuous dependent measures (total time to complete and two variations of a composite score), although whether participants completed the tasks or not also was used for preliminary analyses. Task difficulty also was treated as a dependent measure. Total time to complete (hereafter called TotTime) was available for all people who completed the task within the allotted time (8-minute maximum for simple trip planning tasks, 10 minutes for complex trip planning tasks).

Scoring of the trip planning tasks was completed using two variations of a composite score scheme. Each simple transit trip planning task contained 7 scorable events and each complex session had 10 scorable events (described previously). (Please refer to the participant score sheet contained in Appendix $\mathrm{E}$ for a complete list of scorable events for both simple and complex transit trip planning sessions.) In scoring variation one (hereafter referred to as 
Compos1a), each of the seven scorable events were valued as 3 points for a "yes" response or 0 points for a "no" response, with a maximum value of 21 possible (after adjustment for complex sessions, explained below). In the second scoring variation (hereafter referred to as Compos2a), weighting was added to the scoring scheme to provide more points for the scorable events determined to be most important to transit customers - ability to travel from the origin to the destination and arriving at the destination on-time. Therefore, in the Compos2a scoring scheme, 5 of the 7 scorable events for simple trip planning sessions and 8 of the 10 scorable events in complex trip planning sessions were valued as 3 points for a yes response and 0 points for a "no" response, and the remaining 2 scorable events were valued at 5 points for a yes response or 0 points for a "no" response, with a maximum value of 25 possible points. Scores for complex trip planning sessions were adjusted (summated composite score multiplied by 0.7 for Compos1a, 0.735 for Compos2a) in order to maintain a consistent scaling. Additionally, participants were asked to rate the difficulty of each session (using a 7-point scale, with ratings of $1=$ extremely easy, to $7=$ extremely difficult).

Additional information gathered for the study included participant ratings of specific characteristics of public bus service (convenience, comfort, dependability, personal safety, transit information, flexibility, availability, and vehicle safety), using a 5-point Likert-style scale (with ratings of $1=$ low, to $5=$ high). Participants also were asked to report whether they were familiar with the cities used in the materials presented, as well as whether participation in the exercise increased their confidence in planning a trip using public transportation and whether participation in the exercise increased their likelihood of using public transportation. Observers also evaluated visual symptoms of frustration, annoyance, and nervousness as the participants completed the experimental sessions. Finally, observers also asked a series of open-ended questions following the completion of both sessions.

\section{Findings}

The findings section has been compartmentalized into sections, including pilot study data, final study comparisons, simple condition comparisons, and complex condition comparisons. There also is a brief section regarding the materials used in sessions that people either could not complete or decided to quit the task prior to completion (includes participants who quit only one trip planning task of the two tasks, as well a section dealing with individuals who quit both trip planning sessions). Descriptive statistics (number, mean, and standard deviations) and frequency data are presented in each section (with additional tables containing relevant data located in appendices). Additionally, where appropriate, mean comparison analyses (t-test or analysis of variance [ANOVA]) have also been conducted, and reported. 
Figure 3-1

Horizontal Timetable Alignment Example

ROUTE 17 WASHINGTON ST. \& HWY. $441 \cdot$ WASHINGTON ST. \& S. 37 AVE. • JOHNSON ST. \& N. 35 AVE.

EFFECTIVE DECEMBER 27, 1998

\section{WEEKDAY}

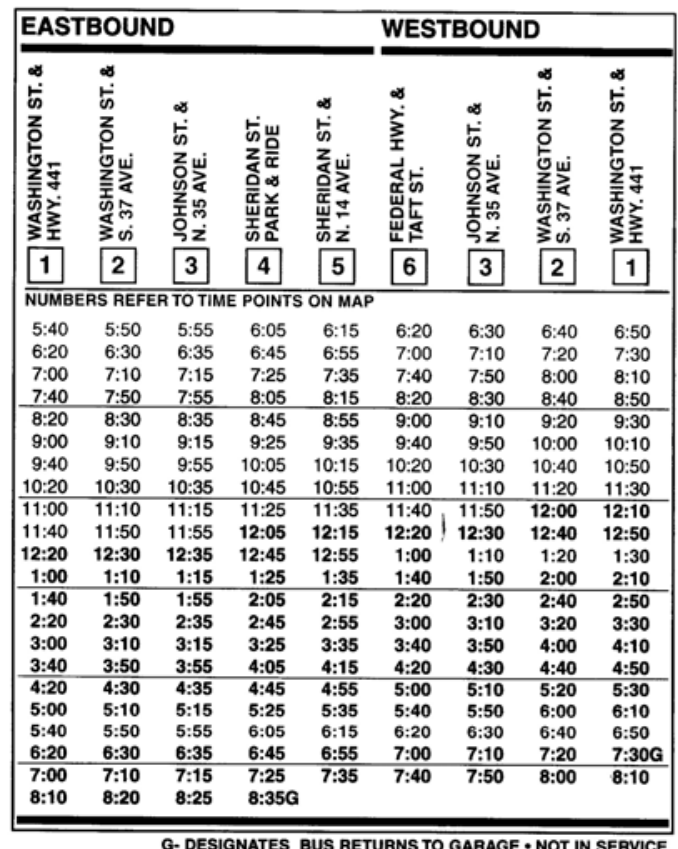

BOLD TYPE INDICATES P.M. HOURS
BOA TO

\begin{tabular}{|c|c|c|c|c|c|c|c|c|}
\hline \multicolumn{5}{|c|}{ EASTBOUND } & \multicolumn{4}{|c|}{ WESTBOUND } \\
\hline 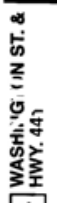 & 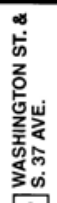 & 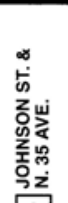 & 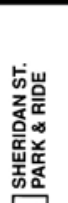 & 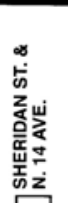 & 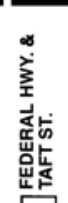 & 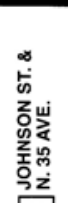 & 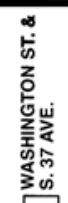 & 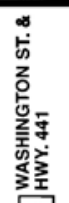 \\
\hline 1 & 2 & 3 & 4 & 5 & 6 & 3 & \begin{tabular}{|l|}
2 \\
\end{tabular} & 1 \\
\hline \multicolumn{9}{|c|}{ NUMBERS REFER TO TIME POINTS ON MAP } \\
\hline & & & & & 6:20 & 6:30 & $6: 40$ & $6: 50$ \\
\hline $6: 20$ & 6:30 & $6: 35$ & $6: 45$ & $6: 55$ & 7:00 & 7:10 & 7:20 & $7: 30$ \\
\hline $7: 00$ & $7: 10$ & 7:15 & $7: 25$ & $7: 35$ & $7: 40$ & 7:50 & $8: 00$ & $8: 10$ \\
\hline $\begin{array}{l}7: 40 \\
\end{array}$ & $7: 50$ & $7: 55$ & 8:05 & $8: 15$ & $8: 20$ & $8: 30$ & $8: 40$ & $8: 50$ \\
\hline $8: 20$ & $8: 30$ & $8: 35$ & $8: 45$ & $8: 55$ & $9: 00$ & $9: 10$ & $9: 20$ & $9: 30$ \\
\hline $9: 00$ & 9:10 & 9:15 & $9: 25$ & $9: 35$ & $9: 40$ & $9: 50$ & $10: 00$ & $10: 10$ \\
\hline $9: 40$ & 9:50 & 9:55 & 10:05 & $10: 15$ & $10: 20$ & $10: 30$ & $10: 40$ & $10: 50$ \\
\hline $10: 20$ & $10: 30$ & $10: 35$ & $10: 45$ & $\begin{array}{l}10: 55 \\
\end{array}$ & $11: 00$ & $11: 10$ & $11: 20$ & $11: 30$ \\
\hline 11:00 & $11: 10$ & $11: 15$ & $11: 25$ & $11: 35$ & $11: 40$ & $11: 50$ & 12:00 & $12: 10$ \\
\hline $11: 40$ & $11: 50$ & $11: 55$ & 12:05 & 12:15 & $12: 20$ & $12: 30$ & $12: 40$ & $12: 50$ \\
\hline $12: 20$ & $12: 30$ & 12:35 & 12:45 & 12:55 & $1: 00$ & 1:10 & 1:20 & $1: 30$ \\
\hline 1:00 & 1:10 & 1:15 & 1:25 & 1:35 & $1: 40$ & 1:50 & 2:00 & 2:10 \\
\hline $1: 40$ & $1: 50$ & 1:55 & 2:05 & 2:15 & $2: 20$ & $2: 30$ & $2: 40$ & $2: 50$ \\
\hline & $2: 30$ & 2:35 & $2: 45$ & 2:55 & 3:00 & 3:10 & $3: 20$ & $3: 30$ \\
\hline 3:00 & 3:10 & 3:15 & $3: 25$ & $3: 35$ & $3: 40$ & 3:50 & 4:00 & 4:10 \\
\hline $3: 40$ & 3:50 & 3:55 & 4:05 & $4: 15$ & $4: 20$ & $4: 30$ & 4:40 & 4:50 \\
\hline $4: 20$ & $4: 30$ & $4: 35$ & $4: 45$ & $4: 55$ & 5:00 & 5:10 & $5: 20$ & $5: 30$ \\
\hline & $5: 10$ & 5:15 & $5: 25$ & $5: 35$ & $5: 40$ & 5:50 & $6: 00$ & $6: 10$ \\
\hline $5: 40$ & $5: 50$ & 5:55 & $6: 05$ & $6: 15$ & $6: 20$ & $6: 30$ & $6: 40$ & $6: 50$ \\
\hline $6: 20$ & $6: 30$ & $6: 35$ & $6: 45$ & $6: 55$ & $7: 00$ & $7: 10$ & $7: 20$ & $7: 30 \mathrm{G}$ \\
\hline $7: 00$ & $7: 10$ & $7: 15$ & $7: 25$ & $7: 35$ & $7: 40$ & $7: 50$ & $8: 00$ & 8:10 \\
\hline $8: 10$ & 8:20 & 8:25 & $8: 35 G$ & & & & & \\
\hline
\end{tabular}


Figure 3-2

\section{Vertical Timetable Alignment}

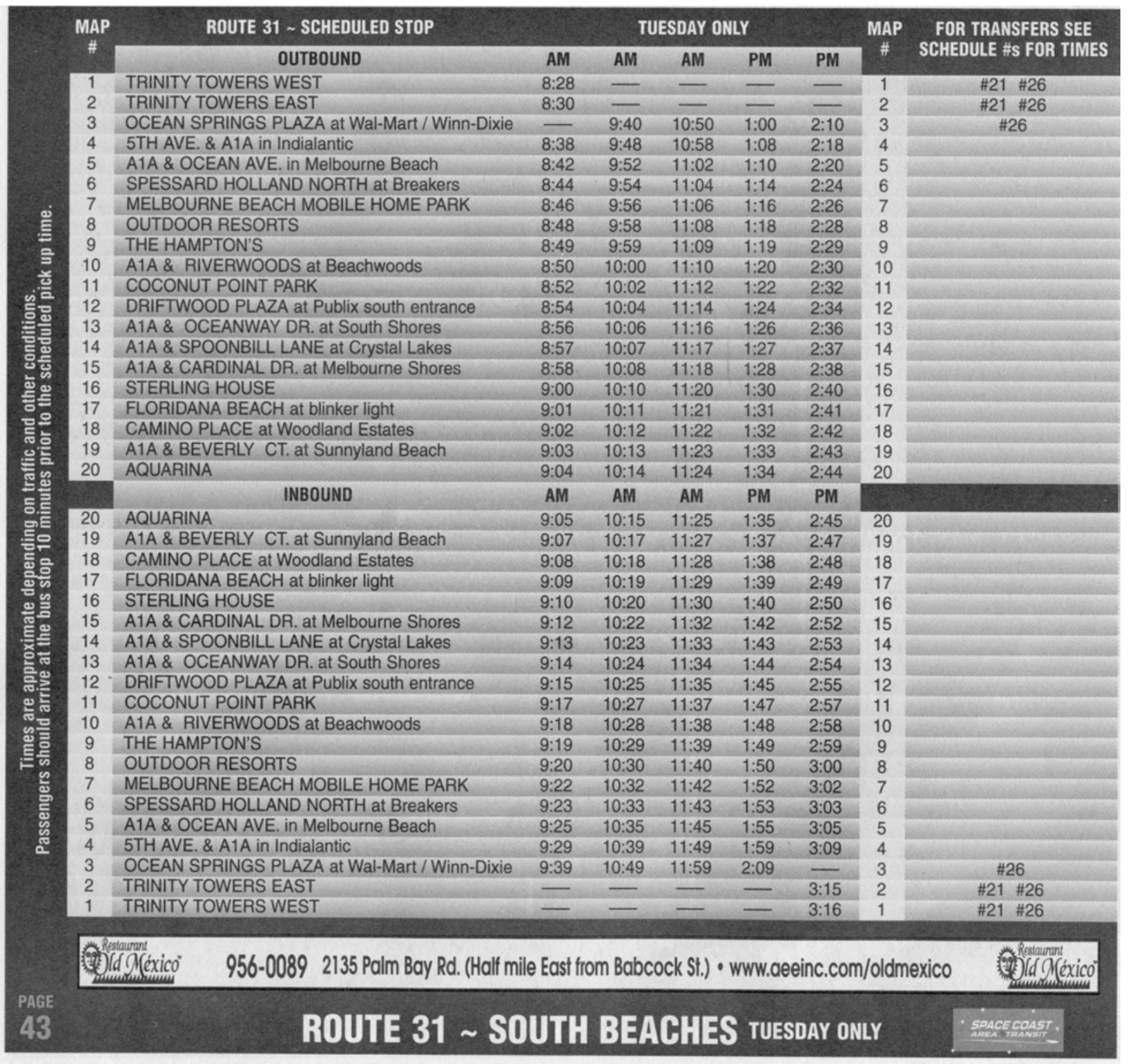


Figure 3-3

Single Route Presentation Example

LINK 44

Clarcona/Zellwood

Monday - Saturday service

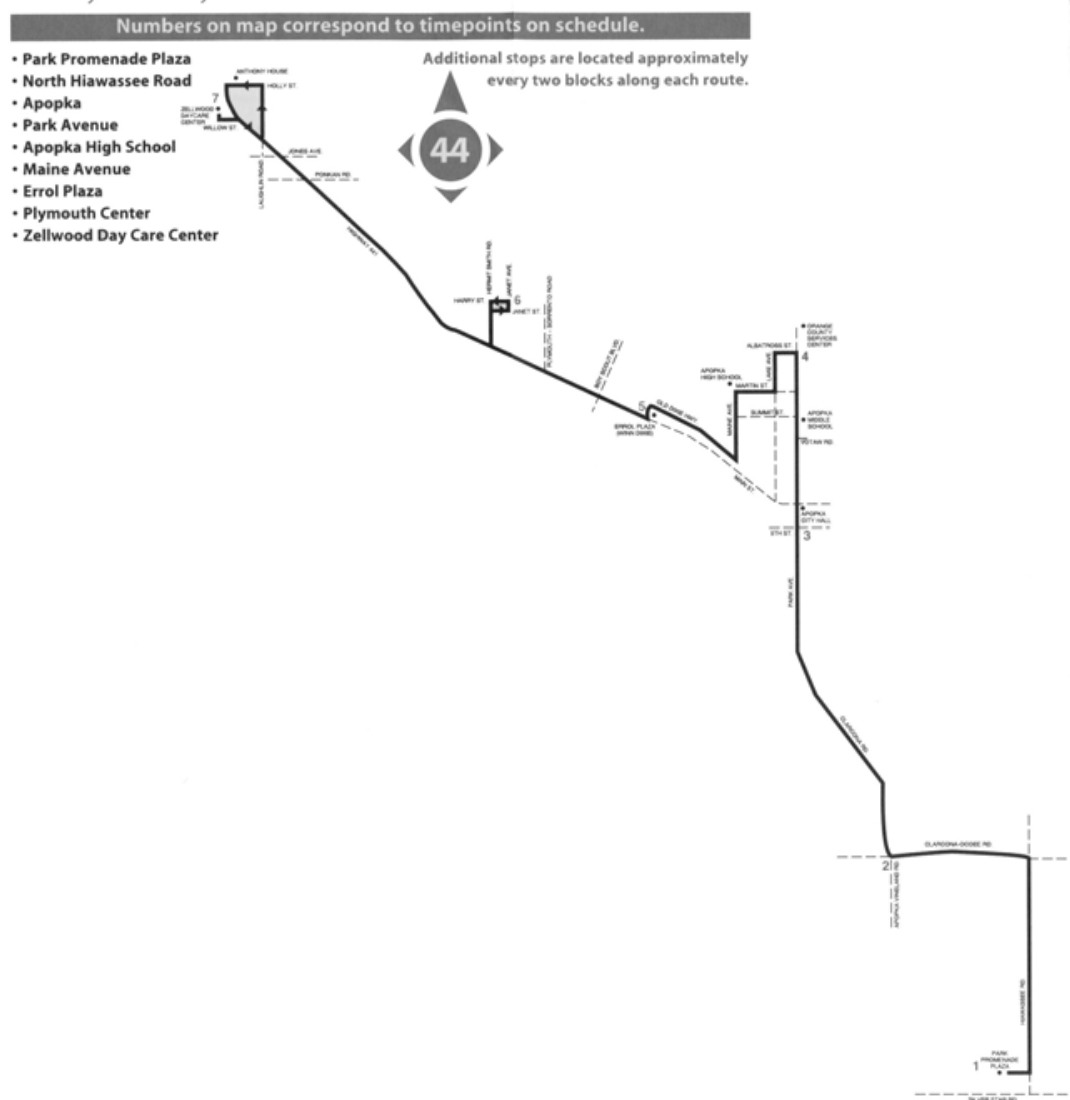

LINK 44 Clarcona/Zellwood

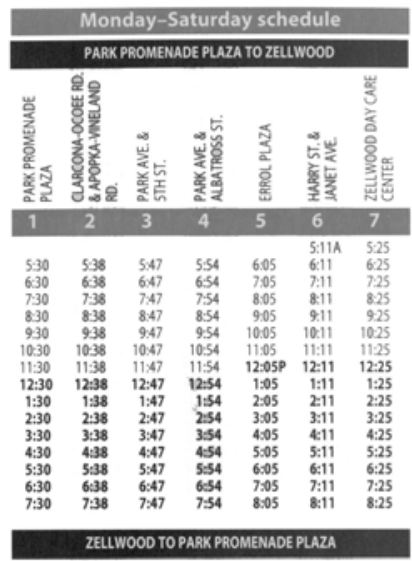


Figure 3-4

All-in-One Ride Guide Example

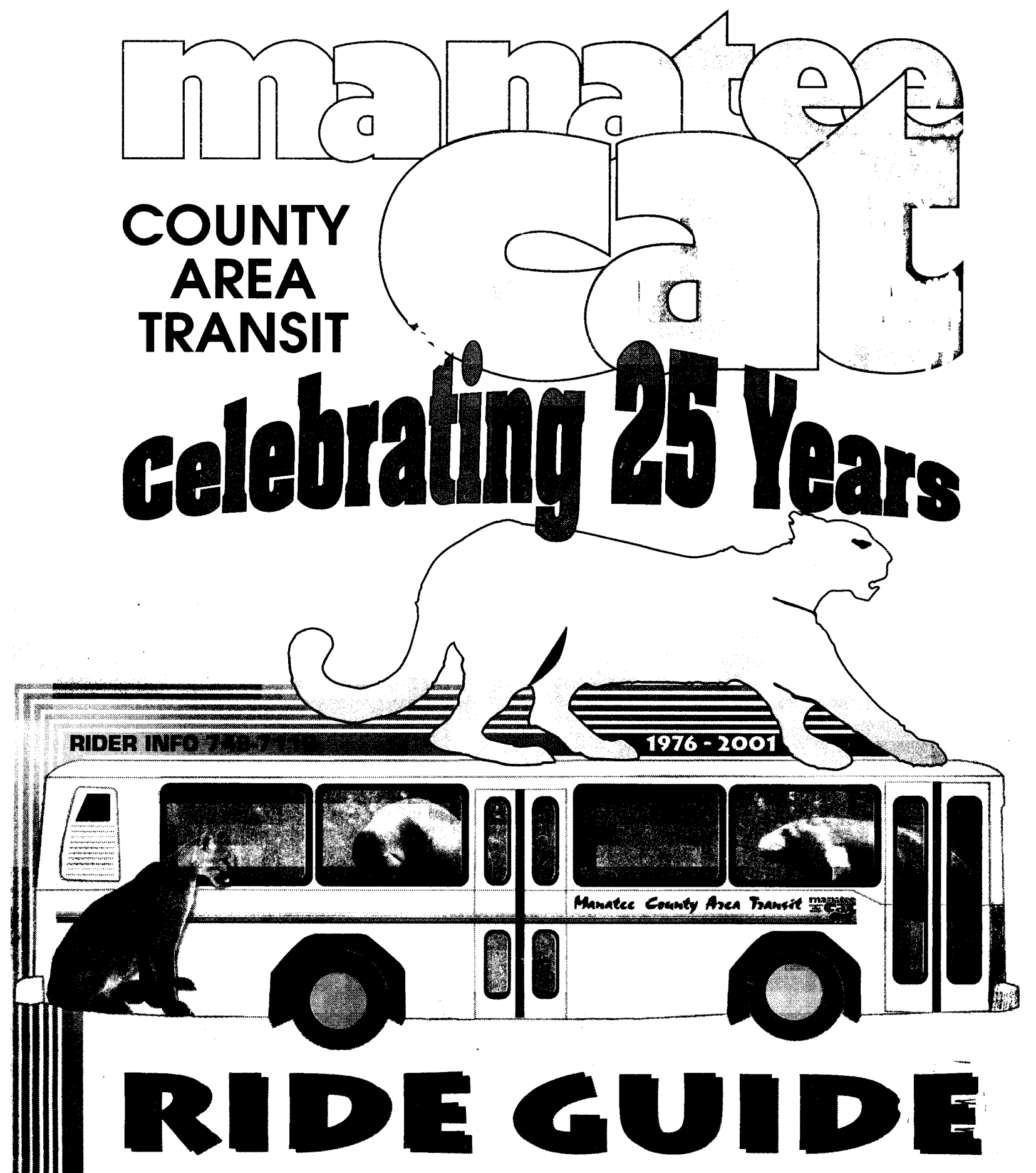

A SERVICE OF MANATEE COUNTY GOVERNMENT

Monday through Saturday Service Plus Tripper Service Mon. through Fri. EFFECTIVE JANUARY 22, 2001 
Figure 3-5

Transfer Information Listed on Map and on Timetable Example

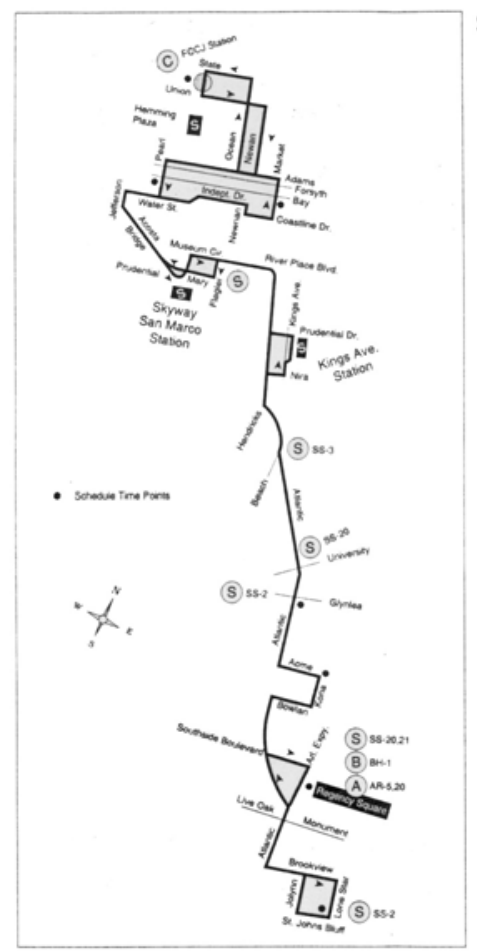

SS-1 Atlantic Blvd. Effective October 2, 2000

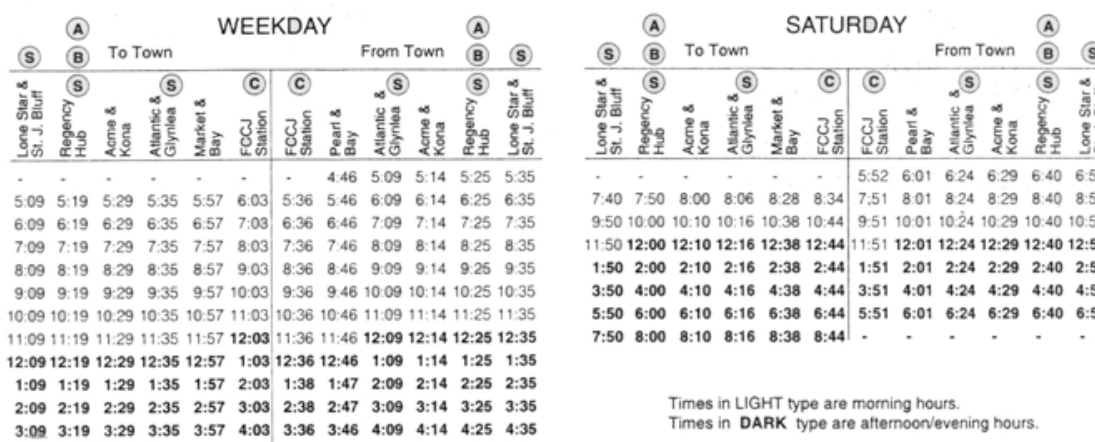

Times in DARK type are afternoonlevening hours. $\begin{array}{lllllllllllll} & 4: 19 & 4: 29 & 4: 35 & 4: 57 & 5: 03 & 4: 36 & 4: 46 & 5: 09 & 5: 14 & 5: 25 & 5: 35\end{array}$ $\begin{array}{llllllllllllll} & 09 & 5: 19 & 5: 29 & 5: 35 & 5: 57 & 6: 03 & 5: 36 & 5: 46 & 6: 09 & 6: 14 & 6: 25 & 6: 35\end{array}$

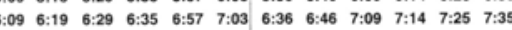

$\begin{array}{llllllllllllll}7: 09 & 7: 19 & 7: 29 & 7: 35 & 7: 57 & 8: 03 & 7: 36 & 7: 46 & 8: 09 & 8: 14 & 8: 25 & 8: 35\end{array}$

Connecting Points to Other Lines: c) All regular Buses \& Skyway Serving FCCJ Station W. Westside Line

(N) Northside Line

A) Arlington Line

(B) Beaches Line

(s) Southside Line

S Skyway Station

IIA

JACKSONVILLE TRANSPORTATION AUTHORITY 
Figure 3-6

Transfer Information Listed on Map Only Example

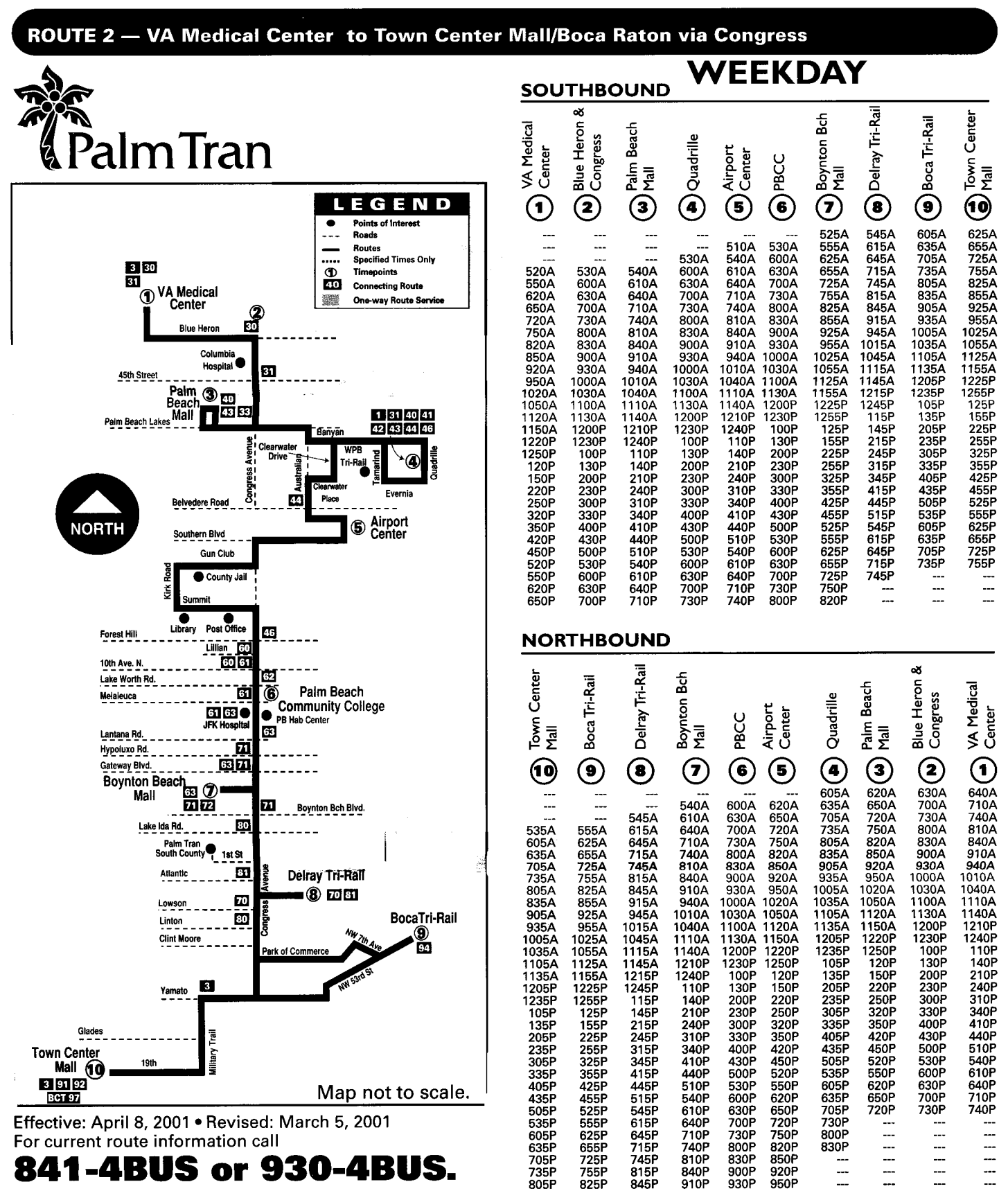


Figure 3-7

Transfer Information Listed on Timetable Only Example
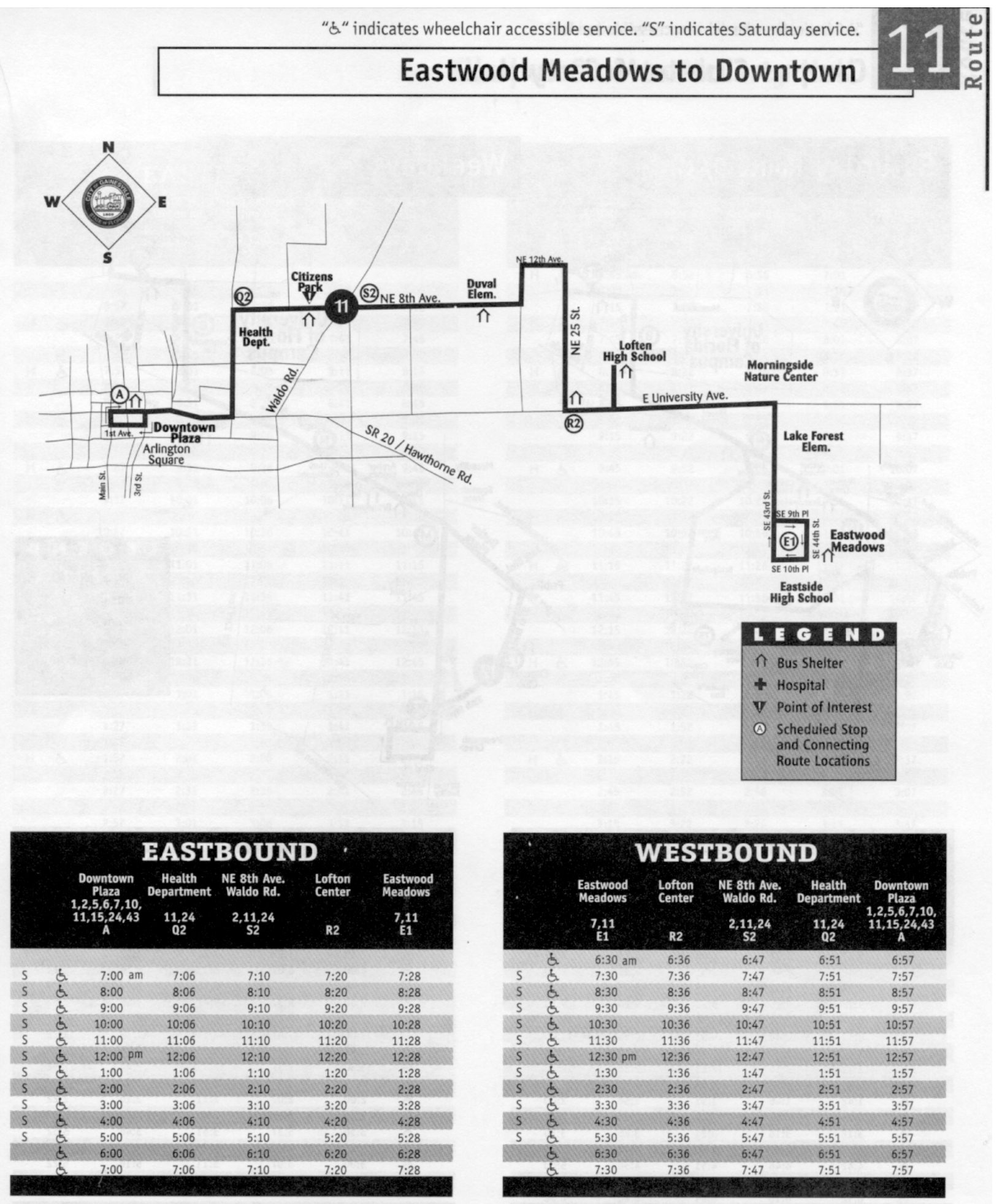
Figure 3-8

\section{Transfer Information Not Listed on Map or Timetable Example}

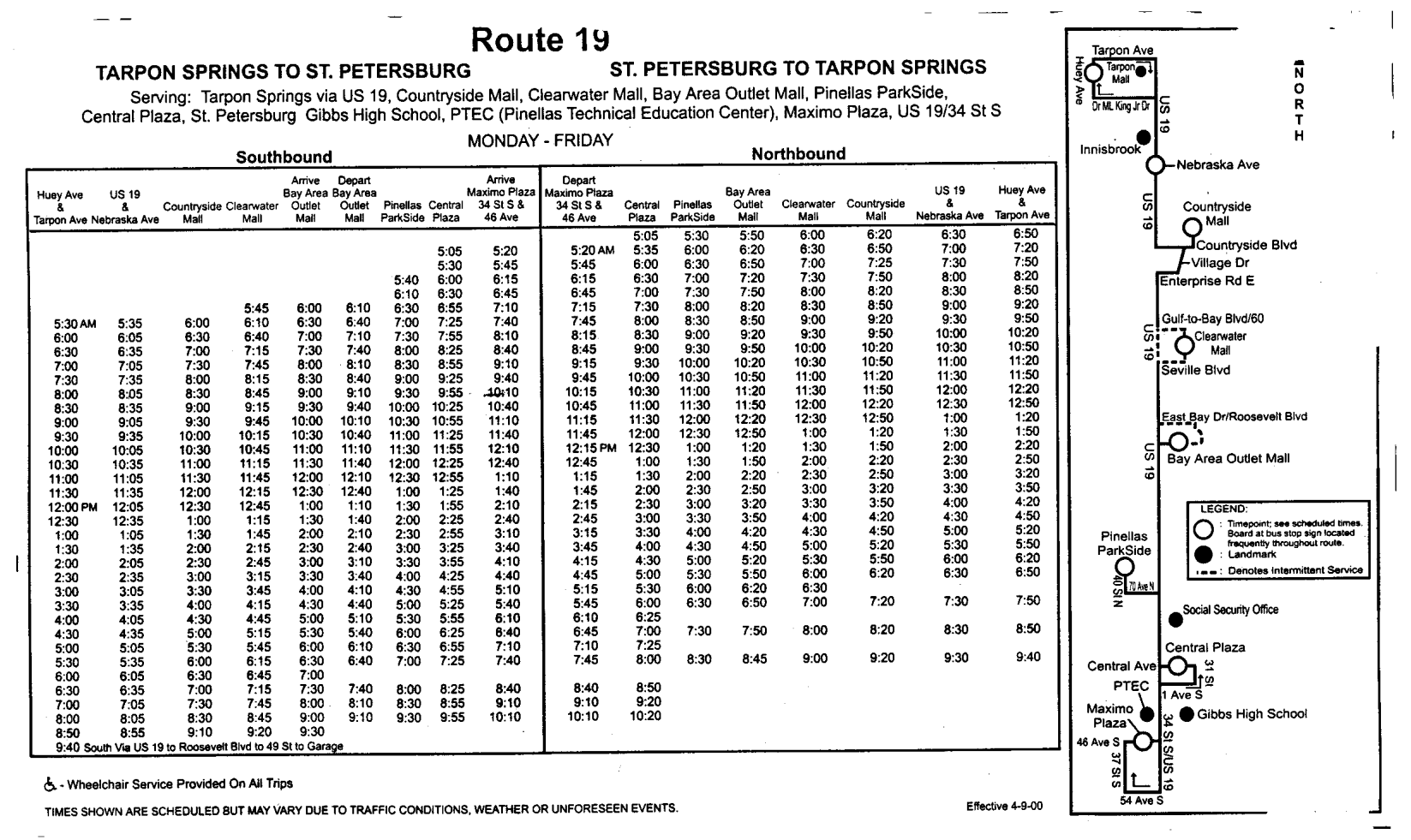


Figure 3-9

Transfer Information Listed Elsewhere Example
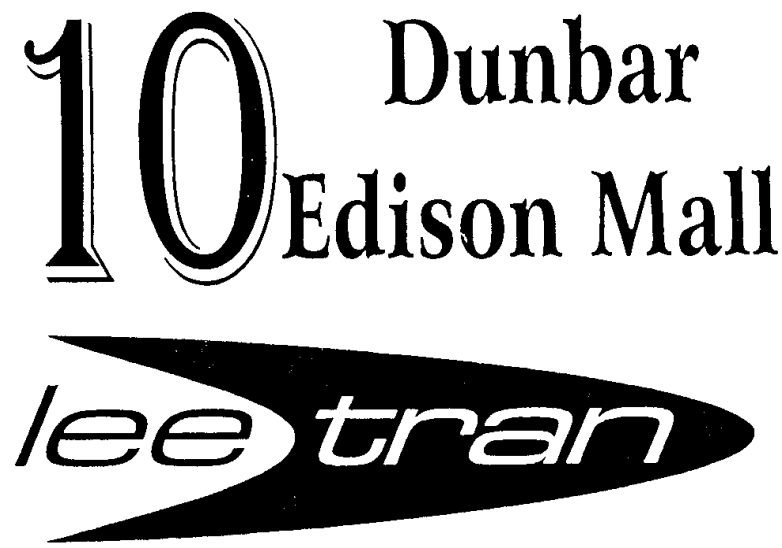

Your Ride Is Here.

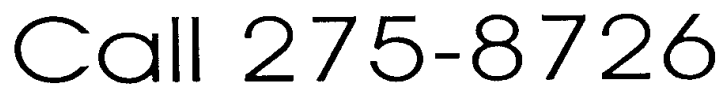

Www.lee-county.com

NOW OFEERING LIMIEE SUNDAY SERVICE

SERVICING:

5. Michigan Links 3 Carrell Corners

s Health Dept./ \ S.W. Regional

Hightech central Hospital

$\checkmark$ Monroe Station 3$\}$ Edison Mall

Downtown

Wheelchair accessible buses available

on most routes. Call us for details

TRANSFERS at MONROE:

Routes $20,70,100,140$

TRANSFERS at VO-TECH

Routes $20 \& 100$

TRANSFERS at EDISON MALL:

Routes $80,110,120,130 \& 140$

Revised 7/21/00 


\section{Pilot Study Findings}

After preparation of all materials and design of the study, the transit information and marketing field test methodology was implemented using a small group of participants, including research assistants, interns, and transportation professionals. Seventeen individuals participated in this pilot study. The primary intent of the pilot study was to test the research design and trip planning instruments so that necessary revisions could be implemented prior to the final study. The mean age of pilot study participants was 32.8 years, with 8 males and 9 females. Sixty-five percent of the participants were White, 18 percent were of Hispanic origin, while 6 percent reported being black/African-American. Fifty-three percent of the respondents reported income levels of $\$ 51,000$ to $\$ 74,000$, with 24 percent reporting income levels of $\$ 31,000$ to $\$ 50,000$. The remaining participants reported income below $\$ 31,000$. All participants of the pilot study reported having at least some college, with 35 percent reporting having a college degree, and 41 percent of participants reported post-graduate experience. Sixty-one percent of pilot study participants reported having one or two household vehicles, with 17 percent reporting no household vehicles, and 12 percent reporting 3 or more household vehicles.

There were three trip planning sessions that were not structured properly and could not be completed as designed. Therefore, for the pilot study, data were gathered from 17 simple trip planning tasks, and from 16 complex trip planning tasks. As illustrated in Table 3-1, the average score for the simple transit trip planning tasks was 14.29 out of 21 total possible points, which equates to a "grade" of 68 percent using Compos1a. The scores using Compos2a also were quite low - 17.24 points out of 25 total possible points (69 percent out of a possible 100 percent). The average scores for the complex trip planning tasks were somewhat lower at 11.94 points out of 21 possible points (57 percent) using Compos1a and 14.10 points out of 25 total possible points (56 percent) using Compos2a. Although the average scores for the simple trip planning tasks were higher than scores for the complex trip planning tasks (14.29 points compared to 11.94 points using Compos1a, 17.24 points compared to 14.10 points using Compos2a), this difference was not statistically significant.

A t-test was conducted for order of presentation, but it was not significant. Pilot study participants were able to complete all of the simple sessions, but completed only 56 percent of the complex sessions. There was a significant difference in the total time to complete, $(\mathrm{t}(24)=$ $2.66, \mathrm{p}<.05)$, as participants completed the simple sessions in an average of 5.32 minutes, and completed the complex sessions in an average of 7.44 minutes. Participants in the pilot study rated the trip planning tasks as fairly difficult with simple tasks receiving the average difficulty rating of 4.12 out of 7 and complex tasks receiving an average difficulty rating of 5.56 out of 7. A t-test also was conducted for ratings of task difficulty and, as expected, participants rated the complex trip planning tasks (mean $=5.56$ ) as more difficult than the simple trip 
planning task (mean $=4.12),(\mathrm{t}(31)=2.34, \mathrm{p}<.05)$. Consistent with the difficulty ratings, observers reported more visible signs of emotion, 16 for complex, 11 for simple, with frustration being the most frequently viewed emotion. (Table 3-11, presented in a later section, contains a summary of reported emotions in all phases of the study.)

Table 3-1

Dependent Measures in Pilot Study: Comparison of Simple and Complex Tasks

\begin{tabular}{|l|c|c|c|c|c|c||}
\hline Measure & \multicolumn{3}{|c|}{ Pilot - Simple Only } & \multicolumn{3}{c||}{ Pilot - Complex Only } \\
\hline \hline & N & Mean & St. Dev. & N & Mean & St. Dev. \\
\hline Compos1a Score & 17 & 14.29 & 8.18 & 16 & 11.94 & 7.34 \\
\hline Compos2a Score & 17 & 17.24 & 9.85 & 16 & 14.10 & 8.87 \\
\hline TotTime (in mins.) & 17 & 5.32 & 1.74 & 9 & 7.44 & 2.30 \\
\hline Task Difficulty Rating & 17 & 4.12 & 1.79 & 16 & 5.56 & 1.75 \\
\hline
\end{tabular}

Note. Maximum possible score for Compos1a was 21, for Compos2a maximum was 25. Maximum TotTime for simple sessions was 8 minutes, Maximum TotTime for Complex sessions was 10 minutes.

Please note that scores for participants in the pilot study are higher than those for participants in the final study, suggesting that college students and transportation professionals can generally complete these types of tasks more readily (especially the simple trip planning tasks). However, even college students and transportation professionals had considerable difficulty in completing the complex trip planning tasks. Additionally, college students and transportation professionals rated the trip planning tasks as difficult, especially the complex trip planning tasks. This finding will be discussed in greater detail in a later section.

Statistical tests (t-tests and ANOVAs) were conducted on pilot study data to identify possible relationships between the scores received by participants, total time to complete the trip planning tasks, and perception of task difficulty and the design elements included in the study, as well as participant demographic characteristics. A t-test was conducted for timetable alignment, but was not statistically significant. A t-test also was conducted for bus route presentation, but there were no significant differences when comparing participants in both simple and complex sessions combined. However, when analyzing the data for pilot study participants in the simple sessions only, participants scored higher when using route materials that consisted of schedule information for single routes rather than those defined as All-in-One Ride Guides (all routes and system map contained within a single booklet) ( $t(15)=2.05$, $p<$ .06 when using Compos1a; $\mathrm{t}(15)=2.07, \mathrm{p}<.06$ when using Compos2a). Participants also reported higher task difficulty for All-in-One Ride Guide materials ( $t(15)=2.19$, $p<.05$ ). 
Table 3-2 contains the breakdown of dependent measures by routes for the simple trip planning tasks and reveals that the average difficulty rating for the individual bus route presentation was 4.37 versus 5.43 for Ride Guide materials.

Table 3-2

Dependent Measures in Pilot Study Simple Sessions: Comparison of Route Materials

\begin{tabular}{|l|c|c|c|c|c|c||}
\hline Measure & \multicolumn{3}{|c|}{ Single Routes } & \multicolumn{3}{c|}{ Ride Guides } \\
\hline \hline & N & Mean & St.Dev. & N & Mean & St.Dev. \\
\hline Compos1a Score & 19 & 14.68 & 7.80 & 14 & 11.08 & 7.47 \\
\hline Compos2a Score & 19 & 17.71 & 9.30 & 14 & 13.02 & 9.11 \\
\hline TotTime (in mins.) & 16 & 5.78 & 2.12 & 10 & 6.50 & 2.27 \\
\hline Task Difficulty Rating & 19 & 4.37 & 2.11 & 14 & 5.43 & 1.40 \\
\hline
\end{tabular}

A t-test comparing gender differences was significant $(\mathrm{t}(31)=2.08, \mathrm{p}<.05)$, with males scoring an average of 16.08 points and females scoring an average of 10.72 points (using Compos1a). Similar patterns and results were found using Compos2a. Additionally, a t-test was conducted for total time to complete by gender, $(\mathrm{t}(24)=3.94, \mathrm{p}<.01)$, with males (mean $=7.28$ minutes) taking longer to complete the trip planning tasks than females (mean $=5.32$ minutes). Females also rated the task as more difficult than did males (both sessions, simple sessions, and complex sessions), although the various t-tests were not significantly different. Table 3-3 contains the means for the various dependent measures presented by gender. This finding of a general gender difference also was found in the final study, although the finding was not as strongly supported via statistical inference testing. This finding also is consistent with research findings indicating that males process spatial information differently than females.

Information also was collected related to the prevalence and content of requests for assistance. Twenty-four percent of participants requested assistance while working with simple trip planning tasks, while 50 percent of participants requested assistance while working with complex tasks. Due to the small sample size of the pilot study, no ANOVAs were conducted for transfer information presentation. 
Table 3-3

Dependent Measures in Pilot Study: Comparison by Gender

\begin{tabular}{|l|c|c|c|c|c|c||}
\hline \hline Measure & \multicolumn{2}{|c|}{ Pilot, Both Sessions } & \multicolumn{2}{c|}{ Pilot, Simple Only } & \multicolumn{2}{c|}{ Pilot, Complex Only } \\
\hline \hline & Male Mean & $\begin{array}{c}\text { Female } \\
\text { Mean }\end{array}$ & Male Mean & $\begin{array}{c}\text { Female } \\
\text { Mean }\end{array}$ & Male Mean & $\begin{array}{c}\text { Female } \\
\text { Mean }\end{array}$ \\
\hline Compos1a Score & $16.08(15)$ & $10.72(18)$ & $16.50(8)$ & $12.33(9)$ & $15.60(7)$ & $9.10(9)$ \\
\hline Compos2a Score & $19.19(15)$ & $12.82(18)$ & $20.00(9)$ & $14.78(9)$ & $18.27(7)$ & $10.86(9)$ \\
\hline TotTime (in mins.) & $4.62(12)$ & $7.29(14)$ & $4.18(8)$ & $6.33(9)$ & $5.50(4)$ & $9.00(5)$ \\
\hline $\begin{array}{l}\text { Task Difficulty } \\
\text { Rating }\end{array}$ & $4.27(15)$ & $5.28(18)$ & $3.38(8)$ & $4.78(9)$ & $5.29(7)$ & $5.78(9)$ \\
\hline
\end{tabular}

Note: Number of valid cases in parentheses.

Finally, pilot study participants completed ratings of specific characteristics of public bus service (convenience, comfort, personal safety, transit information, flexibility, availability, and vehicle safety). These ratings are reported in Table 3-4. The highest ratings (on a 5-point scale) received were for vehicle safety (mean $=3.88$ ) and personal safety (mean $=3.50$ ). Consistent with the findings of the literature review presented in Chapter One, the lowest ratings received were for flexibility (mean $=2.12$ ) and for convenience (mean = 2.35). Additionally, 41 percent of the participants reported some familiarity with the geographic areas covered in the transit information materials that they worked with in the transit trip planning tasks. Thirty percent of respondents also reported greater confidence in planning a future trip using public transportation, but only 12 percent reported an increased likelihood of actually using public transportation as a result of their participation in the field test.

Table 3-4

Specific Characteristics of Public Bus Service (Pilot Study)

\begin{tabular}{|l|c|c||}
\hline Characteristic & Mean & St. Dev. \\
\hline \hline Convenience & 2.35 & 0.99 \\
\hline Comfort & 3.23 & 1.15 \\
\hline Personal Safety & 3.50 & 1.27 \\
\hline Transit Information & 2.76 & 0.97 \\
\hline Flexibility & 2.12 & 0.99 \\
\hline Availability & 2.47 & 1.07 \\
\hline Vehicle Safety & 3.88 & 1.22 \\
\hline
\end{tabular}

Note: $\mathrm{N}=17$; Rating of $1=$ low, $5=$ high; No ratings available for dependability. 


\section{Pilot Study Discussion}

As described previously, the preliminary phase of the transit information and marketing field test was conducted with university students and transportation professionals. Of the 17 participants in the preliminary study, 13 were transportation professionals. As described previously, the primary focus of the pilot study was to test the research design and trip planning instruments so that necessary revisions could be made prior to the final study. However, the results from the preliminary phase study also provided insight into the usability of the transit information materials used in the transit information and marketing field test. As reported earlier, the average score received by participants in the pilot study was 14.3 (approximately 68 percent) using Compos1a, or 17.2 (approximately 69 percent) using Compos2a, for the simple trip planning tasks. Average scores for complex trip planning tasks were even lower - 11.9 (approximately 57 percent) using Compos1a or 14.1 (approximately 56 percent) using Compos2a. These scores are particularly telling given that 76 percent of the pilot study participants were transportation professionals who had some familiarity with public transit and transit information materials. It is, therefore, of significant note that many of these individuals experienced difficulty when faced with the challenge of planning a transit trip using existing Florida transit information materials. Although some individuals in the pilot study received perfect scores, most participants did have some difficulty with one or both trip planning tasks presented to them. These findings are consistent with ratings of task difficulty received from the participants of the pilot study, where the simple trip planning tasks received an average difficulty rating of 4.12 and the complex tasks received an average difficulty rating of 5.56 on a 7-point scale.

In addition to having very specific comments related to how the transit information materials could be improved, participants in the pilot study also exhibited many visible signs of emotion during the trip planning tasks and also made many comments related to their emotional reactions to the tasks presented to them. Most of the participants exhibited signs of anxiety and discomfort while completing the trip planning tasks. As described previously, the observers/interviewers reported many visible signs of emotion from the pilot study participants, especially frustration, irritation, and laughter. The visual cues reported by interviewer/observers are consistent with the verbal expressions of emotions expressed by participants in relation to the transit trip planning tasks that they were asked to complete. When asked how they would feel if they were planning to take an actual bus trip using the materials presented in the field test, many participants commented that trying to use the materials made them feel very frustrated and lacking in confidence. Taken together, these findings suggested to the research team that the task of planning a transit trip using existing transit information materials would present a significant challenge to individuals with little to no transit experience. This hypothesis was supported by the findings from the final field test study. Those findings are presented in the following sections of Chapter Four. 


\section{Final Study Findings}

There were initially 80 participants recruited from four different shopping malls for the final transit information and marketing field test study. However, six participants quit before completing both of the two sessions. One participant also clearly volunteered to receive remuneration only, and did not provide an honest effort (completing both simple and complex tasks in under 2 minutes, and receiving scores of 0 for both tasks). Additionally, due to the loss of transit information materials, one complex session could not be completed as designed. Twelve participants quit prior to the completion of one of their two transit trip planning tasks ( 6 complex and 6 simple), but did complete their other transit trip planning task. Therefore, for all analyses, there were 73 completed simple trip planning sessions and 72 complex trip planning sessions.

Demographic information was collected from each participant in the final study. Fifty-eight percent of the participants were male and 41 percent were female (one respondent did not indicate gender). The average age of the participants was 34.5 years of age. [Authors' note: Two different forms were used to gather data regarding the age of the participants, each using different categories. One form (similar to the one used for the preliminary study) used six categories ( $n=25)$, while the second form used four categories $(n=48)$. Age data can be found in Table 3-5. The reported mean age is derived from combining information from both sides of the table.]

Table 3-5

\section{Age of Participants in Final Study}

\begin{tabular}{|c|c|c|c|}
\hline Age categories & $\begin{array}{c}\text { Number } \\
\text { (Total } \mathrm{N}=48)\end{array}$ & Age categories & $\begin{array}{c}\text { Number } \\
(\text { Total } \mathrm{N}=25) \\
\end{array}$ \\
\hline $18-34$ & 25 & $18-25$ & 11 \\
\hline $35-49$ & 16 & $26-33$ & 5 \\
\hline $50-64$ & 6 & 34-41 & 6 \\
\hline \multirow[t]{3}{*}{65 and older } & 1 & 42-49 & 1 \\
\hline & & $50-57$ & 1 \\
\hline & & 58 and older & 1 \\
\hline
\end{tabular}

Participants were asked to indicate their ethnicity - no pre-coded categories were provided. Twenty-five percent of participants failed to report ethnicity. As illustrated in Table 3-6, of those participants who reported ethnicity, 63 percent were White, 18 percent were 
black/African-American, 13 percent were of Hispanic origin, and 4 percent were of Asiatic origin. In terms of personal income, 18 percent of participants reported personal incomes below $\$ 15,000,33$ percent reported incomes between $\$ 15,001$ and $\$ 30,000,25$ percent reported incomes between $\$ 30,001$ and $\$ 50,000$, and 25 percent reported incomes greater than $\$ 50,001$ (due to rounding, cumulative percentage exceeds 100 percent). The income information received from participants in the final study is included in Table 3-7. Participants also were asked to provide information about their educational background; the response rates to this question are included in Table 3-8. One participant reported having less than a High School education, 32 percent reported having a High School diploma or GED, 43 percent reported having some college, 14 percent reported graduating from college, and 11 percent reported having post-graduate experience.

Table 3-6

Ethnicity

\begin{tabular}{|l|c|c||}
\hline Category & Number & Percentage \\
\hline White & 35 & 63.3 \\
\hline African-American/Black & 10 & 18.3 \\
\hline Hispanic & 7 & 12.8 \\
\hline Asian & 2 & 3.7 \\
\hline Other & 1 & 1.8 \\
\hline No Response & 18 & 24.7 \\
\hline
\end{tabular}

Table 3-7

Household Income

\begin{tabular}{|l|c|c||}
\hline Category & Number & Percentage \\
\hline Below $\mathbf{\$ 1 5 , 0 0 0}$ & 13 & 17.8 \\
\hline $\mathbf{\$ 1 5 , 0 0 1}$ to $\mathbf{\$ 3 0 , 0 0 0}$ & 24 & 32.9 \\
\hline $\mathbf{\$ 3 0 , 0 0 1}$ to $\mathbf{\$ 5 0 , 0 0 0}$ & 18 & 24.7 \\
\hline $\mathbf{\$ 5 0 , 0 0 1}$ to $\mathbf{\$ 7 5 , 0 0 0}$ & 9 & 12.3 \\
\hline More than $\mathbf{\$ 7 5 , 0 0 0}$ & 9 & 12.3 \\
\hline
\end{tabular}

Information also was collected from participants regarding the number of personal vehicles available for household use. As shown in Table 3-9, four percent of respondents reported having no vehicles in the household, 30 percent reported having only one personal vehicle, 40 percent reported having two vehicles in the household, and 26 percent reported having three or 
more vehicles in the household. Forty percent of the respondents also reported that they had used public transportation within the last six months.

Table 3-8

\section{Education Level}

\begin{tabular}{|l|c|c|}
\hline Category & Number & Percentage \\
\hline \hline Less than high School & 1 & 1.4 \\
\hline HS Diploma or GED & 23 & 31.5 \\
\hline Some College & 31 & 42.5 \\
\hline College Graduate & 10 & 13.7 \\
\hline Post-Graduate & 8 & 11.0 \\
\hline
\end{tabular}

Table 3-9

Household Personal Vehicles

\begin{tabular}{|l|c|c|}
\hline Number of Autos & Number & Percentage \\
\hline $\mathbf{0}$ & 3 & 4.1 \\
\hline $\mathbf{1}$ & 22 & 30.1 \\
\hline $\mathbf{2}$ & 29 & 39.7 \\
\hline $\mathbf{3}$ or more & 19 & 26.0 \\
\hline
\end{tabular}

\section{$\underline{\text { Statistical Analysis }}$}

As stated previously, data were gathered from 73 simple transit trip planning sessions and from 72 complex transit trip planning sessions. The same two scoring variation schemes used to calculate composite scores for the pilot study were used for the final study, with Compos1a having 21 total possible points and Compos2a with 25 total possible points. A series of statistical tests (t-tests and ANOVA) were performed on the composite data collected from field test participants in order to determine significant differences in the resulting scores for each transit trip planning task. The statistical tests examine possible relationships between the composite scores received by participants and the complexity and perception of difficulty of the tasks presented, the design elements included in the materials, and the demographic characteristics of participants.

Overall, the scores received by participants for the transit trip planning tasks completed were quite low. As shown in Table 3-10, the average score for the simple transit trip planning 
sessions (no transfer necessary) was 9.25 out of 21 possible points using the Compos1a scoring scheme and 10.70 out of 25 possible points using the weighted scoring scheme, Compos2a. These scores represent average "grades" of 44 percent (Compos1a) and 43 percent (Compos2a). The average scores for complex transit trip planning sessions also were very low - 7.03 out of 21 possible points for Compos1a (33 percent) and 7.95 out of 25 possible points for Compos2a (32 percent). These scores illustrate the overall difficulty encountered by participants in the final study.

Although the average scores for simple and complex trip planning tasks were somewhat low, there were 25 tasks out of the 145 total trip planning tasks that received perfect scores (100 percent). Since 18 of the 25 perfect scores are associated with simple transit trips (no transfer required), these results suggest that participants had less difficulty with simple trip planning tasks than with complex trip planning tasks. The data for those trip plans that received perfect scores were reviewed in order to identify any existing patterns with regard to the transit materials involved. The 25 perfect scores were associated with 15 examples of transit information materials. Sixteen of the perfect scores were from transit information materials that consistently yielded high scores from participants. The transit agencies that produced these materials are Broward County Transit, Bay Town Trolley (simple only), Space Coast Area Transit (simple only), Sarasota County Area Transit (express route only), SunTran, and LeeTran (complex only). These materials contain minimal information, either because the transit system is relatively small or because the trip was designed to be extremely direct without many distractions. In the successful cases of the complex trip designed for the LeeTran system, for example, the materials clearly denoted the major points of interest that were used as the trip origin and destination, as well as contained clearly marked transfer points.

As was expected, the average scores for simple trip planning sessions were higher than scores for complex trip planning sessions (mean $=9.25$ compared to 7.03 using Compos1a, mean $=$ 10.70 compared to 7.95 using Compos $2 a$ ), but this difference was not found to be statistically significant (although approaching significance, with $p<.08$ ). Sixty-six percent of the participants were able to complete the simple transit trip planning sessions, and they completed 53 percent of the complex trip planning sessions. A t-test was conducted to determine whether the order in which participants received simple and complex trip planning tasks affected the resulting scores. However, this statistical test did not return significant results for the effect of presentation order on scores, suggesting that whether a participant received a simple planning task or a complex planning task first did not seem to affect their final trip planning task scores. There was a significant difference in the time necessary to complete the trip planning tasks, $(\mathrm{t}(84)=2.17)$, as participants completed the simple sessions in an average of 5.20 minutes and completed the complex sessions in an average of 6.74 minutes. A t-test also was conducted for ratings of task difficulty, with participants reporting the complex task (average $=5.20$ out of 7.00) as more difficult than the simple task (average $=4.80$ out of 7.00 ), but this was not 
statistically significant. Table 3-10 presents the average scores and standard deviations for the dependent measures included in the final study (two scoring variations, total time to complete task, and perception of task difficulty). There was a significant inverse correlation between ratings of task difficulty and composite score $(r=-.430, p<.01$, for both Compos1a and Compos2a), indicating that participants who found the task difficult tended to perform more poorly. The correlations between TotTime and Compos1a and TotTime and Compos2a were not statistically significant. [Authors' Note: Correlations are located in Table F-20, in Appendix F.]

Table 3-10

Dependent Measures in Final Study: Comparison of Simple and Complex Tasks

\begin{tabular}{|l|c|c|c|c|c|c||}
\hline \multirow{2}{*}{ Measure } & \multicolumn{3}{|c|}{ Simple Planning Tasks } & \multicolumn{3}{c|}{ Complex Planning Tasks } \\
\cline { 2 - 7 } & $\mathbf{N}$ & Mean & St.Dev. & N & Mean & St.Dev. \\
\hline Compos1a Scoring & 73 & 9.25 & 8.42 & 72 & 7.03 & 6.67 \\
\hline Compos2a Scoring & 73 & 10.70 & 10.20 & 72 & 7.95 & 7.97 \\
\hline TotTime (in mins.) & 48 & 5.20 & 1.86 & 38 & 6.74 & 2.55 \\
\hline Task Difficulty Rating & 73 & 4.79 & 1.77 & 72 & 5.19 & 1.69 \\
\hline
\end{tabular}

Note: Maximum possible score for Compos1a $=21$ points, maximum for Compos2a $=$ 25 points, maximum TotTime for simple sessions $=8$ minutes, maximum TotTime for complex sessions $=\mathbf{1 0}$ minutes, maximum Task Difficulty score $=7$.

Consistent with the scoring trends for simple and complex transit trip planning tasks, there also was a noticeable trend in terms of increasing observed emotions with increased task complexity, with observers/interviewers reporting 50 instances of emotion in complex sessions (with frustration most frequent, $\mathrm{N}=16$ ), and 37 instances of emotion in simple sessions (with laughter most frequent, $\mathrm{N}=14$ ). The most frequent observations of emotion reported by observers/interviewers in both the simple and complex transit trip planning sessions were frustration $(\mathrm{N}=25)$ and laughter $(\mathrm{N}=26)$. Observers reported a greater number of observed emotions in complex sessions, and also reported a greater proportion of frustration and irritation in the complex sessions. This finding is consistent with the quantitative and qualitative data (discussed in a later section) that indicate that participants had greater difficulty when presented with a transit trip planning task that required a transfer from one bus to another in order to reach their intended destination. Table 3-11 includes data on observed emotions from all phases of the study. Finally, participants required more assistance from observer/interviewers when completing complex trip planning tasks than during simple trip planning tasks, with 24 percent of participants requesting assistance during simple trip planning sessions and 50 percent of participants requesting assistance during complex sessions. 
Table 3-11

Observed Emotions in All Phases of Study

\begin{tabular}{|l||c|c|c|c|c|c|}
\hline $\begin{array}{l}\text { Observed } \\
\text { Emotion }\end{array}$ & $\begin{array}{c}\text { Preliminary } \\
\text { Study } \\
\text { (Simple) } \\
\text { Frequency } \\
\text { (17) }\end{array}$ & $\begin{array}{c}\text { Preliminary } \\
\text { Study } \\
\text { (Complex) } \\
\text { Frequency } \\
\text { (16) }\end{array}$ & $\begin{array}{c}\text { Final } \\
\text { Study } \\
\text { (Simple) } \\
\text { Frequency } \\
\text { (73) }\end{array}$ & $\begin{array}{c}\text { Final Study } \\
\text { (Complex) } \\
\text { Frequency } \\
\text { (72) }\end{array}$ & $\begin{array}{c}\text { Quit (One } \\
\text { Session } \\
\text { Only) } \\
\text { Frequency } \\
\text { (11) }\end{array}$ & $\begin{array}{c}\text { Quit (Both } \\
\text { Sessions) } \\
\text { Frequency } \\
\text { (12) }\end{array}$ \\
\hline \hline Frustration & 4 & 6 & 9 & 16 & 8 & 5 \\
\hline Irritation & 2 & 3 & 4 & 9 & 4 & 0 \\
\hline Anger & 0 & 0 & 0 & 1 & 0 & 0 \\
\hline Distress & 0 & 2 & 3 & 3 & 0 & 0 \\
\hline Laughter & 4 & 3 & 14 & 12 & 1 & 3 \\
\hline Nervousness & 1 & 2 & 7 & 9 & 0 & 3 \\
\hline
\end{tabular}

Notes: 1. Number of sessions in parentheses.

2. Observers could report multiple observed emotions for each participant.

As described previously, the transit information and marketing field test was designed to collect information related to common design elements used in Florida transit information materials, as well. Specifically, the materials used in the field test were characterized according to three general categories of design elements: alignment of timetables, route presentation, and presentation of transfer information. Statistical tests were conducted to identify any existing relationships between the design elements and composite scores, time required to complete the trip planning tasks, and/or task difficulty. The results of these statistical tests are provided in the following paragraphs.

A t-test was conducted to examine the alignment of timetables (horizontal or vertical) using combined simple and complex trip planning data. The result of this test was not statistically significant. However, while the overall t-test was not significant, there were conflicting findings dealing with alignment when analyzing only simple trip planning sessions or only complex trip planning sessions. Table 3-12 contains the means for the dependent variables by timetable alignment for the overall study, as well as for simple trip planning sessions and for complex trip planning sessions. 
Table 3-12

Dependent Measures in Final Study: Comparison by Timetable Alignment

\begin{tabular}{|c|c|c|c|c|c|c|}
\hline \multirow[b]{2}{*}{ Measure } & \multicolumn{2}{|c|}{ Overall Study } & \multicolumn{2}{|c|}{$\begin{array}{c}\text { Simple planning } \\
\text { tasks }\end{array}$} & \multicolumn{2}{|c|}{ Complex planning tasks } \\
\hline & Horizontal & Vertical & Horizontal & Vertical & Horizontal & Vertical \\
\hline $\begin{array}{l}\text { Compos1a } \\
\text { Scoring }\end{array}$ & $8.13(108)$ & $8.21(37)$ & $8.28(54)$ & $12.00(19)$ & $7.97(54)$ & $4.20(18)$ \\
\hline $\begin{array}{l}\text { Compos2a } \\
\text { Scoring }\end{array}$ & $9.31(108)$ & $9.41(37)$ & $9.54(54)$ & $14.00(19)$ & $9.07(54)$ & $4.57(18)$ \\
\hline $\begin{array}{l}\text { TotTime (in } \\
\text { mins.) }\end{array}$ & $6.02(68)$ & $5.35(18)$ & $5.29(35)$ & $4.98(13)$ & $6.80(33)$ & $6.31(5)$ \\
\hline $\begin{array}{l}\text { Task Difficulty } \\
\text { Rating }\end{array}$ & $4.80(108)$ & $5.57(37)$ & $4.81(54)$ & $4.95(19)$ & $4.85(54)$ & $6.22(18)$ \\
\hline
\end{tabular}

Note: Number of valid cases in parentheses.

A t-test was conducted on data from only simple trip planning sessions looking at timetable alignment and, although not statistically significant, did approach significance $p<.1$ ). Of particular note, average scores (using Compos1a and Compos2a) were greater for materials with horizontal alignment than those with vertical alignment (12.00 compared to 8.28 , and 14.00 compared to 9.54 , respectively). The t-test conducted for timetable alignment using only data collected from complex trip planning tasks showed statistically significant differences. This test indicated that scores for complex trip planning tasks were higher for tasks associated with transit information materials with horizontally-aligned timetables than for those with verticallyaligned timetables. [Using scoring variation Compos1a (21 possible points) as the dependent measure, $\underline{t}(70)=2.13$, with $\underline{p}<.05$, with mean scores of 7.97 (for horizontal alignment) and 4.20 (for vertical alignment).] An almost identical pattern was found when using scoring variation Compos2a (25 possible points) as the dependent measure. However, there were no mean differences when using TotTime or task difficulty as the dependent variable.

The next design element that was evaluated statistically was route information presentation. This design element had two variations: individual bus route schedules with a system wide map and the All-in-One Ride Guide where all bus route schedules and systemwide map are included in a single booklet. A t-test was conducted to evaluate the impact of bus route information presentation on the dependent measures included in the field test. The results of the t-test showed a significant difference when total time to complete the trip planning task (TotTime) was used as the dependent measure $(\mathrm{t}(84)=2.20, \mathrm{p}<.05)$. This result indicates that trip planning tasks that required the use of an All-in-One Ride Guide took longer to complete than did tasks using individual bus route schedules. When all of the trip planning task data were reviewed together, there were no significant differences when using Compos1a, Compos2a, or Task Difficulty as dependent measures, suggesting that the type of route information presentation did not have statistically significant impacts on the scores received by participants or on participant ratings of task difficulty. However, these data showed interesting trends when 
examining simple trip planning tasks only and complex trip planning tasks only. Means for these variables are provided in Table 3-13.

Table 3-13

Dependent Measures in Final Study: Comparison by Route Information Presentation

\begin{tabular}{|l||c|c|c|c||c|c||}
\hline \multirow{2}{*}{} & \multicolumn{2}{|c|}{ Overall Study } & \multicolumn{2}{c|}{$\begin{array}{c}\text { Simple planning } \\
\text { tasks }\end{array}$} & \multicolumn{2}{c|}{$\begin{array}{c}\text { Complex planning } \\
\text { tasks }\end{array}$} \\
\hline Measure & $\begin{array}{c}\text { Single } \\
\text { Routes }\end{array}$ & $\begin{array}{c}\text { Ride } \\
\text { Guides }\end{array}$ & $\begin{array}{c}\text { Single } \\
\text { Routes }\end{array}$ & $\begin{array}{c}\text { Ride } \\
\text { Guides }\end{array}$ & $\begin{array}{c}\text { Single } \\
\text { Routes }\end{array}$ & $\begin{array}{c}\text { Ride } \\
\text { Guides }\end{array}$ \\
\hline \hline Compos1a & $8.16(82)$ & $8.12(63)$ & $9.07(30)$ & $9.50(30)$ & $7.19(40)$ & $6.83(32)$ \\
\hline Compos2a & $9.38(82)$ & $9.27(63)$ & $10.56(30)$ & $10.90(30)$ & $8.10(40)$ & $7.76(32)$ \\
\hline TotTime & $5.46(53)$ & $6.66(33)$ & $4.59(30)$ & $6.23(18)$ & $6.59(23)$ & $6.95(15)$ \\
\hline Task Difficulty & $4.83(82)$ & $5.21(63)$ & $4.65(43)$ & $5.00(30)$ & $5.05(40)$ & $5.38(32)$ \\
\hline
\end{tabular}

Note: Number of valid cases in parentheses.

A t-test also was conducted analyzing route presentation in simple trip planning sessions only and complex trip planning sessions only. There was a significant difference in the simple trip planning sessions when TotTime was used as the dependent measure and route presentation was the independent variable, $(\mathrm{t}(46)=3.26, \mathrm{p}<.01$ ). As with the statistical analysis of route presentation using all of the data collected from participants, the analysis of simple trip planning data indicated that completing the simple trip planning tasks took longer using Ride Guides than simple trip planning tasks using individual bus route schedules. The t-test for route presentation in terms of complex trip planning sessions only was not statistically significant. There were no significant differences when using Compos1a, Compos2a, or Task Difficulty as dependent measures, again indicating that the form of route presentation used in the materials did not have statistically significant impacts on the scores received by participants or on ratings of task difficulty. However, although there were no statistically significant differences evident when using Compos1a and Compos $2 a$ as dependent measures, interesting trends were observed in terms of the scores received for simple and complex trip planning tasks in relation to type of route presentation. Specifically, there was a trend with higher scores received for trip planning tasks completed using Ride Guides for the simple trip planning tasks, while complex trip planning tasks completed using individual bus route schedules received higher scores. The means for these variables are included in Table 3-13.

The final design element that was evaluated in the final study was the method of transfer information presentation. This element had five possible variations: transfer information listed on map and on timetable, listed on map only, listed on timetable only, not listed anywhere, and listed elsewhere. An ANOVA procedure was used to test for mean differences for the transfer information independent variable. The only significant differences found occurred when 
examining scores received in complex trip planning sessions (Compos1a and Compos2a) as dependent measures, and transfers as the independent measure, $(F(4,67)=3.38, p<.05)$ for Compos1a. There were nearly identical results when using Compos2a as the dependent measure, $(F(4,67)=3.40, p<.05)$. These results indicate that the highest scores were obtained by participants using materials in transfer category 5 (transfer information listed elsewhere, mean $=18.20$ and 21.56 , respectively), while the lowest scores were obtained by participants using materials in category 1 (transfer information listed on map and on timetable, mean $=1.05$ and 1.10 , respectively). Both of these categories were represented by transit information materials from only one transit system. The high scores associated with category 5 were obtained using transit information from LeeTran. As described previously, the complex trip designed for LeeTran materials involved an origin and a destination that are clearly marked points of interest on the system map and transfer points are distinctively noted on the system map, as well. The low scores associated with category 1 were obtained using transit information from JTA. JTA's systemwide map was particularly difficult for participants to use as all bus routes were marked on a county road map in the same color, making it very difficult to determine the route names or where one route ends and another begins. Participants using materials from other transfer categories averaged scores of 7.66, 6.69, and 5.25 (categories 2, 3 , and 4, respectively). The ANOVA conducted using Task Difficulty as the dependent measure also was statistically significant, $(F(4,67)=2.50, p<.05)$. These results indicate that participants who used transit information materials from transfer category 1 rated the task "extremely difficult" (7.00 out of 7.00), while those using transit information materials from category 5 rated the task "somewhat easy" (3.00 out of 7.00). Means for the dependent measures, by transfer information presentation, are found below in Table 3-14.

Table 3-14

Dependent Measures in Final Study: Comparison by Transfer Information Presentation - Complex Sessions

\begin{tabular}{||c||c|c|c|c|c||}
\hline \multirow{2}{*}{ Measure } & \multicolumn{5}{|c|}{ Transfer Information Category } \\
\cline { 2 - 6 } & $\begin{array}{c}\text { On Map \& } \\
\text { on TT }\end{array}$ & $\begin{array}{c}\text { On Map } \\
\text { only }\end{array}$ & $\begin{array}{c}\text { On TT } \\
\text { only }\end{array}$ & Not listed & $\begin{array}{c}\text { Listed } \\
\text { Elsewhere }\end{array}$ \\
\hline $\begin{array}{l}\text { Compos1a } \\
\text { Scoring }\end{array}$ & $1.05(2)$ & $7.66(34)$ & $6.68(11)$ & $5.25(22)$ & $18.20(3)$ \\
\hline $\begin{array}{l}\text { Compos2a } \\
\text { Scoring }\end{array}$ & $1.10(2)$ & $8.60(34)$ & $7.68(11)$ & $5.85(22)$ & $21.56(3)$ \\
\hline $\begin{array}{l}\text { TotTime (in } \\
\text { mins.) }\end{array}$ & DNC & $7.02(19)$ & $5.20(4)$ & $6.82(12)$ & $6.67(3)$ \\
\hline $\begin{array}{l}\text { Task Difficulty } \\
\text { Rating }\end{array}$ & $7(2)$ & $5.35(34)$ & $5.64(11)$ & $4.86(22)$ & $3.00(3)$ \\
\hline
\end{tabular}

Notes: 1. Number of valid cases in parentheses. 2. DNC stands for did not complete. 
Statistical tests also were conducted to test for mean differences for the following independent demographic variables: gender, age, ethnicity, education level, personal income, and personal vehicles available for use. T-tests comparing gender differences were not significant; however, patterns of average results similar to those found in the pilot study were present. Similar to pilot study findings, men tended to score higher and take longer to complete the trip planning tasks (especially in the complex planning tasks) than did women. The means for scores, total time to complete tasks, and task difficulty, by gender, are located in Table 3-15.

Table 3-15

Dependent Measures in Final Study: Comparison by Gender

\begin{tabular}{||l|c|c||c|c||}
\hline \multirow{2}{*}{ Measure } & \multicolumn{2}{|c||}{ Simple planning tasks } & \multicolumn{2}{c|}{ Complex planning tasks } \\
\cline { 2 - 5 } & $\begin{array}{c}\text { Male } \\
\text { Mean }\end{array}$ & $\begin{array}{c}\text { Female } \\
\text { Mean }\end{array}$ & $\begin{array}{c}\text { Male } \\
\text { Mean }\end{array}$ & $\begin{array}{c}\text { Female } \\
\text { Mean }\end{array}$ \\
\hline \hline Compos1a Scoring & $9.57(42)$ & $9.10(30)$ & $8.25(41)$ & $5.60(30)$ \\
\hline Compos2a Scoring & $11.10(42)$ & $10.5(30)$ & $9.38(41)$ & $6.27(30)$ \\
\hline TotTime (in mins.) & $5.02(25)$ & $5.40(23)$ & $7.33(25)$ & $5.59(13)$ \\
\hline Task Difficulty Rating & $4.98(42)$ & $4.60(30)$ & $5.12(41)$ & $5.30(30)$ \\
\hline
\end{tabular}

Note. Number of valid cases in parentheses.

Analysis of Variance procedures used to test mean differences for age, ethnicity, education level, and personal income did not reveal statistically significant differences. However, Tables 3-16 and 3-17 provide mean comparisons for the dependent measures, by income level and education level. No obvious trends are evident in terms of scores, total time to complete the tasks, or perception of task difficulty. 
Table 3-16

Dependent Measures in Study: Comparison by Income Level

\begin{tabular}{|c|c|c|c|c|c|c|c|c|c|c|}
\hline \multirow[b]{3}{*}{ Measure } & \multicolumn{10}{|c|}{ Personal Income } \\
\hline & \multicolumn{5}{|c|}{ Simple Planning Tasks } & \multicolumn{5}{|c|}{ Complex Planning Tasks } \\
\hline & $>\$ 15 \mathrm{k}$ & $\begin{array}{l}\$ 15 k- \\
29,999\end{array}$ & $\begin{array}{l}\$ 30 k- \\
49,999\end{array}$ & $\begin{array}{l}\$ 50 \mathrm{k}- \\
74,999\end{array}$ & $\begin{array}{l}\$ 75 \mathrm{k} \\
\text { or } \\
\text { more }\end{array}$ & $>\$ 15 k$ & $\begin{array}{l}\$ 15 k- \\
29,999\end{array}$ & $\begin{array}{l}\$ 30 k- \\
49,999\end{array}$ & $\begin{array}{l}\$ 50 \mathrm{k}- \\
74,999\end{array}$ & $\begin{array}{l}\$ 75 k \text { or } \\
\text { more }\end{array}$ \\
\hline $\begin{array}{l}\text { Compos1a } \\
\text { Scoring }\end{array}$ & $\begin{array}{l}7.85 \\
(13)\end{array}$ & $\begin{array}{l}9.63 \\
(24)\end{array}$ & $\begin{array}{l}8.17 \\
(18)\end{array}$ & $\begin{array}{c}10.33 \\
(9)\end{array}$ & $\begin{array}{c}11.33 \\
(9)\end{array}$ & $\begin{array}{c}4.8 \\
(13)\end{array}$ & $\begin{array}{l}8.31 \\
(24)\end{array}$ & $\begin{array}{l}5.93 \\
(17)\end{array}$ & $\begin{array}{l}6.53 \\
(9)\end{array}$ & $\begin{array}{c}9.33 \\
(9)\end{array}$ \\
\hline $\begin{array}{l}\text { Compos2a } \\
\text { Scoring }\end{array}$ & $\begin{array}{l}8.92 \\
(13)\end{array}$ & $\begin{array}{c}11.21 \\
(24)\end{array}$ & $\begin{array}{l}9.39 \\
(18)\end{array}$ & $\begin{array}{c}12.11 \\
(9)\end{array}$ & $\begin{array}{c}13.11 \\
(9)\end{array}$ & $\begin{array}{l}5.54 \\
(13)\end{array}$ & $\begin{array}{l}9.34 \\
(24)\end{array}$ & $\begin{array}{l}6.66 \\
(17)\end{array}$ & $\begin{array}{c}7.51 \\
(9)\end{array}$ & $\begin{array}{c}10.62 \\
(9)\end{array}$ \\
\hline $\begin{array}{l}\text { TotTime } \\
\text { (in mins.) }\end{array}$ & $\begin{array}{l}4.72 \\
(11)\end{array}$ & $\begin{array}{l}5.67 \\
(11)\end{array}$ & $\begin{array}{l}5.33 \\
(14)\end{array}$ & $\begin{array}{l}4.69 \\
(6)\end{array}$ & $\begin{array}{l}5.47 \\
(6)\end{array}$ & $\begin{array}{l}5.68 \\
(8)\end{array}$ & $\begin{array}{l}8.13 \\
(11)\end{array}$ & $\begin{array}{l}5.79 \\
(10)\end{array}$ & $\begin{array}{l}6.86 \\
(3)\end{array}$ & $\begin{array}{l}7.10 \\
(6)\end{array}$ \\
\hline $\begin{array}{l}\text { Task } \\
\text { Difficulty } \\
\text { Rating }\end{array}$ & $\begin{array}{l}4.69 \\
(13)\end{array}$ & $\begin{array}{l}4.83 \\
(24)\end{array}$ & $\begin{array}{l}4.72 \\
(18)\end{array}$ & $\begin{array}{l}4.89 \\
(9)\end{array}$ & $\begin{array}{c}5.33 \\
(9)\end{array}$ & $\begin{array}{l}5.31 \\
(13)\end{array}$ & $\begin{array}{l}4.92 \\
(24)\end{array}$ & $\begin{array}{l}4.82 \\
(17)\end{array}$ & $\begin{array}{c}6.33 \\
(9)\end{array}$ & $\begin{array}{l}5.33 \\
(9)\end{array}$ \\
\hline
\end{tabular}

Note: Number of valid cases in parentheses.

Table 3-17

Dependent Measures in Final Study: Comparison by Education Level

\begin{tabular}{|c|c|c|c|c|c|c|c|c|c|c|}
\hline \multirow[b]{3}{*}{ Measure } & \multicolumn{10}{|c|}{ Education Level } \\
\hline & \multicolumn{5}{|c|}{ Simple Planning Tasks } & \multicolumn{5}{|c|}{ Complex Planning Tasks } \\
\hline & $>\mathrm{HS}$ & $\begin{array}{c}\text { HS } \\
\text { Diploma }\end{array}$ & $\begin{array}{c}\text { Some } \\
\text { College }\end{array}$ & $\begin{array}{c}\text { College } \\
\text { Grad }\end{array}$ & $\begin{array}{l}\text { Post } \\
\text { Grad }\end{array}$ & $>\mathrm{HS}$ & $\begin{array}{c}\text { HS } \\
\text { Diploma }\end{array}$ & $\begin{array}{c}\text { Some } \\
\text { College }\end{array}$ & $\begin{array}{c}\text { College } \\
\text { Grad }\end{array}$ & $\begin{array}{l}\text { Post } \\
\text { Grad }\end{array}$ \\
\hline $\begin{array}{l}\text { Compos1a } \\
\text { Scoring }\end{array}$ & $\begin{array}{l}18 \\
(1)\end{array}$ & $\begin{array}{l}8.87 \\
(23)\end{array}$ & $\begin{array}{l}8.62 \\
(31)\end{array}$ & $\begin{array}{c}13.80 \\
(10)\end{array}$ & $\begin{array}{c}6.00 \\
(8)\end{array}$ & $\begin{array}{c}10.5 \\
(1)\end{array}$ & $\begin{array}{l}5.93 \\
(23)\end{array}$ & $\begin{array}{l}7.99 \\
(31)\end{array}$ & $\begin{array}{c}6.30 \\
(9)\end{array}$ & $\begin{array}{c}6.83 \\
(8)\end{array}$ \\
\hline $\begin{array}{l}\text { Compos } 2 a \\
\text { Scoring }\end{array}$ & $\begin{array}{l}22 \\
(1)\end{array}$ & $\begin{array}{c}10.09 \\
(23)\end{array}$ & $\begin{array}{l}9.97 \\
(31)\end{array}$ & $\begin{array}{c}16.40 \\
(10)\end{array}$ & $\begin{array}{c}6.75 \\
(8)\end{array}$ & $\begin{array}{c}11.03 \\
(1)\end{array}$ & $\begin{array}{l}6.62 \\
(23)\end{array}$ & $\begin{array}{l}9.10 \\
(31)\end{array}$ & $\begin{array}{c}7.11 \\
(9)\end{array}$ & $\begin{array}{c}7.90 \\
(8)\end{array}$ \\
\hline $\begin{array}{l}\text { TotTime (in } \\
\text { mins.) }\end{array}$ & $\begin{array}{c}6 \\
(1)\end{array}$ & $\begin{array}{l}5.13 \\
(17) \\
\end{array}$ & $\begin{array}{l}4.94 \\
(18) \\
\end{array}$ & $\begin{array}{l}5.36 \\
(8)\end{array}$ & $\begin{array}{c}6.19 \\
(4) \\
\end{array}$ & $\begin{array}{c}9 \\
(1) \\
\end{array}$ & $\begin{array}{l}6.83 \\
(14) \\
\end{array}$ & $\begin{array}{l}6.30 \\
(13) \\
\end{array}$ & $\begin{array}{c}5.60 \\
(5)\end{array}$ & $\begin{array}{c}8.30 \\
(5)\end{array}$ \\
\hline $\begin{array}{l}\text { Task } \\
\text { Difficulty } \\
\text { Rating } \\
\end{array}$ & $\begin{array}{c}3 \\
(1)\end{array}$ & $\begin{array}{l}4.87 \\
(23)\end{array}$ & $\begin{array}{l}4.81 \\
(31)\end{array}$ & $\begin{array}{l}4.90 \\
(10)\end{array}$ & $\begin{array}{c}5.13 \\
(8)\end{array}$ & $\begin{array}{c}2 \\
(1)\end{array}$ & $\begin{array}{l}5.09 \\
(23)\end{array}$ & $\begin{array}{l}5.13 \\
(31)\end{array}$ & $\begin{array}{c}5.44 \\
(9)\end{array}$ & $\begin{array}{c}5.86 \\
(8)\end{array}$ \\
\hline
\end{tabular}

Note: Number of valid cases in parentheses.

The Analysis of Variance procedure that was conducted for personal vehicles available for use was statistically significant. Using total time to complete the trip planning tasks (TotTime) as the dependent variable, there were mean differences between the levels of personal vehicles, $(F(3,82)=2.78, p<.05)$. Post hoc analyses revealed that participants with zero vehicles available for use scored the lowest, but took the least time to complete the trip planning tasks. Using Compos1a and Compos2a as dependent measures, the ANOVAs were not statistically significant, but approached significance $(p<.08$ and $p<.09$, respectively). There also was a significant difference in ratings of task difficulty, $(F(3,141)=3.26, p<.05)$. This result 
indicates that participants who had zero personal vehicles available for use rated the trip planning tasks as much more difficult (6.50 out of 7 ) than the other participants. Means for the dependent measures by personal vehicles are provided in Table 3-18.

Table 3-18

Dependent Measures in Final Study: Comparison by Personal Vehicles

\begin{tabular}{|l||c|c|c|c||}
\hline Measure & 0 Vehicles & 1 Vehicle & 2 Vehicles & $\begin{array}{c}\text { 3 or More } \\
\text { Vehicles }\end{array}$ \\
\hline \hline Compos1a Scoring & $2.4(6)$ & $10.00(44)$ & $8.07(57)$ & $7.01(38)$ \\
\hline Compos2a Scoring & $2.47(6)$ & $11.48(44)$ & $9.26(57)$ & $8.04(38)$ \\
\hline TotTime (in mins.) & $2.83(4)$ & $6.30(25)$ & $5.94(36)$ & $5.85(21)$ \\
\hline Task Difficulty Rating & $6.50(6)$ & $4.57(44)$ & $4.89(57)$ & $5.39(38)$ \\
\hline
\end{tabular}

Note: Number of valid cases in parentheses.

Finally, participants completed ratings of specific characteristics of public bus service (convenience, comfort, personal safety, transit information, flexibility, availability, and vehicle safety), which are reported in Table 3-19. The participants were instructed to rate the characteristics of public bus service based solely on their experience with public transit and/or general perceptions or opinions about public transportation. As indicated in Table 3-19, participants tended to rate characteristics of public bus service as average, with no mean scores below 3.11 on a 5-point scale. The highest ratings received were for vehicle safety (mean = 3.82 ) and dependability (mean $=3.62$ ). The lowest ratings reported were for flexibility (mean $=3.11$ ) and for transit information (mean $=3.38$ ).

Table 3-19

Specific Characteristics of Public Bus Service (Final Study)

\begin{tabular}{|l||c|c|c|}
\hline Characteristic & Valid Number & Mean & St. Dev. \\
\hline \hline Convenience & 73 & 3.53 & 1.23 \\
\hline Comfort & 73 & 3.44 & 1.01 \\
\hline Personal Safety & 73 & 3.52 & 1.11 \\
\hline Transit Information & 72 & 3.38 & 1.14 \\
\hline Flexibility & 72 & 3.11 & 1.17 \\
\hline Availability & 72 & 3.51 & 1.21 \\
\hline Vehicle Safety & 72 & 3.82 & 1.11 \\
\hline Dependability & 47 & 3.62 & 1.28 \\
\hline
\end{tabular}


Participants also were asked to indicate their degree of familiarity with the geographic areas presented to them with their trip planning tasks in order to identify whether prior knowledge of the geographic area would have a positive impact on ability to plan the transit trip. Twenty-one percent of the respondents reported some familiarity with the cities for which the materials pertained, but scores did not appear to be positively impacted by that knowledge. Fifty-three percent of participants reported greater confidence in planning a future trip on public transit as a result of their participation in the transit information and marketing field test. However, only 37 percent of participants reported an increased likelihood of actually using public transportation in the future.

\section{Participants Who Quit One or Both Tasks or Were Unable to Complete in Allotted Time}

Data collected from participants who quit either one or both of their trip planning tasks, as well as those who were unable to complete the trip planning tasks within the allotted time (8 minutes for simple trip planning tasks and 10 minutes for complex trip planning tasks) also were examined for any observable trends. Visual perusal of the demographic data, as well as use of nonparametric data analyses (Chi Square Test of Independence), did not reveal significant differences between these different classifications of participants. However, the demographic data for these participants are included in Appendix F, Tables F-1 and F-31.

There are no data regarding the dependent measures from participants who quit one or both sessions. However, there are data for task difficulty, and for ratings of specific characteristics of public bus service. Means for these variables are reported in Table 3-20. It does appear that participants who quit both sessions had lower ratings of the characteristics of bus service, and viewed the task as being slightly more difficult than those who completed the trip planning tasks. 
Table 3-20

Descriptive statistics for Participants Who Did Not Complete or Quit Sessions

\begin{tabular}{|l|c|c|c|c|}
\hline & $\begin{array}{c}\text { Did Not Complete } \\
\text { Simple Session }\end{array}$ & $\begin{array}{c}\text { Did Not Complete } \\
\text { Complex Session }\end{array}$ & $\begin{array}{c}\text { Quit One } \\
\text { Session }\end{array}$ & $\begin{array}{c}\text { Quit Both } \\
\text { Sessions }\end{array}$ \\
\hline \hline Task Difficulty & $5.88(25)$ & $6.00(34)$ & $6.20(10)$ & $6.42(12)$ \\
\hline Convenience & $3.60(25)$ & $3.26(34)$ & $3.80(10)$ & $2.33(6)$ \\
\hline Comfort & $3.24(25)$ & $3.38(34)$ & $3.40(10)$ & $1.33(6)$ \\
\hline Dependability & $3.70(20)$ & $3.58(24)$ & $3.67(6)$ & $2.50(4)$ \\
\hline Personal safety & $3.64(25)$ & $3.50(34)$ & $3.5(10)$ & $1.83(6)$ \\
\hline Transit Information & $3.24(25)$ & $2.94(34)$ & $2.56(9)$ & $1.83(6)$ \\
\hline Flexibility & $3.16(25)$ & $2.94(34)$ & $2.89(9)$ & $2.17(6)$ \\
\hline Availability & $3.56(25)$ & $3.42(34)$ & $3.56(9)$ & $2.33(6)$ \\
\hline Vehicle Safety & $3.80(25)$ & $3.81(34)$ & $3.89(9)$ & $2.50(6)$ \\
\hline
\end{tabular}

Note: Number of valid cases in Parentheses.

Included in Table 3-21 is a list of the materials used in the trip planning sessions with which participants were unable to successfully complete the trip planning task(s) in the allotted time. These data include participants from the pilot study, from both simple and complex sessions, as well as from sessions in which a participant gave up (in only one of their two sessions, as well as in both sessions). This section is designed to attempt to identify materials that consistently seemed to be difficult to complete. Table 3-21 reveals that the trip planning tasks associated with certain transit information materials were more difficult for participants to complete in the allotted time. These findings are consistent with CUTR's hypotheses related to materials that would be particularly challenging to participants, based on the assessment of each piece of transit information material that was required prior to designing the trip plans that were presented to participants. More detailed discussion of these findings are presented following the discussion of interview findings presented in the next section. 
Table 3-21

Materials that Participants Were Unable to Successfully Complete

\begin{tabular}{|c|c|c|c|c|c|}
\hline Materials & $\begin{array}{c}\text { Preliminary } \\
\text { Study } \\
\text { Frequency } \\
\text { (All Complex) }\end{array}$ & $\begin{array}{c}\text { Simple } \\
\text { Session } \\
\text { Frequency } \\
\text { (All Simple) }\end{array}$ & $\begin{array}{c}\text { Complex } \\
\text { Session } \\
\text { Frequency } \\
\text { (All Complex) }\end{array}$ & $\begin{array}{c}\text { Quit One } \\
\text { Session } \\
\text { Only } \\
\text { Frequency }\end{array}$ & $\begin{array}{l}\text { Quit Both } \\
\text { Sessions } \\
\text { Frequency }\end{array}$ \\
\hline BCT-2 & $\bar{~} 1$ & 0 & 2 & 0 & 0 \\
\hline BTT-29 & 1 & 0 & 2 & 0 & $1-S, 1-C$ \\
\hline ECT-7 & 0 & 1 & 2 & $1-S$ & 0 \\
\hline HRT-2 & 0 & 2 & 1 & $1-C$ & $1-C$ \\
\hline JTA-1 & 1 & 2 & 2 & $1-S$ & $1-C$ \\
\hline LMT-1 & 0 & 1 & 0 & 0 & 0 \\
\hline LNX-4 & 0 & 0 & 1 & $1-C$ & 0 \\
\hline LNX-14 & 1 & 3 & 2 & $1-C$ & 0 \\
\hline LT-5 & 0 & 0 & 0 & 0 & $1-C$ \\
\hline MCT-13 & 1 & 1 & 1 & 0 & 0 \\
\hline MDT-4 & 1 & 1 & 1 & 0 & 0 \\
\hline PST-2 & 0 & 2 & 1 & 0 & $1-S$ \\
\hline RTS-13 & 0 & 2 & 2 & 0 & $1-C$ \\
\hline SCAT-28 & 1 & 1 & 4 & $2-C$ & $1-S$ \\
\hline SCT-17 & 0 & 2 & 3 & 0 & $1-S$ \\
\hline SUN-12 & 0 & 1 & 1 & 0 & 0 \\
\hline TLT-12 & 0 & 1 & 3 & $2-C$ & 0 \\
\hline VOT-17 & 0 & 4 & 2 & $1-S$ & 0 \\
\hline VOT-19 & 0 & 1 & 3 & $1-C$ & $1-S$ \\
\hline
\end{tabular}

Notes: 1. Participants were able to complete all sessions for 4 materials. 2. In column 5 and $6,5=$ Simple and $\mathrm{C}=$ Complex. 


\section{Results: Qualitative Analysis of Participant Interviews}

Following the completion of each transit trip planning task, participants also were interviewed regarding their perception of the tasks and the transit information materials presented as part of the transit information and marketing field test. The analysis of transit trip planning scores presented in the previous section represented the results from 145 of the 160 attempted trip planning tasks, due to the removal of data for those participants who quit one or both trip planning tasks and/or clearly did not attempt to complete the tasks presented. However, the qualitative data presented in this section represents the comments received from all field test trip planning tasks, regardless of whether the participants completed the tasks or quit prior to completion. The comments received from participants provide insight into the potential difficulties encountered by non-users of transit when attempting to use printed transit information materials to plan trips on the public bus. In addition, participants provided feedback on the aspects and qualities of the materials that they found helpful and/or userfriendly. Further, consideration of participant interview responses in concert with the quantitative findings presented in the previous section raises a number of interesting questions related to apparent disconnects between participants' perceptions of ability and actual trip planning results. The trip planning score results presented in the previous section reveal that most of the field test participants found the transit trip planning tasks to be rather complex undertakings. The comments received from participants support this finding and suggest possible conclusions as to the aspects of transit trip planning that are most confusing for nonusers, as well as aspects of transit information material design that assist non-users in the complex task of planning a transit trip. The discussion of the participant interview comments is provided in the following sections: Participant Reactions to Transit Trip Planning, Difficulties Encountered Using Transit Information Materials, and Perceptions of Useful Design Elements.

\section{Participant Reactions to Transit Trip Planning}

Immediately following each transit trip planning task, participants were asked about how they would feel if they were planning to take an actual bus trip using the materials presented to them in the trip planning task. The responses shared by participants revealed a wide range of emotional and cognitive reactions to the trip planning task. It is important to note that the focus of the transit information and marketing field test was on the non-user in order to evaluate the effectiveness of existing printed transit information materials when used by individuals with little to no previous experience with public transportation to plan trips on public bus service. The responses received indicate that the transit trip planning experience is often a complex one that may result in anxiety and frustration. 


\section{Transit Trip Planning - The Frustration Factor}

More than half ( 57 percent) of the responses received from field test participants related to how they would feel if the had to use the transit information materials presented to plan an actual trip on the bus were negative. These comments indicate that the trip planning tasks left most participants feeling quite anxious. Many participants expressed that the transit trip planning tasks were difficult, even with extensive instruction provided by the observer/interviewers. Participants described feeling frustrated, irritated, and confused as a result of the trip planning tasks that they were asked to complete. Taken together, there were over 100 separate comments made related to the printed transit materials being confusing, difficult to understand, or just plain frustrating. One participant was so upset following the trip planning task that they felt compelled to exclaim that they "would want to kill somebody." Although it is unlikely that this participant would actually resort to violence in response to using transit information materials, the comment does express the high level of anxiety that many participants felt and expressed to observers/interviewers. Another common sentiment expressed by respondents was a lack of confidence related to both using the transit information materials to plan a trip on the public bus and actually using public bus service. This lack of confidence often was expressed as fear and apprehension about the possibility of becoming "lost" while trying to use the bus service. Perhaps the most distressing, yet commonly expressed, sentiments from participants were related to feelings of inadequacy and/or stupidity because they were unable to complete the trip planning tasks presented. These comments highlight the important, as well as challenging, role that well-designed, user-friendly transit information materials may play in attracting and retaining new transit users.

Many participant comments were related to the amount of time that would be required to figure out how to use the transit information materials with a degree of confidence. Many participants indicated that a large amount of time would be required to figure out how to correctly use the materials. In addition, these participants expressed that a great deal of planning would be required prior to actually trying to use public bus service. These comments suggest that, for many participants, the printed materials used in the transit information and marketing field test do not exhibit a high degree of user-friendliness and simplicity of use.

The comments received from several participants suggest that some non-users would need to supplement the information in printed transit materials with more personal and direct forms of assistance. Ten respondents indicated that, if faced with the prospect of using the transit information materials to plan an actual trip on the public bus, they would need to seek additional help to plan their trip. These respondents described that they would feel more comfortable making the trip by bus if they were able to call the transit system for route and schedule information, ask another bus rider, or request assistance from the bus operator. 
At least 20 of the field test participants were so flustered by the transit trip planning experience that they indicated they would not even try to make the bus trip if they had to use only the transit information materials presented to them. The responses received from these participants suggest that the task of planning a transit trip using only the printed materials presented pose so great a challenge, that it discourages individuals from trying out public bus service. This finding may suggest a formidable obstacle to attracting potential customers to transit service.

\section{Positive Responses to Transit Trip Planning}

Although the majority of comments regarding how participants would feel if they were using the transit information materials presented to them to plan an actual trip on the public bus indicated unease and discomfort, many affirmative responses also were offered to observers/interviewers. Thirty-six percent of the comments received exhibit a moderate degree of confidence related to both using transit information materials to plan bus trips, as well as using public bus service. These participants expressed that they felt somewhat confident that they would be able to plan and complete the transit trip. From the perspective of these participants, the transit trip planning tasks did not pose too great of a challenge for them and did not appear to cause unease in terms of the prospect of actually using public bus service. Although several of the participants who expressed confidence regarding transit trip planning also received high scores on one or both of their trip planning tasks (between 75 and 100 percent), the majority of these respondents received scores lower than 50 percent, and several actually received either zero points for their trip planning tasks or quit the trip planning task prior to completion. The prevalence of low scores suggests that many of these participants did not fully understand the task that was presented to them and, therefore, did not realize that they had performed poorly on the trip planning tasks. Alternatively, the participants may have desired to "please" the observers/interviewers by providing affirmative responses to the questions presented to them. In either scenario, if an individual attempts to use transit service without a clear understanding of when and where buses travel, there is the risk that they will arrive at their destination late, get lost, or worse. The likelihood would then be slight that such an individual would be enthusiastic about continuing to use transit.

\section{Difficulties Encountered Using Transit Information Materials}

One of the primary objectives of the transit information and marketing field test was to identify elements of the transit trip planning experience that pose a challenge to non-users. As such, the research team was very interested in participant perceptions related to the type and degree of difficulties encountered during completion of the trip planning tasks. Therefore, field test participants also were queried about what they perceived to be the most difficult or least understandable part of using the transit information materials. A review of these data reveals 
that participants felt that a lack of overall knowledge of transit and/or the geographic area presented to them posed an almost insurmountable challenge. In addition, participants expressed difficulties pertaining to the overall layout of some transit information materials, using systemwide and individual bus route maps, understanding timetables, and making transfers in order to complete their bus trip. These comments are addressed in the sections that follow.

\section{Overall Understanding of Transit}

The transit information and marketing field test was designed to simulate the experience of either non-users of transit or individuals unfamiliar with a geographic area who would like to access available public transit services. For these reasons, individuals were recruited who did not have extensive experience with public bus service prior to the field test. Additionally, transit information materials were used from a wide variety of transit systems such that most of the participants received trip planning tasks from unfamiliar transit service areas. Extensive instruction was provided to each participant related to how to use the transit information materials to identify origins and destinations, bus routes, time points, and schedule times, as well as how to complete the trip planning tasks presented to them. Despite the instruction provided to participants, many respondents indicated that they felt they did not have enough knowledge of how to navigate transit services and/or knowledge of the geographic area covered in the printed transit information materials presented to be able to successfully complete the transit trip planning tasks. When asked to indicate the most difficult and/or least understandable part of using the materials provided in the trip planning tasks, several participants responded that a lack of knowledge regarding how bus service functions made understanding the materials and task more difficult. Several participants also reported that lack of knowledge about the area represented on the printed transit information materials also limited their ability to understand the materials and/or complete the exercises to their satisfaction. Additional comments received related to limited understanding of transit service and/or the geographic area presented to participants include difficulty locating a bus stop near the intended destination and confusion whether times listed in the timetables referred to arrival or departure times.

It is quite interesting to note that three of the participants who cited a lack of knowledge as the most difficult aspect of using the transit information materials received perfect scores on their completed trip planning tasks. The remainder of the respondents who offered this type of comment related to difficulties encountered received scores between 0 and 57 percent. Such responses might be expected from respondents in a sample consisting largely of transit nonusers. However, participants were told at the outset that the research team was most interested in administering the trip planning tasks to non-users. For the most part, such responses appear to provide an explanation for the apparent inability to complete the exercises, 
as exhibited by these respondents' scores. The fact that three respondents who gave these types of comments were able to successfully complete the trip planning tasks suggests that there may have been some apprehension on the part of respondents regarding the inability to make sense of the materials to their own satisfaction.

A majority of the participant responses received in relation to the least understandable and/or most difficult aspects of the trip planning tasks pertained to the layout and use of the transit information materials. Many of these comments also appear related to a lack of overall understanding regarding the functioning of public transit. These comments are discussed in the following sections.

\section{Layout of Materials}

In 24 specific instances, respondents reported that the general layout of the transit information materials presented was the most difficult and/or least understandable part of using them to complete the assigned tasks. Further, more than 15 additional general comments were received by participants related to difficulties encountered with the overall layout of materials. These comment ranged from emphasizing the respondents' difficulty in making overall sense of the materials to the very specific critique of the elements included in the printed transit materials. In particular, several respondents who were asked to complete trip planning tasks using the Ride Guide developed for the LYNX transit system in Orlando reported difficulties reading the system map provided in the LYNX Ride Guide. A common sentiment expressed by participants who received these materials was that the print used on both the system map and on individual bus route maps and timetables was much too small. Another common complaint related to these materials was that the system map is spread across nine separate pages, requiring users to flip through several pages in order to link origins with destinations. These combined factors made it particularly difficult for respondents to follow route lines and to identify potential bus stops and/or landmarks.

Another sentiment commonly expressed by participants related to the general layout of transit materials pertained to placement of route maps and timetables. Several respondents expressed dissatisfaction with materials that place maps and timetables on opposite sides of the materials. These participants did not like having to flip a map back and forth in order to see the timetable associated with a particular bus route. These materials appeared to increase the level of frustration associated with the transit trip planning tasks. Additional comments related to specific design elements of transit information materials are discussed in the sections that follow. 


\section{Using System Maps and Individual Route Maps}

The systemwide bus route maps and individual bus route maps also were cited as problematic for many field test participants. In 43 specific instances, respondents indicated that they had some difficulty using system maps and/or individual bus route maps. There were an additional 15 negative comments related to system maps and/or individual route maps offered in response to questioning regarding the participants' general impressions of the transit information materials. Many of these responses emphasized respondent difficulty in identifying bus routes on the systemwide route map. Participants reported particular difficulties using systemwide route maps that did not differentiate individual bus routes effectively. For example, the systemwide map included in the TalTran Ride Guide employs the same color for many adjacent routes. This made it very difficult for participants to determine the correct bus route needed to complete their trip, as well as where one route terminates and another begins. This problem also was cited in relation to the extensive MDT bus route network wherein participants had a difficult time determining were one route terminated and another began. A similar problem was cited consistently in relation to the map of JTA's bus network. This map, essentially a county road map with overlain bus routes, was particularly difficult to use to identify bus route numbers, time points, and other points of interest because the same color was used to outline all of the bus routes. In fact, none of the participants who received trip planning tasks associated with the JTA bus system were able to complete the trip planning tasks in the allotted time and these trip planning tasks received the lowest average scores in the transit trip planning field test, both clear indications of the difficulties inherent in using these materials to plan transit trips.

Another 15 comments emphasize respondent difficulty in identifying the origin and destination points outlined within the transit trip planning tasks. Respondents often reported being unable to find the exact point of origin or destination on the system map. This was especially the case with respondents who were asked to complete exercises involving larger and more complex transit systems, such as the JTA or MDT system. Such responses particularly were notable because the research team provided markers identifying the origin and destination points for trips on all such system maps to avoid undue respondent confusion or difficulty. Despite the presence of markers identifying the exact location of both origin and destination points, respondents still had difficulty discerning the appropriate bus stops necessary for the completion of transit trip planning tasks. This suggests that the difficulties experienced by these participants actually were related to identifying the bus stops (time points) nearest to the origins and destinations associated with the trip planning tasks.

Five responses indicate that respondents had specific difficulty with individual bus route maps. While most of these responses were quite general, one comment specifically identified inconsistencies between the system map and related route maps. This participant reported 
being unable to find points of interest on the individual bus route maps that had been identified on the systemwide route map. These types of inconsistencies may make transit trip planning more difficult for non-users by eliminating important visual and spatial cues necessary to coordinate information from systemwide route maps to the information provided on routespecific maps and schedules.

\section{$\underline{\text { Using Timetables }}$}

Many participants identified timetables as the most problematic aspect of the trip planning tasks. There were 27 specific references to problems with timetables and many more indirect comments pointing to timetable challenges. Overall, these responses suggest a lack of comprehension on the part of respondents with regard to interpretation of departure/arrival times and their relationship to particular bus stops. Many participants complained that they were unclear as to whether the times listed in timetables referred to arrival or departure time, another indication of a lack of overall understanding of how transit services operate. As one of these respondents put it, the most difficult part of the exercise was figuring "whether the numbers on [the] timetable mean anything or not." Perhaps the most interesting, and problematic, response with regard to timetables came from a respondent who identified her own lack of comprehension as the problem, rather than the timetables themselves: "[This is] not difficult. It's difficult for me to work the times out." Such a response, although a singular one, is interesting because it highlights the potential for "test taking anxiety," or that the respondent's state of mind during an exercise may affect the overall completion results. Such expressions of self-directed frustration were not uncommon during this research - respondents in a number of areas related feeling inadequate, uneducated, or even dumb when attempting to explain difficulties experienced during the exercise. This finding is cause for particular concern, as it is unlikely that, given a choice, individuals new to transit service would remain interested in using any service that makes them feel inadequate or unintelligent.

Another 14 responses specifically emphasized participant difficulty in identifying bus stops (time points) and/or important points of interest while completing the assigned trip planning tasks. Half of these comments focus on the respondents' inability to identify what constituted a bus stop specifically, therefore making it difficult for them to know whether the stop(s) they had identified in the exercise were close enough to the assigned destination point. Six additional comments received stress the respondents' difficulty in identifying points of interest that might have helped them find the appropriate bus route or bus stop for successful completion of the trip planning tasks. Such responses provide some indication that respondents did not fully understand how to coordinate the use of timetables and the various maps in order to identify the time points that served as bus stops along a bus route. It should be emphasized that the verbal and written instructions provided to the participants provided explanation that time 
points on the timetables represented bus stops along the bus routes and directed participants to choose the time point closest to the intended origin and destination.

It is surprising that comments related to timetable difficulties were not more prevalent. Review of the transit trip planning worksheets completed by participants, as well as observations made by the observers/interviewers during the field test reveal that participants had a great deal of difficulty interpreting timetables in order to identify the nearest bus stop and the optimal times to catch the bus. In most of the trip planning tasks, participants successfully identified the best bus route(s) required to compete the trip planning task, but were unable to identify bus stops or schedule times associated with the bus route and bus stop. Timetable interpretation is a critical aspect of transit trip planning. Riders must be able to determine where and when to catch their intended bus in order to effectively use transit service. Misinterpretation that leads to late arrival will likely leave a negative impression with the rider. Therefore, it is extremely important that the information contained in transit information timetables be accessible to all potential passengers. The observations noted by observers/interviewers related to participant experiences with timetables, as well as those noted by the participants themselves, indicate that many of the timetable presentations utilized by transit agencies are not particularly intuitive for non-users.

\section{Transferring}

As discussed previously, the average scores received by participants for complex transit trip planning were extremely low, with 7.03 points out of a possible 21 points for Compos1a and 7.95 points out of 25 possible points for Compos2a. The scores received by participants for complex trip planning tasks, along with observations made by observers/interviewers, strongly suggest that the participants experienced difficulties when trying to plan transit trips that required transferring from one bus route to another in order to reach the intended destination. Approximately 20 of the field test participants cited the logistics involved in transferring as the most difficult or least understandable aspect of using the materials. Understandably, the comments related to transferring are associated with complex trip planning tasks (80 sessions out of 160 possible trip planning sessions). The comments focus on identifying actual transfer points, as well as figuring out the logistics of transferring. The relatively low number of these type of comments is somewhat surprising given the overwhelmingly low scores for complex trip planning tasks and visual observations regarding areas of particular participant difficulties.

\section{No Difficulties Identified}

When queried regarding the most difficult and/or least understandable aspect(s) of using the transit information materials presented in the trip planning tasks, participants reported in 17 specific instances that there was nothing difficult about using the materials and/or completing 
the trip planning task(s). These comments are intriguing considering the prevalence of low scores on the trip planning tasks indicating that most participants likely had some difficulty using the materials and/or completing the transit trip planning tasks assigned. The scores received were identified for each instance that this type of comment was received in order to determine whether any patterns related to the transit information materials associated with the comments and scores received. Although participants reported no difficulties in 17 specific instances, there were only four instances of scores of 100 percent for completed trip planning tasks. Another four participants received scores between 60 and 80 percent for the tasks that they reported no difficulties in completing. However, the other scores associated with the trip planning tasks for which participants reported no difficulties suggest a contradictory conclusion. In two of the instances wherein participants reported no difficulties associated with using the materials or completing the trip planning tasks, the participants actually quit the exercise prior to completion. In another instance, the participant received zero points for the completed trip planning task. The remaining six respondents received combined scores of less than 45 percent for their completed trip planning tasks.

\section{Perceptions of Useful Design Elements: What Worked}

In addition to collecting information about the emotional reactions of participants related to using the transit information materials and the difficulties they encountered while completing the trip planning tasks, data were obtained related to positive participant responses to the exercises and/or transit information materials. Participants were asked to identify the least difficult and/or most understandable part of using the transit information materials to complete transit trip planning tasks. The comments received from participants in response to this question are not as varied as the responses to the questions discussed previously. The discussion that follows will illustrate that the design elements and/or aspects of the transit information materials that field test participants found to be the most useful include using the systemwide bus route map and/or individual bus route maps, information related to points of interest and/or the map legend, using timetables, and the sentiment that nothing about the materials was easy to understand.

\section{Bus Route Identification: Using System Maps and Route Maps}

The overwhelming majority of comments received from participants regarding the least difficult or most understandable aspect of using the transit information materials pertained to the identification of bus routes. There were 61 instances wherein participants reported having the least difficulty when working with systemwide route maps and individual route maps. These participants reported having little difficulty identifying the bus route(s) needed in order to plan the transit trip assigned in the exercise. However, as described previously, participants had greater difficulty when attempting to use timetables to identify bus stops, schedule times, and 
transfer points. Review of the transit trip plans completed by participants provides supporting evidence that participants were generally successful at identifying bus routes. In most cases, participants were able to determine the bus route(s) required to complete transit trip planning tasks, especially the simple tasks. However, participants were much more likely to encounter difficulties when trying to determine when and where to catch the identified bus.

Although many of the affirmative comments related to using route maps state a general sense of satisfaction with the ease of bus route identification, several respondents emphasized the use of contrasting colors to designate and differentiate bus routes within system maps as a significant asset toward exercise completion. These comments point to a preference for the color coding of bus routes such that individual routes are able to be differentiated from one another, as well as where individual routes begin and end. It is clear from the comments received from participants that individuals prefer the use of well-defined color contrasts in the design of route maps. As described previously, a greater degree of difficulty was associated with systemwide route maps wherein bus routes were drawn with a single color (JTA) or not clearly differentiated (TalTran).

\section{Points of Interest and the Map Legend}

Several participants also cited information provided about points of interest and information provided in map legends on how to interpret route maps as the most understandable aspects of using the transit information materials. In particular, these participants appreciated information about the bus routes that serve points of interest. This information helped the participants to complete the assigned trip planning tasks. In addition, some participants cited the legends associated with systemwide route maps and individual bus route maps as the most understandable part of using the materials. Legends with clear and concise information and symbols denoting time points, transfer points, and points of interest were particularly helpful to participants.

\section{$\underline{\text { Using Timetables }}$}

Interestingly, there were 21 instances of participants citing timetables as the least difficult or most understandable aspect of using the transit information materials. Most of the comments regarding timetables are very general in content. However, several participants reported that the listing of arrival and departure times on timetables was helpful in completing the trip planning tasks. These comments again suggest that some participants lacked general knowledge of public transit in the United States, despite the instruction provided to participants related to public bus service and use of timetables and route maps. The affirmative comments regarding the timetables presented to participants are also surprising in relation to observations made by observers/interviewers, as well as review of the trip planning worksheets completed by 
participants. The observers/interviewers noted many instances wherein participants had apparent trouble interpreting timetables in order to identify time points and schedule times for particular bus routes, but then cited timetables as the least difficult or most understandable aspect of the trip planning exercise nonetheless. Similarly, a review of the trip planning worksheets completed by participants indicates that, while most participants were able to successfully identify the bus route(s) necessary, participants were much less successful when attempting to choose the closest timepoint and schedule time to complete the assigned trip.

\section{Nothing Was Understandable or Easy}

Finally, there were 14 instances of participants commenting that there was nothing about using the transit information materials that was understandable or easy. Eight of these comments were received in relation to the transit information materials used by three Florida transit systems: JTA, VOTRAN, and LYNX (Ride Guide). Field test participants consistently experienced frustration when using these materials and had difficulty completing the assigned trip planning tasks. Prior to the field test, the CUTR research team also identified these transit information materials as among those that were expected to be the most difficult to use. 


\section{Major Findings of the Transit Information and Marketing Field Test}

The intent of the transit information and marketing field test was to examine the effectiveness of printed transit information materials when presented to potential passengers with little to no previous transit experience, as well as to attempt to identify design elements that are particularly user-friendly. Toward this end, printed information materials from 18 transit systems in Florida were presented to 80 individuals who were asked to plan specific transit trips using only the printed materials provided by the research team. The data collected and analyzed consisted of both quantitative and qualitative information. First, the completed trip plans from the pilot study $(\mathrm{N}=33)$ and the final study $(\mathrm{N}=145)$ were "graded" according to two scoring variations: all elements equally weighted and the use of differential weighting. Statistical tests were then applied to the quantitative data to determine the statistical significance of participant perceptions of difficulty, time required to complete the trip planning tasks, demographic characteristics, socioeconomic characteristics, and specific design elements on the final score received by participants. Next, post-trip planning interview data collected from each of the 80 final study participants were analyzed with regard to participant reactions to transit trip planning, identification of difficulties encountered by participants, and useful design elements cited by participants. The major findings from the quantitative and qualitative data analyses are summarized in the following sections.

\section{Summary of Quantitative Transit Trip Planning Major Findings}

A pilot study that included 17 individuals was conducted to test the research design and transit trip planning instruments so that necessary revisions could be implemented prior to conduct of the final study. However, the findings from the pilot study also provide insight into the usability of the transit information materials included in the field test. The participants of the pilot study included 13 transportation professionals and four university students. Limited statistical analyses were conducted on the pilot study data and the major findings from the analyses are provided below.

- The pilot study was composed of 13 transportation professionals and 4 university students.

- Pilot study participants received higher scores than participants in the final study, but pilot study scores were still low (below "C" grade).

- Many transportation professionals with transit experience experienced difficulties when faced with the challenge of planning transit trips using printed transit information materials.

- The average score for simple transit trip planning tasks was 14.29 out of 21 possible points (68 percent), or 17.24 points out of 25 possible points ( 69 percent). 
- The average score for complex transit trip planning tasks was 11.94 points out of 21 possible points ( 57 percent), or 14.10 points out of 25 possible points (56 percent).

- Participants completed all simple trip plans, but completed only 56 percent of complex trip planning tasks.

- Total time to complete simple tasks showed statistically significant differences from total time to complete complex tasks - 5.32 minutes versus 7.44 minutes.

- Simple trip planning tasks received an average difficulty rating of 4.12 out of 7.

- Complex trip planning tasks received an average difficulty rating of 5.56 out of 7 .

- Frustration was the most frequently reported visible sign of emotion, along with irritation and laughter.

- Participants received higher scores on simple trip planning tasks when using route information from individual route maps than when using All-in-One Ride Guides.

- Participants reported higher task difficulty for All-In-One Ride Guide materials than for materials consisting of individual route schedules and a systemwide route map.

- Score comparisons by gender revealed statistically significant differences with males receiving higher scores than females.

- Males took longer to complete the trip planning tasks than did females, but received higher scores than did females.

The transit information and marketing field test final study initially included 80 participants who were recruited from four shopping malls. Each participant was asked to complete a simple and a complex transit trip plan. However, the final data set analyzed included 73 completed simple trip planning sessions and 72 completed complex trip planning sessions due to the removal of data from individuals who quit one or more trip planning task prior to completion. Two scoring variations (with and without the weighting of some variables) were used to calculate composite scores for the transit trip plans completed by participants. A series of statistical tests were performed on the composite data collected from the participants of the final study in order to identify any statistically significant differences in the resulting scores. The statistical tests examined possible relationships between the scores received by participants and the complexity and perception of difficulty of the trip planning tasks, the design elements contained in the materials, and the demographic characteristics of participants. The major findings from the final study statistical analyses are summarized below.

- A total of 145 completed trip planning tasks were considered in the final study quantitative analysis ( 73 simple trip plans and 72 complex trip plans).

- Twenty-one percent of participants reported some familiarity with the geographic areas presented in the trip planning tasks, but their scores did not appear to be positively impacted by that knowledge.

- Overall, participant scores for both simple and complex trip planning tasks were very low, with average "grades" of 44 percent and 33 percent, respectively. 
- The average score for simple transit trip planning tasks was 9.25 points out of 21 possible points, or 10.70 points out of 25 possible points.

- The average score for complex transit trip planning tasks was 7.03 points out of 21 possible points, or 7.95 points out of 25 possible points.

- Sixty-six percent of participants were able to complete the simple transit trip planning tasks.

- Fifty-three percent of participants were able to complete the complex transit trip planning tasks.

- Participants found the complex trip planning tasks to be more difficult (5.2 out of 7) than simple trip planning tasks (4.8 out of 7).

- Participants who found the trip planning tasks to be difficult tended to perform more poorly than those who did not.

- There was a greater amount of observed emotion in complex trip planning sessions than in simple trip planning sessions, as well as a greater proportion of frustration and irritation.

- Participants required more assistance when completing complex trip planning tasks than when completing simple trip planning tasks.

- Average scores for both simple and complex trip planning tasks were higher for materials with horizontally-aligned timetables than for materials with vertically-aligned timetables.

- Trip planning tasks using Ride Guides took longer to complete than those using individual bus route schedules.

- Higher scores were associated with simple trip planning tasks that were completed using Ride Guides than those completed using individual bus route schedules.

- Higher score were associated with complex trip planning tasks completed using individual bus route schedules than those completed using Ride Guides.

- Participants using transit materials from Category 5 of the transfer information presentation category (transfer information listed elsewhere - LeeTran only) to complete complex trip planning tasks received the highest scores.

- Participants using transit materials from Category 1 of the transfer information presentation category (transfer information listed on map and on timetable - JTA only) to complete complex trip planning tasks received the lowest scores.

- Males tended to score higher and take longer to complete the trip planning tasks than did females.

- Participants with zero personal vehicles took the least amount of time to complete trip planning tasks, but rated the task as "very difficult" and received the lowest scores. 


\section{Summary of Participant Interview Major Findings}

Each of the 80 participants of the transit information and marketing field test were interviewed regarding their reactions, perceptions, and experiences using printed transit information materials to complete trip planning tasks. Comments received by participants provide insight into how the participants were feeling when working with the transit information materials, the potential difficulties encountered by non-users when attempting to plan transit trips using only printed transit route maps and bus schedules, as well as information about the aspects and qualities of transit information materials that are most helpful and useful.

Field test participants provided many comments related to their emotional and cognitive reactions to the prospect of planning bus trips using only the printed materials presented to them. Summary points of the sentiments expressed by participants are as follows:

- Fifty-seven percent of field test participants provided negative comments regarding how they would feel if using the transit information materials to plan an actual bus trip.

- Over 100 comments were made by participants related to the printed materials being confusing, difficult to understand, or frustrating.

- Respondents expressed a lack of confidence related to using printed transit information and/or public bus service.

- Many participants expressed feelings of inadequacy and/or stupidity because they were not able to completed the transit trip planning tasks.

- The need for supplemental assistance in the form of customer service and/or assistance from bus drivers or other passengers was commonly expressed by participants.

- At least 20 field tests participants indicated that the trip planning tasks were challenging enough to discourage them from trying to ever use public bus service.

- Thirty-six percent of the comments regarding participant reactions to transit trip planning exhibit a moderate degree of confidence related to using transit information and/or public bus service.

- Most of the participants who expressed confidence regarding transit trip planning received scores of less than 50 percent for their completed trip planning tasks, suggesting that they either did not fully understand the task presented to them or desired to please observer/interviewers by providing affirmative responses.

Participants also offered a wealth of information regarding the most difficult or least understandable aspects of the transit trip planning tasks and printed information materials presented to them in the transit information and marketing field test. The comments received include: 
- Despite the extensive instructions provided to participants, several responded that a lack of knowledge regarding how bus service operates and/or about the geographic area represented on the printed materials made understanding the materials and trip planning tasks more difficult.

- There were 39 instances of participants reporting difficulties related to the general layout of the printed transit information materials.

- The LYNX schedule book was commonly criticized for its small print and placement of the systemwide route map across nine separate pages.

- Many participants expressed dissatisfaction with materials that place the system map on the opposite side from timetables, thus increasing user frustration by requiring users to flip back and forth.

- Fifty-eight negative comments were made in relation to difficulties encountered using system maps and individual bus route maps.

- In particular, participants reported difficulties using systemwide bus route maps that did not differentiate individual bus routes effectively (e.g., TalTran, JTA, and MDT).

- Despite the presence of markers identifying the location of trip origins and destinations, respondents still reported difficulties related to discerning the appropriate bus stops, suggesting that these participants actually had problems identifying the time points nearest to the trip origins and destinations.

- Inconsistencies between systemwide route maps and individual bus route maps also were cited as problematic for participants

- There were 41 specific, as well as many indirect, references to difficulties associated with using and interpreting timetables.

- Many of the difficulties associated with using and interpreting timetables were related to identifying bus stops (time points) and/or important points of interest.

- Comments received regarding difficulties identifying bus stops and points of interest suggest that many participants did not understand how to coordinate the use of timetables and the various maps in order to identify the time points that served as bus stops, despite verbal and written instructions provided to participants.

- Review of the transit trip planning worksheets and observations made during the field test confirm that participants had a great deal of difficulty using timetables to identify the nearest bus stop and optimal times to catch the bus on the selected route.

- The scores received by participants, along with observations made by observer/interviewers, indicate that participants experienced difficulties when attempting to plan transit trips that required a transfer from one bus route to another.

- Approximately 20 participants also cited the logistics involved in transferring, such as identifying transfer points and times, as the most difficult or least understandable aspect of using the printed transit information materials to complete the trip planning tasks.

- Seventeen participants cited no difficulties associated with using the printed materials or completing the trip planning tasks. However, more than half of these participants either 
quit the trip planning tasks prior to completion or received combined scores of less than 45 percent for their completed trip planning tasks.

Finally, field test participants provided information on their perceptions of the useful and/or user-friendly design elements contained in the printed transit information materials presented to them. The responses received by participants include:

- The majority of comments related to the least difficult or most understandable aspect(s) of using the transit information materials pertained to the identification of bus routes.

- In 61 separate instances, participants reported having little difficulty identifying the bus route(s) necessary to complete their assigned transit trip.

- Review of the transit trip plans completed by participants provides supporting evidence that participants were generally successful at identifying bus routes.

- Many participants offered affirmative comments related to the use of contrasting colors to designate and differentiate bus routes within a systemwide route map.

- Many participants appreciated information provided in the printed transit materials indicating the names/numbers of bus routes that serve particular points of interest.

- Legends with clear and concise information and symbols denoting time points, transfer points, and points of interest were particularly helpful to participants.

- Despite contrary evidence from score results and observations of participants, 21 comments were received citing timetables as the least difficult or most understandable aspect of using the transit information materials, especially the provision of bus arrival and departure times.

- There were 14 instances of participants commenting that there was nothing understandable or easy about using the transit information materials. Eight of these comments were received in relation to materials developed for JTA, VOTRAN, and LYNX (Ride Guide). 


\section{Recommendations: Making Transit Information Materials More User-Friendly}

The transit information and marketing field test was designed to collect preliminary data on the level of transit literacy that non-users may have when attempting to using printed transit information materials, such as route maps and schedules, to plan trips on public transit. As such, transit literacy is being defined as the ability to use existing transit information to make concrete travel plans on public transit, even with little to no prior experience with public transit. Therefore, the focus of the field test was on determining whether existing printed transit information materials would lend themselves to use by individuals unacquainted with public transit. The intent of the field test was to gather and analyze information about the userfriendliness of existing transit information materials in Florida. The field test also was designed to begin exploratory research on effective and user-friendly design elements contained in printed transit information materials. Three specific design elements were included for in-depth analysis: timetable alignment, bus route information presentation, and the presentation of transfer information. Toward these ends, the field test collected information on how well participants could actually plan transit trips by determining bus route(s), bus stop(s), and schedule time(s). These data were then scored numerically using two scoring variations (described previously). Information was collected from 17 pilot study and 80 final study participants. Statistical tests were conducted on the numerical data to determine any relationships that might exist between participant scores, the time required by participants to complete the trip planning tasks, participant ratings of task difficulty, design elements included in the study, and participant sociodemographic characteristics. Additionally, qualitative data were collected from participants pertaining to their perceptions of the trip planning tasks and the transit information materials used. Finally, the CUTR research team reviewed printed transit information materials from all transit systems in the state of Florida and identified characteristics that could be problematic for transit users and non-users attempting to plan transit trips using only the printed materials. The data obtained through each of these efforts have been synthesized in order to provide specific recommendations to transit agencies related to making printed transit information more user-friendly. Specific recommendations resulting from the transit information and marketing field test are detailed in the following sections.

\section{The Big Picture: Transit Knowledge is Not Common Knowledge}

As the previous sections detail, the level of transit literacy among participants in the transit information and marketing field test was quite low. Participants had difficulty completing both simple and complex trip planning tasks and exhibited visual signs of frustration, irritation, and nervousness while attempting the assigned trip planning tasks. The average scores received by participants for both simple and complex trip planning tasks were the equivalent of a grade of "F." Participants consistently found the tasks to be confusing, difficult, and complex. In addition, field test participants often failed in their attempts to complete trip plans for transit 
trips that required a transfer from one bus route to another, a very common situation on public transit in Florida. Each of these findings indicate that it is unlikely that individuals in Florida without transit experience would be able to easily plan trips on transit if provided only existing printed transit materials. In addition, the field test results provide several indications that the experience of using printed transit information materials to plan transit trips might be negative enough for many individuals to "give up" and find another method of transport. Many field test participants also reported that the experience of using the transit information materials make them feel "stupid" and "inadequate," feelings that typically do not lead to positive perceptions of any experience, let alone the transit one. These conclusions are significant for transit agencies that are striving to increase ridership and are committed to making the public transit experience seamless and easy for passengers.

Any recommendations offered as a result of the transit information and marketing field test must be preceded by a discussion of general existing societal and organizational conditions affecting overall transit literacy, as defined by this study. First and foremost, the United States today is, with few exceptions, an automobile-oriented society. At least two generations have passed since public transit was an everyday reality for the majority of Americans. This has significant implications for the marketing of transit. Not only is it crucial for transit agencies to translate the benefits of transit to the general public, but this means that entire generations of Americans must also be educated about how transit operates. The transit industry cannot afford the assumption that "everyone knows how to use bus service." The results of the field test indicate that this is simply not the case. It is also significant that most participants received low scores for completed transit trip plans even after receiving extensive instructions about how transit and transit information materials work. In many cases, more time was spent providing instruction to participants than was allotted for the completion of two trip planning tasks and post-test interviews! The prevalence of comments received regarding arrival and departure times of buses, what constitutes a bus stop, and even regarding what a bus route is indicates that transit knowledge is not common knowledge. Customers who are unclear about how bus service operates likely will have difficulty using transit information materials, or at the very least, feel very uneasy about making trips on transit with only printed transit information as their guide.

Related to the issue of a lack of general public transit knowledge among the population in Florida is the lack of intuitiveness of existing printed transit information materials. As the recommendations that follow will show, most of the transit information materials in circulation today are not designed with an eye towards being understood by people who have not had much, if any, experience using public transportation. Such materials should be designed so that individuals can pick them up and easily interpret the information necessary to plan a trip on public transit, such as locating their intended destination, identifying the bus route(s) that travel to or nearby the origin of travel and intended destination, the closest bus stop, and the 
estimated time that the bus will travel to the individual's origin bus stop and arrive at the destination bus stop. In addition, individuals should be able to use printed transit information materials to identify the need for transferring and how to accomplish the transfer from one bus to another (i.e., how to locate a transfer point, how to determine transfer times, etc.). Review of the existing printed transit information materials in Florida reveals numerous examples wherein the information required to complete a trip plan is either not provided or lacks the clarity necessary for individuals without experience with public transit to figure out the specifics of bus travel. It is important to note that, while many field test participants indicated that they would need to seek additional information from transit system customer service and/or bus operators, this is not an optimal solution to the barrier presented by existing printed transit information materials. One benefit of effective transit information materials is that passengers and potential passengers are able to plan trips and use transit without having to have access to a telephone in order to speak with transit system customer services. In addition, on-time performance may be negatively impacted if vehicle operators are required to provide information in the form of trip planning assistance to passengers on a regular basis. Many of the problems identified with the printed transit information materials included in the field test can be rectified by transit agencies with little to no additional expense. The following recommendations highlight those possible changes, as well as the need for additional research related to user-friendly and effective design elements that assist transit newcomers with the process of transit trip planning.

\section{Recommendation 1: Conduct Additional Research on Most Effective Design Elements}

The quantitative and qualitative analyses conducted in the transit information and marketing field test suggest that the use of certain design elements in printed transit information materials resulted in higher transit trip planning scores and reduced levels of frustration and anxiety among participants. These results include the following findings:

- Materials using horizontally-aligned timetables resulted higher scores.

- Tasks involving Ride Guide materials took longer to complete.

- Simple transit trip plans associated with Ride Guide materials received higher scores.

- Complex transit trip plans associated with individual bus route schedules received higher scores.

- Males tended to receive higher scores than did females.

- Participants with zero personal vehicles available for use received the lowest scores and rated the tasks as "very difficult."

- The use of points of interest information was helpful to participants.

- The use of distinctive symbols denoting time points, transfer points, and other points of interest were helpful in completing transit trip plans. 


\section{OPERATIONAL BARRIERS \& IMPEDIMENTS TO TRANSIT USE-}

While these results provide insight into the design elements that appear to have helped field test participants complete the trip planning tasks, caution must be used when drawing definitive conclusions from these results. Caution should be heeded due to the fact that the field test was not designed in such a way as to be able to isolate individual design elements in order to definitively draw conclusions related to their effect on trip planning scores. The transit information and marketing field test provided existing transit information materials to participants to complete assigned transit trip plans. These materials differed from one another in a multitude of ways, including the use of color, print size, types of paper used, page orientation, and amount of orienting information. For this reason, it is not possible to draw definitive conclusions regarding the cause and effect of specific design elements on trip planning ability, as all of the additional variables were not controlled for in the field test. For, example, it is not possible to conclusively determine whether higher scores were associated with materials with horizontally-aligned timetables or, rather, that these scores were due to larger print type being used by materials that also have horizontally-aligned timetables.

In order to draw definitive conclusions regarding the relationship between specific design elements and the ability to successfully plan transit trips using printed transit information materials, it is recommended that research be conducted that allows for the isolation of specific design elements. Such research should be designed in such a way that the information materials tested differ on only a single variable. It is recommended that additional research be conducted wherein prototype printed transit information materials are developed for field testing. The field testing of these materials would be designed to present materials that differ from one another by only a single variable to field test participants who would be asked to use the materials to plan transit trips. This method would allow for definitive conclusions to be drawn as to the effect of specific design elements on non-user ability to use printed transit information materials to plan transit trips. Specific conclusions and recommendations could then be made regarding the most effective design elements that should be used by transit agencies.

\section{Recommendation 2: Educate Potential Passengers about Transferring}

Transferring from one bus route to another is a common necessity for public transit passengers in Florida. The spatial layout of most transit service areas in the state make it necessary for passengers to make at least one transfer in order to complete their transit trips. The results of both the quantitative and qualitative analyses conducted as part of the transit information and marketing field test indicate that participants had a great deal of difficulty with transit trips that required a transfer from one bus route to another. Review of the transit information materials used in the field test also reveals that an understanding of bus transfers is taken as common knowledge. Little descriptive information is provided to potential passengers related to how to accomplish a bus transfer. Transfer points are rarely shown on maps or marked on timetables. 


\section{OPERATIONAL BARRIERS \& IMPEDIMENTS TO TRANSIT USE-}

While many transit agencies do provide transfer information in the form of "how to ride" guides, these descriptions often do not address the details of actually accomplishing transfers. Additionally, potential passengers should not be expected to obtain multiple pieces of transit information materials in order to gain an understanding of the basics of transit travel. Transit agencies must make a more concerted effort to educate potential passengers about the specifics of transferring. This effort includes providing clear information about transfer points within and throughout Ride Guides and/or individual bus route schedules. Even when transfer information is provided to users, the information is sometimes provided in a confusing manner. For example, transfer points may be listed as " $\mathrm{X} 1$ " or " $\mathrm{M2}$ " where these notations have no apparent relation to the bus routes or route maps provided in the printed transit information materials. The use of transfer point information that is not intuitive to users should be avoided.

\section{Recommendation 3: Help Potential Passengers Use Transit Information Materials}

Effective transit information materials help passengers by presenting clear, concise, and consistent information that leads users step-by-step through the transit process. In order to be effective, the design and construction of printed transit information materials must be attentive to detail. Missing or inconsistent information results in a great deal of confusion among users. The following recommendations are offered, based on comments received by field test participants and review of the printed materials by transit professionals, to help transit agencies improve the clarity and usability of printed transit information materials.

\section{Consistency is Key}

Information provided in printed transit information materials, such as symbols for transfer points, time points, and points of interests, are only useful to passengers if presented in a consistent manner. For example, many field test participants described frustration and confusion related to bus stops (time points) listed on timetables but not included on route maps or vice versa. This includes the terminology used to describe time points. For example, a time point listed on a route map as "Maple Avenue" should not be listed on the corresponding timetable as "U.S. 7." While many streets in Florida are known by several names, printed transit information materials should be consistent in terms of the names used. Similar frustration was expressed regarding points of interest listed in relation to specific bus routes, but not marked on route maps. In addition, symbols used to denote transfer points (such as circles or diamond shapes) should also be applied consistently throughout all printed transit information produced by a transit agency. The use of consistently applied information and/or symbols will result in printed transit information materials that are intuitive and inviting for passengers because multiple cues are provided to guide users through the transit trip planning process. Care should be taken to ensure that consistency is carried through to all route maps and timetables produced for a transit system. The Florida Department of Transportation, 


\section{OPERATIONAL BARRIERS \& IMPEDIMENTS TO TRANSIT USE-}

working in conjunction with transit agencies throughout the state, should also consider the value of ensuring statewide consistency in terms of symbols employed in printed transit information materials. Research should be conducted to develop a report that documents transit mapping symbols recommended for statewide transit marketing efforts.

\section{Provide Explanation about the Meaning and Use of Information}

Many participants in the transit information and marketing field test indicated a lack of understanding related to the information provided in timetables and on route maps, as well as symbols used throughout printed transit information materials. For example, some transit systems list on intersecting streets the numbers or names of transferring bus routes. However, no indication of what the names and/or numbers represent is provided to the person using the route schedule. Therefore, while this type of transfer information can be particularly helpful for transit users, the information is rendered meaningless due to a lack of description provided to the user. Similar problems were identified with printed transit information materials that do not contain any map legends. The potential problems with these materials are obvious - without a descriptive guide available to assist in map interpretation, the information provided on maps is useless. Finally, timetables should not be assumed to be self-explanatory. Descriptive information should be clearly provided to the users of printed transit information materials regarding the information contained in timetables. For example, materials should indicate that time points represent major bus stops, that the times listed in timetables represent when buses are scheduled to arrive at those designated time points, and how to use the information provided in timetables to estimate the arrival times at bus stops that fall between time points included in the timetables. Many field test participants expressed confusion in relation to directional tags assigned to bus routes. For example, the use of "inbound" and "outbound" directional route designators provides little guidance to potential passengers who do not know to what geographical point or major landmark these titles refer. Similar confusion is associated with directional notations such as "north" and "south" in reference to bus routes that do not travel in a strictly northerly or southerly direction. In order to make the information provided in timetables as intuitive as possible, transit agencies also should strive to list time points in a linear fashion wherein the first time point listed corresponds to the first time point on the associated bus route and the last time point listed corresponds to the last timed bus stop on the route. It is not reasonable to expect users to be able to interpret non-linear timetables.

\section{Materials Should Help Spatially Orient Passengers}

Most of the printed transit information materials developed for transit systems in Florida have not been designed in such a way as to help spatially orient passengers. It appears that most transit agencies in Florida design materials from a marketing perspective with an eye toward being aesthetically pleasing for users. Less attention appears to be paid to ensuring that 
layouts are spatially accurate. Maps are rarely drawn to geographic scale and hardly, if ever, provide legend information indicating mileage scale. Review of the materials revealed that landmarks, points of interest, and time points are often clearly misplaced on route and system maps. It is, therefore, impossible for users who are not knowledgeable about all portions of the transit service area to determine the distance from their origin point to a bus stop or from a bus stop to their destination point. This results in unease among passengers who are not able to determine whether their intended bus route or destination is within reasonable walking distance. Similarly, intersecting street information also often is omitted from system and route maps, making it very difficult for users to orient themselves using printed transit information materials. In addition, some transit systems have omitted the use of a north arrow altogether on their maps, while others have north arrows pointing in directions other than the "up" position (i.e., the traditional positioning of the north arrow in cartography is pointing "upward" towards the top of the map page), further confusing individuals attempting to orient themselves both during the planning phase of transit trips, as well as while in-route on transit vehicles. The proliferation of geographic information systems (GIS) has made it possible for transit systems to develop information materials that are geographically accurate. Such accuracy assists passengers and potential passengers and makes the transit trip planning and travel phases less intimidating for those with little transit experience.

\section{Use Contrasting Colors Whenever Possible}

Field tests participants expressed an overwhelming preference for the use of contrasting colors to denote distinct bus routes on systemwide route maps. The use of contrasting colors on route maps allows users to determine where specific bus routes travel and to distinguish individual bus routes from one another. Despite the obvious advantages associated with using color contrasts in systemwide route maps, several transit systems in Florida have developed maps without contrasting colors. These materials were particularly frustrating for field test participants, as they had tremendous difficulty determining the bus route(s) available to complete their transit trips, as well as points where bus routes intersect. Providing color contrasts results in printed transit information materials that are more intuitive for users by helping them to identify bus routes and transfer points.

\section{Include Map Legends and Points of Interest Information}

Map legends play a critical role in the task of map interpretation. Map users rely on the information provided in map legends to decipher the spatial, locational, and situational data presented in maps. Indeed, a map without a legend is akin to a compass without a needle. Without it, travelers would likely find themselves hopelessly lost and utterly confused. It may seem redundant, or even ridiculous, to offer a recommendation that a map legend be included with each systemwide and individual route map developed by transit agencies. However, a 
review of all printed transit information materials available in the state of Florida indicates that map legends are often excluded from the printed materials made available to customers. An additional problem identified in the both the review of materials and the field test of the printed transit information materials is incomplete or inaccurate map legends. In several cases where map legends are provided, important information regarding the interpretation of symbols used in maps and timetables is not provided. Similarly, some agencies have used symbols on the systemwide and/or individual route maps that are not included in the map legend, thereby failing to provide any interpretive guidance to the map user. Transit agencies should strive to include clear and comprehensive data in map legends and to ensure that these data are included with each and every route map produced for the system.

Field test participants consistently expressed a preference for printed transit information materials that include information on points of interest and area landmarks, as well as the bus routes that serve those points. However, problems were noted with materials that listed points of interest and landmarks on the cover of individual bus route schedules and maps, but failed to note those points on either route maps or timetables. This also was a problem identified in relation to systemwide route maps wherein points of interest were noted but no mention of the points was included in individual bus route schedules and maps. The inclusion of points of interest and major landmark information on systemwide and individual bus route schedules and maps helps orient passengers so that they are able to interpolate the information provided in both forms of printed transit information materials. These data should be consistently included in all printed transit information materials provided to passengers and potential passengers.

\section{Avoid the Use of Small Print Type}

Transit agencies are faced with the challenge of presenting a great deal of important information in a limited amount of space to passengers in the form of printed transit information materials. In order to satisfy this need, many transit agencies have resorted to the use of very small print size (8 point type or less). Small print type is not user-friendly for any transit customers and is particularly problematic for customers with vision impairments. The results of the transit information and marketing field test indicate that customers would rather contend with materials of expanded size and/or awkward shape than to be faced with the challenge of interpreting transit information that is barely readable.

\section{Conclusion}

The preliminary recommendations offered in the preceding sections have been developed as a result of the transit information and marketing field test. These recommendations are intended to assist transit agencies in their efforts to increase the effectiveness and usability of printed transit information materials. While the recommendations offered herein present a good 
starting point for the improvement of printed transit information materials, the conduct of additional research is desirable in order to provide more in-depth guidance to transit agencies in relation to effective design materials. The intention of such research would be to offer concrete direction to transit agencies regarding prototype printed transit information materials that have been shown to increase customer success in the trip planning phase of the transit experience and, therefore, increase the likelihood that transit is viewed by potential customers as an accessible and attractive transportation alternative to the personal automobile. 


\section{Chapter Four: \\ Transit Scheduling for Major Activity Centers Field Test}

Transit barriers within the category of service availability and convenience represent the most commonly-cited barriers to transit use, as well as the most challenging to address. Issues frequently raised by non-users in relation to service availability and convenience include system coverage, frequency of service, days and hours of service, wait times, and the need for transfers. While many of these issues potentially could be addressed by transit agencies, the costs associated with the potential solutions, such as increasing the frequency of service, are not always feasible to implement due to limited capital and operating resources. Therefore, it is crucial that transit agencies maximize the efficiency and effectiveness of existing transit services as a method of increasing the attractiveness of these services. This chapter addresses the field test conducted by CUTR in order to examine the effectiveness of existing transit services in Florida in terms of transit scheduling for travel demands.

A very common sentiment expressed by transit users and non-users regarding public transit services is that the bus does not serve desired activity centers at times when passengers wish to travel to those destinations. In some cases, it has been shown that bus schedules have been developed without a complete understanding of the peak travel times to and from major travel attractors such as employment sites, medical centers, and universities. This has led to transit scheduling being completed, for the most part, without consideration for start and end times, common appointment times, normal work schedules, etc. In these cases, individuals may not use transit because buses do not serve their intended destinations during peak travel times. As part of the present project, CUTR examined the effectiveness of existing transit schedules by analyzing the availability of transit service to major activity centers with clear start and end times associated with the activities and/or services offered at those destinations. The analyses that follow seek to provide a preliminary assessment of the existing level of transit service to major activity centers by illustrating patterns of gaps in services and providing a level of transit service comparison between transit properties.

\section{Methodology}

The primary focus of this field test has been to determine whether and to what degree major activity centers throughout Florida are being served by transit. The following sections detail the process that was undertaken to identify major activity centers, define hours of operation, determine the level of transit service access to each activity center, and analyze transit service scheduling in relation to travel demand. 


\section{Major Activity Centers}

The Florida Department of Transportation provided CUTR with the major activity centers that were included in the transit scheduling field test. These data were provided to FDOT by individual transit agencies throughout Florida as required by the Florida MPO Transit Quality of Service Evaluation. The purpose of the quality of service evaluation was for metropolitan planning organizations (MPOs) in areas with fixed-route transit service to evaluate the quality of that service. Due to timing conflicts between the present project and the due date associated with the above-mentioned project, CUTR only received major activity centers from 14 of the 22 transit service areas in the state of Florida.

The Florida MPO Transit Quality of Service Evaluation project provided direction to MPOs for the determination of major activity centers. Depending upon the expanse of the transit service area, each MPO was required to determine six to ten major activity centers that attract the most vehicle traffic. Although some degree of freedom was provided to MPOs in the selection process, large MPOs (those in areas with populations of 200,000 or more) were directed to include activity centers with the following characteristics:

- At least one location in the central business district (CBD) of the largest city;

- Major intermodal terminals, such as passenger airports and AMTRAK stations, if present;

- At least one regional shopping center, if present;

- At least one university or community college, if present;

- At least one major park \& ride facility, if present;

- A large office development outside the CBD; and

- A geographically diverse set of suburbs, neighborhoods, and/or tourist attractions.

Smaller MPOs (those in areas with populations under 200,000) were instructed by FDOT to select their activity centers by considering the following guidelines:

- A representative location in the CBD of the largest city;

- A shopping center;

- A university or community college, if present;

- A hospital;

- A residential neighborhood; and

- A large employment center outside the CBD.

CUTR was provided a total of 136 major activity centers from 14 transit service areas. One entire service area was omitted from the field test due to the degree of difficulty encountered while attempting to utilize the transit agency's available information materials to identify the 
transit routes that serve each reported activity center. The 13 service areas and transit agencies that were included in the field test include:

- Pensacola - Escambia County Area Transit (ECAT)

- Gainesville - Regional Transit System (RTS)

- Ocala - SUNTRAN

- Hillsborough - Hillsborough Area Regional Transit (HART)

- Volusia - VOTRAN

- Broward - Broward County Mass Transit Division (BCT)

- Sarasota - Sarasota County Area Transit (SCAT)

- Manatee - Manatee County Area Transit (MCAT)

- Polk - Lakeland Area Mass Transit District (LAMTD)

- Tallahassee - Tallahassee Transit (TALTRAN)

- Palm Beach - Palm Beach County Transportation Agency (PALMTRAN)

- Miami - Miami-Dade Transit (MDT)

- $\quad$ Brevard - Space Coast Area Transit (SCAT)

Several individual activity centers from these 13 service areas also were eliminated from the analysis for one or more of the following reasons:

- Residential areas - these activity centers are considered traffic generators rather than traffic attractors;

- Transit-specific facilities - these locations are designed specifically for transit use (e.g. park-and-ride lots and transfer centers) and, therefore, do not meet the intent of the present analysis; and

- Unidentifiable activity center - an activity center was eliminated if there was incomplete information available related to location and/or land use category.

A total of 42 major activity centers were omitted from the analysis, resulting in a comparative analysis of the level of transit service access to 94 major activity centers from the 13 included transit service areas.

\section{Land Use Categories and Operating Hours}

For analysis purposes, the major activity centers were grouped according to land use rather than by county or service area, resulting in the following six land use categories:

- Airports (9);

- Medical/Hospital (8);

- Shopping (25); 
- Business/Government (25);

- Education (16); and

- Recreation (11).

One of the primary components necessary to establish whether a particular activity center is served by transit is a comparison of activity center operating hours and the hours of transit service available to each activity center. Therefore, it was necessary to determine the operating hours for each major activity center included in the analysis. This was accomplished by either obtaining the precise hours of a particular activity center via its website or through telephone contact, or by establishing general parameters based on similar resources in the area. A distinction was made between weekday (Monday through Friday), Saturday, and Sunday operating hours. In addition, because the focus of this field test was to evaluate the level of useful transit service access to major activity centers, 30 minutes was added to both the beginning and end of each activity center's operating hours. The purpose of adding this time was to evaluate how well transit service is able to accommodate the travel needs of workers and students who must arrive at an activity center prior to opening and/or depart after completing necessary activities. For example, if a business is actually open from 9:00 AM to 9:00 PM, its operating hours, for the purpose of this analysis, are considered to be 8:30 AM to 9:30 PM. This additional hour is a general range that affords workers the time to arrive prior to the actual start of business and to leave when their closing duties are complete. The operating hours for each land use category are discussed in the following sections.

\section{Airports \& Medical}

Because airports and hospitals are 24-hour operations, the operating hours for the airport and medical land use categories were divided into three general shifts based on the information received from several hospitals and airports regarding their general approach to employee scheduling and peak airport traffic. The three general shifts for airports are defined in this analysis as: Shift 1 - 5:00 AM to 2:00 PM; Shift 2 - 2:00 PM to 11:00 PM; and Shift 3 - 11:00 PM to 5:00 AM. Hospitals have somewhat different scheduling needs and the three most common shifts are considered to be Shift 1 - 7:00 AM to 3:00 PM; Shift 2-3:00 PM to 11:00 PM; and Shift 3 - 11:00 PM to 7:00 AM. Therefore, considering the 30 minutes added to each end of the activity centers' hours, a hospital would be considered served by transit for the first shift if a bus arrived as late as 6:30 AM and one departed the hospital as early as 3:30 PM.

\section{Shopping}

The shopping land use category comprises malls and shopping centers or plazas. Precise operating hours were obtained for each mall and, although individual stores may establish their own hours in the shopping centers and plazas, the hours for these activity centers were derived 
based on generally common mall hours, and are typically considered to be 8:30 AM to 9:30 PM. These operating hours include the 30 minutes that was added to each end of the actual operating hours.

\section{Business/Government}

The operating hours for the business/government land use category (7:30 AM to 6:00 PM) were established based upon the typical traditional workday, with 30 minutes added at each end of the day to allow for arrival and departure opportunities. Governmental centers and office complexes also were included in this classification. Saturday and Sunday were omitted from this land use category, as they are considered weekend days rather than part of the conventional work week of Monday through Friday.

\section{Education}

The education land use category includes community colleges and universities. On-line course schedules were consulted for each institution, and operating hours were established based upon 30 minutes prior to a school's earliest class and 30 minutes after the latest class dismissal time. This affords students time to navigate the campus in order to reach their intended destination or the bus stop when leaving campus. Many community colleges hold frequent Saturday classes and some are also in session on Sunday; these times were considered, as well. When considering whether transit serves a community college or university, only the first and last class were considered. Courses that are scheduled between the earliest and latest classes were not a factor in determining whether the institution is served by transit.

\section{$\underline{\text { Recreation }}$}

Beaches, pedestrian malls, and tourist attraction/entertainment venues were considered within the recreation land use category. Because of the proliferation of hotels and open access to the beach in this environment, beaches were considered 24-hour operations and were assigned the same shift hours as hotels. If available, the exact operating hours of a particular facility, such as a museum, were used, again adding 30 minutes to each end of the activity center's day.

\section{Transit Routes and Frequency of Service}

A second component necessary to analyze the level of transit service access to major activity centers is information about the bus routes that serve each activity center. In addition to identifying the bus route(s) serving each activity center, the analysis also required information about the days and hours of transit service and the frequency of transit service. For many of the transit properties included in the analysis, this information was obtained through the use of 
transit "points of interest" listed on the transit information materials along with information provided related to the bus routes that serve each point of interest. Because most transit system maps are not drawn to scale geographically, CUTR declined to "eyeball" distance from bus routes to activity centers, whenever possible. However, for those activity centers not listed as a point of interest on the transit information materials, as well as those materials that did not include information on bus routes that serve points of interest, the transit system map was used in combination with individual route maps to determine the bus routes that serve a particular major activity center. It should be noted that CUTR used transit information materials collected from transit agencies in March 2001. The materials received were dated between 1999 and 2001. Therefore, it is possible that transit schedule information for the transit agencies included in the analysis may have since changed, as transit service provision is a dynamic process wherein agencies must constantly respond to changing conditions. As a result, it is important to note that the findings of this analysis are valid only for transit schedule information available as of the data collection period, March 2001. For each activity center, the total number of bus routes that serve an activity center are included, as well as the name or number of each individual route. This information has been collected for weekdays, Saturdays, and Sundays.

The frequency of transit service for each individual route was determined by examining the bus route's timetable. For most bus routes, the frequency of transit service is consistent throughout the span of daily service. The number of buses per hour was determined based on how many times a bus accesses each activity center. For example, bus routes with one hour frequency access activity centers with one bus per hour while those with 30 minute frequency have two buses per hour, and so forth. However, some of the bus routes have variable frequencies throughout the span of daily service, typically due to increased frequencies during peak travel times. For those routes, the average number of buses per hour was calculated by dividing the total number of times the bus stops at a particular activity center in a day by the route's daily span of service.

For the purpose of analyzing the level of transit access to major activity centers, the transit span of service is measured as the amount of time between each bus route's earliest arrival and latest departure from an activity center. This measure refers to the earliest time that an individual would be able to arrive at a major activity center and the latest time that one could depart from that activity center using transit. Because many activity centers are served by multiple bus routes, the final transit span used in the analysis of transit level of service refers to the amount of time that elapses between the earliest route that serves the activity center to the latest that any route departs the activity center. Each of these factors was assessed for weekday, Saturday, and Sunday transit service. Appendix G includes the data table containing each of the above-mentioned data elements for each route serving each activity center included in the analysis. 


\section{Transit Scheduling for Major Activity Centers Analysis}

The transit service access to major activity centers was evaluated by weekday, Saturday, and Sunday, as activity center operating hours may vary depending on the day of the week and most transit agencies that operate on Saturday and/or Sunday alter their weekend schedule, as well. The hours of operation of each activity center was compared to the useful hours of operation of the bus route(s) that serve it. This provided a mechanism by which to determine whether a particular activity center is served by transit or not.

The analysis of transit level of service to major activity centers is presented in two parts. First, the existing conditions of transit service availability are discussed. This approach examines the data for each activity center, by land use category, and analyzes the availability of transit service in terms of the earliest and latest trip available to transit patrons. For the purposes of this analysis, an activity center is considered "served" by transit if at least one bus accesses the activity center within one hour before adjusted operating hours (30 minutes before and 30 minutes after). In addition, an activity center is considered "served" by transit as long as at least one bus route accesses the site. This portion of the analysis focuses on whether activity centers are served during the AM and PM, AM only, or PM only. The intent of this approach is to identify patterns of transit service access to activity centers, such as gaps in service and other characteristics of transit service availability.

The second portion of the analysis consists of a comparative analysis of the level of transit service to major activity centers, by land use category. The primary unit of measurement for this portion of the analysis is the number of times per hour that transit service accesses each activity center during the activity center's normal operating hours. This is measured by evaluating the number of routes that serve a particular activity center, the average frequency of transit service to the activity center, and the percentage of the activity center's operating hours that are covered by transit service. Therefore, the following equation was used to calculate the level of transit service access that is provided to each activity center:

\section{Level of transit service access $=\mathrm{N} \times \mathrm{F} \times \mathrm{R}$}

The equation comprises three variables that were calculated to determine the level of transit service access to major activity centers. The variables are expressed as follows:

$$
\begin{aligned}
& \mathrm{N}=\text { Number of bus routes accessing the activity center } \\
& \mathrm{F}=\text { Average frequency of service for all routes serving the activity center }
\end{aligned}
$$




\section{$\mathrm{R}=\underline{\text { Transit span of service }}$ \\ Activity center operating hours}

For example, Shopping Mall X has the weekday operating hours of 9:00 AM to 9:00 PM, or 12 hours. The local transit service provides weekday transit access to the shopping mall from opening until only 7:00 PM, or 10 hours. Five separate routes provide transit service to the shopping mall with an average frequency of 2 buses per hour on weekdays. Using the equation presented above, Shopping Mall $\mathrm{X}$ receives the following level of transit service:

$N(5) \times F(2) \times R(10 / 12)=8.3$ Buses per Activity Center Operating Hour (acoh)

If only 2 bus routes served Shopping Mall $X$ with the frequency of 1 bus per hour, the activity center's level of transit service would be impacted in the following way:

$$
\text { N (2) } x F(1) \times R(10 / 12)=1.7 \text { Buses per Activity Center Operating Hour (acoh) }
$$

The results of the analyses of existing conditions of transit service availability to major activity centers and the level of transit service to major activity centers are provided in the following sections. 


\section{Results: Existing Conditions of Transit Service to Major Activity Centers}

Transit information materials for each system in the study were consulted in order to assess the existing conditions of transit service to and from major activity centers. After establishing the weekday, Saturday, and Sunday operating hours for each major activity center included in the analysis of transit level of service, data were compiled for the number of routes that access each activity center, and the first arrival time and last departure time for each of those routes. Based on this information, a determination was made as to whether each of the routes that travel to the major activity centers provides transit access in the AM-only, the PM-only, or both the AM and PM. Detailed data regarding the provision of transit service access to the major activity centers included in each land use category, by route, are provided in Appendix $\mathrm{H}$. Summary tables are included throughout the remainder of the analysis that report aggregate data for each major activity center, by land use category.

For the purpose of present analysis, the following criteria are used to assess the existing conditions of transit service access to major activity centers:

(1) If a bus route serves a major activity center in the "AM-only," this means that at least one bus on the route arrives at the activity center prior to the beginning of the operating hours associated with that major activity center, but no bus on the route is available for departures at the close of operating hours.

(2) A bus route with a "PM-only" designation signifies that transit service is available for departure from the major activity center at the close of its normal operating hours, but no bus on that route provides access to the activity center prior to the beginning of normal operating hours.

(3) A bus route with "AM/PM" designation signifies that transit service is provided to the major activity center such that a transit patron may arrive by bus for the start of operating hours and may depart the activity center by bus at the close of normal operating hours.

As described previously, the normal operating hours of a major activity center are defined from 30 minutes prior to and 30 minutes following the official operating hours of each major activity center. Additionally, at least one transit bus must arrive within one hour of the adjusted operating hours in order to be considered served by transit. Therefore, an activity center with the actual operating hours of 10:00 AM to 7:00 PM would have, for the purpose of the present analysis, adjusted operating hours of 9:30 AM to 7:30 PM, and would be considered served by transit in the AM and PM if a bus arrived between 8:30 and 9:30 AM, and if a bus was available for departure between 7:30 and 8:30 PM. 
The following sections present overall aggregate bus route service data for each major activity center by land use category, as well a discussion of service trends and potential gaps in transit service. The number of bus routes serving major activity centers in the AM-only, the PM-only, and both the AM and PM are indicated in Tables 4-1 through 4-10.

\section{Airports}

Nine airports were reported as major activity centers by 10 of the 13 transit agencies included in this analysis. Tables 4-1 and 4-2 present information on the total number of bus routes that access each airport, when bus service is provided to each airport, and the total number of bus routes that serve the airport land use category.

Because airports must be staffed 24 hours a day, the airports' operating hours were divided into three general shifts (Shift 1 - 5:00 AM to 2:00 PM; Shift 2-2:00 PM to 11:00 PM; and Shift 3 11:00 PM to 5:00 AM) based upon information obtained by CUTR related to airport operations. As previously stated, prior to determining whether an activity center is served by transit or not, 30 minutes was added to the beginning and end of shift to account for the logistics of arrival and departure of airport employees. Please note that the AM and PM designation of Shifts 1, 2, and 3 in Tables 4-1 and 4-2 refer to the beginning (AM) and end (PM) of the shift, rather than actual AM and PM times. Therefore, the AM of Shift 3 actually refers to 10:30 PM - the shift's starting time (including the extra 30 minutes) - and Shift 3's PM end time is 5:30 AM.

\section{$\underline{\text { Weekday Service }}$}

Table 4-1 provides information on bus service to the nine airports during weekdays, by shifts. A total of 15 routes access these major activity centers Monday through Friday. Shift 1 is considered to be served by bus service exclusively in the PM on weekdays (15 of 15 routes), meaning that one may depart the airport at the end of Shift 1 (2:30 PM or later), but no bus arrives at any of the airports by 4:30 AM, when employees would be required to arrive for the start of a 5:00 AM shift.

For Shift 2 (1:30 PM to 11:30 PM) during weekdays, three of the 15 routes access the activity centers during both the AM and the PM, meaning that one could arrive for the start of a 2:00 PM shift by 1:30 PM and depart the airport at the end of the shift at 11:30 PM. However, the majority of the routes (12) that access the airports only provide service during the AM portion of Shift 2, providing bus service at the beginning of the shift but not at the shift's end. No routes provide service exclusively during the PM of Shift 2. 
As illustrated in Table 4-1, Shift 3 (10:30 PM to 5:30 AM) receives bus service similar to Shift 2. This shift is served by three of the 15 routes for both the AM and PM, and seven routes serve this shift only in its PM. There are no routes that serve Shift 3 only during the AM of the shift.

Table 4-1:

Weekday Transit Service to Airport Major Activity Centers

\begin{tabular}{|c|c|c|c|c|c|c|c|c|c|c|}
\hline \multirow[b]{2}{*}{ Activity Center } & \multirow[b]{2}{*}{$\begin{array}{c}\text { Number } \\
\text { of } \\
\text { Routes }\end{array}$} & \multicolumn{3}{|c|}{ Shift 1} & \multicolumn{3}{|c|}{ Shift 2} & \multicolumn{3}{|c|}{ Shift 3} \\
\hline & & AM/PM & $\begin{array}{c}\text { AM } \\
\text { Only }\end{array}$ & $\begin{array}{l}\text { PM } \\
\text { Only }\end{array}$ & AM/PM & $\begin{array}{l}\text { AM } \\
\text { Only }\end{array}$ & $\begin{array}{l}\text { PM } \\
\text { Only }\end{array}$ & AM/PM & $\begin{array}{l}\text { AM } \\
\text { Only }\end{array}$ & $\begin{array}{l}\text { PM } \\
\text { Only }\end{array}$ \\
\hline Pensacola Regional Total & 1 & 0 & 0 & 1 & 0 & 1 & 0 & 0 & 0 & 0 \\
\hline Tampa International Total & 1 & 0 & 0 & 1 & 0 & 1 & 0 & 0 & 0 & 1 \\
\hline Daytona Beach Total & 1 & 0 & 0 & 1 & 0 & 1 & 0 & 0 & 0 & 0 \\
\hline Ft. Lauderdale/Hollywood Total & 1 & 0 & 0 & 1 & 1 & 0 & 0 & 1 & 0 & 0 \\
\hline $\begin{array}{l}\text { Sarasota (Sarasota County) } \\
\text { Total }\end{array}$ & 2 & 0 & 0 & 2 & 0 & 2 & 0 & 0 & 0 & 1 \\
\hline $\begin{array}{l}\text { Sarasota (Manatee County) } \\
\text { Total }\end{array}$ & 1 & 0 & 0 & 1 & 0 & 1 & 0 & 0 & 0 & 0 \\
\hline Lakeland Lender Regional Total & 1 & 0 & 0 & 1 & 0 & 1 & 0 & 0 & 0 & 1 \\
\hline $\begin{array}{l}\text { West Palm Beach International } \\
\text { Total }\end{array}$ & 2 & 0 & 0 & 2 & 0 & 2 & 0 & 0 & 0 & 2 \\
\hline Miami International Total & 4 & 0 & 0 & 4 & 2 & 2 & 0 & 2 & 0 & 2 \\
\hline Melbourne International Total & 1 & 0 & 0 & 1 & 0 & 1 & 0 & 0 & 0 & 0 \\
\hline Total & 15 & 0 & 0 & 15 & 3 & 12 & 0 & 3 & 0 & 7 \\
\hline
\end{tabular}

\section{Saturday Service}

A total of 14 routes serve the airports on Saturday, as indicated in Table 4-2. Shift 1 (4:30 AM to 2:30 PM), as with the weekday schedule, is served exclusively during the PM-only. All 14 of the routes provide bus service for the AM of Shift 2 (1:30 PM to 11:30 PM), 12 of which are during the AM-only, and two routes serve both the AM and PM. There are no routes providing PM-only service for Shift 2 on Saturdays. Finally, four of the 14 routes provide service during Shift 3 (10:30 PM to 5:30 AM), three routes in the AM-only and one route in the PM-only. None of the routes serve Shift 3 in both the AM and PM.

\section{Sunday Service}

Table 4-2 also shows that a total of nine bus routes provide service to and from the airports on Sundays, and again, Shift 1 is served in the PM-only by all of these routes. All of the routes serve Shift 2 during the AM-only, providing no service for the PM end of this shift. Shift 3 receives bus service by two of the nine routes in the AM-only and one in the PM-only. 
Table 4-2:

Saturday and Sunday Transit Service to Airport Major Activity Centers

\begin{tabular}{|c|c|c|c|c|c|c|c|c|c|c|c|c|c|c|c|c|c|c|c|c|}
\hline \multirow[b]{3}{*}{ Activity Center } & \multicolumn{10}{|c|}{ Saturday Service } & \multicolumn{10}{|c|}{ Sunday Service } \\
\hline & \multirow[b]{2}{*}{$\begin{array}{c}\text { Number } \\
\text { of } \\
\text { Routes }\end{array}$} & \multicolumn{3}{|c|}{ Shift 1} & \multicolumn{3}{|c|}{ Shift 2} & \multicolumn{3}{|c|}{ Shift 3} & \multirow[b]{2}{*}{$\begin{array}{c}\text { Number } \\
\text { of } \\
\text { Routes }\end{array}$} & \multicolumn{3}{|c|}{ Shift 1} & \multicolumn{3}{|c|}{ Shift 2} & \multicolumn{3}{|c|}{ Shift 3} \\
\hline & & AM/PM & $\begin{array}{l}\text { AM } \\
\text { Only }\end{array}$ & $\begin{array}{l}\text { PM } \\
\text { Only }\end{array}$ & AM/PM & $\begin{array}{l}\text { AM } \\
\text { Only }\end{array}$ & $\begin{array}{l}\text { PM } \\
\text { Only }\end{array}$ & AM/PM & $\begin{array}{l}\text { AM } \\
\text { Only }\end{array}$ & $\begin{array}{l}\text { PM } \\
\text { Only }\end{array}$ & & AM/PM & $\begin{array}{l}\text { AM } \\
\text { Only }\end{array}$ & $\begin{array}{l}\text { PM } \\
\text { Only }\end{array}$ & AM/PM & $\begin{array}{l}\text { AM } \\
\text { Only }\end{array}$ & $\begin{array}{l}\text { PM } \\
\text { Only }\end{array}$ & AM/PM & $\begin{array}{l}\text { AM } \\
\text { Only }\end{array}$ & $\begin{array}{l}\text { PM } \\
\text { Only }\end{array}$ \\
\hline $\begin{array}{l}\text { Pensacola Regional } \\
\text { Total }\end{array}$ & 1 & 0 & 0 & 1 & 0 & 1 & 0 & 0 & 0 & 0 & 1 & 0 & 0 & 1 & 0 & 1 & 0 & 0 & 0 & 0 \\
\hline $\begin{array}{l}\text { Tampa International } \\
\text { Total }\end{array}$ & 1 & 0 & 0 & 1 & 0 & 1 & 0 & 0 & 0 & 0 & 1 & 0 & 0 & 1 & 0 & 1 & 0 & 0 & 0 & 0 \\
\hline Daytona Beach Total & 1 & 0 & 0 & 1 & 0 & 1 & 0 & 0 & 0 & 0 & 0 & 0 & 0 & 0 & 0 & 0 & 0 & 0 & 0 & 0 \\
\hline $\begin{array}{l}\text { Ft. } \\
\text { Lauderdale/Hollywood } \\
\text { Total }\end{array}$ & 1 & 0 & 0 & 1 & 1 & 0 & 0 & 0 & 1 & 0 & 1 & 0 & 0 & 1 & 0 & 1 & 0 & 0 & 0 & 0 \\
\hline $\begin{array}{l}\text { Sarasota (Sarasota } \\
\text { County) Total }\end{array}$ & 2 & 0 & 0 & 2 & 0 & 2 & 0 & 0 & 0 & 0 & 0 & 0 & 0 & 0 & 0 & 0 & 0 & 0 & 0 & 0 \\
\hline $\begin{array}{l}\text { Sarasota (Manatee } \\
\text { County) Total }\end{array}$ & 1 & 0 & 0 & 1 & 0 & 1 & 0 & 0 & 0 & 0 & 0 & 0 & 0 & 0 & 0 & 0 & 0 & 0 & 0 & 0 \\
\hline $\begin{array}{l}\text { Lakeland Lender } \\
\text { Regional Total }\end{array}$ & 1 & 0 & 0 & 1 & 0 & 1 & 0 & 0 & 0 & 0 & 0 & 0 & 0 & 0 & 0 & 0 & 0 & 0 & 0 & 0 \\
\hline $\begin{array}{l}\text { West Palm Beach } \\
\text { International Total }\end{array}$ & 1 & 0 & 0 & 1 & 0 & 1 & 0 & 0 & 0 & 0 & 1 & 0 & 0 & 1 & 0 & 1 & 0 & 0 & 0 & 0 \\
\hline $\begin{array}{l}\text { Miami International } \\
\text { Total }\end{array}$ & 4 & 0 & 0 & 4 & 1 & 3 & 0 & 0 & 2 & 1 & 4 & 0 & 0 & 4 & 0 & 4 & 0 & 0 & 2 & 1 \\
\hline $\begin{array}{l}\text { Melbourne } \\
\text { International Total }\end{array}$ & 1 & 0 & 0 & 1 & 0 & 1 & 0 & 0 & 0 & 0 & 1 & 0 & 0 & 1 & 0 & 1 & 0 & 0 & 0 & 0 \\
\hline Total & 14 & 0 & 0 & 14 & 2 & 12 & 0 & 0 & 3 & 1 & 9 & 0 & 0 & 9 & 0 & 9 & 0 & 0 & 2 & 1 \\
\hline
\end{tabular}




\section{Patterns and Assessment}

The totals presented in Tables 4-1 and 4-2 reveal that airports receive less bus service (9 routes) on Sunday than that provided on weekdays (15 routes) and Saturdays (14 routes). This is likely the result of the scaled-back bus service provided by many transit agencies on Sundays, and the fact that many of the systems do not operate on that day. Five of the 13 transit systems included in this analysis do not provide any bus service on Sundays and the remaining 8 provide a reduced level of service on Sundays. In addition, of the nine routes accessing the airports on Sundays, four of these are Miami-Dade Transit routes, the largest system in the study. The remaining five routes that access airports on Sundays are spread among five transit systems, each operating one route to the airport.

The early start time of Shift 1 (4:30 AM) is the most likely reason that none of the routes serve the AM portion of this shift. Although many of the systems have begun service by 6:00 AM, particularly during the weekdays, this timing does not allow for arrival at the airport for workers with a 5:00 AM shift. However, by the mid-afternoon end time of Shift 1 (2:30 PM), all of the systems are providing service that would allow workers to depart the airport at the end of their shift.

It is somewhat the opposite situation for Shift 2 at airports. Because of the time of day this shift begins (1:30 PM), all of the routes serve Shift 2 in the AM. However, the late end-time of the shift (11:30 PM) generally is not served due to the fact that most of the systems have ended their service prior to that time, frequently by a matter of hours. It should be noted that for both weekdays and Saturdays, the five routes that do serve Shift 2 during both the AM and PM are the routes of larger systems, such as Broward County Transit and Miami-Dade Transit. There are no routes that serve the AM and PM of Shift 2 on Sundays.

Due to its late start time (10:30 PM), Shift 3 often is not served for the AM portion of the shift, again because most of the transit systems have ended their service for the day by that time, with the exception of the larger systems. The PM of this shift is more often served because many of the agencies have begun transit service within an hour following 5:30 AM, the end time of this shift for airports.

Of further note, it may be the case that transit scheduling to and from the activity centers in this and other categories in this analysis is structured to serve the patrons of the activity centers rather than the workers. 


\section{Medical}

Similar to airports, medical centers and hospitals are 24-hour operations, but their scheduling is somewhat different than that of the airports. The shifts for the eight activity centers included in the medical category were delineated as such: Shift 1 - 7:00 AM to 3:00 PM; Shift 2 - 3:00 PM to 11:00 PM; and Shift 3 - 11:00 PM to 7:00 AM. Tables 4-3 and 4-4 present data illustrating the totals of the current transit conditions for the major activity centers included in this land use category, according to shifts, for weekdays and Saturdays/Sundays respectively. Tables H-3 and $\mathrm{H}-4$ in Appendix $\mathrm{H}$ detail the individual routes and their portion of service to each activity center. As with the other categories, the declaration as to whether a shift is served is based upon adding 30 minutes to each end of the actual shift, therefore considering Shift 1 as 6:30 AM to 3:30 PM for the purpose of determining whether or not it is served by transit. Furthermore, reference to the AM and PM of the shifts is to the beginning (AM) and end (PM) of a particular shift rather than actual AM or PM hours.

\section{Weekday Service}

The eight major activity centers comprising the medical land use category are accessed by a total of 17 bus routes during weekdays, as illustrated in Table 4-3. For Shift 1 (6:30 AM to 3:30 PM) approximately half of these (9 routes) provide service for both the AM and PM. None of the routes serve only the AM portion of Shift 1 because all of the routes are in service at the shift's end time of 3:30 PM. However, seven of the 17 routes provide service during Shift 1 in the PM-only, a result of a later than 6:30 AM arrival time for many of the bus routes. One route serves neither the AM nor PM of any shift on weekdays because it is an evening route with operating hours that fall within the working hours of Shift 2.

Table 4-3

Weekday Transit Service to Medical Major Activity Centers

\begin{tabular}{|c|c|c|c|c|c|c|c|c|c|c|}
\hline \multirow[b]{2}{*}{ Activity Center } & \multirow[b]{2}{*}{$\begin{array}{c}\text { Number of } \\
\text { Routes }\end{array}$} & \multicolumn{3}{|c|}{ Shift 1} & \multicolumn{3}{|c|}{ Shift 2} & \multicolumn{3}{|c|}{ Shift 3} \\
\hline & & AM/PM & $\begin{array}{l}\text { AM } \\
\text { Only }\end{array}$ & $\begin{array}{l}\text { PM } \\
\text { Only }\end{array}$ & AM/PM & $\begin{array}{l}\text { AM } \\
\text { Only }\end{array}$ & $\begin{array}{l}\text { PM } \\
\text { Only }\end{array}$ & AM/PM & $\begin{array}{l}\text { AM } \\
\text { Only }\end{array}$ & $\begin{array}{l}\text { PM } \\
\text { Only }\end{array}$ \\
\hline Memorial Hospital Total & 2 & 2 & 0 & 0 & 0 & 2 & 0 & 1 & 0 & 1 \\
\hline Holy Cross Hospital Total & 2 & 2 & 0 & 0 & 0 & 2 & 0 & 1 & 0 & 1 \\
\hline Doctor's Hospital Total & 2 & 2 & 0 & 0 & 0 & 2 & 0 & 0 & 0 & 0 \\
\hline Sarasota Memorial Hospital Total & 2 & 1 & 0 & 1 & 0 & 2 & 0 & 0 & 0 & 2 \\
\hline Blake Hospital Total & 2 & 1 & 0 & 1 & 0 & 2 & 0 & 0 & 0 & 2 \\
\hline Lakeland Regional Total & 1 & 1 & 0 & 0 & 0 & 1 & 0 & 0 & 0 & 1 \\
\hline Winter Haven Hospital Total & 1 & 0 & 0 & 1 & 0 & 1 & 0 & 0 & 0 & 1 \\
\hline TMHC Total & 5 & 0 & 0 & 4 & 0 & 4 & 0 & 0 & 0 & 4 \\
\hline Total & 17 & 9 & 0 & 7 & 0 & 16 & 0 & 2 & 0 & 12 \\
\hline
\end{tabular}


Shift 2 (2:30 PM to 11:30 PM) is served by bus transit exclusively in the AM (16 of 16 routes) on weekdays, as all routes access the activity centers only at the start time of this shift. Although some of the larger systems are still in operation at the end time of Shift 2 (11:30 PM), the routes that provide service during the later hours are not serving the particular activity centers in this land use category.

A total of 14 routes serve Shift 3 (10:30 PM to 7:30 AM) during weekdays and this shift is primarily served during the PM-only (12 of 17 routes). Two routes provide service during the AM and PM of the shift, meaning that there is bus service to the activity center between 9:30 and 10:30 PM (the AM of the shift) and that bus service operates early enough so a worker could depart between 7:30 and 8:30 AM, after completing Shift 3. The remaining three routes that access the medical activity centers do not provide service within the defined parameters of useful service.

\section{Saturday Service}

Table 4-4 illustrates the existing transit conditions for the medical land use category on Saturdays. These activity centers are accessed by a total of 16 routes on Saturdays. Eight routes serve Shift 1 in both the AM and PM, therefore arriving prior to 6:30 AM and departing after 3:30 PM, providing service at both ends of Shift 1. Seven routes provide bus service for the PM-only, and no bus routes serve the AM-only portion of Shift 1, indicating that almost half of the routes that access the medical land use category during Saturdays do not arrive early enough for workers to reach these activity centers for the beginning of Shift 1 .

Of the 16 routes that access the medical activity centers on Saturdays, 15 serve Shift 2 in the AM-only. No routes serve both the AM and PM of this shift, and no routes serve the PM-only. Therefore, the only Saturday bus service available to those medical activity centers provides access in the AM of Shift 2 (2:30 PM), necessitating other travel arrangements for departure from the hospital or medical center for those completing a shift at 11:30 PM.

Only two of the 16 routes serve these activity centers in the AM and PM of Shift 3 (10:30 PM to 7:30 AM), but they are served by 12 routes in the PM-only (7:30 AM). No routes provide AMonly (10:30 PM) service for this shift on Saturdays. This is not surprising given that most agencies have begun service prior to 7:30 AM, but many do not operate until 10:30 PM.

\section{Sunday Service}

Table 4-4 also indicates that five routes provide access to the activity centers within the medical land use category on Sundays. Shift 1 is served by all five bus routes in the PM-only, meaning that none arrive at the medical activity centers by 6:30 AM for the start of Shift 1 . As with 
Table 4-4

Saturday and Sunday Transit Service to Medical Major Activity Centers

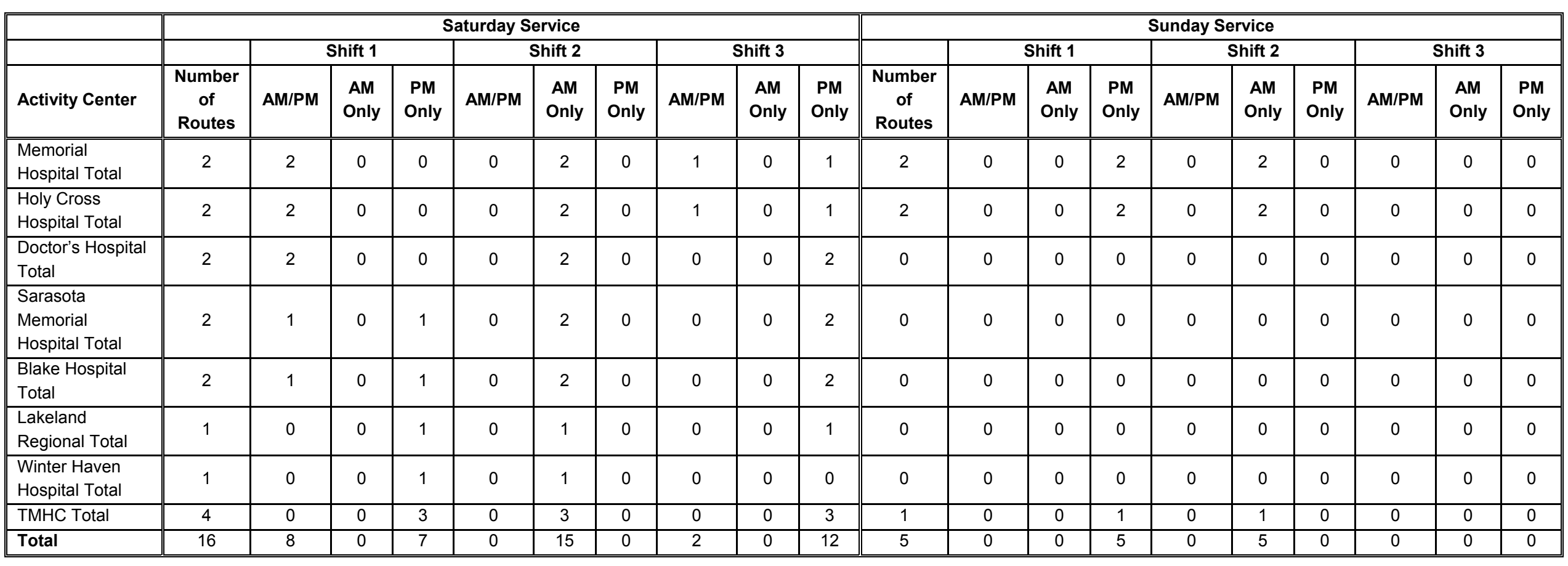


weekdays and Saturdays, Shift 2 is served exclusively by the five routes in the AM-only. Therefore workers may arrive via transit for the start of the shift by 2:30 PM, but there is no service at shift's end (11:30 PM) on Sundays. Regarding Shift 3, there are no routes that provide service to the activity centers in this category at any point during this shift (10:30 PM to 7:30 AM) on Sundays.

\section{Patterns and Assessment}

Similar to airports, the medical land use category is served least on Sundays, despite the fact that, based upon the nature of their service, the shifts for such activity centers do not vary according to the day of the week. As was the case with the airport land use category, the PM of Shift 1 (3:30 PM) at medical activity centers is easily served due to its mid-afternoon time when transit systems are typically in full operation. However, in contrast to the airports, the AM is better served in this category because many transit agencies provide bus service to medical centers by approximately 6:30 AM, but none serve the airports for the 4:30 AM start of Shift 1 .

The AM of Shift 2 (2:30 PM) is served easily by transit for the same reasons as the PM of Shift 1 , but the PM of this shift (11:30 PM) typically is not well served because most systems are not still operating by 11:30 PM. Shift 3 has the opposite pattern in that its AM portion generally is not served by transit due to its late start time, but its PM is served easily as most bus routes are in service by 7:30 AM.

\section{Shopping}

The shopping land use category comprises 25 major activity centers. Most hours of operation were obtained from individual shopping complexes and the hours were generalized for cases such as shopping centers that may have variable hours by individual store. The general hours were determined to be 9:00 AM to 9:00 PM, thereby making the assessed operating hours 8:30 AM to 9:30 PM for the purpose of determining whether they are served by transit. Table 4-5 presents the transit data totals for the shopping category, according to weekday, Saturday, and Sunday service. For information regarding the individual routes that serve the shopping activity centers, please refer to Table $\mathrm{H}-5$ in Appendix $\mathrm{H}$.

\section{Weekday Service}

A total of 80 bus routes access the shopping activity centers during weekdays. The overwhelming majority of these routes (62) serve the shopping areas in the AM-only. Despite typically longer hours of transit service during weekdays, only 12 routes serve these activity centers in the AM and PM. One route provides service in the PM-only. 
Table 4-5:

Transit Service to Major Shopping Activity Centers

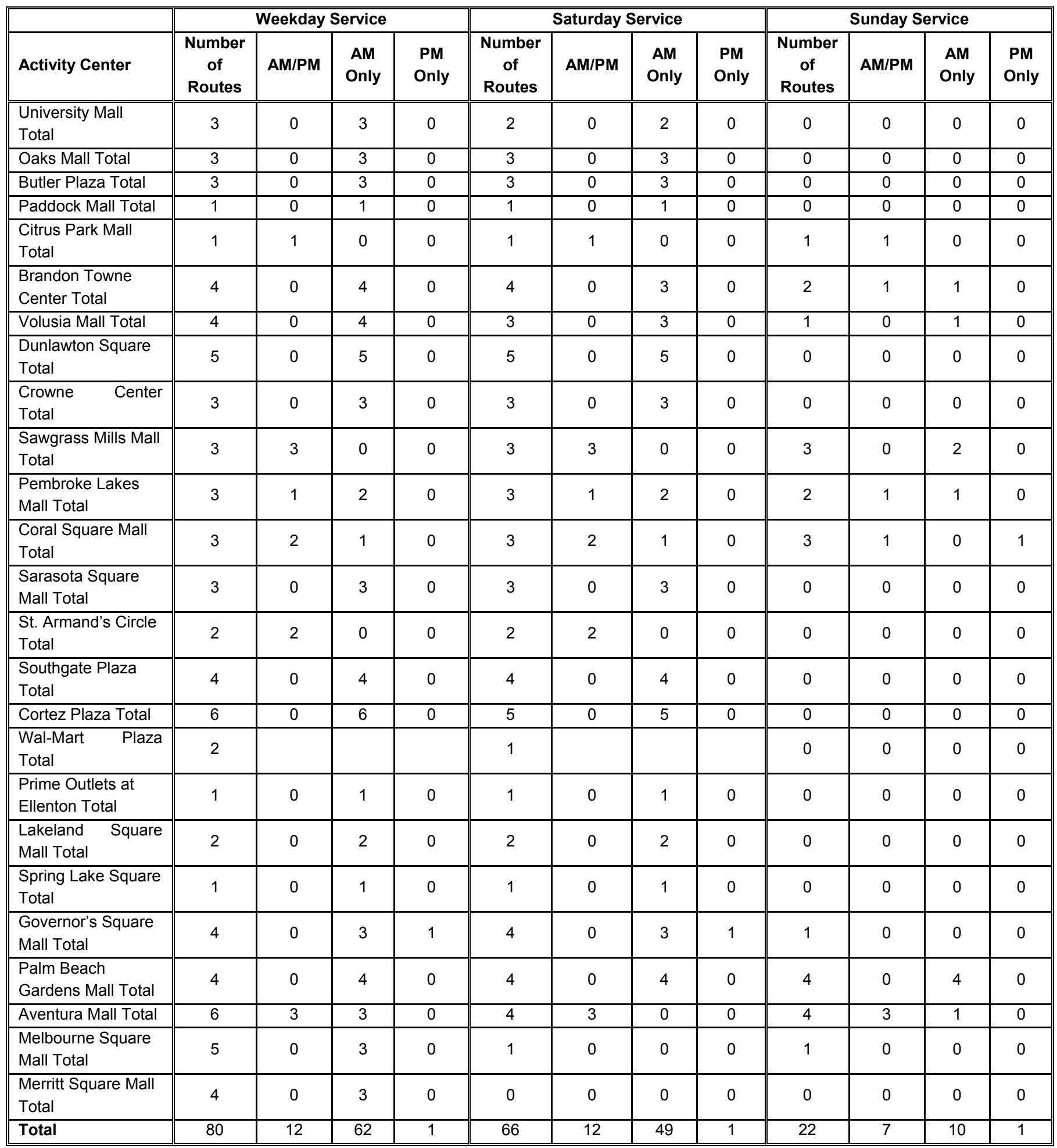




\section{Saturday Service}

Saturday operating hours tend to be the same as weekday operating hours for the shopping activity centers. However Table 4-5 reveals that there is slightly less transit service on Saturdays and that these attractors are accessed by a total of 66 bus routes. As during weekdays, the majority of these routes (49) serve the activity centers in this category in the AM-only. Twelve routes serve the activity centers in both the AM and PM, and one route serves the shopping areas during the PM-only.

\section{Sunday Service}

Shopping establishments and transit tend to have shorter operating hours on Sundays, and a total of 22 routes access the activity centers on this day. As illustrated in Table 4-5, seven routes serve both the $A M$ and PM of shopping operations. Consistent with the pattern of predominantly AM-only service seen for the rest of the week, 10 of the 22 routes serve the AMonly for this day. Also similar to weekdays and Saturdays is that only one route serves the PMonly of shopping areas on Sundays.

\section{Patterns and Assessment}

What is obvious immediately regarding shopping activity center transit service is that the PM is generally not served by transit within the defined operating hour parameters. A common sentiment in relation to transit is that bus service is designed to accommodate the customers of shopping areas rather than the employees of these activity centers. The AM portion of this category's operating hours is particularly well served, thus allowing workers to reach their place of employment in adequate time. However, for those workers who close the shopping activity center, there is a general lack of transit service available at the end of their workday.

Despite the notion that transit to and from shopping areas is designed primarily for the shopping customer, the early arrival times of most routes at the shopping centers suggests other transit functions at the facilities. For example, shopping centers are often used as major transfer points for transit. Additionally, these areas may be used as one core of a modified radial network, particularly within smaller transit agencies. While most malls do not open until approximately 10:00 AM, many transit routes reach these areas in the 6:00 to 7:00 AM range, allowing for transfers to other routes that access the shopping center.

\section{Business/Government}

Table 4-6 reveals that the 25 activity centers comprising the business and government land use category are accessed by a total of 159 transit routes. Each activity center in this land use 
category was assigned the same operating hours (7:30 AM to 6:00 PM) because these are considered to cover the range of a typical business day. Service within this category is considered only Monday through Friday as these days are considered the traditional workweek. Although many of the bus routes may serve business and government centers on Saturday and/or Sunday, for the purpose of this analysis, weekend days have been omitted from consideration and are indicated by N/A in Table 4-6. Information detailing the individual routes and the transit service access provided by them is presented in Table $\mathrm{H}-6$ in Appendix $\mathrm{H}$.

The business/government category generally is well served by the transit routes that access these areas. Of the 159 routes, these activity centers are considered served in both the AM and PM by 114 routes, providing workers the opportunity to reach these areas via transit by 7:30 AM and to depart following a workday ending at approximately 5:30 or 6:00 PM. Another 27 routes serve these areas in the AM-only, and four routes serve in the PM-only. Although there are another 14 routes that access the business and government centers, they are not classified as serving the category because their arrival and/or departure times fall between the hours of 7:30 AM and 6:00 PM. However, these routes likely do provide transit service access to individuals who may not work at the business/government centers, but do need to access their services throughout the day.

\section{Patterns and Assessment}

The business/government land use category likely is well served by transit because most of these activity centers are major employment attractors and typically are situated within the downtowns of most cities. Downtowns often form the central core of a modified radial network from which the majority of a system's routes originate and return at the end of the service day. The primary transfer centers of many transit systems often are located within these downtown areas, as the focus of transit has traditionally been an area's business/government core.

Not all of the business/government centers are in downtown areas, however. Employment centers such as office complexes and corporate campuses commonly are located outside the city center, thereby changing the typical pattern of commuter traffic entering downtowns in the morning and exiting towards the suburbs in the evening. Despite the traditional radial network focus on downtown areas and the rise in suburban employment centers, the outlying business centers in this analysis are relatively well served by transit. Of the nine routes that access the four activity centers that are not located in what may be considered the downtown of a given area, six routes are considered to serve these centers in the AM and PM, and the other three routes serve in the AM-only. 
Table 4-6:

Transit Service to Business and Government Major Activity Centers

\begin{tabular}{|c|c|c|c|c|c|c|c|c|c|c|c|c|}
\hline \multirow[b]{2}{*}{ Activity Center } & \multicolumn{4}{|c|}{ Weekday Service } & \multicolumn{4}{|c|}{ Saturday Service } & \multicolumn{4}{|c|}{ Sunday Service } \\
\hline & $\begin{array}{c}\text { Number } \\
\text { of } \\
\text { Routes }\end{array}$ & AM/PM & $\begin{array}{l}\text { AM } \\
\text { Only }\end{array}$ & $\begin{array}{l}\text { PM } \\
\text { Only }\end{array}$ & $\begin{array}{c}\text { Number } \\
\text { of } \\
\text { Routes }\end{array}$ & AM/PM & $\begin{array}{l}\text { AM } \\
\text { Only }\end{array}$ & $\begin{array}{l}\text { PM } \\
\text { Only }\end{array}$ & $\begin{array}{c}\text { Number } \\
\text { of } \\
\text { Routes }\end{array}$ & AM/PM & $\begin{array}{l}\text { AM } \\
\text { Only }\end{array}$ & $\begin{array}{l}\text { PM } \\
\text { Only }\end{array}$ \\
\hline $\begin{array}{l}\text { M.C. Blanchard Judicial } \\
\text { Building Total }\end{array}$ & 4 & 0 & 4 & 0 & $\mathrm{~N} / \mathrm{A}$ & & & & N/A & & & \\
\hline $\begin{array}{l}\text { Marcus Pointe } \\
\text { Commerce Park Total }\end{array}$ & 2 & 0 & 2 & 0 & $\mathrm{~N} / \mathrm{A}$ & & & & N/A & & & \\
\hline Downtown Plaza Total & 9 & 6 & 2 & 0 & $\mathrm{~N} / \mathrm{A}$ & & & & $\mathrm{N} / \mathrm{A}$ & & & \\
\hline $\begin{array}{l}\text { Downtown Square } \\
\text { Total }\end{array}$ & 2 & 2 & 0 & 0 & $\mathrm{~N} / \mathrm{A}$ & & & & $\mathrm{N} / \mathrm{A}$ & & & \\
\hline $\begin{array}{l}\text { County Courthouse } \\
\text { (Ocala) Total }\end{array}$ & 2 & 2 & 0 & 0 & $\mathrm{~N} / \mathrm{A}$ & & & & N/A & & & \\
\hline $\begin{array}{l}\text { Marion County Health } \\
\text { Dept. Total }\end{array}$ & 3 & 1 & 0 & 0 & N/A & & & & $\mathrm{N} / \mathrm{A}$ & & & \\
\hline Downtown Tampa Total & 29 & 17 & 11 & 1 & $\mathrm{~N} / \mathrm{A}$ & & & & $\mathrm{N} / \mathrm{A}$ & & & \\
\hline $\begin{array}{l}\text { Westshore Business } \\
\text { District Total }\end{array}$ & 4 & 4 & 0 & 0 & N/A & & & & N/A & & & \\
\hline Port Tampa Total & 1 & 1 & 0 & 0 & $\mathrm{~N} / \mathrm{A}$ & & & & $\mathrm{N} / \mathrm{A}$ & & & \\
\hline MacDill AFB Total & 3 & 2 & 1 & 0 & $\mathrm{~N} / \mathrm{A}$ & & & & $\mathrm{N} / \mathrm{A}$ & & & \\
\hline $\begin{array}{l}\text { Downtown Daytona } \\
\text { Beach Total }\end{array}$ & 16 & 13 & 2 & 1 & $\mathrm{~N} / \mathrm{A}$ & & & & $\mathrm{N} / \mathrm{A}$ & & & \\
\hline $\begin{array}{l}\text { New Smyrna } \\
\text { Downtown Total }\end{array}$ & 3 & 0 & 0 & 0 & $\mathrm{~N} / \mathrm{A}$ & & & & N/A & & & \\
\hline $\begin{array}{l}\text { Downtown Ft. } \\
\text { Lauderdale Total }\end{array}$ & 15 & 15 & 0 & 0 & N/A & & & & $\mathrm{N} / \mathrm{A}$ & & & \\
\hline $\begin{array}{l}\text { Downtown Sarasota } \\
\text { Total }\end{array}$ & 13 & 10 & 1 & 1 & N/A & & & & N/A & & & \\
\hline $\begin{array}{l}\text { County Courthouse } \\
\text { (Manatee) Total }\end{array}$ & 5 & 5 & 0 & 0 & $\mathrm{~N} / \mathrm{A}$ & & & & $\mathrm{N} / \mathrm{A}$ & & & \\
\hline $\begin{array}{l}\text { Downtown Palmetto } \\
\text { Total }\end{array}$ & 2 & 2 & 0 & 0 & $\mathrm{~N} / \mathrm{A}$ & & & & $\mathrm{N} / \mathrm{A}$ & & & \\
\hline Lakeland City Hall Total & 2 & 1 & 0 & 0 & $\mathrm{~N} / \mathrm{A}$ & & & & $\mathrm{N} / \mathrm{A}$ & & & \\
\hline $\begin{array}{l}\text { Koger Center } \\
\text { (Tallahassee) Total }\end{array}$ & 2 & 2 & 0 & 0 & $\mathrm{~N} / \mathrm{A}$ & & & & N/A & & & \\
\hline $\begin{array}{l}\text { County Government } \\
\text { Center (Total) }\end{array}$ & 10 & 6 & 4 & 0 & $\mathrm{~N} / \mathrm{A}$ & & & & N/A & & & \\
\hline $\begin{array}{l}\text { TREX Bluelake Office } \\
\text { Complex Total }\end{array}$ & 2 & 2 & 0 & 0 & $\mathrm{~N} / \mathrm{A}$ & & & & $\mathrm{N} / \mathrm{A}$ & & & \\
\hline $\begin{array}{l}\text { Koger Center (Miami) } \\
\text { Total }\end{array}$ & 3 & 3 & 0 & 0 & N/A & & & & $\mathrm{N} / \mathrm{A}$ & & & \\
\hline Downtown Miami Total & 22 & 20 & 0 & 1 & $\mathrm{~N} / \mathrm{A}$ & & & & N/A & & & \\
\hline Titusville CBD Total & 1 & 0 & 0 & 0 & $\mathrm{~N} / \mathrm{A}$ & & & & $\mathrm{N} / \mathrm{A}$ & & & \\
\hline Cocoa CBD Total & 1 & 0 & 0 & 0 & $\mathrm{~N} / \mathrm{A}$ & & & & $\mathrm{N} / \mathrm{A}$ & & & \\
\hline $\begin{array}{l}\text { County Government } \\
\text { Center (Brevard) Total }\end{array}$ & 3 & 0 & 0 & 0 & $\mathrm{~N} / \mathrm{A}$ & & & & $\mathrm{N} / \mathrm{A}$ & & & \\
\hline Total & 159 & 114 & 27 & 4 & $\mathrm{~N} / \mathrm{A}$ & & & & N/A & & & \\
\hline
\end{tabular}




\section{Education}

There are 16 community colleges and universities within the education land use category. The operating hours-defined as the beginning of the first class to the end of the last class of the day, with the additional 30 minutes added to either end of those times-were established based upon information obtained from each institution. Therefore, a school that holds its first class at 8:00 AM and dismisses its last class of the day at 9:45 PM would have operating hours of 7:30 AM to 10:15 PM for the purpose of determining whether it is served by transit. Table 4-7 presents the total routes and hours of transit service access for each activity center. The table also reveals that, although the traditional school week is Monday through Friday, Saturday course meeting times were established for 11 of the 16 institutions included in this study, and one is in session on Sundays. Table $\mathrm{H}-7$ in Appendix $\mathrm{H}$ illustrates the individual routes that access each of these activity centers, as well as whether they serve the AM-only, the PM-only, or both the AM and PM.

\section{$\underline{\text { Weekday Service }}$}

Sixty routes provide access to the education activity centers during weekdays. The majority of these routes (44) serve during the AM-only, and six provide service in both the AM and PM. No routes serve in the PM-only. There are an additional ten routes that access the schools but do not arrive in time for the first class or depart after the last dismissal. The institutions are considered not served by these routes under the previously established definition of served. However, it is likely that a majority of the classes offered at these institutions are held during the hours associated with the traditional workday; and therefore, transit service access is available for many courses on weekdays. Although most courses are held during the day, all of these institutions are in session at some point in the evening, and it is also clear that they are not well served by transit during later hours when night classes are dismissed.

\section{Saturday Service}

Saturday transit service to educational centers is only about half of that which is provided during weekdays, despite the fact that more than half of the institutions hold Saturday classes. Thirty-one routes access 11 activity centers in this category on Saturdays. However, in contrast to the trend of AM-only service during weekdays, 17 routes in the AM and PM and 9 routes in the PM-only serve the education centers, while only 2 routes serve the AM-only on Saturdays. This pattern may be attributed to the fact that none of the Saturday courses extend beyond 7:30 PM, and most are over by approximately 5:00 PM, when the majority of transit systems are still in operation. 
Table 4-7:

Transit Service to Education Major Activity Centers

\begin{tabular}{|c|c|c|c|c|c|c|c|c|c|c|c|c|}
\hline & \multicolumn{4}{|c|}{ Weekday Service } & \multicolumn{4}{|c|}{ Saturday Service } & \multicolumn{4}{|c|}{ Sunday Service } \\
\hline Activity Center & $\begin{array}{c}\text { Number } \\
\text { of } \\
\text { Routes }\end{array}$ & AM/PM & $\begin{array}{c}\text { AM } \\
\text { Only }\end{array}$ & $\begin{array}{l}\text { PM } \\
\text { Only }\end{array}$ & $\begin{array}{c}\text { Number } \\
\text { of } \\
\text { Routes }\end{array}$ & AM/PM & $\begin{array}{l}\text { AM } \\
\text { Only }\end{array}$ & $\begin{array}{l}\text { PM } \\
\text { Only }\end{array}$ & $\begin{array}{c}\text { Number } \\
\text { of } \\
\text { Routes }\end{array}$ & AM/PM & $\begin{array}{l}\text { AM } \\
\text { Only }\end{array}$ & $\begin{array}{l}\text { PM } \\
\text { Only }\end{array}$ \\
\hline $\begin{array}{l}\text { University of } \\
\text { West Florida } \\
\text { Total }\end{array}$ & 1 & 0 & 0 & 0 & $\mathrm{~N} / \mathrm{A}$ & & & & N/A & & & \\
\hline $\begin{array}{l}\text { University of } \\
\text { Florida/Shands } \\
\text { Total }\end{array}$ & 11 & 0 & 7 & 0 & N/A & & & & N/A & & & \\
\hline $\begin{array}{l}\text { SFCC-Main } \\
\text { Campus Total }\end{array}$ & 2 & 0 & 2 & 0 & N/A & & & & N/A & & & \\
\hline $\begin{array}{l}\text { SFCC- } \\
\text { Downtown } \\
\text { Campus Total }\end{array}$ & 3 & 0 & 2 & 0 & $\mathrm{~N} / \mathrm{A}$ & & & & N/A & & & \\
\hline $\begin{array}{l}\text { Central FI } \\
\text { Community } \\
\text { College Total }\end{array}$ & 2 & 0 & 2 & 0 & 2 & 0 & 1 & 0 & N/A & & & \\
\hline $\begin{array}{l}\text { Hillsborough } \\
\text { Community } \\
\text { College Total }\end{array}$ & 2 & 0 & 2 & 0 & 2 & 0 & 0 & 2 & N/A & & & \\
\hline $\begin{array}{l}\text { University of } \\
\text { South Florida } \\
\text { Total }\end{array}$ & 11 & 0 & 10 & 0 & 10 & 5 & 0 & 5 & N/A & & & \\
\hline $\begin{array}{l}\text { Daytona Beach } \\
\text { Community } \\
\text { College Total }\end{array}$ & 4 & 0 & 4 & 0 & 3 & 3 & 0 & 0 & N/A & & & \\
\hline $\begin{array}{l}\text { South Florida } \\
\text { Education } \\
\text { Center Total }\end{array}$ & 2 & 0 & 1 & 0 & $N / A$ & & & & N/A & & & \\
\hline $\begin{array}{l}\text { Manatee } \\
\text { Community } \\
\text { College Total }\end{array}$ & 2 & 0 & 2 & 0 & 2 & 2 & 0 & 0 & N/A & & & \\
\hline $\begin{array}{l}\text { Polk County } \\
\text { Community } \\
\text { College (USF) } \\
\text { Total }\end{array}$ & 2 & 0 & 2 & 0 & 2 & 2 & 0 & 0 & N/A & & & \\
\hline $\begin{array}{l}\text { Polk County } \\
\text { Community } \\
\text { College Total }\end{array}$ & 1 & 0 & 1 & 0 & 1 & 0 & 0 & 1 & $\mathrm{~N} / \mathrm{A}$ & & & \\
\hline FAMU Total & 5 & 1 & 4 & 0 & 3 & 1 & 0 & 0 & N/A & & & \\
\hline $\begin{array}{l}\text { Palm Beach } \\
\text { Community } \\
\text { College Total }\end{array}$ & 3 & 3 & 0 & 0 & 3 & 1 & 1 & 1 & $\mathrm{~N} / \mathrm{A}$ & & & \\
\hline $\begin{array}{l}\text { Miami-Dade CC } \\
\text { North Campus } \\
\text { Total }\end{array}$ & 6 & 2 & 4 & 0 & 3 & 3 & 0 & 0 & 3 & 3 & 0 & 0 \\
\hline $\begin{array}{l}\text { BCC Main } \\
\text { Campus Total }\end{array}$ & 3 & 0 & 1 & 0 & 0 & & & & N/A & & & \\
\hline Total & 60 & 6 & 44 & 0 & 31 & 17 & 2 & 9 & 3 & 3 & 0 & 0 \\
\hline
\end{tabular}




\section{Sunday Service}

Only one of the educational activity centers (Miami-Dade Community College) is in session on Sundays, and it is served in both the AM and PM of its operating hours by all three of the routes that access the school on that day. Although most transit systems decrease the hours of operation on Sundays and often begin service on this day later than during weekdays or even Saturdays, the early start time of Sunday classes (7:30 AM) is within the realm of service for a larger system such as Miami-Dade Transit.

\section{Patterns and Assessment}

In general, the education activity centers are not well served in the PM portion of their operating hours during weekdays. This primarily is due to the fact that, as suggested by the data presented Table 4-7, most of the transit systems have ceased daily operations by the time evening classes have ended. However, many of the major activity centers included in the education land use category do receive transit service during the portion of the school day during which the majority of classes are conducted. Despite a typically shorter transit span of service on Saturdays, more education activity centers that are in operation on that day are served in both the AM and PM because Saturday course scheduling does not exceed the hours of transit operation. Although only one of the education activity centers is in operation on Sunday, it is served in both the AM and PM.

The activity centers in this category are sometimes accessed by transit outside the realm of the operating hours of each activity center, such as on Saturdays or Sundays, because several of the education activity centers, particularly the community colleges, are used as transfer points for some of the transit systems. Transit scheduling, therefore, may not necessarily be structured around class meeting times, but rather at intervals that lend themselves to making transfers to other routes within the system. In addition, the majority of the classes meet within the hours of transit service. This results in several routes that access the education activity centers during their operating hours, but do not serve them in the AM or PM.

\section{Recreation}

The final land use category to be considered in this analysis includes 11 recreational activity centers. The recreation land use category has been divided into shift recreation (5 activity centers) and non-shift recreation (6 activity centers), and the totals for this category are presented in Tables 4-8 through 4-10. Due to the proliferation of hotels on Florida beaches and the nature of that business being a 24-hour operation, all of the beaches and the one hotel provided as major activity centers for this category were considered under the classification of shift recreation (Tables 4-8 and 4-9). Non-shift recreation (Table 4-10) is made up of those 
activity centers with established operating hours that do not necessitate the division of three shifts.

\section{Shift Recreation - Weekday Service}

Information obtained regarding hotel shift hours was similar to that of the major activity centers in the medical land use category. Despite some variation according to job title, Shift 1 is generally considered to be 7:00 AM to 3:00 PM, Shift 2 is 3:00 PM to 11:00 PM, and Shift 3 is 11:00 PM to 7:00 AM. As with the other categories, 30 minutes was added to each end of these shift times to account for the logistics of arrival and departure in determining whether the activity center is served by transit.

As illustrated in Table 4-8, the beaches and hotels of the recreation category are accessed by a total of 12 routes on weekdays. Shift 1 (6:30 AM to 3:30 PM) is served in the AM and PM by five bus routes, and seven bus routes serve the PM-only. There are no bus routes that exclusively serve the AM of this shift. Four bus routes serve Shift 2 (2:30 PM to 11:30 PM) in the $A M$ and $P M$, and seven routes serve this shift in the AM-only. No routes provide service in the PM-only. Shift 3 (10:30 PM to 7:30 AM) is served at some point by ten of the 12 routes. Three bus routes serve this shift in both the AM and PM. Two bus routes serve the shift in the AM-only, and five bus routes serve the third shift in the PM-only during weekdays. It should be noted that the two routes that serve Pensacola Beach during Shift 1 in the PM-only, Shift 2 in the AM and PM, and Shift 3 in the AM-only operate from May to September, and Friday is the only weekday that these routes are in service.

Table 4-8

Weekday Transit Service to Shift Recreation Major Activity Centers

\begin{tabular}{|c|c|c|c|c|c|c|c|c|c|c|}
\hline \multirow[b]{2}{*}{ Activity Center } & \multirow[b]{2}{*}{$\begin{array}{c}\text { Number of } \\
\text { Routes }\end{array}$} & \multicolumn{3}{|c|}{ Shift 1} & \multicolumn{3}{|c|}{ Shift 2} & \multicolumn{3}{|c|}{ Shift 3} \\
\hline & & AM/PM & $\begin{array}{l}\text { AM } \\
\text { Only }\end{array}$ & $\begin{array}{l}\text { PM } \\
\text { Only }\end{array}$ & AM/PM & $\begin{array}{l}\text { AM } \\
\text { Only }\end{array}$ & $\begin{array}{l}\text { PM } \\
\text { Only }\end{array}$ & AM/PM & $\begin{array}{l}\text { AM } \\
\text { Only }\end{array}$ & $\begin{array}{l}\text { PM } \\
\text { Only }\end{array}$ \\
\hline Pensacola Beach Total & 2 & 0 & 0 & $2^{1}$ & $2^{1}$ & 0 & 0 & 0 & $2^{1}$ & 0 \\
\hline $\begin{array}{l}\text { Ft. Lauderdale Beach } \\
\text { Total }\end{array}$ & 4 & 4 & 0 & 0 & 2 & 2 & 0 & 3 & 0 & 1 \\
\hline Manatee Beach Total & 2 & 0 & 0 & 2 & 0 & 2 & 0 & 0 & 0 & 2 \\
\hline $\begin{array}{l}\text { Boca Raton } \\
\text { Hotel/Resort Total }\end{array}$ & 1 & 0 & 0 & 1 & 0 & 1 & 0 & 0 & 0 & 1 \\
\hline $\begin{array}{l}\text { Beaches (Brevard } \\
\text { County) Total }\end{array}$ & 3 & 1 & 0 & 2 & 0 & 2 & 0 & 0 & 0 & 1 \\
\hline Total & 12 & 5 & 0 & 7 & 4 & 7 & 0 & 3 & 2 & 5 \\
\hline
\end{tabular}




\section{Shift Recreation - Saturday Service}

Nine transit routes provide access to the shift recreation activity centers on Saturdays, as presented in Table 4-9. Of these routes, three serve Shift 1 (6:30 AM to 11:30 PM) in the AM and PM and six routes serve Shift 1 in the PM-only. No routes serve the AM-only portion of this shift. Similarly, Shift 2 (2:30 PM to $11: 30$ PM) is served by three bus routes during both the AM and PM, but the remaining six routes for this shift provide service in the AM-only. However, it should be noted that two of the three bus routes that serve the AM and PM portion of Shift 2, and the PM of Shift 1 on Saturdays are the aforementioned summer routes along Pensacola Beach, and their service characteristics apply only from May to September. Shift 3 (10:30 PM to 7:30 AM) is served in a fairly equal distribution by eight of the nine routes that access these activity centers. Three routes serve both the AM and PM, two routes serve the AM-only (both of which are the Pensacola Beach summer routes), and three routes serve the PM-only of this shift on Saturdays.

\section{Shift Recreation - Sunday Service}

Access to the shift recreation centers on Sundays is provided by a total of six bus routes. Indicative of the typically shorter transit operating hours on Sundays, Shift 1 (6:30 AM to 3:30 PM) is served exclusively in the PM-only by these six routes. Two routes serve Shift 2 (2:30 PM to $11: 30 \mathrm{PM})$ in the AM and PM and four routes serve in the AM-only. Shift 3 (10:30 PM to 7:30 AM) is served by two bus routes in the AM-only and one bus route in the PM-only on Sundays. However, as previously stated, the two routes accessing Pensacola Beach operate from May to September only, and the composition of transit service, therefore, changes for the period from October to April. Shift 1 would be served in the PM-only by four routes rather than six; Shift 2 would be served by its four bus routes in the AM-only and no bus routes in both the AM and PM; and Shift 3 would be served by one bus route in the PM-only during this period.

\section{Patterns and Assessment}

As was observed for the airport and medical land use categories, Shift 1 is served most frequently in the PM-only and Shift 2 typically is served in its AM-only. This is to be expected as the beginning time of Shift 1 (6:30 AM) often is prior to the start of transit service and the PM of Shift 2 (11:30 PM) occurs after many transit agencies have ceased operations for the day. Shift 3, if it is served at all, typically is served by transit only during the PM, as most of the systems are in operation by this time (7:30 AM). However, most are not operating at 10:30 PM, the AM of Shift 3. 
Table 4-9

Saturday and Sunday Transit Service to Shift Recreation Major Activity Centers

\begin{tabular}{|c|c|c|c|c|c|c|c|c|c|c|c|c|c|c|c|c|c|c|c|c|}
\hline \multirow[b]{3}{*}{$\begin{array}{l}\text { Activity } \\
\text { Center }\end{array}$} & \multicolumn{10}{|c|}{ "Saturday Service } & \multicolumn{10}{|c|}{ Sunday Service } \\
\hline & \multirow[b]{2}{*}{$\begin{array}{c}\text { Number } \\
\text { of } \\
\text { Routes }\end{array}$} & \multicolumn{3}{|c|}{ Shift 1} & \multicolumn{3}{|c|}{ Shift 2} & \multicolumn{3}{|c|}{ Shift 3} & \multirow[b]{2}{*}{$\begin{array}{c}\text { Number } \\
\text { of } \\
\text { Routes }\end{array}$} & \multicolumn{3}{|c|}{ Shift 1} & \multicolumn{3}{|c|}{ Shift 2} & \multicolumn{3}{|c|}{ Shift 3} \\
\hline & & AM/PM & $\begin{array}{l}\text { AM } \\
\text { Only }\end{array}$ & $\begin{array}{l}\text { PM } \\
\text { Only }\end{array}$ & AM/PM & $\begin{array}{l}\text { AM } \\
\text { Only }\end{array}$ & $\begin{array}{l}\text { PM } \\
\text { Only }\end{array}$ & AM/PM & $\begin{array}{l}\text { AM } \\
\text { Only }\end{array}$ & $\begin{array}{l}\text { PM } \\
\text { Only }\end{array}$ & & AM/PM & $\begin{array}{l}\text { AM } \\
\text { Only }\end{array}$ & $\begin{array}{l}\text { PM } \\
\text { Only }\end{array}$ & AM/PM & $\begin{array}{l}\text { AM } \\
\text { Only }\end{array}$ & $\begin{array}{l}\text { PM } \\
\text { Only }\end{array}$ & AM/PM & $\begin{array}{l}\text { AM } \\
\text { Only }\end{array}$ & $\begin{array}{l}\text { PM } \\
\text { Only }\end{array}$ \\
\hline $\begin{array}{l}\text { Pensacola } \\
\text { Beach }\end{array}$ & 2 & 0 & 0 & $2^{1}$ & $2^{1}$ & 0 & 0 & 0 & $2^{1}$ & 0 & 2 & 0 & 0 & $2^{1}$ & $2^{1}$ & 0 & 0 & 0 & $2^{1}$ & 0 \\
\hline $\begin{array}{l}\text { Ft. } \\
\text { Lauderdale } \\
\text { Beach Total }\end{array}$ & 4 & 3 & 0 & 1 & 1 & 3 & 0 & 3 & 0 & 1 & 3 & 0 & 0 & 3 & 0 & 3 & 0 & 0 & 0 & 1 \\
\hline $\begin{array}{l}\text { Manatee } \\
\text { Beach Total }\end{array}$ & 2 & 0 & 0 & 2 & 0 & 2 & 0 & 0 & 0 & 2 & 0 & 0 & 0 & 0 & 0 & 0 & 0 & 0 & 0 & 0 \\
\hline $\begin{array}{l}\text { Boca Raton } \\
\text { Hotel/Resort } \\
\text { Total }\end{array}$ & 1 & 0 & 0 & 1 & 0 & 1 & 0 & 0 & 0 & 0 & 1 & 0 & 0 & 1 & 0 & 1 & 0 & 0 & 0 & 0 \\
\hline $\begin{array}{l}\text { Beaches } \\
\text { (Brevard } \\
\text { County) } \\
\text { Total }\end{array}$ & 0 & 0 & 0 & 0 & 0 & 0 & 0 & 0 & 0 & 0 & 0 & 0 & 0 & 0 & 0 & 0 & 0 & 0 & 0 & 0 \\
\hline Total & 9 & 3 & 0 & 6 & 3 & 6 & 0 & 3 & 2 & 3 & 6 & 0 & 0 & 6 & 2 & 4 & 0 & 0 & 2 & 1 \\
\hline
\end{tabular}




\section{Non-Shift Recreation - Weekday Service}

There are six activity centers in the non-shift recreation land use category, and these are accessed by a total of 19 routes on weekdays. These attractors are a mix of museums, pedestrian malls, parks, and zoos. An overall majority (15 bus routes) serve the AM-only of these activity centers' operating hours. Three routes provide service in both the AM and PM and one route serves the PM-only. These totals are presented in Table 4-10. The individual routes that access these activity centers are detailed, including the coverage period of service for each, in Table $\mathrm{H}-8$ of Appendix $\mathrm{H}$.

Table 4-10

Transit Service to Non-Shift Recreation Major Activity Centers

\begin{tabular}{|c|c|c|c|c|c|c|c|c|c|c|c|c|}
\hline & \multicolumn{4}{|c|}{ Weekday Service } & \multicolumn{4}{|c|}{ Saturday Service } & \multicolumn{4}{|c|}{ Sunday Service } \\
\hline Activity Center & $\begin{array}{c}\text { Number } \\
\text { of } \\
\text { Routes }\end{array}$ & AM/PM & $\begin{array}{c}\text { AM } \\
\text { Only }\end{array}$ & $\begin{array}{l}\text { PM } \\
\text { Only }\end{array}$ & $\begin{array}{c}\text { Number } \\
\text { of } \\
\text { Routes }\end{array}$ & AM/PM & $\begin{array}{c}\text { AM } \\
\text { Only }\end{array}$ & $\begin{array}{l}\text { PM } \\
\text { Only }\end{array}$ & $\begin{array}{c}\text { Number } \\
\text { of } \\
\text { Routes }\end{array}$ & AM/PM & $\begin{array}{c}\text { AM } \\
\text { Only }\end{array}$ & $\begin{array}{l}\text { PM } \\
\text { Only }\end{array}$ \\
\hline $\begin{array}{l}\text { National } \\
\text { Museum of } \\
\text { Naval Aviation } \\
\text { Total }\end{array}$ & 1 & 0 & 1 & 0 & 1 & 1 & 0 & 0 & 0 & 0 & 0 & 0 \\
\hline $\begin{array}{l}\text { South Beach } \\
\text { Street Total }\end{array}$ & 4 & 0 & 4 & 0 & 4 & 0 & 4 & 0 & 0 & 0 & 0 & 0 \\
\hline $\begin{array}{l}\text { Sun Splash Park } \\
\text { Total }\end{array}$ & 2 & 0 & 2 & 0 & 2 & 0 & 2 & 0 & 0 & 0 & 0 & 0 \\
\hline $\begin{array}{l}\text { Jake Gaither } \\
\text { Park Total }\end{array}$ & 1 & 0 & 1 & 0 & 1 & 0 & 1 & 0 & 0 & 0 & 0 & 0 \\
\hline $\begin{array}{l}\text { Lincoln Road } \\
\text { Total }\end{array}$ & 10 & 3 & 6 & 1 & 8 & 4 & 3 & 1 & 8 & 2 & 5 & 1 \\
\hline MetroZoo Total & 1 & 0 & 1 & 0 & 1 & 0 & 1 & 0 & 1 & 0 & 1 & 0 \\
\hline Total & 19 & 3 & 15 & 1 & 17 & 5 & 11 & 1 & 9 & 2 & 6 & 1 \\
\hline
\end{tabular}

\section{Non-Shift Recreation - Saturday Service}

Table 4-10 also illustrates that seventeen routes access the non-shift recreation activity centers on Saturdays. As during weekdays, the majority of these routes (11) serve the AM-only portion of the activity centers' operating hours. Five provide AM and PM service and one route serves the PM-only.

Non-Shift Recreation - Sunday Service

Following the typical pattern of service for this category, Table 4-10 reveals that the majority of routes providing access to these activity centers serve the AM-only on Sundays. Six of the nine 
bus routes that access these activity centers on Sundays only serve the AM portion of operating hours. Two routes provide service during both the AM and PM and one route serves the PMonly portion of the activity centers' operating hours on Sundays.

\section{Patterns and Assessment}

One of the most obvious characteristics of non-shift recreation service is that these activity centers are primarily served in the AM-only (32 of 45 routes), further indicating that transit is not adequately serving the PM needs of the various activity centers included in this analysis. It also should be noted that the one bus route that consistently served the PM-only within this category is an overnight route in the Miami-Dade system. Only ten of the 45 routes in this category provide both AM and PM service throughout the span of the week.

One reason that these areas may not be well served during the PM of their operating hours is that, with the exception of Lincoln Road Mall in Miami (10 of the 19 weekday routes), these activity centers typically may be considered strictly daytime attractions, and, for the most part, they are. However, current scheduling negates the needs of employees who do not complete their workday in time for the last transit departure from the activity centers.

\section{Conclusion}

The existing conditions of transit service to major activity centers, as reported by the MPOs for the 13 transit service areas included in this analysis, have been evaluated by determining whether an activity center is served by the bus routes within a particular transit system. This determination was made based on whether an activity center is served by transit in the AMonly, the PM-only, or both the AM and PM. While providing service that spans the entire operating hours of an activity center and slightly beyond to account for workers' needs is optimal, structuring transit service around a particular activity center is not always feasible due to financial and operational constraints. However, the categorization of the major activity centers into land use categories and subsequent analysis of their useful transit service allow for the observation of general patterns and trends that may provide insight into the transit needs of the many who access these activity centers, especially the employees of these establishments.

The assessment of the useful transit service accessing the major activity centers in this analysis provides insight into the current conditions of transit service and offers the opportunity to evaluate the gaps in service that may exist, as well as the potential for improvements in the level of transit service for major activity centers. Transit users and non-users alike frequently cite the inconvenience of bus transit scheduling to desirable locations as a barrier to transit use. An evaluation of current transit conditions at popular destinations affords the opportunity to structure bus transit routes and their scheduling to maximize the benefits of transit service. 
Table 4-11

General Operating Hours of Transit Systems Included in Analysis

\begin{tabular}{|c|c|c|c|}
\hline & \multicolumn{3}{|c|}{ General Operating Hours } \\
\hline System & Weekdays & Saturdays & Sundays \\
\hline ECAT & 5:30 AM - 5:30 PM & 6:00 AM - 6:00 PM & 7:45 AM - 7:00 PM ${ }^{1}$ \\
\hline RTS & 6:00 AM - 7:00 PM & 7:00 AM - 6:00 PM & No Service \\
\hline SUNTRAN & $6: 15 \mathrm{AM}-6: 45 \mathrm{PM}$ & $6: 15 \mathrm{AM}-6: 45 \mathrm{PM}$ & No Service \\
\hline HARTLine & 5:00 AM - 9:00 PM & 7:00 AM - 8:00 PM & 7:00 AM - 7:00 PM \\
\hline VOTRAN & 6:00 AM - 7:00 PM & 6:30 AM - 6:30 PM & 7:30 AM - 6:30 $\mathrm{PM}^{2}$ \\
\hline BCT & 5:30 AM - 11:00 PM & 6:00 AM - 10:00 PM & 8:00 AM - 7:00 PM \\
\hline SCAT & 6:00 AM - 6:00 PM & 6:00 AM - 6:00 PM & No Service \\
\hline MCAT & $6: 00 \mathrm{AM}-7: 00 \mathrm{PM}$ & 6:00 AM - 7:00 PM & No Service \\
\hline TALTRAN & 6:00 AM - 6:30 PM & 7:00 AM - 7:00 PM & 12:00 PM - 6:00 PM \\
\hline PALMTRAN & 5:30 AM - 8:00 PM & 7:00 AM - 7:00 PM & 9:00 AM - 5:00 PM \\
\hline MDT & $5: 00 \mathrm{AM}-1: 00 \mathrm{AM}$ & $5: 30 \mathrm{AM}-12: 00 \mathrm{AM}$ & 6:00 AM - 11:00 PM \\
\hline Space Coast & 7:00 AM - 5:00 PM & 8:30 AM - 4:00 PM & 11:30 AM - 2:30 PM \\
\hline LMAT & 5:45 AM - 7:00 PM & 7:00 AM - 6:00 PM & No Service \\
\hline
\end{tabular}




\section{Results: Level of Transit Service Access to Major Activity Centers}

This section of Chapter Four presents the results of a comparative analysis of the level of bus transit service access to major activity centers, by land use category. The comparative analysis provided in this section builds on the data related to existing conditions of transit service access to major activity centers that was presented in the preceding section by addressing the level of transit service that is provided to major activity centers, rather than simply determining whether or not service is provided. This analysis takes into consideration the number of bus routes, frequency of bus service, as well as activity center operating hours covered by transit service. The evaluation of the level of transit service for each land use category is made based upon the number of times per activity center operating hour that a bus accesses each of the activity centers associated with the 13 transit study areas included in this analysis. As described previously, the number of buses per activity center operating hour for each major activity center was ascertained through the use of an equation consisting of the number of routes accessing the activity center, the average frequency of transit service to that activity center, and the percentage of the activity center's operating hours that are served by transit. The maximum, minimum, average, and median number of buses per activity center operating hour (referred to as "acoh" throughout the rest of this analysis) were then calculated for each land use category, and are presented in the tables that follow. The detailed data by activity center are included in Appendix G.

\section{Airport Activity Centers}

The number of buses per activity center operating hour, by weekday, Saturday, and Sunday, for the airport land use category is summarized in Table 4-12. Weekdays have the highest level of transit service, ranging from 0.50 to 5.65 buses per acoh, with the average being 1.45 and the median being 1.00 buses per acoh at the airports. Saturdays show a slight decrease in the level of transit service, with 0.24 being the minimum and 4.08 being the maximum number of buses per acoh that access these activity centers. The average number of buses per acoh on Saturdays is 1.01 and the median is 0.53 . Sundays reveal a lower level of transit service to and from the activity centers in the airport category. The maximum number of times per acoh that buses access this category is 3.14 and, as illustrated in Table 4-12, since 5 of the 13 transit systems do not operate on Sundays, the minimum number of buses per acoh on Sundays is zero. Therefore, the average number of buses per acoh on Sundays is 0.48 and the median is 0.13 . 
Table 4-12

Level of Transit Service Access for Airport Activity Centers

\begin{tabular}{||l|c|c|c|c||}
\hline \multirow{2}{*}{\multicolumn{1}{|c|}{$\mathrm{N}=10$}} & \multicolumn{4}{|c||}{ Buses Per Activity Center Operating Hour } \\
\cline { 2 - 5 } & Maximum & Minimum & Average & Median \\
\hline Weekday Service & 5.65 & 0.50 & 1.45 & 1.00 \\
\hline Saturday Service & 4.08 & 0.24 & 1.01 & 0.53 \\
\hline Sunday Service & 3.14 & 0.00 & 0.48 & 0.13 \\
\hline
\end{tabular}

Airports are considered a 24-hour operation and, as described in the previous section, none of the transit systems included in this analysis access airports for this entire operating period. For this reason, the airport activity centers produced some of the lowest buses per acoh scores among the different land use categories. It also should be noted that for weekdays, Saturdays, and Sundays, Miami-Dade Transit has the maximum number of buses per acoh accessing the activity centers in the airport land use category $(5.65,4.08$, and 3.14 buses per acoh on weekdays, Saturdays, and Sundays, respectively). This transit system is the largest among the 13 included in this evaluation. Comparatively, the second largest system included in the analysis, Broward County Transit, only had 2.12, 1.48, and 0.79 buses per acoh on weekdays, Saturdays, and Sundays, respectively.

\section{Medical Activity Centers}

Table 4-13 presents the number of buses per acoh by weekday, Saturday, and Sunday that access activity centers included in the medical land use category. During weekdays, the average number of buses per acoh that access medical activity centers is 1.84 . The maximum is 5.30 , the minimum is 0.46 , and the median is 1.11 buses per acoh. As with the airport category, the medical activity centers receive slightly less service on Saturdays. The median remains the same, 1.11 , but the maximum number of buses per acoh decreases to 4.49 and the minimum is 0.38 , while the average is 1.66 buses per acoh. Sundays reveal a dramatically decreased level of transit service, with a maximum number of buses per acoh of 1.10 and the minimum and median both equaling zero. The average number of buses per acoh on Sundays is 0.26 . This partially is attributable to the fact that 5 of the 13 transit systems in this analysis do not operate on Sundays, as previously described in Table 4-11. 
Table 4-13

Level of Transit Service Access for Medical Activity Centers

\begin{tabular}{||l|c|c|c|c||}
\hline \multirow{2}{*}{\multicolumn{1}{|c|}{ N=8 }} & \multicolumn{4}{|c||}{ Buses Per Activity Center Operating Hour } \\
\cline { 2 - 5 } & Maximum & Minimum & Average & Median \\
\hline Weekday Service & 5.30 & 0.46 & 1.84 & 1.11 \\
\hline Saturday Service & 4.49 & 0.38 & 1.66 & 1.11 \\
\hline Sunday Service & 1.10 & 0.00 & 0.26 & 0.00 \\
\hline
\end{tabular}

The transit system in Tallahassee provides the highest average level of service in the medical category for weekdays and Saturdays. However, TalTran's limited Sunday service results in Broward County Transit having the highest average level of transit service in the medical category on Sundays, with slightly more than one bus per acoh on that day. Similar to airports, the activity centers in the medical land use category are 24-hour operations and, therefore, receive a lower overall level of service.

\section{Shopping Activity Centers}

The number of buses per acoh accessing the shopping activity centers on weekdays, Saturdays, and Sundays is presented in Table 4-14. The weekday buses per acoh range from a minimum of 0.70 to a maximum of 13.20 at the shopping activity centers, with an average of 4.29 and a median of 3.93 buses per acoh. Saturdays receive only a slightly lesser level of transit service, ranging from a minimum of 0.50 to a maximum of 10.00 buses per acoh. The Saturday average is 3.25 and the median is 3.33 buses per acoh accessing the shopping activity centers. As illustrated in Table 4-14, the typically scaled-back transit service on Sundays results in a maximum buses per acoh of 8.00, while the minimum falls to zero due to some transit systems providing no Sunday service. The Sunday average is 1.14 and the median is 0.00 buses per acoh accessing the shopping activity centers. 
Table 4-14

Level of Transit Service Access for Shopping Activity Centers

\begin{tabular}{||l|c|c|c|c||}
\hline \multirow{2}{*}{\multicolumn{1}{|c|}{ N=25 }} & \multicolumn{4}{|c||}{ Buses Per Activity Center Operating Hour } \\
\cline { 2 - 5 } & Maximum & Minimum & Average & Median \\
\hline Weekday Service & 13.20 & 0.70 & 4.29 & 3.93 \\
\hline Saturday Service & 10.00 & 0.50 & 3.25 & 3.33 \\
\hline Sunday Service & 8.00 & 0.00 & 1.14 & 0.00 \\
\hline
\end{tabular}

As with the airport and medical land use categories, Miami-Dade Transit provides the maximum number of weekday buses per acoh (13.20) in the shopping category, as well. Manatee County Transit provides the minimum level of transit service in the shopping category on weekdays $(0.70)$ and on Saturdays (0.50). However, the activity center with this level of service is a 24hour shopping destination, the only activity center in this category with such hours. Overall, this information indicates that the shopping activity centers appear to be relatively well-served, with an average of more than four buses per acoh on weekdays and more than three buses per acoh on Saturdays.

\section{Business/Government Activity Centers}

The business and government activity centers in this analysis receive the highest level of weekday transit service. As shown in Table 4-15, the maximum number of weekday buses per acoh accessing these activity centers is 59.40 . However, there is a broad range in this service, with a minimum number of buses per acoh of 0.15 . The weekday average is 9.55 and the median is 3.00 buses per acoh. Saturdays and Sundays were not figured into the assessment of this category since the operating hours of the business/government activity centers were considered only for the traditional workweek, i.e., Monday through Friday. 
Table 4-15

Level of Transit Service Access for Business/Government Activity Centers

\begin{tabular}{||l|c|c|c|c||}
\hline \multirow{2}{*}{\multicolumn{1}{|c|}{ N=25 }} & \multicolumn{4}{|c||}{ Buses Per Activity Center Operating Hour } \\
\cline { 2 - 5 } & Maximum & Minimum & Average & Median \\
\hline Weekday Service & 59.40 & 0.15 & 9.55 & 3.00 \\
\hline Saturday Service & N/A & N/A & N/A & N/A \\
\hline Sunday Service & N/A & N/A & N/A & N/A \\
\hline
\end{tabular}

As with the previous categories, Miami-Dade Transit provides the maximum number of buses per acoh accessing the activity centers in this category (59.40). Hillsborough Area Regional Transit (HARTLine) serves Downtown Tampa with 40.60 buses per acoh, the second highest level of transit service to the business/government activity centers. The relatively high level of service to these activity centers may be explained by the fact that radial transit systems were typically developed with downtowns/CBDs as their core, and most of the activity centers in this category are situated in these areas.

The minimum number of buses per acoh (0.15) is provided to the Titusville central business district (CBD) by Space Coast Area Transit (SCAT). It should be noted, however, that this transit system evolved from a door-to-door paratransit operation, originally developed to serve the elderly population in Brevard County. The current transit situation in this area is somewhat of a combined paratransit-type service and regular fixed-route system.

\section{Education Activity Centers}

Table 4-16 reveals that the education category activity centers receive the second highest level of weekday transit service, with a weekday maximum of 29.79 and a minimum of 0.47 . The average is 6.66 and the median is 2.91 buses accessing these activity centers per hour of operation. The range of Saturday transit service in this category is greatly reduced, from the minimum of 0.00 to the maximum of 7.20 buses per acoh. However, the Saturday average is 4.09 bus per acoh and the median is 3.10 buses per acoh, not significantly lower than the weekday average (6.66) and median (2.91). Classes are held on Sundays at only one of the education activity centers and this is the only activity center that receives Sunday transit service, therefore accounting for the identical maximum, minimum, average, and median figures of 4.95 buses per acoh for Sundays. 
Table 4-16

Level of Transit Service Access for Education Activity Centers

\begin{tabular}{||l|c|c|c|c||}
\hline \multirow{2}{*}{\multicolumn{1}{|c|}{ N=17 }} & \multicolumn{4}{|c||}{ Buses Per Activity Center Operating Hour } \\
\cline { 2 - 5 } & Maximum & Minimum & Average & Median \\
\hline Weekday Service & 29.79 & 0.47 & 6.66 & 2.91 \\
\hline Saturday Service & 7.20 & 0.00 & 4.09 & 3.10 \\
\hline Sunday Service & 4.95 & 4.95 & 4.95 & 4.95 \\
\hline
\end{tabular}

As with each of the other land use categories, the education activity centers in Miami-Dade County once again receive the highest level of transit service on weekdays, Saturdays, and Sundays. As illustrated in Table 4-7, 11 of the 16 activity centers in this category hold Saturday classes, although the operating hours are less than those during weekdays. In fact, all but one of the education activity centers receive some transit service on Saturdays, albeit at a reduced level of service than is provided during weekdays. With even shorter operating hours than those of Saturday, one activity center in this category is in operation on Sunday, and is served by 4.95 buses per acoh on that day.

\section{Recreation Activity Centers}

The final land use category addressed in the level of transit service access to major activity centers analysis focuses on recreational facilities. The number of buses per acoh accessing the activity centers in the recreation category is presented in Table 4-17. During weekdays, the activity centers are accessed by a minimum of 0.47 and a maximum of 27.00 buses per acoh. The weekday average is 4.28 and the median is 1.50 buses per acoh. On Saturdays, the recreation activity centers receive a slightly lower level of transit service, with a maximum of 18.40, a minimum of 0.00 , an average of 3.21, and a median of 1.48 buses per acoh. As expected, Table 4-17 reveals a lower level of transit service on Sundays, ranging from the minimum of 0.00 to the maximum of 15.92 buses per acoh. The Sunday average is 1.80 and the median is 0.00 buses per acoh. 
Table 4-17

\section{Level of Transit Service Access for Recreation Activity Centers}

\begin{tabular}{||l|c|c|c|c||}
\hline \multirow{2}{*}{\multicolumn{1}{|c|}{ N=11 }} & \multicolumn{4}{|c||}{ Buses Per Activity Center Operating Hour } \\
\cline { 2 - 5 } & Maximum & Minimum & Average & Median \\
\hline Weekday Service & 27.00 & 0.47 & 4.28 & 1.50 \\
\hline Saturday Service & 18.40 & 0.00 & 3.21 & 1.48 \\
\hline Sunday Service & 15.92 & 0.00 & 1.80 & 0.00 \\
\hline
\end{tabular}

As exhibited in the previous categories, the largest transit system in the analysis, Miami-Dade Transit, provides the highest level of transit service to recreation activity centers on weekdays (27.00), Saturdays (18.40), and Sundays (15.92). The minimum levels of transit service are spread among the transit systems during the three time periods. During weekdays, the minimum (0.47) buses per acoh are provided by PalmTran to the recreation activity center located in Boca Raton. On Saturdays, Space Coast Area Transit does not provide transit service to the recreation activity center within its service area, resulting in 0.00 buses per acoh on that day. However, all of the other activity centers included in the recreation land use category do receive some transit service on Saturdays, as is evident from the Saturday average of 3.21 buses per acoh. This is significant as most recreation activity centers, such as beaches and parks, are most heavily used on the weekends. As with the Sunday service in other categories, the fact that some transit systems do not operate on that day results in zero vehicles serving some of the recreation activity centers on Sundays. In fact, the level of transit service access to the recreation activity centers is drastically reduced on Sundays, as more than half of the activity centers included in this category do not receive any transit service on Sundays. 


\section{Major Findings of the Transit Scheduling for Major Activity Centers Field Test}

A common complaint made by transit passengers, as well as non-users, is that public transit does not travel to desired destinations at the times when people would like to travel to and from those destinations. The intent of the transit scheduling for major activity centers field test was to provide a preliminary assessment of whether and to what degree transit service in Florida is accessing major activity centers in order to identify possible gaps in the scheduling of transit service to activity centers. Toward this end, information was collected and analyzed in relation to the operating hours of and transit service provided to 94 major activity centers located in 13 transit service areas throughout Florida. These data were organized into six land use categories (airports, medical, shopping, business/government, education, and recreation) and compared in order to determine the existing conditions of transit service access to major activity centers in Florida and the level of transit service provided to these activity centers. The existing conditions analysis evaluated whether or not the activity centers included in the analysis are served by transit in terms of the earliest and latest trip(s) available to transit patrons. This analysis focused on the availability of transit service, while the level of transit service access analysis addressed the question of how much transit service is provided to the 94 major activity centers. This was accomplished by considering the number of bus routes, frequency of bus service, and percent of the activity centers' operating hours that receive transit service. Thus, the assessment of the level of transit service access to major activity centers provides a comparative analysis of the number of buses that access each major activity center per activity center operating hour. The major findings from each analysis are provided in the following sections.

\section{Summary of Major Findings - Existing Conditions of Transit Service to Major Activity Centers}

All of the major activity centers included in the existing conditions of transit service to major activity centers analysis are accessible by transit; however, they may or may not be accessible at the most desirable or necessary times. Some activity centers require a relatively early AM start that may not be served by a transit system that is not yet in service for the day. Other activity centers are in operation beyond the daily span of service of many of the transit systems and are, therefore, not served by transit in the PM period. Table 4-11 presents the general operating hours of each of the 13 transit systems included in this analysis. These hours were obtained by examining the printed transit information materials (schedules and route maps), as well as through direct contact with several of the transit agencies. In the event of discrepancies between the printed timetables and the information provided by the transit agencies, an estimation was made to describe a transit system's general hours of operation. 
Based on data presented in Tables 4-1 through 4-10 of this chapter, as well as the information compiled in Table 4-11, the following patterns have been identified related to transit service availability to the major activity centers included in this analysis.

- The major activity centers in the airport land use category are generally not served or are poorly served by transit for the AM portion of the first shift, the PM portion of the second shift, and both portions of the third shift. These times are generally outside the operating hours for most of the transit systems included in this analysis. The airports are consistently served by transit in the PM portion of Shift 1 and AM portion of Shift 2, which are situated in the mid-afternoon when all of the transit systems are in full operation.

- A similar situation exists at the major activity centers of the medical land use category, in that the AM portion of Shift 1 and the PM portion of Shift 2 are frequently not served by transit, but the PM portion of Shift 1 and the AM portion of Shift 2 are consistently served due to their mid-afternoon start (Shift 2) and end (Shift 1) times. As with the airport category, Shift 3 is infrequently served in the AM portion. However, in contrast to the airports, the PM portion of Shift 3 is frequently served by transit because most of the bus routes are in operation by the time this shift ends.

- The overall pattern of transit service at the shopping major activity centers is that they are served in the AM but are generally not served in the PM. The mid- to late-morning AM start times associated with these activity centers allows for transit service, but many systems have ceased daily operations by the typically late-evening PM end times of these activity centers. In addition, the shopping major activity centers often serve as transfer points to other routes, and frequently are served by transit hours before shopping activities begin.

- In general, the business/government major activity centers are well served by transit. The business day falls well within the daily span of service, and these activity centers are commonly located in downtown areas, the traditional hub of transit activity around which a radial network is structured. Those business centers located outside the city center also are relatively well served by transit.

- Major activity centers in the education land use category most frequently are served by transit in the AM-only, although course scheduling results in the PM portion of these activity centers ending in the late evening during weekdays. Similar to the shopping category, most of the transit systems are not in service by the time evening classes have been dismissed, resulting in a gap in service for the PM portion of the education category's day. Saturdays generally are well served in this category, however, because 
most Saturday classes end in the mid- to late-afternoon, prior to the end of transit service for the day.

- When considered jointly, the shift recreation and the non-shift recreation land use categories are primarily served by transit in the AM-only. As with the airport and medical categories, shift recreation is generally served in the PM portion of Shift 1 and the AM portion of Shift 2, again due to the mid-afternoon overlap of these two shifts. The AM portion of Shift 1 and the PM portion of Shift 2 typically fall outside the general hours of operation of most transit systems in Florida. Shift 3, however, typically is served in the PM portion because most transit systems are in operation at the end of this shift. Comprising such major activity centers as museums, parks, pedestrian malls, and zoos, the non-shift recreation category generally is served in the AM-only, as most of these activity centers are commonly considered daytime attractions.

- Because all of the transit systems have either scaled-back service on Sundays or are not in operation at all, those major activity centers that do operate on Sundays receive a decreased level of service as compared to weekdays. All of the activity centers within the shopping category, for example, are in operation on Sundays, but not all of these activity centers are accessed or served by transit on Sundays.

- Regardless of the land use category, the PM coverage period is the most common portion of the activity centers' days that are not served by transit. Those activity centers in such categories as airports, medical, shopping, and education are 24-hour operations, or at least operate well past the typical span of service for transit and are, therefore, generally not served in the late evening and very early morning hours.

\section{Summary of Major Findings - Level of Transit Service Access to Major Activity Centers}

The number of buses that access a particular activity center is one measure of the level of transit service at that activity center - the higher the number of buses per hour, the greater the level of transit service. For example, an activity center that is accessed five times per hour by transit is considered better served by transit than an activity center that is accessed twice per hour. However, it must be taken into consideration that larger transit systems typically have the resources and necessity for more frequent transit service than do their smaller counterparts. Smaller transit systems may actually serve their patrons quite well with less frequent service than that provided by larger transit systems.

Some land use categories, such as business/government, have a wide range of bus routes accessing the activity centers each hour of activity center operation on weekdays, and a relatively high maximum number of buses per activity center operating hour. This may be 
attributable to the fact that business/government activity centers typically are located in downtown areas, which are often the hub of transit activity. Comparatively, other land use categories, such as the medical category, seem to be less well served by transit during weekdays. The low numbers for this category likely are related to the fact that, for the purposes of this study and in reality, medical centers and hospitals are considered to be 24hour operations. Because transit service is generally not provided 24 hours per day, these activity centers appear to have a lower level of transit service.

Furthermore, the level of transit service access to major activity centers is most certainly affected by the day of the week that is being measured. As demonstrated in Table 4-11, several of the transit systems provide shortened service on Saturdays and Sundays, and some do not operate on Sundays at all. In determining the level of transit service access for the major activity centers, the variation of an activity center's operating hours, as well as the variation in the hours of transit operation, must be considered.

Based upon the data compiled in Tables 4-12 through 4-17, the following are general findings in relation to the level of transit service access to the major activity centers in this study.

- Miami-Dade Transit consistently provides the highest level of transit service access to major activity centers when compared with the other 12 transit systems included in the analysis.

- The major activity centers located in Brevard County tend to receive the lowest level of transit service in comparison to the other 12 transit service areas included in the analysis.

- Most of the land use categories included in the analysis appear to receive a sufficient level of transit service during weekdays and Saturdays. However, transit service in most transit service areas is drastically reduced or curtailed on Sundays, resulting in low levels of transit service to major activity centers on this particular day.

- The activity centers categorized under the airport and medical land use categories receive the lowest level of transit service due to the fact that these activity centers are 24-hour per day operations and none of the transit systems included in this analysis provide 24-hour service consistently.

- Airports, while receiving some transit service, are not well served by any transit system included in the analysis. The weekday average of 1.45 buses per acoh and the Saturday average of 1.01 buses per acoh suggest that transit service to airports is not designed to accommodate the airport worker or, in most cases, travelers. Similarly, of the six transit 
systems that provide Sunday bus service to airport activity centers, only Miami-Dade Transit provides airport access of greater than 0.79 buses per acoh.

- Medical activity centers also tend to receive reduced levels of transit service as a result of their 24-hour per day, 7 day per week operations. The level of transit service access to medical activity centers ranges from 0.46 buses per acoh to 5.30 buses per acoh on weekdays, with an average of 1.84 buses per acoh. The range of service is similar on Saturdays - from 0.30 buses per acoh to 4.49 buses per acoh, with a Saturday average of 1.66. However, Sundays experience a drastic reduction of transit service to medical activity centers with five of the eight medical activity centers receiving no transit service and the remaining three activity centers being accessed by transit service with between 0.35 and 1.10 buses per acoh.

- Shopping activity centers are somewhat well served by transit, with an average of 4.29 buses per acoh during weekdays, 3.25 buses per acoh on Saturdays, and 1.14 buses per acoh on Sundays. These averages certainly are affected, however, by the low level of transit service at the single activity center in this category that is in operation 24 hours per day. The level of transit service access provided to the shopping activity centers included in this study also is positively impacted by the use of shopping plazas in key locations as transfer points for many transit systems in Florida.

- The business/government land use category has the highest maximum number of buses accessing its activity centers per acoh (59.40) on weekdays. The average number of buses accessing the business/government activity centers on weekdays is 9.55 buses per acoh, representing a relatively high average for this land use category. The high number of buses per acoh associated with this land use category likely is due to the design of radial transit systems, which typically are focused in downtown areas where the majority of these activity centers generally are located. Downtowns typically are the hub of radial transit systems, providing access to and from the business and government activity centers, as well as serving as points of transfer to other buses within the transit system. Saturdays and Sundays were not considered for this category.

- Education activity centers are second only to business/government in their level of weekday transit service (maximum of 29.79 buses per acoh). Access is greatly reduced to these activity centers on Saturdays (between 0.00 and 7.20 buses per acoh), despite the fact that Saturday classes are held at 11 of the 16 institutions, as presented in Table 4-16. One education center in Dade County is in session on Sundays and it is accessed by a maximum of 4.95 buses per acoh on that day. 
- The weekday range for the level of transit service to recreation activity centers is 0.47 to 27.00 buses per acoh. In accordance with the general pattern of other land use categories, the activity centers included in the recreation category receive a lower level of service on weekends (from 0.00 to 18.40 buses per acoh on Saturdays and between 0.00 to 15.92 buses per acoh on Sundays). However, the activity centers in this category likely are utilized primarily on weekends. Therefore, the results in this category demonstrate a potential need for additional transit service access on Saturdays and Sundays. 


\section{Recommendations: Transit Scheduling for Major Activity Centers}

The transit scheduling for major activity centers field test was conducted to examine the effectiveness of existing transit schedules in Florida by analyzing the availability of transit service to major activity centers, based on a comparison of transit schedules to activity center operating hours. Two types of analyses were conducted: a determination of the existing conditions of transit service access to major activity centers and a level of transit service access analysis that addressed how much transit service is available, on a comparative basis. Together, the existing conditions and level of transit service availability analyses are intended to provide a preliminary assessment of the effectiveness of existing transit scheduling in terms of providing service to major activity centers during the days and hours that patrons desire to access those sites. Ninety-four major activity centers from 13 transit service areas were organized into 6 land use categories for the purpose of the analyses. As the previous sections detail, each of the 94 major activity centers included in the analyses are accessed by widely varying degrees of transit service. Most of the major activity centers examined do not receive a high level of transit service access in the PM period or on Saturdays and Sundays. Sunday transit service access is particularly limited with 5 of the 13 transit agencies included in the review not operating any transit service on Sundays and another 3 transit agencies providing drastically scaled back Sunday services. The land use categories consistently receiving the highest levels of transit service access (business/government, shopping, and education) are also those that typically serve as major transit transfer points for Florida transit systems, suggesting that scheduling at these activity centers is affected more by overall system needs than by transit passenger travel demand. The following recommendations are offered to assist the Florida Department of Transportation and transit systems in Florida to further address and evaluate the effectiveness of transit scheduling in relation to customer travel demands.

\section{Recommendation 1: Conduct Assessment of Transit Service Access to Major Transit Attractors}

While the intent of the transit scheduling for major activity centers field test was to conduct a preliminary assessment of the availability of transit service access to major activity centers, the focus of the analyses was on traffic attractors identified by MPOs for a Transit Quality of Service Evaluation required by the FDOT and based on criteria set by the FDOT. Review of the major activity centers submitted to the FDOT by MPOs throughout the state of Florida suggests that these activity centers do not, in all cases, correspond to the major transit attractors for a given transit service area - the activity centers to and from which transit customers most desire to travel. It is recommended that existing conditions of transit service availability and level of transit service access analyses be conducted with the major activity centers that are associated with existing and latent high transit service demand. These analyses would provide transit agencies with an even wider frame of reference from which to make decisions related to scheduling adjustments, route additions, and/or the reallocation of existing resources. 


\section{Recommendation 2: Evaluate Scheduling Process and Priorities}

Scheduling decisions made by transit planners and schedulers at transit agencies are guided by a myriad of variables that include, but are not limited to, customer travel demands. Scheduling decisions also are influenced by decisions related to transit system priorities such as the goal of geographic coverage versus ridership maximization, union rules, funding considerations and their relationship to the span of service, days of service, and frequency of transit service, as well as political influences related to customer requests and complaints. In order to achieve a full understanding of the transit scheduling process, especially as it relates to transit service access to major activity centers, it is recommended that the transit planning staff and schedulers at each of the 22 Florida transit systems be surveyed to gain insights into the formal and informal scheduling processes employed and the priorities of each system as they pertain to scheduling existing transit services and planning future services.

\section{Recommendation 3: Develop Guidelines for Level of Transit Service Access Standards}

The relative simplicity of the level of transit service access equation that was introduced previously in this document should allow transit agencies throughout the state to conduct similar analyses of their own ridership attractors, as was suggested in a previous recommendation. As the systems conduct this type of analysis, however, invariably, they will want to have a standard or acceptable range with which to compare their scores. To this end, it is recommended that further research be completed on this type of analysis with regard to the development of "rules of thumb" scores (or ranges of scores) for each of the activity center types. This will provide the transit agencies with the comparative values that they will need for their level of transit service access analyses, which can also serve as goals for future accessibility improvements to their activity centers.

\section{Recommendation 4: Assess the "Hub and Spoke" Configuration of Transit Services}

The predominance of "hub and spoke," or radial, configuration of transit services throughout Florida was mentioned several times in this chapter with regard to transit service access to the major activity centers included in the transit scheduling field test. This configuration of transit services is characterized by transit "hubs," typically located in downtown areas, from which transit services "radiate" out into the transit service area. The typical design of this configuration, with the majority of bus routes beginning and ending at hubs located in downtown business districts, was well-suited for past employment and residence patterns. However, the prevalence of suburb-to-suburb travel and commutes today suggests that some transit service areas might be better suited for alternative forms of transit system configurations, wherein suburb-to-suburb travel does not necessitate travel to downtown areas 
that significantly increase total travel time and make transit a less attractive transportation option than the personal automobile. Therefore, it is recommended that, based on the results of the transit service access to major transit activity centers analyses, transit agencies strongly consider alternative system configurations better suited to today's travel demands, as well as those of the future.

\section{Recommendation 5: Consider Increasing Evening Span of Transit Service}

The transit scheduling for major activity centers field test revealed a consistent pattern of ceasing transit operations prior to the closing times associated with the major activity centers included in the analyses. This pattern of AM-only service was evident in each of the six land use categories. This is likely a major source for the common perception that buses do not travel to the places that people wish to go at the times that they wish to travel. The lack of evening service is particularly problematic for workers who wish to use transit for commuting purposes. Of the 13 transit systems included in the field test, only 3 operate services until 9:00 PM or later on weekdays, only 2 transit systems provide service beyond 9:00 PM on Saturdays, and only MDT operates service this late on Sundays. Given the prominent role of the service industry in Florida's economy, it is likely that a very large portion of the permanent and visiting population either works beyond the typical 8:30 AM to 5:30 PM workday or is utilizing services beyond those hours. Therefore, it is recommended that transit agencies consider making later evening service a high priority in either the reallocation of existing resources or the planning of system enhancements. 


\section{Afterword}

We can only imagine what life was like for the thousands of employees of the MTA in New York City in the days following the September 11 attack on the World Trade Center. Several hours passed before there was an assessment of whether there were people trapped in the subway station below the World Trade Center or whether the transit system itself was subject to attack. Street, bridge and tunnel closings forced the MTA to immediately re-route services that have operated on the same routing and schedule for many years. The tireless efforts of MTA employees at every level of the organization created heroes whose stories are not reported in the media; however, the relevance of MTA to the people in New York City and surrounding areas can never be underestimated. In the wake of this tragedy, the relevance of transit may become clearer in all our lives throughout the United States in the months and years to come.

Just like the employees of MTA, transit professionals everywhere experience a myriad of pressures in the day-to-day reality of serving their local communities. In the production of transit information materials, transit agencies are always under time pressure. Changes in bus schedules almost always center around the bidding process, which usually occurs three to four times a year, when bus operators bid on the work they will be performing. Therefore, the process usually entails the bus scheduler(s) developing route schedules and runs, which are then transmitted to the marketing department for production of bus schedules that are eventually distributed to customers. All of these activities must be carefully orchestrated over a period of time to ensure that bus schedules are printed by the time a service change occurs. This process brings up an important issue between an agency's mission to ensure smooth operations and its mission to be customer-oriented.

This report provided preliminary data on the ability of potential transit customers to interpret transit information materials and, to the extent possible, data on design components that facilitate customer understanding. The data presented herein may be controversial to transit professionals who feel that the current level of effort in producing transit materials is the best they can do within the constraints of their agency. However, it is the controversy itself that is the most important component of the report, for if we never reflect on our modes of operating then we will be handicapped in our efforts to continuously improve our methods.

Public transportation service is more demanding than other modes of travel. Imagine a person who has grown up in a hometown whereby navigation is learned through lefts and rights as opposed to directions. Some people never learn or develop the ability to read a map. The manner in which transit operates is not common knowledge. With the exception of major metropolitan areas, there are at least two generations of individuals who have grown up with the automobile as their primary form of transportation and without transit ever being a major 
part of their lives. In this study, the project team found that many people do not intuitively understand the concept of transit service - they do not know how to orient themselves when looking at a map, do not grasp the concept that there are bus stops between timepoints, cannot estimate time between timepoints, and could not plan a trip based on their necessary time of arrival, thus planning the trip backwards.

On the one hand, we should rejoice that transit customers who rely on transit service have been able to adapt to the level of sophistication required to understand transit information materials; however, the problem is that potential customers who have no sense of the nuances are quickly lost and their confidence is almost immediately undermined. Potential customers who have a choice will often choose to not be bothered with the complexities of transit.

Correspondingly, when scheduling services to major activity centers, bus schedulers may face many constraints such as available funds, revenue hours, span and frequency of service, political demands, and geographic coverage and routing. This report shows that almost universally, major activity centers were adequately served in the morning hours but not in the evening hours. Therefore, the most important message for transit planners is that you must constantly stay in touch with activity centers and customers to ensure that services provided to major activity centers reflect the actual customer and potential customer demand. Even in cases where resources are limited, reallocation of resources is possible to meet demand.

Finally, the beauty of research of this nature and scope is that the research team does not face the same kind of time constraints and pressures that transit agencies face in producing schedules and printed transit information materials. The project team was able to utilize many examples and approaches to printed transit information materials in order to identify stumbling blocks and obstacles to using those materials. The next step is to take design techniques and components to develop utopian transit information materials and then conduct a new field test to see if comprehension increases. This would provide transit agencies with definitive data on design schemes that increase comprehension and usability. 


\section{Bibliography}

Abdel-Aty, Mohamed A., Ryuich Kitamura, and Paul P. Jovanis. "Investigating Effect of Advanced Traveler Information on Commuter Tendency to Use Transit." Transportation Research Record 1550 (1996):65-72.

Abdel-Aty, Mohamed A. and Paul P. Jovanis. "The Effect of ITS on Transit Ridership." ITS Quarterly 3(2) (1995):21-25.

Algers, Staffan, Stein Hansen, and Goran Tegner. "Role of Waiting Time, Comfort, and Convenience in Modal Choice for Work Trip." Transportation Research Record 534 (1975):38-51.

Bakr, Mamdouh M. and Richard K. Robinson. "Commuter Preference For Bus Stop Sign Information." Transportation Engineering Journal of ASCE 104 (1978):267-278.

Benjamin, Julian and David Hartgen. The Perception and Incidence of Crime on Middle-Sized Transit Systems in the Southeastern, U.S.A.: An Overview and Case Study. Raleigh, North Carolina: University of North Carolina, Institute for Transportation Research and Education, 1994.

Byrd, Joseph P. IV. "Characteristics, Attitudes, and Perceptions of Transit Nonusers in the Atlanta Region." Transportation Research Record 563 (1976):29-37.

Cervero, Robert. "Tracking Accessibility." Access 11 (1997):27-31.

Center for Urban Transportation Research (CUTR). Performance Evaluation of Florida's Public Transit Systems. Tampa, Florida: Center for Urban Transportation Research, 2000.

Center for Urban Transportation Research (CUTR). Customer Satisfaction Index for Florida Transit Properties. Tampa, Florida: Center for Urban Transportation Research, 2000.

Charles River Associates, Incorporated. Building Transit Ridership: An

Exploration of Transit's Market Share and the Public Policies That

Influence It. Transit Cooperative Research Program, (1997) Report 27.

Washington, DC: Transportation Research Board, National Academy

Press. 
Evans, John E. (Jay) IV, Vijay Perincherry, and G. Bruce Douglas III. "Transit Friendliness Factor: Approach to Quantifying Transit Access Environment in a Transportation Planning Model." Transportation Research Record 1604 (1997):32-39.

Everett, Peter B., Victoria B. Anderson, and Udit Makranczy. "Transit Route Pamphlets: Do They Work?" Transit Journa/3(3) (1977):59-70.

Fielding, Gordon J., Douglas P. Blankenship, and Timothy Tardiff. "Consumer Attitudes Toward Public Transit." Transportation Research Record 563 (1976):22-28.

Foster, Norman S.J., Peter C. Damiano, Elizabeth T. Momany, and Hermine T. McLeran. "Rural Public Transportation: Perceptions of Transit Managers, Directors of Area Agencies on Aging, and Elders." Transportation Research Record 1557 (1996):58-63.

Friman, Margareta, Bo Edvardsson, and Tommy Garling. "Perceived Service Quality Attributes in Public Transport: Inferences from Complaints and Negative Critical Incidents." Journal of Public Transportation 2(1) (1998):67-89.

Gustafson, R.L., H.N. Curd, and T.F. Golob. "User Preferences for a Demand-Responsive Transportation System: A Case Study Report." Highway Research Record 367(1971):3145.

Ingalls, Gerald L., David T. Hartgen, and Timothy W. Owens. "Public Fear of Crime and Its Role in Bus Transit Use." Transportation Research Record 1433 (1994):201-211.

Liff, S. D, Public Information Systems in Urban Mass Transit. Unpublished Master's Thesis. Evanston, Illinois: Northwestern University, 1971.

Linsalata, Jim. Americans in Transit: A Profile of Public Transit Passengers. Washington, DC: American Public Transit Association, 1992.

Loukaitou-Sideris, Anastasia. "Reviving Transit Corridors and Transit Riding." Access 4 (1994):27-31.

Loukaitou-Sideris, Anastasia and Robin Ligget. "On Bus-Stop Crime." Access 16 (2000):27-33.

Mierzejewski, Edward A., and William L. Ball. "New Findings on Factors Related to Transit Use." ITE Journa/ February (1990):34-39. 
Polzin, Steven E. (2000). Public Transportation in the 21 $1^{\text {st }}$ Century: Challenges and Opportunities in Florida. Paper presented at the Transpo2000-The Future is Now! conference, Kissimmee, Florida, April 17-19, 2000.

Pratt, Richard H. Traveler Response to Transportation System Changes: Interim Handbook. Prepared for the Transit Cooperative Research Program, 2000. Transportation Research Board, National Research Council, TCRP Project B-12, Web Document 12.

Reed, Thomas B., Richard R. Wallace, and Daniel A. Rodriguez. "Transit Passenger Perceptions Regarding Transit-Related Crime Reduction Measures." Transportation Research Record, forthcoming.

Rosenbloom, Sandra. Transit Markets of the Future: The Challenge of Change. Transit Cooperative Research Program, 1998, Report 28. Washington, DC: Transportation Research Board, National Academy Press.

Southworth, Michael. "SmartMaps for Public Transit." Access (8) (1996):19-23.

Texas Transportation Institute and Nustats International. Passenger Information Services: $A$ Guidebook for Transit Systems. Transit Cooperative Research Program, 1999, Report 45. Washington, DC: Transportation Research Board, National Academy Press

Urban Mass Transit Administration (UMTA). Transit Information Aids: Mass Transportation Demonstration Project. Washington, D.C.: U.S. Department of Transportation, 1969.

Urbitran Associates, Incorporated. Guidelines for Enhancing Suburban Mobility Using Public Transportation. Transit Cooperative Research Program, 1999, Report 55. Washington, DC: Transportation Research Board, National Academy Press.

Wallace, Richard R., Daniel A. Rodriguez, Christopher White, and Jonathan Levine. "Who Noticed, Who Cares? Passenger Reactions to Transit Safety Measures." Transportation Research Record 1666 (1999):133-138.

Weber, Edward P., David Nice, and Nicholas P. Lovrich. "Understanding Urban Commuters: How are Non-SOV Commuters Different from SOV Commuters?" Transportation Quarterly 54(2) (2000):105-116.

Whelan, Mary S. "A Passenger Information Perspective." In Proceedings of The International Conference on Automatic Vehicle Location In Urban Transit Systems, pp.425-441. Ottawa, Canada: Canadian Urban Transit Authority. 
Winters, Philip L., Rollo C. Axton, and James B. Gunnell. "Transit and Ridesharing Information Study." Transportation Research Record 1321 (1991):97-102. 


\section{Appendix A}

\section{Transit Matrix}


Table A-1

\begin{tabular}{|c|c|c|c|c|c|c|c|c|c|c|c|c|c|c|c|c|c|}
\hline \multirow[b]{2}{*}{ Transit } & \multirow[b]{2}{*}{ Type } & \multicolumn{3}{|c|}{ Time Scheduling } & \multicolumn{10}{|c|}{ Day Scheduling } & \multicolumn{3}{|c|}{ Single Routes } \\
\hline & & $\begin{array}{l}\text { Hourly } \\
\text { (by } \\
\text { Min.) }\end{array}$ & \begin{tabular}{|l|} 
Exact \\
Time \\
\end{tabular} & $\begin{array}{l}\mathrm{AM} / \\
\mathrm{PM}\end{array}$ & $\begin{array}{l}\text { Week- } \\
\text { day } \\
\text { Only }\end{array}$ & $\begin{array}{l}\text { Week- } \\
\text { day /Sat. } \\
\text { Separate }\end{array}$ & $\begin{array}{l}\text { Weekday } \\
\text { /Sat./Sun. } \\
\text { (Week- } \\
\text { end.) } \\
\text { Separate } \\
\end{array}$ & $\begin{array}{c}\text { All } \\
\text { Week }\end{array}$ & $\begin{array}{l}\text { Mon. } \\
\text { Sat. }\end{array}$ & \begin{tabular}{|l} 
Sat. \\
Only
\end{tabular} & $\begin{array}{l}\text { Sun. Only } \\
\text { (May } \\
\text { include } \\
\text { Holidays) }\end{array}$ & $\begin{array}{c}\text { Sat./ } \\
\text { Sun. } \\
\text { Separate }\end{array}$ & $\begin{array}{l}\text { Week- } \\
\text { end } \\
\text { Only }\end{array}$ & Other & $\begin{array}{l}\text { Time } \\
\text { Table } \\
\text { Only }\end{array}$ & $\begin{array}{l}\text { Time } \\
\text { Table } \\
\text { \& Map }\end{array}$ & $\begin{array}{l}\text { Map } \\
\text { Only }\end{array}$ \\
\hline $\begin{array}{l}\text { Baytown } \\
\text { Trolley }\end{array}$ & Ride Guide & $x$ & $x$ & $x$ & & & & $x$ & & & & & & & & & \\
\hline \multirow[t]{15}{*}{$\mathrm{BCT}$} & B Transit Guide & & & & & & & & & & & & & & & & \\
\hline & $\begin{array}{c}\text { Time Table Routes \#1,2,5-7,9- } \\
12,14-15,17,20,28,30- \\
31,34,36,40,50,55- \\
56,60,72,81,83-84,93 \\
\end{array}$ & & $\mathrm{x}$ & & & & $\mathrm{X}$ & & & & & & & & & $\mathrm{x}$ & \\
\hline & Time Table Routes $\# 18,22$ & & $\mathrm{X}$ & & $\mathrm{X}$ & & & & & & & $\mathrm{X}$ & & & & $\mathrm{X}$ & \\
\hline & $\begin{array}{c}\text { Time Table Routes } \\
\# 3,57,62,75,95 \\
\end{array}$ & & $\mathrm{x}$ & & & & & & $\mathrm{x}$ & & & & & & & $\mathrm{x}$ & \\
\hline & Time Table Route \#75 & & $\bar{X}$ & & & & & & $\mathrm{X}$ & & & & & & & $\bar{X}$ & \\
\hline & $\begin{array}{c}\text { Time Table Routes \#92, } 94 \\
\text { Combined } \\
\end{array}$ & & & & & & & & & & & & & $\mathrm{x}$ & & $\mathrm{x}$ & \\
\hline & $\begin{array}{c}\text { Margate Inner-City Routes } \\
(\mathrm{A}, \mathrm{B}, \mathrm{C}, \mathrm{D})\end{array}$ & & $x$ & & & $\mathrm{x}$ & & & & & & & & & & $\mathrm{x}$ & \\
\hline & $\begin{array}{c}\text { Pembrooke Pines Community } \\
\text { Shuttle Bus Service Route and } \\
\text { TimeTable }\end{array}$ & & $\mathrm{x}$ & & & $x$ & & & & & & & & & & $\mathrm{x}$ & \\
\hline & $\begin{array}{c}\text { Miramar Community Shuttle } \\
\text { Bus Service Route and } \\
\text { TimeTable } \\
\end{array}$ & & $\mathrm{x}$ & & $\mathrm{x}$ & & & & & & & & & & & $\mathrm{X}$ & \\
\hline & $\begin{array}{c}\text { Coconut Creek Shuttle Service } \\
\text { Bus Route and Time Table }\end{array}$ & & $\mathrm{x}$ & & $\mathrm{x}$ & & & & & & & & & & & $\mathrm{x}$ & \\
\hline & $\begin{array}{c}\text { Cooper City Community Bus } \\
\text { Route and Time Table }\end{array}$ & & $\mathrm{x}$ & & & $\mathrm{x}$ & & & & & & & & & & $\mathrm{x}$ & \\
\hline & Broward Urban Shuttle & & & & $\mathrm{X}$ & & & & & & & & & & & & $\mathrm{X}$ \\
\hline & Western Express Guides & & $\mathrm{X}$ & $\mathrm{X}$ & $\mathrm{X}$ & & & & & & & & & & & $X$ & \\
\hline & $\begin{array}{l}\text { Tamarac Transit Route } \\
\text { Timetables (Red, Gr, Yw) }\end{array}$ & & $\mathrm{x}$ & $\mathrm{x}$ & $\mathrm{x}$ & & & & & & & & & & & $\mathrm{X}$ & \\
\hline & Free "B" Minibus Service & & & & $\mathrm{X}$ & & & & & & & & & & & & \\
\hline \multirow[t]{2}{*}{ ECAT } & Ride Guide $(7 / 30 / 2000)$ & & $\mathrm{X}$ & & & & $\mathrm{X}$ & & & & & & & & & & \\
\hline & Ride Guide (2/4/2001) & & $\mathrm{X}$ & & & & & & & & & & & $\bar{X}$ & & & \\
\hline
\end{tabular}


Table A-1

\begin{tabular}{|c|c|c|c|c|c|c|c|c|c|c|c|c|c|c|c|c|c|}
\hline \multirow[b]{2}{*}{ Transit } & \multirow[b]{2}{*}{ Type } & \multicolumn{3}{|c|}{ Time Scheduling } & \multicolumn{10}{|c|}{ Day Scheduling } & \multicolumn{3}{|c|}{ Single Routes } \\
\hline & & $\begin{array}{l}\text { Hourly } \\
\text { (by } \\
\text { Min.) }\end{array}$ & $\begin{array}{l}\text { Exact } \\
\text { Time }\end{array}$ & $\begin{array}{l}\text { AM/ } \\
\text { PM }\end{array}$ & $\begin{array}{l}\text { Week- } \\
\text { day } \\
\text { Only }\end{array}$ & $\begin{array}{l}\text { Week- } \\
\text { day /Sat. } \\
\text { Separate }\end{array}$ & $\begin{array}{l}\text { Weekday } \\
\text { /Sat./Sun. } \\
\text { (Week- } \\
\text { end.) } \\
\text { Separate }\end{array}$ & $\begin{array}{c}\text { All } \\
\text { Week }\end{array}$ & $\begin{array}{c}\text { Mon.- } \\
\text { Sat. }\end{array}$ & $\begin{array}{l}\text { Sat. } \\
\text { Only }\end{array}$ & $\begin{array}{c}\text { Sun. Only } \\
\text { (May } \\
\text { include } \\
\text { Holidays) }\end{array}$ & $\begin{array}{c}\text { Sat./ } \\
\text { Sun. } \\
\text { Separate }\end{array}$ & $\begin{array}{l}\text { Week- } \\
\text { end } \\
\text { Only }\end{array}$ & Other & $\begin{array}{l}\text { Time } \\
\text { Table } \\
\text { Only }\end{array}$ & \begin{tabular}{|l|} 
Time \\
Table \\
\& Map
\end{tabular} & $\begin{array}{l}\text { Map } \\
\text { Only }\end{array}$ \\
\hline \multirow[t]{6}{*}{ HARTline } & Transit Guide & & & & & & & & & & & & & & & & \\
\hline & Express Routes & & $\bar{X}$ & & $\mathrm{X}$ & & & & & & & & & & & $\bar{X}$ & \\
\hline & South County Circulator & & & $\bar{X}$ & & $\mathrm{X}$ & & & & & & & & & & $\bar{X}$ & \\
\hline & $\begin{array}{c}\text { Hartline Routes } \# 1,2,5,6,7, \\
8,10,11,12,15,19,30,32,34,36,3 \\
7,46\end{array}$ & & $\mathrm{x}$ & & & & $\mathrm{x}$ & & & & & & & & & $\mathrm{x}$ & \\
\hline & \begin{tabular}{|l} 
Hartline Routes $\# 3,14,39$ \\
\end{tabular} & & $\mathrm{X}$ & & $\mathrm{X}$ & & & & & & & & & & & $\mathrm{X}$ & \\
\hline & $\begin{array}{c}\text { Hartline Routes } \\
\# 4,9,16,17,18,31,33 \\
38,41,87,88 \\
\end{array}$ & & $\mathrm{x}$ & & & $\mathrm{x}$ & & & & & & & & & & $\mathrm{x}$ & \\
\hline \multirow[t]{7}{*}{ JTA } & Transit Guide & & & & & & & & & & & & & & & & \\
\hline & $\begin{array}{l}\text { Routes: BlandingFly, } \\
\text { ArlingtonFly, OrgPkFly, } \\
\text { ArgyleFly, HghldFly }\end{array}$ & & $\mathrm{x}$ & $x$ & $\mathrm{x}$ & & & & & & & & & & & $\mathrm{x}$ & \\
\hline & \begin{tabular}{|c|} 
Routes: St.AugExpSS-35, CC- \\
37 \\
\end{tabular} & & $\mathrm{x}$ & $\mathrm{x}$ & $\mathrm{x}$ & & & & & & & & & & & $\mathrm{x}$ & \\
\hline & \begin{tabular}{|c|} 
Routes: SS-2,4,20; WS- \\
$3,6,10,20 ;$ NS-9,12,22; Arlington \\
$2-3$ \\
\end{tabular} & & $\mathrm{x}$ & $\mathrm{x}$ & & $\mathrm{x}$ & & & & & & & & & & $\mathrm{x}$ & \\
\hline & Routes: Northwest Looper & & $\bar{X}$ & $\mathrm{X}$ & & $\bar{X}$ & & & & & & & & & & $\bar{X}$ & \\
\hline & Route: NS-11 & & $\mathrm{X}$ & $\mathrm{X}$ & & $\bar{X}$ & & & & & & & & & & $\mathrm{X}$ & \\
\hline & $\begin{array}{c}\text { Routes: Arlington 1,5,20; } \mathrm{BH}- \\
\text { 1,2,3; WS-1,2,4,5,7,8,9; SS- } \\
\text { 1,3,5,6,7,8,9,21,40; NS-1- } \\
8,10,15,20 \\
\end{array}$ & & $\mathrm{x}$ & $x$ & & & $\mathrm{x}$ & & & & & & & & & $\mathrm{x}$ & \\
\hline $\begin{array}{c}\text { City of Key } \\
\text { West }\end{array}$ & Bus Schedule & & $\mathrm{x}$ & & & & & & & & & & & $x$ & & & \\
\hline \multirow{2}{*}{$\begin{array}{l}\text { LMAT or } \\
\text { Citrus } \\
\text { Connection }\end{array}$} & $\begin{array}{c}\text { Route Map \& Schedule: Bartow } \\
\text { Express 22X } \\
\end{array}$ & & $\mathrm{x}$ & & $\mathrm{x}$ & & & & & & & & & & & $\mathrm{x}$ & \\
\hline & \begin{tabular}{|c|} 
Route Map \& Schedule (all the \\
rest)
\end{tabular} & & $\mathrm{x}$ & & & & & & $\mathrm{X}$ & & & & & & & $\mathrm{x}$ & \\
\hline
\end{tabular}


Table A-1

\begin{tabular}{|c|c|c|c|c|c|c|c|c|c|c|c|c|c|c|c|c|c|}
\hline \multirow[b]{2}{*}{ Transit } & \multirow[b]{2}{*}{ Type } & \multicolumn{3}{|c|}{ Time Scheduling } & \multicolumn{10}{|c|}{ Day Scheduling } & \multicolumn{3}{|c|}{ Single Routes } \\
\hline & & $\begin{array}{l}\text { Hourly } \\
\text { (by } \\
\text { Min.) }\end{array}$ & $\begin{array}{l}\text { Exact } \\
\text { Time }\end{array}$ & $\begin{array}{l}\mathrm{AM} / \\
\mathrm{PM}\end{array}$ & $\begin{array}{l}\text { Week- } \\
\text { day } \\
\text { Only }\end{array}$ & $\begin{array}{l}\text { Week- } \\
\text { day /Sat. } \\
\text { Separate }\end{array}$ & $\begin{array}{c}\text { Weekday } \\
\text { /Sat./Sun. } \\
\text { (Week- } \\
\text { end.) } \\
\text { Separate }\end{array}$ & $\begin{array}{c}\text { All } \\
\text { Week }\end{array}$ & $\begin{array}{c}\text { Mon.- } \\
\text { Sat. }\end{array}$ & $\begin{array}{l}\text { Sat. } \\
\text { Only }\end{array}$ & \begin{tabular}{|c} 
Sun. Only \\
(May \\
include \\
Holidays)
\end{tabular} & $\begin{array}{c}\text { Sat./ } \\
\text { Sun. } \\
\text { Separate }\end{array}$ & $\begin{array}{l}\text { Week- } \\
\text { end } \\
\text { Only }\end{array}$ & Other & $\begin{array}{l}\text { Time } \\
\text { Table } \\
\text { Only }\end{array}$ & $\begin{array}{l}\text { Time } \\
\text { Table } \\
\text { \& Map }\end{array}$ & $\begin{array}{l}\text { Map } \\
\text { Only }\end{array}$ \\
\hline \multirow[t]{6}{*}{ LeeTran } & Sytem Map & & & & & & & & & & & & & & & & \\
\hline & Trolley Guide & & $\bar{X}$ & & & & & $\mathrm{X}$ & & & & & & & & $\mathrm{X}$ & \\
\hline & Combined Routes: $110 / 115$ & & $\mathrm{X}$ & $\mathrm{X}$ & & & & & $\mathrm{X}$ & & & & & & & $\mathrm{X}$ & \\
\hline & Routes: 20,85 & & $\bar{X}$ & $\bar{X}$ & & & & & $\bar{X}$ & & & & & & & $\bar{X}$ & \\
\hline & Route: 150 & & $\mathrm{X}$ & $\mathrm{X}$ & $\mathrm{X}$ & & & & & & & & & & & $\bar{X}$ & \\
\hline & Route Maps (all the rest) & & $\bar{X}$ & & & & $\bar{X}$ & & & & & & & & & $\bar{X}$ & \\
\hline \multirow[t]{5}{*}{ LYNX } & Public Bus System Map & & & & & & & & & & & & & & & & \\
\hline & Schedule Book & & $\bar{X}$ & $\bar{X}$ & & & & & & & & & & $\bar{X}$ & & & \\
\hline & Downtown Disney Direct & & $\mathrm{X}$ & & & & & $\mathrm{X}$ & & & & & & $\mathrm{x}$ & & & \\
\hline & $\begin{array}{c}\text { Link } 1-3,5,10,12,14,18,27,34,43 \\
44,47,52,54\end{array}$ & & $x$ & $x$ & & $x$ & & & & & & & & & & $x$ & \\
\hline & LINK (all the rest) & & $\bar{x}$ & $\mathrm{X}$ & & & & & $\mathrm{X}$ & & $\mathrm{X}$ & & & & & $\mathrm{X}$ & \\
\hline$\overline{M C A T}$ & Ride Guide & & $\bar{X}$ & & & & & & & & & & & $\bar{X}$ & & & \\
\hline \multirow{14}{*}{$\begin{array}{l}\text { Miami-Dade } \\
\text { Transit }\end{array}$} & STS Rider's Guide & & & & & & & $\bar{X}$ & & & & & & & & & \\
\hline & Transit Rider's Handbook & & & & & & & & & & & & & $\mathrm{X}$ & & & \\
\hline & MetroMover Guide & & & & & & & $\bar{X}$ & & & & & & & & & \\
\hline & Transit Map & & & & & & & & & & & & & & & & \\
\hline & MetroRail Guide & $\mathrm{X}$ & $\bar{X}$ & & & & & $\bar{X}$ & & & & & & & & & \\
\hline & Dade-Monroe Express & & $\bar{X}$ & & & & & $\bar{X}$ & & & & & & & & $\bar{X}$ & \\
\hline & Busway/Coral Reef Max & & $\mathrm{X}$ & & & & $\mathrm{X}$ & & & & & & & & & $\mathrm{X}$ & \\
\hline & $\begin{array}{l}\text { Metro Area Express Routes (the } \\
\text { rest), Tri-Rail Koger Shuttle }\end{array}$ & & $\mathrm{x}$ & & $\mathrm{x}$ & & & & & & & & & & & $\mathrm{x}$ & \\
\hline & Kendall Area Transit & & $\bar{X}$ & & $\mathrm{X}$ & & & & & & & & & & & $\bar{X}$ & \\
\hline & $\begin{array}{c}\text { Busway Local, Night Owl } \\
\text { Shuttle, West Dade \& SeaPort } \\
\text { Connection } \\
\end{array}$ & & $\mathrm{X}$ & & & & $\mathrm{X}$ & & & & & & & & & $\mathrm{X}$ & \\
\hline & North Dade \& Doral Connection & & $x$ & & $x$ & & & & & & & & & & & $x$ & \\
\hline & $\begin{array}{c}\text { Metrobus Schedule: } \mathrm{R}, \mathrm{V}, \\
6,28,29,48,56,57,65,104 \\
\end{array}$ & & $x$ & & $\mathrm{x}$ & & & & & & & & & & & $\mathrm{X}$ & \\
\hline & $\begin{array}{c}\text { Metrobus Schedule: A-W, 1-91 } \\
\text { (Letters \& Numbers not } \\
\text { included in above listing) }\end{array}$ & & $\mathrm{x}$ & & & & $\mathrm{X}$ & & & & & & & & & $\mathrm{X}$ & \\
\hline & Metrobus Schedule: 95X & & $\bar{x}$ & & $\bar{X}$ & & & & & & & & & & & $\bar{X}$ & \\
\hline
\end{tabular}


Table A-1

\begin{tabular}{|c|c|c|c|c|c|c|c|c|c|c|c|c|c|c|c|c|c|}
\hline \multirow[b]{2}{*}{ Transit } & \multirow[b]{2}{*}{ Type } & \multicolumn{3}{|c|}{ Time Scheduling } & \multicolumn{10}{|c|}{ Day Scheduling } & \multicolumn{3}{|c|}{ Single Routes } \\
\hline & & $\begin{array}{l}\text { Hourly } \\
\text { (by } \\
\text { Min.) }\end{array}$ & $\begin{array}{l}\text { Exact } \\
\text { Time }\end{array}$ & $\begin{array}{l}\mathrm{AM} / \\
\mathrm{PM}\end{array}$ & $\begin{array}{l}\text { Week- } \\
\text { day } \\
\text { Only }\end{array}$ & $\begin{array}{l}\text { Week- } \\
\text { day /Sat. } \\
\text { Separate }\end{array}$ & $\begin{array}{l}\text { Weekday } \\
\text { /Sat./Sun. } \\
\text { (Week- } \\
\text { end.) } \\
\text { Separate }\end{array}$ & $\begin{array}{c}\text { All } \\
\text { Week }\end{array}$ & $\begin{array}{c}\text { Mon.- } \\
\text { Sat. }\end{array}$ & $\begin{array}{l}\text { Sat. } \\
\text { Only }\end{array}$ & $\begin{array}{c}\text { Sun. Only } \\
\text { (May } \\
\text { include } \\
\text { Holidays) }\end{array}$ & $\begin{array}{c}\text { Sat./ } \\
\text { Sun. } \\
\text { Separate }\end{array}$ & $\begin{array}{l}\text { Week- } \\
\text { end } \\
\text { Only }\end{array}$ & Other & $\begin{array}{l}\text { Time } \\
\text { Table } \\
\text { Only }\end{array}$ & $\begin{array}{l}\text { Time } \\
\text { Table } \\
\text { \& Map }\end{array}$ & $\begin{array}{l}\text { Map } \\
\text { Only }\end{array}$ \\
\hline $\begin{array}{l}\text { Okaloosa } \\
\text { County } \\
\text { Transit }\end{array}$ & Ride the Wave Guide & & $\mathrm{x}$ & & $\mathrm{x}$ & & & & & & & & & & & & \\
\hline \multirow[t]{7}{*}{ Palm Tran } & System Map \& Rider's Guide & & $\bar{X}$ & & & & & & & & & & & $\bar{X}$ & & & \\
\hline & System Map & & & & & & & & & & & & & $\mathrm{X}$ & & & \\
\hline & Route Map \& Schedule \#42, 60 & & $\mathrm{x}$ & & & & & & $\mathrm{x}$ & & & & & & & $\mathrm{x}$ & \\
\hline & $\begin{array}{l}\text { Route Map \& Schedule } \\
\text { Combined 54/55 }\end{array}$ & & $x$ & & & & & & & & & & & $x$ & & $x$ & \\
\hline & $\begin{array}{c}\text { Route Map \& Schedule \#1 } \\
\text { Weekend Only }\end{array}$ & & $\mathrm{X}$ & & & & & & & & & $\mathrm{X}$ & & & & $\mathrm{X}$ & \\
\hline & $\begin{array}{c}\text { Route Map \& Schedule } \\
\# 1,52,53,94 \text { Weekday Only }\end{array}$ & & $\mathrm{X}$ & & $\mathrm{X}$ & & & & & & & & & & & $\mathrm{X}$ & \\
\hline & Route Maps (all the rest) & & $\bar{X}$ & & & & $\mathrm{X}$ & & & & & & & & & $\mathrm{X}$ & \\
\hline \multirow[t]{2}{*}{ PCPT } & Route Maps \& Schedules & & $\bar{X}$ & & $\bar{X}$ & & & & & & & & & $\bar{x}$ & & $\bar{X}$ & \\
\hline & PCPT System Pocket Map & & & & & & & & & & & & & & & & \\
\hline \multirow[t]{8}{*}{ PSTA } & Suncoast Beach Trolley & & $\mathrm{X}$ & & & & & $\mathrm{X}$ & & & & & & & & $\mathrm{X}$ & \\
\hline & System Map & & & & & & & & & & & & & & & & \\
\hline & $\begin{array}{c}\text { Route Maps \& Schedules: } \\
100 x, 444,58,64,91,92,94,96,99\end{array}$ & & $x$ & & $\mathrm{x}$ & & & & & & & & & & & $\mathrm{x}$ & \\
\hline & Route \#4,19,38,52,59,74 & & $\bar{X}$ & & & & $\bar{X}$ & & & & & & & & & $\bar{X}$ & \\
\hline & Route \#62 & & $\bar{X}$ & & & $\bar{X}$ & & & & & & & & & & $\bar{X}$ & \\
\hline & Routes \#7,75,80 & & $\mathrm{X}$ & & & & & $\mathrm{X}$ & & & & & & & & $\mathrm{X}$ & \\
\hline & Routes \#22,30,32,67,73,78,82 & & $x$ & & & & & & $x$ & & & & & & & $x$ & \\
\hline & $\begin{array}{c}\text { Route Maps \& Schedules (all } \\
\text { the rest) }\end{array}$ & & $\mathrm{x}$ & & & & & & $\mathrm{x}$ & & $\mathrm{x}$ & & & & & $\mathrm{x}$ & \\
\hline RTS & Spring Service Schedule & & $\bar{X}$ & & & & & & & & & & & $\bar{X}$ & & & \\
\hline \multirow{3}{*}{$\begin{array}{c}\text { Sarasota } \\
\text { County Area } \\
\text { Transit }\end{array}$} & South Express County & & $\bar{X}$ & $\bar{X}$ & $\bar{X}$ & & & & & & & & & & & $\bar{X}$ & \\
\hline & $\begin{array}{c}\text { South \& North County Guides } \\
\text { (split county, each one is a } \\
\text { complete guide) }\end{array}$ & & $\mathrm{x}$ & & & & & & $\mathrm{x}$ & & & & & & & & \\
\hline & Sarasota Trolley & $\mathrm{X}$ & $\mathrm{X}$ & $\mathrm{X}$ & & $\mathrm{X}$ & & & & & & & & & & $\mathrm{X}$ & \\
\hline $\begin{array}{l}\text { Space Coast } \\
\text { Area Transit }\end{array}$ & $\begin{array}{c}\text { Countywide Schedules \& Route } \\
\text { Maps }\end{array}$ & & $\mathrm{x}$ & $\mathrm{X}$ & & & & & & & & & & $\mathrm{x}$ & & & \\
\hline SUNTRAN & Bus Route Map & & $\bar{x}$ & $\bar{X}$ & & & & & $\bar{x}$ & & & & & & & & \\
\hline TALTRAN & The Ride Guide & & $\bar{X}$ & & & & & $\bar{X}$ & & & & & & $\bar{X}$ & & & \\
\hline
\end{tabular}


Table A-1

\begin{tabular}{|c|c|c|c|c|c|c|c|c|c|c|c|c|c|c|c|c|c|}
\hline \multirow[b]{2}{*}{ Transit } & \multirow[b]{2}{*}{ Type } & \multicolumn{3}{|c|}{ Time Scheduling } & \multicolumn{10}{|c|}{ Day Scheduling } & \multicolumn{3}{|c|}{ Single Routes } \\
\hline & & $\begin{array}{c}\text { Hourly } \\
\text { (by } \\
\text { Min.) } \\
\end{array}$ & \begin{tabular}{|l|} 
Exact \\
Time \\
\end{tabular} & $\begin{array}{l}\mathrm{AM} / \\
\mathrm{PM}\end{array}$ & $\begin{array}{c}\text { Week- } \\
\text { day } \\
\text { Only }\end{array}$ & $\begin{array}{c}\text { Week- } \\
\text { day /Sat. } \\
\text { Separate }\end{array}$ & $\begin{array}{l}\text { Weekday } \\
\text { /Sat./Sun. } \\
\text { (Week- } \\
\text { end.) } \\
\text { Separate }\end{array}$ & $\begin{array}{c}\text { All } \\
\text { Week }\end{array}$ & $\begin{array}{l}\text { Mon. } \\
\text { Sat. }\end{array}$ & $\begin{array}{l}\text { Sat. } \\
\text { Only }\end{array}$ & \begin{tabular}{|c} 
Sun. Only \\
(May \\
include \\
Holidays)
\end{tabular} & $\begin{array}{c}\text { Sat./ } \\
\text { Sun. } \\
\text { Separate }\end{array}$ & $\begin{array}{l}\text { Week- } \\
\text { end } \\
\text { Only }\end{array}$ & Other & $\begin{array}{l}\text { Time } \\
\text { Table } \\
\text { Only }\end{array}$ & $\begin{array}{l}\text { Time } \\
\text { Table } \\
\text { \& Map }\end{array}$ & $\begin{array}{l}\text { Map } \\
\text { Only }\end{array}$ \\
\hline \multirow[t]{8}{*}{ TRI-RAIL } & $\begin{array}{c}\text { Train Schedule and System } \\
\text { Information }\end{array}$ & & $\mathrm{X}$ & $\mathrm{x}$ & & & & & & & & & & $\mathrm{X}$ & & & \\
\hline & Swap Shop Shuttle & & $\mathrm{X}$ & & & & & & & & & & $x$ & & & $X$ & \\
\hline & TMAX Shuttle & & $\mathrm{X}$ & & & & & & & & & $X$ & & & & $X$ & \\
\hline & Route 63 & & $\mathrm{X}$ & $\mathrm{X}$ & & & $\mathrm{X}$ & & & & & & & & & $\mathrm{X}$ & \\
\hline & MIA Terminal & & $\mathrm{X}$ & & & & $\mathrm{X}$ & & & & & & & & & $\bar{X}$ & \\
\hline & $\begin{array}{c}\text { Koger, Miami Airport Station, \& } \\
\text { Route } 79 \\
\end{array}$ & & $\mathrm{x}$ & & & & & $\mathrm{X}$ & & & & & & & & $\mathrm{X}$ & \\
\hline & $\begin{array}{c}\text { Routes } 33,53, \& 74 ; \text { Boca } \\
\text { Raton Station }\end{array}$ & & $\mathrm{x}$ & $\mathrm{X}$ & $x$ & & & & & & & & & & & $\mathrm{X}$ & \\
\hline & $\begin{array}{c}\text { Combined Routes: } 41 / 42 / 43 \text { \& } \\
23 / 24\end{array}$ & & $x$ & $x$ & & & & $x$ & & & & & & & & $\mathrm{X}$ & \\
\hline \multirow[t]{8}{*}{ VOTRAN } & $\begin{array}{c}\text { Bus Service Guide (Sun. } \\
\text { Service) }\end{array}$ & & $\mathrm{X}$ & $\mathrm{X}$ & & & & & & & $\mathrm{X}$ & & & & & & \\
\hline & Trolley Service & & $\mathrm{X}$ & $\mathrm{X}$ & & & & & $x$ & & & & & & & $\mathrm{X}$ & \\
\hline & Holiday Schedule & & $\bar{X}$ & $\mathrm{X}$ & & & & & & & & & & $\bar{X}$ & & & \\
\hline & Beach Tran & $x$ & & & & & & $x$ & & & & & & & & & $x$ \\
\hline & $\begin{array}{c}\text { West Volusia Bus Service } \\
\text { Guide }\end{array}$ & & $\mathrm{x}$ & $\mathrm{X}$ & & & & & $\mathrm{x}$ & & & & & & & $\mathrm{x}$ & \\
\hline & SE Volusia Bus Service Guide & & $x$ & $x$ & & & & & $\mathrm{X}$ & & & & & & & $x$ & \\
\hline & $\begin{array}{c}\begin{array}{l}\text { Volusia/Orlando Bus Service } \\
\text { Guide }\end{array} \\
\end{array}$ & & $\mathrm{x}$ & $\mathrm{X}$ & $\mathrm{X}$ & & & & & & & & & & & $\mathrm{X}$ & \\
\hline & $\begin{array}{l}\text { Daytona Beach Bus Service } \\
\text { Guide }\end{array}$ & & $\mathrm{X}$ & $x$ & & & & & & & & & & $x$ & & $x$ & \\
\hline WHAT & Route Map \& Schedules & & $\mathrm{X}$ & & & & & & $\bar{x}$ & & & & & & & $\mathrm{X}$ & \\
\hline
\end{tabular}




\begin{tabular}{|c|c|c|c|c|c|c|c|c|c|c|c|}
\hline \multirow[b]{2}{*}{ Transit } & \multirow[b]{2}{*}{ Type } & \multicolumn{4}{|c|}{ Multiple Routes } & \multicolumn{4}{|c|}{ Color Scheme } & \multicolumn{2}{|c|}{ Stop Alignment } \\
\hline & & $\begin{array}{l}\text { Time } \\
\text { Table } \\
\text { Only } \\
\end{array}$ & $\begin{array}{l}\text { Separate } \\
\text { Time } \\
\text { Tables \& } \\
\text { One Map } \\
\end{array}$ & \begin{tabular}{|c|} 
Time \\
Tables \\
$\&$ \\
Multiple \\
Maps \\
\end{tabular} & $\begin{array}{c}\text { Map(s) } \\
\text { Only }\end{array}$ & $\begin{array}{c}2 \\
\text { Color } \\
\end{array}$ & $\begin{array}{l}\text { Multi- } \\
\text { Color }\end{array}$ & $B \& W$ & Pics & $\begin{array}{c}\text { Horizontal } \\
\text { (Left to } \\
\text { Right) }\end{array}$ & $\begin{array}{l}\text { Vertical } \\
\text { (Top to } \\
\text { Bottom) }\end{array}$ \\
\hline $\begin{array}{l}\text { Baytown } \\
\text { Trolley }\end{array}$ & Ride Guide & & $\mathrm{x}$ & & & & $\mathrm{x}$ & & $\mathrm{x}$ & & $\mathrm{x}$ \\
\hline \multirow[t]{15}{*}{$\mathrm{BCT}$} & B Transit Guide & & & & $\bar{X}$ & & $\bar{X}$ & & $\bar{X}$ & & \\
\hline & $\begin{array}{c}\text { Time Table Routes \#1,2,5-7,9- } \\
12,14-15,17,20,28,30- \\
31,34,36,40,50,55- \\
56,60,72,81,83-84,93 \\
\end{array}$ & & & & & & $x$ & & & $\mathrm{x}$ & \\
\hline & Time Table Routes \#18,22 & & & & & & $X$ & & & $X$ & \\
\hline & $\begin{array}{c}\text { Time Table Routes } \\
\# 3,57,62,75,95 \\
\end{array}$ & & & & & & $\mathrm{x}$ & & & $\mathrm{X}$ & \\
\hline & Time Table Route \#75 & & & & & & $\mathrm{X}$ & & & $\mathrm{X}$ & \\
\hline & $\begin{array}{c}\text { Time Table Routes \#92, } 94 \\
\text { Combined } \\
\end{array}$ & & & & & & $x$ & & & $\mathrm{x}$ & \\
\hline & $\begin{array}{c}\text { Margate Inner-City Routes } \\
(A, B, C, D)\end{array}$ & & & & & & $x$ & & & $x$ & \\
\hline & $\begin{array}{c}\text { Pembrooke Pines Community } \\
\text { Shuttle Bus Service Route and } \\
\text { TimeTable }\end{array}$ & & & & & $\mathrm{x}$ & & & & $\mathrm{x}$ & \\
\hline & $\begin{array}{c}\text { Miramar Community Shuttle } \\
\text { Bus Service Route and } \\
\text { TimeTable } \\
\end{array}$ & & & & & $\mathrm{x}$ & & & & $\mathrm{x}$ & \\
\hline & $\begin{array}{c}\text { Coconut Creek Shuttle Service } \\
\text { Bus Route and Time Table }\end{array}$ & & & & & $\mathrm{x}$ & & & & & $x$ \\
\hline & $\begin{array}{c}\text { Cooper City Community Bus } \\
\text { Route and Time Table }\end{array}$ & & & & & $\mathrm{X}$ & & & & $\mathrm{X}$ & \\
\hline & Broward Urban Shuttle & & & & & $\mathrm{X}$ & & & & & \\
\hline & Western Express Guides & & & & & & $\mathrm{X}$ & & & $\mathrm{X}$ & \\
\hline & $\begin{array}{c}\text { Tamarac Transit Route } \\
\text { Timetables (Red, Gr, Yw) }\end{array}$ & & & & & & $x$ & & & $x$ & \\
\hline & Free "B" Minibus Service & & & & $\bar{X}$ & & $\bar{X}$ & & & & \\
\hline \multirow[t]{2}{*}{ ECAT } & Ride Guide $(7 / 30 / 2000)$ & & & $\mathrm{X}$ & & & & $\mathrm{X}$ & & $\mathrm{X}$ & \\
\hline & Ride Guide (2/4/2001) & & & $\mathrm{X}$ & & & & $\mathrm{X}$ & & $\mathrm{X}$ & \\
\hline
\end{tabular}




\begin{tabular}{|c|c|c|c|c|c|c|c|c|c|c|c|}
\hline \multirow[b]{2}{*}{ Transit } & \multirow[b]{2}{*}{ Type } & \multicolumn{4}{|c|}{ Multiple Routes } & \multicolumn{4}{|c|}{ Color Scheme } & \multicolumn{2}{|c|}{ Stop Alignment } \\
\hline & & $\begin{array}{l}\text { Time } \\
\text { Table } \\
\text { Only }\end{array}$ & \begin{tabular}{|l} 
Separate \\
Time \\
Tables \& \\
One Map
\end{tabular} & \begin{tabular}{|c|} 
Time \\
Tables \\
$\&$ \\
Multiple \\
Maps
\end{tabular} & $\begin{array}{c}\text { Map(s) } \\
\text { Only }\end{array}$ & $\begin{array}{c}2 \\
\text { Color }\end{array}$ & $\begin{array}{l}\text { Multi- } \\
\text { Color }\end{array}$ & $B \& W$ & Pics & $\begin{array}{l}\text { Horizontal } \\
\text { (Left to } \\
\text { Right) }\end{array}$ & $\begin{array}{l}\text { Vertical } \\
\text { (Top to } \\
\text { Bottom) }\end{array}$ \\
\hline \multirow[t]{6}{*}{ HARTline } & Transit Guide & & & & $\bar{x}$ & & $\bar{x}$ & & $\bar{x}$ & & \\
\hline & Express Routes & & & & & $\mathrm{X}$ & & & & $\bar{X}$ & \\
\hline & South County Circulator & & & & & & $\mathrm{X}$ & & $\mathrm{X}$ & $\mathrm{X}$ & \\
\hline & $\begin{array}{c}\text { Hartline Routes \#1,2,5,6,7, } \\
8,10,11,12,15,19,30,32,34,36,3 \\
7,46\end{array}$ & & & & & $\mathrm{x}$ & & & & $\mathrm{x}$ & \\
\hline & Hartline Routes \#3,14,39 & & & & & $\mathrm{X}$ & & & & $\mathrm{X}$ & \\
\hline & $\begin{array}{c}\text { Hartline Routes } \\
\# 4,9,16,17,18,31,33 \\
38,41,87,88\end{array}$ & & & & & $\mathrm{x}$ & & & & $\mathrm{x}$ & \\
\hline \multirow[t]{7}{*}{ JTA } & Transit Guide & & & & $\mathrm{X}$ & & $\bar{X}$ & & $\bar{X}$ & & \\
\hline & $\begin{array}{l}\text { Routes: BlandingFly, } \\
\text { ArlingtonFly, OrgPkFly, } \\
\text { ArgyleFly, HghldFly }\end{array}$ & & & & & $\mathrm{x}$ & & & & $\mathrm{x}$ & \\
\hline & \begin{tabular}{|c|} 
Routes: St.AugExpSS-35, CC- \\
37 \\
\end{tabular} & & & & & $\mathrm{x}$ & & & & $\mathrm{x}$ & \\
\hline & \begin{tabular}{|c|} 
Routes: SS-2,4,20; WS- \\
$3,6,10,20 ;$ NS-9,12,22; Arlington \\
$2-3$ \\
\end{tabular} & & & & & $\mathrm{x}$ & & & & $\mathrm{x}$ & \\
\hline & Routes: Northwest Looper & & & & & $\mathrm{X}$ & & & & $\mathrm{X}$ & \\
\hline & Route: NS-11 & & & & & $\mathrm{X}$ & & & & $\mathrm{X}$ & \\
\hline & $\begin{array}{c}\text { Routes: Arlington 1,5,20; } \mathrm{BH}- \\
\text { 1,2,3; WS-1,2,4,5,7,8,9; SS- } \\
\text { 1,3,5,6,7,8,9,21,40; NS-1- } \\
8,10,15,20 \\
\end{array}$ & & & & & $\mathrm{x}$ & & & & $\mathrm{x}$ & \\
\hline $\begin{array}{c}\text { City of Key } \\
\text { West }\end{array}$ & Bus Schedule & & & $\mathrm{x}$ & & & $\mathrm{x}$ & & & $\mathrm{x}$ & \\
\hline \multirow{2}{*}{$\begin{array}{l}\text { LMAT or } \\
\text { Citrus } \\
\text { Connection }\end{array}$} & $\begin{array}{c}\text { Route Map \& Schedule: Bartow } \\
\text { Express } 22 X\end{array}$ & & & & & $\mathrm{x}$ & & & & $\mathrm{x}$ & \\
\hline & $\begin{array}{c}\text { Route Map \& Schedule (all the } \\
\text { rest) }\end{array}$ & & & & & $\mathrm{x}$ & & & & $\mathrm{x}$ & \\
\hline
\end{tabular}




\begin{tabular}{|c|c|c|c|c|c|c|c|c|c|c|c|}
\hline \multirow[b]{2}{*}{ Transit } & \multirow[b]{2}{*}{ Type } & \multicolumn{4}{|c|}{ Multiple Routes } & \multicolumn{4}{|c|}{ Color Scheme } & \multicolumn{2}{|c|}{ Stop Alignment } \\
\hline & & $\begin{array}{l}\text { Time } \\
\text { Table } \\
\text { Only }\end{array}$ & $\begin{array}{l}\text { Separate } \\
\text { Time } \\
\text { Tables \& } \\
\text { One Map }\end{array}$ & \begin{tabular}{|c|} 
Time \\
Tables \\
$\&$ \\
Multiple \\
Maps \\
\end{tabular} & $\begin{array}{c}\text { Map(s) } \\
\text { Only }\end{array}$ & $\begin{array}{c}2 \\
\text { Color }\end{array}$ & $\begin{array}{l}\text { Multi- } \\
\text { Color }\end{array}$ & $B \& W$ & Pics & $\begin{array}{l}\text { Horizontal } \\
\text { (Left to } \\
\text { Right) }\end{array}$ & $\begin{array}{l}\text { Vertical } \\
\text { (Top to } \\
\text { Bottom) }\end{array}$ \\
\hline \multirow[t]{6}{*}{ LeeTran } & Sytem Map & & & & $\mathrm{X}$ & & $\mathrm{X}$ & & & & \\
\hline & Trolley Guide & & & & & $\bar{X}$ & & & & $\bar{X}$ & \\
\hline & Combined Routes: $110 / 115$ & & & & & $\mathrm{X}$ & & & & $\bar{X}$ & \\
\hline & Routes: 20,85 & & & & & $\bar{X}$ & & & & $\bar{X}$ & \\
\hline & Route: 150 & & & & & $\mathrm{X}$ & & & & $x$ & \\
\hline & Route Maps (all the rest) & & & & & $\bar{X}$ & & & & $\bar{X}$ & \\
\hline \multirow[t]{5}{*}{ LYNX } & Public Bus System Map & & & & $\mathrm{X}$ & & $\mathrm{X}$ & & $\bar{x}$ & & \\
\hline & Schedule Book & & & $\bar{X}$ & & & $\bar{X}$ & & & $\bar{X}$ & \\
\hline & Downtown Disney Direct & & & $\mathrm{X}$ & & & $\mathrm{X}$ & & & & $x$ \\
\hline & $\begin{array}{c}\text { Link } 1-3,5,10,12,14,18,27,34,43 \\
44,47,52,54\end{array}$ & & & & & & $\mathrm{x}$ & & & $\mathrm{x}$ & \\
\hline & LINK (all the rest) & & & & & & $\bar{X}$ & & & $\bar{X}$ & \\
\hline$\overline{M C A T}$ & Ride Guide & & & $\bar{X}$ & & & & $\bar{X}$ & & $\bar{X}$ & \\
\hline \multirow{14}{*}{$\begin{array}{l}\text { Miami-Dade } \\
\text { Transit }\end{array}$} & STS Rider's Guide & & & & & & & $\bar{X}$ & & & \\
\hline & Transit Rider's Handbook & & & & $\mathrm{X}$ & & $\bar{x}$ & & $\bar{x}$ & & \\
\hline & MetroMover Guide & & & & $\bar{X}$ & & $\bar{X}$ & & $\bar{X}$ & & \\
\hline & Transit Map & & & & $\mathrm{X}$ & & $\mathrm{X}$ & & $\mathrm{X}$ & & \\
\hline & MetroRail Guide & & & $X$ & & $\bar{x}$ & & & & $\mathrm{X}$ & \\
\hline & Dade-Monroe Express & & & & & $\bar{X}$ & & & & $\bar{X}$ & \\
\hline & Busway/Coral Reef Max & & & & & $\bar{X}$ & & & & $\bar{X}$ & \\
\hline & $\begin{array}{l}\text { Metro Area Express Routes (the } \\
\text { rest), Tri-Rail Koger Shuttle }\end{array}$ & & & & & $\mathrm{x}$ & & & & $\mathrm{x}$ & \\
\hline & Kendall Area Transit & & & & & $\mathrm{X}$ & & & & $\mathrm{X}$ & \\
\hline & $\begin{array}{c}\text { Busway Local, Night Owl } \\
\text { Shuttle, West Dade \& SeaPort } \\
\text { Connection } \\
\end{array}$ & & & & & $\mathrm{X}$ & & & & $\mathrm{X}$ & \\
\hline & North Dade \& Doral Connection & & & & & $x$ & & & & $x$ & \\
\hline & $\begin{array}{c}\text { Metrobus Schedule: } R, \mathrm{~V}, \\
6,28,29,48,56,57,65,104\end{array}$ & & & & & $\mathrm{x}$ & & & & $\mathrm{x}$ & \\
\hline & $\begin{array}{l}\text { Metrobus Schedule: A-W, 1-91 } \\
\text { (Letters \& Numbers not } \\
\text { included in above listing) }\end{array}$ & & & & & $\mathrm{x}$ & & & & $\mathrm{X}$ & \\
\hline & Metrobus Schedule: 95X & & & & & $\bar{X}$ & & & & $\bar{X}$ & \\
\hline
\end{tabular}




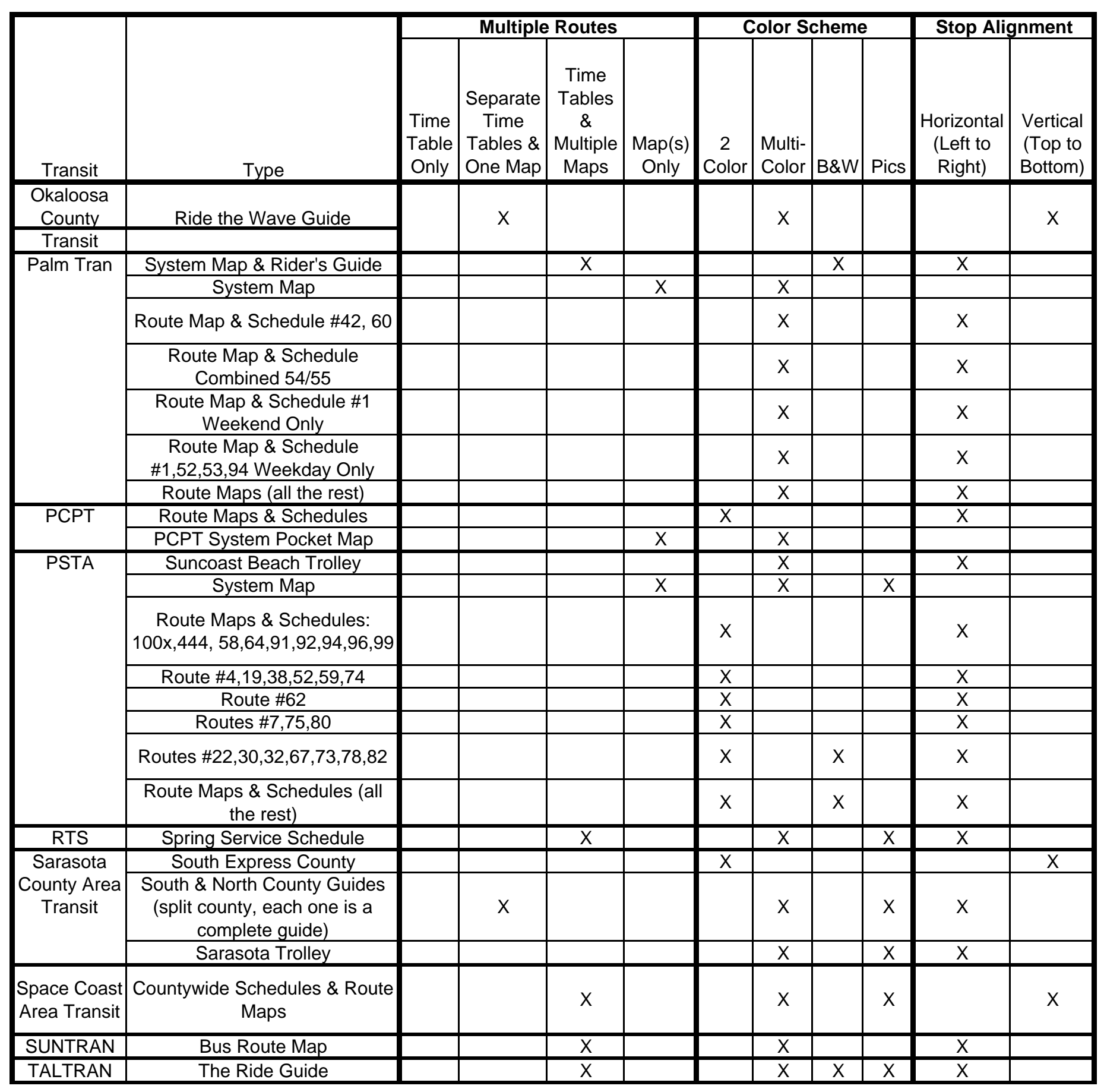




\begin{tabular}{|c|c|c|c|c|c|c|c|c|c|c|c|}
\hline \multirow[b]{2}{*}{ Transit } & \multirow[b]{2}{*}{ Type } & \multicolumn{4}{|c|}{ Multiple Routes } & \multicolumn{4}{|c|}{ Color Scheme } & \multicolumn{2}{|c|}{ Stop Alignment } \\
\hline & & $\begin{array}{l}\text { Time } \\
\text { Table } \\
\text { Only }\end{array}$ & $\begin{array}{c}\text { Separate } \\
\text { Time } \\
\text { Tables \& } \\
\text { One Map }\end{array}$ & \begin{tabular}{|c|} 
Time \\
Tables \\
$\&$ \\
Multiple \\
Maps \\
\end{tabular} & $\begin{array}{c}\text { Map(s) } \\
\text { Only }\end{array}$ & $\begin{array}{c}2 \\
\text { Color } \\
\end{array}$ & $\begin{array}{l}\text { Multi- } \\
\text { Color }\end{array}$ & $B \& W$ & Pics & $\begin{array}{c}\text { Horizontal } \\
\text { (Left to } \\
\text { Right) }\end{array}$ & $\begin{array}{l}\text { Vertical } \\
\text { (Top to } \\
\text { Bottom) }\end{array}$ \\
\hline \multirow[t]{8}{*}{ TRI-RAIL } & $\begin{array}{c}\text { Train Schedule and System } \\
\text { Information }\end{array}$ & & $\mathrm{x}$ & & & & & $\mathrm{X}$ & $\mathrm{x}$ & & $\mathrm{x}$ \\
\hline & Swap Shop Shuttle & & & & & & & $\mathrm{X}$ & & $\mathrm{X}$ & \\
\hline & TMAX Shuttle & & & & & & & $\mathrm{X}$ & & $\mathrm{X}$ & \\
\hline & Route 63 & & & & & & & $\mathrm{X}$ & & $\mathrm{X}$ & \\
\hline & MIA Terminal & & & & & & & $\bar{X}$ & & $\bar{X}$ & \\
\hline & $\begin{array}{c}\text { Koger, Miami Airport Station, \& } \\
\text { Route } 79 \\
\end{array}$ & & & & & & & $x$ & & $x$ & \\
\hline & $\begin{array}{c}\text { Routes } 33,53, \& \text { 74; Boca } \\
\text { Raton Station }\end{array}$ & & & & & & & $x$ & & $\mathrm{x}$ & \\
\hline & $\begin{array}{c}\text { Combined Routes: } 41 / 42 / 43 \& \\
23 / 24\end{array}$ & & & & & & & $\mathrm{X}$ & & $\mathrm{X}$ & \\
\hline \multirow[t]{8}{*}{ VOTRAN } & $\begin{array}{c}\text { Bus Service Guide (Sun. } \\
\text { Service) }\end{array}$ & & & $\mathrm{x}$ & & & $\mathrm{x}$ & & & $\mathrm{X}$ & \\
\hline & Trolley Service & & & & & & $\mathrm{X}$ & & & $\mathrm{X}$ & \\
\hline & Holiday Schedule & $\bar{X}$ & & & & $\bar{x}$ & & & & $\bar{x}$ & \\
\hline & Beach Tran & & & & & $x$ & & & & & \\
\hline & $\begin{array}{c}\text { West Volusia Bus Service } \\
\text { Guide }\end{array}$ & & & & & & $\mathrm{x}$ & & & & $\mathrm{x}$ \\
\hline & SE Volusia Bus Service Guide & & & & & & $x$ & & & $x$ & \\
\hline & $\begin{array}{c}\text { Volusia/Orlando Bus Service } \\
\text { Guide }\end{array}$ & & & & & & $\mathrm{x}$ & & & $\mathrm{X}$ & \\
\hline & $\begin{array}{l}\text { Daytona Beach Bus Service } \\
\text { Guide }\end{array}$ & & & & & & $\mathrm{x}$ & & & & $\mathrm{x}$ \\
\hline$\overline{\text { WHAT }}$ & Route Map \& Schedules & & & & & $\bar{X}$ & & & & $\bar{X}$ & \\
\hline
\end{tabular}




\begin{tabular}{|c|c|c|c|c|c|c|c|c|c|c|c|}
\hline \multirow[b]{2}{*}{ Transit } & \multirow[b]{2}{*}{ Type } & \multicolumn{6}{|c|}{ Route \& Transfers } & \multicolumn{4}{|c|}{ Miscellanous } \\
\hline & & $\begin{array}{c}\text { Info } \\
\text { Narrative }\end{array}$ & $\begin{array}{c}\text { Written } \\
\text { on } \\
\text { Table, } \\
\text { Map, or } \\
\text { List }\end{array}$ & \begin{tabular}{|c} 
Separate \\
Transer \\
Guide \\
and/or \\
Table \\
\end{tabular} & $\begin{array}{c}\text { Letters, } \\
\text { Dots, or } \\
\text { Numbers }\end{array}$ & $\begin{array}{l}\text { Points } \\
\text { on Map }\end{array}$ & $\begin{array}{l}\text { Points } \\
\text { on } \\
\text { Time } \\
\text { Table }\end{array}$ & $\begin{array}{c}\text { System } \\
\text { Info }\end{array}$ & $\begin{array}{c}\text { Fare } \\
\text { Info } \\
\end{array}$ & Legend & \begin{tabular}{|c} 
Non- \\
System \\
Ads.
\end{tabular} \\
\hline $\begin{array}{l}\text { Baytown } \\
\text { Trolley }\end{array}$ & Ride Guide & & & & & & & $\mathrm{x}$ & & $\mathrm{x}$ & \\
\hline \multirow[t]{15}{*}{$\mathrm{BCT}$} & B Transit Guide & & & & & $\bar{X}$ & & $\bar{X}$ & $\bar{X}$ & $\bar{X}$ & \\
\hline & $\begin{array}{c}\text { Time Table Routes \#1,2,5-7,9- } \\
12,14-15,17,20,28,30- \\
31,34,36,40,50,55- \\
56,60,72,81,83-84,93 \\
\end{array}$ & $x$ & $\mathrm{x}$ & & $\mathrm{x}$ & $\mathrm{x}$ & $x$ & $x$ & $x$ & $\mathrm{x}$ & \\
\hline & Time Table Routes \#18,22 & $\mathrm{X}$ & $\mathrm{X}$ & & $\mathrm{X}$ & $\mathrm{X}$ & $\mathrm{X}$ & $X$ & $\mathrm{X}$ & $\mathrm{X}$ & \\
\hline & $\begin{array}{c}\text { Time Table Routes } \\
\# 3,57,62,75,95 \\
\end{array}$ & $\mathrm{X}$ & & & $\mathrm{x}$ & $\mathrm{x}$ & $\mathrm{x}$ & $\mathrm{x}$ & $\mathrm{x}$ & $x$ & \\
\hline & Time Table Route \#75 & $\mathrm{X}$ & & & $X$ & $\mathrm{X}$ & $\mathrm{X}$ & $\mathrm{X}$ & $\mathrm{X}$ & $\mathrm{X}$ & \\
\hline & $\begin{array}{c}\text { Time Table Routes \#92, } 94 \\
\text { Combined }\end{array}$ & $\mathrm{x}$ & & & $\mathrm{x}$ & $\mathrm{x}$ & $x$ & $x$ & $\mathrm{x}$ & $\mathrm{x}$ & \\
\hline & $\begin{array}{c}\text { Margate Inner-City Routes } \\
(\mathrm{A}, \mathrm{B}, \mathrm{C}, \mathrm{D})\end{array}$ & $x$ & $x$ & & $x$ & $\mathrm{x}$ & $x$ & $x$ & $x$ & & \\
\hline & $\begin{array}{c}\text { Pembrooke Pines Community } \\
\text { Shuttle Bus Service Route and } \\
\text { TimeTable }\end{array}$ & & & & $\mathrm{x}$ & $\mathrm{x}$ & $\mathrm{x}$ & $\mathrm{x}$ & $\mathrm{x}$ & $\mathrm{x}$ & \\
\hline & $\begin{array}{c}\text { Miramar Community Shuttle } \\
\text { Bus Service Route and } \\
\text { TimeTable } \\
\end{array}$ & $\mathrm{x}$ & $\mathrm{x}$ & & $\mathrm{x}$ & $\mathrm{x}$ & $\mathrm{x}$ & $\mathrm{x}$ & $\mathrm{x}$ & & \\
\hline & $\begin{array}{c}\text { Coconut Creek Shuttle Service } \\
\text { Bus Route and Time Table }\end{array}$ & $\mathrm{x}$ & $x$ & & & $x$ & $x$ & $\mathrm{X}$ & $x$ & & \\
\hline & $\begin{array}{c}\text { Cooper City Community Bus } \\
\text { Route and Time Table }\end{array}$ & & $\mathrm{x}$ & & & $\mathrm{x}$ & $\mathrm{X}$ & $\mathrm{X}$ & $\mathrm{X}$ & & \\
\hline & Broward Urban Shuttle & $\mathrm{X}$ & $\mathrm{X}$ & & & $X$ & & $X$ & $\mathrm{X}$ & & \\
\hline & Western Express Guides & & & & & & $\mathrm{X}$ & $\mathrm{X}$ & $\mathrm{X}$ & & \\
\hline & $\begin{array}{l}\text { Tamarac Transit Route } \\
\text { Timetables (Red, Gr, Yw) }\end{array}$ & $\mathrm{X}$ & $\mathrm{x}$ & & $\mathrm{x}$ & $\mathrm{x}$ & $x$ & $x$ & $x$ & $\mathrm{x}$ & \\
\hline & Free "B" Minibus Service & $\bar{X}$ & & & & & & $\bar{X}$ & $\bar{X}$ & & \\
\hline \multirow[t]{2}{*}{ ECAT } & Ride Guide $(7 / 30 / 2000)$ & $\mathrm{X}$ & & & $\mathrm{X}$ & $\mathrm{X}$ & $\mathrm{X}$ & $\mathrm{X}$ & $\mathrm{X}$ & $\mathrm{X}$ & \\
\hline & Ride Guide (2/4/2001) & $\bar{X}$ & & & $\mathrm{X}$ & $\bar{X}$ & $\bar{X}$ & $\bar{X}$ & $\mathrm{X}$ & $\bar{X}$ & \\
\hline
\end{tabular}




\begin{tabular}{|c|c|c|c|c|c|c|c|c|c|c|c|}
\hline \multirow[b]{2}{*}{ Transit } & \multirow[b]{2}{*}{ Type } & \multicolumn{6}{|c|}{ Route \& Transfers } & \multicolumn{4}{|c|}{ Miscellanous } \\
\hline & & $\begin{array}{c}\text { Info } \\
\text { Narrative }\end{array}$ & $\begin{array}{c}\text { Written } \\
\text { on } \\
\text { Table, } \\
\text { Map, or } \\
\text { List }\end{array}$ & \begin{tabular}{|c} 
Separate \\
Transer \\
Guide \\
and/or \\
Table \\
\end{tabular} & $\begin{array}{c}\text { Letters, } \\
\text { Dots, or } \\
\text { Numbers }\end{array}$ & $\begin{array}{l}\text { Points } \\
\text { on Map }\end{array}$ & $\begin{array}{l}\text { Points } \\
\text { on } \\
\text { Time } \\
\text { Table }\end{array}$ & $\begin{array}{c}\text { System } \\
\text { Info }\end{array}$ & $\begin{array}{c}\text { Fare } \\
\text { Info } \\
\end{array}$ & Legend & \begin{tabular}{|c} 
Non- \\
System \\
Ads.
\end{tabular} \\
\hline \multirow[t]{6}{*}{ HARTline } & Transit Guide & & & & $\bar{x}$ & $\bar{x}$ & & $\bar{X}$ & $\bar{X}$ & $\bar{x}$ & \\
\hline & Express Routes & & & & $\mathrm{X}$ & $\mathrm{X}$ & $\mathrm{X}$ & $\mathrm{X}$ & $\mathrm{X}$ & $\mathrm{X}$ & \\
\hline & South County Circulator & & $\bar{X}$ & & & $\bar{X}$ & $\bar{X}$ & $\bar{X}$ & $\bar{X}$ & $\bar{X}$ & \\
\hline & $\begin{array}{c}\text { Hartline Routes \#1,2,5,6,7, } \\
8,10,11,12,15,19,30,32,34,36,3 \\
7,46\end{array}$ & & & & $\mathrm{x}$ & $\mathrm{x}$ & $\mathrm{x}$ & $\mathrm{x}$ & $\mathrm{x}$ & & \\
\hline & Hartline Routes \#3,14,39 & & & & $\mathrm{X}$ & $\bar{X}$ & $\bar{X}$ & $\mathrm{X}$ & $\mathrm{X}$ & & \\
\hline & $\begin{array}{c}\text { Hartline Routes } \\
\# 4,9,16,17,18,31,33 \\
38,41,87,88 \\
\end{array}$ & & & & $\mathrm{X}$ & $\mathrm{x}$ & $\mathrm{x}$ & $\mathrm{X}$ & $\mathrm{x}$ & & \\
\hline \multirow[t]{7}{*}{ JTA } & Transit Guide & $\bar{X}$ & $\bar{X}$ & & & $\bar{X}$ & & $\bar{X}$ & $\bar{X}$ & & \\
\hline & $\begin{array}{l}\text { Routes: BlandingFly, } \\
\text { ArlingtonFly, OrgPkFly, } \\
\text { ArgyleFly, HghldFly }\end{array}$ & & $\mathrm{x}$ & & & $\mathrm{x}$ & $\mathrm{x}$ & $\mathrm{X}$ & & $\mathrm{x}$ & \\
\hline & \begin{tabular}{|c} 
Routes: St.AugExpSS-35, CC- \\
37 \\
\end{tabular} & & $\mathrm{x}$ & & & $\mathrm{x}$ & $\mathrm{x}$ & $\mathrm{x}$ & & $\mathrm{x}$ & \\
\hline & \begin{tabular}{|c|} 
Routes: SS-2,4,20; WS- \\
$3,6,10,20 ;$ NS-9,12,22; Arlington \\
$2-3$ \\
\end{tabular} & & & & $\mathrm{x}$ & $\mathrm{x}$ & $\mathrm{x}$ & $\mathrm{X}$ & & $\mathrm{X}$ & \\
\hline & Routes: Northwest Looper & & & & $\mathrm{X}$ & $\mathrm{X}$ & $\mathrm{X}$ & $\mathrm{X}$ & & $\mathrm{X}$ & \\
\hline & Route: NS-11 & & & & $\mathrm{X}$ & $\mathrm{X}$ & $\mathrm{X}$ & $\mathrm{X}$ & & $\mathrm{X}$ & \\
\hline & $\begin{array}{c}\text { Routes: Arlington 1,5,20; BH- } \\
\text { 1,2,3; WS- } 1,2,4,5,7,8,9 ; \mathrm{SS}- \\
1,3,5,6,7,8,9,21,40 ; \mathrm{NS}-1- \\
8,10,15,20 \\
\end{array}$ & & & & $x$ & $x$ & $x$ & $x$ & & $\mathrm{x}$ & \\
\hline $\begin{array}{c}\text { City of Key } \\
\text { West }\end{array}$ & Bus Schedule & & $\mathrm{x}$ & & $\mathrm{x}$ & $\mathrm{x}$ & $\mathrm{x}$ & $\mathrm{x}$ & $\mathrm{x}$ & $\mathrm{X}$ & \\
\hline \multirow{2}{*}{$\begin{array}{l}\text { LMAT or } \\
\text { Citrus } \\
\text { Connection }\end{array}$} & $\begin{array}{c}\text { Route Map \& Schedule: Bartow } \\
\text { Express 22X } \\
\end{array}$ & $\mathrm{x}$ & $\mathrm{x}$ & $\mathrm{x}$ & $\mathrm{x}$ & $\mathrm{x}$ & $\mathrm{x}$ & $\mathrm{x}$ & $\mathrm{x}$ & & \\
\hline & $\begin{array}{c}\text { Route Map \& Schedule (all the } \\
\text { rest) }\end{array}$ & $x$ & $\mathrm{x}$ & $x$ & $x$ & $\mathrm{x}$ & $\mathrm{x}$ & $\mathrm{x}$ & $\mathrm{x}$ & & \\
\hline
\end{tabular}




\begin{tabular}{|c|c|c|c|c|c|c|c|c|c|c|c|}
\hline \multirow[b]{2}{*}{ Transit } & \multirow[b]{2}{*}{ Type } & \multicolumn{6}{|c|}{ Route \& Transfers } & \multicolumn{4}{|c|}{ Miscellanous } \\
\hline & & $\begin{array}{c}\text { Info } \\
\text { Narrative }\end{array}$ & $\begin{array}{c}\text { Written } \\
\text { on } \\
\text { Table, } \\
\text { Map, or } \\
\text { List }\end{array}$ & $\begin{array}{c}\text { Separate } \\
\text { Transer } \\
\text { Guide } \\
\text { and/or } \\
\text { Table } \\
\end{array}$ & $\begin{array}{l}\text { Letters, } \\
\text { Dots, or } \\
\text { Numbers }\end{array}$ & $\begin{array}{l}\text { Points } \\
\text { on Map }\end{array}$ & $\begin{array}{c}\text { Points } \\
\text { on } \\
\text { Time } \\
\text { Table }\end{array}$ & $\begin{array}{l}\text { System } \\
\text { Info }\end{array}$ & $\begin{array}{l}\text { Fare } \\
\text { Info } \\
\end{array}$ & Legend & $\begin{array}{l}\text { Non- } \\
\text { System } \\
\text { Ads. }\end{array}$ \\
\hline \multirow[t]{6}{*}{ LeeTran } & Sytem Map & $\mathrm{X}$ & & & & & & $\mathrm{X}$ & $\mathrm{X}$ & $\mathrm{X}$ & \\
\hline & Trolley Guide & & $\bar{X}$ & & $\bar{X}$ & & & $\bar{X}$ & $\mathrm{X}$ & & \\
\hline & Combined Routes: 110/115 & $\mathrm{X}$ & & & $\mathrm{X}$ & $\mathrm{X}$ & $\mathrm{X}$ & $\mathrm{X}$ & $\mathrm{X}$ & & \\
\hline & Routes: 20,85 & $\bar{X}$ & $\bar{X}$ & & $\bar{X}$ & $\bar{X}$ & & $\bar{X}$ & $\mathrm{X}$ & & \\
\hline & Route: 150 & $\mathrm{X}$ & $\mathrm{X}$ & & $\mathrm{X}$ & $\mathrm{X}$ & & $\mathrm{X}$ & $\mathrm{X}$ & & \\
\hline & Route Maps (all the rest) & $\bar{X}$ & $\bar{X}$ & & $\bar{X}$ & $\bar{X}$ & & $\bar{X}$ & $\mathrm{X}$ & & \\
\hline \multirow[t]{5}{*}{ LYNX } & Public Bus System Map & & & & $\bar{X}$ & $\bar{X}$ & $\mathrm{X}$ & $\bar{X}$ & $\bar{x}$ & $\mathrm{X}$ & $\bar{x}$ \\
\hline & Schedule Book & & & & $\bar{X}$ & $\bar{X}$ & $\bar{X}$ & $\bar{X}$ & $\mathrm{X}$ & & $\bar{X}$ \\
\hline & Downtown Disney Direct & & & $X$ & $\mathrm{X}$ & $\mathrm{X}$ & $\mathrm{X}$ & $x$ & $\mathrm{X}$ & $x$ & \\
\hline & $\begin{array}{c}\text { Link } 1-3,5,10,12,14,18,27,34,43 \\
44,47,52,54\end{array}$ & & & & $\mathrm{x}$ & $\mathrm{x}$ & $\mathrm{x}$ & $\mathrm{x}$ & $\mathrm{x}$ & & \\
\hline & LINK (all the rest) & & $\bar{X}$ & & $\bar{X}$ & $\bar{X}$ & $\bar{X}$ & $\bar{X}$ & $\mathrm{X}$ & & \\
\hline MCAT & Ride Guide & $\bar{X}$ & $\bar{X}$ & & & $\bar{X}$ & $\bar{X}$ & $\bar{X}$ & $\mathrm{X}$ & & \\
\hline \multirow{14}{*}{$\begin{array}{l}\text { Miami-Dade } \\
\text { Transit }\end{array}$} & STS Rider's Guide & $\bar{X}$ & & & & & & $\bar{X}$ & $\mathrm{X}$ & & \\
\hline & Transit Rider's Handbook & $\mathrm{X}$ & & $\bar{x}$ & & $\mathrm{X}$ & & $\bar{X}$ & $\mathrm{X}$ & & \\
\hline & MetroMover Guide & & $\bar{X}$ & & & $\bar{X}$ & & $\bar{X}$ & $\mathrm{X}$ & $\bar{X}$ & \\
\hline & Transit Map & $\mathrm{X}$ & & & & $\bar{X}$ & & $\bar{X}$ & $\mathrm{X}$ & $X$ & $\mathrm{X}$ \\
\hline & MetroRail Guide & $X$ & & & & $\mathrm{X}$ & & $\bar{X}$ & $\mathrm{X}$ & $\mathrm{X}$ & \\
\hline & Dade-Monroe Express & $\bar{X}$ & $\bar{X}$ & & & $\bar{X}$ & $\bar{X}$ & $\bar{X}$ & $\mathrm{X}$ & $\bar{X}$ & \\
\hline & Busway/Coral Reef Max & $\bar{X}$ & $\bar{X}$ & & & $\bar{X}$ & $\mathrm{X}$ & $\mathrm{X}$ & $\mathrm{X}$ & $\bar{X}$ & \\
\hline & $\begin{array}{l}\text { Metro Area Express Routes (the } \\
\text { rest), Tri-Rail Koger Shuttle }\end{array}$ & $\mathrm{X}$ & $\mathrm{x}$ & & & $\mathrm{x}$ & $\mathrm{x}$ & $\mathrm{x}$ & $\mathrm{x}$ & & \\
\hline & Kendall Area Transit & $\mathrm{X}$ & $\mathrm{X}$ & & & $\mathrm{X}$ & $\mathrm{X}$ & $\mathrm{X}$ & $\mathrm{X}$ & $\mathrm{X}$ & \\
\hline & $\begin{array}{c}\text { Busway Local, Night Owl } \\
\text { Shuttle, West Dade \& SeaPort } \\
\text { Connection } \\
\end{array}$ & $\mathrm{X}$ & $\mathrm{x}$ & & & $\mathrm{x}$ & $\mathrm{x}$ & $\mathrm{x}$ & $\mathrm{X}$ & & \\
\hline & North Dade \& Doral Connection & $x$ & $x$ & & & $x$ & $x$ & $x$ & $x$ & & \\
\hline & $\begin{array}{c}\text { Metrobus Schedule: R, V, } \\
6,28,29,48,56,57,65,104 \\
\end{array}$ & $\mathrm{x}$ & $\mathrm{x}$ & & & $\mathrm{x}$ & $\mathrm{x}$ & $\mathrm{x}$ & $\mathrm{X}$ & & \\
\hline & $\begin{array}{c}\text { Metrobus Schedule: A-W, 1-91 } \\
\text { (Letters \& Numbers not } \\
\text { included in above listing) }\end{array}$ & $\mathrm{X}$ & $\mathrm{x}$ & & & $\mathrm{x}$ & $\mathrm{X}$ & $\mathrm{X}$ & $\mathrm{x}$ & & \\
\hline & Metrobus Schedule: 95X & $\bar{X}$ & $\bar{X}$ & & & $\bar{X}$ & $\bar{X}$ & $\bar{X}$ & $\mathrm{X}$ & & \\
\hline
\end{tabular}




\begin{tabular}{|c|c|c|c|c|c|c|c|c|c|c|c|}
\hline \multirow[b]{2}{*}{ Transit } & \multirow[b]{2}{*}{ Type } & \multicolumn{6}{|c|}{ Route \& Transfers } & \multicolumn{4}{|c|}{ Miscellanous } \\
\hline & & $\begin{array}{c}\text { Info } \\
\text { Narrative }\end{array}$ & $\begin{array}{c}\text { Written } \\
\text { on } \\
\text { Table, } \\
\text { Map, or } \\
\text { List }\end{array}$ & $\begin{array}{c}\text { Separate } \\
\text { Transer } \\
\text { Guide } \\
\text { and/or } \\
\text { Table }\end{array}$ & $\begin{array}{c}\text { Letters, } \\
\text { Dots, or } \\
\text { Numbers }\end{array}$ & $\begin{array}{l}\text { Points } \\
\text { on Map }\end{array}$ & $\begin{array}{c}\text { Points } \\
\text { on } \\
\text { Time } \\
\text { Table }\end{array}$ & $\begin{array}{l}\text { System } \\
\text { Info }\end{array}$ & $\begin{array}{c}\text { Fare } \\
\text { Info }\end{array}$ & Legend & $\begin{array}{l}\text { Non- } \\
\text { System } \\
\text { Ads. }\end{array}$ \\
\hline \multirow[t]{7}{*}{ Palm Tran } & System Map \& Rider's Guide & $\bar{X}$ & $\bar{X}$ & & $\bar{X}$ & $\bar{X}$ & $\bar{X}$ & $\bar{X}$ & $\bar{X}$ & $\bar{X}$ & $\bar{X}$ \\
\hline & System Map & $\bar{X}$ & $\mathrm{X}$ & $\mathrm{X}$ & $\mathrm{X}$ & $\bar{X}$ & & $\mathrm{X}$ & $\mathrm{X}$ & $\mathrm{X}$ & \\
\hline & Route Map \& Schedule \#42, 60 & $\mathrm{x}$ & & & $\mathrm{x}$ & $\mathrm{x}$ & $\mathrm{x}$ & $\mathrm{x}$ & $\mathrm{x}$ & $\mathrm{x}$ & \\
\hline & $\begin{array}{c}\text { Route Map \& Schedule } \\
\text { Combined } 54 / 55\end{array}$ & $\mathrm{x}$ & & & $\mathrm{x}$ & $\mathrm{x}$ & $\mathrm{x}$ & $\mathrm{x}$ & $\mathrm{x}$ & $\mathrm{x}$ & \\
\hline & $\begin{array}{c}\text { Route Map \& Schedule \#1 } \\
\text { Weekend Only }\end{array}$ & $\mathrm{x}$ & & & $\mathrm{x}$ & $\mathrm{x}$ & $\mathrm{x}$ & $\mathrm{x}$ & $\mathrm{x}$ & $\mathrm{x}$ & \\
\hline & $\begin{array}{c}\text { Route Map \& Schedule } \\
\# 1,52,53,94 \text { Weekday Only }\end{array}$ & $x$ & & & $\mathrm{x}$ & $\mathrm{x}$ & $x$ & $\mathrm{x}$ & $\mathrm{x}$ & $x$ & \\
\hline & Route Maps (all the rest) & $\mathrm{X}$ & & & $\mathrm{X}$ & $\mathrm{X}$ & $\mathrm{X}$ & $\mathrm{X}$ & $\mathrm{X}$ & $\mathrm{X}$ & \\
\hline \multirow[t]{2}{*}{ PCPT } & Route Maps \& Schedules & & & & $\bar{X}$ & $\bar{X}$ & $\bar{X}$ & $\bar{X}$ & $\mathrm{X}$ & $\bar{X}$ & \\
\hline & PCPT System Pocket Map & & & & $\bar{X}$ & $\bar{X}$ & & $\bar{X}$ & $\bar{X}$ & $\bar{X}$ & \\
\hline \multirow[t]{8}{*}{ PSTA } & Suncoast Beach Trolley & & $\bar{X}$ & & & $\bar{X}$ & $\bar{X}$ & $\bar{X}$ & $\bar{X}$ & & \\
\hline & System Map & & $\mathrm{X}$ & & $\mathrm{X}$ & $\bar{X}$ & & $\mathrm{X}$ & $\mathrm{X}$ & $\mathrm{X}$ & $\bar{X}$ \\
\hline & $\begin{array}{c}\text { Route Maps \& Schedules: } \\
100 x, 444,58,64,91,92,94,96,99\end{array}$ & & $\mathrm{x}$ & & & $x$ & $\mathrm{x}$ & $\mathrm{x}$ & $\mathrm{x}$ & $\mathrm{x}$ & \\
\hline & Route \#4,19,38,52,59,74 & & $\mathrm{X}$ & & & $\mathrm{X}$ & $\bar{X}$ & $\mathrm{X}$ & $\mathrm{X}$ & $\mathrm{X}$ & \\
\hline & Route \#62 & & $\mathrm{X}$ & & & $\mathrm{X}$ & $\mathrm{X}$ & $\bar{X}$ & $\mathrm{X}$ & $\mathrm{X}$ & \\
\hline & Routes \#7,75,80 & & $\bar{X}$ & & & $\bar{X}$ & $\mathrm{X}$ & $\mathrm{X}$ & $\mathrm{X}$ & $\mathrm{X}$ & \\
\hline & Routes \#22,30,32,67,73,78,82 & & $x$ & & & $x$ & $x$ & $x$ & $x$ & $x$ & \\
\hline & $\begin{array}{c}\text { Route Maps \& Schedules (all } \\
\text { the rest) }\end{array}$ & & $\mathrm{x}$ & & & $\mathrm{x}$ & $\mathrm{x}$ & $\mathrm{x}$ & $\mathrm{x}$ & $\mathrm{x}$ & \\
\hline RTS & Spring Service Schedule & $\bar{X}$ & $\bar{X}$ & $\bar{X}$ & $\bar{X}$ & $\bar{X}$ & $\bar{X}$ & $\bar{X}$ & $\bar{X}$ & $\bar{X}$ & \\
\hline \multirow{3}{*}{$\begin{array}{l}\text { Sarasota } \\
\text { County Area } \\
\text { Transit }\end{array}$} & South Express County & $\mathrm{X}$ & $\mathrm{X}$ & & & & & $\mathrm{X}$ & $\mathrm{X}$ & & \\
\hline & $\begin{array}{l}\text { South \& North County Guides } \\
\text { (split county, each one is a } \\
\text { complete guide) }\end{array}$ & $\mathrm{x}$ & $\mathrm{x}$ & & $\mathrm{x}$ & $\mathrm{x}$ & $\mathrm{x}$ & $\mathrm{x}$ & $\mathrm{x}$ & $\mathrm{x}$ & \\
\hline & Sarasota Trolley & & $\mathrm{X}$ & & $\mathrm{X}$ & $\mathrm{X}$ & $\mathrm{X}$ & & & $\mathrm{X}$ & \\
\hline $\begin{array}{l}\text { Space Coast } \\
\text { Area Transit }\end{array}$ & $\begin{array}{c}\text { Countywide Schedules \& Route } \\
\text { Maps }\end{array}$ & $\mathrm{X}$ & $x$ & & $\mathrm{x}$ & $\mathrm{x}$ & $\mathrm{x}$ & $\mathrm{x}$ & $x$ & $x$ & \\
\hline SUNTRAN & Bus Route Map & & & & $\bar{X}$ & $\bar{X}$ & $\bar{X}$ & $\bar{X}$ & $\bar{X}$ & $\bar{X}$ & \\
\hline TALTRAN & The Ride Guide & $\mathrm{X}$ & & & $\bar{x}$ & $\mathrm{X}$ & $\bar{X}$ & $\bar{X}$ & $\mathrm{X}$ & $\mathrm{X}$ & \\
\hline
\end{tabular}




\begin{tabular}{|c|c|c|c|c|c|c|c|c|c|c|c|}
\hline \multirow[b]{2}{*}{ Transit } & \multirow[b]{2}{*}{ Type } & \multicolumn{6}{|c|}{ Route \& Transfers } & \multicolumn{4}{|c|}{ Miscellanous } \\
\hline & & $\begin{array}{c}\text { Info } \\
\text { Narrative }\end{array}$ & $\begin{array}{c}\text { Written } \\
\text { on } \\
\text { Table, } \\
\text { Map, or } \\
\text { List }\end{array}$ & $\begin{array}{c}\text { Separate } \\
\text { Transer } \\
\text { Guide } \\
\text { and/or } \\
\text { Table }\end{array}$ & $\begin{array}{l}\text { Letters, } \\
\text { Dots, or } \\
\text { Numbers }\end{array}$ & $\begin{array}{c}\text { Points } \\
\text { on Map }\end{array}$ & $\begin{array}{l}\text { Points } \\
\text { on } \\
\text { Time } \\
\text { Table }\end{array}$ & $\begin{array}{c}\text { System } \\
\text { Info }\end{array}$ & $\begin{array}{c}\text { Fare } \\
\text { Info }\end{array}$ & Legend & $\begin{array}{l}\text { Non- } \\
\text { System } \\
\text { Ads. }\end{array}$ \\
\hline \multirow[t]{8}{*}{ TRI-RAIL } & $\begin{array}{c}\text { Train Schedule and System } \\
\text { Information }\end{array}$ & $x$ & $x$ & & $x$ & $x$ & $x$ & $x$ & $x$ & $\mathrm{x}$ & \\
\hline & Swap Shop Shuttle & & $\mathrm{X}$ & & $\mathrm{X}$ & $X$ & & & & $\mathrm{X}$ & \\
\hline & TMAX Shuttle & & $\bar{X}$ & & $\bar{X}$ & $\bar{X}$ & $\bar{X}$ & & & & \\
\hline & Route 63 & & & & $\mathrm{X}$ & $\mathrm{X}$ & $\mathrm{X}$ & & & & \\
\hline & MIA Terminal & & $\bar{X}$ & & & & $\mathrm{X}$ & & & & \\
\hline & $\begin{array}{l}\text { Koger, Miami Airport Station, \& } \\
\text { Route } 79\end{array}$ & & $x$ & & $x$ & $x$ & $x$ & & & $x$ & \\
\hline & $\begin{array}{c}\text { Routes } 33,53, \& 74 ; \text { Boca } \\
\text { Raton Station } \\
\end{array}$ & & & & $x$ & $x$ & $x$ & & & $x$ & \\
\hline & $\begin{array}{c}\text { Combined Routes: } 41 / 42 / 43 \text { \& } \\
23 / 24\end{array}$ & & & & $\mathrm{x}$ & $\mathrm{x}$ & $\mathrm{x}$ & & & & \\
\hline \multirow[t]{8}{*}{ VOTRAN } & $\begin{array}{l}\text { Bus Service Guide (Sun. } \\
\text { Service) }\end{array}$ & $x$ & $x$ & & & $x$ & $x$ & $x$ & $x$ & $x$ & \\
\hline & Trolley Service & & $\mathrm{X}$ & & & $\mathrm{X}$ & $\mathrm{X}$ & $\mathrm{X}$ & $\mathrm{X}$ & & \\
\hline & Holiday Schedule & & $\mathrm{X}$ & & & & $\mathrm{X}$ & & & & \\
\hline & Beach Tran & & $x$ & & & $x$ & & $x$ & $x$ & & \\
\hline & $\begin{array}{c}\text { West Volusia Bus Service } \\
\text { Guide }\end{array}$ & $\mathrm{x}$ & $\mathrm{x}$ & & $\mathrm{x}$ & $\mathrm{x}$ & $\mathrm{x}$ & $x$ & $x$ & $x$ & \\
\hline & SE Volusia Bus Service Guide & $x$ & $x$ & & $x$ & $x$ & $x$ & $x$ & $x$ & $x$ & \\
\hline & $\begin{array}{c}\text { Volusia/Orlando Bus Service } \\
\text { Guide }\end{array}$ & & $\mathrm{x}$ & & $\mathrm{x}$ & $\mathrm{x}$ & $\mathrm{x}$ & $\mathrm{x}$ & $\mathrm{x}$ & & \\
\hline & $\begin{array}{c}\text { Daytona Beach Bus Service } \\
\text { Guide }\end{array}$ & $\mathrm{x}$ & $\mathrm{x}$ & & $\mathrm{x}$ & $\mathrm{x}$ & $\mathrm{x}$ & $x$ & $\mathrm{x}$ & $\mathrm{x}$ & \\
\hline WHAT & Route Map \& Schedules & $\bar{X}$ & $\bar{X}$ & $\bar{X}$ & $\bar{X}$ & $\bar{X}$ & $\bar{X}$ & $\bar{X}$ & $\bar{X}$ & & \\
\hline
\end{tabular}




\begin{tabular}{|c|c|c|c|c|c|c|c|c|c|}
\hline \multirow[b]{2}{*}{ Transit } & \multirow[b]{2}{*}{ Type } & \multicolumn{3}{|c|}{ System-Wide } & \multicolumn{5}{|c|}{ Transfer Routes } \\
\hline & & \begin{tabular}{|c|} 
Ride \\
Guide \\
(All \\
routes/ \\
No \\
SWM) \\
\end{tabular} & $\begin{array}{c}\text { Ride } \\
\text { Guide } \\
\text { with } \\
\text { System } \\
\text { Wide } \\
\text { Map } \\
\end{array}$ & $\begin{array}{l}\text { System } \\
\text { Map } \\
\text { Guide } \\
\text { Only } \\
\end{array}$ & $\begin{array}{l}\text { On } \\
\text { Map/ } \\
\text { On } \\
\text { TT }\end{array}$ & \begin{tabular}{|c|} 
On \\
Map/ \\
Not \\
on TT \\
\end{tabular} & \begin{tabular}{|l|} 
Not \\
on \\
Map/ \\
On \\
TT \\
\end{tabular} & \begin{tabular}{|c|} 
Not \\
on \\
Map/ \\
Not \\
on TT \\
\end{tabular} & Other \\
\hline $\begin{array}{l}\text { Baytown } \\
\text { Trolley }\end{array}$ & Ride Guide & & $\mathrm{x}$ & & & & & $\mathrm{x}$ & \\
\hline \multirow[t]{15}{*}{$\mathrm{BCT}$} & B Transit Guide & & & $\bar{X}$ & & & & & \\
\hline & $\begin{array}{c}\text { Time Table Routes \#1,2,5-7,9- } \\
12,14-15,17,20,28,30- \\
31,34,36,40,50,55- \\
56,60,72,81,83-84,93 \\
\end{array}$ & & & & & $\mathrm{x}$ & & & \\
\hline & Time Table Routes \#18,22 & & & & & $\mathrm{X}$ & & & \\
\hline & $\begin{array}{c}\text { Time Table Routes } \\
\# 3,57,62,75,95 \\
\end{array}$ & & & & & $\mathrm{x}$ & & & \\
\hline & Time Table Route \#75 & & & & & & & $X$ & \\
\hline & $\begin{array}{c}\text { Time Table Routes \#92, } 94 \\
\text { Combined } \\
\end{array}$ & & & & & $\mathrm{x}$ & & & \\
\hline & $\begin{array}{c}\text { Margate Inner-City Routes } \\
(A, B, C, D)\end{array}$ & & & & & & & $\mathrm{X}$ & \\
\hline & $\begin{array}{c}\text { Pembrooke Pines Community } \\
\text { Shuttle Bus Service Route and } \\
\text { TimeTable }\end{array}$ & & & & & $\mathrm{x}$ & & & \\
\hline & $\begin{array}{c}\text { Miramar Community Shuttle } \\
\text { Bus Service Route and } \\
\text { TimeTable } \\
\end{array}$ & & & & & $\mathrm{x}$ & & & \\
\hline & $\begin{array}{c}\text { Coconut Creek Shuttle Service } \\
\text { Bus Route and Time Table }\end{array}$ & & & & & & & $\mathrm{x}$ & \\
\hline & $\begin{array}{c}\text { Cooper City Community Bus } \\
\text { Route and Time Table }\end{array}$ & & & & & $\mathrm{X}$ & & & \\
\hline & Broward Urban Shuttle & & & & & & & $\mathrm{X}$ & \\
\hline & Western Express Guides & & & & & & & $\mathrm{X}$ & \\
\hline & $\begin{array}{l}\text { Tamarac Transit Route } \\
\text { Timetables (Red, Gr, Yw) }\end{array}$ & & & & & $\mathrm{X}$ & & & \\
\hline & Free "B" Minibus Service & & & & & $\bar{X}$ & & & \\
\hline \multirow[t]{2}{*}{ ECAT } & Ride Guide $(7 / 30 / 2000)$ & $\mathrm{X}$ & & & & & & & \\
\hline & Ride Guide (2/4/2001) & $\bar{x}$ & & & & $\mathrm{X}$ & & & \\
\hline
\end{tabular}




\begin{tabular}{|c|c|c|c|c|c|c|c|c|c|}
\hline \multirow[b]{2}{*}{ Transit } & \multirow[b]{2}{*}{ Type } & \multicolumn{3}{|c|}{ System-Wide } & \multicolumn{5}{|c|}{ Transfer Routes } \\
\hline & & $\begin{array}{l}\text { Ride } \\
\text { Guide } \\
\text { (All } \\
\text { routes/ } \\
\text { No } \\
\text { SWM) }\end{array}$ & \begin{tabular}{|c|} 
Ride \\
Guide \\
with \\
System \\
Wide \\
Map
\end{tabular} & $\begin{array}{l}\text { System } \\
\text { Map } \\
\text { Guide } \\
\text { Only }\end{array}$ & $\begin{array}{l}\text { On } \\
\text { Map/ } \\
\text { On } \\
\text { TT }\end{array}$ & \begin{tabular}{|c|} 
On \\
Map/ \\
Not \\
on TT
\end{tabular} & $\begin{array}{c}\text { Not } \\
\text { on } \\
\text { Map/ } \\
\text { On } \\
\text { TT }\end{array}$ & $\begin{array}{l}\text { Not } \\
\text { on } \\
\text { Map/ } \\
\text { Not } \\
\text { on TT }\end{array}$ & Other \\
\hline \multirow[t]{6}{*}{ HARTline } & Transit Guide & & & $\bar{x}$ & & & & & \\
\hline & Express Routes & & & & & & & $\bar{X}$ & \\
\hline & South County Circulator & & & & & & & $\mathrm{X}$ & \\
\hline & $\begin{array}{c}\text { Hartline Routes } \# 1,2,5,6,7 \\
8,10,11,12,15,19,30,32,34,36,3 \\
7,46\end{array}$ & & & & & $\mathrm{x}$ & & & \\
\hline & Hartline Routes $\# 3,14,39$ & & & & & $\bar{X}$ & & & \\
\hline & $\begin{array}{c}\text { Hartline Routes } \\
\# 4,9,16,17,18,31,33 \\
38,41,87,88\end{array}$ & & & & & $\mathrm{x}$ & & & \\
\hline \multirow[t]{7}{*}{ JTA } & Transit Guide & & & $\bar{X}$ & & & & $\bar{X}$ & \\
\hline & $\begin{array}{l}\text { Routes: BlandingFly, } \\
\text { ArlingtonFly, OrgPkFly, } \\
\text { ArgyleFly, HghldFly }\end{array}$ & & & & & & & $\mathrm{x}$ & \\
\hline & \begin{tabular}{|c|} 
Routes: St.AugExpSS-35, CC- \\
37
\end{tabular} & & & & $\mathrm{x}$ & & & & \\
\hline & \begin{tabular}{|c|} 
Routes: SS-2,4,20; WS- \\
$3,6,10,20 ;$ NS-9,12,22; Arlington \\
$2-3$ \\
\end{tabular} & & & & $\mathrm{x}$ & & & & \\
\hline & Routes: Northwest Looper & & & & & $\mathrm{X}$ & & & \\
\hline & Route: NS-11 & & & & & & & $\mathrm{X}$ & \\
\hline & $\begin{array}{c}\text { Routes: Arlington } 1,5,20 ; \mathrm{BH}- \\
1,2,3 ; \text { WS- } 1,2,4,5,7,8,9 ; \mathrm{SS}- \\
1,3,5,6,7,8,9,21,40 ; \mathrm{NS}-1- \\
8,10,15,20 \\
\end{array}$ & & & & $\mathrm{x}$ & & & & \\
\hline $\begin{array}{l}\text { City of Key } \\
\text { West }\end{array}$ & Bus Schedule & & $\mathrm{x}$ & & & & & $\mathrm{x}$ & \\
\hline \multirow{2}{*}{$\begin{array}{l}\text { LMAT or } \\
\text { Citrus } \\
\text { Connection }\end{array}$} & $\begin{array}{c}\text { Route Map \& Schedule: Bartow } \\
\text { Express } 22 X\end{array}$ & & & & $\mathrm{x}$ & & & & \\
\hline & $\begin{array}{c}\begin{array}{c}\text { Route Map \& Schedule (all the } \\
\text { rest) }\end{array} \\
\end{array}$ & & & & $\mathrm{X}$ & & & & \\
\hline
\end{tabular}




\begin{tabular}{|c|c|c|c|c|c|c|c|c|c|}
\hline \multirow[b]{2}{*}{ Transit } & \multirow[b]{2}{*}{ Type } & \multicolumn{3}{|c|}{ System-Wide } & \multicolumn{5}{|c|}{ Transfer Routes } \\
\hline & & $\begin{array}{l}\text { Ride } \\
\text { Guide } \\
\text { (All } \\
\text { routes/ } \\
\text { No } \\
\text { SWM) }\end{array}$ & \begin{tabular}{|c|} 
Ride \\
Guide \\
with \\
System \\
Wide \\
Map \\
\end{tabular} & $\begin{array}{c}\text { System } \\
\text { Map } \\
\text { Guide } \\
\text { Only }\end{array}$ & $\begin{array}{l}\text { On } \\
\text { Map/ } \\
\text { On } \\
\text { TT } \\
\end{array}$ & \begin{tabular}{|c|} 
On \\
Map/ \\
Not \\
on TT \\
\end{tabular} & $\begin{array}{c}\text { Not } \\
\text { on } \\
\text { Map/ } \\
\text { On } \\
\text { TT } \\
\end{array}$ & $\begin{array}{c}\text { Not } \\
\text { on } \\
\text { Map/ } \\
\text { Not } \\
\text { on TT } \\
\end{array}$ & Other \\
\hline \multirow[t]{6}{*}{ LeeTran } & Sytem Map & & & $\bar{X}$ & & $\bar{x}$ & & & \\
\hline & Trolley Guide & & & & & & & $\mathrm{X}$ & \\
\hline & Combined Routes: $110 / 115$ & & & & & & & & $\mathrm{X}$ \\
\hline & Routes: 20,85 & & & & & & & & $\mathrm{X}$ \\
\hline & Route: 150 & & & & & & & & $\mathrm{X}$ \\
\hline & Route Maps (all the rest) & & & & & & & & $\bar{X}$ \\
\hline \multirow[t]{5}{*}{ LYNX } & Public Bus System Map & & & $\mathrm{X}$ & & & & $\bar{x}$ & \\
\hline & Schedule Book & & $\bar{X}$ & & & & & $\bar{X}$ & \\
\hline & Downtown Disney Direct & & & & & & & $X$ & \\
\hline & $\begin{array}{c}\text { Link } 1-3,5,10,12,14,18,27,34,43 \\
44,47,52,54\end{array}$ & & & & & & & $\mathrm{x}$ & \\
\hline & LINK (all the rest) & & & & & & & $\mathrm{X}$ & \\
\hline MCAT & Ride Guide & & $\bar{X}$ & & & & $\bar{X}$ & & \\
\hline \multirow{14}{*}{$\begin{array}{l}\text { Miami-Dade } \\
\text { Transit }\end{array}$} & STS Rider's Guide & & & & & & & & \\
\hline & Transit Rider's Handbook & & & & & & & & \\
\hline & MetroMover Guide & & & & & & & $\mathrm{X}$ & \\
\hline & Transit Map & & & $\bar{X}$ & & $\bar{X}$ & & & \\
\hline & MetroRail Guide & & & & & & & $\mathrm{X}$ & \\
\hline & Dade-Monroe Express & & & & & & & & \\
\hline & Busway/Coral Reef Max & & & & & & & & \\
\hline & $\begin{array}{c}\text { Metro Area Express Routes (the } \\
\text { rest), Tri-Rail Koger Shuttle }\end{array}$ & & & & & & & $\mathrm{x}$ & \\
\hline & Kendall Area Transit & & & & & & & $\bar{X}$ & \\
\hline & $\begin{array}{c}\text { Busway Local, Night Owl } \\
\text { Shuttle, West Dade \& SeaPort } \\
\text { Connection } \\
\end{array}$ & & & & & & & $\mathrm{x}$ & \\
\hline & North Dade \& Doral Connection & & & & & & & $x$ & \\
\hline & $\begin{array}{c}\text { Metrobus Schedule: } R, \mathrm{~V}, \\
6,28,29,48,56,57,65,104\end{array}$ & & & & & & & $\mathrm{x}$ & \\
\hline & $\begin{array}{c}\text { Metrobus Schedule: A-W, 1-91 } \\
\text { (Letters \& Numbers not } \\
\text { included in above listing) }\end{array}$ & & & & & & & $\mathrm{x}$ & \\
\hline & Metrobus Schedule: $95 \mathrm{X}$ & & & & & & & $\mathrm{X}$ & \\
\hline
\end{tabular}




\begin{tabular}{|c|c|c|c|c|c|c|c|c|c|}
\hline \multirow[b]{2}{*}{ Transit } & \multirow[b]{2}{*}{ Type } & \multicolumn{3}{|c|}{ System-Wide } & \multicolumn{5}{|c|}{ Transfer Routes } \\
\hline & & \begin{tabular}{|c} 
Ride \\
Guide \\
(All \\
routes/ \\
No \\
SWM)
\end{tabular} & \begin{tabular}{|c|} 
Ride \\
Guide \\
with \\
System \\
Wide \\
Map \\
\end{tabular} & $\begin{array}{l}\text { System } \\
\text { Map } \\
\text { Guide } \\
\text { Only }\end{array}$ & $\begin{array}{l}\text { On } \\
\text { Map/ } \\
\text { On } \\
\text { TT }\end{array}$ & \begin{tabular}{|c|} 
On \\
Map/ \\
Not \\
on TT
\end{tabular} & $\begin{array}{c}\text { Not } \\
\text { on } \\
\text { Map/ } \\
\text { On } \\
\text { TT }\end{array}$ & \begin{tabular}{|c|} 
Not \\
on \\
Map/ \\
Not \\
on TT \\
\end{tabular} & Other \\
\hline $\begin{array}{c}\begin{array}{c}\text { Okaloosa } \\
\text { County }\end{array} \\
\text { Transit }\end{array}$ & Ride the Wave Guide & & $\mathrm{x}$ & & & & & $\mathrm{x}$ & $\begin{array}{l}\text { very } \\
\text { bad }\end{array}$ \\
\hline \multirow{7}{*}{ Palm Tran } & System Map \& Rider's Guide & & $\bar{X}$ & & & $\bar{x}$ & & & \\
\hline & System Map & & & $\mathrm{X}$ & $?$ & $?$ & $?$ & $?$ & \\
\hline & Route Map \& Schedule \#42, 60 & & & & & $x$ & & & \\
\hline & $\begin{array}{c}\text { Route Map \& Schedule } \\
\text { Combined 54/55 }\end{array}$ & & & & & & & $\mathrm{x}$ & \\
\hline & $\begin{array}{c}\text { Route Map \& Schedule \#1 } \\
\text { Weekend Only }\end{array}$ & & & & & $\mathrm{x}$ & & & \\
\hline & $\begin{array}{c}\text { Route Map \& Schedule } \\
\# 1,52,53,94 \text { Weekday Only }\end{array}$ & & & & & $\mathrm{X}$ & & & \\
\hline & Route Maps (all the rest) & & & & & $\mathrm{X}$ & & & \\
\hline \multirow[t]{2}{*}{ PCPT } & Route Maps \& Schedules & & & & & & & & $\bar{X}$ \\
\hline & PCPT System Pocket Map & & & $\bar{X}$ & & $\mathrm{X}$ & & & \\
\hline \multirow[t]{8}{*}{ PSTA } & Suncoast Beach Trolley & & & & & & & & \\
\hline & System Map & & & $\mathrm{X}$ & & $\mathrm{X}$ & & & \\
\hline & $\begin{array}{c}\text { Route Maps \& Schedules: } \\
100 x, 444,58,64,91,92,94,96,99\end{array}$ & & & & & & & $\mathrm{x}$ & \\
\hline & Route \#4,19,38,52,59,74 & & & & & & & $\mathrm{X}$ & \\
\hline & Route \#62 & & & & & & & $\mathrm{X}$ & \\
\hline & Routes \#7,75,80 & & & & & & & $\bar{X}$ & \\
\hline & Routes \#22,30,32,67,73,78,82 & & & & & & & $x$ & \\
\hline & $\begin{array}{c}\text { Route Maps \& Schedules (all } \\
\text { the rest) }\end{array}$ & & & & & & & $\mathrm{x}$ & \\
\hline RTS & Spring Service Schedule & & $\bar{X}$ & & & & $\bar{X}$ & & \\
\hline \multirow{3}{*}{$\begin{array}{c}\text { Sarasota } \\
\text { County Area } \\
\text { Transit }\end{array}$} & South Express County & & & & & $\mathrm{X}$ & & & \\
\hline & $\begin{array}{c}\text { South \& North County Guides } \\
\text { (split county, each one is a } \\
\text { complete guide) }\end{array}$ & & $\mathrm{x}$ & & & $\mathrm{x}$ & & & \\
\hline & Sarasota Trolley & & & & & & & & \\
\hline $\begin{array}{l}\text { Space Coast } \\
\text { Area Transit }\end{array}$ & $\begin{array}{c}\text { Countywide Schedules \& Route } \\
\text { Maps }\end{array}$ & & $\mathrm{x}$ & & & & $\mathrm{x}$ & & \\
\hline SUNTRAN & Bus Route Map & & $\bar{x}$ & & & $\bar{x}$ & & & \\
\hline TALTRAN & The Ride Guide & & $\bar{x}$ & & & $\mathrm{X}$ & & & \\
\hline
\end{tabular}




\begin{tabular}{|c|c|c|c|c|c|c|c|c|c|}
\hline \multirow[b]{2}{*}{ Transit } & \multirow[b]{2}{*}{ Type } & \multicolumn{3}{|c|}{ System-Wide } & \multicolumn{5}{|c|}{ Transfer Routes } \\
\hline & & $\begin{array}{l}\text { Ride } \\
\text { Guide } \\
\text { (All } \\
\text { routes/ } \\
\text { No } \\
\text { SWM) }\end{array}$ & $\begin{array}{c}\text { Ride } \\
\text { Guide } \\
\text { with } \\
\text { System } \\
\text { Wide } \\
\text { Map }\end{array}$ & $\begin{array}{l}\text { System } \\
\text { Map } \\
\text { Guide } \\
\text { Only }\end{array}$ & $\begin{array}{l}\text { On } \\
\text { Map/ } \\
\text { On } \\
\text { TT }\end{array}$ & $\begin{array}{c}\text { On } \\
\text { Map/ } \\
\text { Not } \\
\text { on TT }\end{array}$ & $\begin{array}{c}\text { Not } \\
\text { on } \\
\text { Map/ } \\
\text { On } \\
\text { TT }\end{array}$ & $\begin{array}{c}\text { Not } \\
\text { on } \\
\text { Map/ } \\
\text { Not } \\
\text { on TT }\end{array}$ & Other \\
\hline \multirow[t]{8}{*}{ TRI-RAIL } & $\begin{array}{c}\text { Train Schedule and System } \\
\text { Information }\end{array}$ & & $\mathrm{X}$ & & & & & & \\
\hline & Swap Shop Shuttle & & & & & & & & \\
\hline & TMAX Shuttle & & & & & & & & \\
\hline & Route 63 & & & & & & & & \\
\hline & MIA Terminal & & & & & & & & \\
\hline & $\begin{array}{l}\text { Koger, Miami Airport Station, \& } \\
\text { Route } 79\end{array}$ & & & & & & & & \\
\hline & $\begin{array}{c}\text { Routes } 33,53, \& 74 ; \text { Boca } \\
\text { Raton Station } \\
\end{array}$ & & & & & & & & \\
\hline & $\begin{array}{c}\text { Combined Routes: } 41 / 42 / 43 \text { \& } \\
23 / 24\end{array}$ & & & & & & & & \\
\hline \multirow[t]{8}{*}{ VOTRAN } & $\begin{array}{c}\text { Bus Service Guide (Sun. } \\
\text { Service) }\end{array}$ & & & & & & & $\mathrm{x}$ & $\begin{array}{l}\text { See } \\
\text { Map } \\
\end{array}$ \\
\hline & Trolley Service & & & & & & & & \\
\hline & Holiday Schedule & & & & & & & $\bar{X}$ & \\
\hline & Beach Tran & & & & & & & $\mathrm{x}$ & $\begin{array}{l}\text { Very } \\
\text { Bad }\end{array}$ \\
\hline & $\begin{array}{c}\text { West Volusia Bus Service } \\
\text { Guide }\end{array}$ & & & & & & & $\mathrm{x}$ & $\begin{array}{l}\text { Very } \\
\text { Bad } \\
\end{array}$ \\
\hline & SE Volusia Bus Service Guide & & & & $?$ & $?$ & $?$ & $?$ & $\begin{array}{l}\text { Very } \\
\text { Bad }\end{array}$ \\
\hline & $\begin{array}{c}\text { Volusia/Orlando Bus Service } \\
\text { Guide }\end{array}$ & & & & & & & $\mathrm{x}$ & $\begin{array}{l}\text { Very } \\
\text { Bad } \\
\end{array}$ \\
\hline & $\begin{array}{l}\text { Daytona Beach Bus Service } \\
\text { Guide }\end{array}$ & & & & & & & $x$ & $\begin{array}{l}\text { Very } \\
\text { Bad }\end{array}$ \\
\hline WHAT & Route Map \& Schedules & & & & $?$ & $?$ & $?$ & $?$ & \\
\hline
\end{tabular}




\section{Appendix B}

\section{Observation Guide}




\section{ACTIVITY 1:}

\section{Activity/Materials Code}

Present transit information materials and written task instructions to participant. Verbally explain the task that the participant is being asked to complete. Ask the participant if she/he has any questions. Instruct the participant to begin the activity.

Time Activity Started:

(Projected end time: )

(No more than 8 minutes for each "SIMPLE" activity)

(No more than 10 minutes for each "COMPLEX" activity)

\section{Visual Observations:}

Please note areas where the participant appears to be having difficulty with the activity (be specific - e.g., Difficulty understanding timetable; difficulty locating destination, etc.)

Did the participant display any of the following emotions while completing the task? (Please check all that apply)

$\begin{array}{ll}\text { “ } & \text { Frustration } \\ \text { “ } & \text { Irritation } \\ \text { “ } & \text { Anger } \\ \text { “ } & \text { Distress } \\ \text { “ } & \text { Laughter } \\ & \text { Nervousness }\end{array}$

Please note the content of any requests for assistance.

Participant completed activity within allotted time:

“ Yes

“ No 


\section{PARTICIPANT \#:}

\section{ACTIVITY 2:}

\section{Activity/Materials Code}

Present transit information materials and written task instructions to participant. Verbally explain the task that the participant is being asked to complete. Ask the participant if she/he has any questions. Instruct the participant to begin the activity.

Time Activity Started:

(Projected end time: )

(No more than 8 minutes for each "SIMPLE" activity)

(No more than 10 minutes for each "COMPLEX" activity)

\section{Visual Observations:}

Please note areas where the participant appears to be having difficulty with the activity (be specific - e.g., Difficulty understanding timetable; difficulty locating destination, etc.)

Did the participant display any of the following emotions while completing the task? (Please check all that apply)

$\begin{array}{ll}\text { “ } & \text { Frustration } \\ \text { “ } & \text { Irritation } \\ \text { “ } & \text { Anger } \\ \text { “ } & \text { Distress } \\ \text { “ } & \text { Laughter } \\ & \text { Nervousness }\end{array}$

Please note the content of any requests for assistance.

Participant completed activity within allotted time:

“ Yes

“ No 


\section{Appendix C}

\section{Interview Guide}


PARTICIPANT \#:

\section{Activity 1 Post-Test Interview:}

How would you rate the task that you were asked to complete in terms of difficulty?

“ Extremely difficult

" Moderately difficult

" Somewhat difficult

“ Neither difficult, nor easy

“ Somewhat easy

" Moderately easy

“ Extremely Easy

Based on your experience with these materials, how would you feel if you were actually planning to take a trip by bus?

What is your general impression of the information materials? (E.g., colors, map, clear information, etc.)

What was the most difficult and/or the least understandable part of using these materials?

What was the least difficult and/or most understandable part of using these materials? 
PARTICIPANT \#:

Are you familiar with the area presented to you in this activity?

“ Yes " No

If yes, how familiar with the area are you?

“ Very familiar

“ Moderately familiar

“ Minimally familiar 
PARTICIPANT \#:

\section{Activity 2 Post-Test Interview:}

How would you rate the task that you were asked to complete in terms of difficulty?

“ Extremely difficult

" Moderately difficult

" Somewhat difficult

“ Neither difficult, nor easy

“ Somewhat easy

" Moderately easy

“ Extremely Easy

Based on your experience with these materials, how would you feel if you were actually planning to take a trip by bus?

What is your general impression of the information materials? (E.g., colors, map, clear information, etc.)

What was the most difficult and/or the least understandable part of using these materials?

What was the least difficult and/or most understandable part of using these materials? 


\section{PARTICIPANT \#:}

Are you familiar with the area presented to you in this activity?

“Yes " No

If yes, how familiar with the area are you?

“ Very familiar

“ Moderately familiar

“ Minimally familiar

Based on your general feelings and opinions about public bus service, how would rate the following aspects of bus service, based on a scale from 1 to 5 with 5 being the highest rating and 1 the lowest rating?

$\begin{array}{llllll}\text { Convenience } & 5 & 4 & 3 & 2 & 1 \\ \text { Comfort } & 5 & 4 & 3 & 2 & 1 \\ \text { Dependability } & 5 & 4 & 3 & 2 & 1 \\ \text { Personal Safety } & 5 & 4 & 3 & 2 & 1 \\ \text { Transit Information } & 5 & 4 & 3 & 2 & 1 \\ \text { Flexibility } & 5 & 4 & 3 & 2 & 1 \\ \text { Availability } & 5 & 4 & 3 & 2 & 1 \\ \text { Vehicle Safety } & 5 & 4 & 3 & 2 & 1\end{array}$

Has your participation in this activity resulted in greater confidence related to planning a trip on the public bus, or not?
“ Yes
“ No
Don't know

Are you now more likely to use transit as a result of your participation today, or not?

“ Yes

“ No

“ Don't know

Thank you for participating in this study. We are collecting this information in order to make transit information materials more user-friendly. The final piece of information that we would like from you is some demographic information. All of the information that you provide to us will remain anonymous and confidential. Thank you again for your time and participation! 


\section{Appendix D}

\section{Demographics Questionnaire}




\section{PARTICIPANT \#:}

Thank you for choosing to participate in our research. Please answer the following questions as accurately, as possible. Your responses will be used for statistical purposes only. Your name will not be connected to these responses in any way and all information you provide shall remain confidential at all times.

\section{What is your:}

Sex:
“ Male
“Female (check one)

Age (check one of the following ranges):

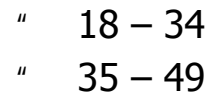

$$
\begin{array}{ll}
\text { “ } \quad 50-64 \\
\quad 65 \text { and older }
\end{array}
$$

Ethnicity:

Personal income (check one of the following ranges):

$$
\begin{array}{ll}
\text { “ } & \text { Less than } \$ 15,000 \\
\text { “ } & \$ 15,000 \text { to } \$ 29,999 \\
\text { “ } & \$ 30,000 \text { to } \$ 49,999 \\
\text { “ } & \$ 50,000 \text { to } \$ 74,999 \\
\text { “ } & \$ 75,000 \text { or more }
\end{array}
$$

Education Level (check last grade level completed):

“ Less than High School Diploma

“ High School Diploma or GED

“ Some College

“ College Graduate

“ Post - Graduate

How many personal vehicles are available in your household? (please check one)

$$
\begin{array}{ll}
\text { “ } & 0 \\
\text { “ } & 1 \\
\text { “ } & 2 \\
& 3 \text { or more }
\end{array}
$$

Do you use public transit buses at least once per week? (please check one)

$$
\text { “Yes " No }
$$

Have you used public transportation in the past six months? (please check one)

$$
\text { “Yes " No }
$$

If yes, where? 


\section{Appendix E}

\section{Participant Worksheet \\ \&. \\ Participant Score Sheet}




\section{TRIP PLANNING WORKSHEET}

\section{BTT-29-S}

It's Monday. You're at the Panama City Mall and you need to get to the Greyhound Bus Station by 4 PM. What is the most direct route(s) to take in order to get there on time? Please note any required transfers. Assume that you are on time if you arrive on or before the destination time. Please choose the arrival time that is closest to your required destination time and the listed bus stop that is nearest to your destination.

\section{Origin Information:}

Route:

Bus Stop:

Time:

Transfer Information (If necessary):

Route:

Bus Stop:

Time:

\section{Destination Information:}

Bus Stop:

Time: 


\section{TRIP PLANNING WORKSHEET}

\section{LNX-4-C}

It's Saturday and you are at the Altamonte Mall. You need to get to Orange Blossom Trail and Central Florida Parkway (Greenway) by 6:00 PM. What is the most direct route(s) to take in order to get there on time? Please note any required transfers. Assume that you are on time if you arrive on or before the destination time. Please choose the arrival time that is closest to your required destination time and the listed bus stop that is nearest to your destination.

\section{Origin Information:}

Route:

Bus Stop:

Time:

Transfer Information (If necessary):

Route:

Bus Stop:

Time:

\section{Destination Information:}

Bus Stop:

Time: 


\section{Activity 1 Score Sheet}

\section{Activity/Materials Code}

Total Time required to complete task:

“ $0-3$ minutes

“ $3-6$ minutes

“ 6- 10 minutes

“ Not completed in allotted time

Did the participant request assistance?

“ Yes “ No

If Yes, please specify the type(s) of assistance requested

Was the participant able to plan the requested trip (i.e., travel from origin to intended destination)?

“ Yes

No

Did the participant arrive to the destination on-time?

“ Yes “ No

Did the participant choose the optimal initial route for their trip?

$$
\text { “ Yes “ No }
$$

Did the participant choose the best origin bus stop for their trip?

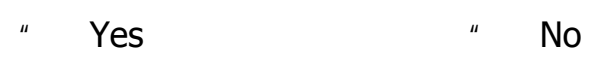

Did the participant choose the best time point at the origin?

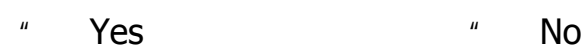

Did the participant choose the best transfer route?
“ Yes
“ No
“ N/A

Did the participant choose the best transfer point?
“ Yes
“ No
“ N/A

Did the participant choose the best transfer time?
“ Yes
“ No
“ N/A

Did the participant choose the best bus stop at the destination?
“ Yes
No

Did the participant choose the best time at the destination?

“Yes “ No




\section{Activity 2 Score Sheet}

\section{Activity/Materials Code}

Total Time required to complete task:

“ $0-3$ minutes

“ $3-6$ minutes

“ $6-10$ minutes

“ Not completed in allotted time

Did the participant request assistance?

“Yes “ No

If Yes, please specify the type(s) of assistance requested

Was the participant able to plan the requested trip (i.e., travel from origin to intended destination)?

“ Yes

No

Did the participant arrive to the destination on-time?

“ Yes “ No

Did the participant choose the optimal initial route for their trip?

$$
\text { “ Yes “ No }
$$

Did the participant choose the best origin bus stop for their trip?

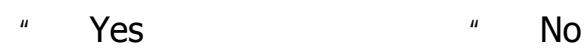

Did the participant choose the best time point at the origin?

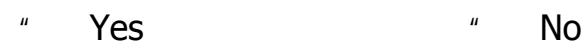

Did the participant choose the best transfer route?
“ Yes
“ No
“ N/A

Did the participant choose the best transfer point?
“ Yes
“ No
“ N/A

Did the participant choose the best transfer time?
“ Yes
“ No
“ N/A

Did the participant choose the best bus stop at the destination?
“ Yes
No

Did the participant choose the best time at the destination?

“Yes “ No 


\section{Appendix F}

\section{Additional Demographic Data \\ $\&$ \\ Statistical Correlations}


SECTION 1: PRELIMINARY STUDY DATA, INCLUDING DEMOGRAPHICS

Table F -1

Gender of participants in Preliminary Study

\begin{tabular}{|c|c|c|c|c|}
\hline & Frequency & Percent & $\begin{array}{c}\text { Valid } \\
\text { Percent }\end{array}$ & $\begin{array}{c}\text { Cumulative } \\
\text { Percent }\end{array}$ \\
\hline Valid $\mathbf{1 . 0 0}$ & 8 & 47.1 & 47.1 & 47.1 \\
\hline $\mathbf{2 . 0 0}$ & 9 & 52.9 & 52.9 & 100.0 \\
\hline Total & 17 & 100.0 & 100.0 & \\
\hline
\end{tabular}

Table F - 2

Age of participants in Preliminary Study

\begin{tabular}{|c|c|c|c|c|}
\hline & Frequency & Percent & $\begin{array}{c}\text { Valid } \\
\text { Percent }\end{array}$ & $\begin{array}{c}\text { Cumulative } \\
\text { Percent }\end{array}$ \\
\hline Valid $\mathbf{1 . 0 0}$ & 4 & 23.5 & 23.5 & 23.5 \\
\hline $\mathbf{2 . 0 0}$ & 6 & 35.3 & 35.3 & 58.8 \\
\hline $\mathbf{3 . 0 0}$ & 4 & 23.5 & 23.5 & 82.4 \\
\hline $\mathbf{4 . 0 0}$ & 2 & 11.8 & 11.8 & 94.1 \\
\hline $\mathbf{5 . 0 0}$ & 1 & 5.9 & 5.9 & 100.0 \\
\hline Total & 17 & 100.0 & 100.0 & \\
\hline
\end{tabular}

Table F - 3

Ethnicity of participants in Preliminary Study

\begin{tabular}{|c|c|c|c|c|}
\hline & Frequency & Percent & $\begin{array}{c}\text { Valid } \\
\text { Percent }\end{array}$ & $\begin{array}{c}\text { Cumulative } \\
\text { Percent }\end{array}$ \\
\hline Valid $\mathbf{1 . 0 0}$ & 11 & 64.7 & 68.8 & 68.8 \\
\hline $\mathbf{2 . 0 0}$ & 1 & 5.9 & 6.3 & 75.0 \\
\hline $\mathbf{3 . 0 0}$ & 3 & 17.6 & 18.8 & 93.8 \\
\hline $\mathbf{5 . 0 0}$ & 1 & 5.9 & 6.3 & 100.0 \\
\hline Total & 16 & 94.1 & 100.0 & \\
\hline Missing System & 1 & 5.9 & & \\
\hline Total & 17 & 100.0 & & \\
\hline
\end{tabular}


Table F -4

Household Income of participants in Preliminary Study

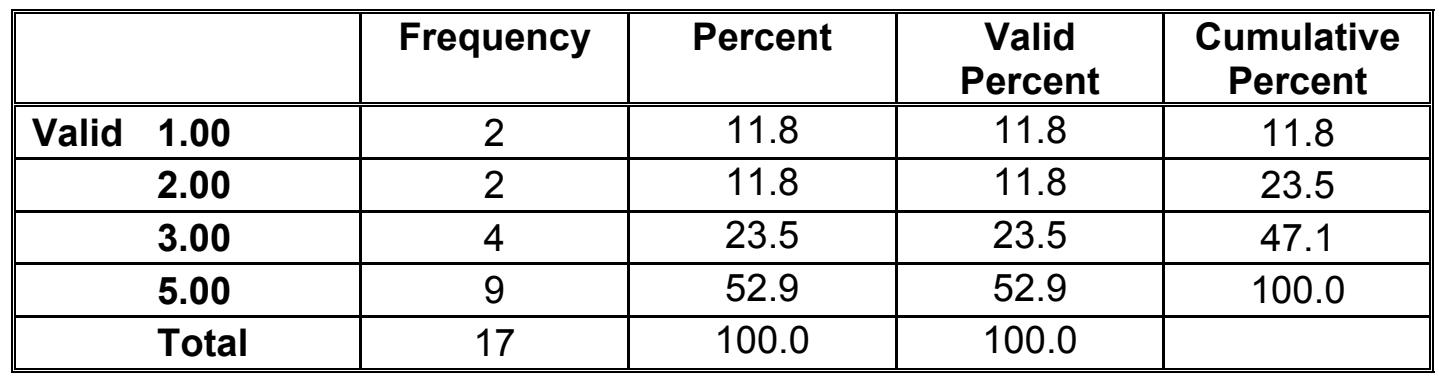

Table F - 5

Education Level of participants in Preliminary Study

\begin{tabular}{|c|c|c|c|c|c|}
\hline & & Frequency & Percent & $\begin{array}{c}\text { Valid } \\
\text { Percent }\end{array}$ & $\begin{array}{c}\text { Cumulative } \\
\text { Percent }\end{array}$ \\
\hline Valic & 3.00 & 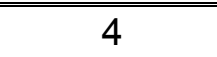 & 23.5 & 23.5 & 23.5 \\
\hline & 4.00 & 6 & 35.3 & 35.3 & 58.8 \\
\hline & 5.00 & 7 & 41.2 & 41.2 & 100.0 \\
\hline & Total & 17 & 100.0 & 100.0 & \\
\hline
\end{tabular}

Table F - 6

Personal Vehicles in Household of participants in Preliminary Study

\begin{tabular}{||c|c|c|c|c||}
\hline & Frequency & Percent & $\begin{array}{c}\text { Valid } \\
\text { Percent }\end{array}$ & $\begin{array}{c}\text { Cumulative } \\
\text { Percent }\end{array}$ \\
\hline Valid $\mathbf{1 . 0 0}$ & 3 & 17.6 & 17.6 & 17.6 \\
\hline $\mathbf{2 . 0 0}$ & 5 & 29.4 & 29.4 & 47.1 \\
\hline $\mathbf{3 . 0 0}$ & 7 & 41.2 & 41.2 & 88.2 \\
\hline $\mathbf{5 . 0 0}$ & 2 & 11.8 & 11.8 & 100.0 \\
\hline Total & 17 & 100.0 & 100.0 & \\
\hline
\end{tabular}

Table F - 7

Use of Public Transportation by participants in Preliminary Study

\begin{tabular}{|c|c|c|c|c||}
\hline & Frequency & Percent & $\begin{array}{c}\text { Valid } \\
\text { Percent }\end{array}$ & $\begin{array}{c}\text { Cumulative } \\
\text { Percent }\end{array}$ \\
\hline \hline Valid $\mathbf{1 . 0 0}$ & 9 & 52.9 & 90.0 & 90.0 \\
\hline $\mathbf{2 . 0 0}$ & 1 & 5.9 & 10.0 & 100.0 \\
\hline Total & 10 & 58.8 & 100.0 & \\
\hline Missing System & 7 & 41.2 & & \\
\hline Total & 17 & 100.0 & & \\
\hline
\end{tabular}


Table F - 8

Comparative statistics for Preliminary Study

(comparing simple and complex sessions)

\begin{tabular}{|c|c|c|c|c|c|}
\hline \multicolumn{2}{|c|}{ SIMPCOMP } & $\mathbf{N}$ & Mean & $\begin{array}{c}\text { Std. } \\
\text { Deviation }\end{array}$ & $\begin{array}{c}\text { Std. Error } \\
\text { Mean }\end{array}$ \\
\hline \multirow[t]{2}{*}{ COMPOS1A } & 1.00 & 17 & 14.2941 & 8.18 .36 & 1.9848 \\
\hline & 2.00 & 16 & 11.9438 & 7.3437 & 1.8359 \\
\hline \multirow[t]{2}{*}{ COMPOS2A } & 1.00 & 17 & 17.2353 & 9.8459 & 2.3880 \\
\hline & 2.00 & 16 & 14.1028 & 8.8657 & 2.2164 \\
\hline
\end{tabular}

Table F - 9

Comparative statistics for Preliminary Study (comparing males and females)

\begin{tabular}{|c|c|c|c|c|c|}
\hline \multicolumn{2}{|c|}{ GENDER } & $\mathbf{N}$ & Mean & $\begin{array}{c}\text { Std. } \\
\text { Deviation }\end{array}$ & $\begin{array}{l}\text { Std. Error } \\
\text { Mean }\end{array}$ \\
\hline \multirow[t]{2}{*}{ CoMPos1A } & 1.00 & 15 & 16.0800 & 5.7704 & 1.4899 \\
\hline & 2.00 & 18 & 10.7167 & 8.4870 & 2.0004 \\
\hline \multirow[t]{2}{*}{ COMPOS2A } & 1.00 & 15 & 19.1927 & 7.0621 & 1.8234 \\
\hline & 2.00 & 18 & 12.8197 & 10.2338 & 2.4121 \\
\hline
\end{tabular}

Table F - 10

Comparative statistics for Preliminary Study

(comparing simple and complex sessions, total time as dependent measure)

\begin{tabular}{||cc|c|c|c|c|}
\hline \multicolumn{2}{|c|}{ SIMPCOMP } & N & Mean & $\begin{array}{c}\text { Std. } \\
\text { Deviation }\end{array}$ & $\begin{array}{c}\text { Std. Error } \\
\text { Mean }\end{array}$ \\
\hline \hline TOTTTIME & $\mathbf{1 . 0 0}$ & 17 & 5.3176 & 1.7367 & .4212 \\
& $\mathbf{2 . 0 0}$ & 9 & 7.4444 & 2.2973 & .7658 \\
\hline
\end{tabular}

Table F - 11

Comparative statistics for Preliminary Study

(comparing males and females, total time as dependent measure)

\begin{tabular}{||cc|c|c|c|c|}
\hline \multicolumn{2}{|c|}{ GENDER } & $\mathbf{N}$ & Mean & $\begin{array}{c}\text { Std. } \\
\text { Deviation }\end{array}$ & $\begin{array}{c}\text { Std. Error } \\
\text { Mean }\end{array}$ \\
\hline \hline TOTTTIME & $\mathbf{1 . 0 0}$ & 12 & 4.6167 & 1.1366 & .3281 \\
& $\mathbf{2 . 0 0}$ & 14 & 7.2857 & 2.0913 & .5589 \\
\hline
\end{tabular}


Table F - 12

Comparative statistics for Preliminary Study (comparing simple and complex sessions, task difficulty as dependent measure)

\begin{tabular}{||cc|c|c|c|c||}
\hline \multicolumn{2}{|c|}{ SIMPCOMP } & $\mathbf{N}$ & Mean & $\begin{array}{c}\text { Std. } \\
\text { Deviation }\end{array}$ & $\begin{array}{c}\text { Std. Error } \\
\text { Mean }\end{array}$ \\
\hline TASKDIFF & $\mathbf{1 . 0 0}$ & 17 & 4.1176 & 1.7987 & .4362 \\
& $\mathbf{2 . 0 0}$ & 16 & 5.5625 & 1.7500 & .4375 \\
\hline
\end{tabular}


SECTION 2: DATA FOR FINAL STUDY

Table F - 13

Gender of Participants of Study

\begin{tabular}{|c|c|c|c|c|}
\hline & Frequency & Percent & $\begin{array}{c}\text { Valid } \\
\text { Percent }\end{array}$ & $\begin{array}{c}\text { Cumulative } \\
\text { Percent }\end{array}$ \\
\hline Valid 1.00 & 42 & 57.5 & 58.3 & 58.3 \\
\hline 2.00 & 30 & 41.1 & 41.7 & 100.0 \\
\hline Total & 72 & 98.6 & 100.0 & \\
\hline Missing System & 1 & 1.4 & & \\
\hline Total & 73 & 100.0 & & \\
\hline
\end{tabular}

Table F - 14

Table for Age of Participants of Study

\begin{tabular}{|l|c||l|c||}
\hline Age Categories & Number (Total N = 48) & Age Categories & Number (Total N = 25) \\
\hline \hline $18-34$ & 25 & $18-25$ & 11 \\
\hline $35-49$ & 16 & $26-33$ & 5 \\
\hline $50-64$ & 6 & $34-41$ & 6 \\
\hline 65 and older & 1 & $42-49$ & 1 \\
\hline & & $50-57$ & 1 \\
\hline & \multicolumn{2}{|l|}{58 and older } & 1 \\
\hline
\end{tabular}

Table F - 15

Ethnicity of Participants of Study

\begin{tabular}{||c|c|c|c|c||}
\hline & Frequency & Percent & $\begin{array}{c}\text { Valid } \\
\text { Percent }\end{array}$ & $\begin{array}{c}\text { Cumulative } \\
\text { Percent }\end{array}$ \\
\hline \hline Valid $\mathbf{1 . 0 0}$ & 35 & 47.9 & 63.6 & 63.6 \\
\hline $\mathbf{2 . 0 0}$ & 10 & 13.7 & 18.2 & 81.8 \\
\hline $\mathbf{3 . 0 0}$ & 7 & 9.6 & 12.7 & 94.5 \\
\hline $\mathbf{4 . 0 0}$ & 2 & 2.7 & 3.6 & 98.2 \\
\hline $\mathbf{5 . 0 0}$ & 1 & 1.4 & 1.8 & 100.0 \\
\hline Total & 55 & 75.3 & 100.0 & \\
\hline Missing System & 18 & 24.7 & & \\
\hline Total & 73 & 100.0 & & \\
\hline
\end{tabular}


Table F - 16

Household Income of Participants of Study

\begin{tabular}{|c|c|c|c|c||}
\hline & Frequency & Percent & $\begin{array}{c}\text { Valid } \\
\text { Percent }\end{array}$ & $\begin{array}{c}\text { Cumulative } \\
\text { Percent }\end{array}$ \\
\hline \hline Valid $\mathbf{1 . 0 0}$ & 13 & 17.8 & 17.8 & 17.8 \\
\hline $\mathbf{2 . 0 0}$ & 24 & 32.9 & 32.9 & 50.7 \\
\hline $\mathbf{3 . 0 0}$ & 18 & 24.7 & 24.7 & 75.3 \\
\hline $\mathbf{4 . 0 0}$ & 9 & 12.3 & 12.3 & 87.7 \\
\hline $\mathbf{5 . 0 0}$ & 9 & 12.3 & 12.3 & 100.0 \\
\hline Total & 73 & 100.0 & 100.0 & \\
\hline
\end{tabular}

Table F - 17

Education Level of Participants of Study

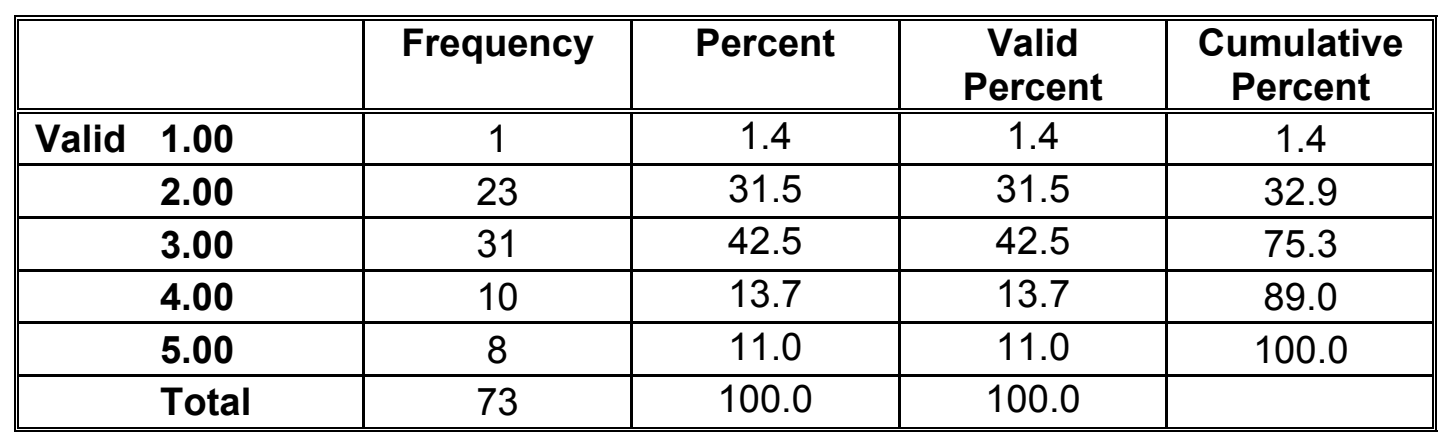

Table F - 18

Personal Vehicles of Participants of Study

\begin{tabular}{|c|c|c|c|c|}
\hline & Frequency & Percent & $\begin{array}{c}\text { Valid } \\
\text { Percent }\end{array}$ & $\begin{array}{c}\text { Cumulative } \\
\text { Percent }\end{array}$ \\
\hline Valid $\mathbf{1 . 0 0}$ & 3 & 4.1 & 4.1 & 4.1 \\
\hline $\mathbf{2 . 0 0}$ & 22 & 30.1 & 30.1 & 34.2 \\
\hline $\mathbf{3 . 0 0}$ & 29 & 39.7 & 39.7 & 74.0 \\
\hline $\mathbf{4 . 0 0}$ & 19 & 26.0 & 26.0 & 100.0 \\
\hline Total & 73 & 100.0 & 100.0 & \\
\hline
\end{tabular}

Table F - 19

Public Transportation usage of Participants of Study

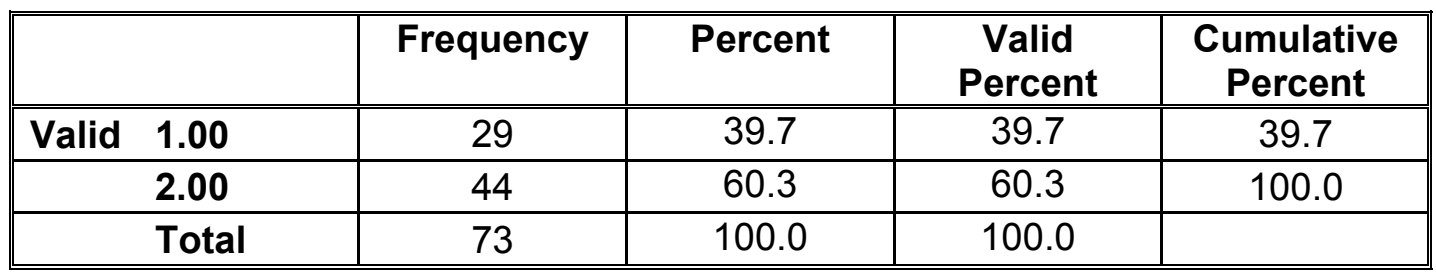


Primary Dependent measures:

Compos1a : 3 points for each of the 7 (simple) and 10 (complex) component parts of the route, with simple not having transfer items, and complex having the 3 transfer items. This is then adjusted by .7 for complex scores to create max of 21 for both simple and complex.

Compos2a: 5 points for first 2 items, then 3 points for each of the other 5 (simple) and 8 (complex) component parts of the route, with simple not having transfer items, and complex having the 3 transfer items. This is then adjusted by .735 for complex scores to create max of 25 for both simple and complex TotTime (total time): this was only available for those that completed task within maximum allowable time.

Table F - 20

Intercorrelations between primary dependent measures, as well as ratings of task difficulty.

\begin{tabular}{|c|r|r|r|r||}
\hline & TOTTIME & COMPOS1A & COMPOS2A & TASKDIFF \\
\hline \hline TOTTIME Peason Correlation & 1.000 & -.047 & -.055 & .203 \\
Sig. (2-tailed) &. & .668 & .617 & .060 \\
$\mathbf{N}$ & 86 & 86 & 86 & 86 \\
\hline COMPOS1A Peason Correlation & -.047 & 1.000 & $.998^{* *}$ & $-.430^{* *}$ \\
Sig. (2-tailed) & .668 &. & .000 & .000 \\
$\mathbf{N}$ & 86 & 145 & 145 & 145 \\
\hline COMPOS2A Peason Correlation & -.055 & $.998^{* *}$ & 1.000 & $-.430^{* *}$ \\
Sig. (2-tailed) & .617 & .000 &. & .000 \\
$\mathbf{N}$ & 86 & 145 & 145 & 145 \\
\hline Peason Correlation & .203 & $-.430^{* *}$ & $-.430^{* *}$ & 1.000 \\
Sig. (2-tailed) & .060 & .000 & .000 &. \\
$\mathbf{N}$ & 86 & 145 & 145 & 145 \\
\hline
\end{tabular}

${ }^{* *}$ Correlation is significant at the 0.01 level (2-tailed)

Table F - 21

Descriptive Statistics for Primary Dependent Measures, Simple Sessions

\begin{tabular}{|l|r|r|r|r|r||}
\hline \hline & N & Minimum & Maximum & \multicolumn{1}{|c|}{ Mean } & \multicolumn{1}{c|}{$\begin{array}{c}\text { Std. } \\
\text { Deviation }\end{array}$} \\
\hline \hline TOTTIME & 48 & 2.00 & 8.10 & 5.2044 & 1.8566 \\
COMPOS1A & 73 & .00 & 21.00 & 9.2466 & 8.4225 \\
COMPOS2A & 73 & .00 & 25.00 & 10.6986 & 10.1990 \\
Valid N (listwise) & 48 & & & & \\
\hline \hline
\end{tabular}


Table F - 22

Descriptive Statistics for Primary Dependent Measures, Complex Sessions

\begin{tabular}{|l|r|r|r|r|r|}
\hline & \multicolumn{1}{|c|}{ N } & Minimum & Maximum & Mean & \multicolumn{1}{c|}{$\begin{array}{c}\text { Std. } \\
\text { Deviation }\end{array}$} \\
\hline \hline TOTTIME & 38 & 1.00 & 10.24 & 6.7363 & 2.5533 \\
COMPOS1A & 72 & .00 & 21.00 & 7.0292 & 6.6703 \\
COMPOS2A & 72 & .00 & 24.99 & 7.9523 & 7.9692 \\
Valid N (listwise) & 38 & & & & \\
\hline
\end{tabular}

Table F -23

Means of Primary Dependent Measures by Materials used, simple sessions

\begin{tabular}{|ll|r|r|r|}
\hline MATERIAL & TOTTIME & COMPOS1A & COMPOS2A \\
\hline BCT-19-S & Mean & 4.8250 & 17.2500 & 20.2500 \\
& $\mathbf{N}$ & 4 & 4 & 4 \\
& Std. Deviation & 2.5145 & 7.5000 & 9.5000 \\
\hline BCT-2-S & Mean & 3.2800 & 16.000 & 19.3333 \\
& $\mathbf{N}$ & 3 & 3 & 3 \\
& Std. Deviation & 1.2701 & 1.2701 & 5.5076 \\
\hline BTT-29-S & Mean & 5.0000 & 21.0000 & 25.0000 \\
& $\mathbf{N}$ & 1 & 1 & 1 \\
& Std. Deviation &. &. &. \\
\hline ECT-7-S & Mean & 4.6667 & 11.2500 & 13.2500 \\
& $\mathbf{N}$ & 3 & 4 & 4 \\
& Std. Deviation & 1.1547 & 8.6168 & 10.2429 \\
\hline HRT-2-S & Mean & 4.0000 & 5.0000 & 5.0000 \\
& $\mathbf{N}$ & 1 & 3 & 3 \\
& Std. Deviation &. & 1.7321 & 1.7321 \\
\hline JTA-1-S & Mean & 2.4900 & 7.0000 & 8.3333 \\
& $\mathbf{N}$ & 1 & 3 & 3 \\
& Std. Deviation &. & 12.1244 & 14.4338 \\
\hline LMT-1-S1 & Mean & 4.0950 & 9.0000 & 10.3333 \\
& $\mathbf{N}$ & 2 & 3 & 3 \\
& Std. Deviation & .1344 & 10.8167 & 13.0512 \\
\hline LNX-14-S & Mean & 6.0000 & 4.5000 & 5.5000 \\
& $\mathbf{N}$ & 1 & 4 & 4 \\
& Std. Deviation &. & 9.0000 & 11.0000 \\
\hline LNX-4-S & Mean & 6.0167 & 7.0000 & 8.3333 \\
& $\mathbf{N}$ & 3 & 3 & 3 \\
& Std. Deviation & $2.887 E-02$ & 9.6437 & 11.9304 \\
\hline LT-5-S & Mean & 4.8700 & 8.2500 & 9.2500 \\
& $\mathbf{N}$ & 4 & 4 & 4 \\
& Std. Deviation & 1.5731 & 8.9582 & 10.8743 \\
\hline
\end{tabular}


Table F - 23

Means of Primary Dependent Measures by Materials used, simple sessions (cont.)

\begin{tabular}{|c|c|c|c|c|}
\hline \multicolumn{2}{|r|}{ MATERIAL } & \multirow{2}{*}{$\begin{array}{r}\text { TOTTIME } \\
8.0350\end{array}$} & COMPOS1A & \multirow{2}{*}{$\begin{array}{r}\text { COMPOS2A } \\
8.0000\end{array}$} \\
\hline MCT-13-S & Mean & & 8.0000 & \\
\hline & $\mathbf{N}$ & 2 & 3 & 3 \\
\hline & Std. Deviation & 4.950E-02 & 1.7321 & 1.7321 \\
\hline \multirow[t]{3}{*}{ MDT-4-S } & Mean & 3.7100 & 7.0000 & 8.3333 \\
\hline & $\mathbf{N}$ & 2 & 3 & 3 \\
\hline & Std. Deviation & 2.2627 & 6.9282 & 9.2376 \\
\hline \multirow[t]{3}{*}{ PST-2-S } & Mean & 5.0000 & 4.5000 & 5.5000 \\
\hline & $\mathbf{N}$ & 2 & 4 & 4 \\
\hline & Std. Deviation & 1.4142 & 7.1414 & 9.1104 \\
\hline \multirow[t]{3}{*}{ PT-2-S } & Mean & 5.2000 & 10.5000 & 11.5000 \\
\hline & $\mathbf{N}$ & 2 & 2 & 2 \\
\hline & Std. Deviation & .2828 & 2.1213 & 3.5355 \\
\hline \multirow[t]{3}{*}{ RTS-13-S } & Mean & 5.0000 & 7.5000 & 8.5000 \\
\hline & $\mathbf{N}$ & 2 & 4 & 4 \\
\hline & Std. Deviation & .0000 & 9.9499 & 11.7898 \\
\hline \multirow[t]{3}{*}{ SCAT-28S } & Mean & 6.0000 & 14.0000 & 16.0000 \\
\hline & $\mathbf{N}$ & 2 & 3 & 3 \\
\hline & Std. Deviation & 2.8284 & 7.5498 & 9.5394 \\
\hline \multirow[t]{3}{*}{ SCT-17-S } & Mean & 4.4175 & 17.2500 & 20.2500 \\
\hline & $\mathbf{N}$ & 4 & 4 & 4 \\
\hline & Std. Deviation & 2.8325 & 7.5000 & 9.5000 \\
\hline \multirow[t]{3}{*}{ SCT-7-NS } & Mean & 5.0000 & 9.7500 & 10.7500 \\
\hline & $\mathbf{N}$ & 2 & 4 & 4 \\
\hline & Std. Deviation & 1.4142 & 7.8899 & 9.8107 \\
\hline \multirow[t]{3}{*}{ SUN-12-S } & Mean & 8.0333 & 15.7500 & 18.7500 \\
\hline & $\mathbf{N}$ & 3 & 4 & 4 \\
\hline & Std. Deviation & 5.774E-02 & 10.5000 & 12.5000 \\
\hline \multirow[t]{3}{*}{ TLT-12-S } & Mean & 7.5000 & 1.0000 & 1.0000 \\
\hline & $\mathbf{N}$ & 2 & 3 & 3 \\
\hline & Std. Deviation & .7071 & 1.7321 & 1.7321 \\
\hline
\end{tabular}


Table F - 23

Means of Primary Dependent Measures by Materials used, simple sessions (cont.)

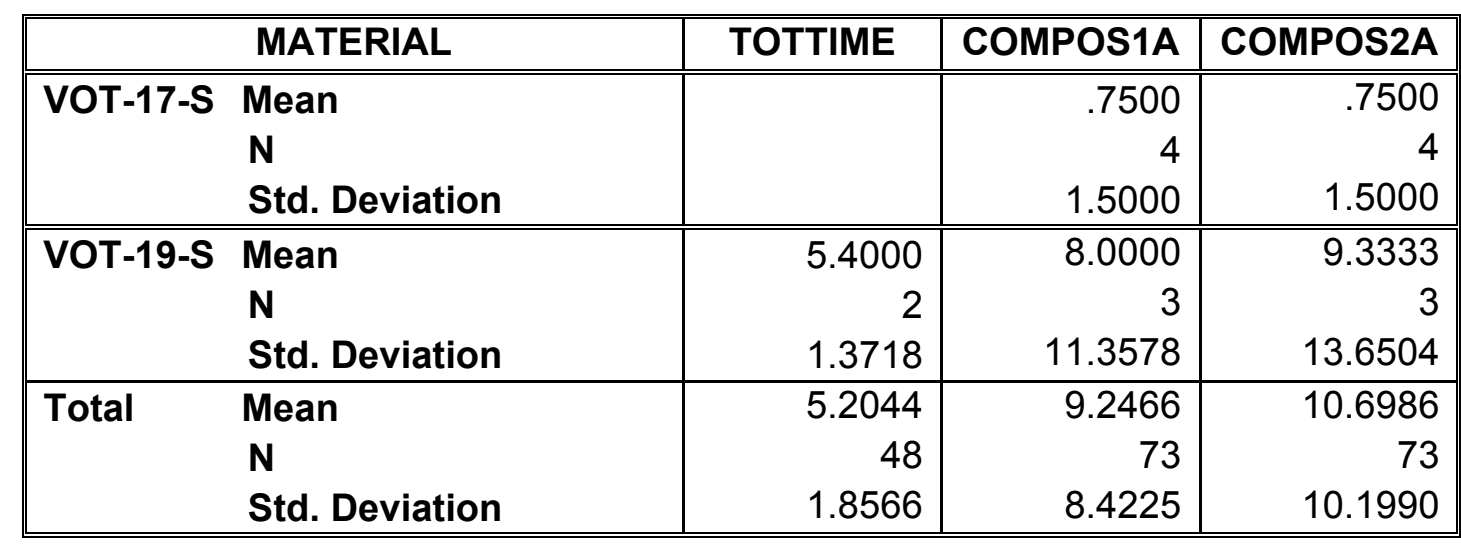


Table F - 24

Means of Primary Dependent Measures by Materials used, complex sessions

\begin{tabular}{|c|c|c|c|c|}
\hline \multicolumn{2}{|r|}{ MATERIAL } & "TOTTIME & COMPOS1A & COMPOS2A \\
\hline \multirow[t]{3}{*}{ BCT-2-C } & Mean & 3.1400 & 4.7250 & 4.9613 \\
\hline & $\mathbf{N}$ & & 4 & 4 \\
\hline & Std. Deviation & 3.0264 & 1.0500 & 1.1025 \\
\hline \multirow[t]{3}{*}{ BTT-29-C } & Mean & 6.1500 & 4.9000 & 5.1450 \\
\hline & $\mathbf{N}$ & 1 & 3 & 3 \\
\hline & Std. Deviation & . & 5.2849 & 5.5491 \\
\hline \multirow[t]{3}{*}{ ECT-7-C } & Mean & 10.0000 & 11.2000 & 13.2300 \\
\hline & $\mathbf{N}$ & 1 & 3 & 3 \\
\hline & Std. Deviation & . & 10.5698 & 12.5597 \\
\hline \multirow[t]{3}{*}{ HRT-2-C } & Mean & 9.0000 & 7.3500 & 7.7175 \\
\hline & $\mathbf{N}$ & 1 & 2 & 2 \\
\hline & Std. Deviation & . & 4.4548 & 4.6775 \\
\hline \multirow[t]{3}{*}{ JTA-1-C } & Mean & & 1.0500 & 1.1025 \\
\hline & $\mathbf{N}$ & & 2 & 2 \\
\hline & Std. Deviation & & 1.4849 & 1.5592 \\
\hline \multirow[t]{3}{*}{ LNX-14-C } & Mean & 5.7550 & .0000 & .0000 \\
\hline & $\mathbf{N}$ & 2 & 4 & 4 \\
\hline & Std. Deviation & 5.3104 & .0000 & .0000 \\
\hline \multirow[t]{3}{*}{ LNX-4-C } & Mean & 7.1533 & 6.3000 & 6.9825 \\
\hline & $\mathbf{N}$ & 3 & 4 & 4 \\
\hline & Std. Deviation & 2.4904 & 4.5365 & 5.4509 \\
\hline \multirow[t]{3}{*}{ LT-5-C } & Mean & 6.6667 & 18.2000 & 21.5600 \\
\hline & $\mathbf{N}$ & 3 & 3 & 3 \\
\hline & Std. Deviation & .5774 & 4.8497 & 5.9409 \\
\hline
\end{tabular}


Table F - 24

Means of Primary Dependent Measures by Materials used, complex sessions (cont.)

\begin{tabular}{|ll|r|r|r|}
\hline MATERIAL & TOTTIME & COMPOS1A & COMPOS2A \\
\hline MCT-13-C Mean & 5.4567 & 12.6000 & 15.0675 \\
& $\mathbf{N}$ & 3 & 4 & 4 \\
& Std. Deviation & 1.5019 & 10.2879 & 12.2034 \\
\hline MDT-4-C & Mean & 7.2500 & 5.7750 & 6.0638 \\
& $\mathbf{N}$ & 3 & 4 & 4 \\
& Std. Deviation & 2.4192 & 4.6564 & 4.8893 \\
\hline PST-2-C & Mean & 7.0000 & 10.5000 & 12.4950 \\
& $\mathbf{N}$ & 3 & 4 & 4 \\
& Std. Deviation & 2.6458 & 7.2746 & 9.3358 \\
\hline PT-2-C & Mean & 6.7050 & 10.5000 & 11.5000 \\
& $\mathbf{N}$ & 4 & 5 & 5 \\
& Std. Deviation & 2.9329 & 7.8575 & 9.5324 \\
\hline RTS-13-C Mean & 4.4400 & 2.8000 & 2.9400 \\
& $\mathbf{N}$ & 1 & 3 & 3 \\
& Std. Deviation &. & 2.4249 & 2.5461 \\
\hline SCAT-28C Mean & & 3.6750 & 3.8588 \\
& $\mathbf{N}$ & 4 & 4 \\
Std. Deviation & & 3.5864 & 3.7658 \\
\hline SCT-17-C Mean & $\mathbf{N}$ & 4.0000 & 3.6750 & 3.8588 \\
& $\mathbf{N}$ & 1 & 4 & 4 \\
Std. Deviation &. & 3.5864 & 3.7658 \\
\hline SCT-7-SC & Mean & 3.6667 & 4.9000 & 5.1450 \\
N & 3 & 3 & 3 \\
Std. Deviation & 1.5275 & 5.2849 & 5.5491 \\
\hline SUN-12-C Mean & 7.1633 & 13.1250 & 15.6188 \\
N & 3 & 4 & 4 \\
Std. Deviation & 2.4698 & 6.2708 & 7.8791 \\
\hline
\end{tabular}


Table F - 24

Means of Primary Dependent Measures by Materials used, complex sessions (cont.)

\begin{tabular}{|c|c|c|c|c|}
\hline \multicolumn{2}{|r|}{ MATERIAL } & TOTTIME & COMPOS1A & COMPOS2A \\
\hline \multirow[t]{3}{*}{ TLT-12-C } & Mean & 8.3200 & 7.3500 & 7.7175 \\
\hline & $\mathbf{N}$ & 1 & 4 & 4 \\
\hline & Std. Deviation & & 6.0622 & 6.3653 \\
\hline \multirow[t]{3}{*}{ VOT-17-C } & Mean & 7.1300 & 5.8800 & 6.7620 \\
\hline & $\mathbf{N}$ & 3 & 5 & 5 \\
\hline & Std. Deviation & 4.4760 & 7.7728 & 9.4040 \\
\hline \multirow[t]{3}{*}{ VOT-19-C } & Mean & & 3.5000 & 3.6750 \\
\hline & $\mathbf{N}$ & & 3 & 3 \\
\hline & Std. Deviation & & 3.2078 & 3.3682 \\
\hline \multirow[t]{3}{*}{ Total } & Mean & 6.7363 & 7.0292 & 7.9523 \\
\hline & $\mathbf{N}$ & 38 & 72 & 72 \\
\hline & Std. Deviation & 2.5533 & 6.6703 & 7.9692 \\
\hline
\end{tabular}


Table F - 25

Frequency of Categories of Alignment in Simple Sessions

\begin{tabular}{|c|c|c|c|c|c|}
\hline & & Frequency & Percent & $\begin{array}{c}\text { Valid } \\
\text { Percent }\end{array}$ & $\begin{array}{c}\text { Cumulative } \\
\text { Percent }\end{array}$ \\
\hline Valic & 1.00 & 54 & 74.0 & 74.0 & 74.0 \\
\hline & 2.00 & 19 & 26.0 & 26.0 & 100.0 \\
\hline & Total & 73 & 100.0 & 100.0 & \\
\hline
\end{tabular}

Table F - 26

Frequency of Categories of Routes in Simple Sessions

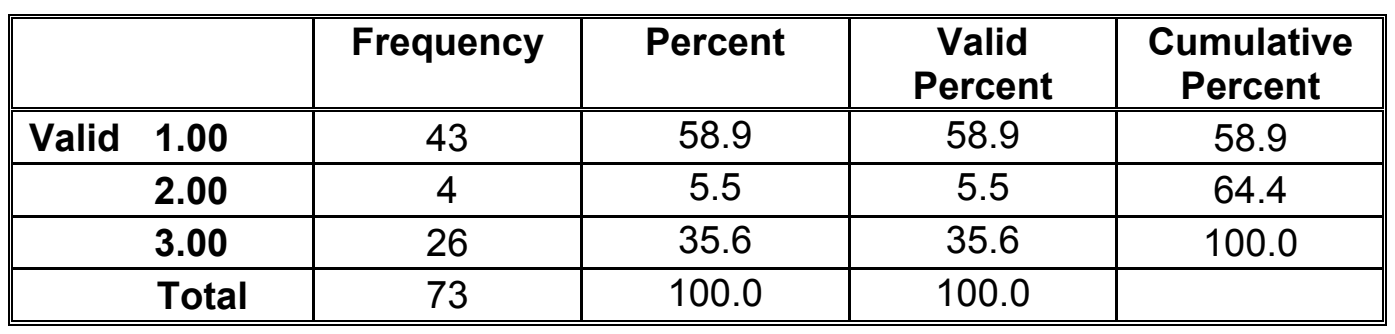

Table F - 27

Frequency of Categories of transfers in Simple Sessions

\begin{tabular}{||c|c|c|c|c||}
\hline & Frequency & Percent & $\begin{array}{c}\text { Valid } \\
\text { Percent }\end{array}$ & $\begin{array}{c}\text { Cumulative } \\
\text { Percent }\end{array}$ \\
\hline \hline Valid $\mathbf{1 . 0 0}$ & 5 & 6.8 & 6.8 & 6.8 \\
\hline $\mathbf{2 . 0 0}$ & 31 & 42.5 & 42.5 & 49.3 \\
\hline $\mathbf{3 . 0 0}$ & 10 & 13.7 & 13.7 & 63.0 \\
\hline $\mathbf{4 . 0 0}$ & 23 & 31.5 & 31.5 & 94.5 \\
\hline $\mathbf{5 . 0 0}$ & 4 & 5.5 & 5.5 & 100.0 \\
\hline Total & 73 & 100.0 & 100.0 & \\
\hline
\end{tabular}

Table F - 28

Frequency of Categories of Alignment in Complex Sessions

\begin{tabular}{|c|c|c|c|c|}
\hline & Frequency & Percent & $\begin{array}{c}\text { Valid } \\
\text { Percent }\end{array}$ & $\begin{array}{c}\text { Cumulative } \\
\text { Percent }\end{array}$ \\
\hline Valid 1.00 & 254 & 75.0 & 75.0 & 75.0 \\
\hline 2.00 & 18 & 25.0 & 25.0 & 100.0 \\
\hline Total & 72 & 100.0 & 100.0 & \\
\hline
\end{tabular}


Table F - 29

Frequency of Categories of Routes in Complex Sessions

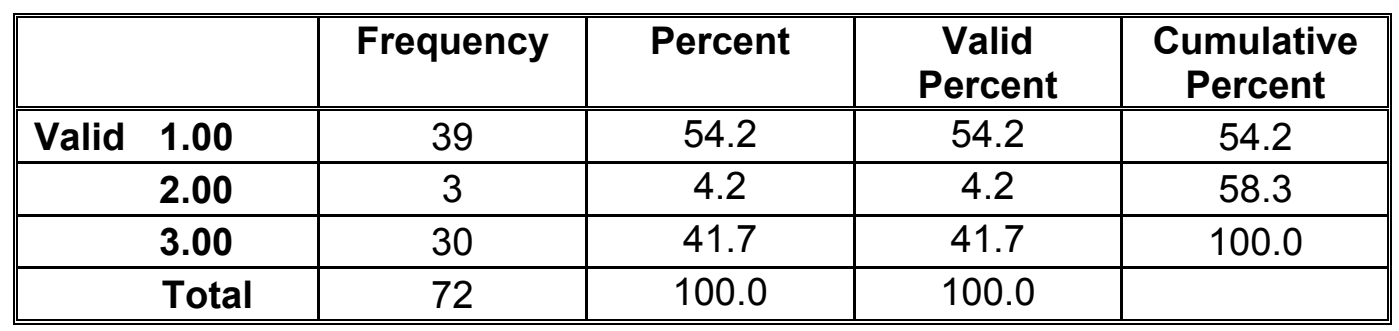

Table F - 30

Frequency of Categories of Transfers in Complex Sessions

\begin{tabular}{||c|c|c|c|c||}
\hline & Frequency & Percent & $\begin{array}{c}\text { Valid } \\
\text { Percent }\end{array}$ & $\begin{array}{c}\text { Cumulative } \\
\text { Percent }\end{array}$ \\
\hline \hline Valid $\mathbf{1 . 0 0}$ & 2 & 2.8 & 2.8 & 2.8 \\
\hline $\mathbf{2 . 0 0}$ & 34 & 47.2 & 47.2 & 50.0 \\
\hline $\mathbf{3 . 0 0}$ & 11 & 15.3 & 15.3 & 65.3 \\
\hline $\mathbf{4 . 0 0}$ & 22 & 30.6 & 30.6 & 95.8 \\
\hline $\mathbf{5 . 0 0}$ & 3 & 4.2 & 4.2 & 100.0 \\
\hline Total & 72 & 100.0 & 100.0 & \\
\hline
\end{tabular}

Demographics for participants who quit both sessions

Table F - 31

Gender of participants who quit both sessions

\begin{tabular}{|c|c|c|c|c||}
\hline & Frequency & Percent & $\begin{array}{c}\text { Valid } \\
\text { Percent }\end{array}$ & $\begin{array}{c}\text { Cumulative } \\
\text { Percent }\end{array}$ \\
\hline Valid $\mathbf{1 . 0 0}$ & 1 & 16.7 & 20.0 & 20.0 \\
\hline $\mathbf{2 . 0 0}$ & 4 & 66.7 & 80.0 & 100.0 \\
\hline Total & 5 & 83.3 & & \\
\hline Missing System & 1 & 16.7 & & \\
\hline Total & 6 & 100.0 & & \\
\hline
\end{tabular}


Table F - 32

Age of participants who quit both sessions

\begin{tabular}{||c|c|c|c|c||}
\hline & Frequency & Percent & $\begin{array}{c}\text { Valid } \\
\text { Percent }\end{array}$ & $\begin{array}{c}\text { Cumulative } \\
\text { Percent }\end{array}$ \\
\hline Valid $\mathbf{1 . 0 0}$ & 1 & 16.7 & 16.7 & 16.7 \\
\hline $\mathbf{2 . 0 0}$ & 2 & 33.3 & 33.3 & 50.0 \\
\hline $\mathbf{3 . 0 0}$ & 3 & 50.0 & 50.0 & 100.0 \\
\hline Total & 6 & 100.0 & 100.0 & \\
\hline
\end{tabular}

Table F - 33

Ethnicity of participants who quit both sessions

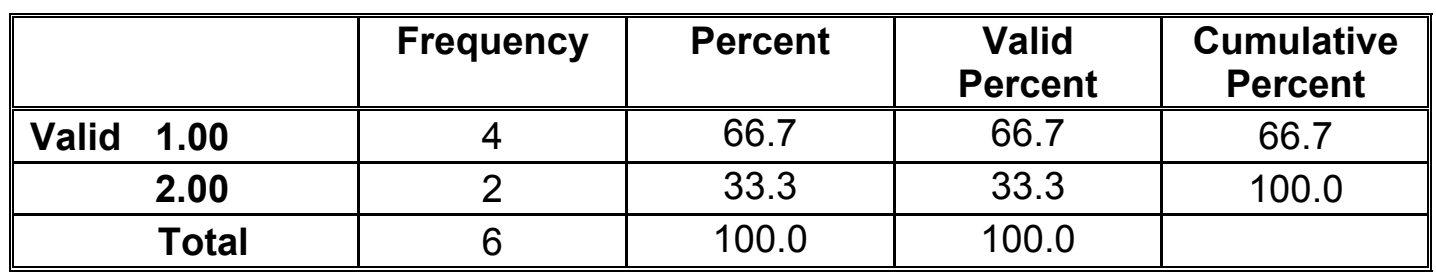

Table F - 34

Household Income of participants who quit both sessions

\begin{tabular}{||c|c|c|c|c||}
\hline & Frequency & Percent & $\begin{array}{c}\text { Valid } \\
\text { Percent }\end{array}$ & $\begin{array}{c}\text { Cumulative } \\
\text { Percent }\end{array}$ \\
\hline Valid $\mathbf{1 . 0 0}$ & 1 & 16.7 & 16.7 & 16.7 \\
\hline $\mathbf{2 . 0 0}$ & 2 & 33.3 & 33.3 & 50.0 \\
\hline $\mathbf{3 . 0 0}$ & 1 & 16.7 & 16.7 & 66.7 \\
\hline $\mathbf{4 . 0 0}$ & 2 & 33.3 & 33.3 & 100.0 \\
\hline Total & 6 & 100.0 & 100.0 & \\
\hline
\end{tabular}

Table F - 35

Education Level of participants who Quit both sessions

\begin{tabular}{|c|c|c|c|c|c|}
\hline & & Frequency & Percent & $\begin{array}{c}\text { Valid } \\
\text { Percent }\end{array}$ & $\begin{array}{c}\text { Cumulative } \\
\text { Percent }\end{array}$ \\
\hline Valic & 1.00 & 1 & 16.7 & 16.7 & 16.7 \\
\hline & 2.00 & 1 & 16.7 & 16.7 & 33.3 \\
\hline & 3.00 & 3 & 50.0 & 50.0 & 83.3 \\
\hline & 5.00 & 1 & 16.7 & 16.7 & 100.0 \\
\hline & Total & 6 & 100.0 & 100.0 & \\
\hline
\end{tabular}


Table F - 36

Personal Vehicles of participants who quit both sessions

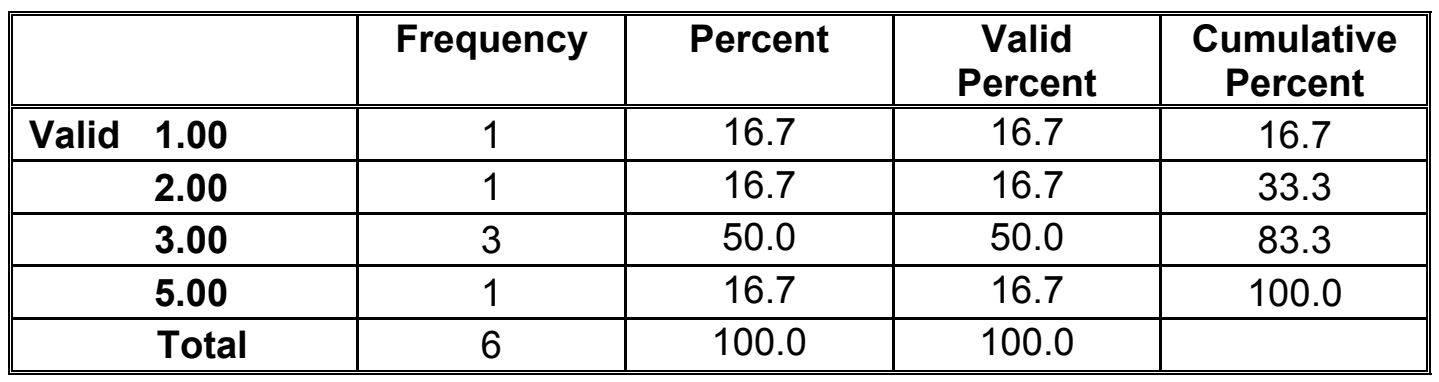

Table F - 37

Public Transportation usage of participants who quit both sessions

\begin{tabular}{|c|c|c|c|c|}
\hline & Frequency & Percent & $\begin{array}{c}\text { Valid } \\
\text { Percent }\end{array}$ & $\begin{array}{c}\text { Cumulative } \\
\text { Percent }\end{array}$ \\
\hline \hline Valid $\mathbf{1 . 0 0}$ & 1 & 16.7 & 16.7 & 16.7 \\
\hline $\mathbf{2 . 0 0}$ & 5 & 83.3 & 83.3 & 100.0 \\
\hline Total & 6 & 100.0 & 100.0 & \\
\hline
\end{tabular}




\section{Appendix G}

\section{Major Activity Centers Detailed Data}




\begin{tabular}{|c|c|c|c|c|c|c|c|c|c|c|c|c|c|c|c|c|}
\hline 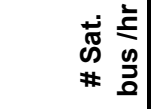 & & $\stackrel{\circ}{\circ}$ & $\stackrel{\circ}{r}$ & $\stackrel{\circ}{\mathrm{N}}$ & $\stackrel{\circ}{\mathrm{N}}$ & $\stackrel{\circ}{-}$ & $\stackrel{\circ}{r}$ & $\stackrel{\circ}{-}$ & $\stackrel{\circ}{-}$ & $\stackrel{\circ}{r}$ & & $\stackrel{\nabla}{\leftarrow}$ & $\stackrel{\digamma}{\digamma}$ & $\stackrel{\circ}{-}$ & 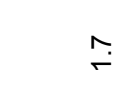 & $\stackrel{\circ}{\circ}$ \\
\hline 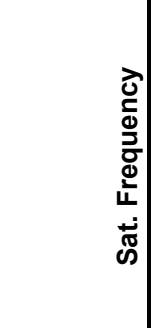 & & 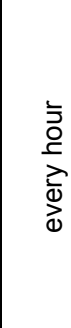 & 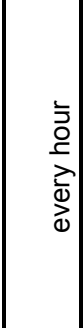 & 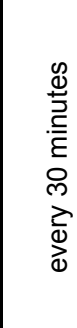 & 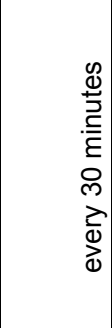 & 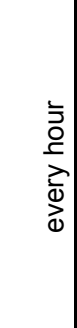 & 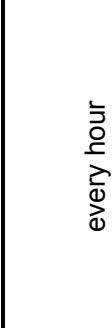 & 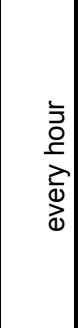 & 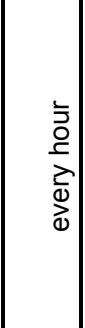 & $\begin{array}{l}\vdots \\
0 \\
\frac{1}{2} \\
⿱ 亠 乂 \\
0 \\
0\end{array}$ & & 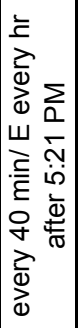 & 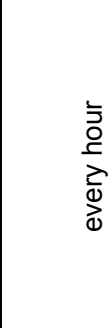 & $\begin{array}{l}\bar{y} \\
0 \\
\frac{1}{2} \\
\frac{1}{0} \\
0 \\
0\end{array}$ & 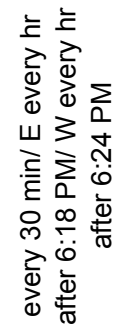 & 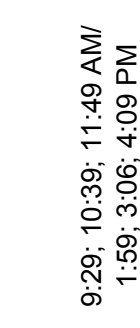 \\
\hline 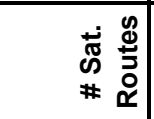 & $r$ & & - & $r$ & $r$ & $\mathbf{N}$ & & - & - & -1 & & $\nabla$ & & & & \\
\hline 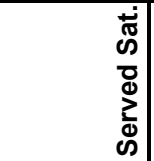 & & $\begin{array}{l}n \\
\infty \\
\sum_{0} \\
\vdots \\
\infty \\
\infty\end{array}$ & \begin{tabular}{|l|}
$\infty$ \\
$\infty$ \\
$\sum_{\alpha} \sum$ \\
$\bar{\infty}$ \\
$\infty$
\end{tabular} & \begin{tabular}{|l|} 
\\
$\infty$ \\
$\sum_{0} \sum$ \\
$\bar{\infty}$
\end{tabular} & 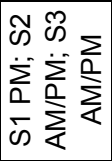 & \begin{tabular}{|l|}
$\infty$ \\
$\infty$ \\
$\sum_{0} \sum_{0}$ \\
$\bar{c}$ \\
$\bar{c}$
\end{tabular} & 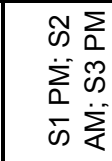 & \begin{tabular}{|l|}
$\infty$ \\
$\infty$ \\
$\sum_{0} \sum$ \\
$\infty$ \\
$\infty$
\end{tabular} & \begin{tabular}{|l|}
$\infty$ \\
$\infty$ \\
$\sum_{n} \sum$ \\
$\bar{\infty}$ \\
\end{tabular} & 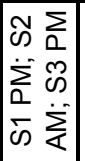 & & 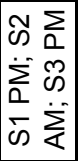 & 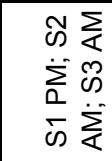 & 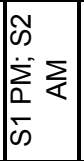 & 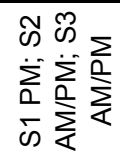 & $\begin{array}{l}\text { N } \\
\sum_{0} \sum_{\bar{\alpha}} \\
\bar{\infty}\end{array}$ \\
\hline 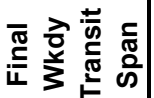 & $\stackrel{\infty}{\stackrel{\circ}{=}}$ & & $\begin{array}{l}\tilde{\omega} \\
\dot{q} \\
\dot{q}\end{array}$ & $\stackrel{\text { ధ̊ }}{=}$ & 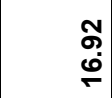 & 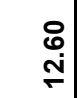 & & $\begin{array}{l}\stackrel{8}{\grave{~}} \\
\stackrel{+}{+}\end{array}$ & $\stackrel{\stackrel{N}{\mathbf{N}}}{\stackrel{\mathrm{N}}{ }}$ & $\begin{array}{l}\stackrel{\sim}{m} \\
\stackrel{m}{m}\end{array}$ & & $\begin{array}{l}\mathscr{\%} \\
\stackrel{0}{\sigma} \\
\stackrel{\sigma}{\sigma}\end{array}$ & & & & స్త \\
\hline 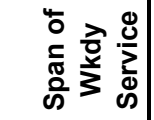 & $\stackrel{\infty}{\stackrel{\infty}{\Gamma}}$ & & $\begin{array}{l}\hat{\omega} \\
\dot{\sim}\end{array}$ & $\stackrel{\circ}{\stackrel{\circ}{\rightleftarrows}}$ & 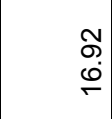 & 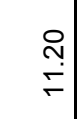 & $\begin{array}{l}\stackrel{\leftrightarrow}{\mathrm{U}} \\
\stackrel{\mathrm{N}}{ }\end{array}$ & $\begin{array}{l}\stackrel{8}{\circ} \\
\stackrel{\text { in }}{ }\end{array}$ & $\begin{array}{l}\stackrel{N}{\grave{N}} \\
\stackrel{N}{\sim}\end{array}$ & $\begin{array}{l}\stackrel{8}{\circ} \\
\stackrel{\mathrm{N}}{\sim}\end{array}$ & $\begin{array}{l}\stackrel{m}{ } \\
\stackrel{\sim}{\sim}\end{array}$ & $\begin{array}{l}R \\
b \\
L\end{array}$ & $\begin{array}{l}\stackrel{m}{\infty} \\
\stackrel{\infty}{\sigma}\end{array}$ & $\begin{array}{l}\underset{N}{\sim} \\
\underset{\leftarrow}{+}\end{array}$ & 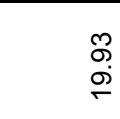 & $\stackrel{?}{\stackrel{9}{\circ}}$ \\
\hline 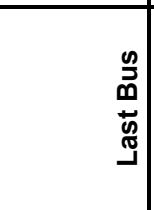 & $\begin{array}{l}\sum_{n} \\
\frac{L}{n} \\
\dot{0}\end{array}$ & & 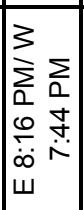 & $\begin{array}{l}\sum_{0} \\
\vdots \\
⿱ 亠 䒑 \\
0 \\
0\end{array}$ & 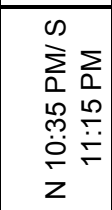 & 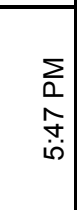 & 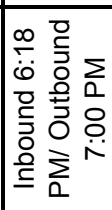 & $\begin{array}{l}\sum_{0} \\
0 \\
0 \\
0 \\
0\end{array}$ & $\begin{array}{c}\sum_{0} \\
\bar{q} \\
\dot{0}\end{array}$ & 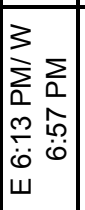 & 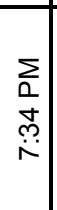 & 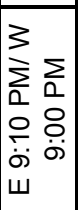 & 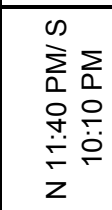 & 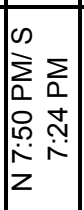 & 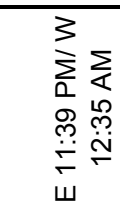 & $\begin{array}{l}\sum_{0} \\
\stackrel{i}{i}\end{array}$ \\
\hline 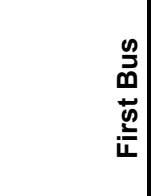 & 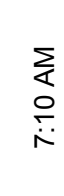 & & 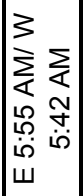 & 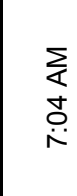 & 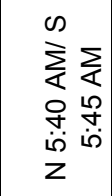 & 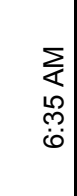 & 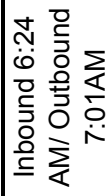 & 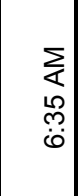 & 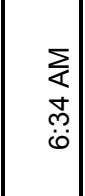 & 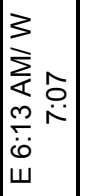 & 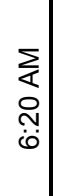 & 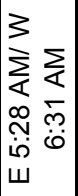 & 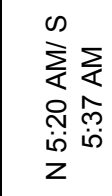 & 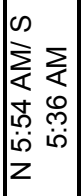 & 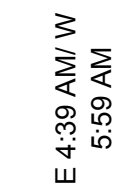 & 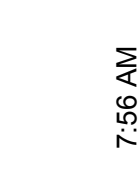 \\
\hline 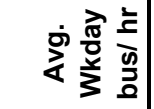 & $\stackrel{\circ}{r}$ & & $\stackrel{\stackrel{i}{i}}{ }$ & $\stackrel{\circ}{\mathbf{N}}$ & $\stackrel{\circ}{\circ}$ & $\stackrel{\circ}{-}$ & & $\stackrel{\leftrightarrow}{-}$ & $\stackrel{\circ}{-1}$ & $\stackrel{\circ}{\leftarrow}$ & & 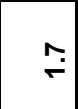 & & & & $\stackrel{m}{\sim}$ \\
\hline 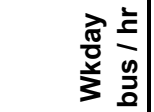 & $\stackrel{\circ}{r}$ & $\stackrel{\circ}{\circ}$ & $\stackrel{0}{\mathrm{~N}}$ & $\stackrel{\circ}{\mathrm{N}}$ & $\stackrel{\circ}{\circ}$ & $\stackrel{\circ}{-}$ & $\stackrel{\circ}{r}$ & $\stackrel{\circ}{-}$ & $\stackrel{\circ}{-}$ & $\stackrel{\circ}{r}$ & $\stackrel{\circ}{\circ}$ & $\stackrel{\nabla}{\leftarrow}$ & $\stackrel{\circ}{\longrightarrow}$ & $\stackrel{\circ}{-}$ & $\stackrel{m}{N}$ & $\stackrel{m}{\sim}$ \\
\hline 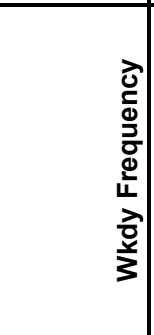 & 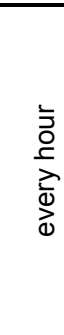 & & 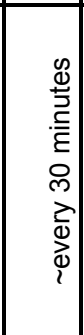 & 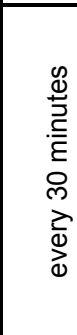 & 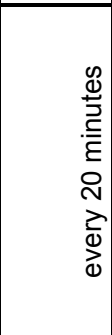 & 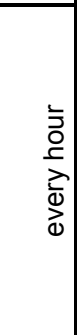 & $\begin{array}{l}\bar{y} \\
\frac{1}{2} \\
\frac{1}{0} \\
\frac{1}{0}\end{array}$ & 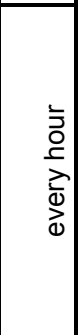 & 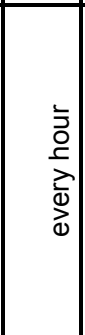 & 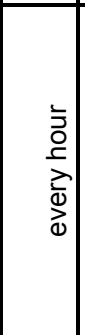 & 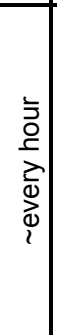 & 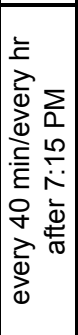 & 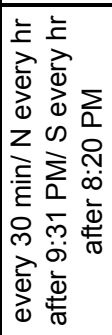 & 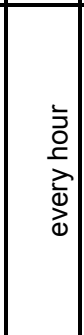 & 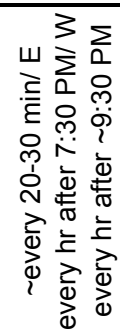 & 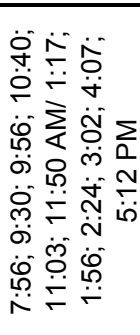 \\
\hline 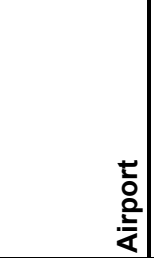 & 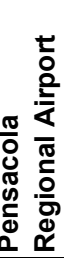 & & 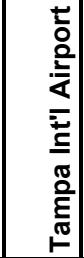 & 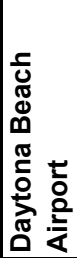 & 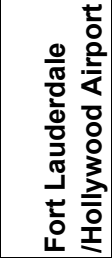 & 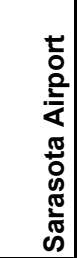 & & 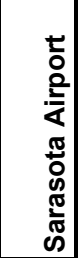 & 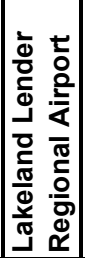 & 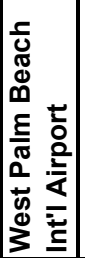 & & 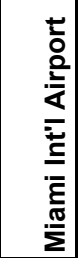 & & & & 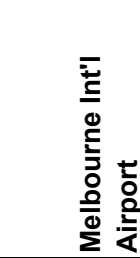 \\
\hline
\end{tabular}




\begin{tabular}{|c|c|c|c|c|c|c|c|c|c|c|c|c|c|c|c|}
\hline 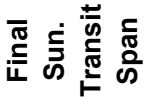 & $\underset{0}{\stackrel{0}{0}}$ & & $\begin{array}{l}\text { în } \\
\text { pr }\end{array}$ & & $\begin{array}{l}\text { மొ } \\
\text { के }\end{array}$ & & & & & 오 & $\stackrel{\text { Һ }}{\stackrel{2}{F}}$ & & & & $\stackrel{\text { i }}{\text { in }}$ \\
\hline 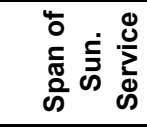 & & & & & & & & & & & $\stackrel{\infty}{\stackrel{\infty}{r}}$ & $\begin{array}{l}\hat{N} \\
\stackrel{\sigma}{0}\end{array}$ & 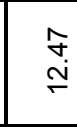 & 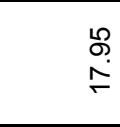 & \\
\hline 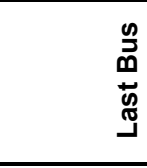 & & $\begin{array}{l}\sum_{0} \\
0 \\
0 \\
\text { i̊ } \\
\end{array}$ & 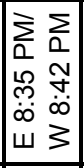 & & 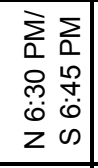 & & & & & \begin{tabular}{|ll|} 
& $\vdots$ \\
0 & 0 \\
0 & 0 \\
$m$ & 0 \\
\hdashline & 0 \\
$\dot{m}$ & $\vdots$ \\
$\omega$ & 3 \\
\end{tabular} & 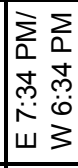 & 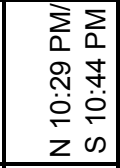 & 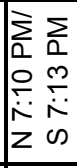 & 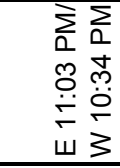 & 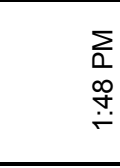 \\
\hline 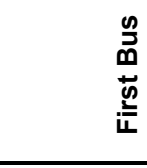 & & 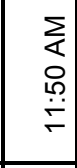 & 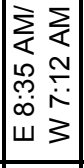 & & 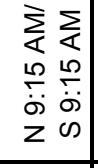 & & & & & 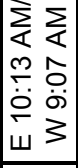 & 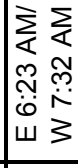 & 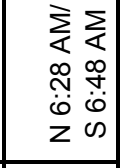 & 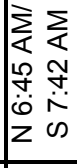 & 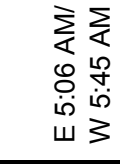 & 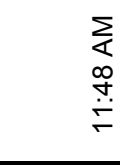 \\
\hline 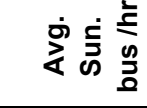 & గึ̊ & ధ̊̊ & $\begin{array}{l}\text { ho } \\
0\end{array}$ & & 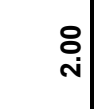 & & & & & 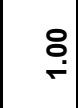 & $\stackrel{\text { }}{-}$ & & & & مִ \\
\hline 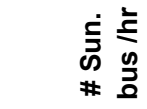 & $\stackrel{\circ}{\circ}$ & นึ̊ & $\begin{array}{l}\text { ధ̊ } \\
0 \\
0\end{array}$ & & $\begin{array}{l}\stackrel{\Delta}{ } \\
\text { in }\end{array}$ & & & & & & $\check{r}$ & $\check{\ulcorner}$ & $\stackrel{\circ}{-}$ & $\check{r}$ & مீ \\
\hline 心 & & 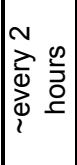 & 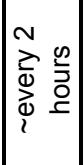 & & $\begin{array}{l}\text { N } \\
\sum_{0} \sum \\
\bar{\infty}\end{array}$ & & & & & 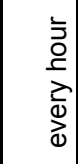 & 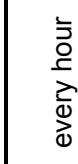 & $\begin{array}{l}\bar{y} \\
\frac{0}{2} \\
\frac{1}{0} \\
\stackrel{0}{0}\end{array}$ & 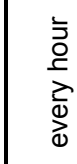 & $\begin{array}{l}\bar{\vdots} \\
\frac{1}{2} \\
\geq \overline{0} \\
\overrightarrow{0} \\
1\end{array}$ & 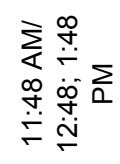 \\
\hline 焉 & & 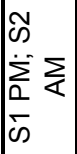 & $\left|\begin{array}{l}\infty \\
\infty \\
\dddot{\sum} \\
\bar{n} \\
\bar{\infty}\end{array}\right|$ & & $\begin{array}{l}\tilde{N} \\
\sum_{0} \sum \\
\bar{\infty}\end{array}$ & & & & & $\mid \begin{array}{l}\tilde{N} \\
\infty \\
\sum_{0} \sum \\
\bar{\infty}\end{array}$ & 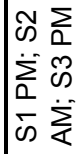 & 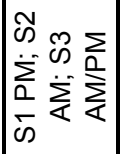 & $\mid \begin{array}{l}\infty \\
\infty \\
\sum_{0} \sum \\
\bar{c} \\
\bar{\infty}\end{array}$ & 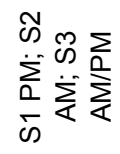 & $\begin{array}{l}\text { N } \\
\sum_{0}^{\infty} \sum_{\infty} \\
\bar{\infty}\end{array}$ \\
\hline 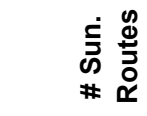 & - & & - & 0 & - & 0 & & 0 & 0 & $r$ & $\nabla$ & & & & $r$ \\
\hline 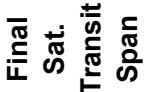 & 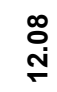 & & $\begin{array}{l}\underset{m}{m} \\
\stackrel{m}{\sigma}\end{array}$ & $\begin{array}{l}8 \\
\stackrel{0}{\circ}\end{array}$ & 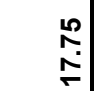 & 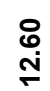 & & 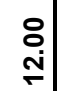 & $\begin{array}{c}N \\
\\
0\end{array}$ & $\begin{array}{l}\stackrel{8}{0} \\
\stackrel{ }{0}\end{array}$ & $\begin{array}{l}\stackrel{\llcorner}{\infty} \\
\infty \\
\infty\end{array}$ & & & & ஜी \\
\hline 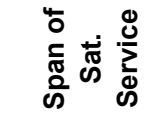 & : & $\begin{array}{l}\text { o } \\
\stackrel{\text { V}}{ }\end{array}$ & 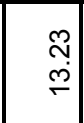 & $\begin{array}{l}\stackrel{8}{\circ} \\
\stackrel{\circ}{\circ}\end{array}$ & 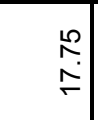 & & & & & & 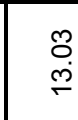 & 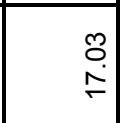 & 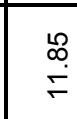 & 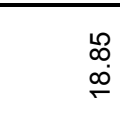 & \\
\hline 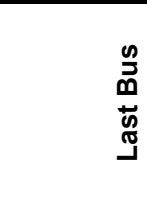 & & $\begin{array}{l}\sum_{0} \\
\substack { 0 \\
\begin{subarray}{c}{0 \\
\infty{ 0 \\
\begin{subarray} { c } { 0 \\
\infty } }\end{array}$ & 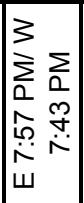 & $\begin{array}{l}\sum \\
0 \\
0 \\
0 \\
\dot{0}\end{array}$ & 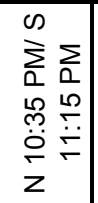 & 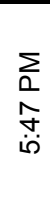 & 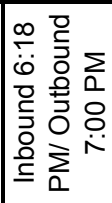 & $\begin{array}{l}\sum \\
0 \\
\infty \\
0 \\
0 \\
0\end{array}$ & 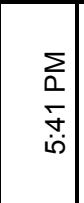 & \begin{tabular}{|l|l|}
3 & \\
$\sum_{0}$ & 0 \\
0 & 0 \\
0 & 0 \\
0 & 0 \\
0 & 0 \\
$w$ & 0 \\
\end{tabular} & 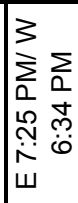 & 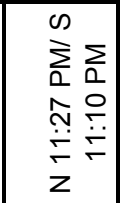 & 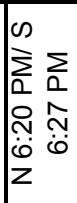 & 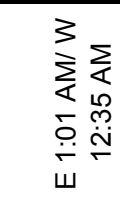 & $\begin{array}{l}\sum_{0} \\
0 \\
\stackrel{0}{+} \\
\dot{+}\end{array}$ \\
\hline 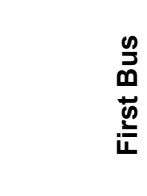 & & 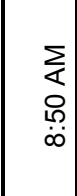 & 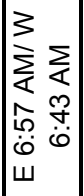 & 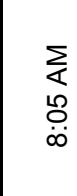 & 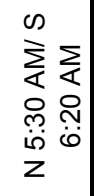 & $\begin{array}{l}\sum \\
\sum \\
0 \\
m \\
0\end{array}$ & 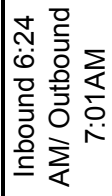 & $\begin{array}{l}\sum \\
\sum \\
\infty \\
0 \\
\dot{0}\end{array}$ & 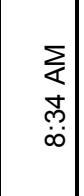 & 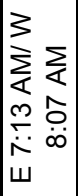 & 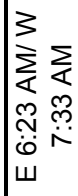 & 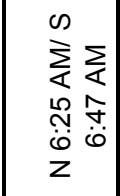 & 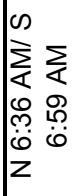 & 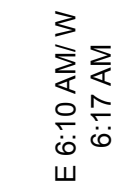 & 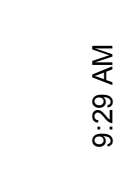 \\
\hline 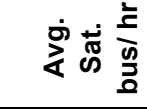 & $\stackrel{\circ}{r}$ & & $\stackrel{\circ}{-}$ & $\stackrel{i}{i}$ & $\stackrel{\text { ì }}{\text { in }}$ & $\stackrel{\circ}{\stackrel{P}{0}}$ & & $\stackrel{\circ}{-}$ & $\stackrel{\circ}{-}$ & $\stackrel{\circ}{-}$ & $\stackrel{m}{r}$ & & & & \\
\hline 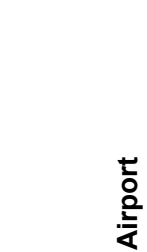 & 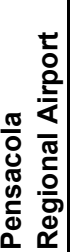 & & 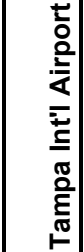 & 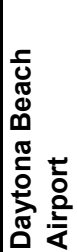 & 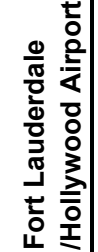 & 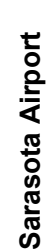 & & 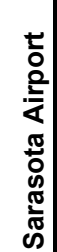 & 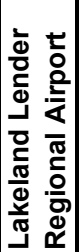 & 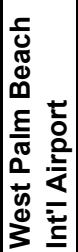 & 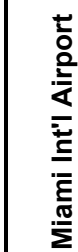 & & & & 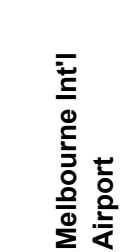 \\
\hline
\end{tabular}




\begin{tabular}{|c|c|c|c|c|c|c|c|c|c|c|c|c|c|c|c|c|c|c|c|}
\hline 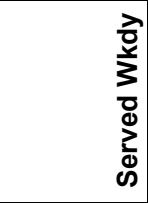 & $\sum_{\substack{n \\
<}}^{\sum}$ & $\sum$ & 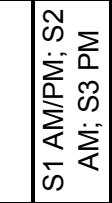 & 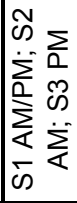 & 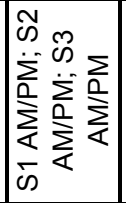 & 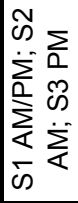 & 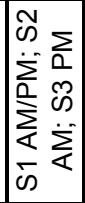 & 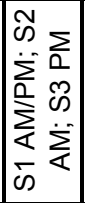 & 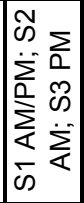 & 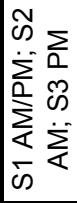 & 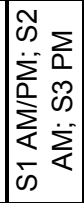 & 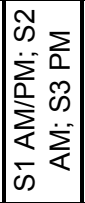 & 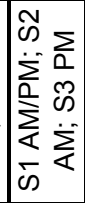 & 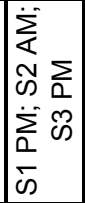 & 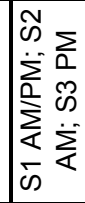 & 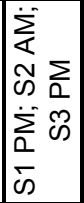 & 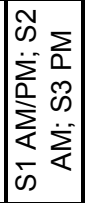 & 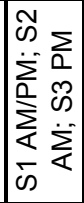 & \\
\hline 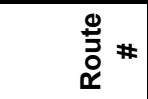 & $N$ & 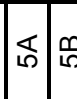 & $\sigma$ & $\mp$ & 으 & 尺ి & $\stackrel{\nabla}{ }$ & $\stackrel{60}{\llcorner}$ & 10 & $\mp$ & $\nabla$ & 0 & ธิ & จ & $\nabla$ & 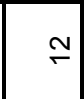 & $\stackrel{\varphi}{\circ}$ & $\stackrel{\infty}{\sim}$ & N \\
\hline 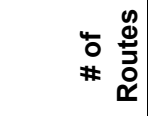 & $m$ & & $N$ & & $N$ & & $N$ & & $N$ & & $N$ & & - & $r$ & in & & & & \\
\hline $\begin{array}{l}5 \\
0 \\
0\end{array}$ & & & $\stackrel{\Delta}{N}$ & $\stackrel{d}{N}$ & $\mathbf{N}$ & $\stackrel{d}{N}$ & $\mathbb{N}$ & $\mathbb{N}$ & $\stackrel{+}{N}$ & ป & N & 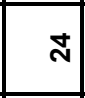 & $\mathbb{N}$ & $\stackrel{\mathbb{N}}{\text { S }}$ & $\stackrel{d}{N}$ & A & $\mathbb{N}$ & N & I \\
\hline 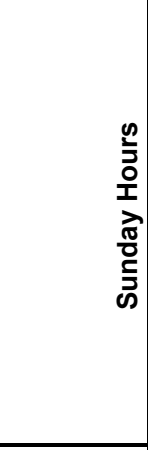 & & & 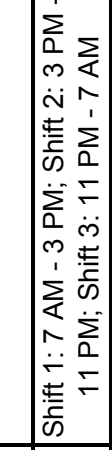 & & 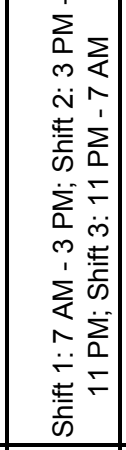 & & 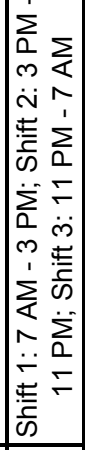 & & 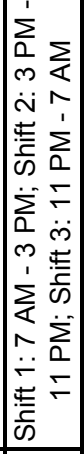 & & 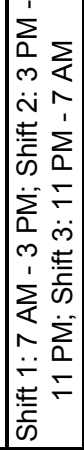 & & 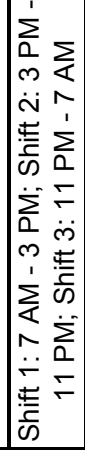 & 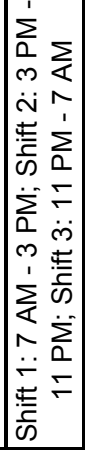 & 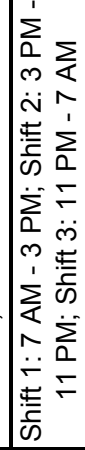 & & & & \\
\hline 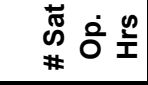 & & & $\underset{N}{*}$ & $\mathbb{N}$ & $\mathbb{N}$ & $\stackrel{\mathbb{N}}{ }$ & N & $\mathbb{N}$ & $\mathbf{N}$ & $\mathbb{N}$ & $\stackrel{d}{N}$ & $\mathbb{N}$ & $\stackrel{d}{N}$ & 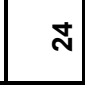 & $\stackrel{N}{ }$ & $\mathbb{N}$ & $\mathbb{N}$ & $\mathbb{N}$ & $\stackrel{N}{N}$ \\
\hline 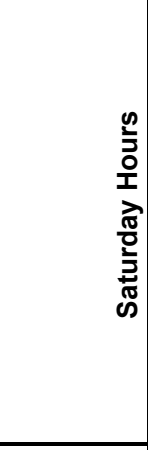 & & & 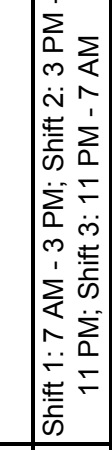 & & 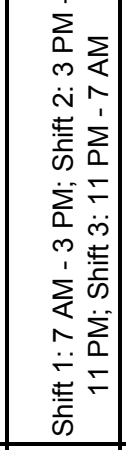 & & 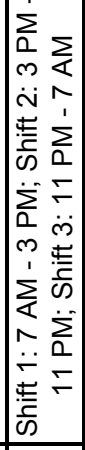 & & 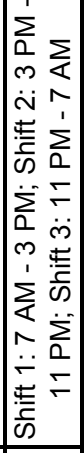 & & 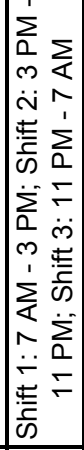 & & 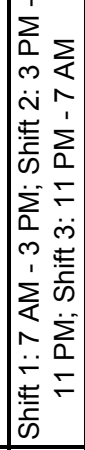 & 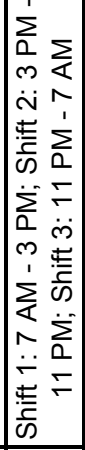 & 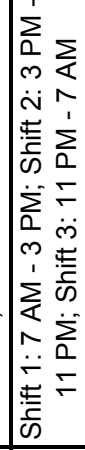 & & & & \\
\hline 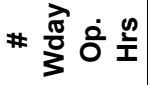 & $\begin{array}{l}n \\
0 \\
0\end{array}$ & $\mid$\begin{tabular}{l|l}
$n$ \\
0 \\
0
\end{tabular} & $\begin{array}{l}0 \\
\stackrel{0}{0} \\
\stackrel{0}{\circ}\end{array}$ & $\mathbb{N}$ & $\mathbb{N}$ & $\mathbb{N}$ & $\stackrel{\text { N }}{ }$ & $\mathbb{N}$ & $\stackrel{\mathbb{N}}{*}$ & I & $\stackrel{I}{N}$ & $\mathbb{N}$ & $\stackrel{N}{ }$ & I & $\stackrel{\sim}{N}$ & $\mathbb{N}$ & $\mathbb{N}$ & $\mathbb{N}$ & $\mathbb{N}$ \\
\hline 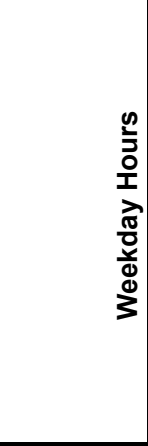 & $\begin{array}{l}\sum \\
0 \\
0 \\
0 \\
\dot{0} \\
1 \\
\sum \\
\vdots \\
0 \\
\stackrel{m}{n}\end{array}$ & & 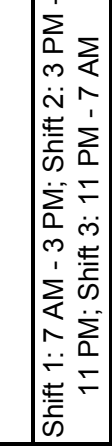 & & 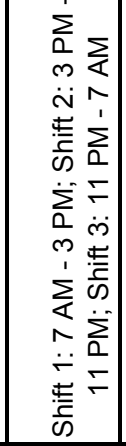 & & 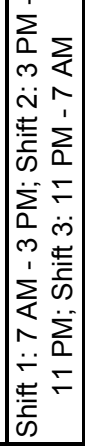 & & 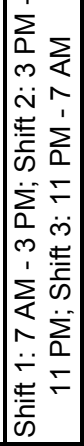 & & 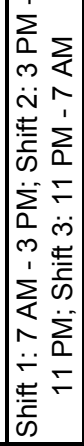 & & 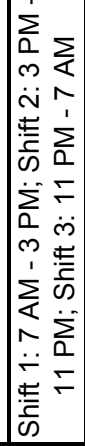 & 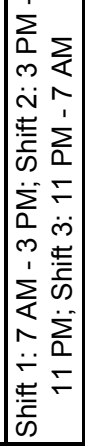 & 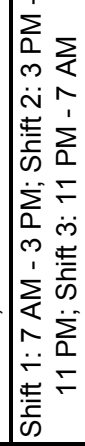 & & & & \\
\hline 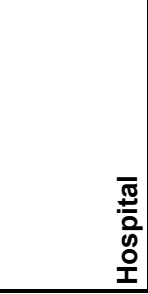 & 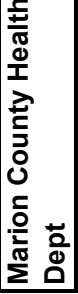 & & 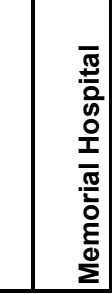 & & 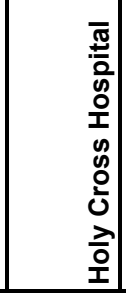 & & 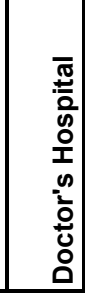 & & 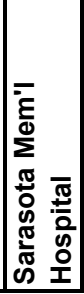 & & 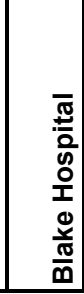 & & 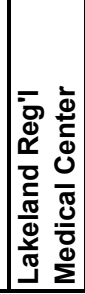 & 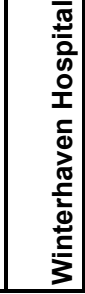 & 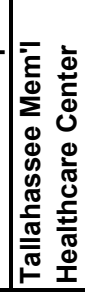 & & & & \\
\hline
\end{tabular}




\begin{tabular}{|c|c|c|c|c|c|c|c|c|c|c|c|c|c|c|c|c|c|c|c|c|}
\hline 家芯高 & $\hat{o}$ & & & $\stackrel{m}{\sim}$ & & $\stackrel{\infty}{\rightarrow}$ & & $\stackrel{\circ}{-}$ & & $\stackrel{\leftrightarrow}{\longrightarrow}$ & & $\stackrel{\circ}{\longrightarrow}$ & & ì & & $\stackrel{\infty}{\Gamma}$ & & & & \\
\hline 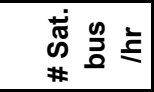 & $\stackrel{\circ}{\stackrel{\circ}{ }}$ & | & $\mid \begin{array}{l}0 \\
0 \\
0\end{array}$ & $\stackrel{\circ}{\circ}$ & $\stackrel{\text { po }}{\longrightarrow}$ & $\stackrel{\circ}{\mathrm{N}}$ & $\stackrel{\text { po }}{\longrightarrow}$ & $\stackrel{\circ}{\circ}$ & $\stackrel{\circ}{\longrightarrow}$ & $\stackrel{\circ}{-}$ & $\stackrel{\circ}{\longrightarrow}$ & $\stackrel{\circ}{\dot{C}}$ & $\stackrel{\circ}{-}$ & $\stackrel{\circ}{\mathrm{N}}$ & $\stackrel{\circ}{-}$ & $\stackrel{\text { ?ִ }}{\longrightarrow}$ & $\stackrel{n}{\longrightarrow}$ & $\begin{array}{l}0 \\
0\end{array}$ & $\stackrel{\circ}{\stackrel{r}{0}}$ & $\vec{m}$ \\
\hline 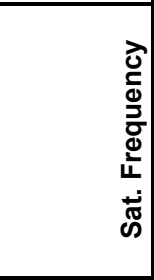 & 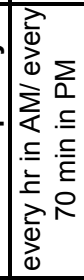 & 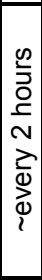 & 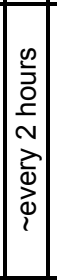 & 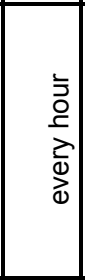 & 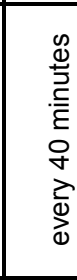 & 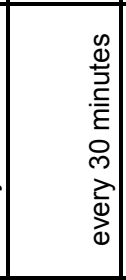 & 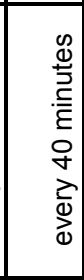 & 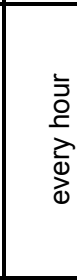 & 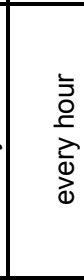 & 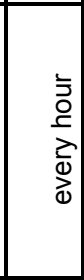 & 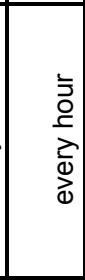 & $\begin{array}{l}\bar{y} \\
\frac{0}{2} \\
⿱ 亠 乂 \\
0 \\
0\end{array}$ & 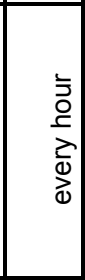 & 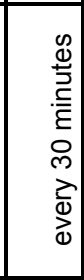 & $\begin{array}{l}\bar{z} \\
0 \\
\frac{1}{2} \\
\text { d } \\
0\end{array}$ & 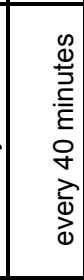 & 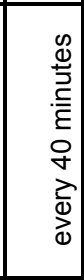 & & 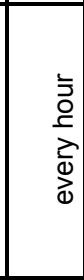 & 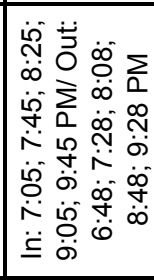 \\
\hline 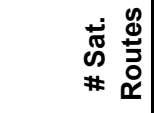 & & & & $\mathbf{N}$ & & $N$ & & $N$ & & $N$ & & $\mathbf{N}$ & & - & - & $\nabla$ & & & & \\
\hline 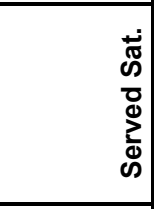 & & & & 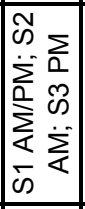 & 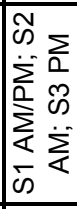 & 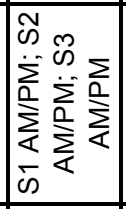 & 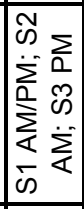 & 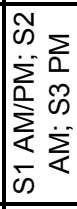 & 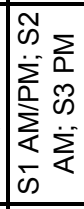 & 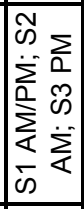 & 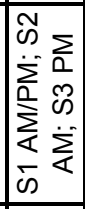 & 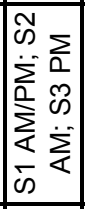 & 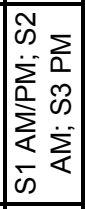 & 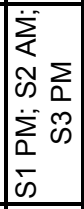 & 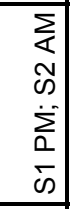 & 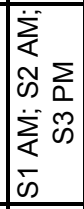 & 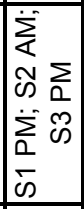 & & 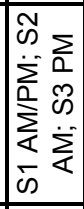 & \\
\hline 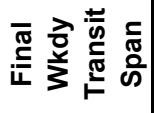 & 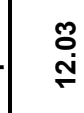 & & & 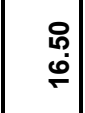 & & 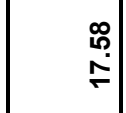 & & 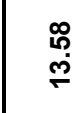 & & 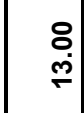 & & $\stackrel{\infty}{\stackrel{\infty}{N}}$ & & $\begin{array}{l}\stackrel{8}{\mathrm{~N}} \\
\stackrel{2}{2}\end{array}$ & $\stackrel{\circ}{\stackrel{\circ}{\leftarrow}}$ & $\begin{array}{l}\hat{\sigma} \\
\dot{x}\end{array}$ & & & & \\
\hline 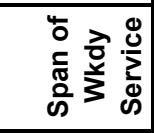 & 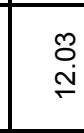 & $\mid$ & $\frac{\infty}{\sigma}$ & $\begin{array}{l}\stackrel{m}{m} \\
\dot{0}\end{array}$ & $\begin{array}{l}\stackrel{\circ}{\circ} \\
\stackrel{+}{+}\end{array}$ & $\begin{array}{l}\stackrel{\infty}{\circ} \\
\stackrel{h}{\sim}\end{array}$ & 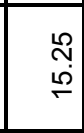 & $\begin{array}{l}\hat{\hat{~}} \\
\stackrel{\sim}{\sim}\end{array}$ & 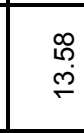 & $\stackrel{\stackrel{o}{+}}{\stackrel{i}{\sim}}$ & 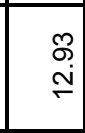 & $\begin{array}{l}\stackrel{\text { Oे }}{\mathrm{i}} \\
\stackrel{\mathrm{I}}{ }\end{array}$ & $\begin{array}{l}\stackrel{\infty}{\sim} \\
\stackrel{\sim}{\sim}\end{array}$ & $\begin{array}{l}\stackrel{8}{0} \\
\stackrel{\mathrm{i}}{\sim}\end{array}$ & $\underset{8}{\stackrel{8}{+}}$ & $\stackrel{?}{\stackrel{?}{r}}$ & \begin{tabular}{l}
\multirow{2}{*}{} \\
$\stackrel{-}{\circ}$
\end{tabular} & 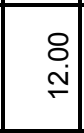 & $\stackrel{\infty}{\stackrel{\infty}{\sim}}$ & $\stackrel{\mathscr{\Omega}}{\stackrel{2}{N}}$ \\
\hline 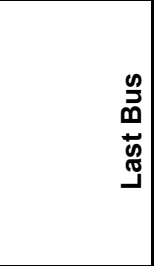 & 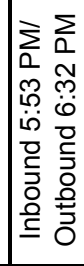 & $\mid \begin{array}{l}\sum_{0} \\
\vdots \\
0 \\
0 \\
0\end{array}$ & $\left|\begin{array}{c}\Sigma \\
0 \\
0 \\
\hdashline \\
i n\end{array}\right|$ & 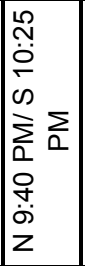 & 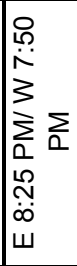 & 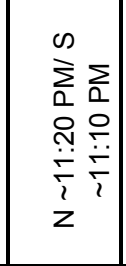 & $\begin{array}{ll}\infty & \\
\sum_{0} & \sum \\
0 & 0 \\
0 & 0 \\
0 & f \\
0 & 0 \\
i & 0 \\
1 & i \\
z & 1\end{array}$ & 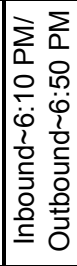 & 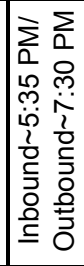 & 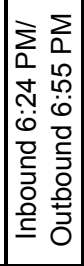 & 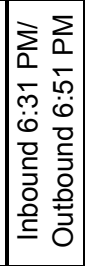 & $\begin{array}{l}\sum \\
0 \\
0 \\
\dddot{0} \\
0\end{array}$ & 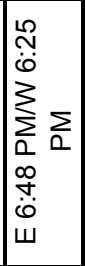 & $\begin{array}{l}\sum_{0} \\
0 \\
\stackrel{1}{0} \\
\dot{i} \\
i\end{array}$ & $\begin{array}{l}\sum_{0} \\
\infty \\
\stackrel{0}{0}\end{array}$ & 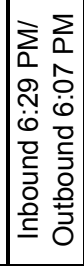 & 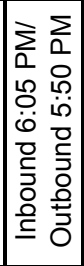 & 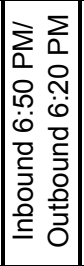 & 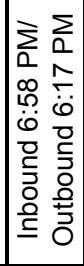 & 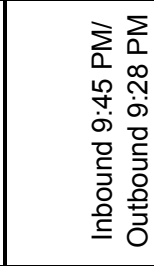 \\
\hline 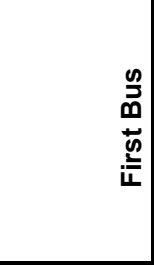 & 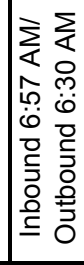 & $\mid$\begin{tabular}{l}
$\sum$ \\
\multirow{\alpha}{\alpha}{} \\
0 \\
0 \\
0
\end{tabular} & 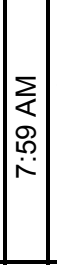 & 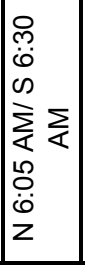 & 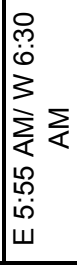 & 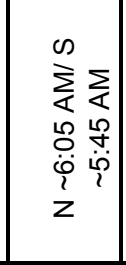 & 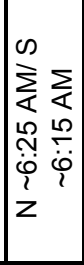 & 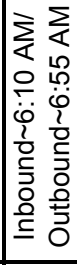 & 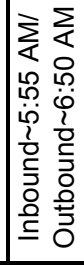 & 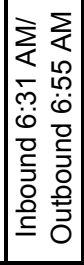 & 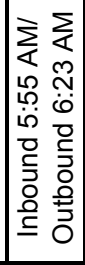 & $\begin{array}{l}\sum \\
i \\
\infty \\
00 \\
00\end{array}$ & 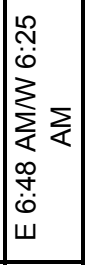 & $\begin{array}{l}\sum_{4} \\
\stackrel{n}{2} \\
\stackrel{0}{i} \\
i\end{array}$ & $\begin{array}{l}\sum_{<} \\
\infty \\
亡 \\
亡\end{array}$ & 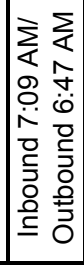 & 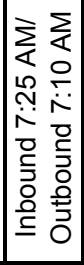 & 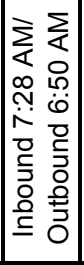 & 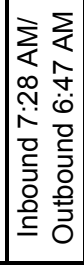 & 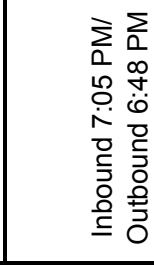 \\
\hline 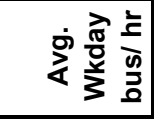 & ố & & & $\stackrel{n}{\leftarrow}$ & & $\stackrel{\infty}{r}$ & & $\stackrel{\circ}{-}$ & & $\stackrel{\circ}{\longrightarrow}$ & & $\stackrel{\circ}{-}$ & & $\stackrel{\circ}{\mathrm{i}}$ & $\stackrel{\circ}{-}$ & $\cong$ & & & & \\
\hline 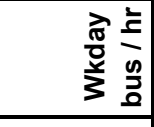 & $\stackrel{\circ}{r}$ & | & مْ & $\stackrel{0}{\sim}$ & مִ & $\stackrel{\circ}{\mathrm{N}}$ & $\stackrel{\text { ?ִ }}{\longrightarrow}$ & & $\stackrel{\circ}{-}$ & $\stackrel{\leftrightarrow}{-}$ & $\stackrel{\circ}{\stackrel{\leftrightarrow}{2}}$ & $\stackrel{\circ}{-}$ & $\stackrel{\circ}{-}$ & $\stackrel{\circ}{\mathrm{N}}$ & $\stackrel{\circ}{-}$ & $\stackrel{\circ}{\longrightarrow}$ & $\stackrel{\text { ?ִ }}{\longrightarrow}$ & $\stackrel{\circ}{r}$ & $\stackrel{\circ}{\stackrel{\leftrightarrow}{0}}$ & $\stackrel{\nabla}{m}$ \\
\hline 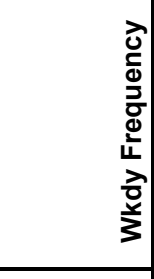 & 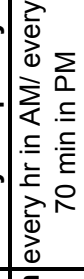 & 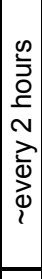 & 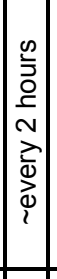 & 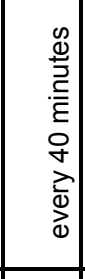 & 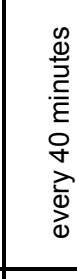 & 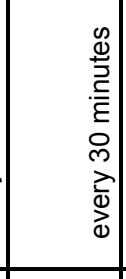 & 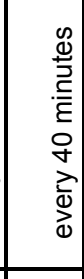 & 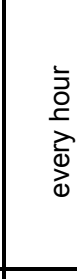 & 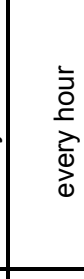 & 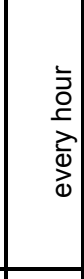 & 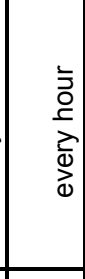 & 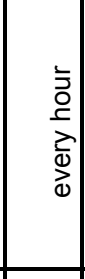 & 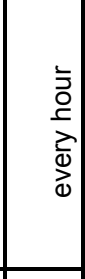 & 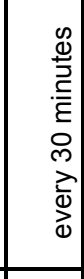 & 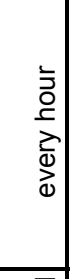 & 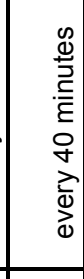 & 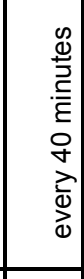 & $\begin{array}{l}\bar{y} \\
\text { c } \\
⿱ 亠 乂 \\
0 \\
\overline{0}\end{array}$ & 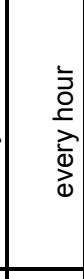 & 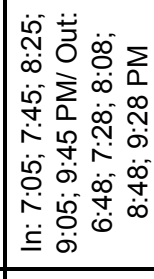 \\
\hline $\begin{array}{l}\bar{\pi} \\
\frac{\pi}{0} \\
\frac{0}{0} \\
\text { 운 }\end{array}$ & 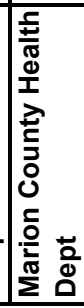 & & & 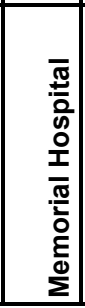 & & 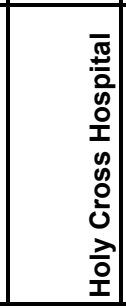 & & 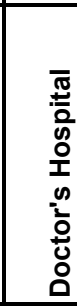 & & 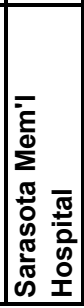 & & 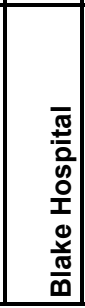 & & 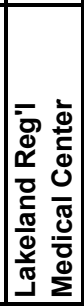 & 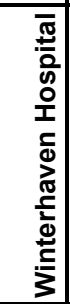 & 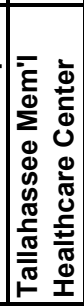 & & & & \\
\hline
\end{tabular}




\begin{tabular}{|c|c|c|c|c|c|c|c|c|c|c|c|c|c|c|c|c|c|c|}
\hline 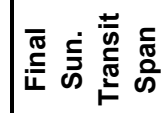 & & & รั้ & & 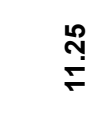 & & & & & & & & & & کึ. & & & \\
\hline 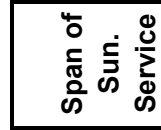 & & & & & & & & & & & & & & & & & & \\
\hline 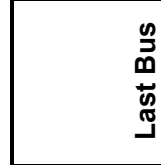 & & & \begin{tabular}{|ll}
$\sum_{0}$ & $\sum$ \\
0 & 0 \\
$\infty$ & 0 \\
\hdashline & 0 \\
$\dot{0}$ & 0 \\
$z$ & $\infty$
\end{tabular} & $\begin{array}{ll}\sum_{0} & \sum \\
0 & 0 \\
1 & 0 \\
0 & 0 \\
0 & 0 \\
0 & 0 \\
\omega & 3\end{array}$ & 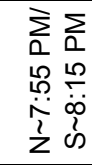 & $\mid \begin{array}{ll}\sum & \sum \\
0 & 0 \\
0 & 0 \\
0 & 0 \\
0 \\
0 & 0 \\
1 & 0 \\
z & 0\end{array}$ & & & & & & & & & & & & 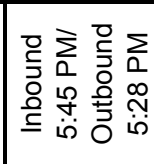 \\
\hline $\begin{array}{l}\stackrel{0}{0} \\
\stackrel{0}{0} \\
\stackrel{0}{*}\end{array}$ & & & $\mid$\begin{tabular}{ll}
$\sum$ & $\sum$ \\
$<$ & \\
$<$ & 0 \\
0 & 0 \\
0 & 0 \\
\hdashline & 0 \\
$z$ & 0
\end{tabular} & 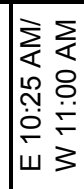 & 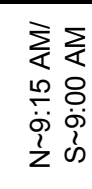 & 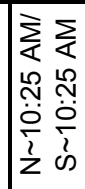 & & & & & & & & & & & & 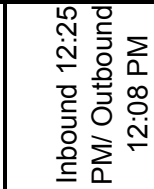 \\
\hline 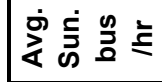 & & & $\stackrel{\infty}{\stackrel{\infty}{0}}$ & & $\stackrel{5}{F}$ & & & & & & & & & & ํํำ & & & \\
\hline 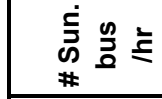 & & & $\begin{array}{l}\stackrel{2}{2} \\
0\end{array}$ & 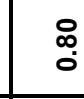 & $\stackrel{m}{\leftarrow}$ & $\stackrel{8}{-}$ & & & & & & & & & & & & గִ \\
\hline 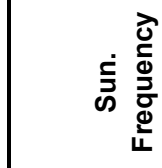 & & & 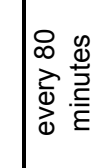 & 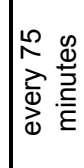 & 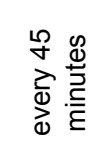 & 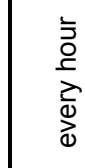 & & & & & & & & & & & & 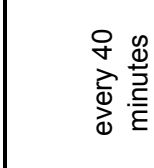 \\
\hline 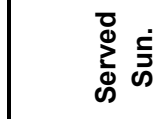 & & & 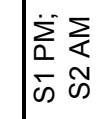 & 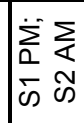 & 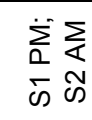 & $\begin{array}{ll}\sum_{0} & \sum \\
\infty & \vdots \\
\infty & \infty\end{array}$ & & & & & & & & & & & & 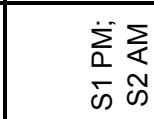 \\
\hline 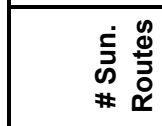 & 0 & & $N$ & & $N$ & & 0 & & 0 & & 0 & & 0 & & - & & & \\
\hline 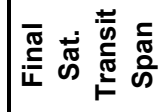 & 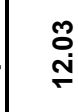 & & $\begin{array}{l}\stackrel{\infty}{\infty} \\
\stackrel{\rho}{\complement}\end{array}$ & & $\stackrel{\stackrel{\infty}{\circ}}{\stackrel{n}{\sim}}$ & & 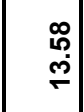 & & $\begin{array}{l}\stackrel{8}{9} \\
\stackrel{\dot{m}}{=}\end{array}$ & & 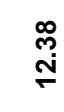 & & ڤึ. & ò & $\begin{array}{l}\hat{S} \\
\dot{+}\end{array}$ & & & \\
\hline 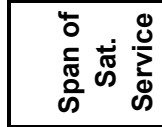 & 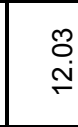 & 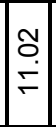 & & & & & & & & & & & & & & & & \\
\hline 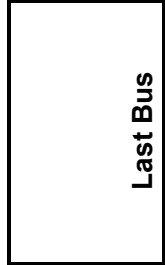 & & & \begin{tabular}{|l|} 
\\
0 \\
0 \\
0 \\
$\infty$ \\
0 \\
$\sum_{0} \sum$ \\
0 \\
0 \\
0 \\
0 \\
$\dot{0}$ \\
$z$ \\
\end{tabular} & 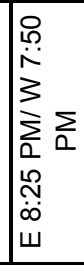 & 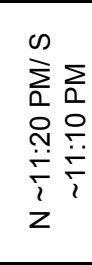 & $\begin{array}{ll}\infty & \\
\sum_{0} & \sum \\
0 & 0 \\
0 & 0 \\
0 & 0 \\
0 & 0 \\
1 & 0 \\
z & 1 \\
z & 1\end{array}$ & 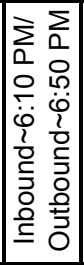 & 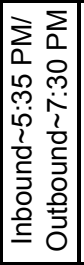 & 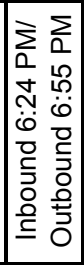 & 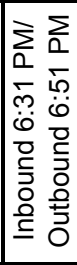 & $\begin{array}{l}\sum_{0} \\
10 \\
\substack{0 \\
0}\end{array}$ & 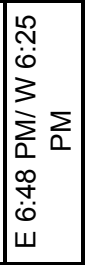 & 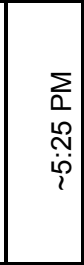 & $\begin{array}{l}\sum_{0} \\
\infty \\
i \infty \\
i \infty \\
\end{array}$ & 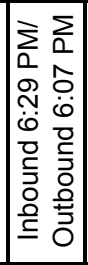 & 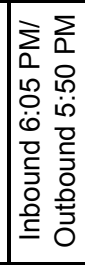 & 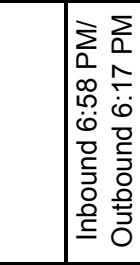 & 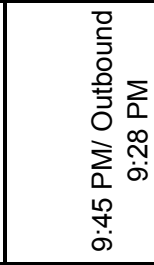 \\
\hline 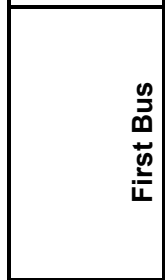 & & & 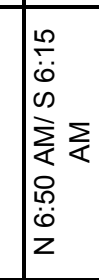 & 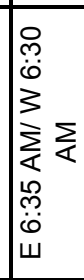 & 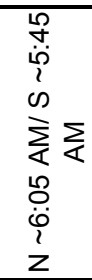 & 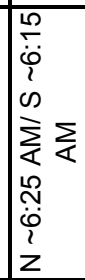 & 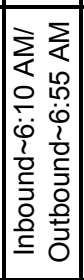 & 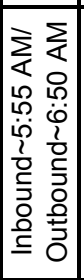 & 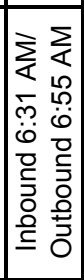 & 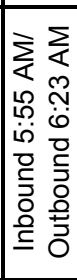 & 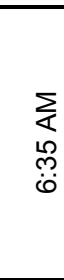 & 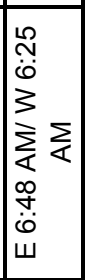 & 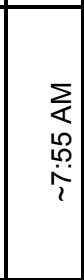 & $\begin{array}{l}\sum_{\substack{\alpha \\
\infty}}^{\infty} \\
\frac{\infty}{\infty}\end{array}$ & 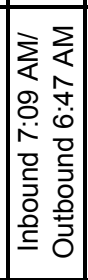 & 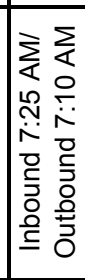 & 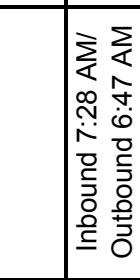 & 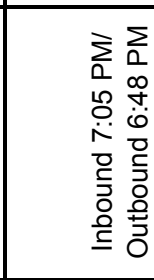 \\
\hline $\begin{array}{l}\overline{\underline{m}} \\
\overline{0} \\
\overline{0} \\
0 \\
\overline{1} \\
\end{array}$ & 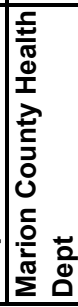 & & 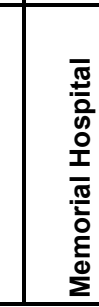 & & 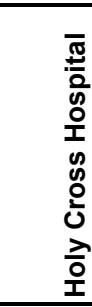 & & 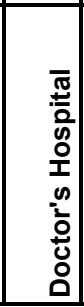 & & 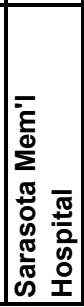 & & 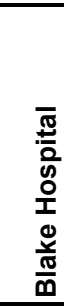 & & 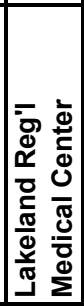 & 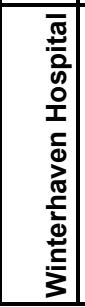 & 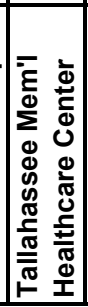 & & & \\
\hline
\end{tabular}




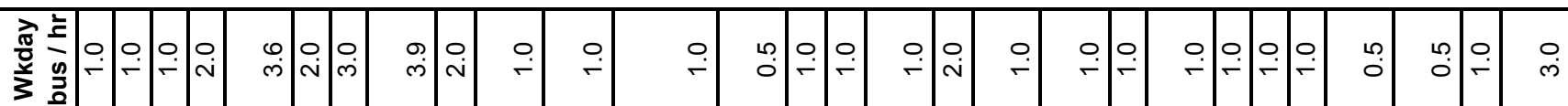

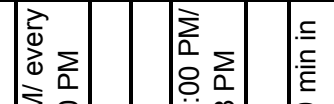

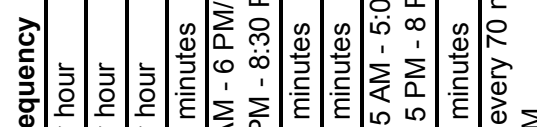

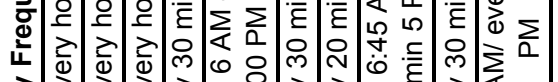

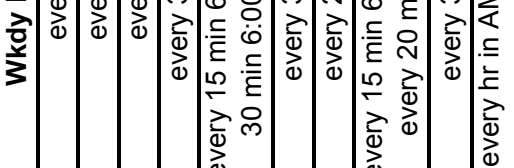

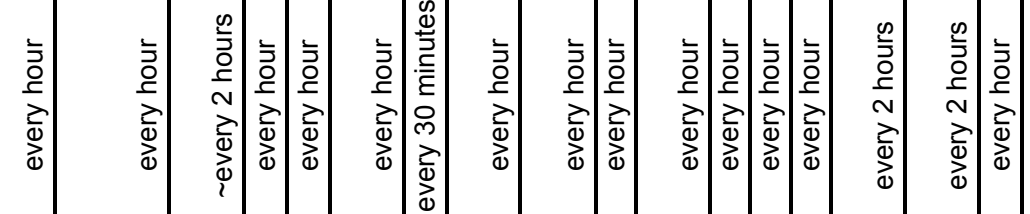

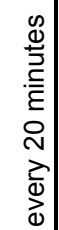

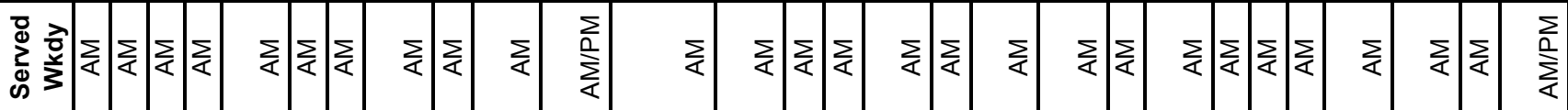

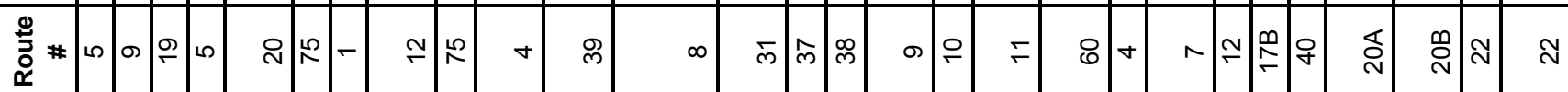

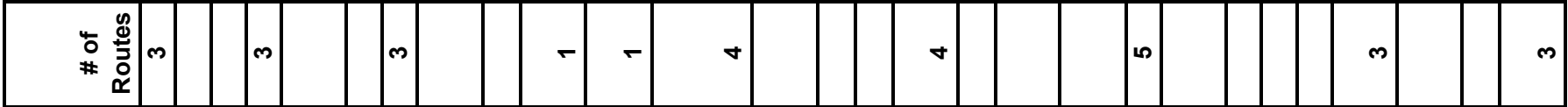

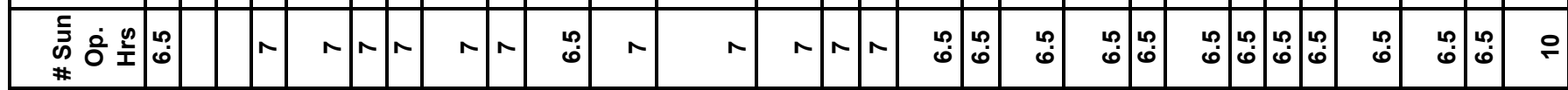

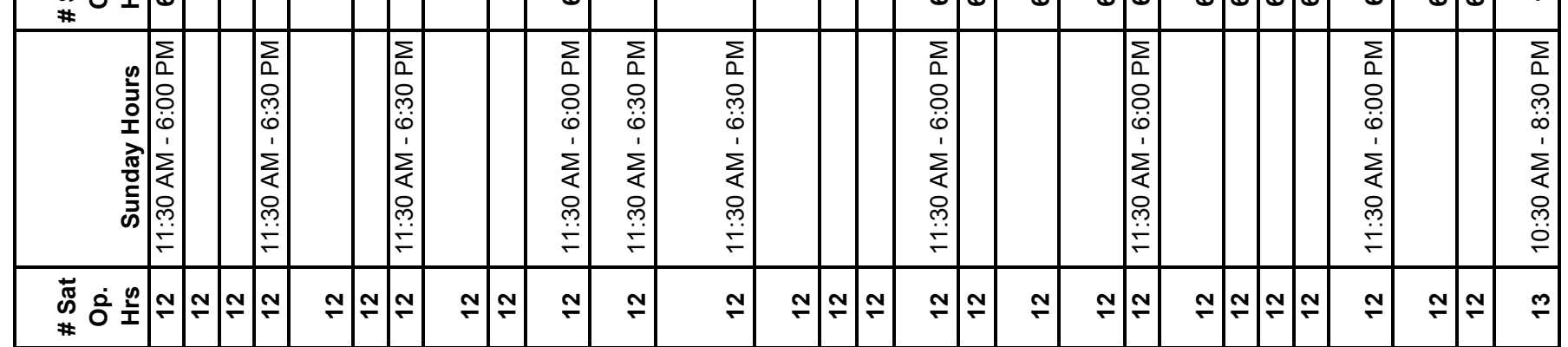

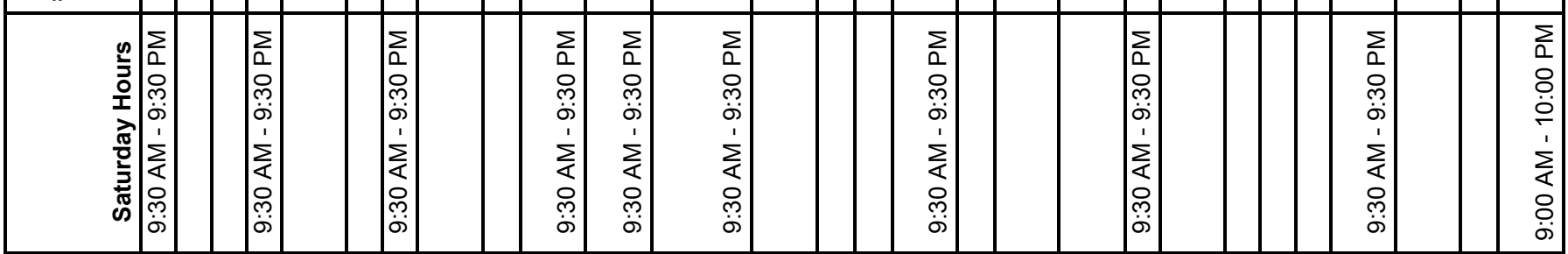

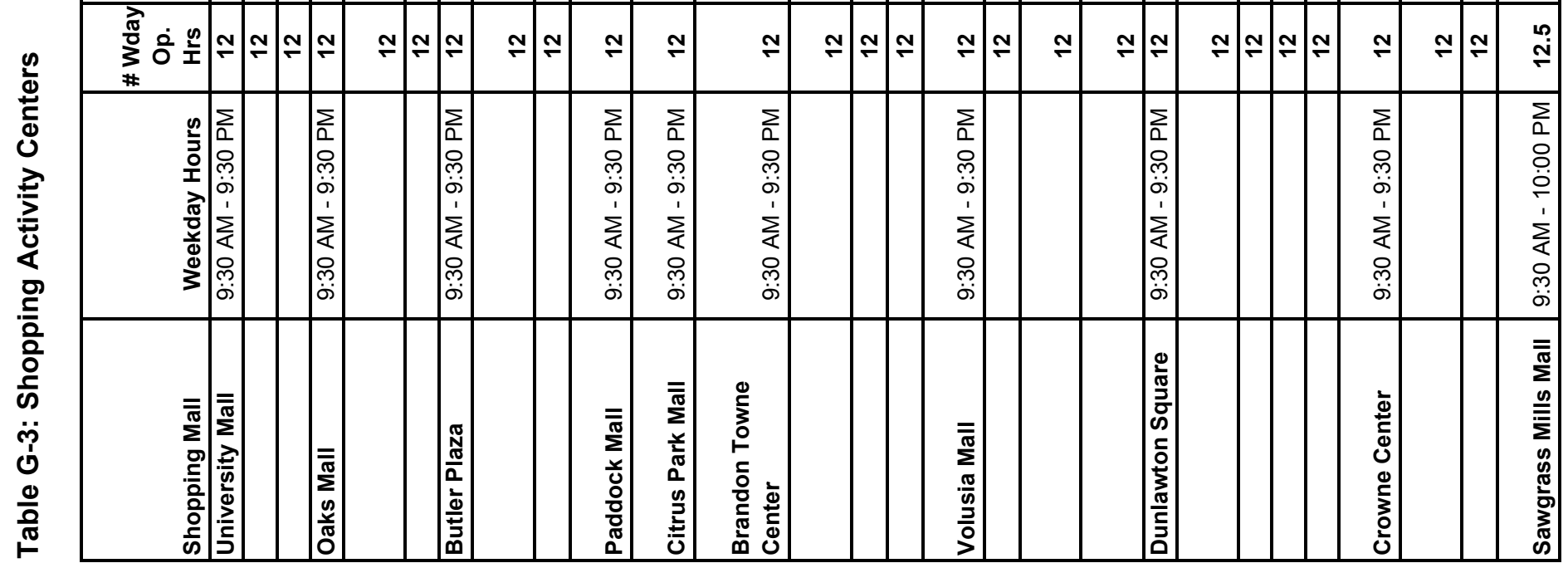




\begin{tabular}{|c|c|c|c|c|c|c|c|c|c|c|c|c|c|c|c|c|c|c|c|c|c|c|c|c|c|}
\hline 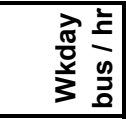 & ○्ले & $\stackrel{\circ}{r}$ & $\stackrel{\circ}{\circ}$ & $\stackrel{\circ}{\sim}$ & $\stackrel{\leftrightarrow}{\mathrm{N}}$ & $\stackrel{m}{-}$ & $\stackrel{\circ}{i}$ & $\stackrel{\circ}{-}$ & $\stackrel{\circ}{-}$ & $\stackrel{\circ}{\dot{C}}$ & $\stackrel{\circ}{\circ}$ & 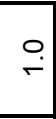 & $\stackrel{\circ}{\circ}$ & $\stackrel{\circ}{-}$ & $\mid \stackrel{\circ}{-}$ & $\stackrel{\circ}{\leftarrow}$ & $\stackrel{\circ}{\circ}$ & $\stackrel{-}{-}$ & $\stackrel{\leftrightarrow}{\rightarrow} \stackrel{\circ}{\rightarrow}$ & $: \stackrel{\circ}{r}$ & $\begin{array}{l}0 \\
0 \\
0\end{array}$ & $\stackrel{\circ}{\circ}$ & $\begin{array}{l}0 \\
0\end{array}$ & & 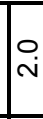 \\
\hline 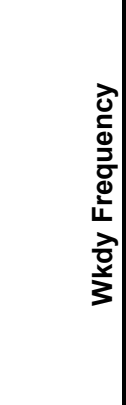 & 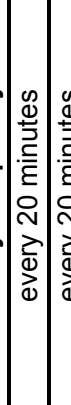 & $\begin{array}{l}\bar{\vdots} \\
0 \\
\frac{c}{2} \\
\frac{\lambda}{0} \\
0\end{array}$ & $\begin{array}{l}\bar{े} \\
\overline{0} \\
\overline{\mathbf{d}} \\
\mathrm{d}\end{array}$ & 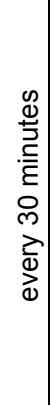 & 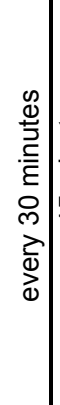 & 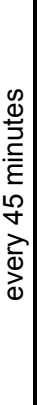 & 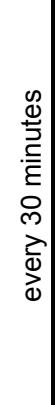 & 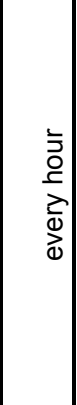 & 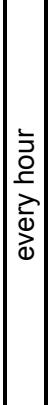 & $\begin{array}{l}\bar{\jmath} \\
\overline{0} \\
\frac{1}{d} \\
0 \\
0\end{array}$ & $\begin{array}{l}\bar{\vdots} \\
\overline{0} \\
\bar{d} \\
\bar{d} \\
\bar{d}\end{array}$ & 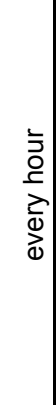 & $\begin{array}{l}\bar{\vdots} \\
\overline{0} \\
⿱ 亠 乂 \\
\overline{0} \\
\overline{0}\end{array}$ & 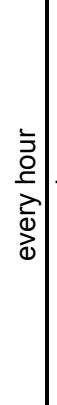 & 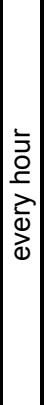 & $\begin{array}{l}\bar{\jmath} \\
\overline{0} \\
\frac{1}{d} \\
0 \\
0\end{array}$ & $\begin{array}{l}\bar{\vdots} \\
\overline{0} \\
\frac{1}{0} \\
\stackrel{0}{0}\end{array}$ & $\left|\begin{array}{l}1 \\
0 \\
\frac{1}{2} \\
\grave{\partial} \\
\overline{0} \\
0\end{array}\right|$ & 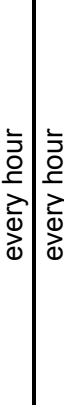 & 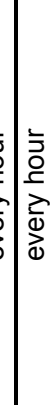 & 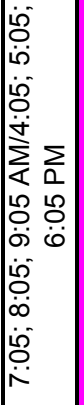 & | & 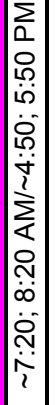 & 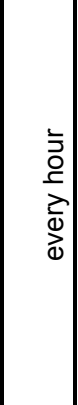 & 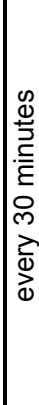 \\
\hline 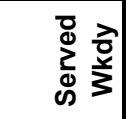 & $\sum_{\substack{n \\
\alpha}}^{\substack{n \\
\sum}}$ & 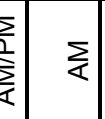 & $\sum$ & $\sum_{\substack{k \\
<}}^{\infty}$ & $\sum_{\substack{n \\
\alpha}}^{1}$ & $\sum$ & $\sum_{\substack{n \\
\sum}}^{1}$ & $\sum$ & $\sum$ & $\sum_{<1}$ & $\sum_{\substack{n \\
<}}^{1}$ & $\sum_{\substack{k \\
<}}^{\infty}$ & $\sum_{<}$ & $\sum_{2}$ & $\mid \sum$ & $\sum_{\&}$ & $\sum_{<}$ & $\sum$ & $\sum_{<} \sum_{<}$ & $\sum_{<}$ & $\sum_{<}$ & & & & $\sum$ \\
\hline 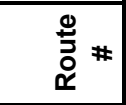 & 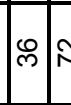 & $m$ & 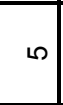 & $\wedge$ & $N$ & రి & $\infty$ & 10 & 0 & $\mp$ & $\nabla$ & $\stackrel{\infty}{\sim}$ & ம) & $\mp$ & $\neq$ & $\mp$ & $\sim$ & 0. & $\infty \mid \sigma$ & $1 \div$ & $\stackrel{\circ}{\llcorner}$ & $\infty$ & مص & - & is \\
\hline 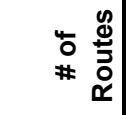 & & $m$ & & & $m$ & & & $m$ & & & $N$ & & $\nabla$ & & & & 0 & & & & & $N$ & & - & $\mathbf{N}$ \\
\hline 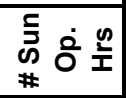 & $\div=$ & $N$ & $\wedge$ & $N$ & $\infty$ & $\infty$ & $\infty$ & ְొ & $\left|\begin{array}{l}\mid \\
0 \\
0\end{array}\right|$ & $\begin{array}{l}\mathscr{0} \\
0\end{array}$ & & & $\begin{array}{l}\mathscr{1} \\
0\end{array}$ & $\begin{array}{l}\mathscr{0} \\
\emptyset\end{array}$ & $\left|\begin{array}{l}n \\
0 \\
0\end{array}\right|$ & $\begin{array}{l}\text { ధ̊ } \\
\emptyset\end{array}$ & $\begin{array}{l}10 \\
0\end{array}$ & 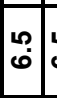 & 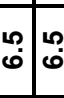 & مُ & $\begin{array}{l}n \\
0 \\
0\end{array}$ & N & $\mathbb{N}$ & $\infty$ & | \\
\hline 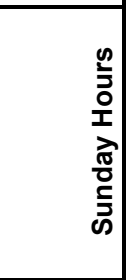 & & 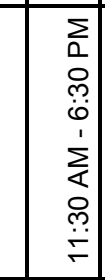 & & & 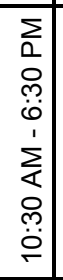 & & & 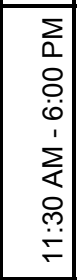 & & & & & 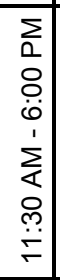 & & & & $\begin{array}{l}\sum \\
0 \\
8 \\
\dot{0} \\
1 \\
\sum \\
0 \\
0 \\
\stackrel{5}{+} \\
\end{array}$ & & & & & 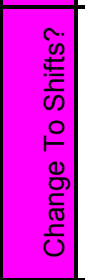 & & 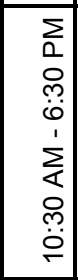 & $\begin{array}{l}\sum \\
0 \\
0 \\
0 \\
\dot{0} \\
1 \\
\sum \\
0 \\
0 \\
0 \\
\dot{\sigma} \\
\end{array}$ \\
\hline 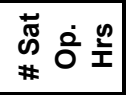 & $m$ & $\cong$ & $\stackrel{\sim}{\sim}$ & $\stackrel{\sim}{2}$ & 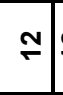 & 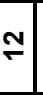 & $\simeq$ & $\cong$ & $\cong$ & $\mathbb{N}$ & $\infty$ & 0 & 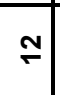 & 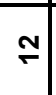 & $\cong$ & $\mathfrak{\sim}$ & $\simeq$ & 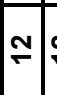 & $\cong \cong$ & 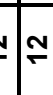 & $\cong$ & A & A & $\simeq$ & $\cong$ \\
\hline 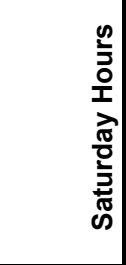 & & $\begin{array}{l}\sum \\
0 \\
0 \\
\tilde{m} \\
0 \\
1 \\
\sum \\
0 \\
0 \\
0 \\
\dot{0}\end{array}$ & & & $\begin{array}{l}\sum \\
0 \\
0 \\
0 \\
0 \\
1 \\
\sum \\
0 \\
0 \\
0 \\
\dot{0}\end{array}$ & & & $\begin{array}{l}\sum \\
0 \\
0 \\
0 \\
0 \\
1 \\
\sum \\
\vdots \\
0 \\
0 \\
\dot{0}\end{array}$ & & & $\begin{array}{l}\sum \\
0 \\
8 \\
0 \\
\dot{0} \\
1 \\
\sum \\
0 \\
8 \\
\dot{0}\end{array}$ & & 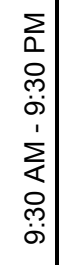 & & & & $\begin{array}{l}\sum \\
0 \\
0 \\
0 \\
0 \\
1 \\
\sum \\
0 \\
0 \\
0 \\
\dot{0}\end{array}$ & & & & & 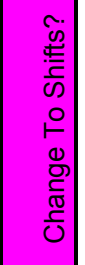 & & $\begin{array}{l}\sum \\
0 \\
0 \\
0 \\
0 \\
1 \\
\sum \\
0 \\
0 \\
\dot{0}\end{array}$ & $\begin{array}{l}\Sigma \\
0 \\
0 \\
0 \\
0 \\
0 \\
1 \\
\sum \\
0 \\
0 \\
0 \\
0 \dot{0}\end{array}$ \\
\hline$\sum_{\#}^{\frac{\pi}{0}} \frac{\dot{0}}{0} \frac{0}{\underline{1}}$ & 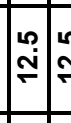 & $\mp$ & 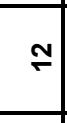 & 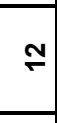 & $\cong$ & 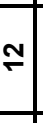 & $\cong$ & $\cong$ & $\cong$ & $\mathbb{Y}$ & 0 & 0 & 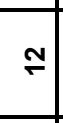 & $\mathbb{N}$ & $\cong$ & $\mathbb{N}$ & $\simeq$ & 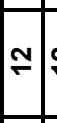 & $\cong \cong$ & $\approx$ & $\cong$ & N & $\mathbb{N}$ & $\simeq$ & $\cong$ \\
\hline 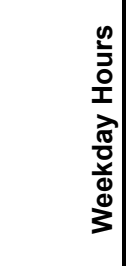 & & 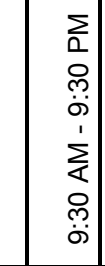 & & & 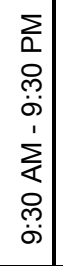 & & & $\begin{array}{l}\sum \\
n \\
0 \\
0 \\
0 \\
1 \\
1 \\
\vdots \\
0 \\
0 \\
0 \\
0\end{array}$ & & & $\begin{array}{l}\sum \\
0 \\
0 \\
0 \\
\dot{0} \\
1 \\
\sum \\
\vdots \\
0 \\
\dot{0}\end{array}$ & & 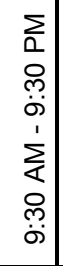 & & & & 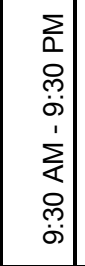 & & & & & 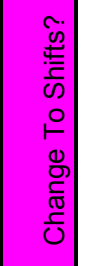 & & 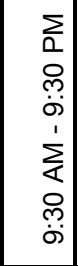 & 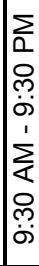 \\
\hline $\begin{array}{l}\overline{\bar{\sigma}} \\
\overline{2} \\
\frac{0}{0} \\
\overline{0} \\
\overline{0} \\
\bar{\omega} \\
\end{array}$ & & 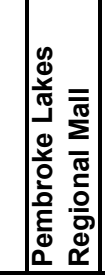 & & & 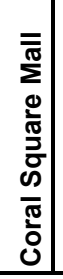 & & & 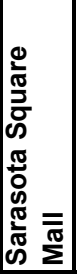 & & & 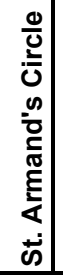 & & 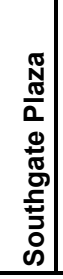 & & & & 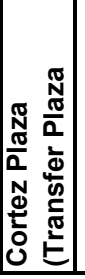 & & & & & 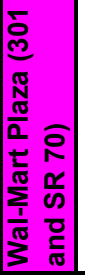 & . & 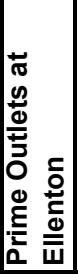 & 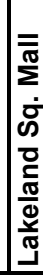 \\
\hline
\end{tabular}




\begin{tabular}{|c|c|c|c|c|c|c|c|c|c|c|c|c|c|c|c|c|c|c|c|c|c|c|}
\hline 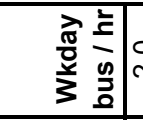 & $\stackrel{\circ}{i}$ & $\stackrel{\circ}{r}$ & $\stackrel{\circ}{r}$ & $\stackrel{\circ}{\circ}$ & مִ & $\stackrel{\sim}{\sim}$ & $\stackrel{\circ}{i}$ & $\stackrel{\sim}{-}$ & $\stackrel{\circ}{-}$ & $\widehat{i}$ & $\stackrel{\sim}{-}$ & $\begin{array}{l}0 \\
0\end{array}$ & 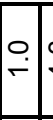 & 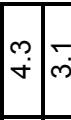 & $\dot{\sim}$ & $\circ$ & $\stackrel{0}{-}$ & مْْ & $\stackrel{\text { po }}{r}$ & $\mid$ & & $\stackrel{\circ}{\circ}$ \\
\hline 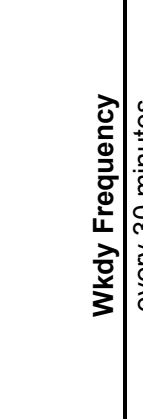 & 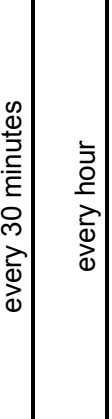 & 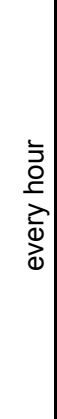 & 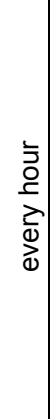 & 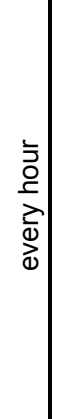 & 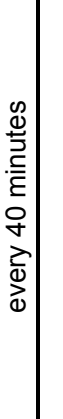 & 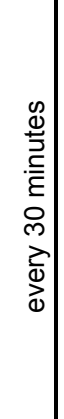 & 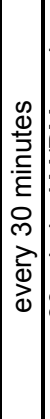 & 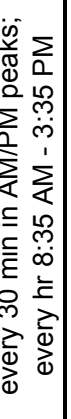 & 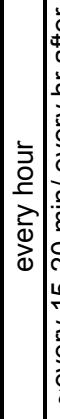 & 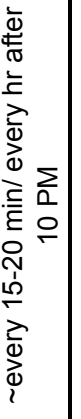 & 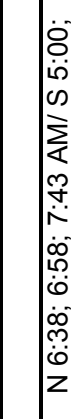 & 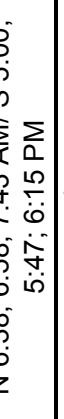 & 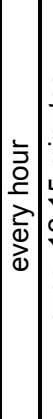 & 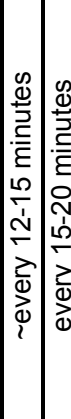 & 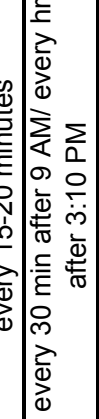 & $\left|\begin{array}{l}\bar{y} \\
0 \\
\frac{1}{2} \\
\frac{\lambda}{0} \\
\stackrel{0}{\alpha}\end{array}\right|$ & 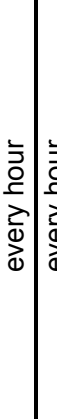 & 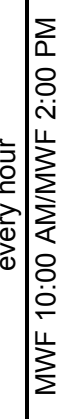 & 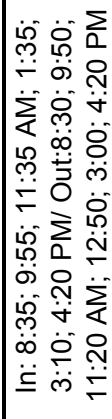 & 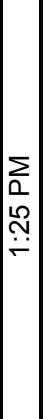 & & 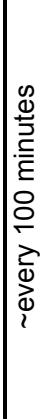 \\
\hline 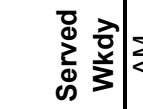 & $\sum_{<}$ & $\sum$ & $\sum_{k}$ & $\sum_{<}$ & $\mid \sum_{0}$ & $\sum$ & $\sum$ & $\sum$ & $\sum$ & $\sum_{<}^{\infty}$ & $\mid \sum_{\substack{n \\
\sum \\
\sum}}$ & $\sum$ & $\sum$ & $\sum_{\substack{\infty \\
<}} \sum_{<}$ & $\sum$ & $\sum$ & $\sum$ & $\sum$ & $\sum_{\&}$ & $\mid \sum_{4}$ & $\sum_{<}$ & \\
\hline 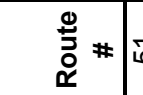 & is & $\mathbb{N}$ & $\stackrel{\mathscr{n}}{N}$ & $\stackrel{0}{N}$ & $\mathbb{N}$ & - & $m$ & จิ & $\mid \bar{N}$ & $m$ & $\sigma$ & 骣 & $\omega$ & $\infty \sum_{0}^{x}$ & $\bar{N}$ & $\stackrel{\Upsilon}{\sim}$ & $\stackrel{\searrow}{\sim}$ & N) & 0 & N & $\infty$ & 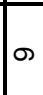 \\
\hline 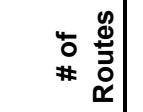 & -1 & $\nabla$ & & & & $\forall$ & & & & 0 & & & & & in & & & & $\nabla$ & & & \\
\hline 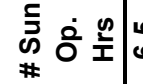 & ڤִ & 0 & 0 & 0 & 0 & $N$ & 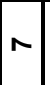 & $N$ & $r$ & o) & & 0 & 0 & 00 & $\Lambda$ & $\wedge$ & N & $r$ & r & N & $\wedge$ & r \\
\hline 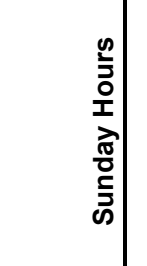 & $\begin{array}{l}\Sigma \\
0 \\
0 \\
\dot{0} \\
1 \\
\sum_{0} \\
0 \\
\stackrel{0}{\rightleftharpoons} \\
=\end{array}$ & $\begin{array}{l}\sum \\
0 \\
0 \\
\dot{0} \\
1 \\
\sum_{0} \\
0 \\
0 \\
\dot{i} \\
\end{array}$ & & & & 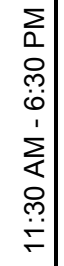 & & & & $\begin{array}{l}\sum \\
0 \\
0 \\
\stackrel{\sim}{1} \\
\sum_{0}^{1} \\
0 \\
0 \\
\dot{0}\end{array}$ & & & & & $\begin{array}{l}\sum \\
0 \\
0 \\
0 \\
0 \\
0 \\
1 \\
\vdots \\
0 \\
0 \\
\stackrel{0}{=}\end{array}$ & & & & 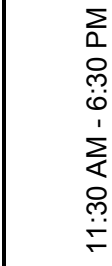 & & & \\
\hline 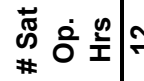 & 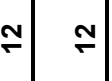 & $\cong$ & $\simeq$ & 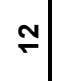 & $\mp$ & 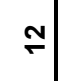 & $\cong$ & $\cong$ & $\cong$ & $\stackrel{n}{\stackrel{0}{\sim}}$ & & $\stackrel{\sim}{\stackrel{n}{\sim}}$ & : & 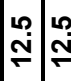 & 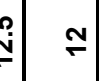 & 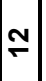 & $\stackrel{\overbrace{}}{\simeq}$ & $\mathfrak{N} \mid \simeq$ & 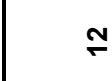 & $\cong$ & $\cong$ & $\cong$ \\
\hline 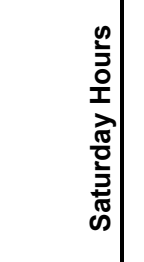 & 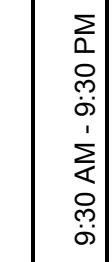 & 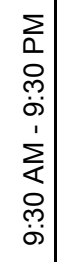 & & & & 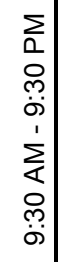 & & & & 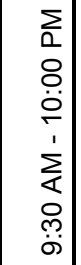 & & & & & $\begin{array}{l}\sum \\
0 \\
0 \\
0 \\
0 \\
1 \\
\sum_{\alpha} \\
0 \\
0 \\
0 \\
0\end{array}$ & & & & 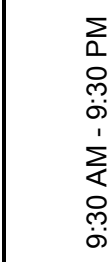 & & & \\
\hline 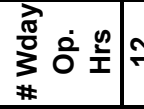 & $\cong$ & 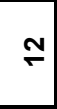 & $\cong$ & 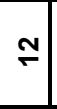 & $\cong$ & $\cong$ & $\cong$ & $\cong$ & $\cong$ & $\stackrel{\sim}{\stackrel{0}{N}}$ & & $\stackrel{\sim}{\stackrel{n}{ }}$ & 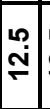 & 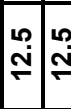 & $\simeq$ & $\cong$ & $\stackrel{F}{*}$ & $\mathbb{N} \mid \simeq$ & & $\cong$ & 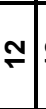 & $\cong$ \\
\hline 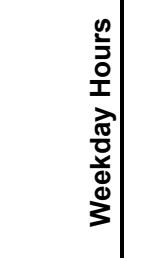 & 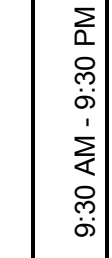 & $\begin{array}{l}\sum \\
0 \\
0 \\
0 \\
0 \\
\dot{1} \\
\sum_{0} \\
0 \\
0 \\
\dot{0}\end{array}$ & & & & 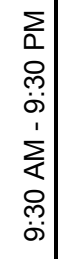 & & & & $\begin{array}{l}2 \\
0 \\
0 \\
0 \\
\dot{0} \\
1 \\
\sum_{0} \\
0 \\
0 \\
\dot{0}\end{array}$ & & & & & $\begin{array}{l}\sum \\
0 \\
0 \\
m \\
0 \\
1 \\
\sum_{0} \\
0 \\
0 \\
0 \\
0\end{array}$ & & & & 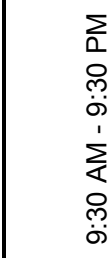 & & & \\
\hline 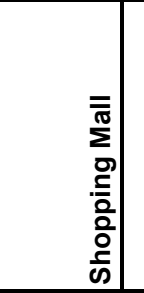 & 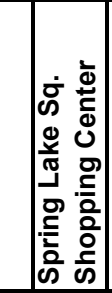 & 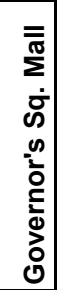 & & & 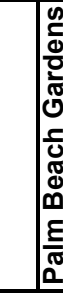 & 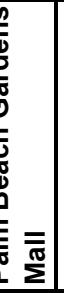 & & & & 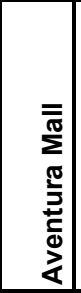 & & & & & 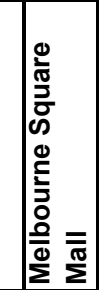 & & & & 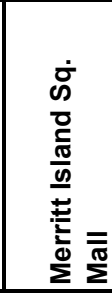 & & & \\
\hline
\end{tabular}




\begin{tabular}{|c|c|c|c|c|c|c|c|c|c|c|c|c|c|c|c|c|c|c|c|c|c|c|c|c|}
\hline 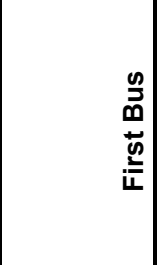 & 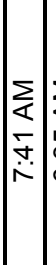 & $\left|\begin{array}{l}\sum \\
< \\
\infty \\
\infty \\
0 \\
0\end{array}\right|$ & 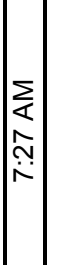 & 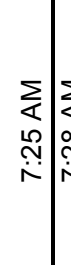 & 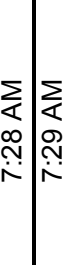 & 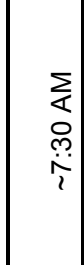 & $\mid$ & 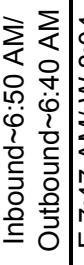 & 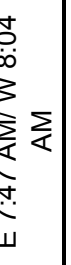 & 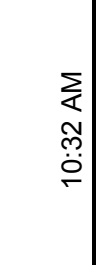 & 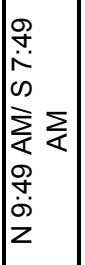 & 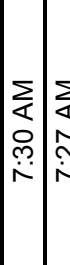 & 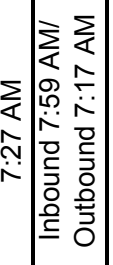 & 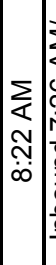 & 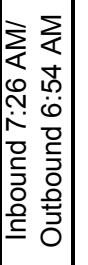 & & 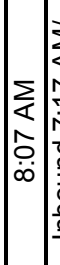 & 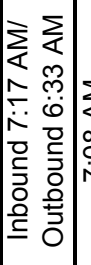 & 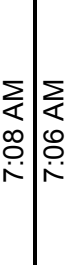 & : & 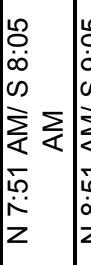 & 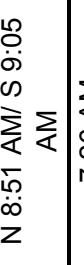 & 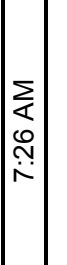 & 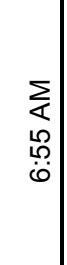 \\
\hline 完芯高 & $\stackrel{\circ}{-}$ & & $\stackrel{\infty}{-}$ & & $\stackrel{\circ}{-}$ & & & $\stackrel{\circ}{-}$ & $\stackrel{\circ}{-}$ & $\stackrel{\infty}{0}$ & & & $\stackrel{m}{\rightarrow}$ & & & & $\stackrel{0}{\circ}$ & & & & $\hat{\circ}$ & & & $\stackrel{\circ}{\mathbf{N}}$ \\
\hline 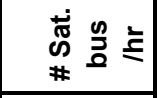 & $\stackrel{\circ}{-}$ & $\stackrel{\circ}{-}$ & ì & ํ. & $\stackrel{m}{\stackrel{\infty}{\sim}}$ & $\stackrel{m}{\leftarrow}$ & $\stackrel{m}{-}$ & $\stackrel{\circ}{r}$ & $\stackrel{\circ}{-}$ & م. & : & $\stackrel{\circ}{-}$ & $\stackrel{\circ}{-}$ & $\stackrel{\circ}{\sim}$ & $\stackrel{\circ}{\dot{r}}$ & $\because$ & $\stackrel{\circ}{r}$ & $\stackrel{\circ}{-}$ & $\stackrel{\circ}{-}$ & $\stackrel{\circ}{-}$ & مْ & ?ִ & $\stackrel{\circ}{-}$ & $\stackrel{\circ}{i}$ \\
\hline 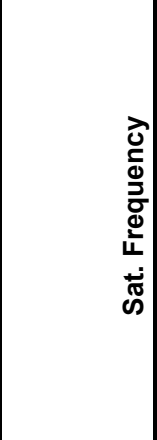 & 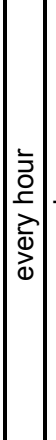 & 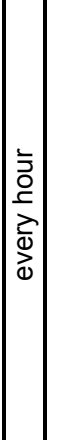 & 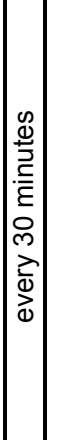 & 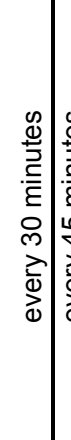 & 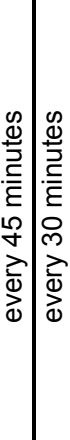 & 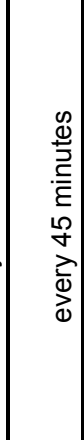 & 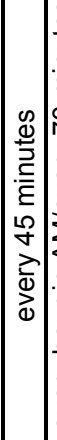 & 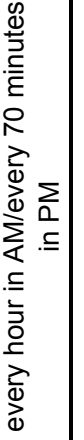 & 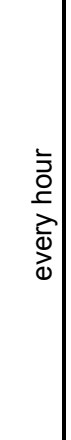 & 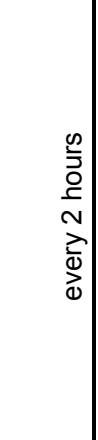 & 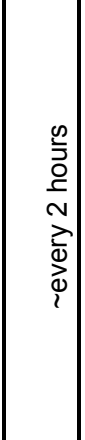 & 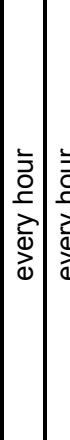 & 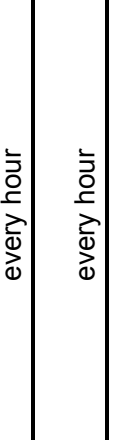 & 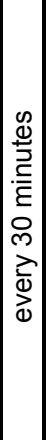 & 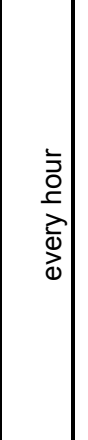 & & 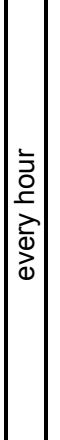 & 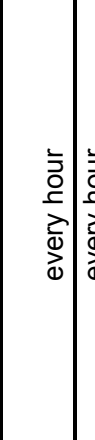 & 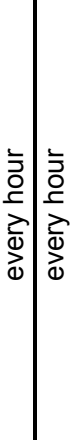 & 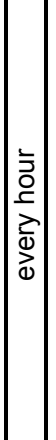 & 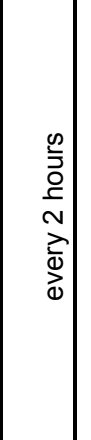 & 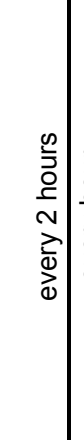 & 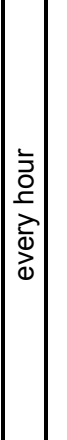 & 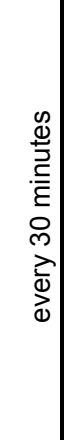 \\
\hline 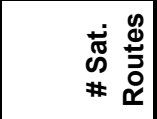 & N & & & & & & & & & & & & $m$ & & & & in & & & & $m$ & & & m \\
\hline 离 & $\sum_{<}$ & $\mid \sum$ & $\sum$ & $\sum_{<}$ & $\sum_{<} \mid \sum_{<}$ & $\sum$ & $\sum_{<}$ & $\sum$ & $\sum_{\substack{n \\
<}}^{\infty}$ & & $\sum$ & $\sum \sum$ & $\sum_{<}$ & $\sum$ & $\sum$ & & $\mid \sum$ & $\sum \sum$ & $\sum_{<} \sum_{<}$ & $\mid \sum$ & $\sum$ & $\sum$ & $\mid \sum$ & $\sum_{\substack{\infty \\
c}}^{\infty}$ \\
\hline 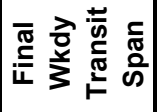 & 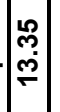 & & $\mid$ & & m̧ & & & $\stackrel{\circ}{\circ}$ & $\begin{array}{l}\stackrel{m}{\infty} \\
\stackrel{\rho}{\sim}\end{array}$ & 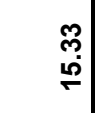 & & & $\stackrel{\infty}{\stackrel{\oplus}{N}}$ & & & & 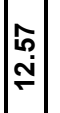 & & & & 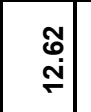 & & & 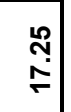 \\
\hline 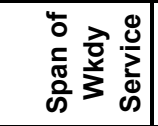 & 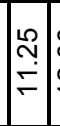 & 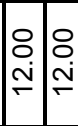 & $\mid$ & 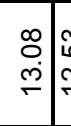 & 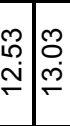 & $\begin{array}{l}8 \\
\dot{m} \\
\stackrel{\square}{-}\end{array}$ & $\mid$ & $\stackrel{8}{+}$ & $\begin{array}{l}\stackrel{m}{m} \\
\stackrel{p}{\sim}\end{array}$ & 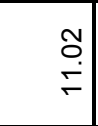 & $\begin{array}{l}\stackrel{\sim}{\sim} \\
\stackrel{\sim}{\sim}\end{array}$ & 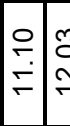 & $\stackrel{\hat{N}}{\stackrel{\Gamma}{\leftarrow}}$ & $\stackrel{f}{\stackrel{f}{r}}$ & $\stackrel{\stackrel{\circ}{\circ}}{\leftarrow}$ & 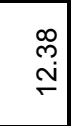 & 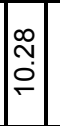 & 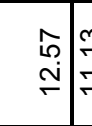 & $\stackrel{m}{\stackrel{m}{\rightleftarrows}}$ & 占 & $\begin{array}{l}\stackrel{N}{1} \\
\stackrel{\circ}{0}\end{array}$ & 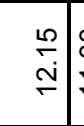 & 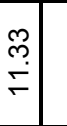 & $\begin{array}{l}\infty \\
0 \\
\oplus\end{array}$ \\
\hline 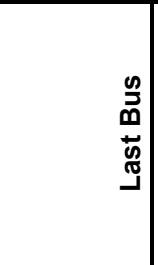 & $\left|\begin{array}{l}\sum \\
0 \\
0 \\
0 \\
0\end{array}\right|$ & 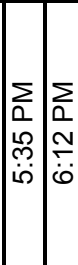 & $\left|\begin{array}{l}\mid \\
0 \\
0 \\
0 \\
0 \\
0\end{array}\right|$ & 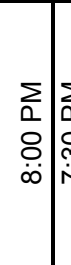 & 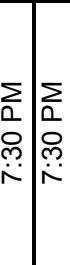 & $\mid \begin{array}{ll}3 & \\
\sum_{n} & \vdots \\
0 & 0 \\
0 & 0 \\
p & 0 \\
& 1 \\
1 & 1 \\
w & 1\end{array}$ & 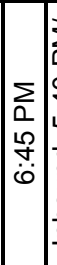 & 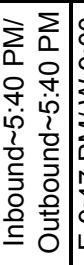 & 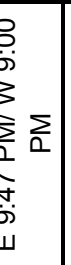 & 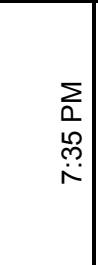 & 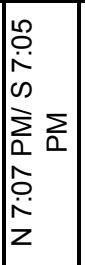 & 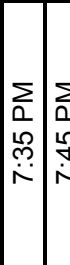 & 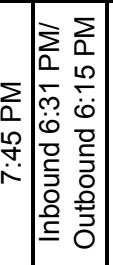 & 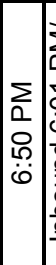 & 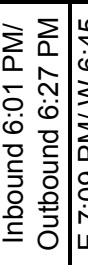 & 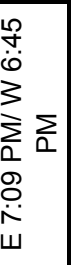 & 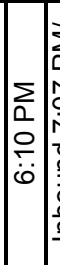 & 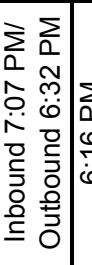 & 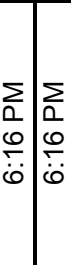 & 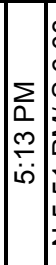 & 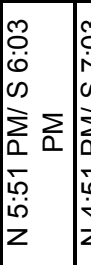 & 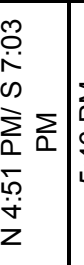 & $\mid \begin{array}{l}\sum_{0} \\
0 \\
0 \\
0 \\
i j \\
i\end{array}$ & $\begin{array}{l}\sum \\
0 \\
0 \\
0 \\
0 \\
0\end{array}$ \\
\hline 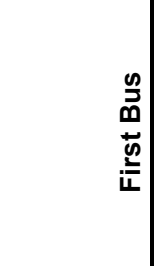 & $\left|\begin{array}{l}\sum \\
\vdots \\
\dot{x} \\
\dot{\lambda}\end{array}\right|$ & 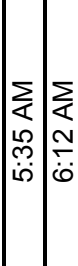 & 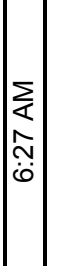 & 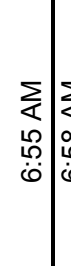 & 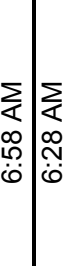 & $\mid \begin{array}{ll}3 & \\
\sum & 2 \\
\vdots & 2 \\
0 & 8 \\
0 & 0 \\
0 & 0 \\
1 & 1 \\
w & 1\end{array}$ & 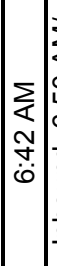 & 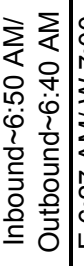 & 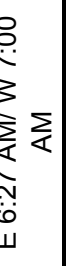 & $\begin{array}{c} \\
\sum \\
\infty \\
\infty \\
\infty \\
\dot{0}\end{array}$ & 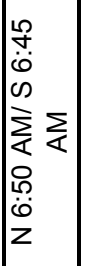 & 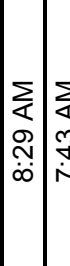 & 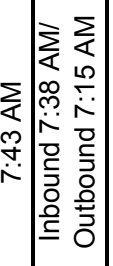 & 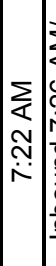 & 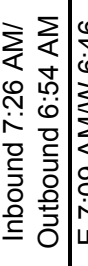 & 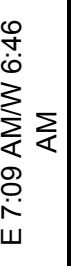 & 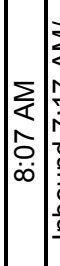 & 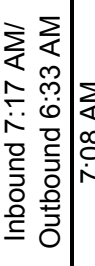 & 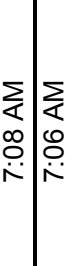 & 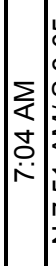 & 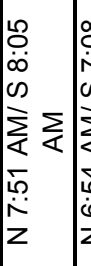 & 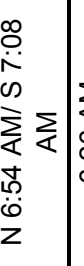 & 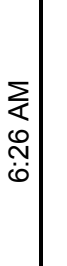 & 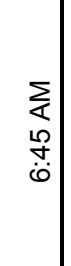 \\
\hline 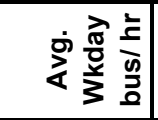 & $\stackrel{\circ}{-}$ & & $\mid$ & & ip & & & $\stackrel{\circ}{r}$ & $\stackrel{0}{-}$ & $\stackrel{\circ}{\circ}$ & & & $\stackrel{m}{\sim}$ & & & & $\stackrel{0}{-}$ & & & & $\hat{\circ}$ & & & $\stackrel{0}{\circ}$ \\
\hline 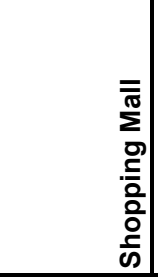 & 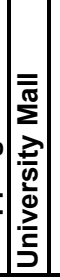 & & 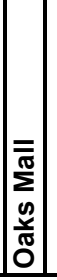 & & 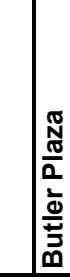 & & & 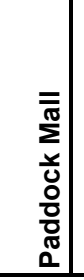 & 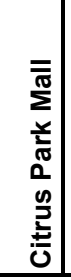 & 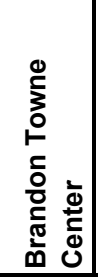 & & & 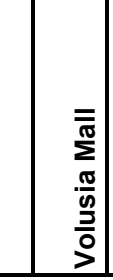 & & & & 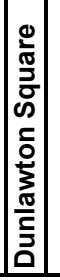 & & & & 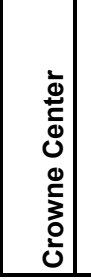 & & & 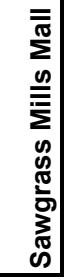 \\
\hline
\end{tabular}




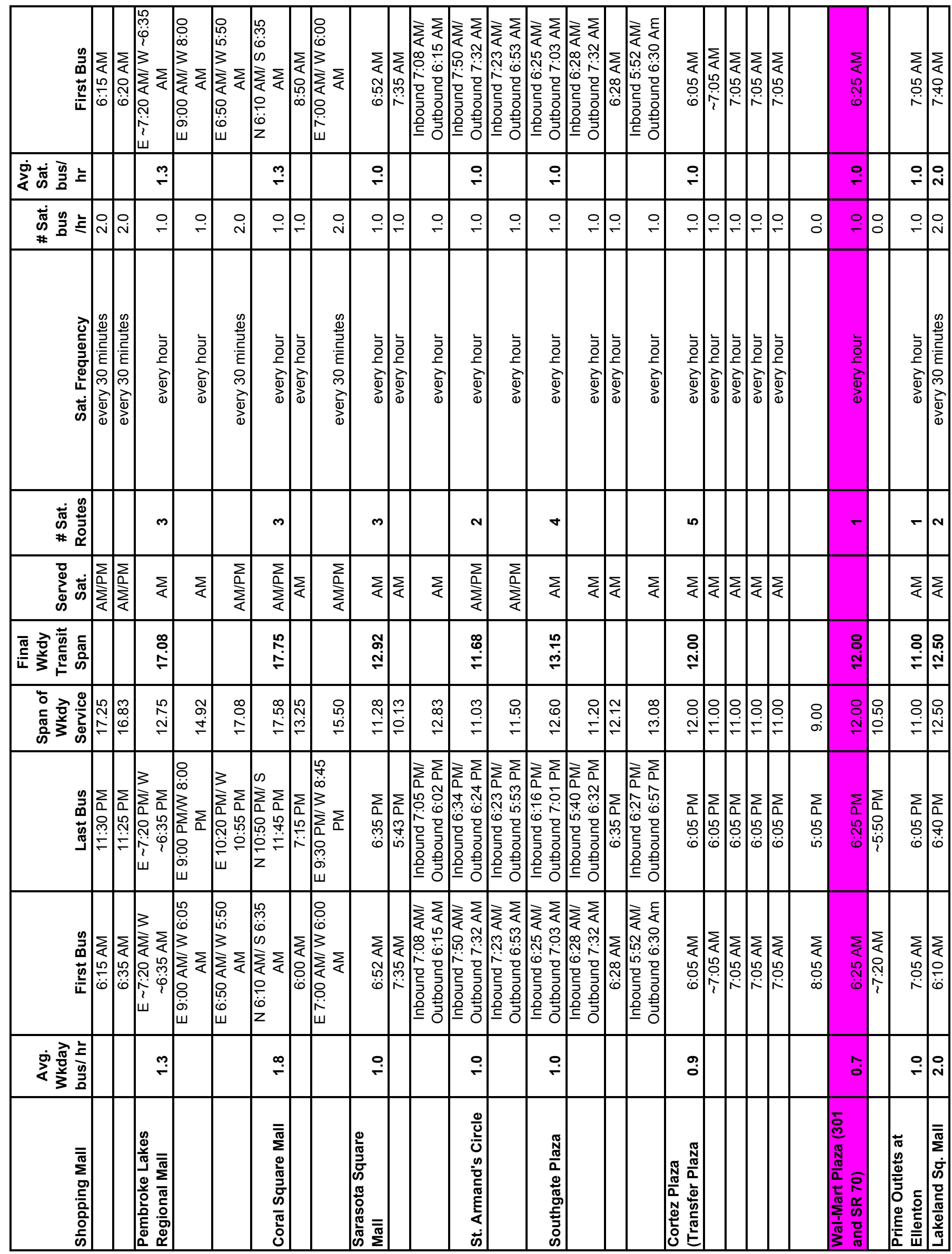




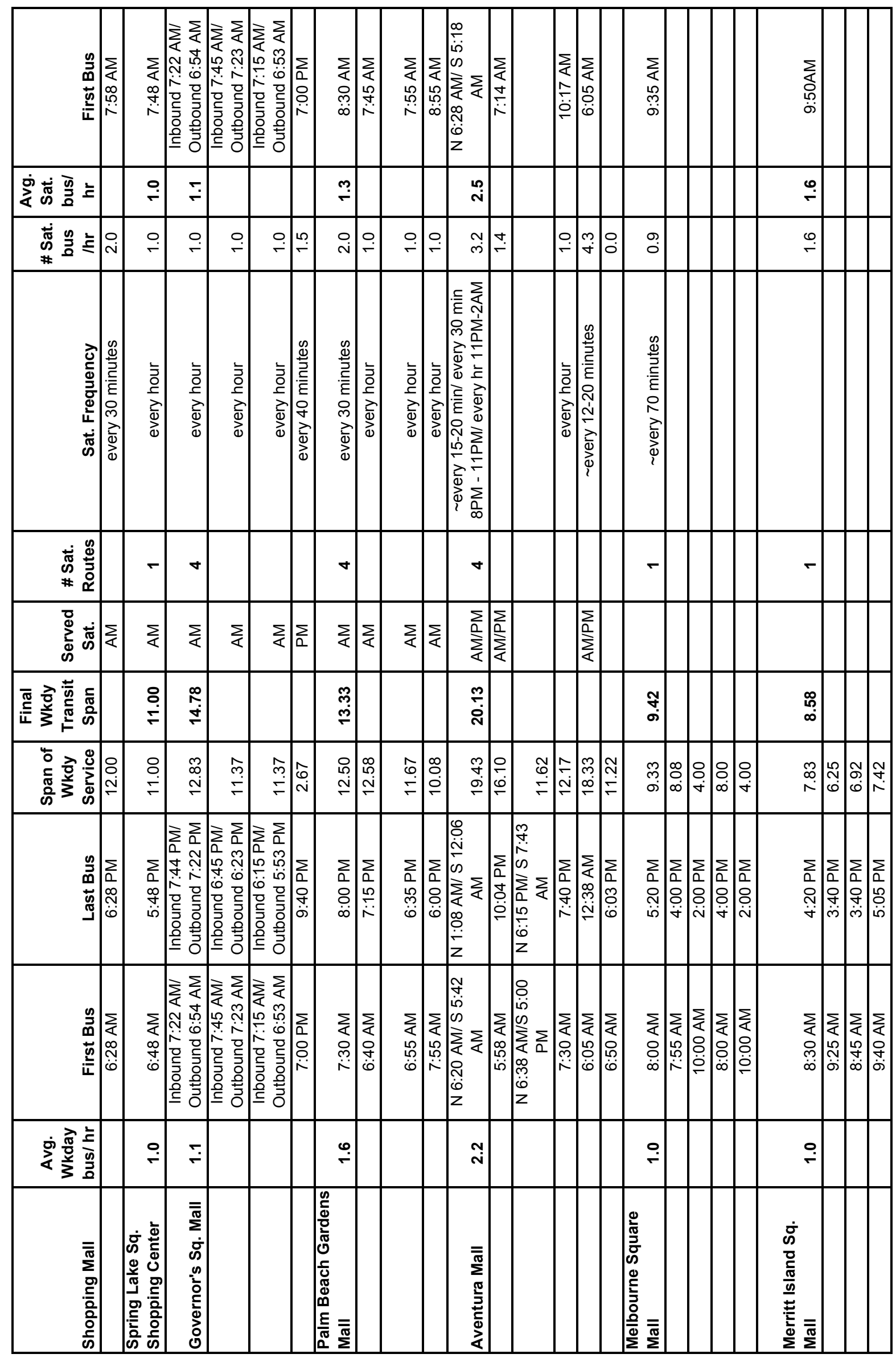




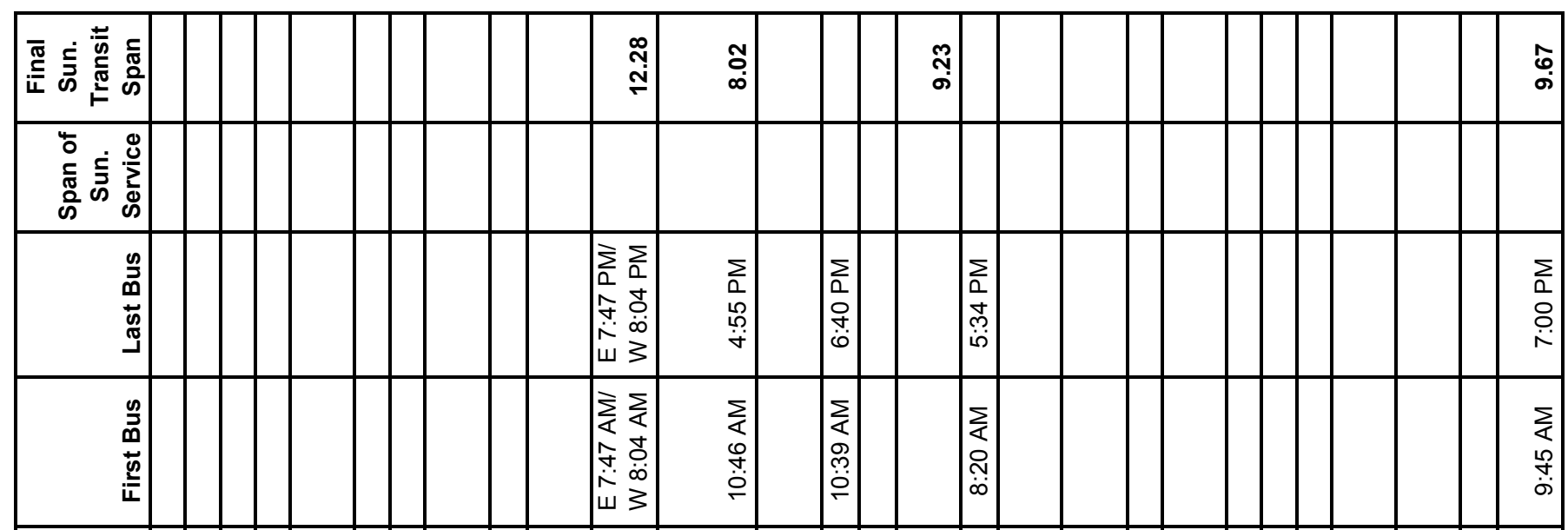

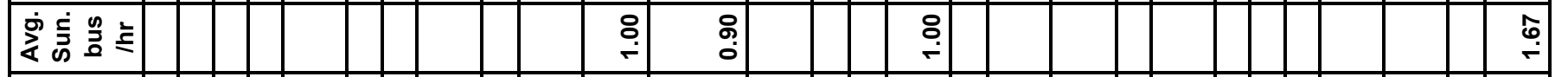

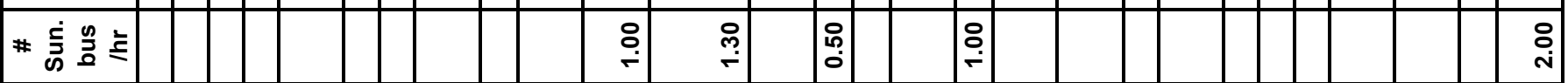

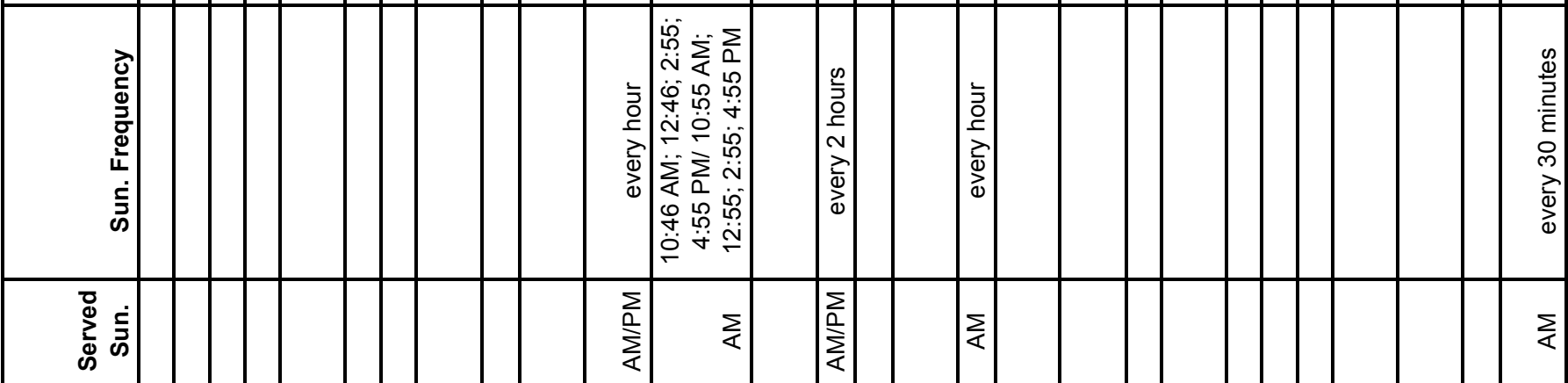

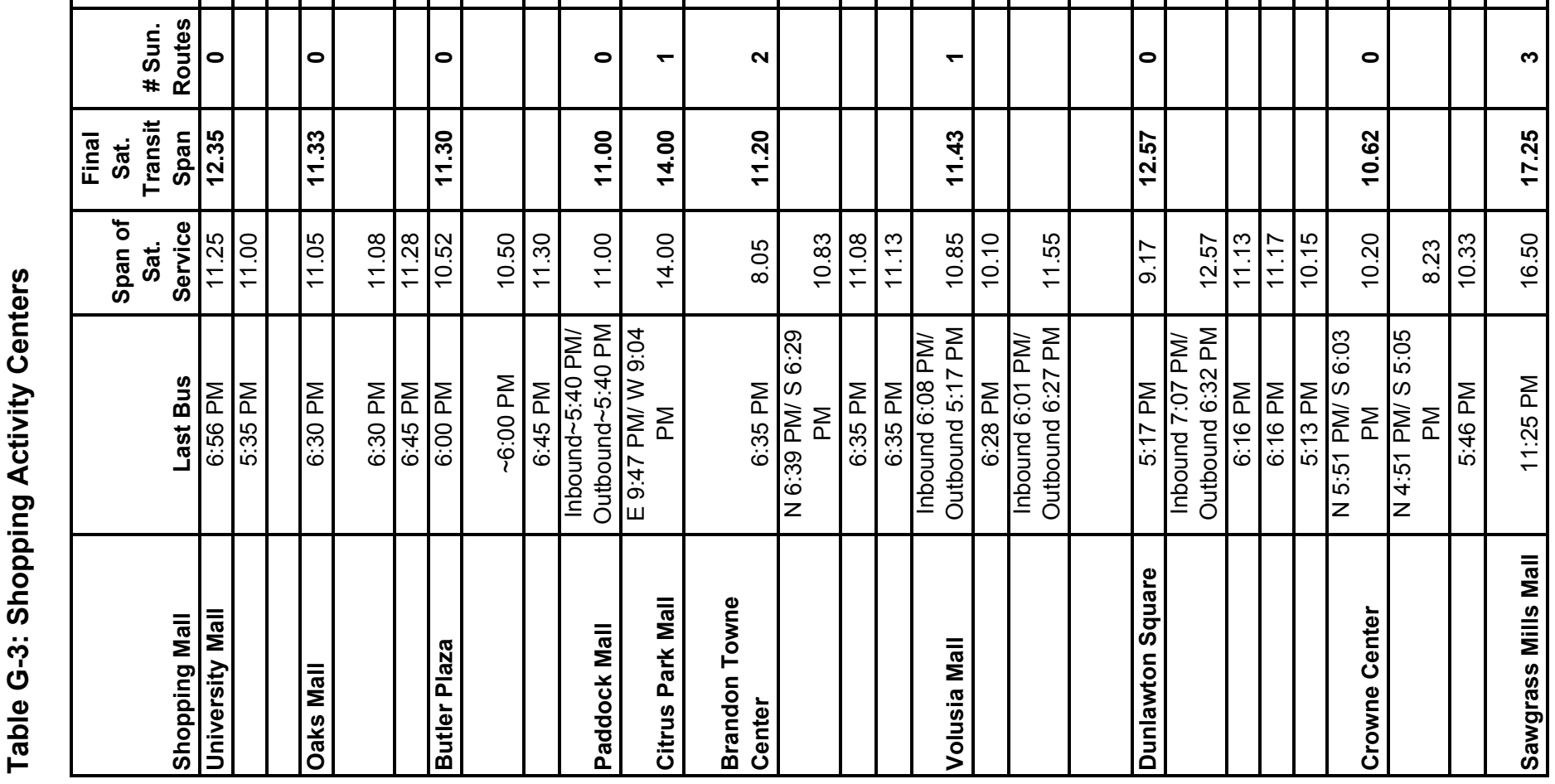




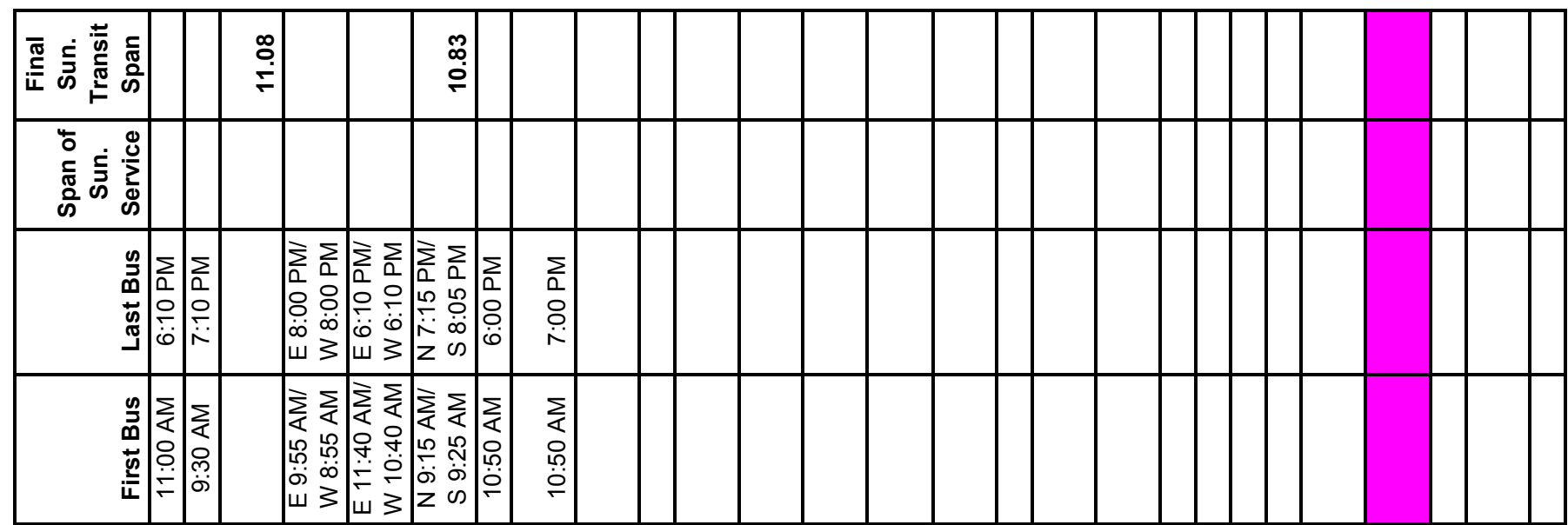

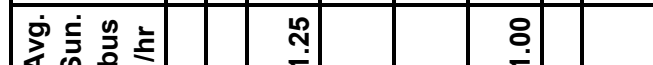

* 它 号主

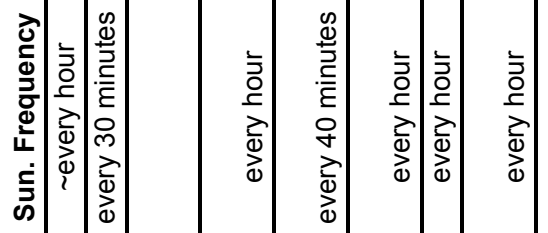

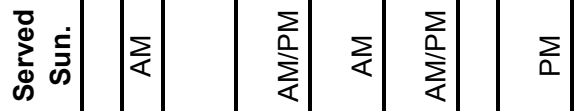

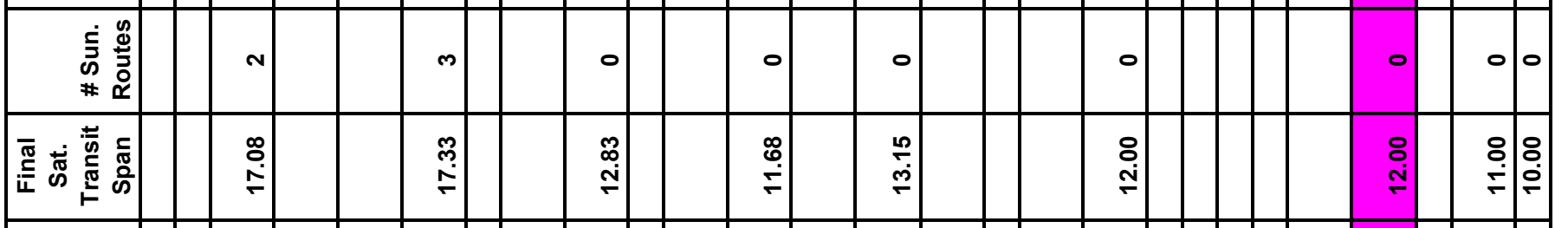

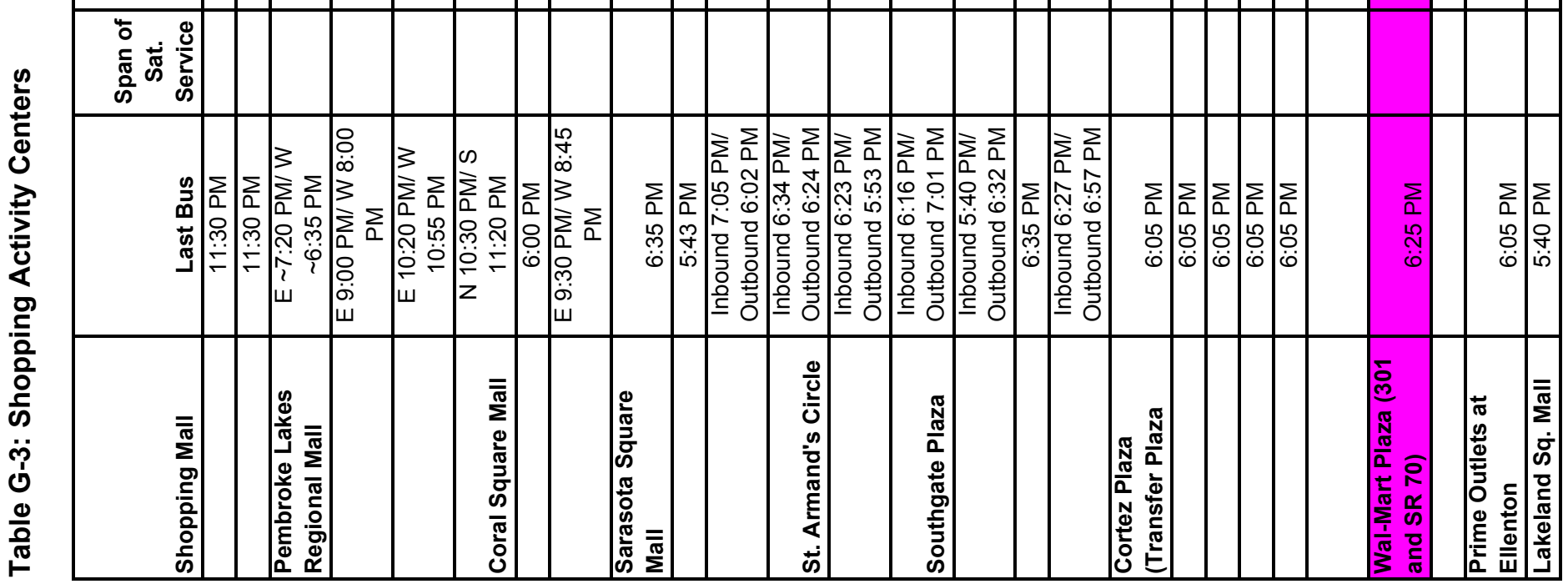




\begin{tabular}{|c|c|c|c|c|c|c|c|c|c|c|c|c|c|c|c|c|c|}
\hline 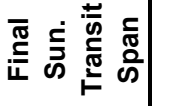 & & ल⿸户 & & & & $\stackrel{\sim}{N}$ & & & & 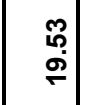 & & & & $\frac{0}{i}$ & & & \\
\hline 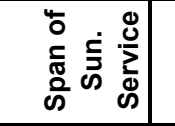 & & & & & & & & & & $\begin{array}{l}L \\
0 \\
\stackrel{\circ}{\circ}\end{array}$ & $\stackrel{-}{\dot{\sim}}$ & & 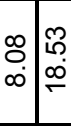 & & & & \\
\hline 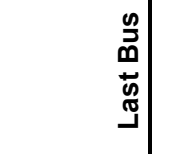 & & & & & $\mid \begin{array}{l}\Sigma \\
0 \\
0 \\
0 \\
\text { in }\end{array}$ & $\begin{array}{l}\sum_{0} \\
\vdots \\
0 \\
\dot{i}\end{array}$ & 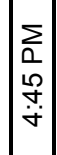 & 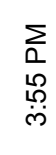 & $\mid \begin{array}{l}\Sigma \\
0 \\
\varnothing \\
\dot{+}\end{array}$ & 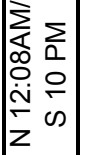 & 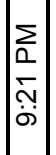 & & 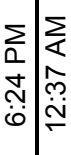 & $\begin{array}{l}\sum_{0} \\
0 \\
\dot{i} \\
\text { in }\end{array}$ & & & \\
\hline 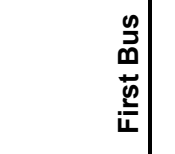 & & & & & 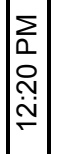 & 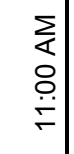 & 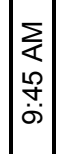 & $\begin{array}{l}\sum \\
\llcorner \\
0 \\
0 \\
0\end{array}$ & 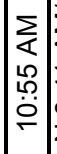 & 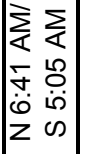 & 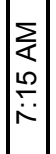 & & 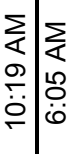 & $\begin{array}{l}\underset{\Sigma}{\Sigma} \\
\dot{t} \\
\stackrel{+}{\leftarrow}\end{array}$ & & & \\
\hline 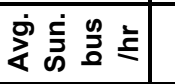 & & ํํㅁ & & & & $\stackrel{8}{\circ}$ & & & & $\begin{array}{l} \\
\text { ì } \\
\end{array}$ & & & & $\begin{array}{l}0 \\
\infty \\
\end{array}$ & & $\begin{array}{l}0 \\
\\
0\end{array}$ & \\
\hline \#空号 & & & & & ?ִ & $\stackrel{8}{\circ}$ & $\stackrel{8}{-}$ & $\stackrel{8}{-}$ & ষ্் & $\stackrel{\bullet}{\sim}$ & 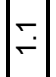 & & $\stackrel{\circ}{-} \underset{m}{m}$ & $\begin{array}{l}\mathscr{D} \\
\stackrel{N}{i}\end{array}$ & & $\stackrel{8}{0}$ & \\
\hline 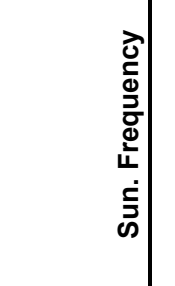 & & & & & 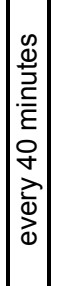 & $\begin{array}{l}\vdots \\
0 \\
\frac{0}{2} \\
⿱ 亠 乂 \\
0 \\
0 \\
0\end{array}$ & 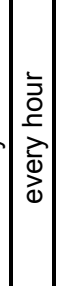 & 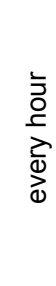 & 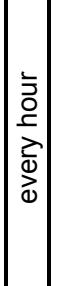 & 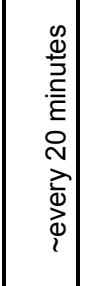 & & & 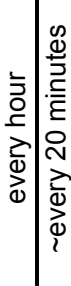 & 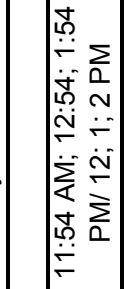 & & & \\
\hline 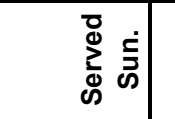 & & & & & & $\sum_{<}$ & $\sum_{<}$ & $\sum_{<}$ & $\left|\sum\right|$ & $\sum_{\substack{n \\
<}}^{\infty}$ & $\sum_{\substack{\infty \\
<}}$ & & $\sum_{<} \sum_{\substack{\infty \\
<}}$ & & & & \\
\hline 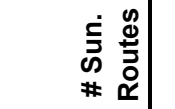 & 0 & - & & & & $\nabla$ & & & & $\nabla$ & & & & - & & 0 & \\
\hline 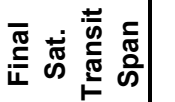 & $\stackrel{8}{\circ}$ & 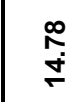 & & & & $\stackrel{\infty}{\stackrel{\infty}{+}}$ & & & & 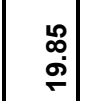 & & & & @̣ & & 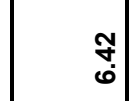 & \\
\hline 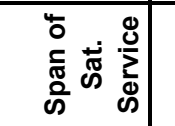 & & & & & & & & & & 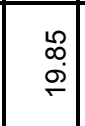 & 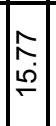 & & 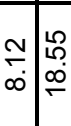 & & & & \\
\hline 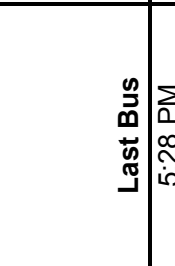 & $\begin{array}{l}\sum_{0} \\
\infty \\
\dot{+} \\
\dot{+}\end{array}$ & 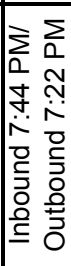 & 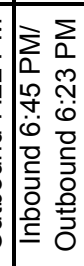 & 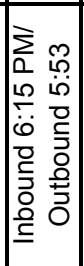 & $\begin{array}{l}\Sigma \\
0 \\
0 \\
0 \\
0 \\
0 \\
0\end{array}$ & $\begin{array}{l}\sum \\
0 \\
0 \\
0 \\
0\end{array}$ & 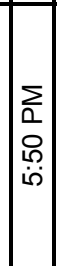 & $\begin{array}{l}\sum_{0} \\
0 \\
0 \\
\dot{\rho}\end{array}$ & 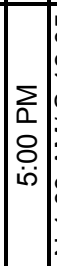 & 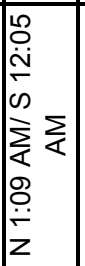 & $\mid \begin{array}{l}2 \\
0 \\
0 \\
0 \\
\\
\end{array}$ & & 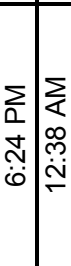 & 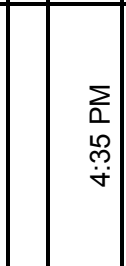 & & 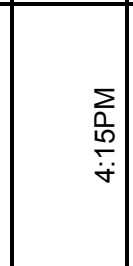 & \\
\hline $\begin{array}{l}\overline{\bar{\sigma}} \\
\sum_{0} \\
\frac{0}{\bar{c}} \\
\overline{\frac{0}{0}} \\
\frac{0}{\omega}\end{array}$ & 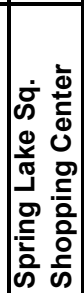 & 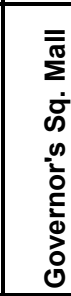 & & & & 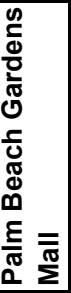 & & & & 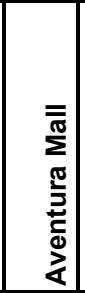 & & & & 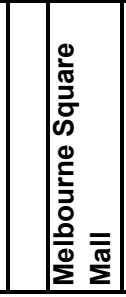 & & 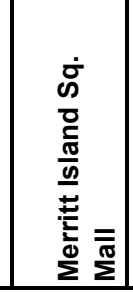 & \\
\hline
\end{tabular}


\#志

空

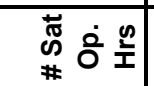
离 $\frac{\underline{\varphi}}{\frac{\varphi}{I}}$

产党 *

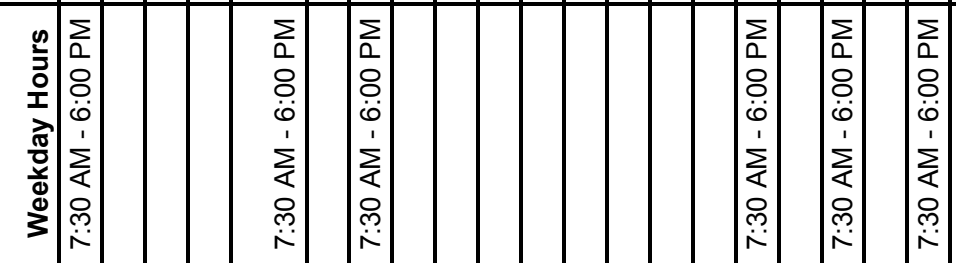

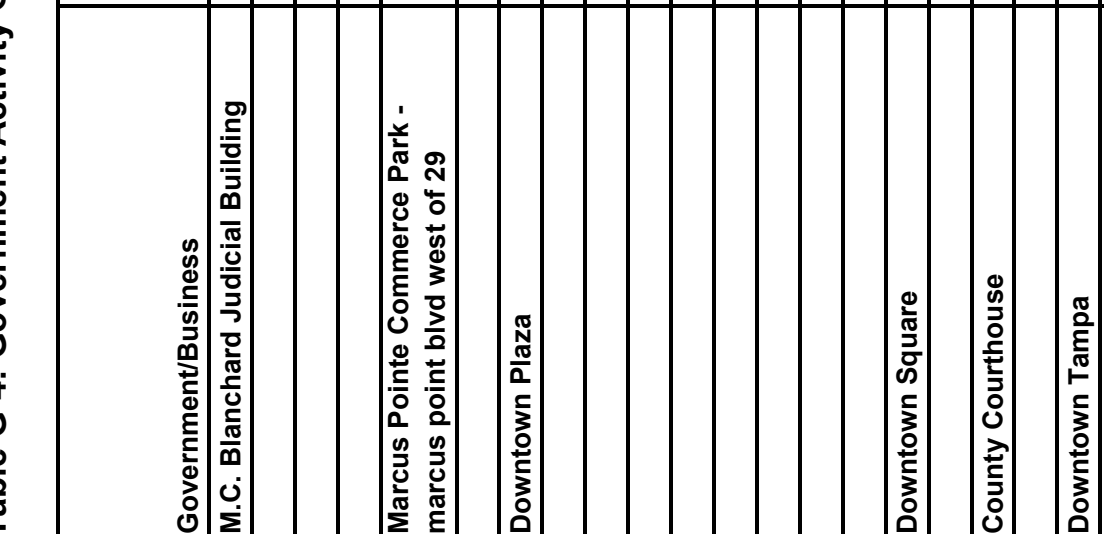




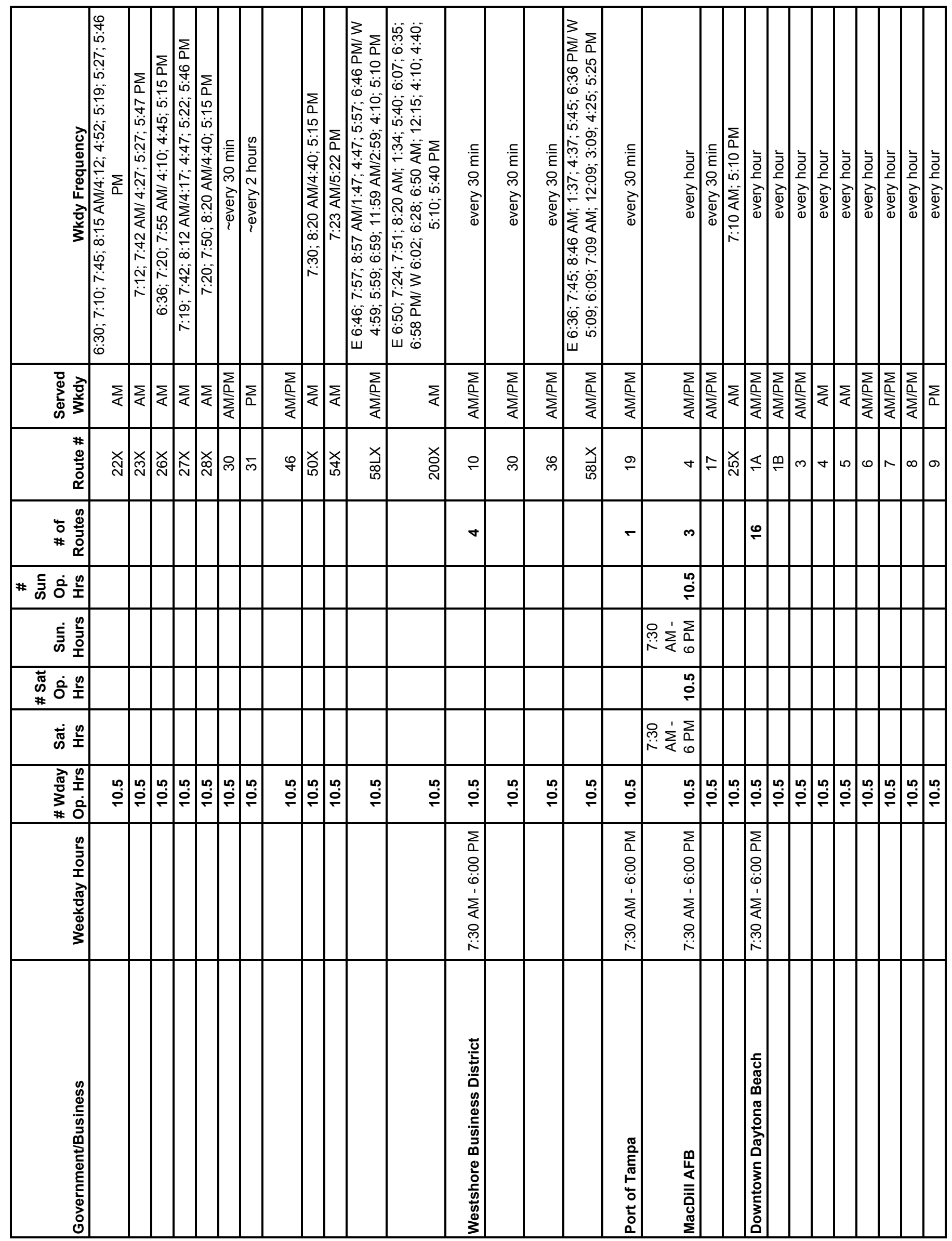




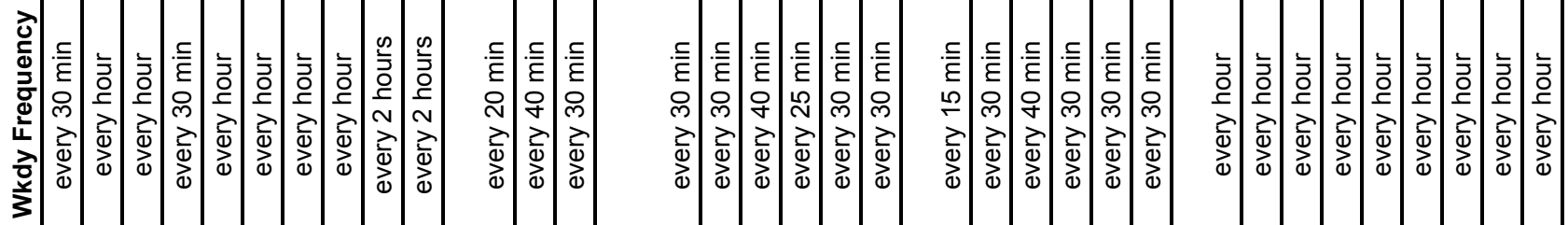

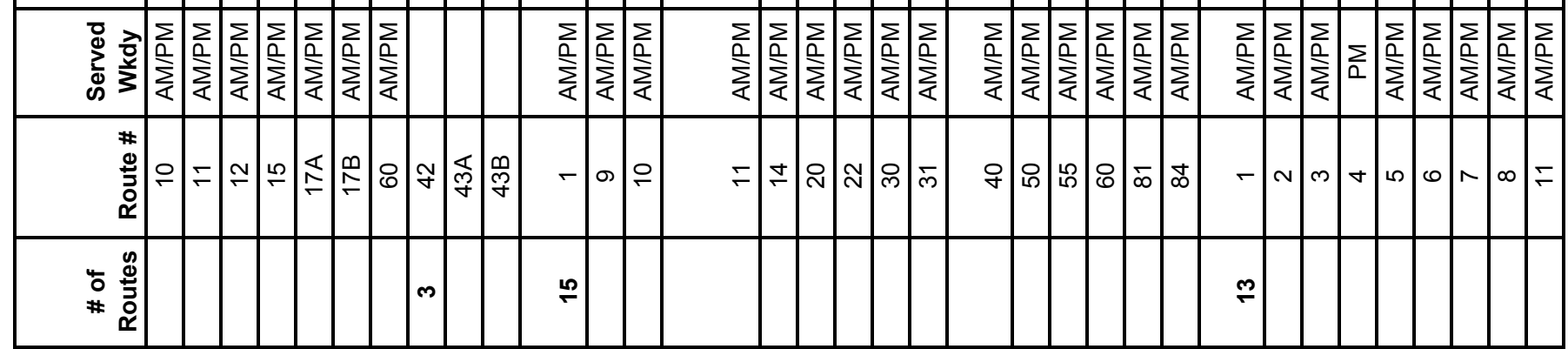

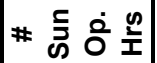

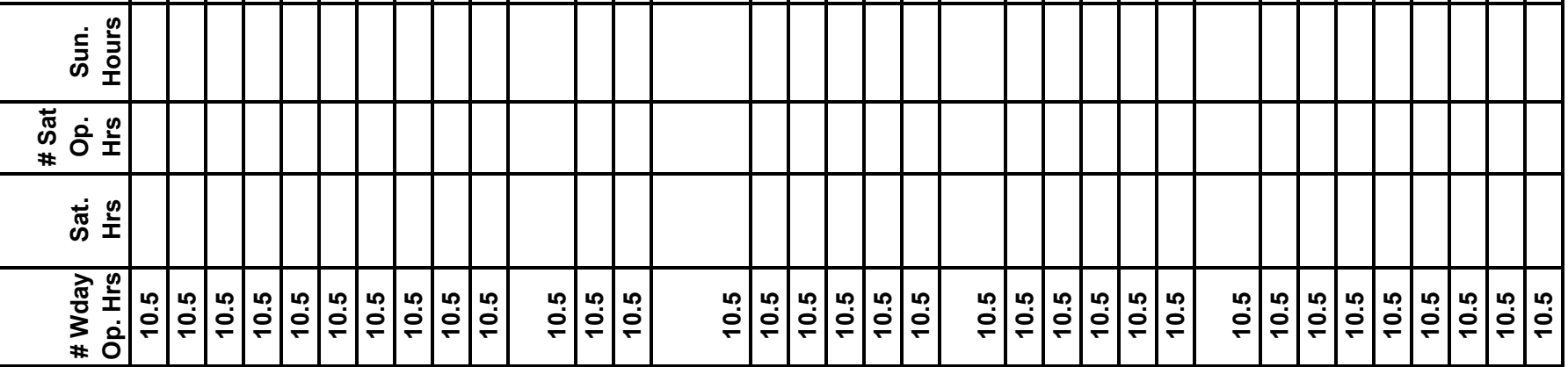

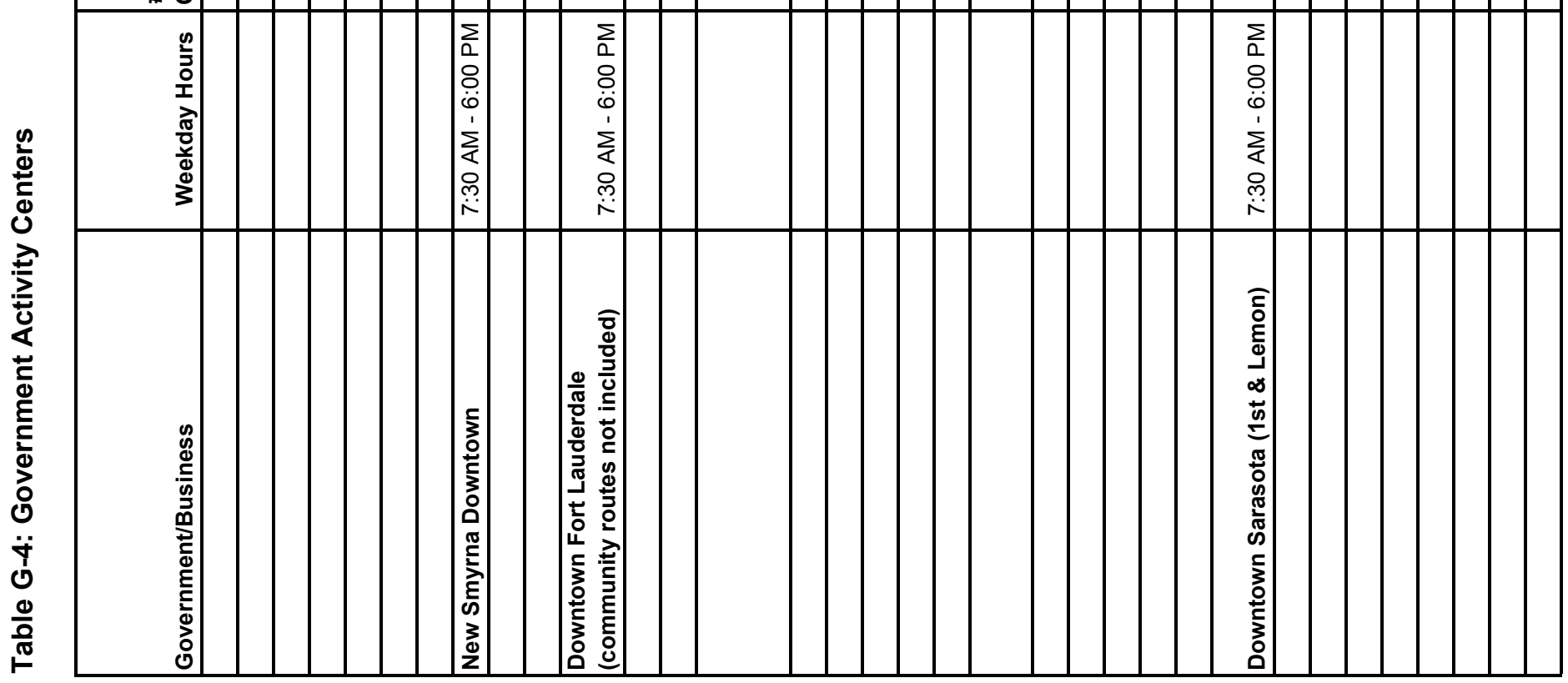




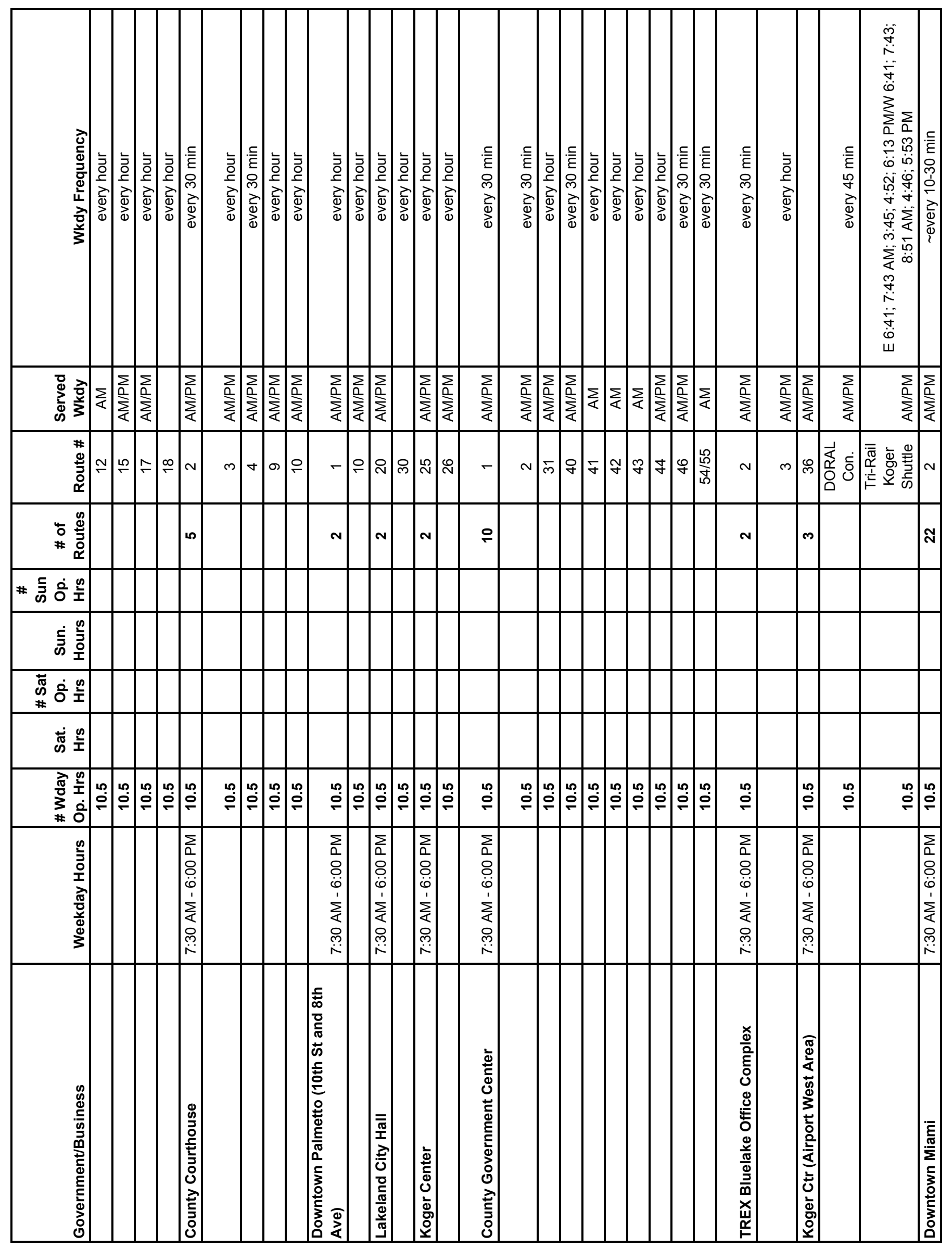




\begin{tabular}{|c|c|c|c|c|c|c|c|c|c|c|c|c|c|c|c|c|c|c|c|c|c|c|}
\hline 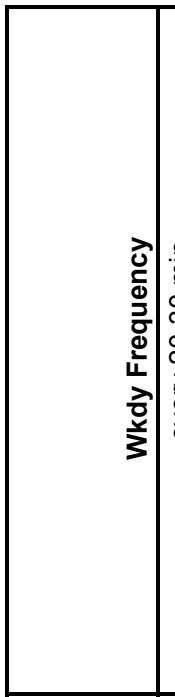 & 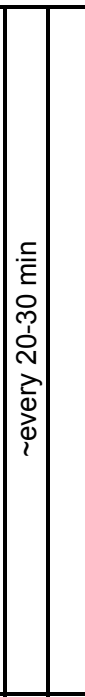 & 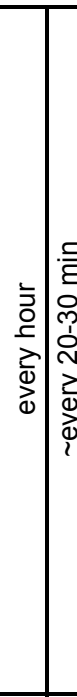 & 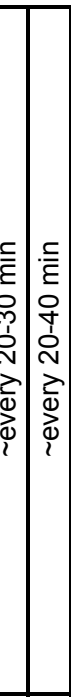 & 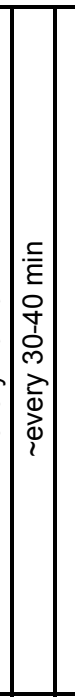 & 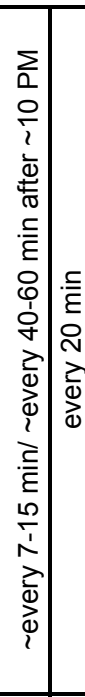 & 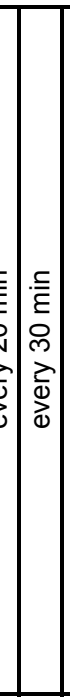 & 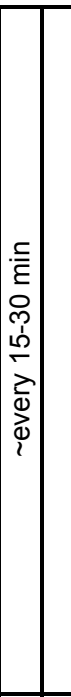 & 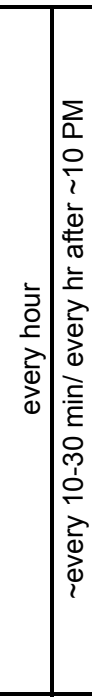 & 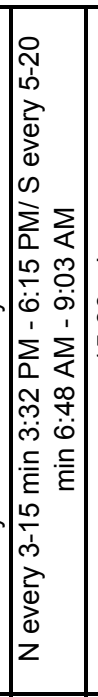 & 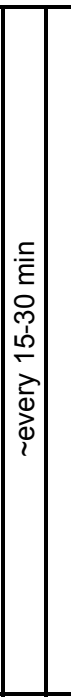 & 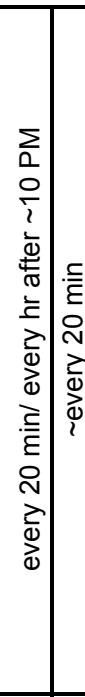 & 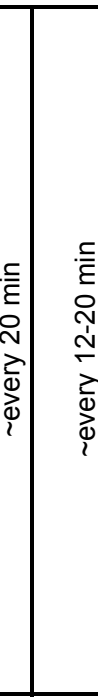 & 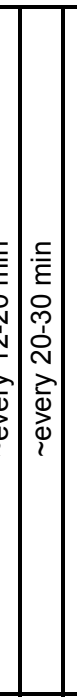 & 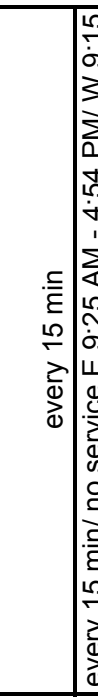 & 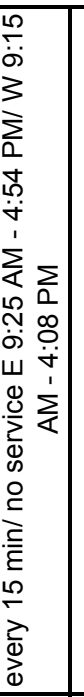 & 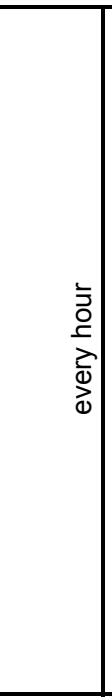 & 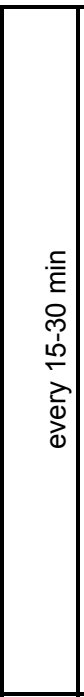 & 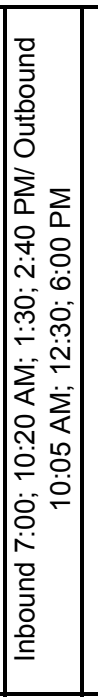 & 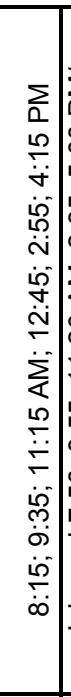 & 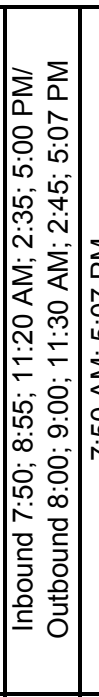 & 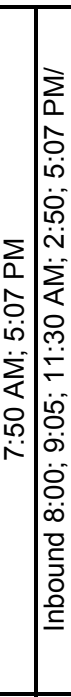 & 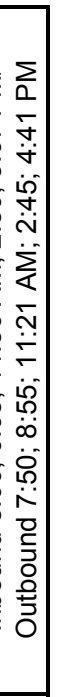 \\
\hline 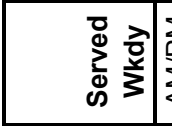 & $\sum_{\substack{1 \\
\sum}}$ & $\sum_{\substack{\infty \\
\infty}}^{\infty}$ & 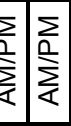 & $\sum_{\substack{\infty \\
\sum}}^{\infty}$ & $\sum_{\substack{0 \\
\sum}} \sum_{\substack{\infty \\
\sum}}$ & $\sum \sum_{\substack{\infty \\
\sum}}$ & $\sum_{\substack{n \\
\sum}}$ & 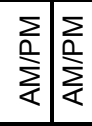 & $\sum_{\substack{n \\
<}}$ & $\sum_{\substack{n \\
\sum}}$ & $\sum_{\substack{0 \\
\sum}} \sum_{\substack{k \\
\sum}}$ & $\sum_{\substack{\infty \\
\sum}}$ & 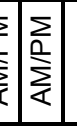 & $\sum_{\substack{n \\
<}}$ & $\sum_{\substack{0 \\
\sum}}$ & $\sum_{0}$ & $\sum_{\substack{\infty \\
<}}^{1}$ & $\sum$ & & & & \\
\hline 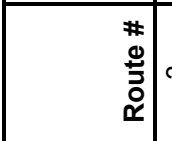 & m & $0 \wedge$ & 0 & 은 & $\mp \because$ & $2 \bar{N}$ & $\stackrel{\Delta}{N}$ & $\stackrel{\infty}{\sim} \mid \widehat{\wedge}$ & $\begin{array}{l}\times \\
\text { 怘 }\end{array}$ & $\infty$ & צ| & $\infty$ & 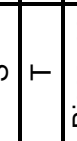 & 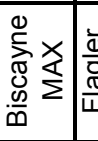 & 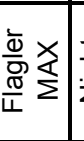 & 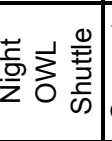 & 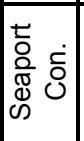 & م & 0 & $\infty:$ & $\mp$ & $\stackrel{N}{N}$ \\
\hline 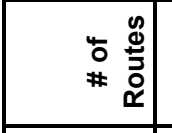 & & & & & & & & & & & & & & & & & & $r$ & $r$ & $m$ & & \\
\hline 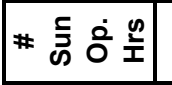 & & & & & & & & & & & & & & & & & & & & & & \\
\hline 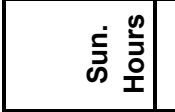 & & & & & & & & & & & & & & & & & & & & & & \\
\hline 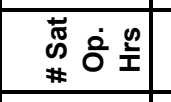 & & & & & & & & & & & & & & & & & & & & & & \\
\hline 芯茥 & & & & & & & & & & & & & & & & & & & & & & \\
\hline 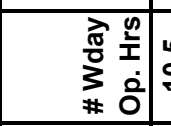 & $\begin{array}{l}0 \\
0 \\
0\end{array}$ & $\begin{array}{lll}0 \\
0 \\
0\end{array}$ & 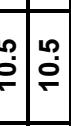 & 足 & $\begin{array}{lll}0 \\
0\end{array}$ & $\begin{array}{l}? \\
? \\
:\end{array}$ & \begin{tabular}{l}
$\mid$ \\
0 \\
0 \\
\hdashline
\end{tabular} & \begin{tabular}{l|l}
0 \\
0 \\
0
\end{tabular} & : & $\mid \begin{array}{l}0 \\
0 \\
0\end{array}$ & $\begin{array}{l}n \\
\stackrel{0}{0}\end{array}$ & \begin{tabular}{l}
0 \\
$\stackrel{0}{0}$ \\
\hdashline
\end{tabular} & 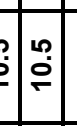 & $\begin{array}{l}\stackrel{\varphi}{0} \\
\stackrel{0}{0}\end{array}$ & $\begin{array}{l}\text { مُ } \\
\stackrel{0}{0}\end{array}$ & $\begin{array}{l}0 \\
\stackrel{0}{0} \\
\stackrel{0}{2}\end{array}$ & $\begin{array}{l}0 \\
0 \\
0\end{array}$ & $\begin{array}{l}n \\
\stackrel{0}{0} \\
0\end{array}$ & $\begin{array}{l}\text { D. } \\
\stackrel{0}{0}\end{array}$ & 占: & $\begin{array}{l}0 \\
0 \\
0\end{array}$ & $\stackrel{\text { ְ̊ }}{\stackrel{\rho}{\circ}}$ \\
\hline 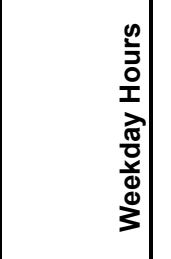 & & & & & & & & & & & & & & & & & & $\begin{array}{l}\sum \\
0 \\
0 \\
0 \\
0 \\
1 \\
\vdots \\
\vdots \\
0 \\
0 \\
\stackrel{1}{i}\end{array}$ & $\begin{array}{l}2 \\
0 \\
0 \\
0 \\
0 \\
1 \\
\sum \\
0 \\
0 \\
0 \\
\end{array}$ & 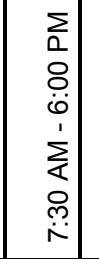 & & \\
\hline 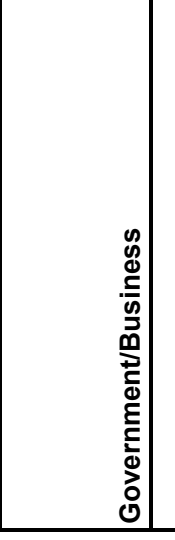 & & & & & & & & & & & & & & & & & & 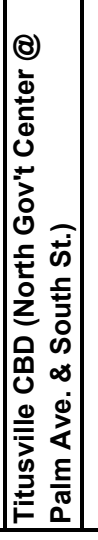 & 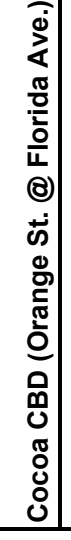 & 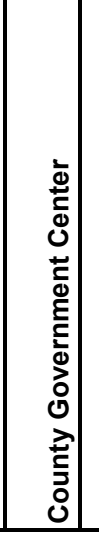 & & \\
\hline
\end{tabular}




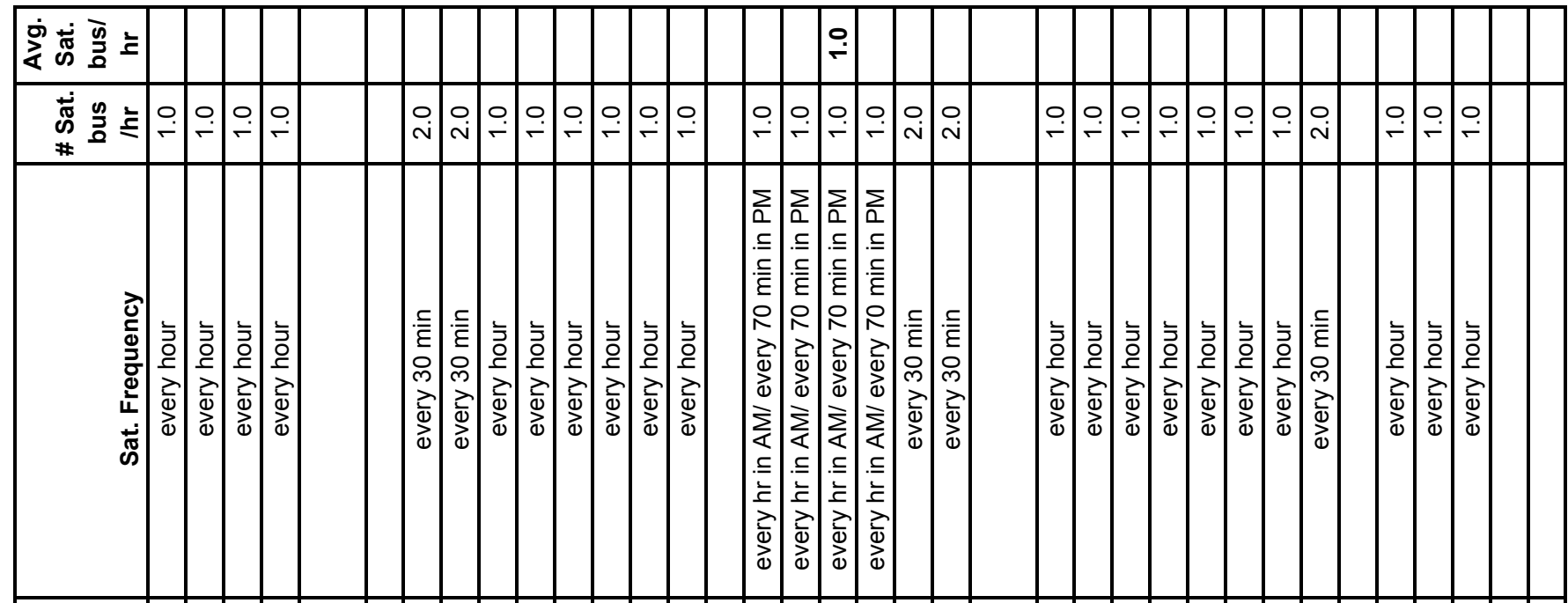

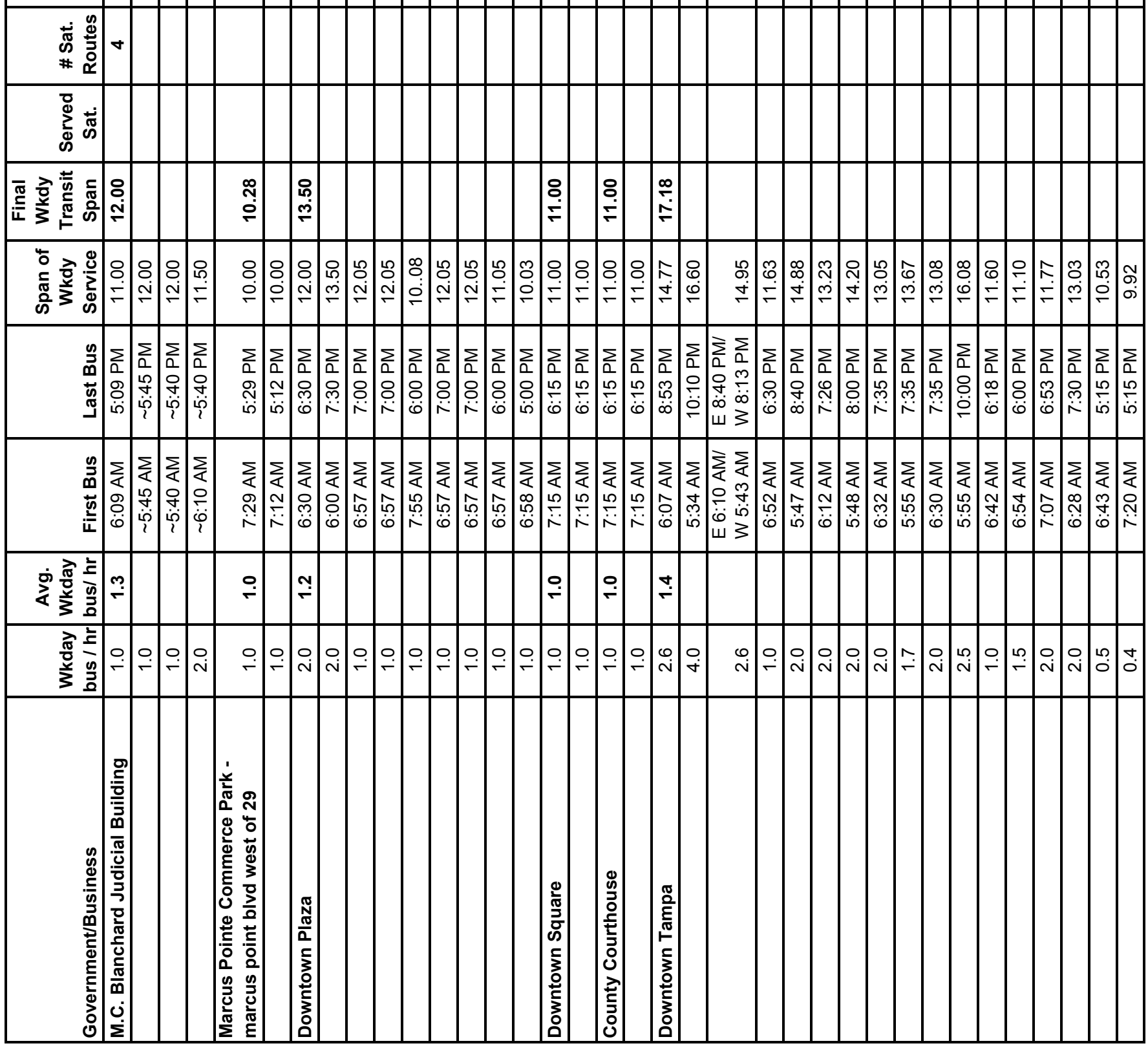




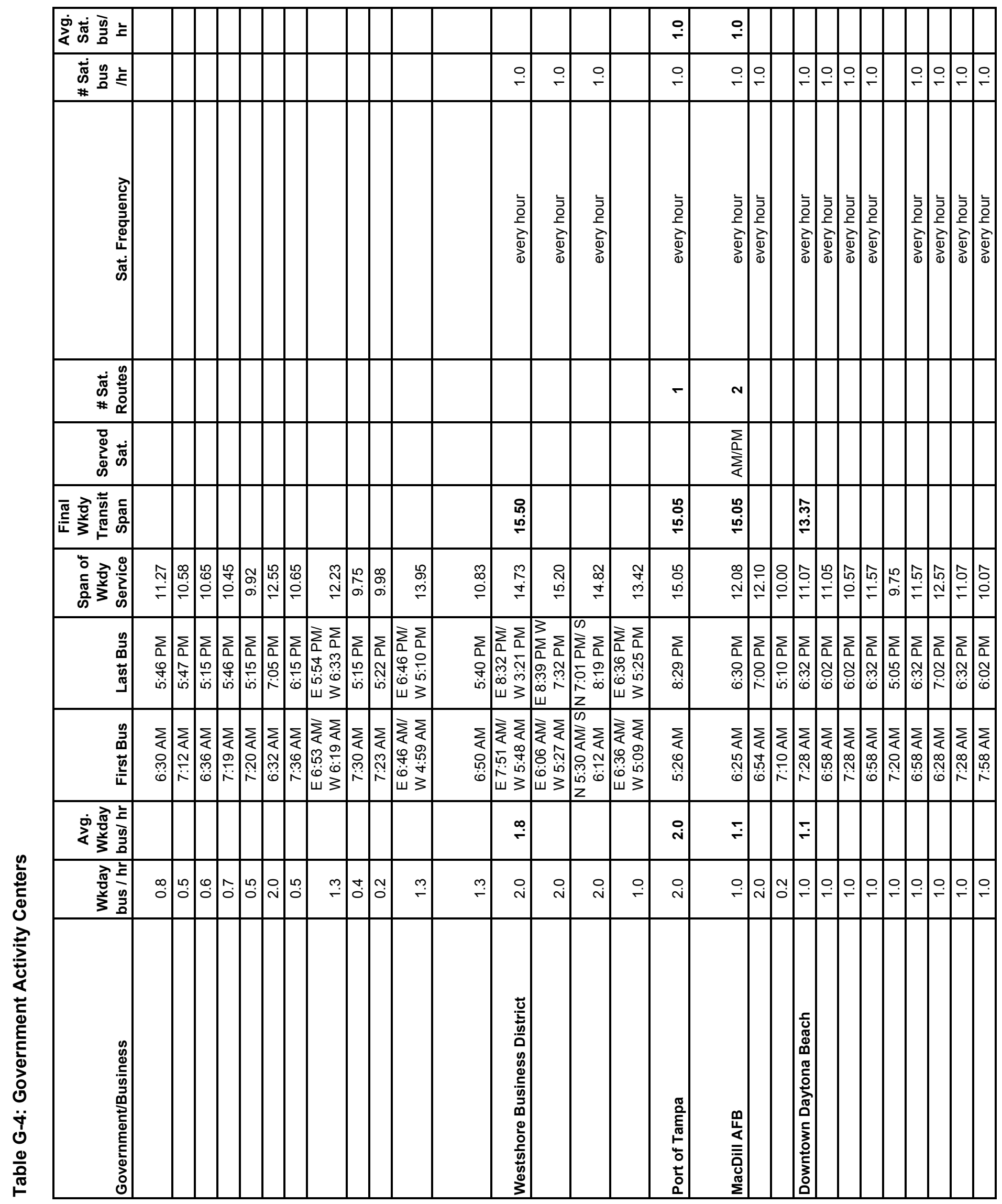




\begin{tabular}{|c|c|c|c|c|c|c|c|c|c|c|c|c|c|c|c|c|c|c|c|c|c|c|c|c|c|c|c|c|c|c|}
\hline \multicolumn{31}{|l|}{ 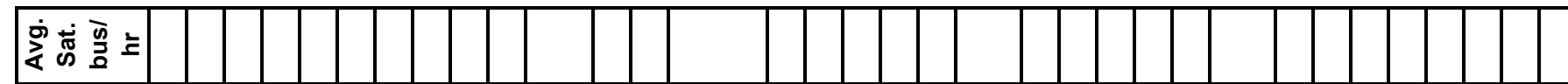 } \\
\hline 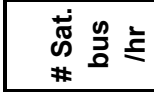 & ì & $\stackrel{\circ}{-}$ & $\stackrel{\circ}{\circ}$ & $\stackrel{\mathrm{N}}{\mathrm{i}}$ & $\stackrel{\circ}{\circ}$ & $\stackrel{\circ}{-}$ & & $\stackrel{\circ}{\circ}$ & $\begin{array}{lll}0 \\
0\end{array}$ & $\stackrel{\circ}{\mathrm{N}}$ & $\stackrel{\circ}{-}$ & 억 & $\stackrel{\circ}{\mathrm{i}}$ & $\stackrel{\circ}{-}$ & $\stackrel{8}{\circ}$ & 잉 & $\begin{array}{ll}\dot{v} \\
\dot{-}\end{array}$ & $\stackrel{\circ}{+}$ & $\stackrel{0}{\leftarrow}$ & $\stackrel{0}{\circ}$ & $\stackrel{\substack{* \\
N}}{i}$ & 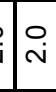 & $\stackrel{\circ}{-}$ & $\stackrel{\circ}{-}:$ & $\stackrel{\circ}{\circ}$ & 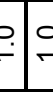 & $\stackrel{\circ}{-}$ & $\stackrel{\circ}{-}$ & $\stackrel{\circ}{\stackrel{\circ}{\circ}}$ & $\stackrel{\circ}{\circ}$ \\
\hline 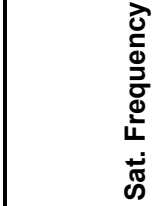 & 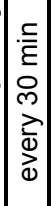 & 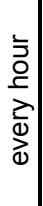 & $\begin{array}{l}1 \\
\vdots \\
0 \\
\frac{0}{2} \\
\frac{2}{0} \\
0 \\
0\end{array}$ & 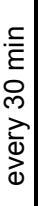 & 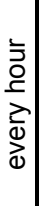 & \begin{tabular}{|c|} 
\\
$\overline{0}$ \\
$\frac{0}{0}$ \\
$\bar{d}$ \\
0
\end{tabular} & & 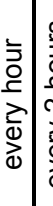 & 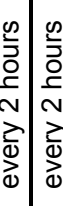 & 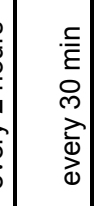 & 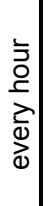 & 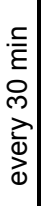 & 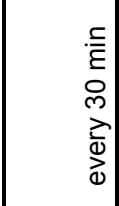 & $\mid \begin{array}{l}\vdots \\
0 \\
0 \\
\geq \\
0 \\
0 \\
0 \\
0\end{array}$ & 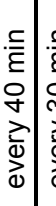 & 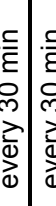 & 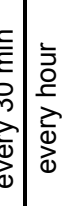 & 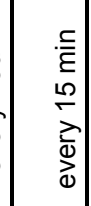 & 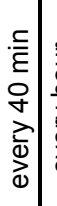 & 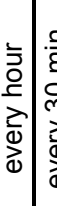 & 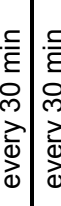 & 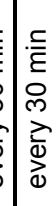 & 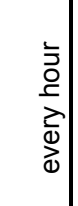 & 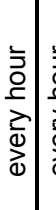 & 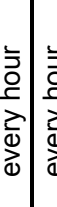 & 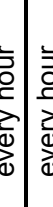 & 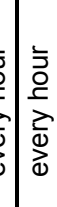 & 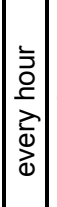 & 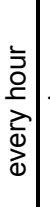 & 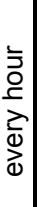 \\
\hline 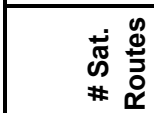 & & & & & & & & & & & & & & & & & & & & & & & & & & & & & & \\
\hline 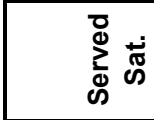 & & & & & & & & & & & & & & & & & & & & & & & & & & & & & & \\
\hline 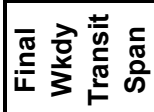 & & & & & & & & $\begin{array}{l}\infty \\
\vdots \\
\vdots\end{array}$ & & 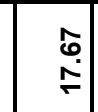 & & & & & & & & & & & & & $\begin{array}{r}\hat{o} \\
\stackrel{\sim}{-}\end{array}$ & & & & & & & \\
\hline 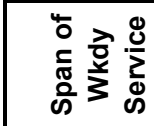 & 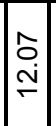 & 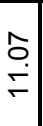 & î & 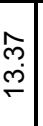 & مِ & 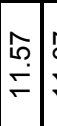 & 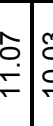 & \begin{tabular}{l|l}
$m$ & 0 \\
0 & 0 \\
0 & 0
\end{tabular} & $\begin{array}{ll}\infty \\
\stackrel{\infty}{\infty}\end{array}$ & $\begin{array}{l}8 \\
\\
\leftarrow\end{array}$ & $\mid \begin{array}{l}\infty \\
\infty \\
\dot{\leftarrow}\end{array}$ & 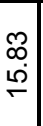 & $\begin{array}{l}\hat{0} \\
\stackrel{0}{\circ}\end{array}$ & 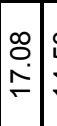 & 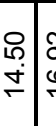 & 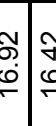 & 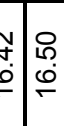 & $\begin{array}{l}\infty \\
\infty \\
0 \\
\oplus\end{array}$ & $\begin{array}{c}\stackrel{m}{m} \\
\stackrel{6}{\leftarrow}\end{array}$ & 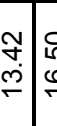 & 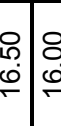 & 文 & $\begin{array}{l}\stackrel{2}{\circ} \\
\stackrel{\leftrightarrow}{ }\end{array}$ & $\stackrel{m}{\underset{\leftarrow}{\leftarrow}}$ & $\stackrel{\infty}{\stackrel{\infty}{\circ}}$ & $=\frac{\infty}{\stackrel{v}{*}}$ & 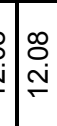 & \begin{tabular}{l}
$\infty$ \\
$\stackrel{\infty}{\sim}$ \\
\hdashline
\end{tabular} & $\begin{array}{l}\infty \\
\stackrel{\infty}{\stackrel{\sim}{r}}\end{array}$ & 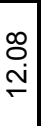 \\
\hline 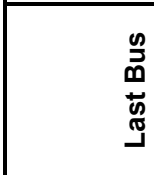 & 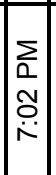 & $\begin{array}{l}\sum \\
0 \\
N \\
0 \\
\dot{0}\end{array}$ & $\left|\begin{array}{l}\sum \\
0 \\
0 \\
0 \\
0\end{array}\right|$ & $\begin{array}{l}\sum_{0} \\
\vdots \\
\vdots \\
\end{array}$ & 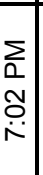 & 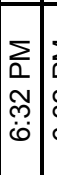 & 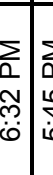 & 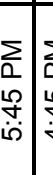 & 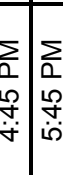 & $\begin{array}{l}\sum \\
0 \\
0 \\
\stackrel{\square}{=}\end{array}$ & 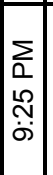 & 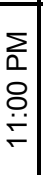 & 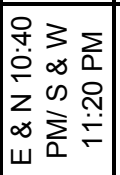 & 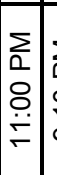 & 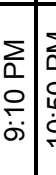 & 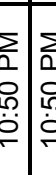 & 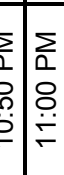 & 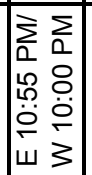 & 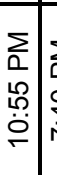 & 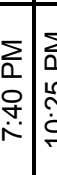 & 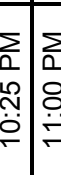 & 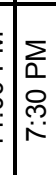 & 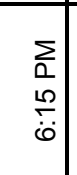 & 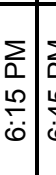 & 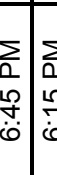 & 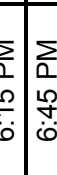 & $\left\{\begin{array}{l}\sum \\
0 \\
0 \\
10 \\
\vdots \\
0\end{array}\right.$ & $\left|\begin{array}{l}\sum \\
0 \\
0 \\
\check{0} \\
\dot{0}\end{array}\right|$ & $\begin{array}{l}\sum_{0} \\
0 \\
\vdots \\
0 \\
0\end{array}$ & $\begin{array}{l}\sum \\
0 \\
b \\
0 \\
0\end{array}$ \\
\hline 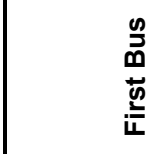 & 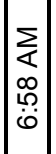 & $\begin{array}{l}\sum_{\alpha} \\
\infty \\
0 \\
0\end{array}$ & 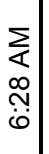 & 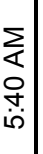 & 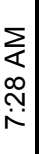 & 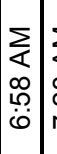 & 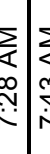 & 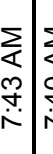 & 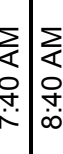 & 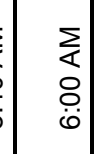 & 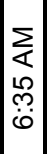 & $\begin{array}{l}\sum_{0} \\
0 \\
0 \\
\dot{0}\end{array}$ & 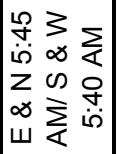 & 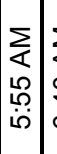 & 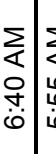 & 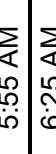 & 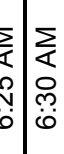 & 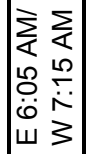 & 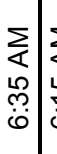 & 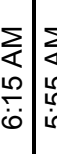 & 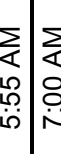 & 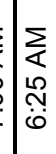 & 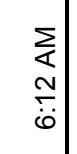 & 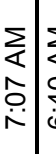 & 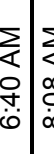 & 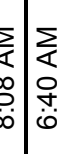 & 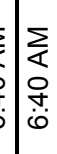 & $\mid$\begin{tabular}{c}
$\sum$ \\
$\frac{1}{2}$ \\
0 \\
\hdashline$\ddot{0}$
\end{tabular} & 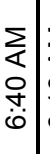 & $\begin{array}{l}\underset{⿱}{2} \\
\stackrel{0}{0} \\
\dot{0}\end{array}$ \\
\hline 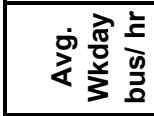 & & & & & & & & $\hat{o}$ & & $\bar{i}$ & & & & & & & & & & & & & $\stackrel{\circ}{r}$ & & & & & & & \\
\hline 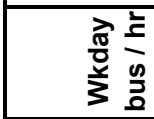 & $\stackrel{\circ}{\mathrm{N}}$ & $\stackrel{\circ}{-}$ & $\stackrel{0}{\stackrel{1}{-}}$ & $\stackrel{\circ}{\mathrm{N}}$ & $\stackrel{\circ}{-}$ & $\stackrel{\circ}{-}$ & $\stackrel{\leftrightarrow}{\circ}$ & $\stackrel{\circ}{\circ}$ & \begin{tabular}{l|lll}
0 \\
0
\end{tabular} & 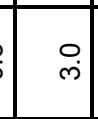 & $\mid$ & $\stackrel{\circ}{i}$ & $\stackrel{\circ}{\mathrm{N}}$ & $\stackrel{\circ}{\stackrel{N}{ }}$ & ح| & $\stackrel{\nabla}{*}$ & $\begin{array}{l}\dot{v} \\
\dot{v}\end{array}$ & $\stackrel{+}{\circ}$ & $\stackrel{\circ}{\mathrm{N}}$ & $\stackrel{\overbrace{}}{\overbrace{}}$ & iv & 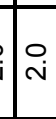 & $\stackrel{\circ}{-}$ & $\stackrel{\circ}{-}$ & • & - & $\stackrel{\leftrightarrow}{\stackrel{\circ}{\prime}}$ & $\stackrel{\circ}{-}$ & $\stackrel{\circ}{\sim}$ & $\stackrel{\circ}{\stackrel{1}{-}}$ \\
\hline 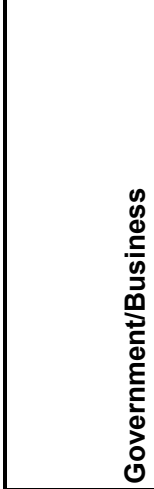 & & & & & & & 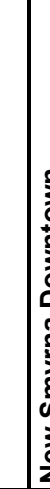 & 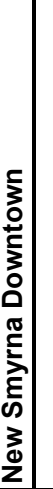 & & 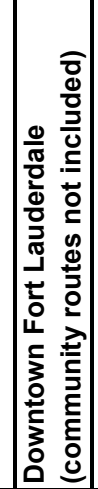 & & & & & & & & & & & & & 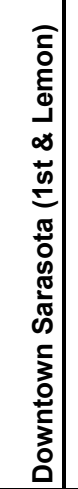 & & & & & & & \\
\hline
\end{tabular}




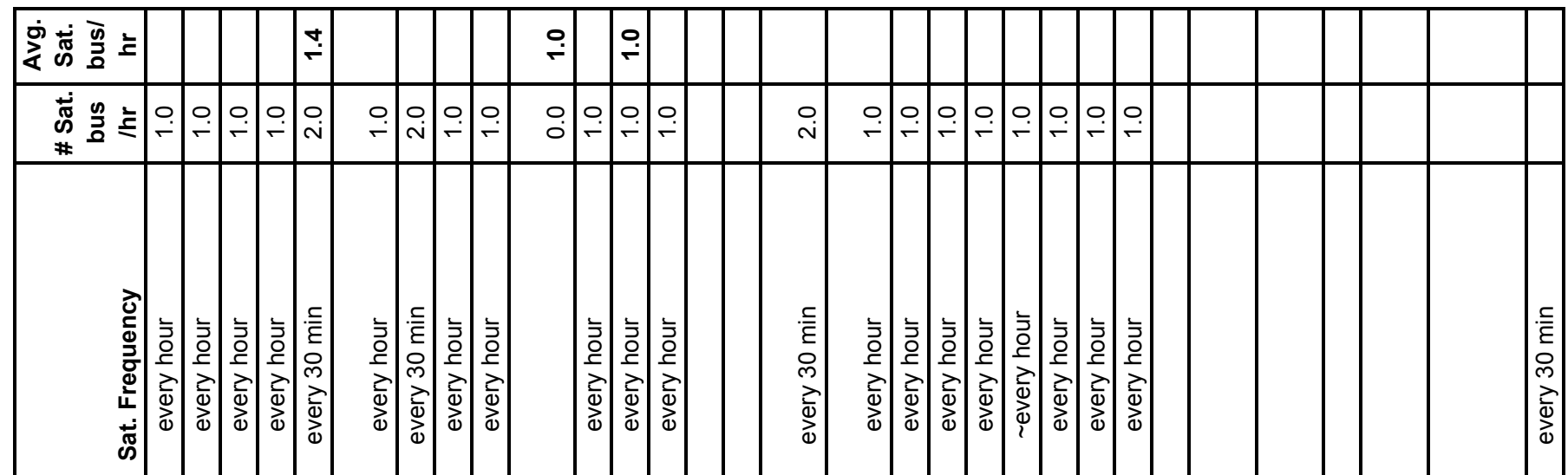

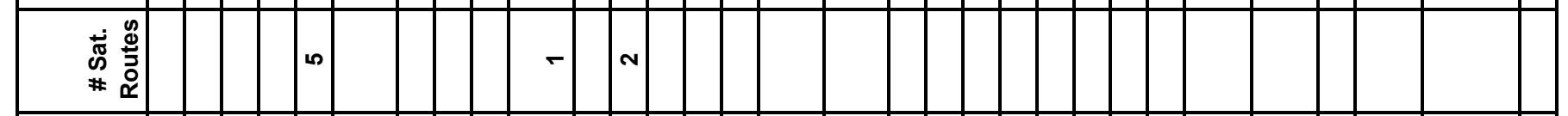

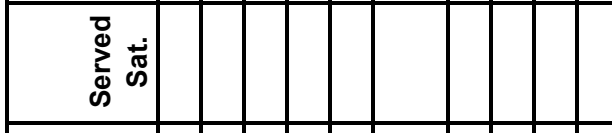

\begin{tabular}{|c|c|c|c|c|c|c|c|c|c|c|c|c|c|c|c|c|c|c|c|c|c|c|c|}
\hline & & i̊n & & & & 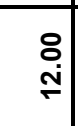 & $\stackrel{\overbrace{}}{\Re}$ & & 吊 & $\begin{array}{l}\circ \\
\stackrel{0}{\circ}\end{array}$ & & & & & & & & $\begin{array}{l}\stackrel{0}{0} \\
+ \\
\dot{+}\end{array}$ & 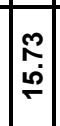 & & \\
\hline 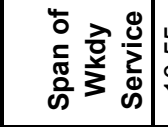 & \begin{tabular}{l|l}
$\stackrel{\infty}{0}$ \\
$\stackrel{0}{\odot}$
\end{tabular} & 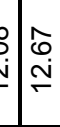 & $\frac{m}{\circ}$ & i̊n & $\begin{array}{l}\stackrel{8}{1} \\
\stackrel{1}{1}\end{array}$ & \begin{tabular}{l|l}
$\stackrel{8}{0}$ \\
$\stackrel{\mathrm{v}}{-}$
\end{tabular} & 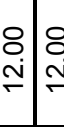 & $\begin{array}{l}\stackrel{8}{ } \\
\stackrel{1}{\longrightarrow}\end{array}$ & 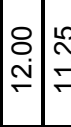 & 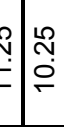 & & $\begin{array}{l}8 \\
\stackrel{0}{\rho} \\
\stackrel{1}{n}\end{array}$ & $\begin{array}{l}\stackrel{8}{\dot{\square}} \\
\dot{+}\end{array}$ & 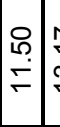 & $\stackrel{n}{\stackrel{n}{c}}$ & $\begin{array}{l}\mid \\
0 \\
0 \\
0\end{array}$ & 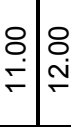 & $\stackrel{\stackrel{N}{\grave{N}}}{\stackrel{\sim}{\sim}}$ & $\underset{\Gamma}{\stackrel{m}{\rightleftarrows}}$ & & $\begin{array}{l}\stackrel{\mathfrak{r}}{2} \\
\stackrel{\rho}{\rho}\end{array}$ & 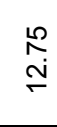 & 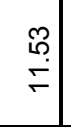 \\
\hline
\end{tabular}

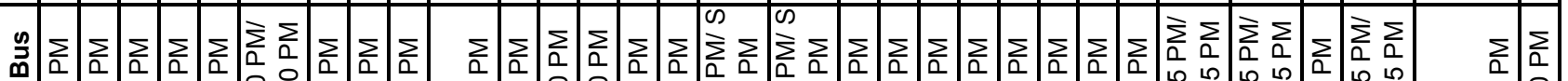

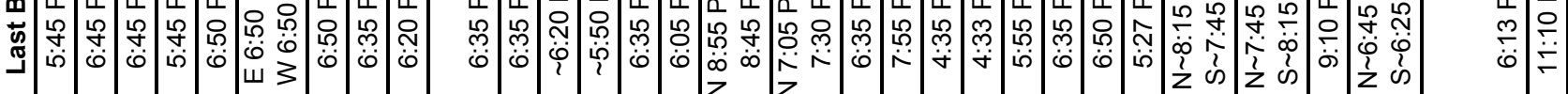

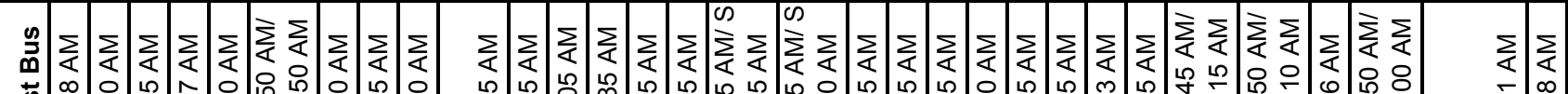

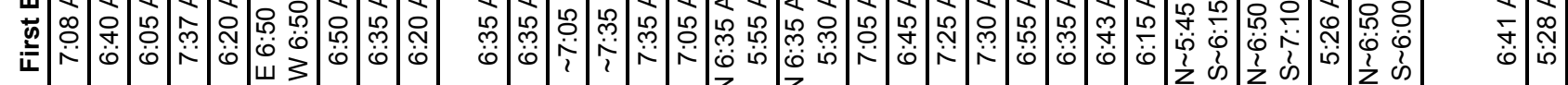

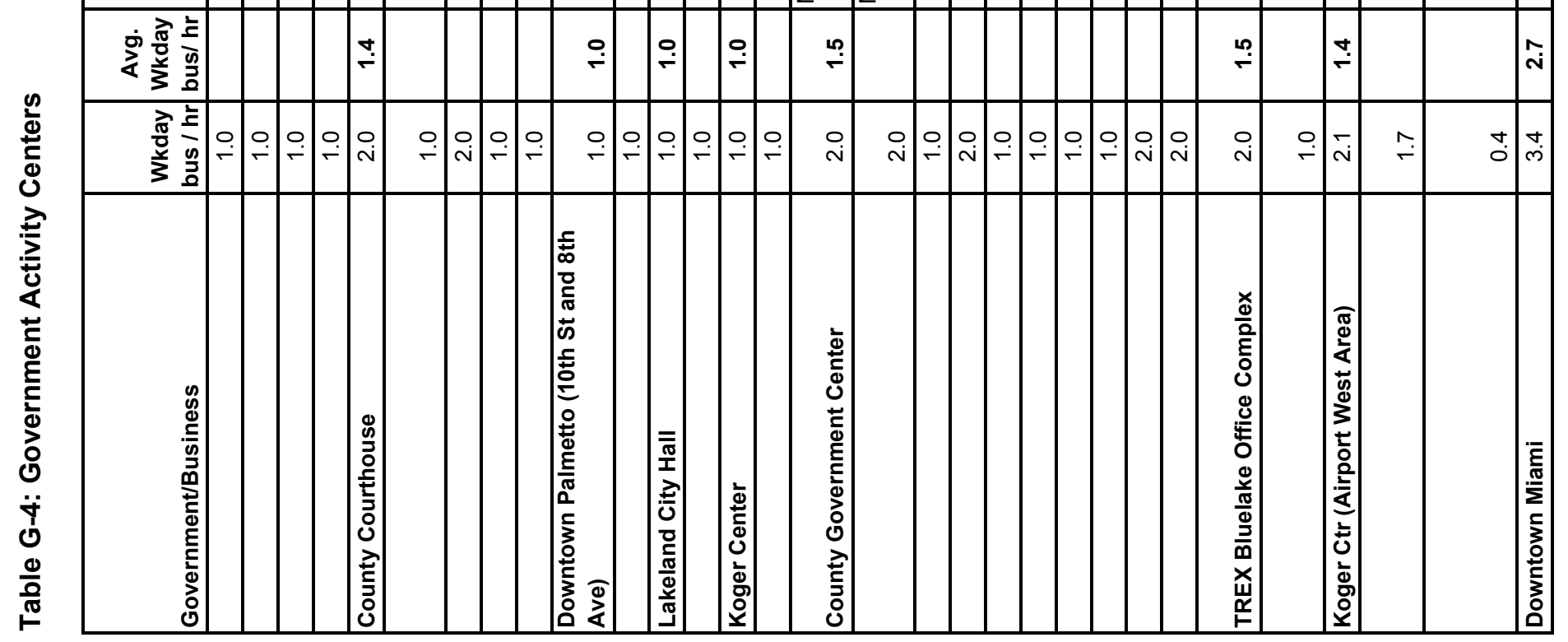




\begin{tabular}{|c|c|c|c|c|c|c|c|c|c|c|c|c|c|c|c|c|c|c|c|c|c|c|c|c|c|c|}
\hline 完离高 & & & & & & & & & & & & & & & & & & & & & & & $\stackrel{0}{0}$ & & & \\
\hline 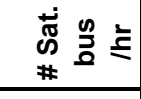 & & & & & & & $\stackrel{\circ}{N}$ & $\stackrel{\circ}{\stackrel{0}{ }}$ & & & & & | & & \begin{tabular}{l|} 
\\
\end{tabular} & & $\stackrel{\circ}{\mathrm{i}}$ & & & $\stackrel{\circ}{-}$ & $\stackrel{\circ}{\mathrm{N}}$ & & & & & \\
\hline 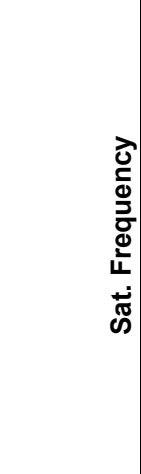 & 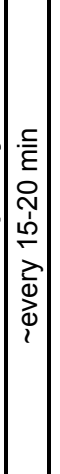 & & 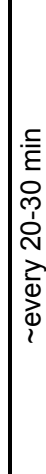 & 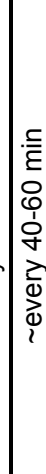 & 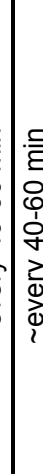 & 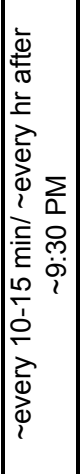 & 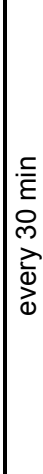 & 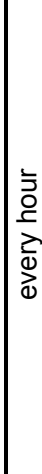 & 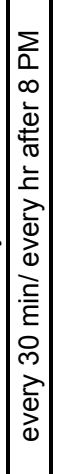 & & 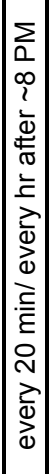 & & 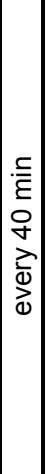 & 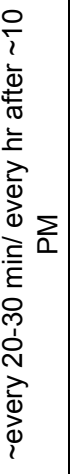 & 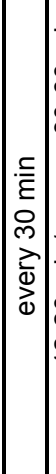 & 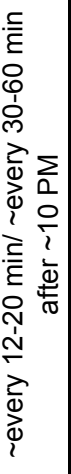 & 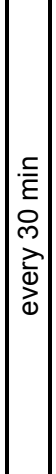 & & & $\begin{array}{l}\bar{y} \\
0 \\
\frac{0}{2} \\
\frac{1}{0} \\
2\end{array}$ & 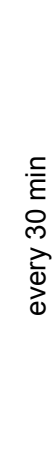 & & & & & \\
\hline 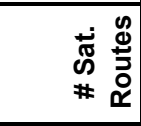 & & & & & & & & & & & & & & & & & & & & & & & 0 & & & \\
\hline 焉 & & & & & & & & & & & & & & & & & & & & & & & & & & \\
\hline 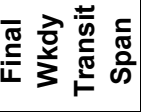 & & & & & & & & & & & & & & & & & & & & & & $\stackrel{\infty}{\stackrel{\infty}{N}}$ & $\begin{array}{l}8 \\
\infty \\
\infty\end{array}$ & 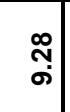 & & \\
\hline 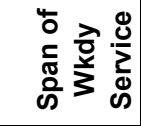 & $\begin{array}{l}0 \\
0 \\
0 \\
0 \\
0\end{array}$ & $\stackrel{\infty}{\infty}$ & فֶ. & مִ & 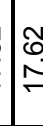 & $\begin{array}{l}\hat{\sigma} \\
\stackrel{\sigma}{\sigma}\end{array}$ & $\begin{array}{l}\hat{n} \\
\stackrel{0}{\circ}\end{array}$ & ז & $\mid \begin{array}{c}0 \\
\infty \\
\infty \\
\infty\end{array}$ & 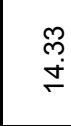 & $\left|\begin{array}{l}0 \\
i \\
0 \\
-1\end{array}\right|$ & 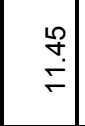 & $\mid$ & $\begin{array}{l}\stackrel{8}{\infty} \\
\infty \\
\infty\end{array}$ & 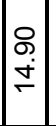 & $\begin{array}{l}\stackrel{8}{0} \\
\stackrel{9}{\circ}\end{array}$ & $\mid \begin{array}{l}\infty \\
0 \\
\dot{+} \\
\end{array}$ & $\stackrel{\mathscr{R}}{\stackrel{R}{\leftarrow}}$ & 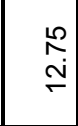 & 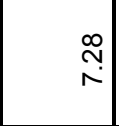 & $\stackrel{m}{\stackrel{m}{L}}$ & 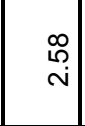 & $\begin{array}{l}8 \\
\infty \\
\infty\end{array}$ & 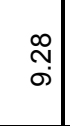 & 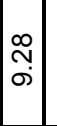 & 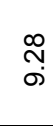 \\
\hline 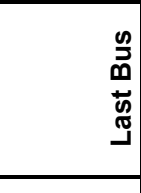 & 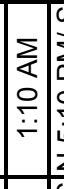 & 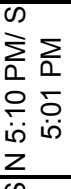 & 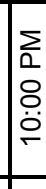 & 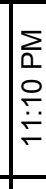 & 年 & 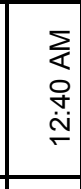 & 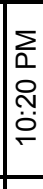 & 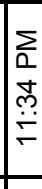 & 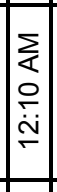 & 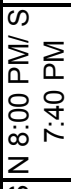 & \begin{tabular}{l} 
\\
\\
0 \\
\hdashline \\
\end{tabular} & 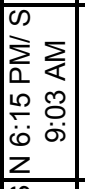 & \begin{tabular}{|l|}
$\Sigma$ \\
0 \\
0 \\
0 \\
$\dot{1}$ \\
1 \\
\end{tabular} & $\begin{array}{l}\sum \\
0 \\
\stackrel{N}{N} \\
\grave{i}\end{array}$ & $\left|\begin{array}{l}\Sigma \\
0 \\
\sim \\
o \\
o j\end{array}\right|$ & 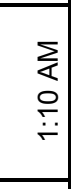 & $\left|\begin{array}{l}\Sigma \\
0 \\
0 \\
0 \\
0 \\
0\end{array}\right|$ & $\begin{array}{l}\sum \\
0 \\
0 \\
0 \\
0 \\
0\end{array}$ & $\mid \begin{array}{ll}\sum & \sum \\
0 & 0 \\
0 & 0 \\
0 & 0 \\
\dot{1} & 0 \\
\omega & 3 \\
\end{array}$ & $\left|\begin{array}{lll}0 & 3 & 2 \\
\hdashline & 0 & 0 \\
0 & 0 & 0 \\
3 & 0 & 0 \\
0 & \sum & 0 \\
0 & 0 & 0\end{array}\right|$ & $\begin{array}{l}\sum_{0} \\
0 \\
0 \\
0 \\
0\end{array}$ & 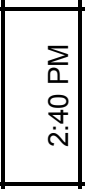 & $\begin{array}{l}\sum \\
0 \\
0 \\
\check{\dot{r}}\end{array}$ & $\begin{array}{l}\vdots \\
0 \\
0 \\
i \\
i\end{array}$ & $\left|\begin{array}{l}\sum \\
0 \\
0 \\
0 \\
i \\
i\end{array}\right|$ & $\begin{array}{l}\sum \\
0 \\
0 \\
0 \\
\dot{0}\end{array}$ \\
\hline 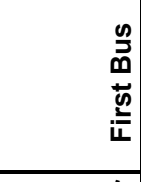 & 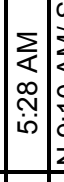 & 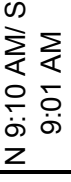 & 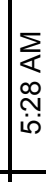 & 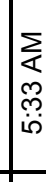 & 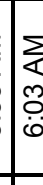 & $\begin{array}{l}\sum_{<}^{\infty} \\
\underset{i}{\infty}\end{array}$ & $\mid \begin{array}{l}\sum \\
\infty \\
\infty \\
0 \\
i j \\
i j\end{array}$ & 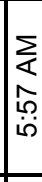 & 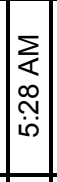 & 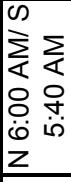 & 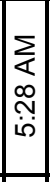 & 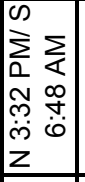 & 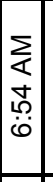 & 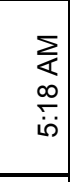 & $\left|\begin{array}{l}\sum \\
0 \\
0 \\
0 \\
\dot{0}\end{array}\right|$ & $\begin{array}{l}\sum \\
\vdots \\
\vdots \\
e j \\
\text { in }\end{array}$ & $\mid \begin{array}{l}\mid \\
< \\
\infty \\
0 \\
0 \\
0\end{array}$ & $\begin{array}{l}\sum \\
\infty \\
\infty \\
0 \\
0 \\
\end{array}$ & 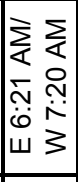 & 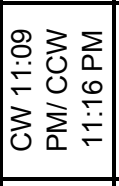 & 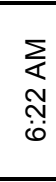 & 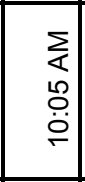 & 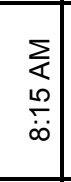 & $\begin{array}{l}\sum \\
0 \\
\substack{n\\
}\end{array}$ & 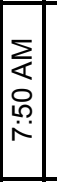 & 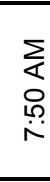 \\
\hline 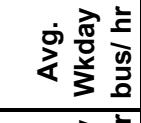 & & & & & & & & & & & & & & & & & & & & & & $\stackrel{0}{0}$ & $\begin{array}{l}\infty \\
0 \\
0\end{array}$ & $\begin{array}{l}\infty \\
0 \\
0\end{array}$ & & \\
\hline 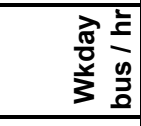 & $\stackrel{0}{i}$ & $\stackrel{\circ}{\stackrel{r}{0}}$ & $\stackrel{\infty}{\sim}$ & هִ & $\stackrel{\text { Pִ }}{\longrightarrow}$ & ثే. & $\stackrel{\circ}{\circ}$ & $\stackrel{\circ}{i}$ & $\mid \begin{array}{c}m \\
m\end{array}$ & $\stackrel{\circ}{r}$ & $\overline{\dot{\theta}}$ & $\stackrel{-}{+}$ & $\left|\begin{array}{l}0 \\
\dot{m}\end{array}\right|$ & $\grave{i}$ & $\left|\begin{array}{l}\infty \\
i\end{array}\right|$ & 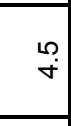 & $\mid$ & $\stackrel{m}{i}$ & 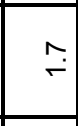 & $\stackrel{\circ}{\rightarrow}$ & $\stackrel{\circ}{\circ}$ & $\stackrel{0}{0}$ & $\begin{array}{l}\infty \\
0 \\
0\end{array}$ & $\stackrel{-}{-}$ & \begin{tabular}{|c|} 
Na \\
\hdashline
\end{tabular} & $=$ \\
\hline 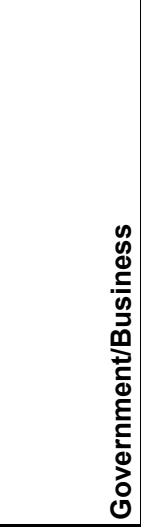 & & & & & & & & & & & & & & & & & & & & & & 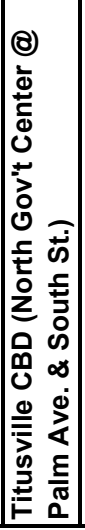 & 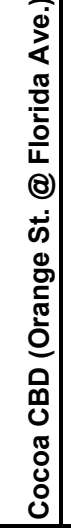 & 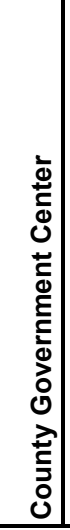 & & \\
\hline
\end{tabular}




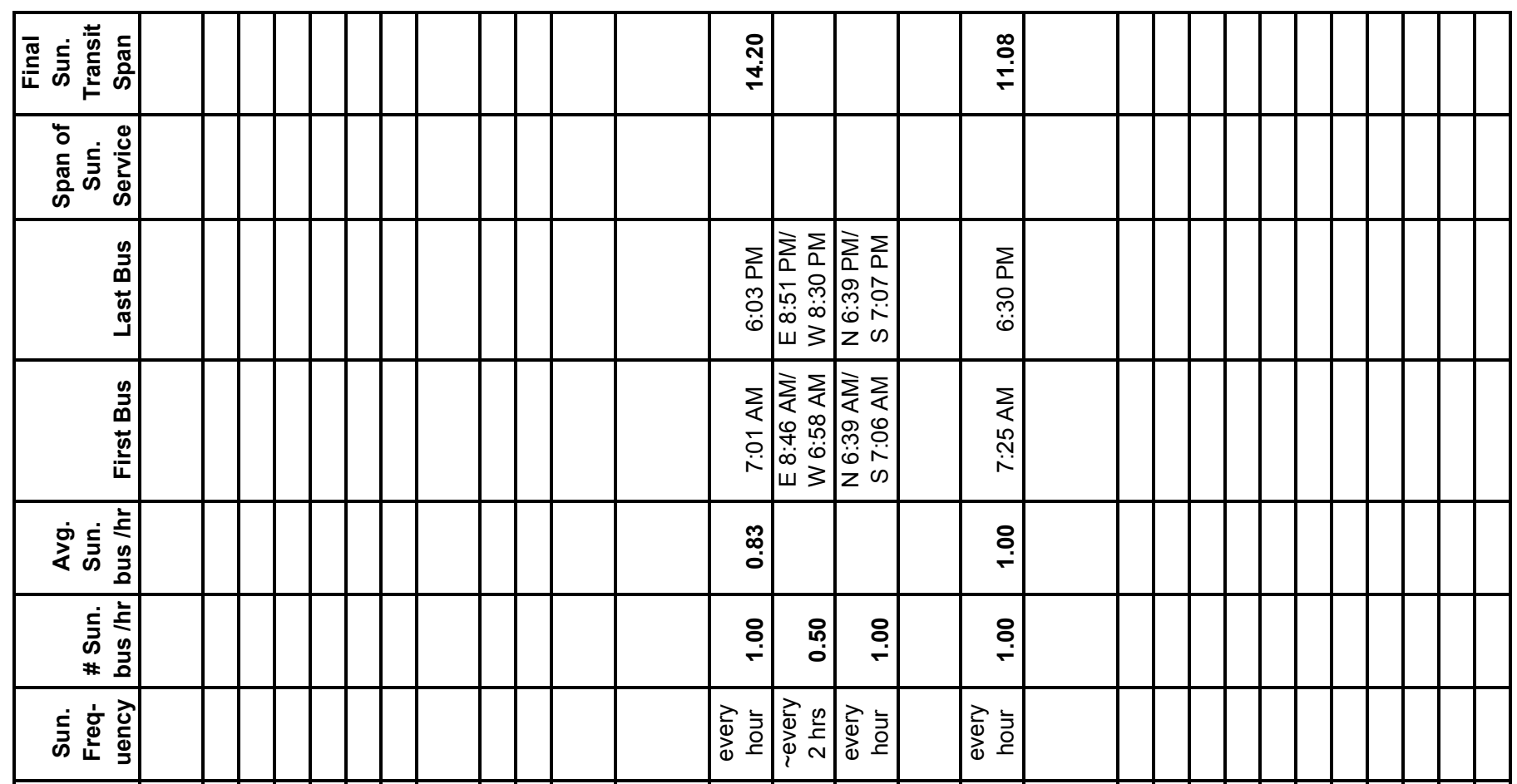

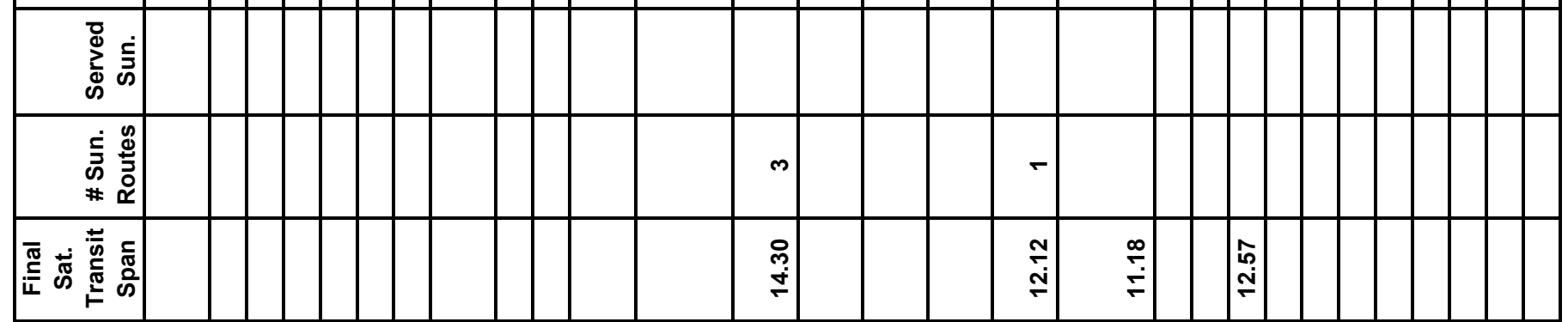

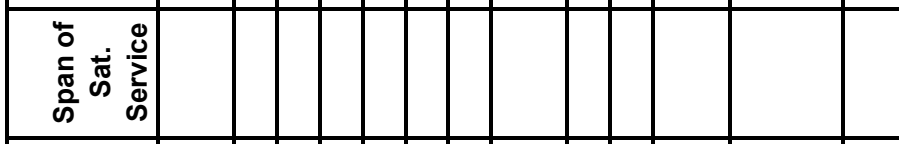

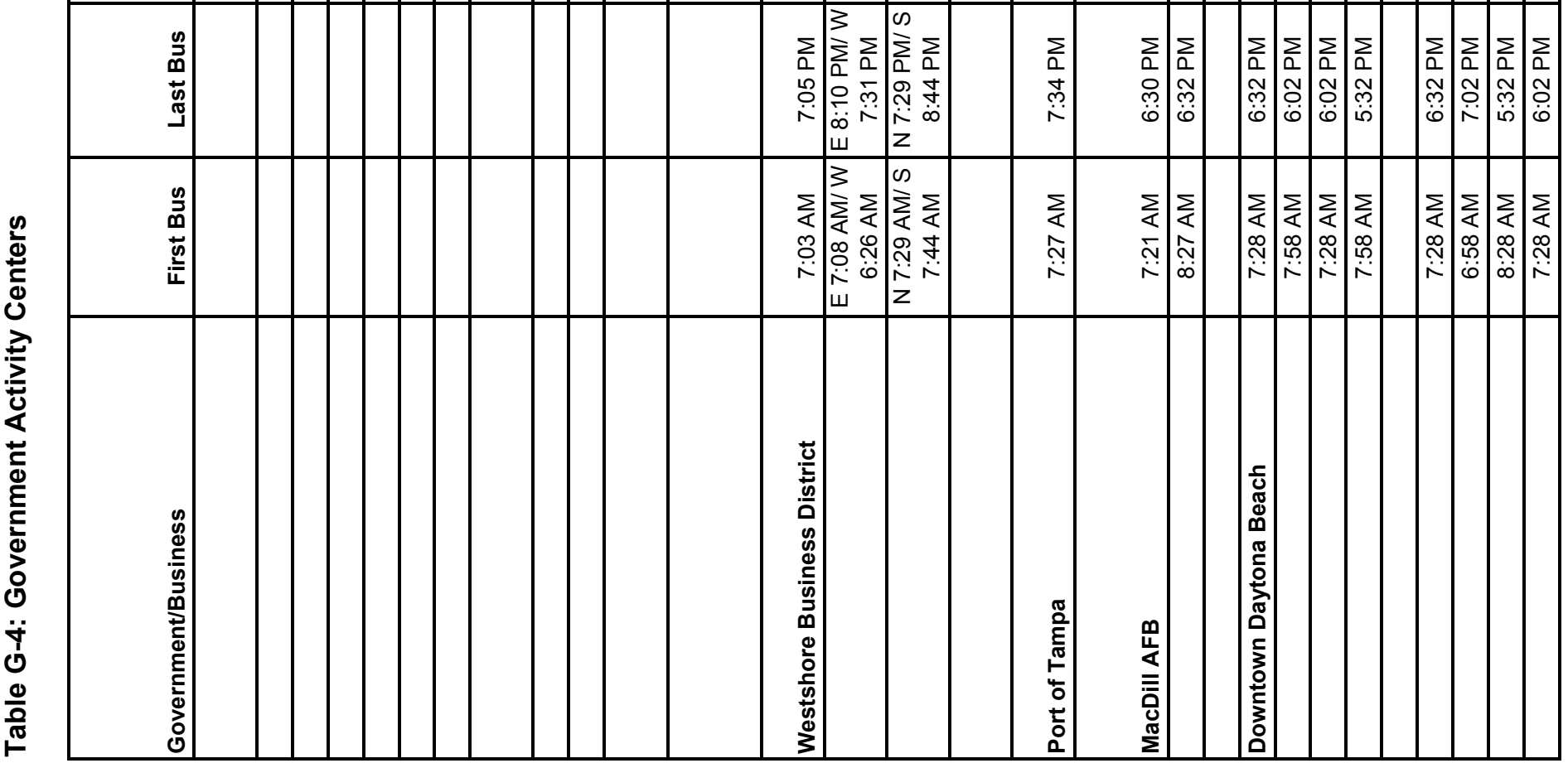




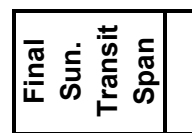

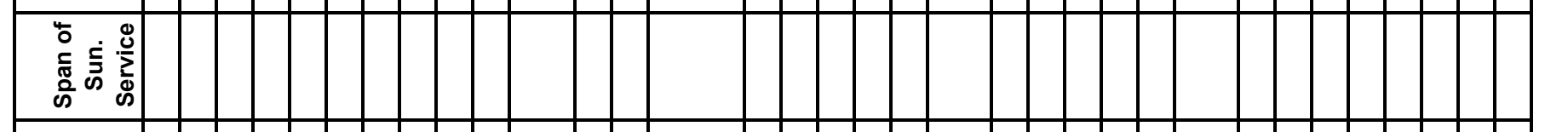

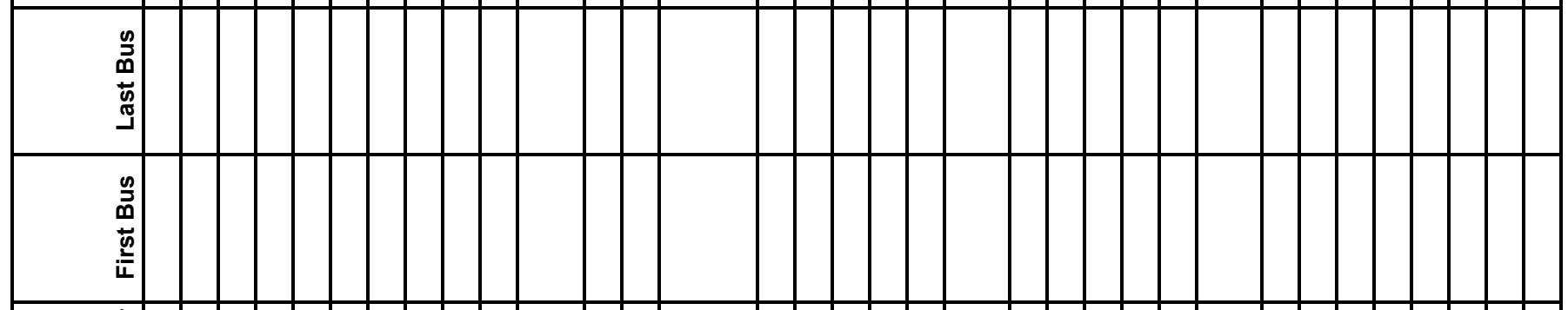

\begin{tabular}{|c|}
\hline 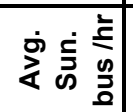 \\
\hline \begin{tabular}{ll|}
$\dot{5}$ & $\vdots$ \\
0 & $\vdots$ \\
0 & 0 \\
$\#$ & 0
\end{tabular} \\
\hline
\end{tabular}

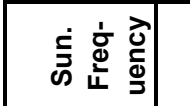

离离灾

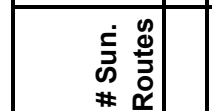

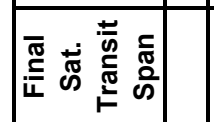

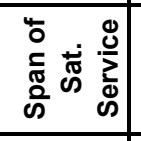

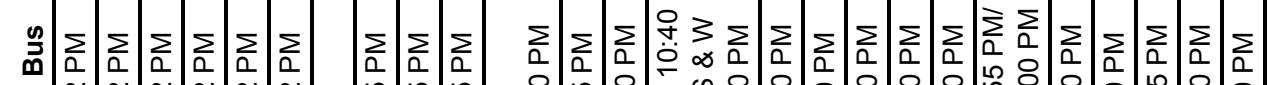

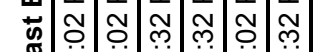

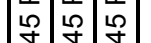

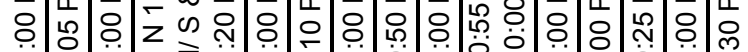

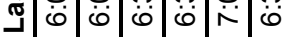

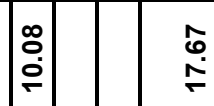

$\stackrel{\grave{o}}{\stackrel{\mathrm{i}}{ }}$

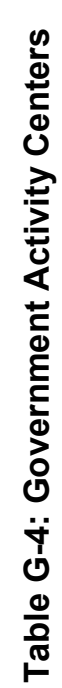

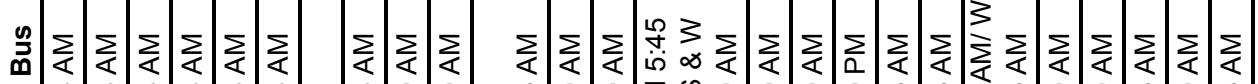

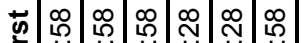

m

i

ᄂ

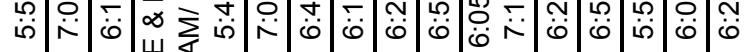

$\sum_{n} \sum_{n} \sum_{n} \sum_{n} \sum_{n} \sum_{n} \sum_{n} \sum_{n} \sum_{n}$

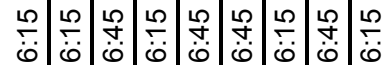

$\sum \sum \sum \sum \sum \sum \sum \sum$

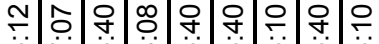

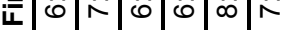

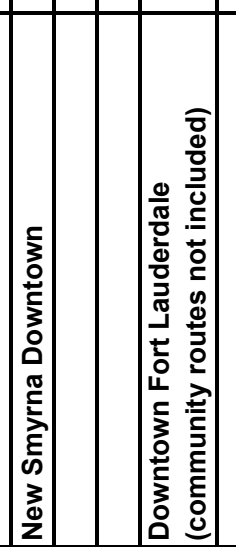




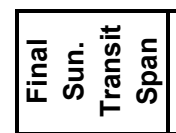

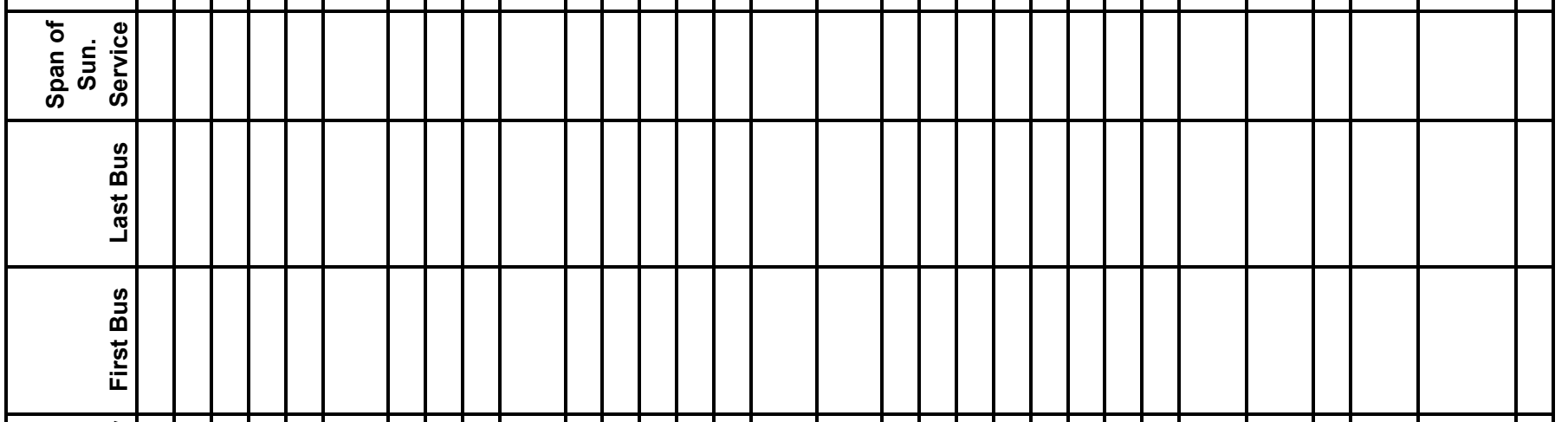

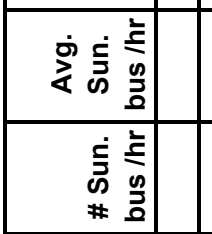

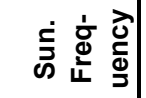

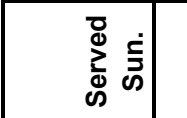

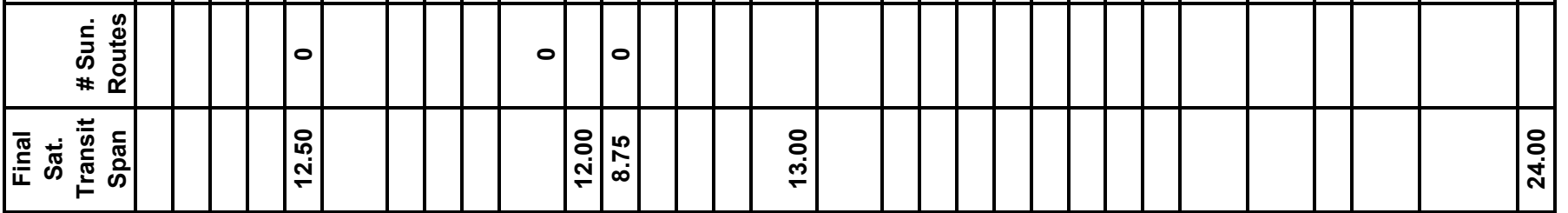

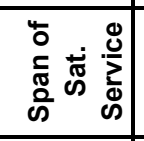

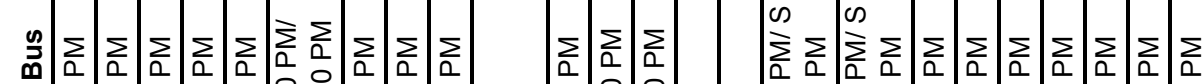

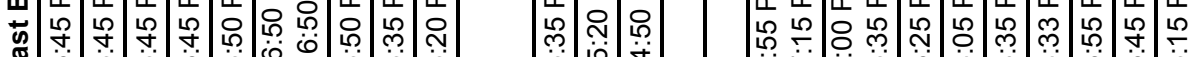

J 1 ف ف

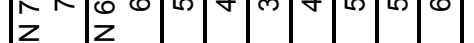

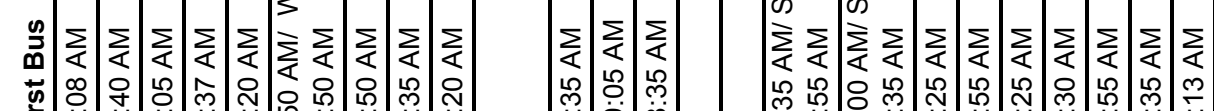

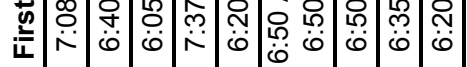

فี

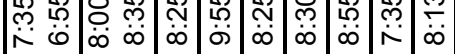

$\begin{array}{lll}x & 0 \\ z & \end{array}$ 


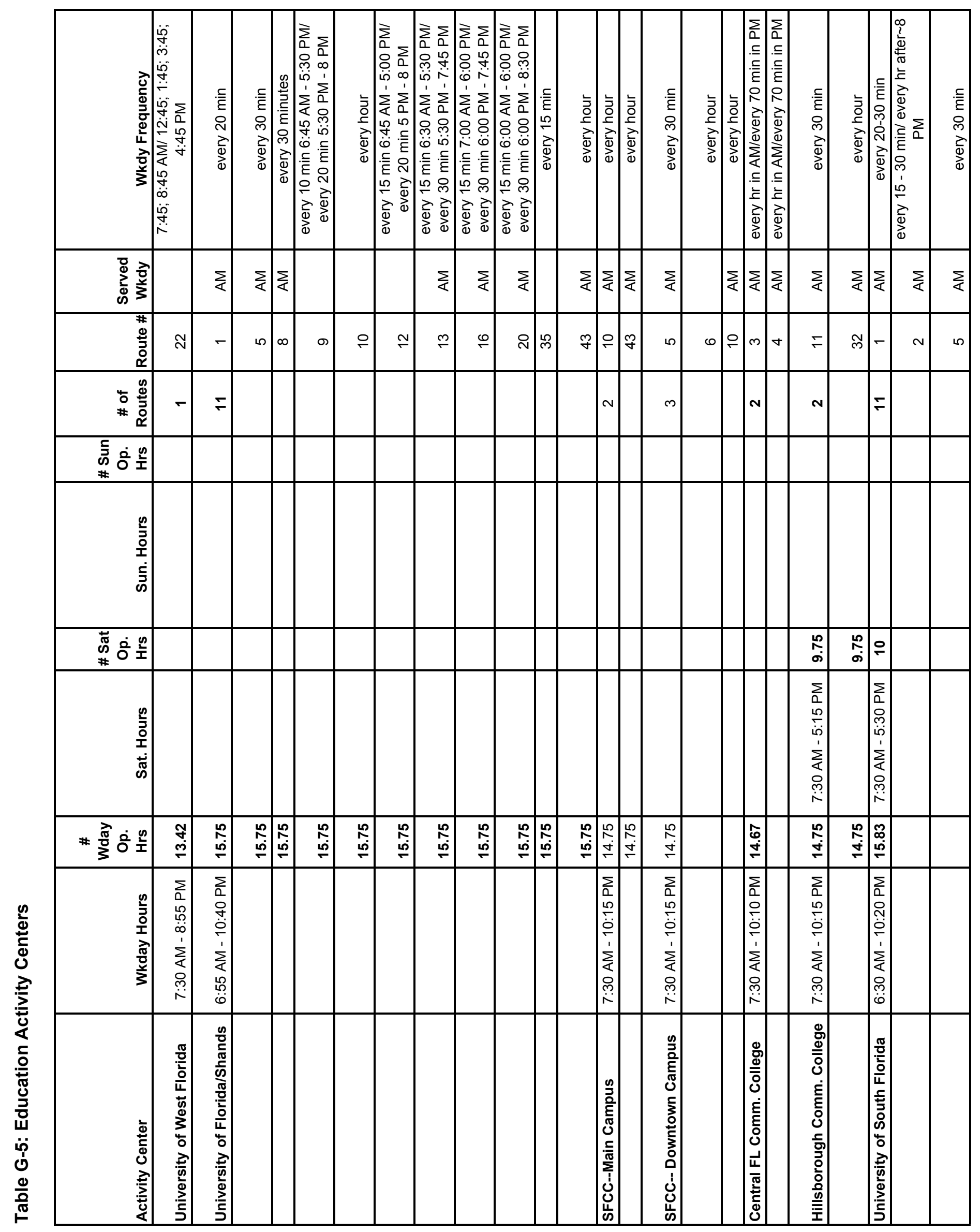




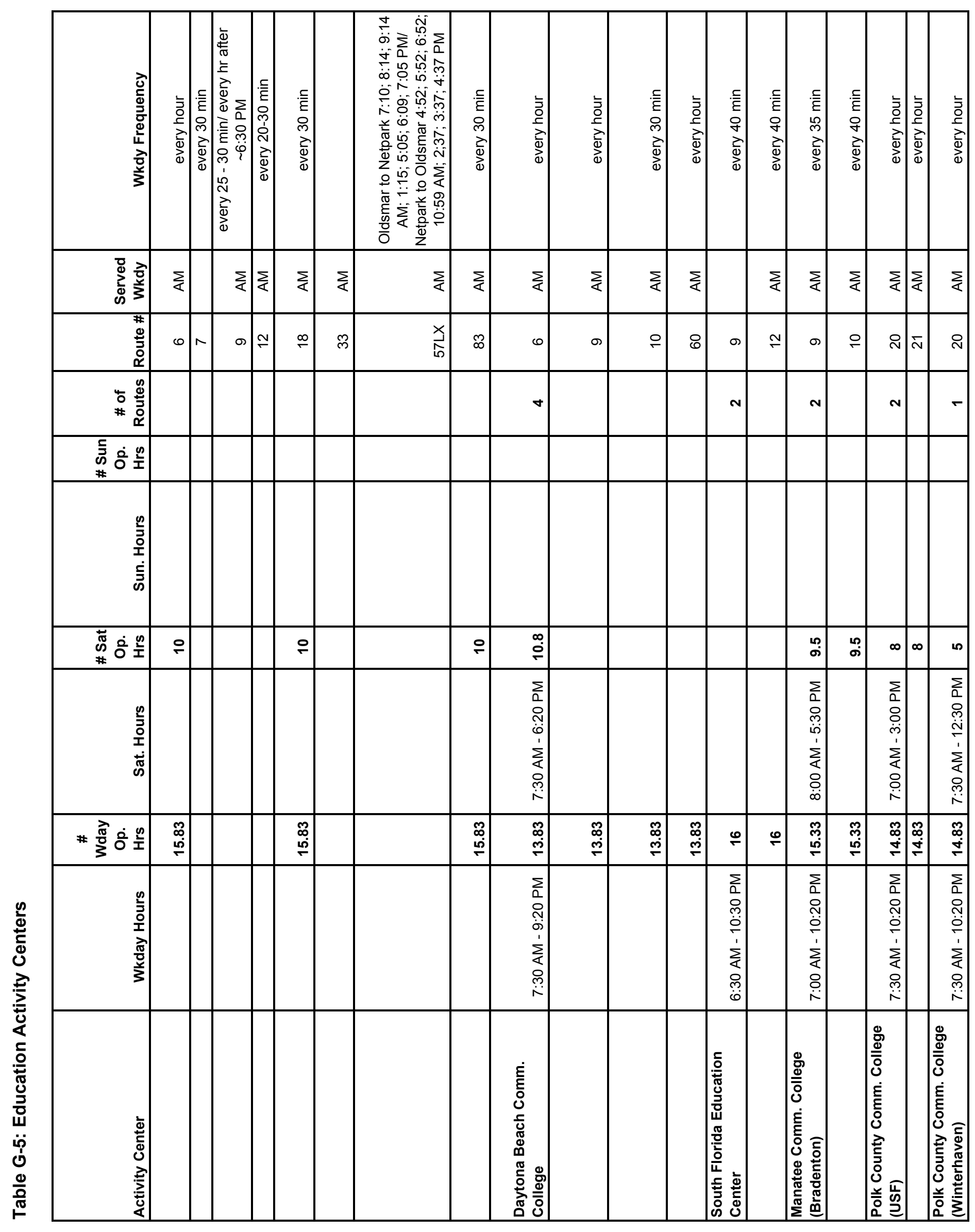




\begin{tabular}{|c|c|c|c|c|c|c|c|c|c|c|c|c|c|c|c|c|c|}
\hline 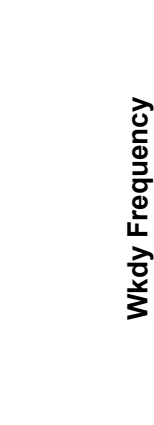 & 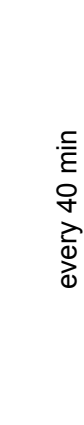 & 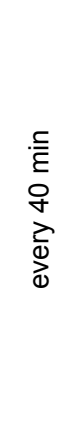 & 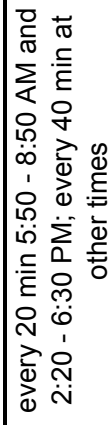 & 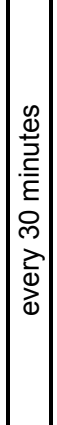 & 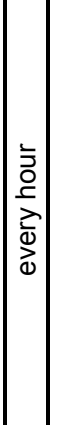 & 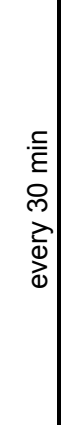 & 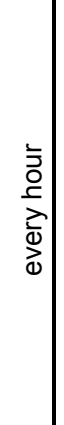 & 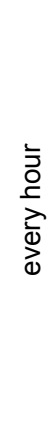 & & 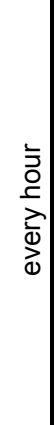 & 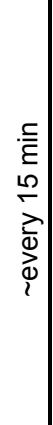 & 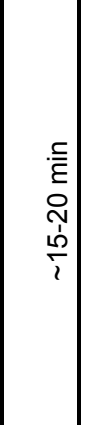 & 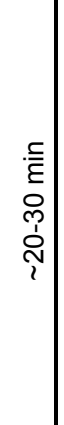 & 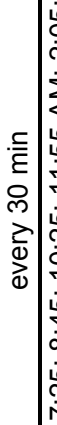 & 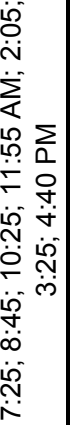 & 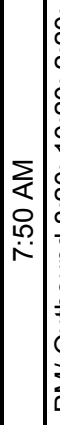 & 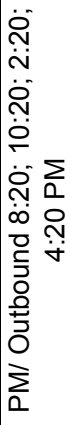 \\
\hline 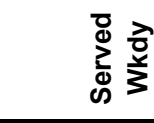 & $\sum_{<}$ & $\gtreqless$ & $\sum_{\substack{\infty \\
<}}^{\sum}$ & $\sum$ & $\sum$ & $\gtreqless$ & $\sum$ & $\sum_{<}$ & $\sum$ & $\sum_{<}$ & $\sum_{\substack{0 \\
\sum}}^{n}$ & $\sum$ & 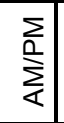 & $\sum$ & $\sum_{<}$ & & \\
\hline 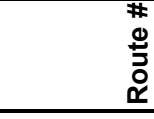 & م & $\mp$ & $\stackrel{\nabla}{\sim}$ & ₹ & $\stackrel{\mathscr{f}}{\mathscr{\sigma}}$ & $\sim$ & $\overline{0}$ & $\widetilde{\mho}$ & $\Lambda$ & $\bar{N}$ & $\hat{\sim}$ & 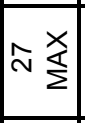 & న్ల & $\stackrel{2}{\stackrel{2}{2}}$ & 0 & $\div$ & ৪ \\
\hline 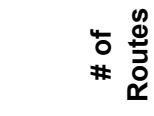 & r & & & & & $m$ & & & 0 & & & & & & $m$ & & \\
\hline 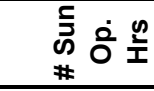 & & & & & & & & & N & $N$ & $N$ & $\Lambda$ & $N$ & $\Lambda$ & & & \\
\hline $\begin{array}{l}\text { ڤొ } \\
\bar{\Xi} \\
\text { 오 }\end{array}$ & & & & & & & & & 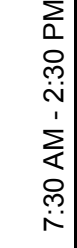 & & & & & & & & \\
\hline 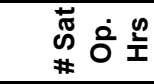 & $\stackrel{m}{=}$ & $\stackrel{m}{=}$ & $\stackrel{m}{=}$ & & & 우 & 우 & 우 & 0 & $\sigma$ & 0 & 0 & 0 & 0 & 우 & 우 & 우 \\
\hline 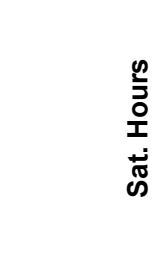 & $\begin{array}{l}\sum_{0} \\
0 \\
\stackrel{0}{0} \\
\stackrel{1}{1} \\
\sum_{0}^{1} \\
0 \\
0 \\
0\end{array}$ & & & & & $\begin{array}{l}2 \\
0 \\
0 \\
0 \\
0 \\
1 \\
\sum_{0} \\
0 \\
0 \\
\end{array}$ & & & 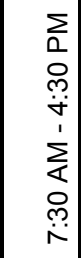 & & & & & & 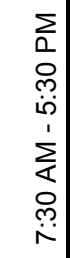 & & \\
\hline 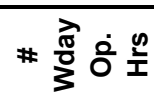 & 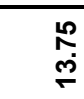 & 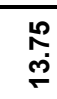 & $\stackrel{\stackrel{n}{\stackrel{m}{m}}}{\stackrel{m}{\sim}}$ & 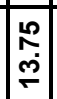 & 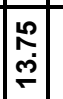 & 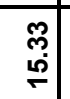 & 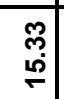 & $\begin{array}{l}\stackrel{m}{0} \\
\stackrel{\rho}{\rho}\end{array}$ & $\mp$ & $₹$ & 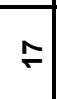 & $\approx$ & $\mp$ & 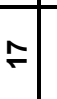 & \pm & 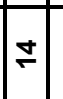 & \pm \\
\hline 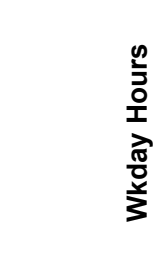 & 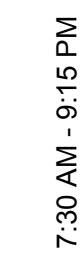 & & & & & $\begin{array}{l}\Sigma \\
0 \\
0 \\
0 \\
0 \\
0 \\
1 \\
\sum_{0} \\
0 \\
0 \\
\end{array}$ & & & $\begin{array}{l}\sum \\
0 \\
0 \\
\stackrel{m}{c} \\
\stackrel{1}{1} \\
\sum_{0} \\
0 \\
0 \\
0 \\
0\end{array}$ & & & & & & $\begin{array}{l}\sum \\
0 \\
0 \\
0 \\
0 \\
1 \\
\sum_{0}^{1} \\
0 \\
\stackrel{0}{n}\end{array}$ & & \\
\hline 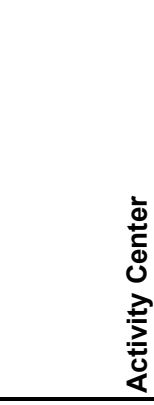 & 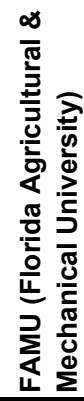 & & & & & 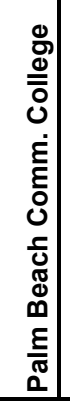 & & & 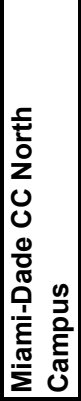 & & & & & & 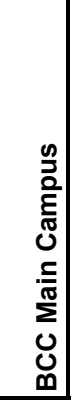 & & \\
\hline
\end{tabular}




\begin{tabular}{|c|c|c|c|c|c|c|c|c|c|c|c|c|c|c|c|c|c|c|c|c|c|c|}
\hline 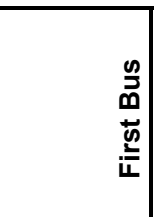 & & 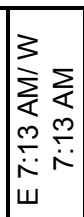 & 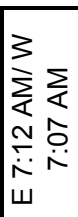 & 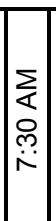 & & 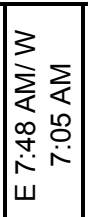 & 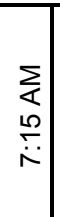 & 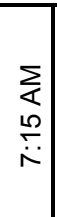 & 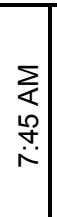 & 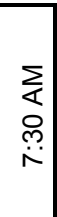 & & & 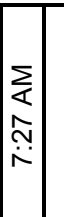 & 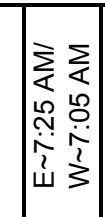 & 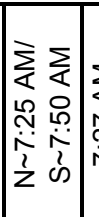 & 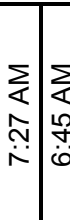 & 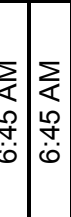 & 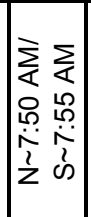 & 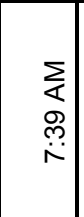 & $\left|\begin{array}{l}\sum \\
\vdots \\
0 \\
\\
\end{array}\right|$ & 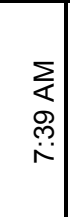 & 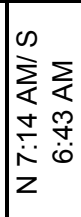 \\
\hline 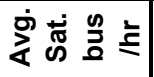 & $\stackrel{\circ}{0}$ & $\stackrel{\leftrightarrow}{\leftarrow}$ & & & & & & & & & & & & & & $\stackrel{0}{\circ}$ & $\stackrel{\circ}{\circ}$ & $\stackrel{\sim}{\sim}$ & & $\stackrel{\square}{-}$ & & \\
\hline \# & & $\stackrel{\circ}{\mathrm{N}}$ & $\stackrel{\circ}{i}$ & $\stackrel{0}{-}$ & $\circ$ & $\stackrel{\circ}{-}$ & $\stackrel{m}{r}$ & $\stackrel{\circ}{-}$ & $\stackrel{\circ}{\circ}$ & $\stackrel{\circ}{i}$ & $\begin{array}{l}0 \\
0\end{array}$ & $\stackrel{\circ}{\circ}$ & $\stackrel{\circ}{-}$ & $\stackrel{\circ}{\mathrm{i}}$ & $\stackrel{\circ}{-}$ & $\stackrel{0}{-} \cdot 0$ & $\stackrel{0}{-} \stackrel{0}{-}$ & $\stackrel{\circ}{-}$ & $\stackrel{m}{-}$ & $\stackrel{\circ}{i}$ & $\stackrel{\circ}{\mathrm{N}}$ & $\stackrel{\circ}{r}$ \\
\hline 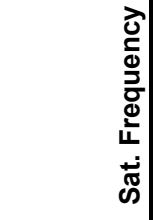 & & 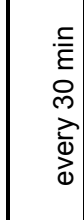 & 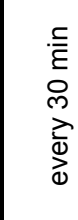 & 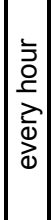 & & 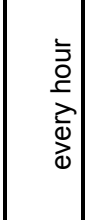 & 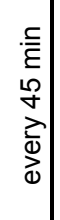 & $\begin{array}{l}\vdots \\
\vdots \\
\bar{c} \\
⿱ 亠 乂 \\
0 \\
0\end{array}$ & 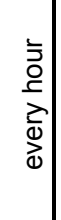 & 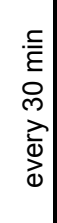 & & & 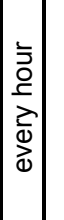 & 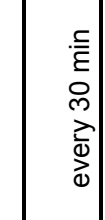 & $\begin{array}{l}\vdots \\
\bar{\vdots} \\
\frac{c}{2} \\
\overline{0} \\
0\end{array}$ & 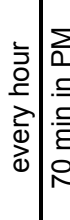 & 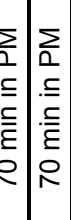 & $\begin{array}{l}\bar{y} \\
0 \\
\frac{0}{2} \\
\frac{1}{0} \\
0\end{array}$ & 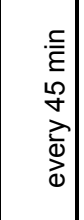 & 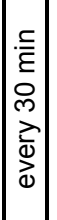 & 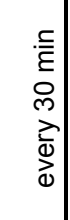 & 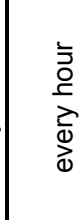 \\
\hline 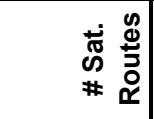 & & $\infty$ & & & & & & & & & & & & & & & & & & 웅 & & \\
\hline 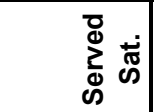 & & & & & & & & & & & & & & & & $\sum$ & $\sum_{<}$ & $\sum_{0}$ & $\sum_{0}$ & $\sum_{0}$ & $\sum_{0}$ & $\sum_{\substack{n \\
<}}$ \\
\hline 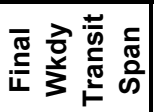 & هั & $\underset{\text { T̃ }}{\leftarrow}$ & & & & & & & & & & & 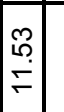 & 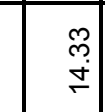 & & 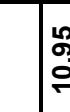 & : & $\begin{array}{c}\tilde{S} \\
\stackrel{\sim}{\sim}\end{array}$ & & $\mid$\begin{tabular}{l}
$\hat{a}$ \\
$\dot{0}$ \\
\hdashline
\end{tabular} & & \\
\hline 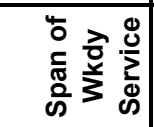 & 우 & $\begin{array}{l}\stackrel{\leftrightarrow}{\oplus} \\
\stackrel{\leftrightarrow}{\leftarrow}\end{array}$ & $\begin{array}{l}\underset{N}{+} \\
\stackrel{+}{\sim}\end{array}$ & $\mid$ & $\begin{array}{l}\hat{0} \\
\stackrel{\leftrightarrow}{ஸ}\end{array}$ & $\begin{array}{c}\infty \\
\infty \\
亡 \\
\leftarrow\end{array}$ & $\begin{array}{l}\stackrel{\mathfrak{S}}{\mathrm{S}} \\
\stackrel{\mathrm{v}}{\mathrm{V}}\end{array}$ & $\begin{array}{l}\stackrel{\Delta}{0} \\
\dot{m}\end{array}$ & $\begin{array}{l}\stackrel{\Delta}{0} \\
\dot{m}\end{array}$ & $\begin{array}{l}\stackrel{g}{0} \\
\stackrel{m}{\leftarrow}\end{array}$ & $\mid \begin{array}{l}\infty \\
2 \\
0 \\
0\end{array}$ & 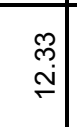 & : & $\begin{array}{l}\stackrel{m}{m} \\
\dot{\sim}\end{array}$ & $\begin{array}{l}\stackrel{\circ}{0} \\
\dot{\leftrightarrow}\end{array}$ & \begin{tabular}{l|l}
8 & 0 \\
\hdashline & 0 \\
\hdashline & 0 \\
& 0
\end{tabular} & 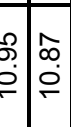 & $\begin{array}{l}\stackrel{N}{O} \\
\dot{\sim}\end{array}$ & $\stackrel{m}{\stackrel{m}{\grave{r}}}$ & & & $\begin{array}{l}\circ \\
6 \\
0 \\
0\end{array}$ \\
\hline 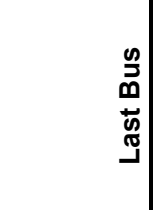 & $\begin{array}{l}\sum_{0} \\
10 \\
\dot{+} \\
\dot{\sigma}\end{array}$ & 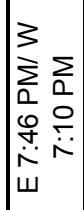 & 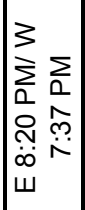 & $\mid \begin{array}{l} \\
\Sigma \\
0 \\
2 \\
0 \\
\end{array}$ & 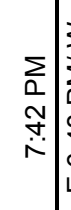 & 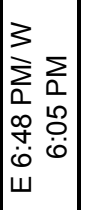 & 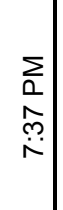 & 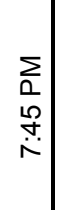 & 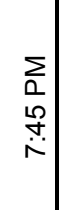 & $\begin{array}{l}\sum_{0} \\
0 \\
\stackrel{0}{i} \\
\end{array}$ & 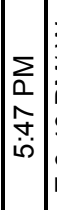 & 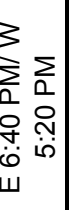 & 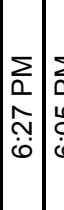 & 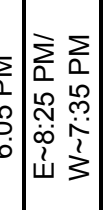 & 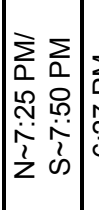 & 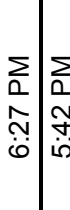 & 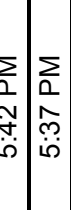 & $\left|\begin{array}{ll}\sum_{0} & 2 \\
0 & 0 \\
0 & 0 \\
0 & 0 \\
00 & 1 \\
0 & 1 \\
z & 0\end{array}\right|$ & 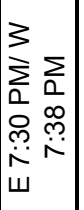 & 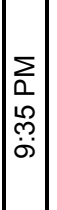 & $\begin{array}{l}\sum \\
0 \\
0 \\
\dot{0}\end{array}$ & 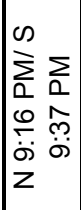 \\
\hline 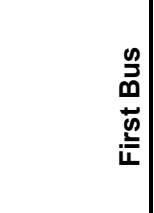 & 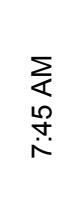 & $\mid \begin{array}{ll}3 & \\
\sum_{0} & 2 \\
0 & 0 \\
0 & 0 \\
0 & 0 \\
w & 0\end{array}$ & 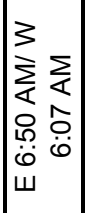 & 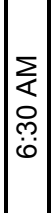 & 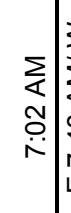 & 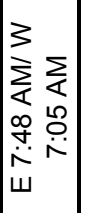 & $\begin{array}{l}\sum \\
\vdots \\
o \\
\end{array}$ & 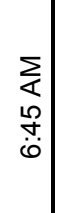 & 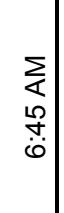 & 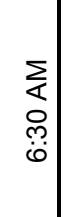 & 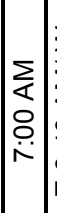 & 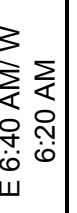 & 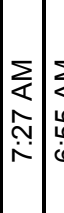 & 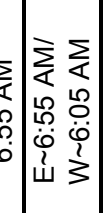 & 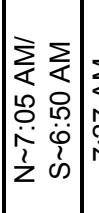 & 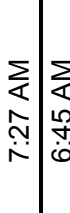 & 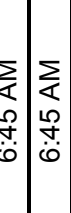 & 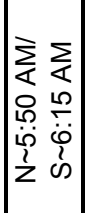 & 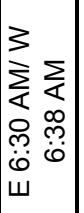 & $\left|\begin{array}{c}\sum \\
\vdots \\
0 \\
0 \\
i 0\end{array}\right|$ & 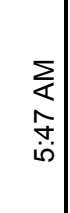 & 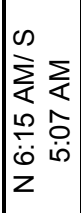 \\
\hline 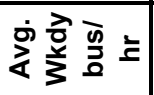 & $\hat{o}$ & $\stackrel{\circ}{\circ}$ & & & & & & & & & & & & & & $\stackrel{\circ}{-}$ & $\stackrel{\circ}{\circ}$ & $\stackrel{n}{\sim}$ & & $\stackrel{\infty}{\stackrel{\infty}{r}}$ & & \\
\hline 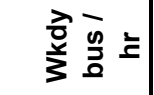 & $\hat{o}$ & $\stackrel{\circ}{\circ}$ & $\stackrel{\circ}{\mathrm{N}}$ & 오․ & மூ & $\stackrel{\circ}{r}$ & 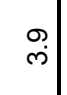 & $\stackrel{\infty}{\dot{m}^{\prime}}$ & $\hat{m}$ & $\stackrel{\varphi}{\dot{m}^{\prime}}$ & $\stackrel{\circ}{\circ}$ & $\stackrel{\circ}{r}$ & ح. & $\stackrel{\circ}{\mathrm{N}}$ & S: & \begin{tabular}{l|l}
0 & 0 \\
- & -
\end{tabular} & $\stackrel{0}{-} \stackrel{0}{-}$ & $\stackrel{\circ}{\mathrm{N}}$ & $\stackrel{\circ}{\sim}$ & $\left|\begin{array}{l}\infty \\
\sim \\
\sim\end{array}\right|$ & $\stackrel{\sim}{\mathrm{N}}$ & $\stackrel{\circ}{\mathrm{N}}$ \\
\hline 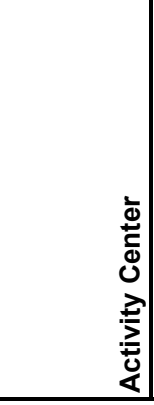 & 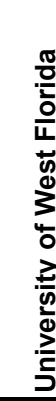 & 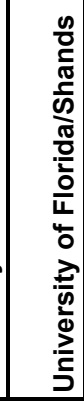 & & & & & & & & & & & 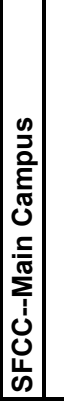 & 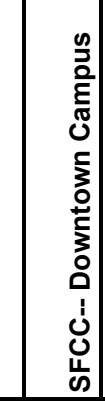 & & 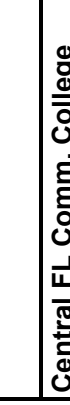 & 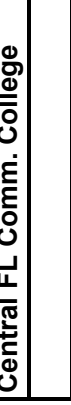 & 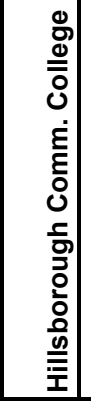 & & 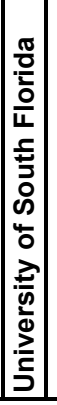 & & \\
\hline
\end{tabular}




\begin{tabular}{|c|c|c|c|c|c|c|c|c|c|c|c|c|c|c|c|c|c|c|c|}
\hline 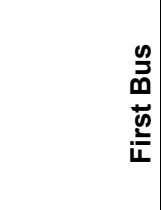 & 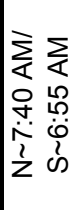 & 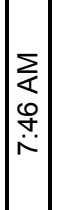 & 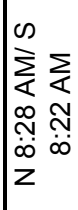 & 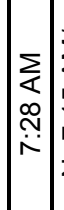 & 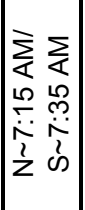 & 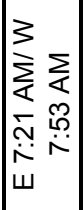 & & 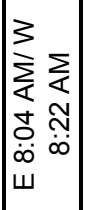 & 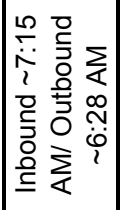 & 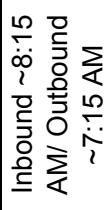 & 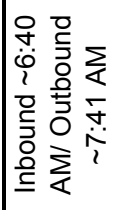 & & 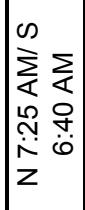 & 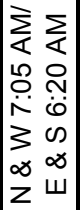 & 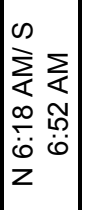 & 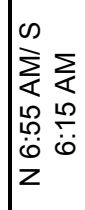 & 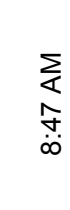 & 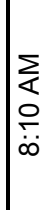 & 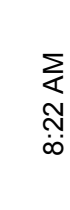 \\
\hline 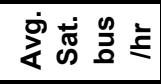 & & & & & & & & & $\stackrel{m}{?}$ & & & & 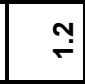 & & $\stackrel{0}{\circ}$ & & $\stackrel{-}{\circ}$ & & $\stackrel{\circ}{-}$ \\
\hline \#离号 & $\stackrel{\circ}{\circ}$ & $\stackrel{\circ}{\circ}$ & $\stackrel{\circ}{\circ}$ & $\begin{array}{l} \\
\text { i }\end{array}$ & $\stackrel{\circ}{\circ}$ & \begin{tabular}{l}
$\infty$ \\
\hdashline \\
0
\end{tabular} & : & $\stackrel{\circ}{i}$ & $\stackrel{\circ}{\circ}$ & $\stackrel{\circ}{\circ}$ & $\stackrel{\circ}{\mathrm{N}}$ & & $\stackrel{\circ}{\circ}$ & $\stackrel{m}{\rightarrow}$ & $\stackrel{\sim}{\sim}$ & $\stackrel{n}{\sim}$ & $\stackrel{\circ}{\circ}$ & $\stackrel{\circ}{\circ}$ & $\stackrel{\circ}{\circ}$ \\
\hline 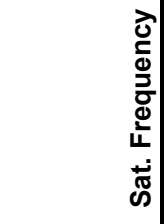 & 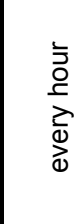 & 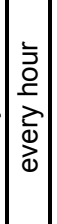 & 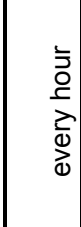 & 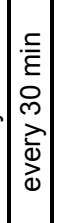 & 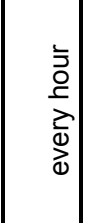 & 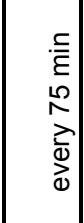 & & 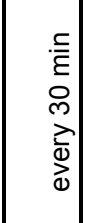 & 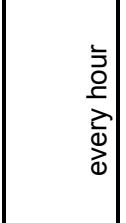 & 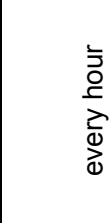 & 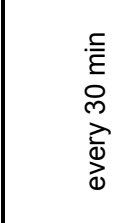 & & 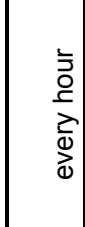 & 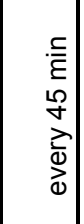 & 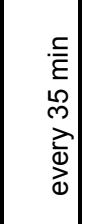 & 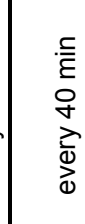 & $\begin{array}{l}\overline{0} \\
\frac{0}{2} \\
\frac{1}{0} \\
\text { d }\end{array}$ & 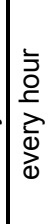 & $\begin{array}{l}\bar{\vdots} \\
\frac{1}{c} \\
\frac{7}{0} \\
\text { d }\end{array}$ \\
\hline 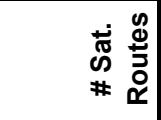 & & & & & & & & & $m$ & & & & $N$ & & $N$ & & $N$ & & $r$ \\
\hline 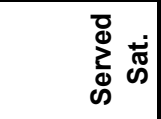 & $\sum_{\substack{\infty \\
<}}^{\infty}$ & $\sum$ & $\sum_{0}$ & 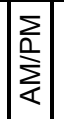 & $\sum_{\substack{n \\
<}}^{\infty}$ & $\sum_{\substack{n \\
<}}^{\infty}$ & & $\sum_{0}$ & $\sum_{\substack{n \\
<}}^{\infty}$ & $\sum_{\substack{\infty \\
\sum}}^{\infty}$ & $\sum_{\substack{\infty \\
<}}^{\infty}$ & & & & $\sum_{\substack{n \\
<}}^{\infty}$ & $\sum_{\substack{n \\
<}}^{\infty}$ & $\sum_{\substack{\infty \\
<}}^{\infty}$ & $\sum_{i}^{\infty}$ & $\sum_{\Omega}$ \\
\hline 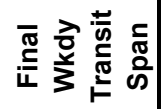 & & & & & & & & & $\begin{array}{c}\mathfrak{N} \\
\stackrel{m}{\longrightarrow}\end{array}$ & & & & $\begin{array}{l}\text { مी } \\
\text { مீ }\end{array}$ & & $\begin{array}{l}\stackrel{\leftrightarrow}{\leftrightarrow} \\
\stackrel{\sim}{\sim}\end{array}$ & & $\underset{\text { S }}{\stackrel{8}{N}}$ & & $\stackrel{8}{+}$ \\
\hline 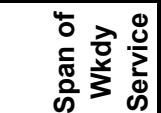 & $\begin{array}{l}\infty \\
\infty \\
\stackrel{\infty}{L} \\
\stackrel{\rho}{L}\end{array}$ & & & & $\begin{array}{l}\stackrel{0}{\circ} \\
\stackrel{+}{\leftarrow}\end{array}$ & & & $\begin{array}{l}0 \\
\stackrel{0}{0} \\
\stackrel{0}{0}\end{array}$ & $\begin{array}{l}\stackrel{\leftrightarrow}{\mathrm{i}} \\
\stackrel{\mathrm{N}}{ }\end{array}$ & 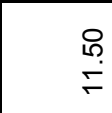 & 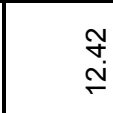 & $\stackrel{\stackrel{\infty}{\infty}}{\stackrel{\leftrightarrow}{ }}$ & $\begin{array}{c}\stackrel{m}{\oplus} \\
\stackrel{\rho}{\leftarrow}\end{array}$ & $\begin{array}{l}\infty \\
\stackrel{\infty}{\longrightarrow} \\
\stackrel{p}{\longrightarrow}\end{array}$ & 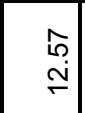 & $\begin{array}{l}\hat{O} \\
\stackrel{\leftrightarrow}{\leftarrow}\end{array}$ & $\stackrel{\text { \& }}{\underset{\mathrm{O}}{\mathrm{O}}}$ & $\stackrel{8}{\dot{8}}$ & $\stackrel{8}{\stackrel{8}{\leftarrow}}$ \\
\hline 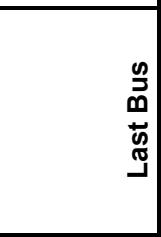 & 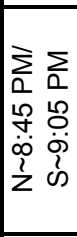 & $\mid \begin{array}{l}\Sigma \\
0 \\
8 \\
0 \\
\dot{\sigma}\end{array}$ & 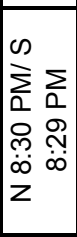 & $\begin{array}{l}\vdots \\
0 \\
0 \\
\dot{0} \\
-\end{array}$ & $\left|\begin{array}{cc|}\sum_{0} & \sum \\
0 & 0 \\
0 & 0 \\
j & 0 \\
\dot{1} & 0 \\
\hat{1} & 0 \\
z & 0\end{array}\right|$ & $\left|\begin{array}{ll}3 & \\
\sum_{0} & \vdots \\
0 & 0 \\
0 & 0 \\
0 & 0 \\
0 & 0 \\
w & 0\end{array}\right|$ & 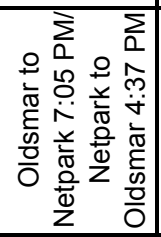 & 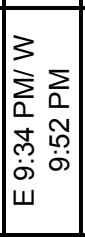 & 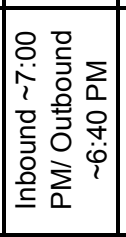 & 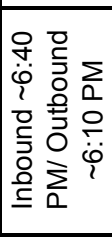 & 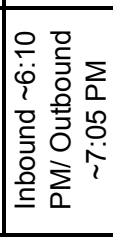 & 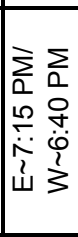 & 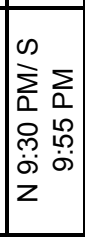 & $\left|\begin{array}{ll}\sum & 2 \\
0 & 0 \\
0 & 0 \\
0 & 0 \\
& 0 \\
3 & 0 \\
\infty & 0 \\
\infty & \infty \\
z & w\end{array}\right|$ & $\left|\begin{array}{ll}\infty & \\
\sum_{0} & \sum \\
0 & 0 \\
\infty & 1 \\
\hdashline & 0 \\
0 & 0 \\
z & 0\end{array}\right|$ & $\begin{array}{ll}\infty & \\
\sum_{0} & \Sigma \\
0 & 0 \\
0 & 10 \\
0 & 10 \\
0 & 0 \\
z & 0 \\
z\end{array}$ & \begin{tabular}{l}
$\sum_{0}$ \\
\multirow{0}{*}{} \\
$\dot{0}$
\end{tabular} & \begin{tabular}{l}
$\sum_{0}$ \\
0 \\
\hdashline 0
\end{tabular} & 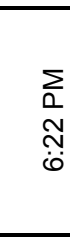 \\
\hline 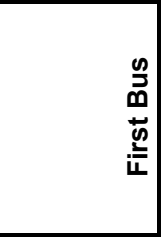 & 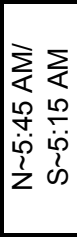 & 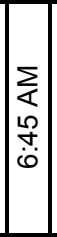 & 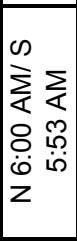 & 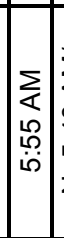 & 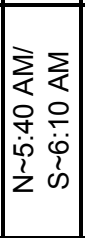 & 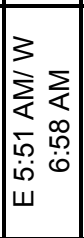 & 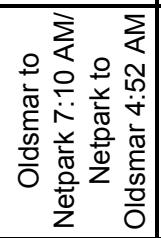 & 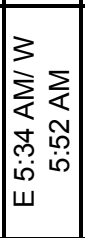 & 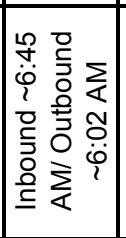 & 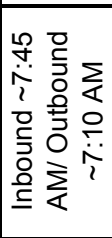 & 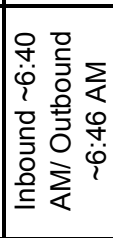 & 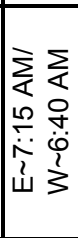 & 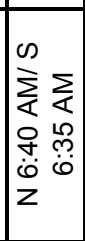 & 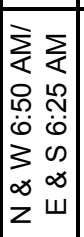 & 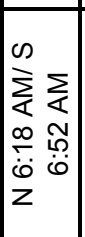 & 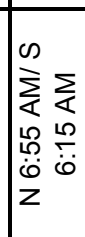 & $\begin{array}{l}\sum_{\overleftarrow{\alpha}} \\
f \\
\dot{0}\end{array}$ & 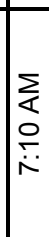 & 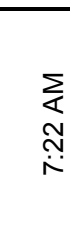 \\
\hline 穴 & & & & & & & & & $\stackrel{m}{r}$ & & & & مִ & & $\stackrel{\leftrightarrow}{\leftarrow}$ & & $\stackrel{\circ}{r}$ & & 우 \\
\hline 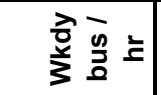 & $\stackrel{\circ}{\longrightarrow}$ & 워․ & $\stackrel{\leftrightarrow}{-}$ & $\mid$ & $\stackrel{\circ}{\mathrm{N}}$ & $\stackrel{\circ}{\circ}$ & $\stackrel{\sim}{\longrightarrow}$ & $\stackrel{\circ}{\mathrm{i}}$ & $\stackrel{\circ}{\circ}$ & $\stackrel{\circ}{\stackrel{P}{*}}$ & $\stackrel{\circ}{\mathrm{N}}$ & $\stackrel{\circ}{r}$ & مִ & مִ & $\stackrel{r}{\circ}$ & $\stackrel{\text { Pִ }}{\longrightarrow}$ & $\stackrel{\circ}{\circ}$ & $\stackrel{\circ}{\stackrel{r}{r}}$ & $\stackrel{\circ}{r}$ \\
\hline 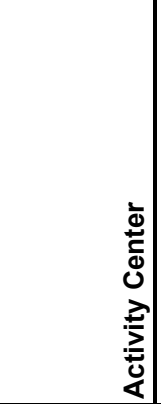 & & & & & & & & & 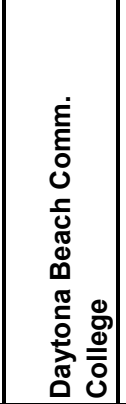 & & & & 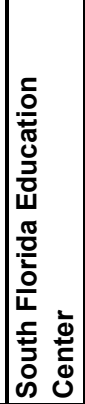 & & 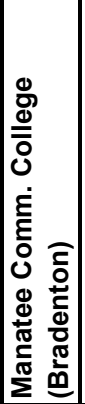 & & 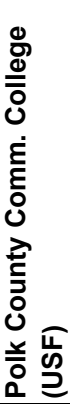 & & 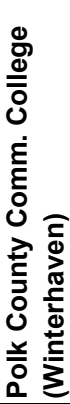 \\
\hline
\end{tabular}




\begin{tabular}{|c|c|c|c|c|c|c|c|c|c|c|c|c|c|c|c|c|c|}
\hline 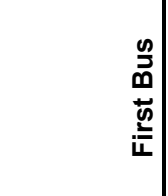 & 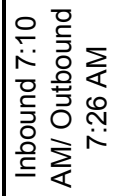 & 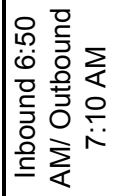 & 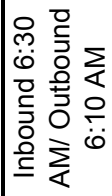 & & & 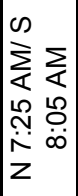 & 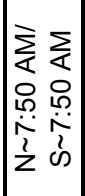 & 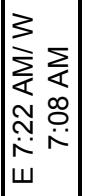 & 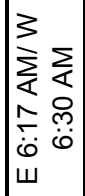 & & 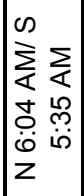 & & 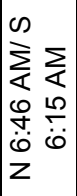 & & & & \\
\hline 安酸气 & $\stackrel{n}{r}$ & & & & & $\stackrel{\circ}{-}$ & & & $\stackrel{⿱ 亠 凶}{\mathbf{N}}$ & & & & & & $\stackrel{\circ}{0}$ & & \\
\hline \# & $\stackrel{n}{\stackrel{n}{~}}$ & $\stackrel{n}{r}$ & $\stackrel{n}{r}$ & Oי & 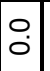 & $\stackrel{\circ}{\circ}$ & $\stackrel{\circ}{-}$ & $\stackrel{\circ}{-}$ & $\stackrel{0}{N}$ & $\stackrel{\circ}{\circ}$ & $\stackrel{\circ}{m}$ & $\stackrel{\circ}{\circ}$ & $\stackrel{2}{\longrightarrow}$ & : & & & \\
\hline 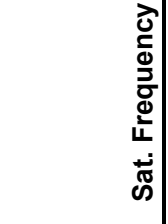 & 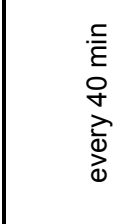 & 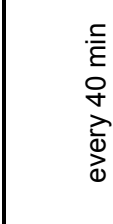 & 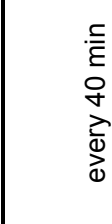 & & & $\begin{array}{l}\vdots \\
\vdots \\
\frac{1}{2} \\
\overline{0} \\
\text { d }\end{array}$ & 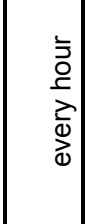 & $\begin{array}{l}\vdots \\
0 \\
\frac{0}{2} \\
⿱ 亠 乂 \\
0 \\
0\end{array}$ & & & $\begin{array}{l}\cdot \frac{c}{\bar{c}} \\
\stackrel{2}{N} \\
\vec{d} \\
\bar{d} \\
i \\
i\end{array}$ & & 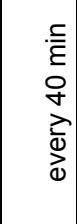 & & & & \\
\hline 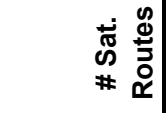 & $m$ & & & & & $m$ & & & $m$ & & & & & & 0 & & \\
\hline 㟒 & & & $\sum_{\substack{\infty \\
<}}^{\infty}$ & & & $\sum_{\substack{0 \\
0}}^{\infty}$ & $\sum_{0}$ & $\gtreqless$ & $\sum_{\substack{\infty \\
<}}^{\infty}$ & & $\sum_{\substack{n \\
k}}^{\infty}$ & & $\sum_{\substack{0 \\
0}}^{\substack{1 \\
k}}$ & & & & \\
\hline 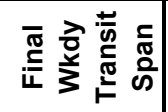 & & & & & & $\begin{array}{l}8 \\
\dot{0} \\
0\end{array}$ & & & 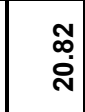 & & & & & & $\stackrel{\substack{n \\
\infty}}{\mid}$ & & \\
\hline 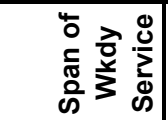 & $\stackrel{8}{\stackrel{\leftrightarrow}{\leftarrow}}$ & $\stackrel{\hat{\varphi}}{\stackrel{\leftrightarrow}{r}}$ & $\begin{array}{l}\stackrel{m}{\oplus} \\
\stackrel{\leftrightarrow}{\oplus}\end{array}$ & $\mid$ & $\begin{array}{l}\stackrel{0}{\infty} \\
\sigma \\
\sigma\end{array}$ & $\begin{array}{l}8 \\
0 \\
6\end{array}$ & $\begin{array}{l}\stackrel{\circ}{0} \\
\stackrel{\mathrm{i}}{\sim}\end{array}$ & $\begin{array}{l}\stackrel{m}{m} \\
\stackrel{m}{\sim}\end{array}$ & $\begin{array}{l}0 \\
\stackrel{\leftrightarrow}{0} \\
0 \\
0\end{array}$ & 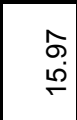 & 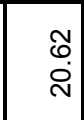 & 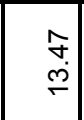 & $\begin{array}{l}\hat{f} \\
\infty \\
\stackrel{\infty}{+}\end{array}$ & \begin{tabular}{l}
$\infty$ \\
0 \\
0 \\
\hdashline
\end{tabular} & $\stackrel{\stackrel{2}{N}}{\sigma}$ & $\left|\begin{array}{l}\pi \\
0 \\
0\end{array}\right|$ & $\begin{array}{l}\infty \\
\infty \\
\infty\end{array}$ \\
\hline 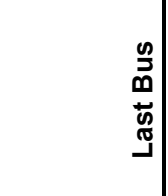 & 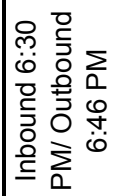 & 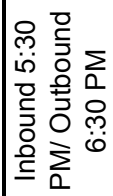 & 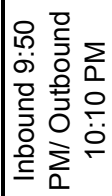 & 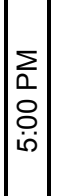 & $\begin{array}{l} \\
\vdots \\
0 \\
0 \\
\dot{0} \\
i\end{array}$ & \begin{tabular}{ll}
$\infty$ & \\
\hdashline & \\
$\vdots 0$ & 0 \\
0 & 0 \\
0 & 0 \\
0 & 0 \\
0 & $\infty$ \\
$z$ & 0
\end{tabular} & $\left|\begin{array}{ll}\sum_{n} & 2 \\
0 & 0 \\
0 & 0 \\
0 & 0 \\
0 & 0 \\
0 & 0 \\
1 & 0 \\
z & 0\end{array}\right|$ & $\left|\begin{array}{ll|}3 & \\
\sum & \vdots \\
0 & 0 \\
0 & 0 \\
0 & 0 \\
i & i \\
w & \end{array}\right|$ & $\begin{array}{ll}3 & \\
\vdots & \Sigma \\
0 & 0 \\
0 & 0 \\
0 & 0 \\
0 & 0 \\
0 & 0 \\
4\end{array}$ & $\mid \begin{array}{ll}\infty & \\
\sum_{0} & \sum_{0} \\
0 & 0 \\
0 & m \\
\vdots & 5 \\
0 & 0 \\
z & 0\end{array}$ & 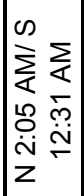 & 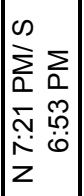 & 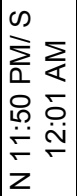 & $\begin{array}{l}\sum \\
0 \\
0 \\
0 \\
0 \\
0\end{array}$ & 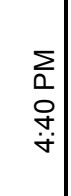 & 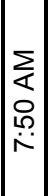 & $\begin{array}{l}\sum_{0} \\
\stackrel{N}{N} \\
\stackrel{\sim}{\sim}\end{array}$ \\
\hline 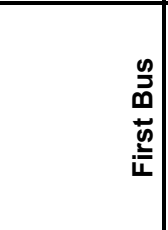 & 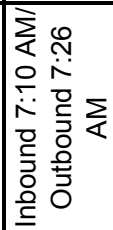 & 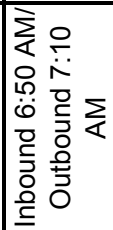 & 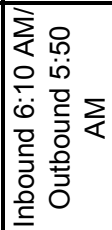 & 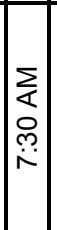 & 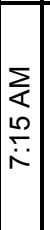 & $\mid \begin{array}{ll}0 & \\
\sum_{i} & \sum \\
0 & \\
0 & 0 \\
0 & 0 \\
0 & i n \\
z\end{array}$ & $\left|\begin{array}{ll}\sum & \sum \\
< & 2 \\
0 & 0 \\
0 & 0 \\
0 & 0 \\
0 & 0 \\
1 & 1 \\
z & 0\end{array}\right|$ & 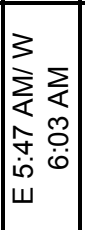 & 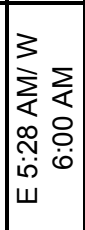 & 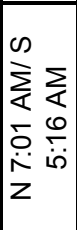 & 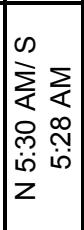 & 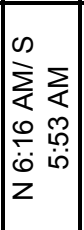 & 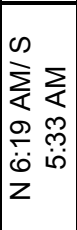 & 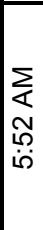 & 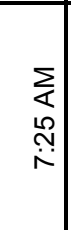 & 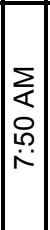 & 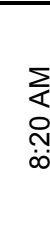 \\
\hline 穴 & 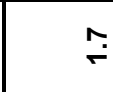 & & & & & $\stackrel{m}{\longrightarrow}$ & & & $\overline{\mathrm{i}}$ & & & & & & $\stackrel{9}{0}$ & & \\
\hline 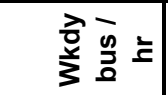 & $\stackrel{\circ}{\Gamma}$ & $\stackrel{\text { Pم }}{\longrightarrow}$ & $\stackrel{m}{N}$ & ì & $\stackrel{\circ}{\circ}$ & $\stackrel{\circ}{\mathrm{N}}$ & $\stackrel{\circ}{\circ}$ & $\stackrel{\circ}{-}$ & $\stackrel{\infty}{\sim}$ & $\stackrel{\circ}{\circ}$ & ָָ & $\stackrel{n}{\longrightarrow}$ & $\stackrel{N}{N}$ & $\stackrel{\circ}{i}$ & $\stackrel{\infty}{\circ}$ & $\stackrel{0}{-}$ & $\stackrel{\circ}{r}$ \\
\hline 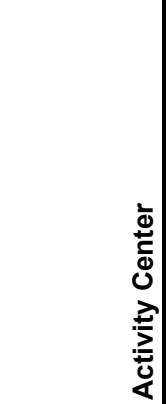 & 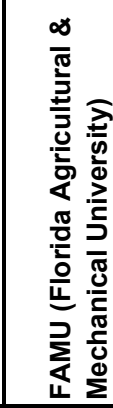 & & & & & 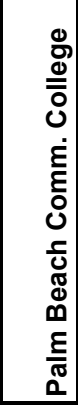 & & & 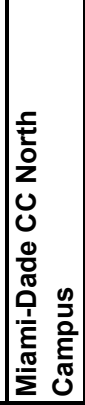 & & & & & & 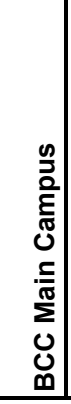 & & \\
\hline
\end{tabular}




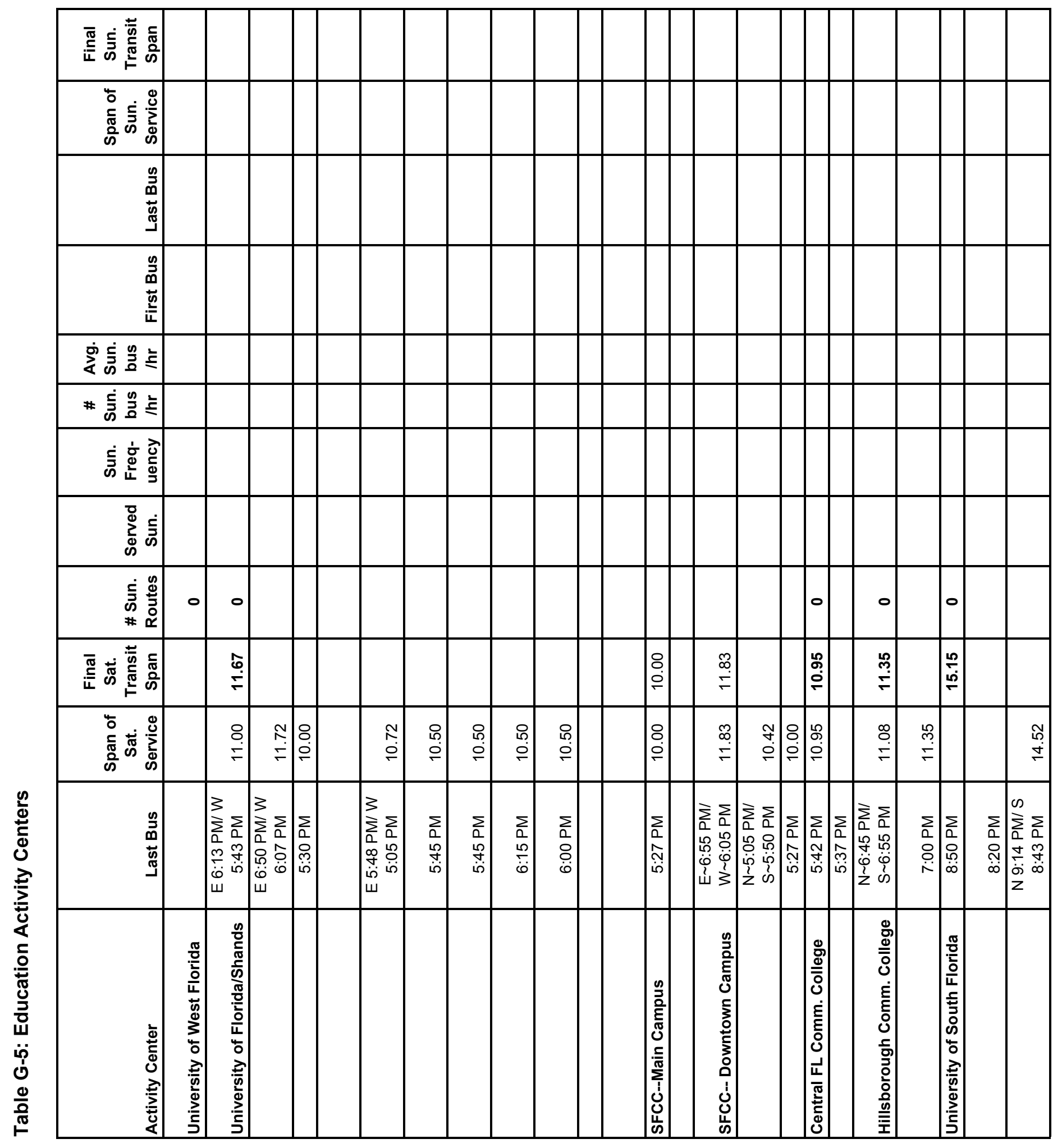




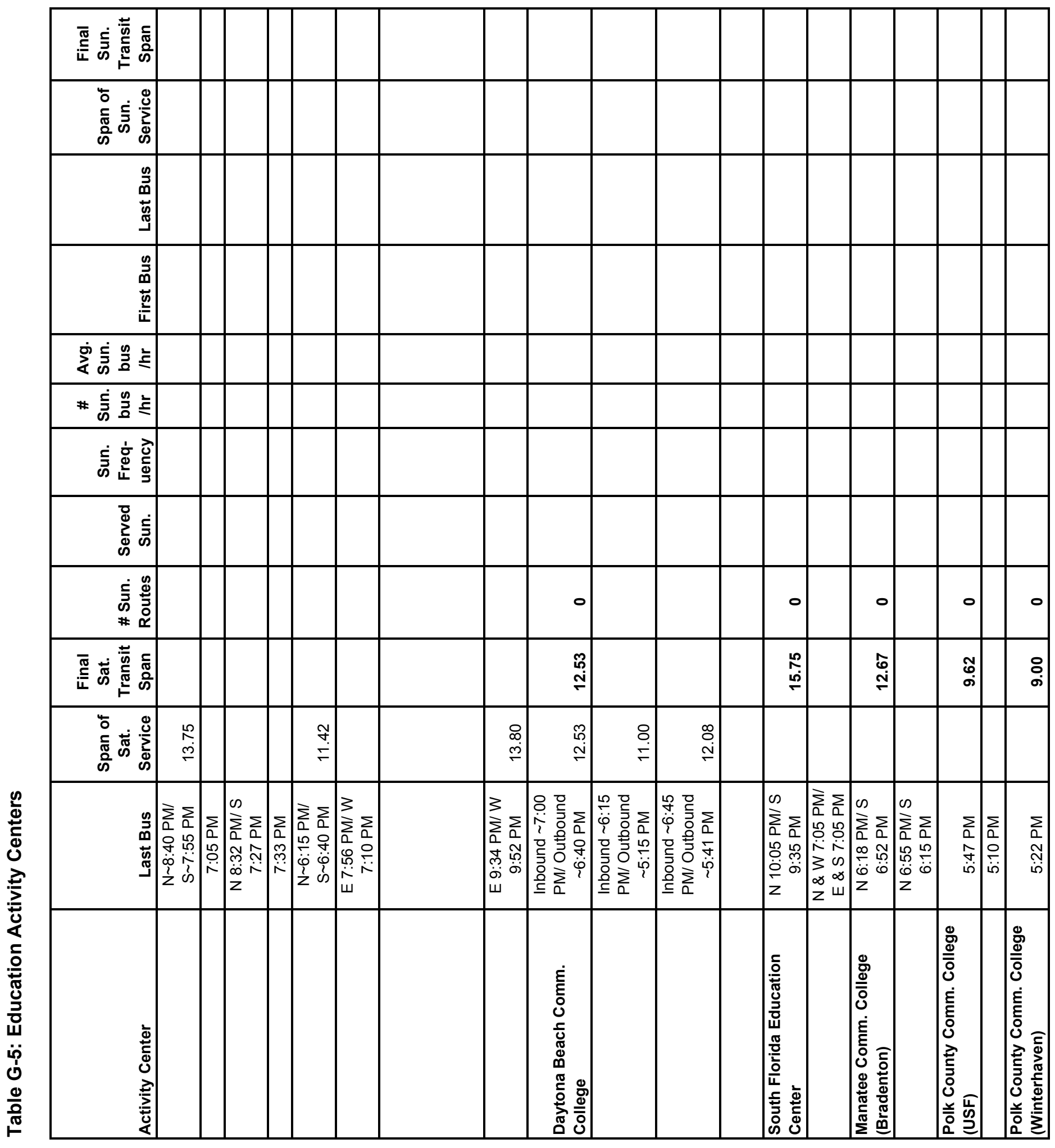




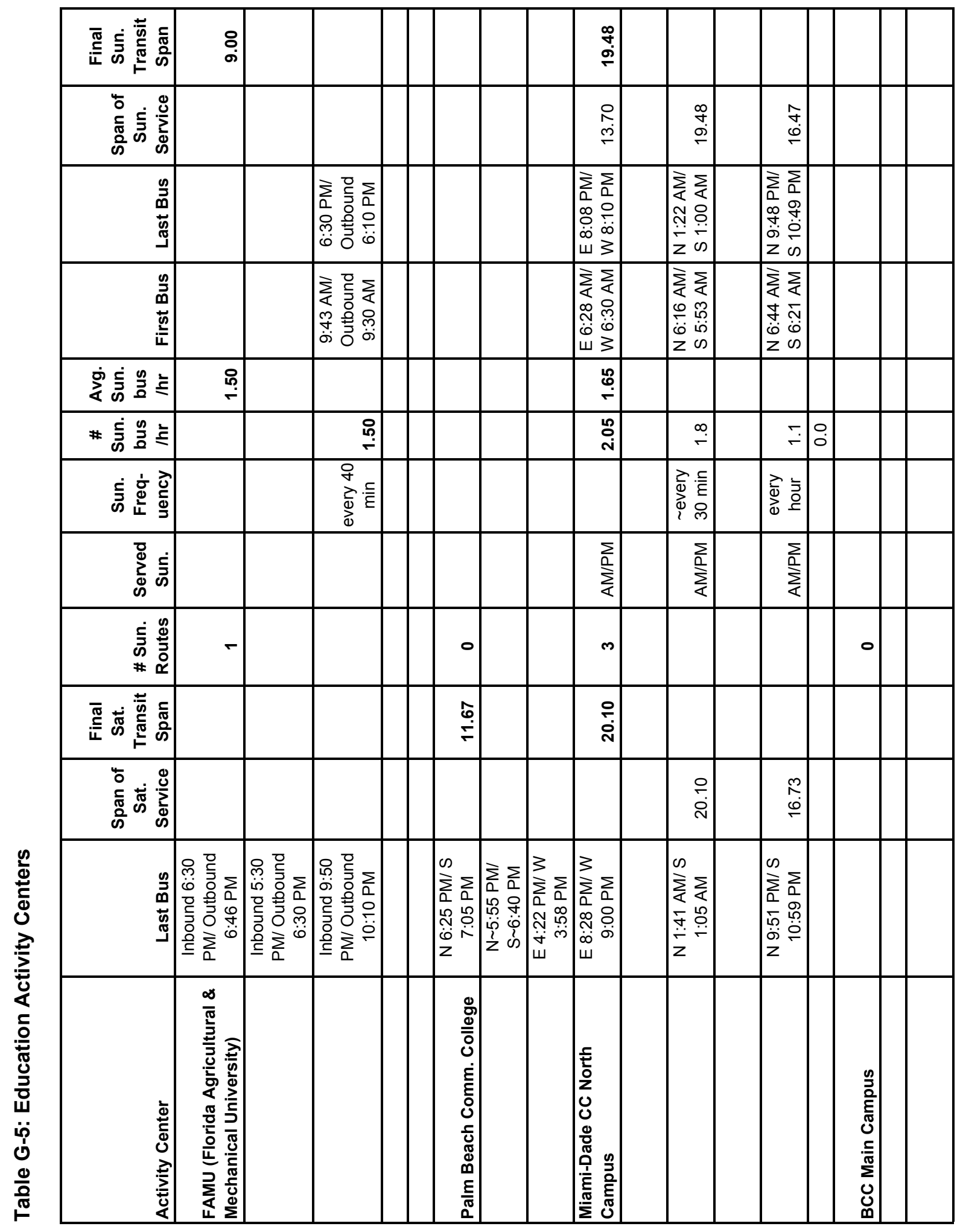




\begin{tabular}{|c|c|c|c|c|c|c|c|c|c|c|c|c|c|c|c|c|c|c|c|c|}
\hline 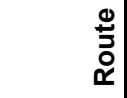 & $\stackrel{\nabla}{\sim}$ & & $\varangle$ & $\nabla$ & $\wedge$ & $\stackrel{N}{\sim}$ & $\mathbb{\$}$ & $\stackrel{\oplus}{\sim}$ & $\mp$ & ల్ల & $\widetilde{\delta}$ & $\mathbb{N}$ & $m$ & $\infty$ & ம & ๙ু & $\varangle$ & 0 & $I$ & \lrcorner \\
\hline 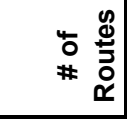 & - & & $\nabla$ & & & & $N$ & & $\nabla$ & & & & $N$ & & - & - & 으 & & & \\
\hline 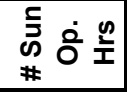 & 0 & $\mathbb{N}$ & นึ & $\begin{array}{l}\qquad \\
\dot{0}\end{array}$ & $\begin{array}{l}n \\
0 \\
0\end{array}$ & $\begin{array}{l}n \\
0 \\
0\end{array}$ & & & $\stackrel{\sim}{N}$ & $\mathbb{N}$ & $\mathbb{N}$ & $\mathbb{N}$ & $\mathbb{N}$ & & 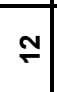 & $\mathbb{N}$ & $\stackrel{m}{=}$ & & $\stackrel{m}{\sim}$ & $\stackrel{m}{\sim}$ \\
\hline 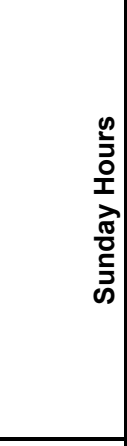 & $\begin{array}{l}\sum \\
0 \\
0 \\
0 \\
i 0 \\
\sum^{1} \\
\sum_{0} \\
0 \\
\infty \\
\infty \\
\infty\end{array}$ & 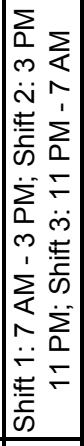 & 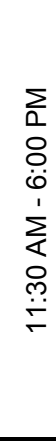 & & & & & & 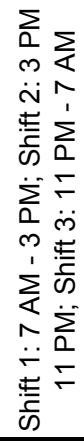 & & & & 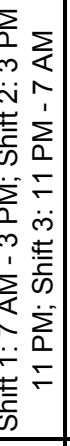 & & \begin{tabular}{c|} 
\\
$\sum$ \\
0 \\
0 \\
0 \\
00 \\
1 \\
$\sum_{1}$ \\
0 \\
0 \\
$\dot{\infty}$ \\
0
\end{tabular} & 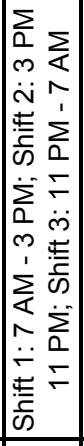 & 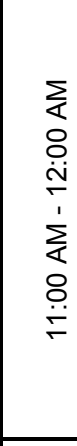 & & & \\
\hline 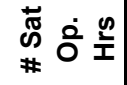 & 0 & $\mathbb{N}$ & 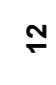 & $\cong$ & $\simeq$ & 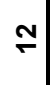 & & & $\mathbb{N}$ & $\mathbb{N}$ & $\mathbb{N}$ & $\mathbf{N}$ & $\mathbb{N}$ & $\mathbf{N}$ & $\simeq$ & $\mathbb{N}$ & $\stackrel{m}{=}$ & & $\stackrel{m}{q}$ & $\stackrel{m}{\rho}$ \\
\hline 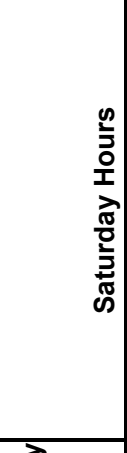 & 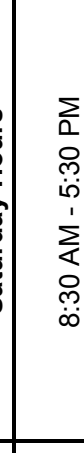 & 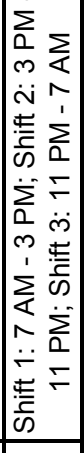 & $\begin{array}{l}\sum \\
0 \\
0 \\
0 \\
0 \\
\dot{\sigma} \\
1 \\
\sum \\
0 \\
0 \\
0 \\
\sigma\end{array}$ & & & & & & 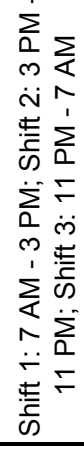 & & & & 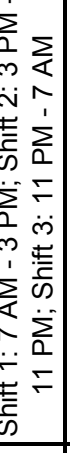 & & 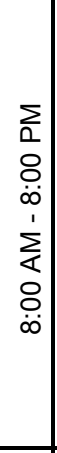 & 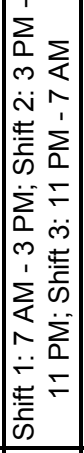 & 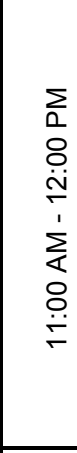 & & & \\
\hline$\sum_{\#}^{\frac{\pi}{0}}$ & 0 & $\stackrel{\mathbb{N}}{\mathbf{S}}$ & 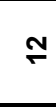 & $\simeq$ & $\mathfrak{\simeq}$ & 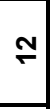 & & & N & $\mathbb{N}$ & $\stackrel{\mathbb{N}}{\mathbf{s}}$ & $\mathbf{N}$ & 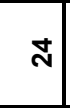 & $\mathbb{N}$ & 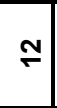 & $\mathbb{N}$ & \pm & & $\underset{\nabla}{ }$ & 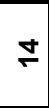 \\
\hline 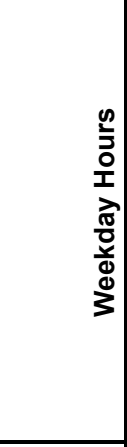 & 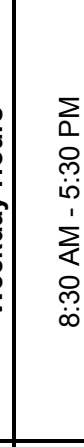 & 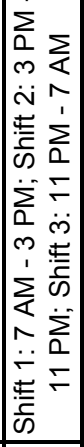 & $\begin{array}{l}\sum \\
0 \\
0 \\
0 \\
0 \\
0 \\
1 \\
\sum \\
0 \\
0 \\
m \\
\dot{0}\end{array}$ & & & & & & 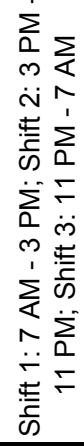 & & & & 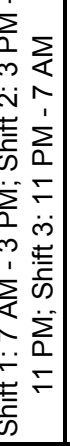 & & $\begin{array}{c}\sum_{0} \\
0 \\
0 \\
\dot{\infty} \\
1 \\
\sum_{0} \\
0 \\
0 \\
\dot{\infty}\end{array}$ & 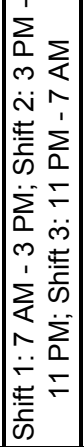 & 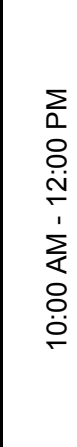 & & & \\
\hline 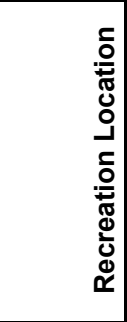 & 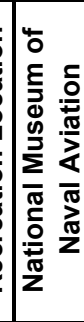 & $\begin{array}{l}\frac{c}{0} \\
\bar{d} \\
0 \\
0 \\
\frac{\pi}{0} \\
0 \\
0 \\
0 \\
0 \\
0 \\
0 \\
0\end{array}$ & 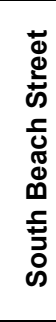 & & & & 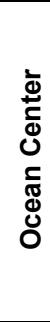 & & 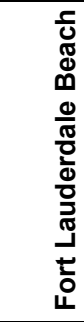 & & & & 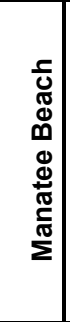 & & 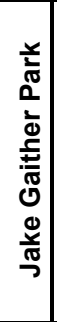 & 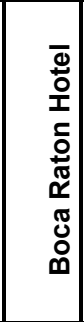 & 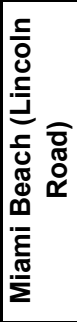 & & & \\
\hline
\end{tabular}




\begin{tabular}{|c|c|c|c|c|c|c|c|c|c|c|}
\hline \begin{tabular}{l}
$\#$ \\
\multirow{2}{*}{} \\
$\stackrel{ \pm}{0}$ \\
$\stackrel{0}{\alpha}$
\end{tabular} & $\Sigma$ & $\simeq$ & $\infty$ & 3 & $\begin{array}{l}x \\
\sum \\
\frac{x}{\Delta} \\
\frac{\bar{\omega}}{\sigma} \\
\frac{\pi}{4}\end{array}$ & 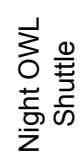 & 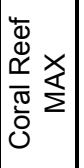 & の & $\mp$ & $\stackrel{N}{N}$ \\
\hline 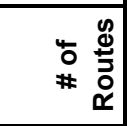 & & & & & & & - & $m$ & & \\
\hline $\begin{array}{c}5 \\
0 \\
\#\end{array}$ & $\stackrel{m}{\sim}$ & $\stackrel{m}{\square}$ & $m$ & $\stackrel{m}{=}$ & $\stackrel{m}{\check{2}}$ & $\stackrel{m}{=}$ & o) & $\stackrel{\text { N }}{ }$ & & \\
\hline 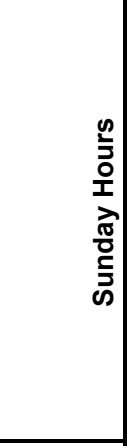 & & & & & & & $\begin{array}{l}\sum \\
0 \\
0 \\
\dot{0} \\
1 \\
\sum \\
\vdots \\
8 \\
0 \\
\dot{0}\end{array}$ & 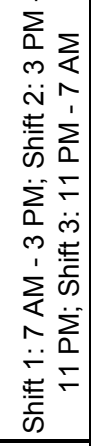 & & \\
\hline 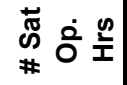 & $\stackrel{m}{\check{2}}$ & $\stackrel{m}{q}$ & $\stackrel{m}{\check{2}}$ & $\stackrel{m}{=}$ & $\stackrel{m}{\check{2}}$ & $\stackrel{m}{=}$ & 0 & $\mathbb{N}$ & & \\
\hline 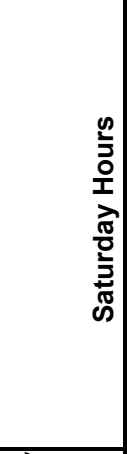 & & & & & & & $\begin{array}{l}\sum \\
0 \\
0 \\
\dot{0} \\
1 \\
\sum_{1} \\
8 \\
8 \\
\dot{0}\end{array}$ & 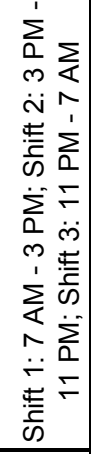 & & \\
\hline$\sum_{\#}^{\frac{\pi}{0}}$ & 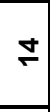 & $\underset{\nabla}{ }$ & & \pm & \pm & 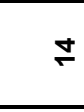 & 0 & $\stackrel{\sim}{N}$ & & \\
\hline 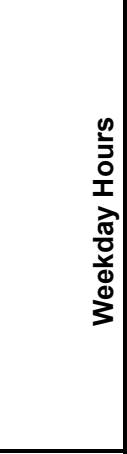 & & & & & & & $\begin{array}{l}2 \\
0 \\
8 \\
0 \\
\dot{0} \\
\sum_{1} \\
8 \\
0 \\
\dot{0}\end{array}$ & 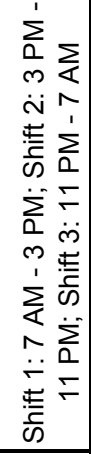 & & \\
\hline 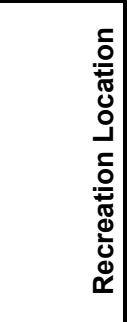 & & & & & & & 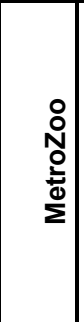 & 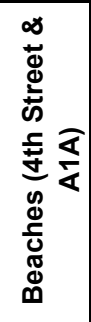 & & \\
\hline
\end{tabular}




\begin{tabular}{|c|c|c|c|c|c|c|c|c|c|c|c|c|c|c|c|c|c|c|c|c|}
\hline 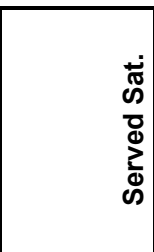 & $\sum_{\substack{n \\
<}}^{\sum}$ & & $\sum_{<}$ & $\sum_{<}$ & $\sum_{<}$ & $\sum$ & & & 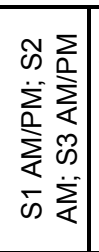 & 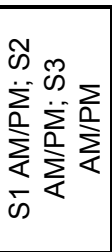 & 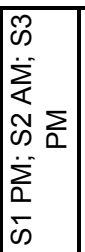 & 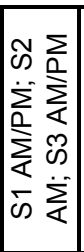 & 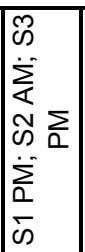 & 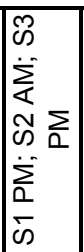 & $\sum$ & $\begin{array}{l}\sum \\
\vdots \\
\infty \\
\sum_{0} \\
\bar{\infty} \\
\bar{n}\end{array}$ & $\sum$ & $\sum_{\substack{n \\
<}}^{\infty}$ & $\sum$ & $\sum_{\substack{n \\
c}}^{\infty}$ \\
\hline 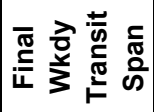 & $\stackrel{\circ}{=}$ & & $\begin{array}{c}\tilde{N} \\
\stackrel{\rho}{\rho}\end{array}$ & & & & & & $\begin{array}{l}\stackrel{\llcorner}{\infty} \\
\stackrel{\infty}{\leftarrow}\end{array}$ & & & & 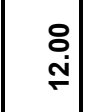 & & 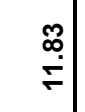 & 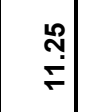 & $\begin{array}{l}8 \\
\dot{\sim} \\
\dot{\sim}\end{array}$ & & & \\
\hline 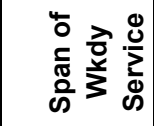 & 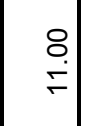 & & 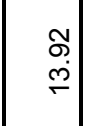 & $\stackrel{\stackrel{\infty}{\circ}}{\leftarrow}$ & $\begin{array}{l}\stackrel{Q}{0} \\
\stackrel{m}{\sim}\end{array}$ & $\stackrel{\stackrel{m}{\sim}}{\stackrel{\sim}{\sim}}$ & $\begin{array}{l}\stackrel{\llcorner}{0} \\
\stackrel{m}{\sim}\end{array}$ & 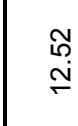 & $\begin{array}{l}\stackrel{\infty}{\rho} \\
\stackrel{\rho}{\leftarrow}\end{array}$ & $\begin{array}{l}\stackrel{̃}{\infty} \\
\stackrel{0}{\infty}\end{array}$ & $\begin{array}{l}\stackrel{\infty}{0} \\
\stackrel{\sim}{\sim}\end{array}$ & $\begin{array}{l}\infty \\
\infty \\
0 \\
0\end{array}$ & $\begin{array}{l}\stackrel{8}{\circ} \\
\leftarrow\end{array}$ & $\begin{array}{l}\stackrel{O}{0} \\
\stackrel{\text { in }}{\mathrm{V}}\end{array}$ & 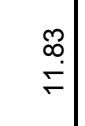 & & $\begin{array}{l}\stackrel{2}{\circ} \\
\stackrel{\text { }}{ }\end{array}$ & & $\begin{array}{l}9 \\
+ \\
\infty \\
\leftarrow\end{array}$ & $\begin{array}{l}\infty \\
\infty \\
\stackrel{\infty}{N}\end{array}$ \\
\hline 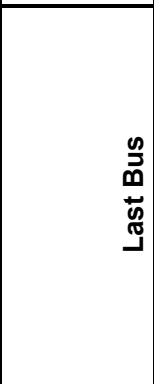 & 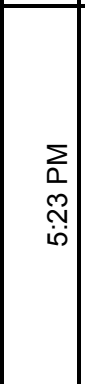 & & 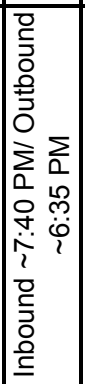 & 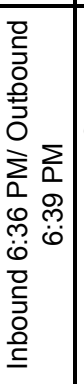 & 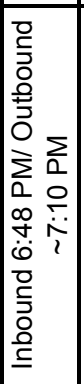 & 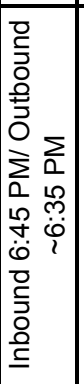 & 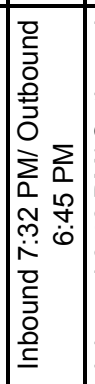 & 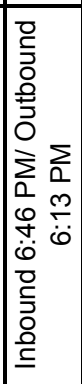 & $\begin{array}{ll}\infty \\
0 \\
0 \\
\sum_{0} & \vdots \\
0 & 0 \\
0 & 0 \\
0 & 0 \\
0 & \overline{1} \\
1 & 1 \\
0 & 0 \\
0 & 0 \\
0 & 0 \\
0 & 0 \\
z & 3 \\
\infty & \\
w & \end{array}$ & 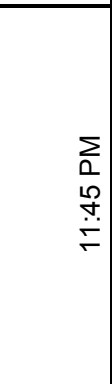 & $\begin{array}{l}\vdots \\
0 \\
\stackrel{\sim}{i}\end{array}$ & 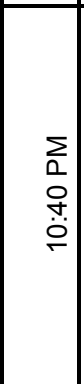 & $\begin{array}{l}\sum \\
0 \\
L \\
\check{0} \\
0\end{array}$ & 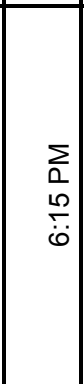 & 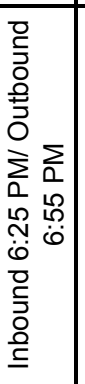 & $\begin{array}{l}\sum \\
0 \\
8 \\
0 \\
\dot{0} \\
3 \\
\sum \\
0 \\
0 \\
\square \\
0 \\
w\end{array}$ & $\begin{array}{l}\Sigma \\
0 \\
0 \\
\end{array}$ & 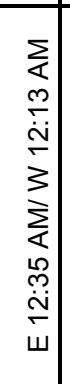 & 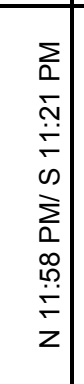 & 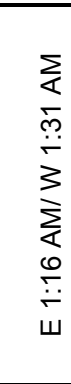 \\
\hline 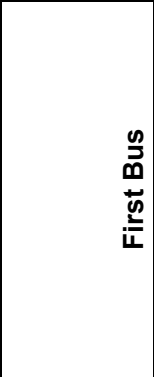 & 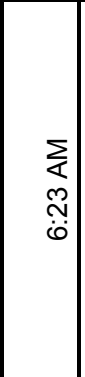 & & 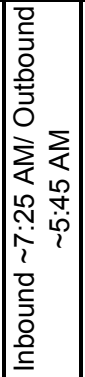 & 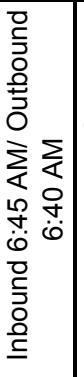 & 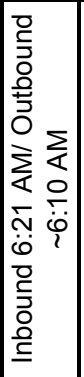 & 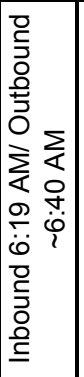 & 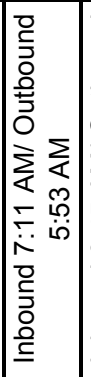 & 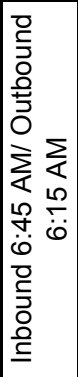 & 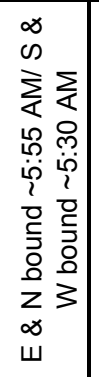 & 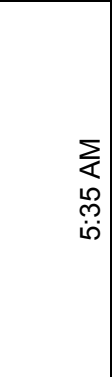 & 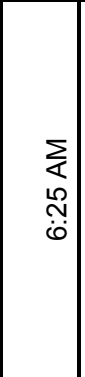 & 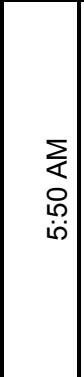 & 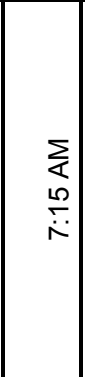 & $\begin{array}{l}\sum \\
\vdots \\
0 \\
\dot{0} \\
\end{array}$ & 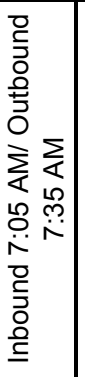 & 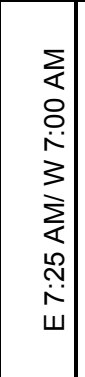 & $\begin{array}{l}\sum \\
\vdots \\
0 \\
\dot{0}\end{array}$ & 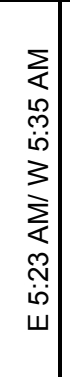 & 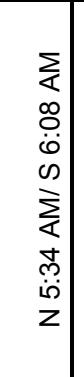 & $\begin{array}{l}\sum \\
\vdots \\
o \\
+ \\
\dot{+} \\
3 \\
\sum \\
\sum_{0} \\
0 \\
0 \\
\dot{0} \\
w\end{array}$ \\
\hline 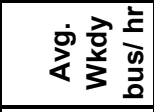 & $\stackrel{\circ}{-}$ & & $\stackrel{\circ}{r}$ & & & & & & $\stackrel{m}{N}$ & & & & $\stackrel{\circ}{-}$ & & مִ & $\stackrel{0}{-}$ & $\hat{\mathrm{N}}$ & & & \\
\hline 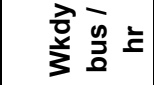 & $\stackrel{\circ}{\circ}$ & & $\stackrel{\circ}{-}$ & $\stackrel{\circ}{r}$ & $\stackrel{\circ}{-}$ & $\stackrel{\circ}{-}$ & $\stackrel{\circ}{r}$ & $\stackrel{\circ}{-}$ & $\stackrel{\mathrm{N}}{\mathrm{i}}$ & $\stackrel{\circ}{\circ}$ & $\stackrel{m}{r}$ & $\stackrel{0}{\dot{m}}$ & $\stackrel{\circ}{-}$ & $\stackrel{\circ}{-}$ & $\stackrel{\text { pִ }}{\leftarrow}$ & $\stackrel{\circ}{-}$ & $\stackrel{\circ}{\oplus}$ & $\hat{i}$ & $\hat{\mathrm{N}}$ & $\check{r}$ \\
\hline 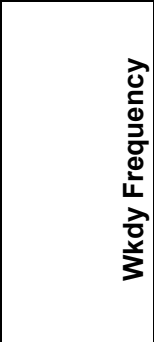 & $\begin{array}{l}\bar{y} \\
0 \\
\frac{1}{2} \\
⿱ 亠 乂 \\
0 \\
0\end{array}$ & & 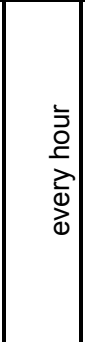 & 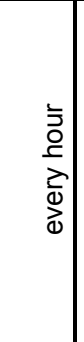 & 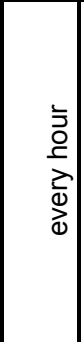 & 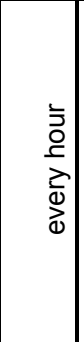 & $\begin{array}{l}\bar{े} \\
0 \\
\frac{1}{70} \\
\bar{d} \\
0\end{array}$ & $\begin{array}{l}\bar{y} \\
0 \\
\frac{c}{2} \\
⿱ 亠 乂 \\
0 \\
0 \\
0\end{array}$ & 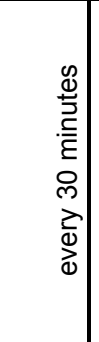 & 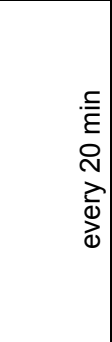 & 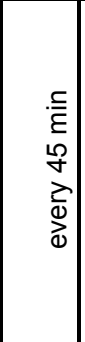 & 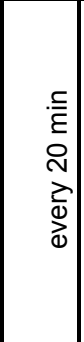 & $\begin{array}{l}\bar{y} \\
0 \\
\frac{1}{2} \\
\frac{\lambda}{0} \\
\stackrel{0}{0}\end{array}$ & 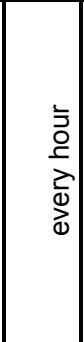 & 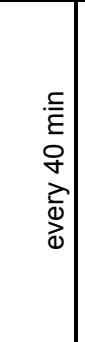 & 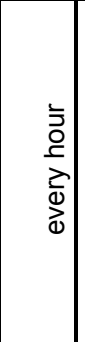 & 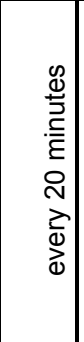 & & 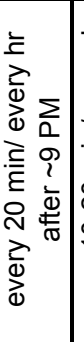 & 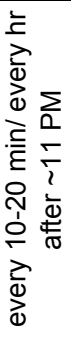 \\
\hline 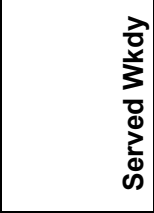 & $\sum$ & & $\sum_{<}$ & $\sum_{<}$ & $\sum_{<}$ & $\sum$ & & & 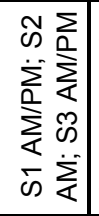 & 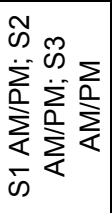 & 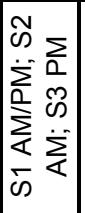 & 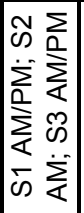 & 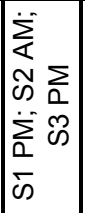 & 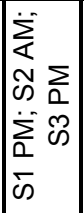 & $\sum_{<}$ & 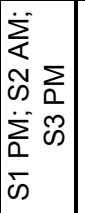 & $\sum_{<}$ & $\sum_{\substack{n \\
<}}^{\infty}$ & $\sum$ & $\sum_{\substack{n \\
<}}^{\infty}$ \\
\hline 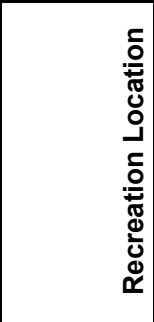 & 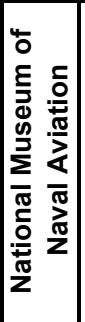 & $\begin{array}{l}\frac{c}{0} \\
\overline{0} \\
0 \\
0 \\
\frac{\pi}{0} \\
0 \\
0 \\
0 \\
0 \\
0 \\
0\end{array}$ & 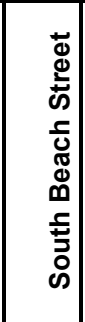 & & & & 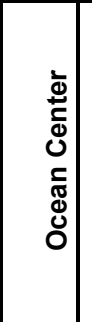 & & 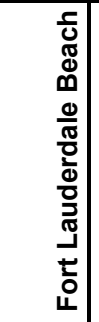 & & & & 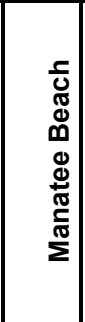 & & 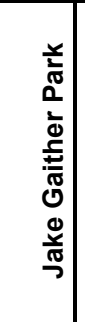 & 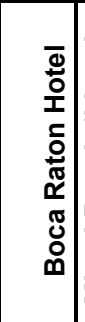 & 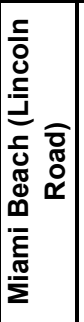 & & & \\
\hline
\end{tabular}




\begin{tabular}{|c|c|c|c|c|c|c|c|c|c|c|c|}
\hline 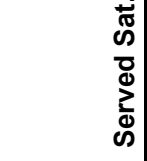 & $\sum$ & & $\sum_{\substack{\infty \\
k}}^{\infty}$ & $\sum_{\substack{n \\
<}}^{\infty}$ & & $\sum_{0}$ & $\sum_{<}$ & & & & \\
\hline 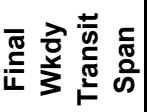 & & & & & & & 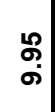 & 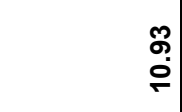 & & & \\
\hline 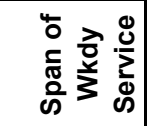 & $\stackrel{\stackrel{\sim}{N}}{\sim}$ & 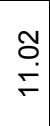 & 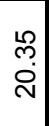 & $\begin{array}{c}\stackrel{N}{\sim} \\
\stackrel{ }{\sim}\end{array}$ & 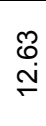 & 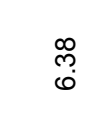 & $\begin{array}{l}\mathscr{2} \\
\stackrel{\sigma}{\sigma}\end{array}$ & 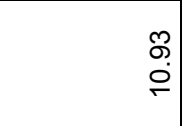 & $\stackrel{\stackrel{\sim}{\sim}}{\sim}$ & 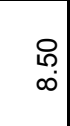 & 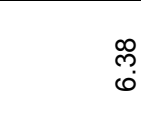 \\
\hline 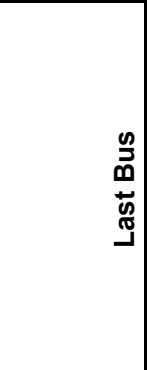 & 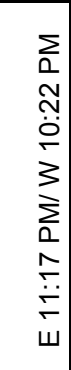 & 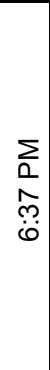 & 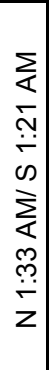 & $\begin{array}{c}\sum_{0} \\
m \\
m \\
\infty \\
\infty\end{array}$ & $\begin{array}{l}\sum_{0} \\
0 \\
0 \\
0 \\
0 \\
3 \\
\sum_{0} \\
0 \\
\stackrel{1}{i} \\
w\end{array}$ & 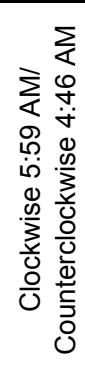 & 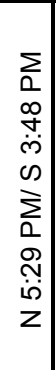 & 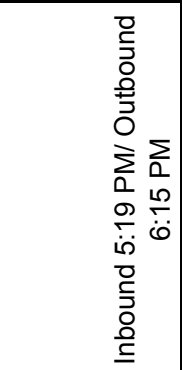 & 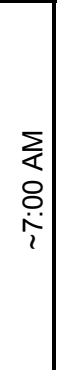 & 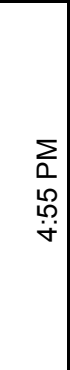 & 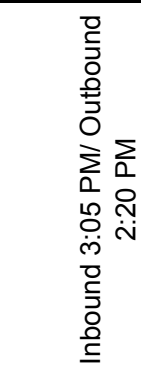 \\
\hline 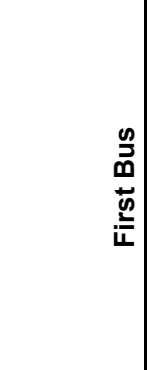 & $\begin{array}{l}\sum \\
\Sigma \\
0 \\
0 \\
0 \\
0 \\
3 \\
\vdots \\
\vdots \\
0 \\
0 \\
0 \\
0 \\
w\end{array}$ & 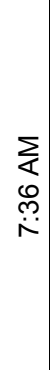 & 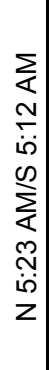 & 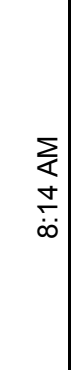 & 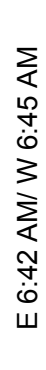 & 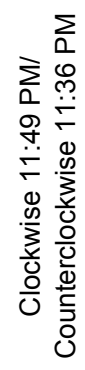 & 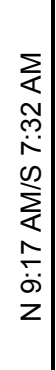 & 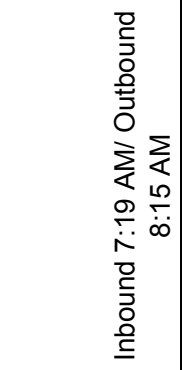 & 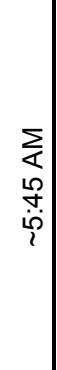 & 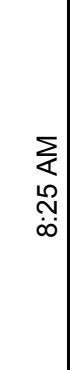 & 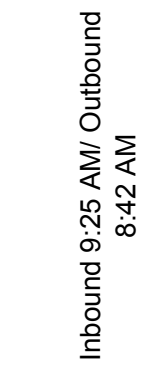 \\
\hline 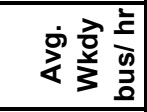 & & & & & & & $\stackrel{n}{\stackrel{0}{\longrightarrow}}$ & & & & \\
\hline 忞商 & $\stackrel{\infty}{\sim}$ & $\check{\square}$ & iे & 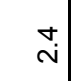 & & $\stackrel{\circ}{-}$ & $\stackrel{\text { po }}{\longrightarrow}$ & $\stackrel{m}{\longrightarrow}$ & $\stackrel{\leftrightarrow}{-}$ & $\hat{\circ}$ & $\stackrel{\circ}{\stackrel{\circ}{ }}$ \\
\hline 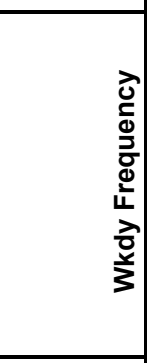 & 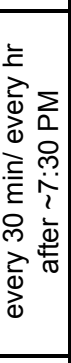 & 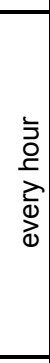 & 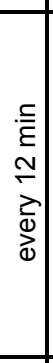 & 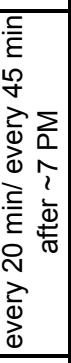 & 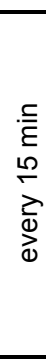 & 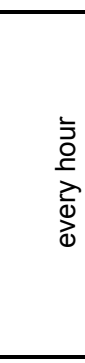 & 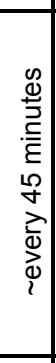 & 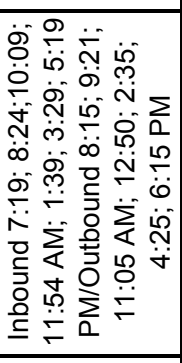 & $\begin{array}{c}\sum \\
\vdots \\
0 \\
0 \\
i \\
i \\
\dot{0} \\
\dot{p} \\
i \\
1\end{array}$ & 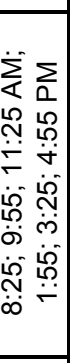 & 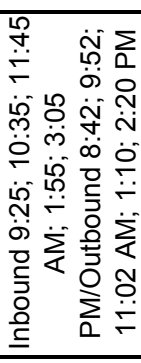 \\
\hline 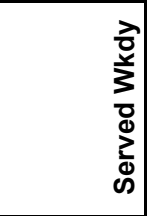 & $\sum$ & $\sum_{<}$ & $\sum_{\substack{n \\
<}}^{\infty}$ & $\sum$ & $\sum_{<}$ & $\sum_{0}$ & $\sum_{<1}$ & 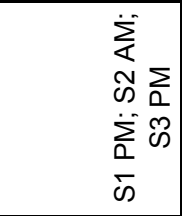 & $\begin{array}{l}\sum_{k} \\
\bar{n}\end{array}$ & 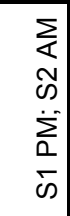 & \\
\hline 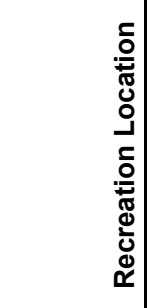 & & & & & & & 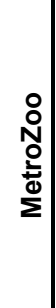 & 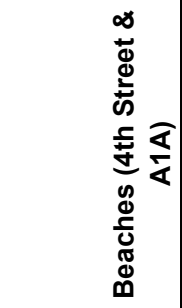 & & & \\
\hline
\end{tabular}




\begin{tabular}{|c|c|c|c|c|c|c|c|c|c|c|c|c|c|c|c|c|c|c|c|c|}
\hline 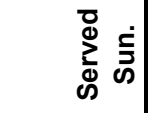 & & & & & & & & & 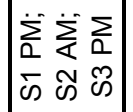 & 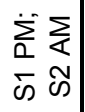 & & 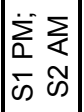 & & & & 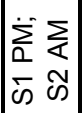 & $\sum$ & $\sum_{<}$ & $\sum$ & $\frac{\sum_{0}}{\substack{0 \\
\frac{1}{4}}}$ \\
\hline 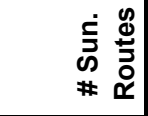 & 0 & & 0 & & & & & & $m$ & & & & 0 & & 0 & - & $\infty$ & & & \\
\hline 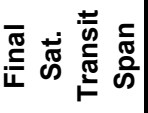 & $\stackrel{8}{=}$ & & 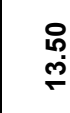 & & & & & & $\begin{array}{l}\stackrel{m}{0} \\
\infty \\
\infty\end{array}$ & & & & 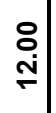 & & 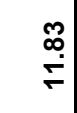 & $\begin{array}{l}\stackrel{R}{\leftarrow} \\
\stackrel{\Gamma}{T}\end{array}$ & $\begin{array}{l}\stackrel{8}{+} \\
\dot{N}\end{array}$ & & & \\
\hline 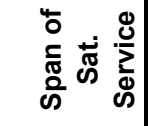 & $\underset{ }{\stackrel{8}{\leftarrow}}$ & & $\begin{array}{l}\stackrel{\infty}{\circ} \\
\stackrel{M}{\sim}\end{array}$ & 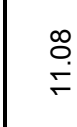 & $\begin{array}{l}8 \\
\stackrel{m}{~}\end{array}$ & $\stackrel{\sim}{\stackrel{N}{\sim}}$ & 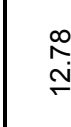 & $\stackrel{\text { N̂}}{\stackrel{N}{\sim}}$ & & & & & & & & & $\stackrel{ }{\stackrel{ }{ }}$ & & $\begin{array}{l}\hat{o} \\
\infty \\
\stackrel{0}{c}\end{array}$ & 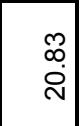 \\
\hline 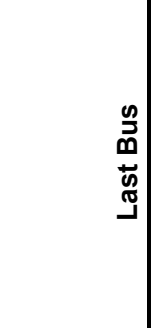 & $\begin{array}{l}\sum_{0} \\
0 \\
0 \\
\dot{0}\end{array}$ & & 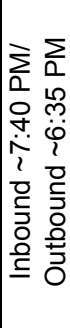 & 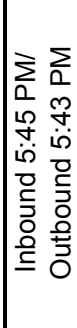 & 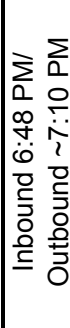 & 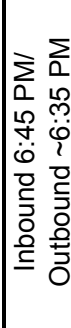 & 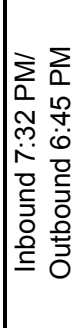 & 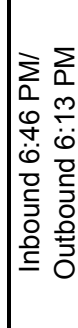 & 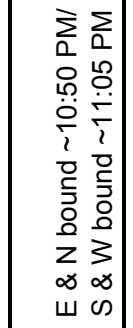 & 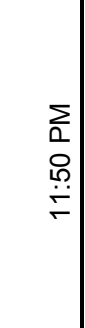 & 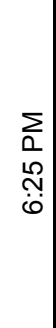 & 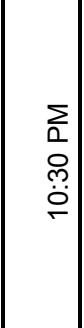 & 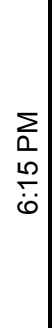 & $\begin{array}{l}\sum_{0} \\
L \\
\vdots \\
0\end{array}$ & 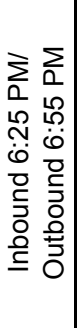 & $\begin{array}{l}\sum_{0} \\
0 \\
0 \\
i \\
i \\
3 \\
\vdots \\
0 \\
0 \\
0 \\
0 \\
w\end{array}$ & $\begin{array}{l}\sum \\
0 \\
0 \\
0 \\
0 \\
0\end{array}$ & 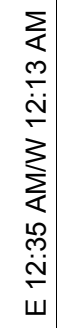 & 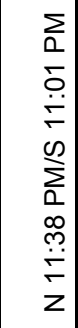 & 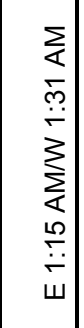 \\
\hline 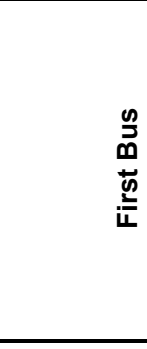 & $\begin{array}{l}\sum \\
\vdots \\
\infty \\
\stackrel{1}{r}\end{array}$ & & 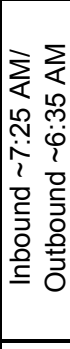 & 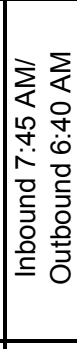 & 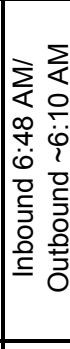 & 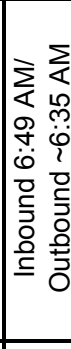 & 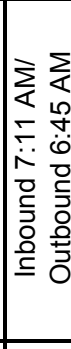 & 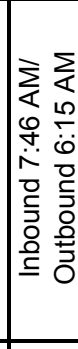 & 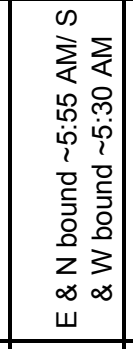 & 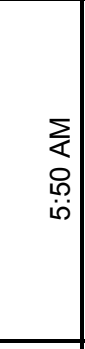 & 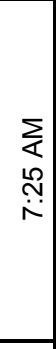 & $\begin{array}{l}\sum \\
0 \\
0 \\
\dddot{0} \\
0\end{array}$ & $\begin{array}{l}\sum \\
\Sigma \\
6 \\
亡 \\
\end{array}$ & 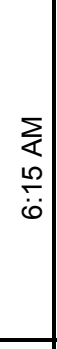 & 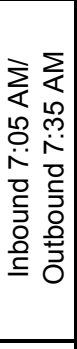 & 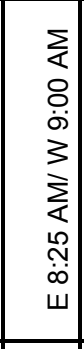 & 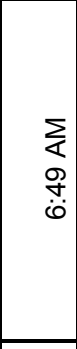 & 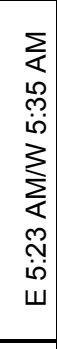 & 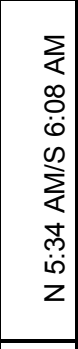 & 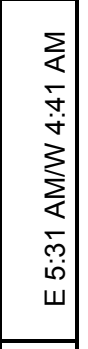 \\
\hline 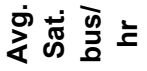 & $\stackrel{\circ}{-}$ & & $\stackrel{\circ}{-}$ & & & & & & $\stackrel{\infty}{-}$ & & & & $\stackrel{\circ}{r}$ & & $\stackrel{n}{-}$ & $\stackrel{\circ}{-}$ & $\stackrel{m}{N}$ & & & \\
\hline \#若号 三 & $\stackrel{\circ}{-}$ & & $\stackrel{\circ}{r}$ & $\stackrel{\circ}{r}$ & $\stackrel{\circ}{\circ}$ & $\stackrel{\circ}{\circ}$ & $\stackrel{\circ}{-}$ & $\stackrel{\circ}{-}$ & $\stackrel{\circ}{i}$ & $\stackrel{\circ}{\mathrm{N}}$ & $\stackrel{0}{-}$ & $\stackrel{\circ}{\mathrm{N}}$ & $\stackrel{\circ}{-}$ & $\stackrel{\circ}{-}$ & $\stackrel{n}{\longrightarrow}$ & $\stackrel{\circ}{-}$ & $\stackrel{n}{\sim}$ & $\hat{N}$ & $\hat{N}$ & $\bar{m}$ \\
\hline 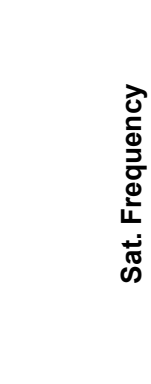 & 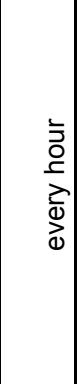 & & 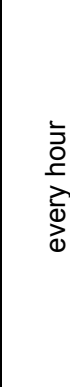 & 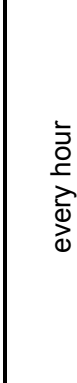 & 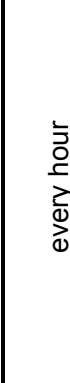 & 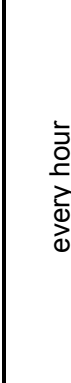 & $\begin{array}{l}\text { 訁े } \\
\text { o } \\
\text { z } \\
\text { Q } \\
\text { d }\end{array}$ & 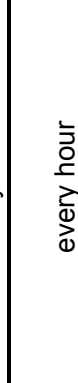 & 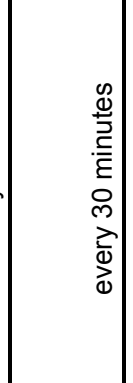 & 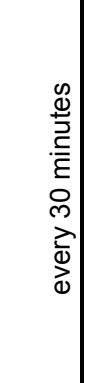 & 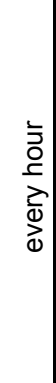 & 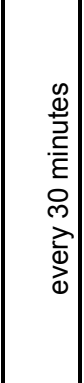 & 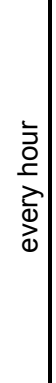 & 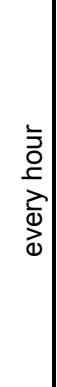 & 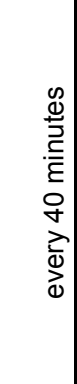 & $\begin{array}{l}\bar{y} \\
\text { c } \\
\frac{1}{2} \\
\stackrel{0}{0}\end{array}$ & 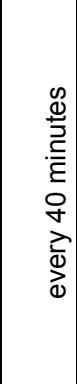 & & 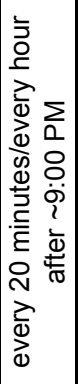 & 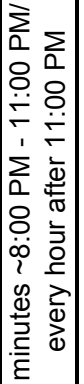 \\
\hline 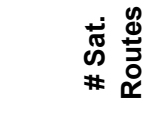 & & & $\nabla$ & & & & & & + & & & & $\mathbf{N}$ & & - & - & $\infty$ & & & \\
\hline 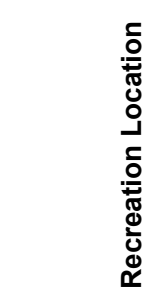 & 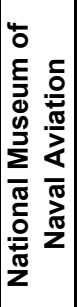 & 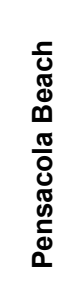 & 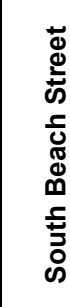 & & & & ○ & & 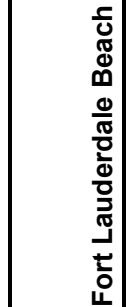 & & & & 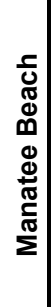 & & 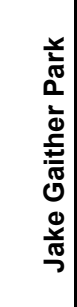 & 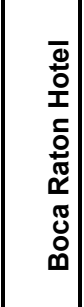 & 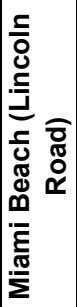 & & & \\
\hline
\end{tabular}




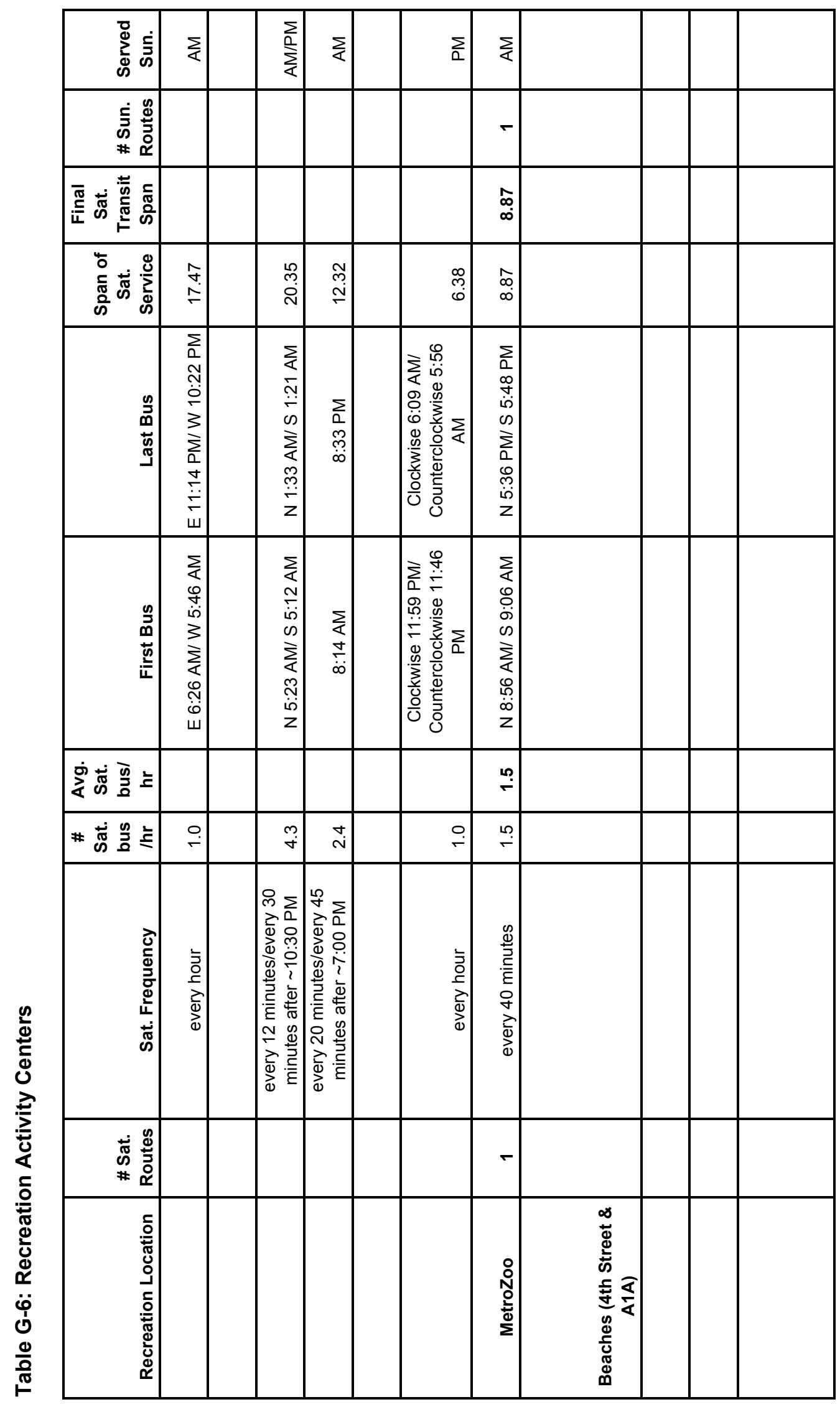




\section{Appendix H}

\section{Route Transit Service Tables}


Table H-1:

Airports-Weekday

\begin{tabular}{|c|c|c|c|c|c|c|c|c|c|c|c|}
\hline \multicolumn{12}{|c|}{ Weekday Service } \\
\hline \multirow[b]{2}{*}{$\begin{array}{l}\text { Activity } \\
\text { Center }\end{array}$} & \multirow[b]{2}{*}{$\begin{array}{l}\text { Number of } \\
\text { Routes }\end{array}$} & \multirow[b]{2}{*}{ Routes } & \multicolumn{3}{|c|}{ Shift 1} & \multicolumn{3}{|c|}{ Shift 2} & \multicolumn{3}{|c|}{ Shift 3} \\
\hline & & & $\begin{array}{l}\text { AM/ } \\
\text { PM }\end{array}$ & $\begin{array}{l}\text { AM } \\
\text { Only }\end{array}$ & $\begin{array}{l}\text { PM } \\
\text { Only }\end{array}$ & $\begin{array}{l}\text { AM/ } \\
\text { PM }\end{array}$ & $\begin{array}{l}\text { AM } \\
\text { Only }\end{array}$ & $\begin{array}{l}\text { PM } \\
\text { Only }\end{array}$ & $\begin{array}{l}\text { AM/ } \\
\text { PM }\end{array}$ & $\begin{array}{l}\text { AM } \\
\text { Only }\end{array}$ & $\begin{array}{l}\text { PM } \\
\text { Only }\end{array}$ \\
\hline Pensacola Regional & 1 & & & & & & & & & & \\
\hline & & 2 & & & $\checkmark$ & & $\checkmark$ & & & & \\
\hline Pensacola Regional Total & 1 & & 0 & 0 & 1 & 0 & 1 & 0 & 0 & 0 & 0 \\
\hline Tampa International & 1 & & & & & & & & & & \\
\hline & & 30 & & & $\checkmark$ & & $\checkmark$ & & & & $\checkmark$ \\
\hline Tampa International Total & 1 & & 0 & 0 & 1 & 0 & 1 & 0 & 0 & 0 & 1 \\
\hline & & & & & & & & & & & \\
\hline Daytona Beach & 1 & & & & & & & & & & \\
\hline & & 10 & & & $\checkmark$ & & $\checkmark$ & & & & \\
\hline Daytona Beach Total & 1 & & 0 & 0 & 1 & 0 & 1 & 0 & 0 & 0 & 0 \\
\hline Ft Lauderdale/Hollvwood & 1 & & & & & & & & & & \\
\hline & & 1 & & & $\checkmark$ & $\checkmark$ & & & $\checkmark$ & & \\
\hline Ft. Lauderdale/Hollywood Total & 1 & & 0 & 0 & 1 & 1 & 0 & 0 & 1 & 0 & 0 \\
\hline Saraceta (Saraceta County) & 0 & & & & & & & & & & \\
\hline & & 2 & & & 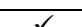 & & & & & & \\
\hline & & $\frac{L}{2}$ & & & & & & & & & \\
\hline $\begin{array}{c}\text { Sarasota (Sarasota County) } \\
\text { Total }\end{array}$ & 2 & & 0 & 0 & 2 & 0 & 2 & 0 & 0 & 0 & 1 \\
\hline Sarasota (Manatee County) & 1 & & & & & & & & & & \\
\hline & & 10 & & & $\checkmark$ & & $\checkmark$ & & & & \\
\hline $\begin{array}{c}\text { Sarasota (Manatee County) } \\
\text { Total }\end{array}$ & 1 & & 0 & 0 & 1 & 0 & 1 & 0 & 0 & 0 & 0 \\
\hline & & & & & & & & & & & \\
\hline Lakeland Lender Regional & 1 & & & & & & & & & & \\
\hline & & $40 \mathrm{X}$ & & & $\checkmark$ & & $\checkmark$ & & & & $\checkmark$ \\
\hline $\begin{array}{c}\text { Lakeland Lender Regional } \\
\text { Total }\end{array}$ & 1 & & 0 & 0 & 1 & 0 & 1 & 0 & 0 & 0 & 1 \\
\hline West Palm Beach International & 2 & & & & & & & & & & \\
\hline & & 44 & & & $\checkmark$ & & $\checkmark$ & & & & $\checkmark$ \\
\hline & & 53 & & & $\checkmark$ & & $\checkmark$ & & & & $\checkmark$ \\
\hline $\begin{array}{c}\text { West Palm Beach International } \\
\text { Total }\end{array}$ & 2 & & 0 & 0 & 2 & 0 & 2 & 0 & 0 & 0 & 2 \\
\hline Miami International & 4 & & & & & & & & & & \\
\hline & & 7 & & & $\checkmark$ & & $\checkmark$ & & & & $\checkmark$ \\
\hline & & 37 & & & $\checkmark$ & $\checkmark$ & & & $\checkmark$ & & \\
\hline
\end{tabular}




\begin{tabular}{|c|c|c|c|c|c|c|c|c|c|c|c|}
\hline \multicolumn{12}{|c|}{ Weekday Service } \\
\hline & & & & Shift & & & Shift & & & Shift 3 & \\
\hline \multirow[t]{3}{*}{$\begin{array}{l}\text { Activity } \\
\text { Center }\end{array}$} & $\begin{array}{l}\text { Number of } \\
\text { Routes }\end{array}$ & Routes & $\begin{array}{l}\text { AM/ } \\
\text { PM }\end{array}$ & $\begin{array}{l}\text { AM } \\
\text { Only }\end{array}$ & $\begin{array}{l}\text { PM } \\
\text { Only }\end{array}$ & $\begin{array}{l}\text { AM/ } \\
\text { PMM }\end{array}$ & $\begin{array}{c}\text { AM } \\
\text { Only }\end{array}$ & $\begin{array}{l}\text { PM } \\
\text { Only }\end{array}$ & $\begin{array}{l}\text { AM/ } / \\
\text { PM }\end{array}$ & $\begin{array}{l}\text { AM } \\
\text { Only }\end{array}$ & $\begin{array}{l}\text { PM } \\
\text { Only }\end{array}$ \\
\hline & & 42 & & & $\checkmark$ & & $\checkmark$ & & & & $\checkmark$ \\
\hline & & $\mathrm{J}$ & & & $\checkmark$ & $\checkmark$ & & & $\checkmark$ & & \\
\hline Miami International Total & 4 & & 0 & 0 & 4 & 2 & 2 & 0 & 2 & 0 & 2 \\
\hline \multirow{2}{*}{ Melbourne International } & 1 & & & & & & & & & & \\
\hline & & 21 & & & $\checkmark$ & & $\checkmark$ & & & & \\
\hline Melbourne International Total & 1 & & 0 & 0 & 1 & 0 & 1 & 0 & 0 & 0 & 0 \\
\hline
\end{tabular}


Table H-2:

Airports-Saturday/Sunday

\begin{tabular}{|c|c|c|c|c|c|c|c|c|c|c|c|c|c|c|c|c|c|c|c|c|c|c|}
\hline \multicolumn{12}{|c|}{ Saturday Service } & \multicolumn{11}{|c|}{ Sunday Service } \\
\hline \multirow[b]{2}{*}{$\begin{array}{l}\text { Activity } \\
\text { Center }\end{array}$} & \multirow[b]{2}{*}{$\begin{array}{c}\text { Number } \\
\text { of } \\
\text { Routes }\end{array}$} & \multirow[b]{2}{*}{ Routes } & \multicolumn{3}{|c|}{ Shift 1} & \multicolumn{3}{|c|}{ Shift 2} & \multicolumn{3}{|c|}{ Shift 3} & \multirow[b]{2}{*}{$\begin{array}{c}\text { Number } \\
\text { of } \\
\text { Routes }\end{array}$} & \multirow[b]{2}{*}{ Routes } & \multicolumn{3}{|c|}{ Shift 1} & \multicolumn{3}{|c|}{ Shift 2} & \multicolumn{3}{|c|}{ Shift 3} \\
\hline & & & $\begin{array}{l}\text { AM/ } \\
\text { PM }\end{array}$ & $\begin{array}{l}\text { AM } \\
\text { Only }\end{array}$ & $\begin{array}{l}\text { PM } \\
\text { Only }\end{array}$ & $\begin{array}{l}\text { AM/ } \\
\text { PM }\end{array}$ & $\begin{array}{l}\text { AM } \\
\text { Only }\end{array}$ & $\begin{array}{l}\text { PM } \\
\text { Only }\end{array}$ & $\begin{array}{l}\text { AM/ } \\
\text { PM }\end{array}$ & $\begin{array}{l}\text { AM } \\
\text { Only }\end{array}$ & $\begin{array}{l}\text { PM } \\
\text { Only }\end{array}$ & & & $\begin{array}{l}\text { AM/ } \\
\text { PM }\end{array}$ & $\begin{array}{l}\text { AM } \\
\text { Only }\end{array}$ & $\begin{array}{l}\text { PM } \\
\text { Only }\end{array}$ & $\begin{array}{l}\text { AM/ } \\
\text { PM }\end{array}$ & $\begin{array}{l}\text { AM } \\
\text { Only }\end{array}$ & $\begin{array}{l}\text { PM } \\
\text { Only }\end{array}$ & $\begin{array}{l}\text { AM/ } \\
\text { PM }\end{array}$ & $\begin{array}{c}\text { AM } \\
\text { Only }\end{array}$ & $\begin{array}{l}\text { PM } \\
\text { Only }\end{array}$ \\
\hline Pensacola Regional & 1 & & & & & & & & & & & 1 & & & & & & & & & & \\
\hline & & 18 & & & $\checkmark$ & & $\checkmark$ & & & & & & 18 & & & $\checkmark$ & & $\checkmark$ & & & & \\
\hline $\begin{array}{c}\text { Pensacola Regional } \\
\text { Total }\end{array}$ & 1 & & 0 & 0 & 1 & 0 & 1 & 0 & 0 & 0 & 0 & 1 & & 0 & 0 & 1 & 0 & 1 & 0 & 0 & 0 & 0 \\
\hline Tampa International & 1 & & & & & & & & & & & 1 & & & & & & & & & & \\
\hline & & 30 & & & $\checkmark$ & & $\checkmark$ & & & & & & 30 & & & $\checkmark$ & & $\checkmark$ & & & & \\
\hline $\begin{array}{l}\text { Tampa International } \\
\text { Total }\end{array}$ & 1 & & 0 & 0 & 1 & 0 & 1 & 0 & 0 & 0 & 0 & 1 & & 0 & 0 & 1 & 0 & 1 & 0 & 0 & 0 & 0 \\
\hline & & & & & & & & & & & & & & & & & & & & & & \\
\hline Daytona Beach & 1 & & & & & & & & & & & 0 & & & & & & & & & & \\
\hline & & 10 & & & $\checkmark$ & & $\checkmark$ & & & & & & & & & & & & & & & \\
\hline Daytona Beach Total & 1 & & 0 & 0 & 1 & 0 & 1 & 0 & 0 & 0 & 0 & 0 & & & & & & & & & & \\
\hline & & & & & & & & & & & & & & & & & & & & & & \\
\hline $\begin{array}{c}\text { Ft. } \\
\text { Lauderdale/Hollywood }\end{array}$ & 1 & & & & & & & & & & & 1 & & & & & & & & & & \\
\hline & & 1 & & & $\checkmark$ & $\checkmark$ & & & $\checkmark$ & & & & 1 & & & $\checkmark$ & & $\checkmark$ & & & & \\
\hline $\begin{array}{c}\text { Ft. } \\
\text { Lauderdale/Hollywood } \\
\text { Total }\end{array}$ & 1 & & 0 & 0 & 1 & 1 & 0 & 0 & 1 & 0 & 0 & 1 & & 0 & 0 & 1 & 0 & 1 & 0 & 0 & 0 & 0 \\
\hline & & & & & & & & & & & & & & & & & & & & & & \\
\hline $\begin{array}{c}\text { Sarasota (Sarasota } \\
\text { County) }\end{array}$ & 2 & & & & & & & & & & & 0 & & & & & & & & & & \\
\hline & & 2 & & & $\checkmark$ & & $\checkmark$ & & & & & & & & & & & & & & & \\
\hline & & 15 & & & $\checkmark$ & & $\checkmark$ & & & & $\checkmark$ & & & & & & & & & & & \\
\hline $\begin{array}{c}\text { Sarasota (Sarasota } \\
\text { County) Total }\end{array}$ & 2 & & 0 & 0 & 2 & 0 & 2 & 0 & 0 & 0 & 1 & 0 & & & & & & & & & & \\
\hline $\begin{array}{l}\text { Sarasota (Manatee } \\
\text { County) }\end{array}$ & 1 & & & & & & & & & & & 0 & & & & & & & & & & \\
\hline & & 10 & & & $\checkmark$ & & $\checkmark$ & & & & & & & & & & & & & & & \\
\hline $\begin{array}{l}\text { Sarasota (Manatee } \\
\text { County) Total }\end{array}$ & 1 & & 0 & 0 & 1 & 0 & 1 & 0 & 0 & 0 & 0 & 0 & & & & & & & & & & \\
\hline & & & & & & & & & & & & & & & & & & & & & & \\
\hline $\begin{array}{c}\text { Lakeland Lender } \\
\text { Regional }\end{array}$ & 1 & & & & & & & & & & & 0 & & & & & & & & & & \\
\hline & & $40 \mathrm{X}$ & & & $\checkmark$ & & $\checkmark$ & & & & & & & & & & & & & & & \\
\hline $\begin{array}{l}\text { Lakeland Lender } \\
\text { Regional Total }\end{array}$ & 1 & & 0 & 0 & 1 & 0 & 1 & 0 & 0 & 0 & 0 & 0 & & & & & & & & & & \\
\hline & & & & & & & & & & & & & & & & & & & & & & \\
\hline West Palm Beach & 1 & & & & & & & & & & & 1 & & & & & & & & & & \\
\hline
\end{tabular}




\begin{tabular}{|c|c|c|c|c|c|c|c|c|c|c|c|c|c|c|c|c|c|c|c|c|c|c|}
\hline \multicolumn{12}{|c|}{ Saturday Service } & \multicolumn{11}{|c|}{ Sunday Service } \\
\hline \multirow[b]{2}{*}{$\begin{array}{l}\text { Activity } \\
\text { Center }\end{array}$} & \multirow[b]{2}{*}{$\begin{array}{c}\begin{array}{c}\text { Number } \\
\text { of } \\
\text { Routes }\end{array} \\
\end{array}$} & \multirow[b]{2}{*}{ Routes } & \multicolumn{3}{|c|}{ Shift 1} & \multicolumn{3}{|c|}{ Shift 2} & \multicolumn{3}{|c|}{ Shift 3} & \multirow[b]{2}{*}{$\begin{array}{c}\text { Number } \\
\text { of } \\
\text { Routes }\end{array}$} & \multirow[b]{2}{*}{ Routes } & \multicolumn{3}{|c|}{ Shift 1} & \multicolumn{3}{|c|}{ Shift 2} & \multicolumn{3}{|c|}{ Shift 3} \\
\hline & & & $\begin{array}{l}\text { AM/ } \\
\text { PM }\end{array}$ & $\begin{array}{l}\text { AM } \\
\text { Only }\end{array}$ & $\begin{array}{l}\text { PM } \\
\text { Only }\end{array}$ & $\begin{array}{l}\text { AM/ } \\
\text { PM }\end{array}$ & $\begin{array}{l}\text { AM } \\
\text { Only }\end{array}$ & $\begin{array}{l}\text { PM } \\
\text { Only }\end{array}$ & $\begin{array}{l}\text { AM/ } \\
\text { PM }\end{array}$ & $\begin{array}{l}\text { AM } \\
\text { Only }\end{array}$ & $\begin{array}{l}\text { PM } \\
\text { Only }\end{array}$ & & & $\begin{array}{l}\text { AM/ } \\
\text { PM }\end{array}$ & $\begin{array}{l}\text { AM } \\
\text { Only }\end{array}$ & $\begin{array}{l}\text { PM } \\
\text { Only }\end{array}$ & $\begin{array}{l}\text { AM/ } \\
\text { PM }\end{array}$ & $\begin{array}{l}\text { AM } \\
\text { Only }\end{array}$ & $\begin{array}{l}\text { PM } \\
\text { Only }\end{array}$ & $\begin{array}{l}\text { AM/ } \\
\text { PM }\end{array}$ & $\begin{array}{l}\text { AM } \\
\text { Only }\end{array}$ & $\begin{array}{l}\text { PM } \\
\text { Only }\end{array}$ \\
\hline \multicolumn{23}{|l|}{ International } \\
\hline & & 44 & & & $\checkmark$ & & $\checkmark$ & & & & $\checkmark$ & & 44 & & & $\checkmark$ & & $\checkmark$ & & & & \\
\hline $\begin{array}{l}\text { West Palm Beach } \\
\text { International Total }\end{array}$ & 1 & & 0 & 0 & 1 & 0 & 1 & 0 & 0 & 0 & 1 & 1 & & 0 & 0 & 1 & 0 & 1 & 0 & 0 & 0 & 0 \\
\hline \multirow[t]{5}{*}{ Miami International } & 4 & & & & & & & & & & & 4 & & & & & & & & & & \\
\hline & & 7 & & & $\checkmark$ & & $\checkmark$ & & & & $\checkmark$ & & 7 & & & $\checkmark$ & & $\checkmark$ & & & & $\checkmark$ \\
\hline & & 37 & & & $\checkmark$ & & $\checkmark$ & & & $\checkmark$ & & & 37 & & & $\checkmark$ & & $\checkmark$ & & $\checkmark$ & & \\
\hline & & 42 & & & $\checkmark$ & & $\checkmark$ & & & & & & 42 & & & $\checkmark$ & & $\checkmark$ & & & & \\
\hline & & $\mathrm{J}$ & & & $\checkmark$ & $\checkmark$ & & & & $\checkmark$ & & & $\mathrm{J}$ & & & $\checkmark$ & & $\checkmark$ & & $\checkmark$ & & \\
\hline $\begin{array}{c}\text { Miami International } \\
\text { Total }\end{array}$ & 4 & & 0 & 0 & 4 & 1 & 3 & 0 & 0 & 2 & 1 & 4 & & 0 & 0 & 4 & 0 & 4 & 0 & 2 & 0 & 1 \\
\hline \multirow[t]{2}{*}{$\begin{array}{l}\text { Melbourne } \\
\text { International }\end{array}$} & 1 & & & & & & & & & & & 1 & & & & & & & & & & \\
\hline & & 21 & & & $\checkmark$ & & $\checkmark$ & & & & & & 21 & & & $\checkmark$ & & $\checkmark$ & & & & \\
\hline $\begin{array}{c}\text { Melbourne } \\
\text { International Total }\end{array}$ & 1 & & 0 & 0 & 1 & 0 & 1 & 0 & 0 & 0 & 0 & 1 & & 0 & 0 & 1 & 0 & 1 & 0 & 0 & 0 & 0 \\
\hline
\end{tabular}


Table H-3

Medical-Weekday

\begin{tabular}{|c|c|c|c|c|c|c|c|c|c|c|c|}
\hline \multicolumn{12}{|c|}{ Weekday Service } \\
\hline \multirow[b]{2}{*}{$\begin{array}{l}\text { Activity } \\
\text { Center }\end{array}$} & \multirow[b]{2}{*}{$\begin{array}{c}\text { Number } \\
\text { of } \\
\text { Routes }\end{array}$} & \multirow[b]{2}{*}{ Routes } & \multicolumn{3}{|c|}{ Shift 1} & \multicolumn{3}{|c|}{ Shift 2} & \multicolumn{3}{|c|}{ Shift 3} \\
\hline & & & $\begin{array}{l}\text { AM/ } \\
\text { PM }\end{array}$ & $\begin{array}{l}\text { AM } \\
\text { Only }\end{array}$ & $\begin{array}{l}\text { PM } \\
\text { Only }\end{array}$ & $\begin{array}{l}\text { AM/ } \\
\text { PM }\end{array}$ & $\begin{array}{l}\text { AM } \\
\text { Only }\end{array}$ & $\begin{array}{l}\text { PM } \\
\text { Only }\end{array}$ & $\begin{array}{l}\text { AM/ } \\
\text { PM }\end{array}$ & $\begin{array}{l}\text { AM } \\
\text { Only }\end{array}$ & $\begin{array}{l}\text { PM } \\
\text { Only }\end{array}$ \\
\hline \multirow[t]{3}{*}{ Memorial Hospital } & 2 & & & & & & & & & & \\
\hline & & 9 & $\checkmark$ & & & & $\checkmark$ & & $\checkmark$ & & \\
\hline & & 17 & $\checkmark$ & & & & $\checkmark$ & & & & $\checkmark$ \\
\hline Memorial Hospital Total & 2 & & 2 & 0 & 0 & 0 & 2 & 0 & 1 & 0 & 1 \\
\hline \multirow{3}{*}{ Holy Cross Hospital } & 2 & & & & & & & & & & \\
\hline & & 10 & $\checkmark$ & & & & $\checkmark$ & & $\checkmark$ & & \\
\hline & & 20 & $\checkmark$ & & & & $\checkmark$ & & & & $\checkmark$ \\
\hline $\begin{array}{c}\text { Holy Cross Hospital } \\
\text { Total } \\
\end{array}$ & 2 & & 2 & 0 & 0 & 0 & 2 & 0 & 1 & 0 & 1 \\
\hline \multirow{3}{*}{ Doctor's Hospital } & 2 & & & & & & & & & & \\
\hline & & 14 & $\checkmark$ & & & & $\checkmark$ & & & & $\checkmark$ \\
\hline & & 15 & $\checkmark$ & & & & $\checkmark$ & & & & $\checkmark$ \\
\hline Doctor's Hospital Total & 2 & & 2 & 0 & 0 & 0 & 2 & 0 & 0 & 0 & 0 \\
\hline \multirow{4}{*}{$\begin{array}{c}\text { Sarasota Memorial } \\
\text { Hospital }\end{array}$} & & & & & & & & & & & \\
\hline & 2 & & & & & & & & & & \\
\hline & & 5 & & & $\checkmark$ & & $\checkmark$ & & & & $\checkmark$ \\
\hline & & 17 & $\checkmark$ & & & & $\checkmark$ & & & & $\checkmark$ \\
\hline \multirow[t]{2}{*}{$\begin{array}{c}\text { Sarasota Memorial } \\
\text { Hospital Total }\end{array}$} & 2 & & 1 & 0 & 1 & 0 & 2 & 0 & 0 & 0 & 2 \\
\hline & & & & & & & & & & & \\
\hline \multirow[t]{3}{*}{ Blake Hospital } & 2 & & & & & & & & & & \\
\hline & & 4 & & & $\checkmark$ & & $\checkmark$ & & & & $\checkmark$ \\
\hline & & 6 & $\checkmark$ & & & & $\checkmark$ & & & & $\checkmark$ \\
\hline \multirow[t]{2}{*}{ Blake Hospital Total } & 2 & & 1 & 0 & 1 & 0 & 2 & 0 & 0 & 0 & 2 \\
\hline & & & & & & & & & & & \\
\hline \multirow[t]{2}{*}{$\begin{array}{l}\text { Lakeland Regional } \\
\text { Medical Center }\end{array}$} & 1 & & & & & & & & & & \\
\hline & & 52 & $\checkmark$ & & & & $\checkmark$ & & & & $\checkmark$ \\
\hline \multirow[t]{2}{*}{ Lakeland Regional Total } & 1 & & 1 & 0 & 0 & 0 & 1 & 0 & 0 & 0 & 1 \\
\hline & & & & & & & & & & & \\
\hline \multirow[t]{2}{*}{ Winterhaven Hospital } & 1 & & & & & & & & & & \\
\hline & & 20 & & & $\checkmark$ & & $\checkmark$ & & & & $\checkmark$ \\
\hline $\begin{array}{c}\text { Winterhaven Hospital } \\
\text { Total } \\
\end{array}$ & 1 & & 0 & 0 & 1 & 0 & 1 & 0 & 0 & 0 & 1 \\
\hline \multirow[t]{6}{*}{ TMHC } & 5 & & & & & & & & & & \\
\hline & & 4 & & & $\checkmark$ & & $\checkmark$ & & & & $\checkmark$ \\
\hline & & 12 & & & $\checkmark$ & & $\checkmark$ & & & & $\checkmark$ \\
\hline & & 16 & & & $\checkmark$ & & $\checkmark$ & & & & $\checkmark$ \\
\hline & & 18 & & & $\checkmark$ & & $\checkmark$ & & & & $\checkmark$ \\
\hline & & 29 & & & & & & & & & \\
\hline TMHC Total & 5 & & 0 & 0 & 4 & 0 & 4 & 0 & 0 & 0 & 4 \\
\hline
\end{tabular}


Table H-4:

Medical-- Saturday/Sunday

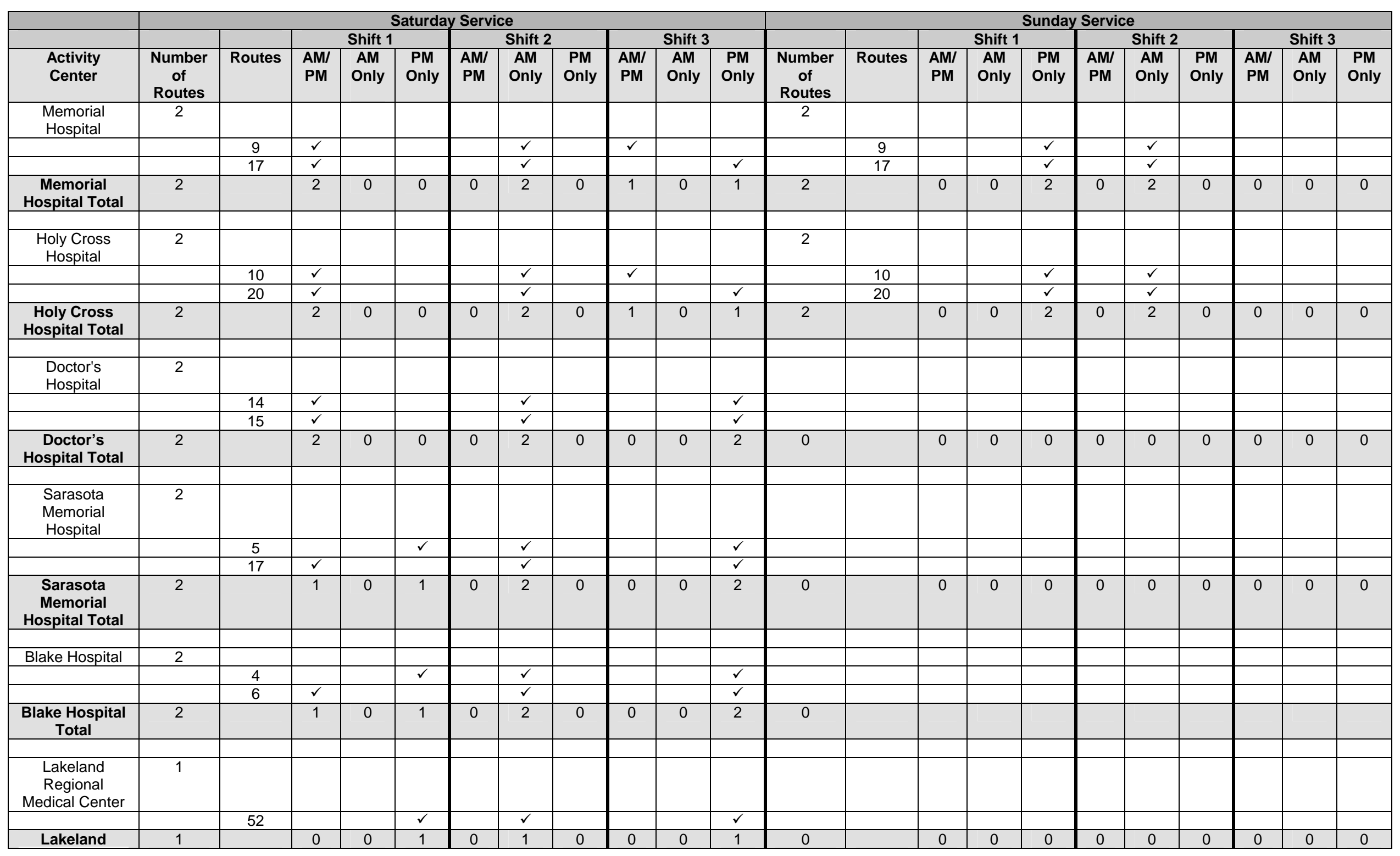




\begin{tabular}{|c|c|c|c|c|c|c|c|c|c|c|c|c|c|c|c|c|c|c|c|c|c|c|}
\hline \multirow[b]{3}{*}{$\begin{array}{l}\text { Activity } \\
\text { Center }\end{array}$} & \multicolumn{11}{|c|}{ Saturday Service } & \multicolumn{11}{|c|}{ Sunday Service } \\
\hline & \multirow[b]{2}{*}{$\begin{array}{l}\text { Number } \\
\text { of } \\
\text { Routes }\end{array}$} & \multirow[b]{2}{*}{ Routes } & \multicolumn{3}{|c|}{ Shift 1} & \multicolumn{3}{|c|}{ Shift 2} & \multicolumn{3}{|c|}{ Shift 3} & \multirow[b]{2}{*}{$\begin{array}{c}\text { Number } \\
\text { of } \\
\text { Routes }\end{array}$} & \multirow[b]{2}{*}{ Routes } & \multicolumn{3}{|c|}{ Shift 1} & \multicolumn{3}{|c|}{ Shift 2} & \multicolumn{3}{|c|}{ Shift 3} \\
\hline & & & $\begin{array}{l}\text { AM/ } \\
\text { PM }\end{array}$ & $\begin{array}{l}\text { AM } \\
\text { Only }\end{array}$ & $\begin{array}{l}\text { PM } \\
\text { Only }\end{array}$ & $\begin{array}{l}\text { AM/ } \\
\text { PM }\end{array}$ & $\begin{array}{l}\text { AM } \\
\text { Only }\end{array}$ & $\begin{array}{l}\text { PM } \\
\text { Only }\end{array}$ & $\begin{array}{l}\text { AM/ } \\
\text { PM }\end{array}$ & $\begin{array}{l}\text { AM } \\
\text { Only }\end{array}$ & $\begin{array}{l}\text { PM } \\
\text { Only }\end{array}$ & & & $\begin{array}{l}\text { AM/ } \\
\text { PM }\end{array}$ & $\begin{array}{l}\text { AM } \\
\text { Only }\end{array}$ & $\begin{array}{l}\text { PM } \\
\text { Only }\end{array}$ & $\begin{array}{l}\text { AM/ } \\
\text { PM }\end{array}$ & $\begin{array}{l}\text { AM } \\
\text { Only }\end{array}$ & $\begin{array}{l}\text { PM } \\
\text { Only }\end{array}$ & $\begin{array}{l}\text { AM/ } \\
\text { PM }\end{array}$ & $\begin{array}{l}\text { AM } \\
\text { Only }\end{array}$ & $\begin{array}{l}\text { PM } \\
\text { Only }\end{array}$ \\
\hline \multicolumn{23}{|l|}{ Regional Total } \\
\hline & & & & & & & & & & & & & & & & & & & & & & \\
\hline \multirow[t]{2}{*}{$\begin{array}{c}\text { Winterhaven } \\
\text { Hospital }\end{array}$} & 1 & & & & & & & & & & & & & & & & & & & & & \\
\hline & & 20 & & & $\checkmark$ & & $\checkmark$ & & & & & & & & & & & & & & & \\
\hline $\begin{array}{l}\text { Winterhaven } \\
\text { Hospital Total }\end{array}$ & 1 & & 0 & 0 & 1 & 0 & 1 & 0 & 0 & 0 & 0 & 0 & & 0 & 0 & 0 & 0 & 0 & 0 & 0 & 0 & 0 \\
\hline & & & & & & & & & & & & & & & & & & & & & & \\
\hline \multirow[t]{5}{*}{ TMHC } & 4 & & & & & & & & & & & 1 & & & & & & & & & & \\
\hline & & 4 & & & $\checkmark$ & & $\checkmark$ & & & & $\checkmark$ & & 29 & & & $\checkmark$ & & $\checkmark$ & & & & \\
\hline & & 12 & & & $\checkmark$ & & $\checkmark$ & & & & $\checkmark$ & & & & & & & & & & & \\
\hline & & 18 & & & $\checkmark$ & & $\checkmark$ & & & & $\checkmark$ & & & & & & & & & & & \\
\hline & & 29 & & & & & & & & & & & & & & & & & & & & \\
\hline TMHC Total & 4 & & 0 & 0 & 3 & 0 & 3 & 0 & 0 & 0 & 3 & 1 & & 0 & 0 & 1 & 0 & 1 & 0 & 0 & 0 & 0 \\
\hline
\end{tabular}


Table H-5:

Shopping

\begin{tabular}{|c|c|c|c|c|c|c|c|c|c|c|c|c|c|c|c|}
\hline \multirow[b]{2}{*}{$\begin{array}{l}\text { Activity } \\
\text { Center }\end{array}$} & \multicolumn{5}{|c|}{ Weekday Service } & \multicolumn{5}{|c|}{ Saturday Service } & \multicolumn{5}{|c|}{ Sunday Service } \\
\hline & $\begin{array}{c}\text { Number } \\
\text { of } \\
\text { Routes }\end{array}$ & Routes & $\begin{array}{l}\text { AM/ } \\
\text { PM }\end{array}$ & $\begin{array}{l}\text { AM } \\
\text { Only }\end{array}$ & $\begin{array}{l}\text { PM } \\
\text { Only }\end{array}$ & $\begin{array}{l}\text { Number of } \\
\text { Routes }\end{array}$ & Routes & $\begin{array}{l}\text { AM/ } \\
\text { PM }\end{array}$ & $\begin{array}{l}\text { AM } \\
\text { Only }\end{array}$ & $\begin{array}{l}\text { PM } \\
\text { Only }\end{array}$ & $\begin{array}{l}\text { Number of } \\
\text { Routes }\end{array}$ & Routes & $\begin{array}{l}\text { AM/ } \\
\text { PM }\end{array}$ & $\begin{array}{l}\text { AM } \\
\text { Only }\end{array}$ & $\begin{array}{l}\text { PM } \\
\text { Only }\end{array}$ \\
\hline \multirow[t]{4}{*}{ University Mall } & 3 & & & & & 2 & 5 & & & & 0 & & & & \\
\hline & & 5 & & $\checkmark$ & & & 9 & & $\checkmark$ & & & & & & \\
\hline & & 9 & & $\checkmark$ & & & & & $\checkmark$ & & & & & & \\
\hline & & 19 & & $\checkmark$ & & & & & & & & & & & \\
\hline \multirow[t]{2}{*}{ University Mall Total } & 3 & & 0 & 3 & 0 & 2 & & 0 & 2 & 0 & 0 & & & & \\
\hline & & & & & & & & & & & & & & & \\
\hline \multirow{4}{*}{ Oaks Mall } & 3 & & & & & 3 & & & & & 0 & & & & \\
\hline & & 5 & & $\checkmark$ & & & 5 & & $\checkmark$ & & & & & & \\
\hline & & 20 & & $\checkmark$ & & & 20 & & $\checkmark$ & & & & & & \\
\hline & & 75 & & $\checkmark$ & & & 75 & & $\checkmark$ & & & & & & \\
\hline \multirow[t]{2}{*}{ Oaks Mall Total } & 3 & & 0 & 3 & 0 & 3 & & 0 & 3 & 0 & 0 & & & & \\
\hline & & & & & & & & & & & & & & & \\
\hline \multirow[t]{4}{*}{ Butler Plaza } & 3 & & & & & 3 & & & & & 0 & & & & \\
\hline & & 1 & & $\checkmark$ & & & 1 & & $\checkmark$ & & & & & & \\
\hline & & 12 & & $\checkmark$ & & & 12 & & $\checkmark$ & & & & & & \\
\hline & & 75 & & $\checkmark$ & & & 75 & & $\checkmark$ & & & & & & \\
\hline \multirow[t]{2}{*}{ Butler Plaza Total } & 3 & & 0 & 3 & 0 & 3 & & 0 & 3 & 0 & 0 & & & & \\
\hline & & & & & & & & & & & & & & & \\
\hline \multirow[t]{2}{*}{ Paddock Mall } & 1 & & & & & 1 & & & & & 0 & & & & \\
\hline & & 4 & & $\checkmark$ & & & 4 & & $\checkmark$ & & & & & & \\
\hline \multirow[t]{2}{*}{ Paddock Mall Total } & 1 & & 0 & 1 & 0 & 1 & & 0 & 1 & 0 & 0 & & & & \\
\hline & & & & & & & & & & & & & & & \\
\hline \multirow[t]{2}{*}{ Citrus Park Mall } & 1 & & & & & 1 & & & & & 1 & & & & \\
\hline & & 39 & $\checkmark$ & & & & 39 & $\checkmark$ & & & & 39 & $\checkmark$ & & \\
\hline \multirow[t]{2}{*}{ Citrus Park Mall Total } & 1 & & 1 & 0 & 0 & 1 & & 1 & 0 & 0 & 1 & & 1 & 0 & 0 \\
\hline & & & & & & & & & & & & & & & \\
\hline \multirow[t]{5}{*}{ Brandon Towne Center } & 4 & & & & & 4 & & & & & 2 & & & & \\
\hline & & 8 & & $\checkmark$ & & & 8 & & & & & 8 & & $\checkmark$ & \\
\hline & & 31 & & $\checkmark$ & & & 31 & & $\checkmark$ & & & 37 & $\checkmark$ & & \\
\hline & & 37 & & $\checkmark$ & & & 37 & & $\checkmark$ & & & & & & \\
\hline & & 38 & & $\checkmark$ & & & 38 & & $\checkmark$ & & & & & & \\
\hline $\begin{array}{c}\text { Brandon Towne Center } \\
\text { Total }\end{array}$ & 4 & & 0 & 4 & 0 & 4 & & 0 & 3 & 0 & 2 & & 1 & 1 & 0 \\
\hline & & & & & & & & & & & & & & & \\
\hline \multirow{5}{*}{ Volusia Mall } & 4 & & & & & 3 & & & & & 1 & & & & \\
\hline & & 9 & & $\checkmark$ & & & 9 & & $\checkmark$ & & & 10 & & $\checkmark$ & \\
\hline & & 10 & & $\checkmark$ & & & 10 & & $\checkmark$ & & & & & & \\
\hline & & 11 & & $\checkmark$ & & & 11 & & $\checkmark$ & & & & & & \\
\hline & & 60 & & $\checkmark$ & & & & & & & & & & & \\
\hline Volusia Mall Total & 4 & & 0 & 4 & 0 & 3 & & 0 & 3 & 0 & 1 & & 0 & 1 & 0 \\
\hline & & & & & & & & & & & & & & & \\
\hline Dunlawton Square & 5 & & & & & 5 & & & & & 0 & & & & \\
\hline
\end{tabular}




\begin{tabular}{|c|c|c|c|c|c|c|c|c|c|c|c|c|c|c|c|}
\hline \multirow[b]{2}{*}{$\begin{array}{l}\text { Activity } \\
\text { Center }\end{array}$} & \multicolumn{5}{|c|}{ Weekday Service } & \multicolumn{5}{|c|}{ Saturday Service } & \multicolumn{5}{|c|}{ Sunday Service } \\
\hline & $\begin{array}{c}\text { Number } \\
\text { of } \\
\text { Routes }\end{array}$ & Routes & $\begin{array}{c}\text { AM/ } \\
\text { PM }\end{array}$ & $\begin{array}{l}\text { AM } \\
\text { Only }\end{array}$ & $\begin{array}{l}\text { PM } \\
\text { Only }\end{array}$ & $\begin{array}{l}\text { Number of } \\
\text { Routes }\end{array}$ & Routes & $\begin{array}{l}\mathbf{A M} / \\
\mathbf{P M}\end{array}$ & $\begin{array}{l}\text { AM } \\
\text { Only }\end{array}$ & $\begin{array}{l}\text { PM } \\
\text { Only }\end{array}$ & $\begin{array}{l}\text { Number of } \\
\text { Routes }\end{array}$ & Routes & $\begin{array}{l}\mathbf{A M} / \\
\mathbf{P M}\end{array}$ & $\begin{array}{l}\text { AM } \\
\text { Only }\end{array}$ & $\begin{array}{l}\text { PM } \\
\text { Only }\end{array}$ \\
\hline & & 4 & & $\checkmark$ & & & 4 & & $\checkmark$ & & & & & & \\
\hline & & 7 & & $\checkmark$ & & & 7 & & $\checkmark$ & & & & & & \\
\hline & & 12 & & $\checkmark$ & & & 12 & & $\checkmark$ & & & & & & \\
\hline & & 17B & & $\checkmark$ & & & 17B & & $\checkmark$ & & & & & & \\
\hline & & 40 & & $\checkmark$ & & & 40 & & $\checkmark$ & & & & & & \\
\hline Dunlawton Square Total & 5 & & 0 & 5 & 0 & 5 & & 0 & 5 & 0 & 0 & & & & \\
\hline & & & & & & & & & & & & & & & \\
\hline Crowne Center & 3 & & & & & 3 & & & & & 0 & & & & \\
\hline & & $20 \mathrm{~A}$ & & $\checkmark$ & & & $20 \mathrm{~A}$ & & $\checkmark$ & & & & & & \\
\hline & & $20 \mathrm{~B}$ & & $\checkmark$ & & & $20 \mathrm{~B}$ & & $\checkmark$ & & & & & & \\
\hline & & 22 & & $\checkmark$ & & & 22 & & $\checkmark$ & & & & & & \\
\hline Crowne Center Total & 3 & & 0 & 3 & 0 & 3 & & 0 & 3 & 0 & 0 & & & & \\
\hline & & & & & & & & & & & & & & & \\
\hline Sawgrass Mills Mall & 3 & & & & & 3 & & & & & 3 & & & & \\
\hline & & 22 & $\checkmark$ & & & & 22 & $\checkmark$ & & & & 22 & & $\checkmark$ & \\
\hline & & 36 & $\checkmark$ & & & & 36 & $\checkmark$ & & & & 36 & & & \\
\hline & & 72 & $\checkmark$ & & & & 72 & $\checkmark$ & & & & 72 & & $\checkmark$ & \\
\hline Sawgrass Mills Mall Total & 3 & & 3 & 0 & 0 & 3 & & 3 & 0 & 0 & 3 & & 0 & 2 & 0 \\
\hline & & & & & & & & & & & & & & & \\
\hline Pembroke Lakes Mall & 3 & & & & & 3 & & & & & 2 & & & & \\
\hline & & 3 & & $\checkmark$ & & & 3 & & $\checkmark$ & & & 5 & $\checkmark$ & & \\
\hline & & 5 & & $\checkmark$ & & & 5 & & $\checkmark$ & & & 7 & & $\checkmark$ & \\
\hline & & 7 & $\checkmark$ & & & & 7 & $\checkmark$ & & & & & & & \\
\hline $\begin{array}{c}\text { Pembroke Lakes Mall } \\
\text { Total }\end{array}$ & 3 & & 1 & 2 & 0 & 3 & & 1 & 2 & 0 & 2 & & 1 & 1 & 0 \\
\hline & & & & & & & & & & & & & & & \\
\hline Coral Square Mall & 3 & & & & & 3 & & & & & 3 & & & & \\
\hline & & 2 & $\checkmark$ & & & & 2 & $\checkmark$ & & & & 2 & $\checkmark$ & & \\
\hline & & 62 & & $\checkmark$ & & & 62 & & $\checkmark$ & & & 62 & & & \\
\hline & & 83 & $\checkmark$ & & & & 83 & $\checkmark$ & & & & 83 & & & $\checkmark$ \\
\hline Coral Square Mall Total & 3 & & 2 & 1 & 0 & 3 & & 2 & 1 & 0 & 3 & & 1 & 0 & 1 \\
\hline & & & & & & & & & & & & & & & \\
\hline Sarasota Square Mall & 3 & & & & & 3 & & & & & 0 & & & & \\
\hline & & 5 & & $\checkmark$ & & & 5 & & $\checkmark$ & & & & & & \\
\hline & & 6 & & $\checkmark$ & & & 6 & & $\checkmark$ & & & & & & \\
\hline & & 17 & & $\checkmark$ & & & 17 & & $\checkmark$ & & & & & & \\
\hline Sarasota Square Mall Total & 3 & & 0 & 3 & 0 & 3 & & 0 & 3 & 0 & 0 & & & & \\
\hline & & & & & & & & & & & & & & & \\
\hline St. Armand's Circle & 2 & & & & & 2 & & & & & 0 & & & & \\
\hline & & 4 & $\checkmark$ & & & & 4 & $\checkmark$ & & & & & & & \\
\hline & & 18 & $\checkmark$ & & & & 18 & $\checkmark$ & & & & & & & \\
\hline St. Armand's Circle Total & 2 & & 2 & 0 & 0 & 2 & & 2 & 0 & 0 & 0 & & & & \\
\hline & & & & & & & & & & & & & & & \\
\hline Southgate Plaza & 4 & & & & & 4 & & & & & 0 & & & & \\
\hline & & 5 & & $\checkmark$ & & & 5 & & $\checkmark$ & & & & & & \\
\hline
\end{tabular}




\begin{tabular}{|c|c|c|c|c|c|c|c|c|c|c|c|c|c|c|c|}
\hline \multirow[b]{2}{*}{$\begin{array}{l}\text { Activity } \\
\text { Center }\end{array}$} & \multicolumn{5}{|c|}{ Weekday Service } & \multicolumn{5}{|c|}{ Saturday Service } & \multicolumn{5}{|c|}{ Sunday Service } \\
\hline & $\begin{array}{c}\text { Number } \\
\text { of } \\
\text { Routes }\end{array}$ & Routes & $\begin{array}{l}\text { AM/ } \\
\text { PM }\end{array}$ & $\begin{array}{l}\text { AM } \\
\text { Only }\end{array}$ & $\begin{array}{l}\text { PM } \\
\text { Only }\end{array}$ & $\begin{array}{c}\text { Number of } \\
\text { Routes }\end{array}$ & Routes & $\begin{array}{l}\text { AM/ } \\
\text { PM }\end{array}$ & $\begin{array}{l}\text { AM } \\
\text { Only }\end{array}$ & $\begin{array}{l}\text { PM } \\
\text { Only }\end{array}$ & $\begin{array}{l}\text { Number of } \\
\text { Routes }\end{array}$ & Routes & $\begin{array}{l}\text { AM/ } \\
\text { PM }\end{array}$ & $\begin{array}{l}\text { AM } \\
\text { Only }\end{array}$ & $\begin{array}{l}\text { PM } \\
\text { Only }\end{array}$ \\
\hline & & 11 & & $\checkmark$ & & & 11 & & $\checkmark$ & & & & & & \\
\hline & & 14 & & $\checkmark$ & & & 14 & & $\checkmark$ & & & & & & \\
\hline & & 17 & & $\checkmark$ & & & 17 & & $\checkmark$ & & & & & & \\
\hline Southgate Plaza Total & 4 & & 0 & 4 & 0 & 4 & & 0 & 4 & 0 & 0 & & & & \\
\hline & & & & & & & & & & & & & & & \\
\hline Cortez Plaza & 6 & & & & & 5 & & & & & 0 & & & & \\
\hline & & 2 & & $\checkmark$ & & & 2 & & $\checkmark$ & & & & & & \\
\hline & & 6 & & $\checkmark$ & & & 6 & & $\checkmark$ & & & & & & \\
\hline & & 8 & & $\checkmark$ & & & 8 & & $\checkmark$ & & & & & & \\
\hline & & 9 & & $\checkmark$ & & & 9 & & $\checkmark$ & & & & & & \\
\hline & & 10 & & $\checkmark$ & & & 10 & & $\checkmark$ & & & & & & \\
\hline & & 15 & & $\checkmark$ & & & & & & & & & & & \\
\hline Cortez Plaza Total & 6 & & 0 & 6 & 0 & 5 & & 0 & 5 & 0 & 0 & & & & \\
\hline & & & & & & & & & & & & & & & \\
\hline Wal-Mart Plaza & 2 & & & & & 1 & & & & & 0 & & & & \\
\hline & & 8 & & & & & 8 & & & & & & & & \\
\hline & & 15 & & & & & & & & & & & & & \\
\hline Wal-Mart Plaza Total & 2 & & & & & 1 & & & & & 0 & & & & \\
\hline & & & & & & & & & & & & & & & \\
\hline Prime Outlets at Ellenton & 1 & & & & & 1 & & & & & 0 & & & & \\
\hline & & 1 & & $\checkmark$ & & & 1 & & $\checkmark$ & & & & & & \\
\hline $\begin{array}{c}\text { Prime Outlets at Ellenton } \\
\text { Total }\end{array}$ & 1 & & 0 & 1 & 0 & 1 & & 0 & 1 & 0 & 0 & & & & \\
\hline & & & & & & & & & & & & & & & \\
\hline Lakeland Square Mall & 2 & & & & & 2 & & & & & 0 & & & & \\
\hline & & 50 & & $\checkmark$ & & & 50 & & $\checkmark$ & & & & & & \\
\hline & & 51 & & $\checkmark$ & & & 51 & & $\checkmark$ & & & & & & \\
\hline $\begin{array}{c}\text { Lakeland Square Mall } \\
\text { Total }\end{array}$ & 2 & & 0 & 2 & 0 & 2 & & 0 & 2 & 0 & 0 & & & & \\
\hline & & & & & & & & & & & & & & & \\
\hline Spring Lake Square & 1 & & & & & 1 & & & & & 0 & & & & \\
\hline & & 10 & & $\checkmark$ & & & 10 & & $\checkmark$ & & & & & & \\
\hline Spring Lake Square Total & 1 & & 0 & 1 & 0 & 1 & & 0 & 1 & 0 & 0 & & & & \\
\hline Governor'c Souare Mall & & & & & & & & & & & & & & & \\
\hline Governor's Square Mall & 4 & & & & & 4 & & & & & 1 & & & & \\
\hline & & 22 & & $\checkmark$ & & & 22 & & $\checkmark$ & & & 29 & & & \\
\hline & & 25 & & $\checkmark$ & & & 25 & & $\checkmark$ & & & & & & \\
\hline & & 26 & & $\checkmark$ & & & 26 & & $\checkmark$ & & & & & & \\
\hline & & 29 & & & $\checkmark$ & & 29 & & & $\checkmark$ & & & & & \\
\hline $\begin{array}{c}\text { Governor's Square Mall } \\
\text { Total }\end{array}$ & 4 & & 0 & 3 & 1 & 4 & & 0 & 3 & 1 & 1 & & 0 & 0 & 0 \\
\hline Palm Reach Gardens Mall & 4 & & & & & 4 & & & & & 4 & & & & \\
\hline Palm Beach Gardens Mall & 4 & 1 & & $\checkmark$ & & 4 & 1 & & $\checkmark$ & & 4 & 1 & & $\checkmark$ & \\
\hline
\end{tabular}




\begin{tabular}{|c|c|c|c|c|c|c|c|c|c|c|c|c|c|c|c|}
\hline \multirow[b]{2}{*}{$\begin{array}{l}\text { Activity } \\
\text { Center }\end{array}$} & \multicolumn{5}{|c|}{ Weekday Service } & \multicolumn{5}{|c|}{ Saturday Service } & \multicolumn{5}{|c|}{ Sunday Service } \\
\hline & $\begin{array}{c}\begin{array}{c}\text { Number } \\
\text { of } \\
\text { Routes }\end{array} \\
\end{array}$ & Routes & $\begin{array}{l}\mathbf{A M} / \\
\mathrm{PM}\end{array}$ & $\begin{array}{l}\text { AM } \\
\text { Only }\end{array}$ & $\begin{array}{l}\text { PM } \\
\text { Only }\end{array}$ & $\begin{array}{l}\text { Number of } \\
\text { Routes }\end{array}$ & Routes & $\begin{array}{l}\mathbf{A M} / \\
\mathbf{P M}\end{array}$ & $\begin{array}{l}\text { AM } \\
\text { Only }\end{array}$ & $\begin{array}{l}\text { PM } \\
\text { Only }\end{array}$ & $\begin{array}{l}\text { Number of } \\
\text { Routes }\end{array}$ & Routes & $\begin{array}{l}\mathrm{AM} / \\
\mathrm{PM}\end{array}$ & $\begin{array}{l}\text { AM } \\
\text { Only }\end{array}$ & $\begin{array}{l}\text { PM } \\
\text { Only }\end{array}$ \\
\hline & & 3 & & $\checkmark$ & & & 3 & & $\checkmark$ & & & 3 & & $\checkmark$ & \\
\hline & & 20 & & $\checkmark$ & & & 20 & & $\checkmark$ & & & 20 & & $\checkmark$ & \\
\hline & & 21 & & $\checkmark$ & & & 21 & & $\checkmark$ & & & 21 & & $\checkmark$ & \\
\hline $\begin{array}{c}\text { Palm Beach Gardens Mall } \\
\text { Total }\end{array}$ & 4 & & 0 & 4 & 0 & 4 & & 0 & 4 & 0 & 4 & & 0 & 4 & 0 \\
\hline & & & & & & & & & & & & & & & \\
\hline Aventura Mall & 6 & & & & & 4 & & & & & 4 & & & & \\
\hline & & 3 & $\checkmark$ & & & & 3 & $\checkmark$ & & & & 3 & $\checkmark$ & & \\
\hline & & 9 & $\checkmark$ & & & & 9 & $\checkmark$ & & & & 9 & $\checkmark$ & & \\
\hline & & $95 X$ & & $\checkmark$ & & & $\mathrm{E}$ & & & & & $\mathrm{E}$ & & $\checkmark$ & \\
\hline & & $\mathrm{E}$ & & $\checkmark$ & & & $S$ & $\checkmark$ & & & & $S$ & $\checkmark$ & & \\
\hline & & S & $\checkmark$ & & & & & & & & & & & & \\
\hline & & $\begin{array}{l}\text { Biscayne } \\
\text { MAX }\end{array}$ & & $\checkmark$ & & & & & & & & & & & \\
\hline Aventura Mall Total & 6 & & 3 & 3 & 0 & 4 & & 3 & 0 & 0 & 4 & & 3 & 1 & 0 \\
\hline & & & & & & & & & & & & & & & \\
\hline Melbourne Square Mall & 5 & & & & & 1 & & & & & 1 & & & & \\
\hline & & 21 & & $\checkmark$ & & & 21 & & & & & 21 & & & \\
\hline & & 23 & & $\checkmark$ & & & & & & & & & & & \\
\hline & & 24 & & & & & & & & & & & & & \\
\hline & & 28 & & $\checkmark$ & & & & & & & & & & & \\
\hline & & 32 & & & & & & & & & & & & & \\
\hline $\begin{array}{c}\text { Melbourne Square Mall } \\
\text { Total }\end{array}$ & 5 & & 0 & 3 & 0 & 1 & & 0 & 0 & 0 & 1 & & 0 & 0 & 0 \\
\hline & & & & & & & & & & & & & & & \\
\hline Merritt Square Mall & 4 & & & & & 1 & & & & & 0 & & & & \\
\hline & & 6 & & $\checkmark$ & & & 9 & & & & & & & & \\
\hline & & 7 & & $\checkmark$ & & & & & & & & & & & \\
\hline & & 8 & & $\checkmark$ & & & & & & & & & & & \\
\hline & & 9 & & & & & & & & & & & & & \\
\hline Merritt Square Mall Total & 4 & & 0 & 3 & 0 & 1 & & 0 & 0 & 0 & 0 & & & & \\
\hline
\end{tabular}


Table H-6:

Business-Government

\begin{tabular}{|c|c|c|c|c|c|c|c|c|c|c|c|c|c|c|c|}
\hline & \multicolumn{5}{|c|}{ Weekday Service } & \multicolumn{5}{|c|}{ Saturday Service } & \multicolumn{5}{|c|}{ Sunday Service } \\
\hline $\begin{array}{l}\text { Activity } \\
\text { Center }\end{array}$ & $\begin{array}{c}\text { Number } \\
\text { Of } \\
\text { Routes }\end{array}$ & Routes & $\begin{array}{l}\text { AM/ } \\
\text { PM }\end{array}$ & $\begin{array}{l}\text { AM } \\
\text { Only }\end{array}$ & $\begin{array}{l}\text { PM } \\
\text { Only }\end{array}$ & $\begin{array}{c}\text { Number } \\
\text { Of } \\
\text { Routes }\end{array}$ & Routes & $\begin{array}{l}\text { AM/ } \\
\text { PM }\end{array}$ & $\begin{array}{l}\text { AM } \\
\text { Only }\end{array}$ & $\begin{array}{l}\text { PM } \\
\text { Only }\end{array}$ & $\begin{array}{l}\text { Number } \\
\text { Of } \\
\text { Routes }\end{array}$ & Routes & $\begin{array}{l}\text { AM/ } \\
\text { PM }\end{array}$ & $\begin{array}{l}\text { AM } \\
\text { Only }\end{array}$ & $\begin{array}{l}\text { PM } \\
\text { Only }\end{array}$ \\
\hline \multirow[t]{5}{*}{$\begin{array}{l}\text { M.C. Blanchard Judicial } \\
\text { Building }\end{array}$} & 4 & & & & & & & & & & & & & & \\
\hline & & 4 & & $\checkmark$ & & & & & & & & & & & \\
\hline & & 6 & & $\checkmark$ & & & & & & & & & & & \\
\hline & & 15 & & $\checkmark$ & & & & & & & & & & & \\
\hline & & 16 & & $\checkmark$ & & & & & & & & & & & \\
\hline \multirow[t]{2}{*}{$\begin{array}{l}\text { M.C. Blanchard } \\
\text { Judicial Building } \\
\text { Total } \\
\end{array}$} & 4 & & 0 & 4 & 0 & $\mathrm{~N} / \mathrm{A}$ & & & & & $\mathrm{N} / \mathrm{A}$ & & & & \\
\hline & & & & & & & & & & & & & & & \\
\hline \multirow[t]{3}{*}{$\begin{array}{l}\text { Marcus Pointe } \\
\text { Commerce Park }\end{array}$} & 2 & & & & & & & & & & & & & & \\
\hline & & $10 \mathrm{~A}$ & & $\checkmark$ & & & & & & & & & & & \\
\hline & & 10B & & $\checkmark$ & & & & & & & & & & & \\
\hline \multirow[t]{2}{*}{$\begin{array}{c}\text { Marcus Pointe } \\
\text { Commerce Park Total }\end{array}$} & 2 & & 0 & 2 & 0 & $\mathrm{~N} / \mathrm{A}$ & & & & & $\mathrm{N} / \mathrm{A}$ & & & & \\
\hline & & & & & & & & & & & & & & & \\
\hline \multirow[t]{10}{*}{$\begin{array}{c}\text { Downtown Plaza } \\
\text { (Gainesville) }\end{array}$} & 9 & & & & & & & & & & & & & & \\
\hline & & 2 & $\checkmark$ & & & & & & & & & & & & \\
\hline & & 5 & $\checkmark$ & & & & & & & & & & & & \\
\hline & & 6 & $\checkmark$ & & & & & & & & & & & & \\
\hline & & 7 & $\checkmark$ & & & & & & & & & & & & \\
\hline & & 10 & & & & & & & & & & & & & \\
\hline & & 11 & $\checkmark$ & & & & & & & & & & & & \\
\hline & & 15 & $\checkmark$ & & & & & & & & & & & & \\
\hline & & 24 & & $\checkmark$ & & & & & & & & & & & \\
\hline & & 43 & & $\checkmark$ & & & & & & & & & & & \\
\hline \multirow[t]{2}{*}{ Downtown Plaza Total } & 9 & & 6 & 2 & 0 & $\mathrm{~N} / \mathrm{A}$ & & & & & $\mathrm{N} / \mathrm{A}$ & & & & \\
\hline & & & & & & & & & & & & & & & \\
\hline \multirow[t]{3}{*}{$\begin{array}{c}\text { Downtown Square } \\
\text { (Ocala) }\end{array}$} & 2 & & & & & & & & & & & & & & \\
\hline & & 3 & $\checkmark$ & & & & & & & & & & & & \\
\hline & & 4 & $\checkmark$ & & & & & & & & & & & & \\
\hline $\begin{array}{c}\text { Downtown Square } \\
\text { Total }\end{array}$ & 2 & & 2 & 0 & 0 & $\mathrm{~N} / \mathrm{A}$ & & & & & $\mathrm{N} / \mathrm{A}$ & & & & \\
\hline & & & & & & & & & & & & & & & \\
\hline \multirow[t]{3}{*}{$\begin{array}{c}\text { County Courthouse } \\
\text { (Ocala) }\end{array}$} & 2 & & & & & & & & & & & & & & \\
\hline & & 3 & $\checkmark$ & & & & & & & & & & & & \\
\hline & & 4 & $\checkmark$ & & & & & & & & & & & & \\
\hline
\end{tabular}




\begin{tabular}{|c|c|c|c|c|c|c|c|c|c|c|c|c|c|c|c|}
\hline \multirow[b]{2}{*}{$\begin{array}{l}\text { Activity } \\
\text { Center }\end{array}$} & \multicolumn{5}{|c|}{ Weekday Service } & \multicolumn{5}{|c|}{ Saturday Service } & \multicolumn{5}{|c|}{ Sunday Service } \\
\hline & $\begin{array}{c}\text { Number } \\
\text { Of } \\
\text { Routes }\end{array}$ & Routes & $\begin{array}{l}\text { AM/ } \\
\text { PM }\end{array}$ & $\begin{array}{l}\text { AM } \\
\text { Only }\end{array}$ & $\begin{array}{l}\text { PM } \\
\text { Only }\end{array}$ & $\begin{array}{c}\text { Number } \\
\text { Of } \\
\text { Routes }\end{array}$ & Routes & $\begin{array}{l}\text { AM/ } \\
\text { PM }\end{array}$ & $\begin{array}{l}\text { AM } \\
\text { Only }\end{array}$ & $\begin{array}{l}\text { PM } \\
\text { Only }\end{array}$ & $\begin{array}{c}\text { Number } \\
\text { Of } \\
\text { Routes }\end{array}$ & Routes & $\begin{array}{l}\text { AM/ } \\
\text { PM }\end{array}$ & $\begin{array}{l}\text { AM } \\
\text { Only }\end{array}$ & $\begin{array}{l}\text { PM } \\
\text { Only }\end{array}$ \\
\hline $\begin{array}{c}\text { County Courthouse } \\
\text { Total }\end{array}$ & 2 & & 2 & 0 & 0 & $\mathrm{~N} / \mathrm{A}$ & & & & & $\mathrm{N} / \mathrm{A}$ & & & & \\
\hline & & & & & & & & & & & & & & & \\
\hline \multirow[t]{4}{*}{$\begin{array}{l}\text { Marion County Health } \\
\text { Dept. }\end{array}$} & 3 & & & & & & & & & & & & & & \\
\hline & & 2 & $\checkmark$ & & & & & & & & & & & & \\
\hline & & $5 \mathrm{~A}$ & & & & & & & & & & & & & \\
\hline & & $5 \mathrm{~B}$ & & & & & & & & & & & & & \\
\hline $\begin{array}{l}\text { Marion County Health } \\
\text { Dept. Total }\end{array}$ & 3 & & 1 & 0 & 0 & $\mathrm{~N} / \mathrm{A}$ & & & & & $\mathrm{N} / \mathrm{A}$ & & & & \\
\hline & & & & & & & & & & & & & & & \\
\hline \multirow[t]{30}{*}{ Downtown Tampa } & 29 & & & & & & & & & & & & & & \\
\hline & & 1 & $\checkmark$ & & & & & & & & & & & & \\
\hline & & 2 & $\checkmark$ & & & & & & & & & & & & \\
\hline & & 3 & $\checkmark$ & & & & & & & & & & & & \\
\hline & & 4 & $\checkmark$ & & & & & & & & & & & & \\
\hline & & 5 & $\checkmark$ & & & & & & & & & & & & \\
\hline & & 6 & $\checkmark$ & & & & & & & & & & & & \\
\hline & & 7 & $\checkmark$ & & & & & & & & & & & & \\
\hline & & 8 & $\checkmark$ & & & & & & & & & & & & \\
\hline & & 9 & $\checkmark$ & & & & & & & & & & & & \\
\hline & & 10 & $\checkmark$ & & & & & & & & & & & & \\
\hline & & 12 & $\checkmark$ & & & & & & & & & & & & \\
\hline & & 14 & $\checkmark$ & & & & & & & & & & & & \\
\hline & & 17 & & $\checkmark$ & & & & & & & & & & & \\
\hline & & 18 & $\checkmark$ & & & & & & & & & & & & \\
\hline & & 19 & $\checkmark$ & & & & & & & & & & & & \\
\hline & & $20 X$ & & $\checkmark$ & & & & & & & & & & & \\
\hline & & $21 X$ & & $\checkmark$ & & & & & & & & & & & \\
\hline & & $22 X$ & & $\checkmark$ & & & & & & & & & & & \\
\hline & & $23 X$ & & $\checkmark$ & & & & & & & & & & & \\
\hline & & $26 X$ & & $\checkmark$ & & & & & & & & & & & \\
\hline & & $27 X$ & & $\checkmark$ & & & & & & & & & & & \\
\hline & & $28 X$ & & $\checkmark$ & & & & & & & & & & & \\
\hline & & 30 & $\checkmark$ & & & & & & & & & & & & \\
\hline & & 31 & & & $\checkmark$ & & & & & & & & & & \\
\hline & & 46 & $\checkmark$ & & & & & & & & & & & & \\
\hline & & $50 X$ & & $\checkmark$ & & & & & & & & & & & \\
\hline & & $54 X$ & & $\checkmark$ & & & & & & & & & & & \\
\hline & & $58 \mathrm{LX}$ & $\checkmark$ & & & & & & & & & & & & \\
\hline & & $200 X$ & & $\checkmark$ & & & & & & & & & & & \\
\hline $\begin{array}{c}\text { Downtown Tampa } \\
\text { Total }\end{array}$ & 29 & & 17 & 11 & 1 & $\mathrm{~N} / \mathrm{A}$ & & & & & $\mathrm{N} / \mathrm{A}$ & & & & \\
\hline Westshore Business & 4 & & & & & & & & & & & & & & \\
\hline
\end{tabular}




\begin{tabular}{|c|c|c|c|c|c|c|c|c|c|c|c|c|c|c|c|}
\hline \multirow[b]{2}{*}{$\begin{array}{l}\text { Activity } \\
\text { Center }\end{array}$} & \multicolumn{5}{|c|}{ Weekday Service } & \multicolumn{5}{|c|}{ Saturday Service } & \multicolumn{5}{|c|}{ Sunday Service } \\
\hline & $\begin{array}{c}\text { Number } \\
\text { Of } \\
\text { Routes }\end{array}$ & Routes & $\begin{array}{l}\mathbf{A M} / \\
\mathbf{P M}\end{array}$ & $\begin{array}{l}\text { AM } \\
\text { Only }\end{array}$ & $\begin{array}{l}\text { PM } \\
\text { Only }\end{array}$ & $\begin{array}{c}\text { Number } \\
\text { Of } \\
\text { Routes }\end{array}$ & Routes & $\begin{array}{l}\text { AM/ } \\
\text { PM }\end{array}$ & $\begin{array}{l}\text { AM } \\
\text { Only }\end{array}$ & $\begin{array}{l}\text { PM } \\
\text { Only }\end{array}$ & $\begin{array}{c}\text { Number } \\
\text { Of } \\
\text { Routes }\end{array}$ & Routes & $\begin{array}{l}\text { AM/ } \\
\text { PM }\end{array}$ & $\begin{array}{l}\text { AM } \\
\text { Only }\end{array}$ & $\begin{array}{l}\text { PM } \\
\text { Only }\end{array}$ \\
\hline \multicolumn{16}{|l|}{ District } \\
\hline & & 10 & $\checkmark$ & & & & & & & & & & & & \\
\hline & & 30 & $\checkmark$ & & & & & & & & & & & & \\
\hline & & 36 & $\checkmark$ & & & & & & & & & & & & \\
\hline & & $58 \mathrm{X}$ & $\checkmark$ & & & & & & & & & & & & \\
\hline $\begin{array}{l}\text { Westshore Business } \\
\text { District Total }\end{array}$ & 4 & & 4 & 0 & 0 & $\mathrm{~N} / \mathrm{A}$ & & & & & $\mathrm{N} / \mathrm{A}$ & & & & \\
\hline & & & & & & & & & & & & & & & \\
\hline \multirow[t]{2}{*}{ Port Tampa } & 1 & & & & & & & & & & & & & & \\
\hline & & 19 & $\checkmark$ & & & & & & & & & & & & \\
\hline Port Tampa Total & 1 & & 1 & 0 & 0 & $\mathrm{~N} / \mathrm{A}$ & & & & & $\mathrm{N} / \mathrm{A}$ & & & & \\
\hline & & & & & & & & & & & & & & & \\
\hline \multirow[t]{4}{*}{ MacDill AFB } & 3 & & & & & 2 & & & & & 0 & & & & \\
\hline & & 4 & $\checkmark$ & & & & 4 & $\checkmark$ & & & & & & & \\
\hline & & 17 & $\checkmark$ & & & & 17 & & & & & & & & \\
\hline & & $25 X$ & & $\checkmark$ & & & & & & & & & & & \\
\hline MacDill AFB Total & 3 & & 2 & 1 & 0 & 2 & & 1 & 0 & 0 & 0 & & & & \\
\hline & & & & & & & & & & & & & & & \\
\hline \multirow[t]{17}{*}{$\begin{array}{c}\text { Downtown Daytona } \\
\text { Beach }\end{array}$} & 16 & & & & & & & & & & & & & & \\
\hline & & $1 \mathrm{~A}$ & $\checkmark$ & & & & & & & & & & & & \\
\hline & & $1 \mathrm{~B}$ & $\checkmark$ & & & & & & & & & & & & \\
\hline & & 3 & $\checkmark$ & & & & & & & & & & & & \\
\hline & & 4 & & $\checkmark$ & & & & & & & & & & & \\
\hline & & 5 & & $\checkmark$ & & & & & & & & & & & \\
\hline & & 6 & $\checkmark$ & & & & & & & & & & & & \\
\hline & & 7 & $\checkmark$ & & & & & & & & & & & & \\
\hline & & 8 & $\checkmark$ & & & & & & & & & & & & \\
\hline & & 9 & & & $\checkmark$ & & & & & & & & & & \\
\hline & & 10 & $\checkmark$ & & & & & & & & & & & & \\
\hline & & 11 & $\checkmark$ & & & & & & & & & & & & \\
\hline & & 12 & $\checkmark$ & & & & & & & & & & & & \\
\hline & & 15 & $\checkmark$ & & & & & & & & & & & & \\
\hline & & $17 \mathrm{~A}$ & $\checkmark$ & & & & & & & & & & & & \\
\hline & & $17 \mathrm{~B}$ & $\checkmark$ & & & & & & & & & & & & \\
\hline & & 60 & $\checkmark$ & & & & & & & & & & & & \\
\hline $\begin{array}{c}\text { Downtown Daytona } \\
\text { Beach Total }\end{array}$ & 16 & & 13 & 2 & 1 & & & & & & & & & & \\
\hline & & & & & & & & & & & & & & & \\
\hline \multirow[t]{4}{*}{$\begin{array}{l}\text { New Smyrna } \\
\text { Downtown }\end{array}$} & 3 & & & & & & & & & & & & & & \\
\hline & & 42 & & & & & & & & & & & & & \\
\hline & & $43 \mathrm{~A}$ & & & & & & & & & & & & & \\
\hline & & $43 \mathrm{~B}$ & & & & & & & & & & & & & \\
\hline New Smyrna & 3 & & 0 & 0 & 0 & $\mathrm{~N} / \mathrm{A}$ & & & & & $\mathrm{N} / \mathrm{A}$ & & & & \\
\hline
\end{tabular}




\begin{tabular}{|c|c|c|c|c|c|c|c|c|c|c|c|c|c|c|c|}
\hline \multirow[b]{2}{*}{$\begin{array}{l}\text { Activity } \\
\text { Center }\end{array}$} & \multicolumn{5}{|c|}{ Weekday Service } & \multicolumn{5}{|c|}{ Saturday Service } & \multicolumn{5}{|c|}{ Sunday Service } \\
\hline & $\begin{array}{c}\text { Number } \\
\text { Of } \\
\text { Routes }\end{array}$ & Routes & $\begin{array}{l}\text { AM/ } \\
\text { PM }\end{array}$ & $\begin{array}{l}\text { AM } \\
\text { Only }\end{array}$ & $\begin{array}{l}\text { PM } \\
\text { Only }\end{array}$ & $\begin{array}{c}\text { Number } \\
\text { Of } \\
\text { Routes }\end{array}$ & Routes & $\begin{array}{l}\text { AM/ } \\
\text { PM }\end{array}$ & $\begin{array}{l}\text { AM } \\
\text { Only }\end{array}$ & $\begin{array}{l}\text { PM } \\
\text { Only }\end{array}$ & $\begin{array}{l}\text { Number } \\
\text { Of } \\
\text { Routes }\end{array}$ & Routes & $\begin{array}{l}\text { AM/ } \\
\text { PM }\end{array}$ & $\begin{array}{l}\text { AM } \\
\text { Only }\end{array}$ & $\begin{array}{l}\text { PM } \\
\text { Only }\end{array}$ \\
\hline \multicolumn{16}{|l|}{ Downtown Total } \\
\hline & & & & & & & & & & & & & & & \\
\hline \multirow[t]{16}{*}{$\begin{array}{l}\text { Downtown Ft. } \\
\text { Lauderdale }\end{array}$} & 15 & & & & & & & & & & & & & & \\
\hline & & 1 & $\checkmark$ & & & & & & & & & & & & \\
\hline & & 9 & $\checkmark$ & & & & & & & & & & & & \\
\hline & & 10 & $\checkmark$ & & & & & & & & & & & & \\
\hline & & 11 & $\checkmark$ & & & & & & & & & & & & \\
\hline & & 14 & $\checkmark$ & & & & & & & & & & & & \\
\hline & & 20 & $\checkmark$ & & & & & & & & & & & & \\
\hline & & 22 & $\checkmark$ & & & & & & & & & & & & \\
\hline & & 30 & $\checkmark$ & & & & & & & & & & & & \\
\hline & & 31 & $\checkmark$ & & & & & & & & & & & & \\
\hline & & 40 & $\checkmark$ & & & & & & & & & & & & \\
\hline & & 50 & $\checkmark$ & & & & & & & & & & & & \\
\hline & & 55 & $\checkmark$ & & & & & & & & & & & & \\
\hline & & 60 & $\checkmark$ & & & & & & & & & & & & \\
\hline & & 81 & $\checkmark$ & & & & & & & & & & & & \\
\hline & & 84 & $\checkmark$ & & & & & & & & & & & & \\
\hline $\begin{array}{c}\text { Downtown Ft. } \\
\text { Lauderdale Total }\end{array}$ & 15 & & 15 & 0 & 0 & $\mathrm{~N} / \mathrm{A}$ & & & & & $\mathrm{N} / \mathrm{A}$ & & & & \\
\hline & & & & & & & & & & & & & & & \\
\hline \multirow[t]{14}{*}{ Downtown Sarasota } & 13 & & & & & & & & & & & & & & \\
\hline & & 1 & $\checkmark$ & & & & & & & & & & & & \\
\hline & & 2 & $\checkmark$ & & & & & & & & & & & & \\
\hline & & 3 & $\checkmark$ & & & & & & & & & & & & \\
\hline & & 4 & & & $\checkmark$ & & & & & & & & & & \\
\hline & & 5 & $\checkmark$ & & & & & & & & & & & & \\
\hline & & 6 & $\checkmark$ & & & & & & & & & & & & \\
\hline & & 7 & $\checkmark$ & & & & & & & & & & & & \\
\hline & & 8 & $\checkmark$ & & & & & & & & & & & & \\
\hline & & 11 & $\checkmark$ & & & & & & & & & & & & \\
\hline & & 12 & & $\checkmark$ & & & & & & & & & & & \\
\hline & & 15 & $\checkmark$ & & & & & & & & & & & & \\
\hline & & 17 & $\checkmark$ & & & & & & & & & & & & \\
\hline & & 18 & & & & & & & & & & & & & \\
\hline $\begin{array}{c}\text { Downtown Sarasota } \\
\text { Total }\end{array}$ & 13 & & 10 & 1 & 1 & $\mathrm{~N} / \mathrm{A}$ & & & & & $\mathrm{N} / \mathrm{A}$ & & & & \\
\hline & & & & & & & & & & & & & & & \\
\hline \multirow[t]{5}{*}{$\begin{array}{c}\text { County Courthouse } \\
\text { (Manatee) }\end{array}$} & 5 & & & & & & & & & & & & & & \\
\hline & & 2 & $\checkmark$ & & & & & & & & & & & & \\
\hline & & 3 & $\checkmark$ & & & & & & & & & & & & \\
\hline & & 4 & $\checkmark$ & & & & & & & & & & & & \\
\hline & & 9 & $\checkmark$ & & & & & & & & & & & & \\
\hline
\end{tabular}




\begin{tabular}{|c|c|c|c|c|c|c|c|c|c|c|c|c|c|c|c|}
\hline \multirow[b]{2}{*}{$\begin{array}{l}\text { Activity } \\
\text { Center }\end{array}$} & \multicolumn{5}{|c|}{ Weekday Service } & \multicolumn{5}{|c|}{ Saturday Service } & \multicolumn{5}{|c|}{ Sunday Service } \\
\hline & $\begin{array}{l}\text { Number } \\
\text { Of } \\
\text { Routes }\end{array}$ & Routes & $\begin{array}{l}\text { AM/ } \\
\text { PM }\end{array}$ & $\begin{array}{l}\text { AM } \\
\text { Only }\end{array}$ & $\begin{array}{l}\text { PM } \\
\text { Only }\end{array}$ & $\begin{array}{c}\text { Number } \\
\text { Of } \\
\text { Routes }\end{array}$ & Routes & $\begin{array}{l}\text { AM/ } \\
\text { PM }\end{array}$ & $\begin{array}{l}\text { AM } \\
\text { Only }\end{array}$ & $\begin{array}{l}\text { PM } \\
\text { Only }\end{array}$ & $\begin{array}{l}\text { Number } \\
\text { Of } \\
\text { Routes }\end{array}$ & Routes & $\begin{array}{l}\text { AM/ } \\
\text { PM }\end{array}$ & $\begin{array}{l}\text { AM } \\
\text { Only }\end{array}$ & $\begin{array}{l}\text { PM } \\
\text { Only }\end{array}$ \\
\hline & & 10 & $\checkmark$ & & & & & & & & & & & & \\
\hline $\begin{array}{c}\text { County Courthouse } \\
\text { Total }\end{array}$ & 5 & & 5 & 0 & 0 & $\mathrm{~N} / \mathrm{A}$ & & & & & $\mathrm{N} / \mathrm{A}$ & & & & \\
\hline & & & & & & & & & & & & & & & \\
\hline \multirow[t]{3}{*}{ Downtown Palmetto } & 2 & & & & & & & & & & & & & & \\
\hline & & 1 & $\checkmark$ & & & & & & & & & & & & \\
\hline & & 10 & $\checkmark$ & & & & & & & & & & & & \\
\hline $\begin{array}{c}\text { Downtown Palmetto } \\
\text { Total }\end{array}$ & 2 & & 2 & 0 & 0 & $\mathrm{~N} / \mathrm{A}$ & & & & & $\mathrm{N} / \mathrm{A}$ & & & & \\
\hline & & & & & & & & & & & & & & & \\
\hline \multirow[t]{3}{*}{ Lakeland City Hall } & 2 & & & & & & & & & & & & & & \\
\hline & & 20 & $\checkmark$ & & & & & & & & & & & & \\
\hline & & 30 & & & & & & & & & & & & & \\
\hline $\begin{array}{l}\text { Lakeland City Hall } \\
\text { Total }\end{array}$ & 2 & & 1 & 0 & 0 & $\mathrm{~N} / \mathrm{A}$ & & & & & $\mathrm{N} / \mathrm{A}$ & & & & \\
\hline & & & & & & & & & & & & & & & \\
\hline \multirow[t]{3}{*}{$\begin{array}{l}\text { Koger Center } \\
\text { (Tallahassee) }\end{array}$} & 2 & & & & & & & & & & & & & & \\
\hline & & 25 & $\checkmark$ & & & & & & & & & & & & \\
\hline & & 26 & $\checkmark$ & & & & & & & & & & & & \\
\hline Koger Center Total & 2 & & 2 & 0 & 0 & $\mathrm{~N} / \mathrm{A}$ & & & & & $\mathrm{N} / \mathrm{A}$ & & & & \\
\hline & & & & & & & & & & & & & & & \\
\hline \multirow[t]{11}{*}{$\begin{array}{c}\text { County Government } \\
\text { Center (Palm Beach } \\
\text { County) }\end{array}$} & 10 & & & & & & & & & & & & & & \\
\hline & & 1 & $\checkmark$ & & & & & & & & & & & & \\
\hline & & 2 & $\checkmark$ & & & & & & & & & & & & \\
\hline & & 31 & $\checkmark$ & & & & & & & & & & & & \\
\hline & & 40 & $\checkmark$ & & & & & & & & & & & & \\
\hline & & 41 & & $\checkmark$ & & & & & & & & & & & \\
\hline & & 42 & & $\checkmark$ & & & & & & & & & & & \\
\hline & & 43 & & $\checkmark$ & & & & & & & & & & & \\
\hline & & 44 & $\checkmark$ & & & & & & & & & & & & \\
\hline & & 46 & $\checkmark$ & & & & & & & & & & & & \\
\hline & & $54 / 55$ & & $\checkmark$ & & & & & & & & & & & \\
\hline $\begin{array}{l}\text { County Government } \\
\text { Center (Total) }\end{array}$ & 10 & & 6 & 4 & 0 & $\mathrm{~N} / \mathrm{A}$ & & & & & $\mathrm{N} / \mathrm{A}$ & & & & \\
\hline & & & & & & & & & & & & & & & \\
\hline \multirow[t]{3}{*}{$\begin{array}{c}\text { TREX Bluelake Office } \\
\text { Complex }\end{array}$} & 2 & & & & & & & & & & & & & & \\
\hline & & 2 & $\checkmark$ & & & & & & & & & & & & \\
\hline & & 3 & $\checkmark$ & & & & & & & & & & & & \\
\hline $\begin{array}{c}\text { TREX Bluelake Office } \\
\text { Complex Total }\end{array}$ & 2 & & 2 & 0 & 0 & $\mathrm{~N} / \mathrm{A}$ & & & & & $\mathrm{N} / \mathrm{A}$ & & & & \\
\hline & & & & & & & & & & & & & & & \\
\hline
\end{tabular}




\begin{tabular}{|c|c|c|c|c|c|c|c|c|c|c|c|c|c|c|c|}
\hline & \multicolumn{5}{|c|}{ Weekday Service } & \multicolumn{5}{|c|}{ Saturday Service } & \multicolumn{5}{|c|}{ Sunday Service } \\
\hline $\begin{array}{l}\text { Activity } \\
\text { Center }\end{array}$ & $\begin{array}{l}\text { Number } \\
\text { Of } \\
\text { Routes }\end{array}$ & Routes & $\begin{array}{l}\text { AM/ } \\
\text { PM }\end{array}$ & $\begin{array}{l}\text { AM } \\
\text { Only }\end{array}$ & $\begin{array}{l}\text { PM } \\
\text { Only }\end{array}$ & $\begin{array}{c}\text { Number } \\
\text { Of } \\
\text { Routes }\end{array}$ & Routes & $\begin{array}{l}\text { AM/ } \\
\text { PM }\end{array}$ & $\begin{array}{l}\text { AM } \\
\text { Only }\end{array}$ & $\begin{array}{l}\text { PM } \\
\text { Only }\end{array}$ & $\begin{array}{l}\text { Number } \\
\text { Of } \\
\text { Routes }\end{array}$ & Routes & $\begin{array}{l}\text { AM/ } \\
\text { PM }\end{array}$ & $\begin{array}{c}\text { AM } \\
\text { Only }\end{array}$ & $\begin{array}{l}\text { PM } \\
\text { Only }\end{array}$ \\
\hline \multirow{3}{*}{ Koger Center (Miami) } & 3 & 36 & $\checkmark$ & & & & & & & & & & & & \\
\hline & & $\begin{array}{c}\text { DORAL } \\
\text { Connection }\end{array}$ & $\checkmark$ & & & & & & & & & & & & \\
\hline & & $\begin{array}{c}\text { Tri-Rail Koger } \\
\text { Shuttle }\end{array}$ & $\checkmark$ & & & & & & & & & & & & \\
\hline Koger Center Total & 3 & & 3 & 0 & 0 & $\mathrm{~N} / \mathrm{A}$ & & & & & $\mathrm{N} / \mathrm{A}$ & & & & \\
\hline & & & & & & & & & & & & & & & \\
\hline \multirow[t]{23}{*}{ Downtown Miami } & 22 & & & & & & & & & & & & & & \\
\hline & & 2 & $\checkmark$ & & & & & & & & & & & & \\
\hline & & 3 & $\checkmark$ & & & & & & & & & & & & \\
\hline & & 6 & & & & & & & & & & & & & \\
\hline & & 7 & $\checkmark$ & & & & & & & & & & & & \\
\hline & & 9 & $\checkmark$ & & & & & & & & & & & & \\
\hline & & 10 & $\checkmark$ & & & & & & & & & & & & \\
\hline & & 11 & $\checkmark$ & & & & & & & & & & & & \\
\hline & & 16 & $\checkmark$ & & & & & & & & & & & & \\
\hline & & 21 & $\checkmark$ & & & & & & & & & & & & \\
\hline & & 24 & $\checkmark$ & & & & & & & & & & & & \\
\hline & & 48 & $\checkmark$ & & & & & & & & & & & & \\
\hline & & 77 & $\checkmark$ & & & & & & & & & & & & \\
\hline & & $95 \mathrm{X}$ & $\checkmark$ & & & & & & & & & & & & \\
\hline & & $\mathrm{B}$ & $\checkmark$ & & & & & & & & & & & & \\
\hline & & $\mathrm{C}$ & $\checkmark$ & & & & & & & & & & & & \\
\hline & & $\mathrm{K}$ & $\checkmark$ & & & & & & & & & & & & \\
\hline & & $\mathrm{S}$ & $\checkmark$ & & & & & & & & & & & & \\
\hline & & $T$ & $\checkmark$ & & & & & & & & & & & & \\
\hline & & BiscayneMAX & $\checkmark$ & & & & & & & & & & & & \\
\hline & & FlaglerMAX & $\checkmark$ & & & & & & & & & & & & \\
\hline & & $\begin{array}{l}\text { Night OWL } \\
\text { Shuttle }\end{array}$ & & & $\checkmark$ & & & & & & & & & & \\
\hline & & $\begin{array}{c}\text { Seaport } \\
\text { Connection }\end{array}$ & $\checkmark$ & & & & & & & & & & & & \\
\hline $\begin{array}{c}\text { Downtown Miami } \\
\text { Total }\end{array}$ & 22 & & 20 & & 1 & $\mathrm{~N} / \mathrm{A}$ & & & & & $\mathrm{N} / \mathrm{A}$ & & & & \\
\hline & & & & & & & & & & & & & & & \\
\hline Titusville CBD & 1 & & & & & & & & & & & & & & \\
\hline & & 5 & & & & & & & & & & & & & \\
\hline Titusville CBD Total & 1 & & 0 & 0 & 0 & $\mathrm{~N} / \mathrm{A}$ & & & & & $\mathrm{N} / \mathrm{A}$ & & & & \\
\hline & & & & & & & & & & & & & & & \\
\hline Cocoa CBD & 1 & & & & & & & & & & & & & & \\
\hline & & 6 & & & & & & & & & & & & & \\
\hline Cocoa CBD Total & 1 & & 0 & 0 & 0 & $\mathrm{~N} / \mathrm{A}$ & & & & & $\mathrm{N} / \mathrm{A}$ & & & & \\
\hline & & & & & & & & & & & & & & & \\
\hline County Government & & & & & & & & & & & & & & & \\
\hline
\end{tabular}




\begin{tabular}{|c|c|c|c|c|c|c|c|c|c|c|c|c|c|c|c|}
\hline & \multicolumn{5}{|c|}{ Weekday Service } & \multicolumn{5}{|c|}{ Saturday Service } & \multicolumn{5}{|c|}{ Sunday Service } \\
\hline $\begin{array}{l}\text { Activity } \\
\text { Center }\end{array}$ & $\begin{array}{c}\text { Number } \\
\text { Of } \\
\text { Routes }\end{array}$ & Routes & $\begin{array}{l}\text { AM/ } \\
\text { PM }\end{array}$ & $\begin{array}{l}\text { AM } \\
\text { Only }\end{array}$ & $\begin{array}{l}\text { PM } \\
\text { Only }\end{array}$ & $\begin{array}{c}\text { Number } \\
\text { Of } \\
\text { Routes }\end{array}$ & Routes & $\begin{array}{l}\text { AM/ } \\
\text { PM }\end{array}$ & $\begin{array}{l}\text { AM } \\
\text { Only }\end{array}$ & $\begin{array}{l}\text { PM } \\
\text { Only }\end{array}$ & $\begin{array}{c}\text { Number } \\
\text { Of } \\
\text { Routes }\end{array}$ & Routes & $\begin{array}{l}\text { AM/ } \\
\text { PM }\end{array}$ & $\begin{array}{l}\text { AM } \\
\text { Only }\end{array}$ & $\begin{array}{l}\text { PM } \\
\text { Only }\end{array}$ \\
\hline $\begin{array}{l}\text { Center (Brevard } \\
\text { County) }\end{array}$ & . & & & & & & & & & & & & & & \\
\hline & & 5 & & & & & & & & & & & & & \\
\hline & & 11 & & & & & & & & & & & & & \\
\hline & & 29 & & & & & & & & & & & & & \\
\hline $\begin{array}{c}\text { County Government } \\
\text { Center Total }\end{array}$ & 3 & & 0 & 0 & 0 & $\mathrm{~N} / \mathrm{A}$ & & & & & $\mathrm{N} / \mathrm{A}$ & & & & \\
\hline
\end{tabular}


Table H-7:

Education

\begin{tabular}{|c|c|c|c|c|c|c|c|c|c|c|c|c|c|c|c|}
\hline \multirow[b]{2}{*}{ Activity Center } & \multicolumn{5}{|c|}{ Weekday Service } & \multicolumn{5}{|c|}{ Saturday Service } & \multicolumn{5}{|c|}{ Sunday Service } \\
\hline & $\begin{array}{l}\text { Number } \\
\text { of Routes }\end{array}$ & Routes & $\begin{array}{l}\text { AM/ } \\
\text { PM }\end{array}$ & $\begin{array}{l}\text { AM } \\
\text { Only }\end{array}$ & $\begin{array}{l}\text { PM } \\
\text { Only }\end{array}$ & $\begin{array}{c}\text { Number } \\
\text { of } \\
\text { Routes }\end{array}$ & Routes & $\begin{array}{l}\text { AM/ } \\
\text { PM }\end{array}$ & $\begin{array}{l}\text { AM } \\
\text { Only }\end{array}$ & $\begin{array}{l}\text { PM } \\
\text { Only }\end{array}$ & $\begin{array}{c}\text { Number of } \\
\text { Routes }\end{array}$ & Routes & $\begin{array}{l}\text { AM/ } \\
\text { PM }\end{array}$ & $\begin{array}{l}\text { AM } \\
\text { Only }\end{array}$ & $\begin{array}{l}\text { PM } \\
\text { Only }\end{array}$ \\
\hline $\begin{array}{c}\text { University of West } \\
\text { Florida }\end{array}$ & 1 & & & & & & & & & & & & & & \\
\hline & & 22 & & & & & & & & & & & & & \\
\hline $\begin{array}{c}\text { University of West } \\
\text { Florida Total }\end{array}$ & 1 & & 0 & 0 & 0 & $\mathrm{~N} / \mathrm{A}$ & & & & & $\mathrm{N} / \mathrm{A}$ & & & & \\
\hline $\begin{array}{c}\text { University of } \\
\text { Florida/ } \\
\text { Shands } \\
\end{array}$ & 11 & & & & & & & & & & & & & & \\
\hline & & 1 & & $\checkmark$ & & & & & & & & & & & \\
\hline & & 5 & & $\checkmark$ & & & & & & & & & & & \\
\hline & & 8 & & $\checkmark$ & & & & & & & & & & & \\
\hline & & 9 & & & & & & & & & & & & & \\
\hline & & 10 & & & & & & & & & & & & & \\
\hline & & 12 & & & & & & & & & & & & & \\
\hline & & 13 & & $\checkmark$ & & & & & & & & & & & \\
\hline & & 16 & & $\checkmark$ & & & & & & & & & & & \\
\hline & & 20 & & $\checkmark$ & & & & & & & & & & & \\
\hline & & 35 & & & & & & & & & & & & & \\
\hline & & 43 & & $\checkmark$ & & & & & & & & & & & \\
\hline $\begin{array}{c}\text { University of } \\
\text { Florida/ } \\
\text { Shands Total }\end{array}$ & 11 & & 0 & 7 & 0 & & & & & & $\mathrm{~N} / \mathrm{A}$ & & & & \\
\hline & & & & & & & & & & & & & & & \\
\hline $\begin{array}{l}\text { SFCC--Main } \\
\text { Campus }\end{array}$ & 2 & & & & & & & & & & & & & & \\
\hline & & 10 & & $\checkmark$ & & & & & & & & & & & \\
\hline & & 43 & & $\checkmark$ & & & & & & & & & & & \\
\hline $\begin{array}{l}\text { SFCC-Main } \\
\text { Campus Total }\end{array}$ & 2 & & 0 & 2 & 0 & $\mathrm{~N} / \mathrm{A}$ & & & & & $\mathrm{N} / \mathrm{A}$ & & & & \\
\hline $\begin{array}{l}\text { SFCC--Downtown } \\
\text { Campus }\end{array}$ & 3 & & & & & & & & & & & & & & \\
\hline & & 5 & & $\checkmark$ & & & & & & & & & & & \\
\hline & & 6 & & & & & & & & & & & & & \\
\hline & & 10 & & $\checkmark$ & & & & & & & & & & & \\
\hline $\begin{array}{c}\text { SFCC- } \\
\text { Downtown } \\
\text { Campus Total }\end{array}$ & 3 & & 0 & 2 & 0 & $\mathrm{~N} / \mathrm{A}$ & & & & & N/A & & & & \\
\hline & & & & & & & & & & & & & & & \\
\hline Central FI & 2 & & & & & & & & & & & & & & \\
\hline
\end{tabular}




\begin{tabular}{|c|c|c|c|c|c|c|c|c|c|c|c|c|c|c|c|}
\hline \multirow[b]{2}{*}{ Activity Center } & \multicolumn{5}{|c|}{ Weekday Service } & \multicolumn{5}{|c|}{ Saturday Service } & \multicolumn{5}{|c|}{ Sunday Service } \\
\hline & $\begin{array}{l}\text { Number } \\
\text { of Routes }\end{array}$ & Routes & $\begin{array}{l}\text { AM/ } \\
\text { PM }\end{array}$ & $\begin{array}{l}\text { AM } \\
\text { Only }\end{array}$ & $\begin{array}{l}\text { PM } \\
\text { Only }\end{array}$ & $\begin{array}{c}\begin{array}{c}\text { Number } \\
\text { of } \\
\text { Routes }\end{array} \\
\end{array}$ & Routes & $\begin{array}{l}\text { AM/ } \\
\text { PM }\end{array}$ & $\begin{array}{c}\text { AM } \\
\text { Only }\end{array}$ & $\begin{array}{l}\text { PM } \\
\text { Only }\end{array}$ & $\begin{array}{c}\text { Number of } \\
\text { Routes }\end{array}$ & Routes & $\begin{array}{l}\text { AM/ } \\
\text { PM }\end{array}$ & $\begin{array}{l}\text { AM } \\
\text { Only }\end{array}$ & $\begin{array}{l}\text { PM } \\
\text { Only }\end{array}$ \\
\hline Community College & & & & & & 2 & & & & & & & & & \\
\hline & & 3 & & $\checkmark$ & & & 3 & & $\checkmark$ & & & & & & \\
\hline & & 4 & & $\checkmark$ & & & 4 & & & & & & & & \\
\hline $\begin{array}{c}\text { Central FI } \\
\text { Community } \\
\text { College Total }\end{array}$ & 2 & & 0 & 2 & 0 & 2 & & 0 & 1 & 0 & $\mathrm{~N} / \mathrm{A}$ & & & & \\
\hline $\begin{array}{c}\text { Hillsborough } \\
\text { Community College }\end{array}$ & 2 & & & & & 2 & & & & & & & & & \\
\hline & & 11 & & $\checkmark$ & & & 11 & & & $\checkmark$ & & & & & \\
\hline & & 32 & & $\checkmark$ & & & 31 & & & $\checkmark$ & & & & & \\
\hline $\begin{array}{c}\text { Hillsborough } \\
\text { Community } \\
\text { College Total }\end{array}$ & 2 & & 0 & 2 & 0 & 2 & & 0 & 0 & 2 & $\mathrm{~N} / \mathrm{A}$ & & & & \\
\hline $\begin{array}{l}\text { University of South } \\
\text { Florida }\end{array}$ & 11 & & & & & 10 & & & & & & & & & \\
\hline & & 1 & & $\checkmark$ & & & 1 & & & $\checkmark$ & & & & & \\
\hline & & 2 & & $\checkmark$ & & & 2 & & & $\checkmark$ & & & & & \\
\hline & & 5 & & $\checkmark$ & & & 5 & $\checkmark$ & & & & & & & \\
\hline & & 6 & & $\checkmark$ & & & 6 & $\checkmark$ & & & & & & & \\
\hline & & 7 & & & & & 7 & & & $\checkmark$ & & & & & \\
\hline & & 9 & & $\checkmark$ & & & 9 & & & $\checkmark$ & & & & & \\
\hline & & 12 & & $\checkmark$ & & & 12 & $\checkmark$ & & & & & & & \\
\hline & & 18 & & $\checkmark$ & & & 18 & $\checkmark$ & & & & & & & \\
\hline & & 33 & & $\checkmark$ & & & 33 & $\checkmark$ & & & & & & & \\
\hline & & $57 L X$ & & $\checkmark$ & & & 83 & & & $\checkmark$ & & & & & \\
\hline & & 83 & & $\checkmark$ & & & & & & & & & & & \\
\hline $\begin{array}{c}\text { University of } \\
\text { South Florida } \\
\text { Total } \\
\end{array}$ & 11 & & 0 & 10 & 0 & 10 & & 5 & 0 & 5 & $\mathrm{~N} / \mathrm{A}$ & & & & \\
\hline $\begin{array}{c}\text { Daytona Beach } \\
\text { Community College }\end{array}$ & 4 & & & & & 3 & & & & & & & & & \\
\hline & & 6 & & $\checkmark$ & & & 6 & $\checkmark$ & & & & & & & \\
\hline & & 9 & & $\checkmark$ & & & 9 & $\checkmark$ & & & & & & & \\
\hline & & 10 & & $\checkmark$ & & & 10 & $\checkmark$ & & & & & & & \\
\hline & & 60 & & $\checkmark$ & & & & & & & & & & & \\
\hline $\begin{array}{c}\text { Daytona Beach } \\
\text { Community } \\
\text { College Total }\end{array}$ & 4 & & 0 & 4 & 0 & 3 & & 3 & 0 & 0 & $\mathrm{~N} / \mathrm{A}$ & & & & \\
\hline & & & & & & & & & & & & & & & \\
\hline
\end{tabular}




\begin{tabular}{|c|c|c|c|c|c|c|c|c|c|c|c|c|c|c|c|}
\hline \multirow[b]{2}{*}{ Activity Center } & \multicolumn{5}{|c|}{ Weekday Service } & \multicolumn{5}{|c|}{ Saturday Service } & \multicolumn{5}{|c|}{ Sunday Service } \\
\hline & $\begin{array}{l}\text { Number } \\
\text { of Routes }\end{array}$ & Routes & $\begin{array}{l}\text { AM/ } \\
\text { PM }\end{array}$ & $\begin{array}{l}\text { AM } \\
\text { Only }\end{array}$ & $\begin{array}{l}\text { PM } \\
\text { Only }\end{array}$ & $\begin{array}{c}\begin{array}{c}\text { Number } \\
\text { of } \\
\text { Routes }\end{array} \\
\end{array}$ & Routes & $\begin{array}{l}\text { AM/ } \\
\text { PM }\end{array}$ & $\begin{array}{l}\text { AM } \\
\text { Only }\end{array}$ & $\begin{array}{l}\text { PM } \\
\text { Only }\end{array}$ & $\begin{array}{c}\text { Number of } \\
\text { Routes }\end{array}$ & Routes & $\begin{array}{l}\text { AM/ } \\
\text { PM }\end{array}$ & $\begin{array}{l}\text { AM } \\
\text { Only }\end{array}$ & $\begin{array}{l}\text { PM } \\
\text { Only }\end{array}$ \\
\hline $\begin{array}{c}\text { South Florida } \\
\text { Education Center }\end{array}$ & 2 & & & & & & & & & & & & & & \\
\hline & & 9 & & & & & & & & & & & & & \\
\hline & & 12 & & $\checkmark$ & & & & & & & & & & & \\
\hline $\begin{array}{c}\text { South Florida } \\
\text { Education Center } \\
\text { Total } \\
\end{array}$ & 2 & & 0 & 1 & 0 & $\mathrm{~N} / \mathrm{A}$ & & & & & $\mathrm{N} / \mathrm{A}$ & & & & \\
\hline $\begin{array}{c}\text { Manatee } \\
\text { Community College } \\
\text { (Bradenton) }\end{array}$ & 2 & & & & & 2 & & & & & & & & & \\
\hline & & 9 & & $\checkmark$ & & & 9 & $\checkmark$ & & & & & & & \\
\hline & & 10 & & $\checkmark$ & & & 10 & $\checkmark$ & & & & & & & \\
\hline $\begin{array}{c}\text { Manatee } \\
\text { Community } \\
\text { College Total }\end{array}$ & 2 & & 0 & 2 & 0 & 2 & & 2 & 0 & 0 & $\mathrm{~N} / \mathrm{A}$ & & & & \\
\hline $\begin{array}{c}\text { Polk County } \\
\text { Community College } \\
\text { (USF) }\end{array}$ & 2 & & & & & 2 & & & & - & & & & & \\
\hline & & 20 & & $\checkmark$ & & & 20 & $\checkmark$ & & & & & & & \\
\hline & & 21 & & $\checkmark$ & & & 21 & $\checkmark$ & & & & & & & \\
\hline $\begin{array}{c}\text { Polk County } \\
\text { Community } \\
\text { College (USF) } \\
\text { Total } \\
\end{array}$ & 2 & & 0 & 2 & 0 & 2 & & 2 & 0 & 0 & $\mathrm{~N} / \mathrm{A}$ & & & & \\
\hline $\begin{array}{c}\text { Polk County } \\
\text { Community College } \\
\text { (Winterhaven) }\end{array}$ & 1 & & & & & 1 & & & & & & & & & \\
\hline & & 20 & & $\checkmark$ & & & 20 & & & $\checkmark$ & & & & & \\
\hline $\begin{array}{l}\text { Polk County } \\
\text { Community } \\
\text { College Total }\end{array}$ & 1 & & 0 & 1 & 0 & 1 & & 0 & 0 & 1 & $\mathrm{~N} / \mathrm{A}$ & & & & \\
\hline & & & & & & & & & & & & & & & \\
\hline $\begin{array}{l}\text { FAMU (Florida } \\
\text { Agricultural and } \\
\text { Mechanical } \\
\text { University) } \\
\end{array}$ & 5 & & & & & 3 & & & & & & & & & \\
\hline & & 5 & & $\checkmark$ & & & 5 & & & & & & & & \\
\hline & & 11 & & $\checkmark$ & & & 11 & & & & & & & & \\
\hline & & 14 & $\checkmark$ & & & & 14 & $\checkmark$ & & & & & & & \\
\hline & & 42 & & $\checkmark$ & & & & & & & & & & & \\
\hline & & 43 & & $\checkmark$ & & & & & & & & & & & \\
\hline
\end{tabular}




\begin{tabular}{|c|c|c|c|c|c|c|c|c|c|c|c|c|c|c|c|}
\hline \multirow[b]{2}{*}{ Activity Center } & \multicolumn{5}{|c|}{ Weekday Service } & \multicolumn{5}{|c|}{ Saturday Service } & \multicolumn{5}{|c|}{ Sunday Service } \\
\hline & $\begin{array}{l}\text { Number } \\
\text { of Routes }\end{array}$ & Routes & $\begin{array}{l}\text { AM/ } \\
\text { PM }\end{array}$ & $\begin{array}{l}\text { AM } \\
\text { Only }\end{array}$ & $\begin{array}{l}\text { PM } \\
\text { Only }\end{array}$ & $\begin{array}{c}\begin{array}{c}\text { Number } \\
\text { of } \\
\text { Routes }\end{array} \\
\end{array}$ & Routes & $\begin{array}{l}\text { AM/ } \\
\text { PM }\end{array}$ & $\begin{array}{l}\text { AM } \\
\text { Only }\end{array}$ & $\begin{array}{l}\text { PM } \\
\text { Only }\end{array}$ & $\begin{array}{c}\text { Number of } \\
\text { Routes }\end{array}$ & Routes & $\begin{array}{l}\mathbf{A M} / \\
\mathbf{P M}\end{array}$ & $\begin{array}{l}\text { AM } \\
\text { Only }\end{array}$ & $\begin{array}{l}\text { PM } \\
\text { Only }\end{array}$ \\
\hline FAMU Total & 5 & & 1 & 4 & 0 & 3 & & 1 & 0 & 0 & N/A & & & & \\
\hline $\begin{array}{c}\text { Palm Beach } \\
\text { Community College }\end{array}$ & 3 & & & & & 3 & & & & & & & & & \\
\hline & & 2 & $\checkmark$ & & & & 2 & $\checkmark$ & & & & & & & \\
\hline & & 61 & $\checkmark$ & & & & 61 & & & $\checkmark$ & & & & & \\
\hline & & 62 & $\checkmark$ & & & & 62 & & $\checkmark$ & & & & & & \\
\hline $\begin{array}{l}\text { Palm Beach } \\
\text { Community } \\
\text { College Total }\end{array}$ & 3 & & 3 & 0 & 0 & 3 & & 1 & 1 & 1 & $\mathrm{~N} / \mathrm{A}$ & & & & \\
\hline & & & & & & & & & & & & & & & \\
\hline $\begin{array}{l}\text { Miami-Dade CC } \\
\text { North Campus }\end{array}$ & 6 & & & & & 3 & & & & & 3 & & & & \\
\hline & & 7 & & $\checkmark$ & & & 7 & $\checkmark$ & & & & 7 & $\checkmark$ & & \\
\hline & & 21 & & $\checkmark$ & & & 27 & $\checkmark$ & & & & 27 & $\checkmark$ & & \\
\hline & & 27 & $\checkmark$ & & & & 32 & $\checkmark$ & & & & 32 & $\checkmark$ & & \\
\hline & & $27 \mathrm{MAX}$ & & $\checkmark$ & & & & & & & & & & & \\
\hline & & 32 & $\checkmark$ & & & & & & & & & & & & \\
\hline & & 75 & & $\checkmark$ & & & & & & & & & & & \\
\hline $\begin{array}{c}\text { Miami-Dade CC } \\
\text { North Campus } \\
\text { Total } \\
\end{array}$ & 6 & & 2 & 4 & 0 & 3 & & 3 & 0 & 0 & 3 & & 3 & 0 & 0 \\
\hline BCC Main Campus & 3 & & & & & 0 & & & & & $\mathrm{~N} / \mathrm{A}$ & & & & \\
\hline & & 6 & & $\checkmark$ & & & & & & & & & & & \\
\hline & & 10 & & & & & & & & & & & & & \\
\hline & & 30 & & & & & & & & & & & & & \\
\hline $\begin{array}{c}\text { BCC Main } \\
\text { Campus Total }\end{array}$ & 3 & & 0 & 1 & 0 & 0 & & & & & $\mathrm{~N} / \mathrm{A}$ & & & & \\
\hline
\end{tabular}


Table H-8:

Non-Shift Recreation

\begin{tabular}{|c|c|c|c|c|c|c|c|c|c|c|c|c|c|c|c|}
\hline \multirow[b]{2}{*}{$\begin{array}{l}\text { Activity } \\
\text { Center }\end{array}$} & \multicolumn{5}{|c|}{ Weekday Service } & \multicolumn{5}{|c|}{ Saturday Service } & \multicolumn{5}{|c|}{ Sunday Service } \\
\hline & $\begin{array}{l}\text { Number of } \\
\text { Routes }\end{array}$ & Routes & $\begin{array}{l}\text { AM/ } \\
\text { PM }\end{array}$ & $\begin{array}{l}\text { AM } \\
\text { Only }\end{array}$ & $\begin{array}{l}\text { PM } \\
\text { Only }\end{array}$ & $\begin{array}{l}\text { Number of } \\
\text { Routes }\end{array}$ & Routes & $\begin{array}{l}\text { AM/ } \\
\text { PM }\end{array}$ & $\begin{array}{l}\text { AM } \\
\text { Only }\end{array}$ & $\begin{array}{l}\text { PM } \\
\text { Only }\end{array}$ & $\begin{array}{l}\text { Number of } \\
\text { Routes }\end{array}$ & Routes & $\begin{array}{l}\text { AM/ } \\
\text { PM }\end{array}$ & $\begin{array}{l}\text { AM } \\
\text { Only }\end{array}$ & $\begin{array}{l}\text { PM } \\
\text { Only }\end{array}$ \\
\hline \multirow[t]{2}{*}{$\begin{array}{c}\text { National Museum of } \\
\text { Naval Aviation }\end{array}$} & 1 & & & & & 1 & & & & & & & & & \\
\hline & & 14 & & $\checkmark$ & & & 14 & $\checkmark$ & & & & & & & \\
\hline \multirow[t]{2}{*}{$\begin{array}{l}\text { National Museum of } \\
\text { Naval Aviation Total }\end{array}$} & 1 & & 0 & 1 & 0 & 1 & & 1 & 0 & 0 & 0 & & & & \\
\hline & & & & & & & & & & & & & & & \\
\hline \multirow[t]{5}{*}{ South Beach Street } & 4 & & & & & 4 & & & & & & & & & \\
\hline & & $1 \mathrm{~A}$ & & $\checkmark$ & & & $1 \mathrm{~A}$ & & $\checkmark$ & & & & & & \\
\hline & & 4 & & $\checkmark$ & & & 4 & & $\checkmark$ & & & & & & \\
\hline & & 7 & & $\checkmark$ & & & 7 & & $\checkmark$ & & & & & & \\
\hline & & 12 & & $\checkmark$ & & & 12 & & $\checkmark$ & & & & & & \\
\hline \multirow[t]{2}{*}{$\begin{array}{c}\text { South Beach Street } \\
\text { Total }\end{array}$} & 4 & & 0 & 4 & 0 & 4 & & 0 & 4 & 0 & 0 & & & & \\
\hline & & & & & & & & & & & & & & & \\
\hline \multirow[t]{3}{*}{ Sun Splash Park } & 2 & & & & & 2 & & & & & & & & & \\
\hline & & $1 \mathrm{~A}$ & & $\checkmark$ & & & $1 \mathrm{~A}$ & & $\checkmark$ & & & & & & \\
\hline & & 1B & & $\checkmark$ & & & 1B & & $\checkmark$ & & & & & & \\
\hline \multirow[t]{2}{*}{$\begin{array}{c}\text { Sun Splash Park } \\
\text { Total } \\
\end{array}$} & 2 & & 0 & 2 & 0 & 2 & & 0 & 2 & 0 & 0 & & & & \\
\hline & & & & & & & & & & & & & & & \\
\hline \multirow[t]{2}{*}{ Jake Gaither Park } & 1 & & & & & 1 & & & & & & & & & \\
\hline & & 5 & & $\checkmark$ & & & 5 & & $\checkmark$ & & & & & & \\
\hline \multirow[t]{2}{*}{$\begin{array}{c}\text { Jake Gaither Park } \\
\text { Total }\end{array}$} & 1 & & 0 & 1 & 0 & 1 & & 0 & 1 & 0 & 0 & & & & \\
\hline & & & & & & & & & & & & & & & \\
\hline \multirow[t]{11}{*}{ Lincoln Road } & 10 & & & & & 8 & & & & & 8 & & & & \\
\hline & & $\mathrm{A}$ & & $\checkmark$ & & & $\mathrm{A}$ & & $\checkmark$ & & & $\mathrm{A}$ & & $\checkmark$ & \\
\hline & & C & $\checkmark$ & & & & C & $\checkmark$ & & & & C & & $\checkmark$ & \\
\hline & & $\mathrm{H}$ & & $\checkmark$ & & & $\mathrm{H}$ & & $\checkmark$ & & & $\mathrm{H}$ & & $\checkmark$ & \\
\hline & & $\mathrm{L}$ & $\checkmark$ & & & & $\mathrm{L}$ & $\checkmark$ & & & & $\mathrm{L}$ & $\checkmark$ & & \\
\hline & & $\mathrm{M}$ & & $\checkmark$ & & & $\mathrm{M}$ & & $\checkmark$ & & & $\mathrm{M}$ & & $\checkmark$ & \\
\hline & & $\mathrm{R}$ & & $\checkmark$ & & & $\mathrm{S}$ & $\checkmark$ & & & & $\mathrm{S}$ & $\checkmark$ & & \\
\hline & & $\mathrm{S}$ & $\checkmark$ & & & & W & $\checkmark$ & & & & W & & $\checkmark$ & \\
\hline & & W & & $\checkmark$ & & & Night OWL & & & $\checkmark$ & & $\begin{array}{l}\text { Night } \\
\text { OWL }\end{array}$ & & & $\checkmark$ \\
\hline & & $\begin{array}{c}\text { FlaglerMA } \\
\mathrm{X}\end{array}$ & & $\checkmark$ & & & & & & & & & & & \\
\hline & & Night OWL & & & $\checkmark$ & & & & & & & & & & \\
\hline Lincoln Road Total & 10 & & 3 & 6 & 1 & 8 & & 4 & 3 & 1 & 8 & & 2 & 5 & 1 \\
\hline \multirow{3}{*}{ MetroZoo } & & & & & & & & & & & & & & & \\
\hline & 1 & & & & & 1 & & & & & 1 & & & & \\
\hline & & Coral Reef & & $\checkmark$ & & & Coral Reef & & $\checkmark$ & & & Coral & & $\checkmark$ & \\
\hline
\end{tabular}




\begin{tabular}{|c|c|c|c|c|c|c|c|c|c|c|c|c|c|c|c|}
\hline \multirow[b]{2}{*}{$\begin{array}{l}\text { Activity } \\
\text { Center }\end{array}$} & \multicolumn{5}{|c|}{ Weekday Service } & \multicolumn{5}{|c|}{ Saturday Service } & \multicolumn{5}{|c|}{ Sunday Service } \\
\hline & $\begin{array}{c}\text { Number of } \\
\text { Routes }\end{array}$ & Routes & $\begin{array}{l}\text { AM/ } \\
\text { PM }\end{array}$ & $\begin{array}{l}\text { AM } \\
\text { Only }\end{array}$ & $\begin{array}{l}\text { PM } \\
\text { Only }\end{array}$ & $\begin{array}{c}\text { Number of } \\
\text { Routes }\end{array}$ & Routes & $\begin{array}{l}\text { AM/ } \\
\text { PM }\end{array}$ & $\begin{array}{c}\text { AM } \\
\text { Only }\end{array}$ & $\begin{array}{l}\text { PM } \\
\text { Only }\end{array}$ & $\begin{array}{c}\text { Number of } \\
\text { Routes }\end{array}$ & Routes & $\begin{array}{l}\mathbf{A M} / \\
\mathbf{P M}\end{array}$ & $\begin{array}{l}\text { AM } \\
\text { Only }\end{array}$ & $\begin{array}{l}\text { PM } \\
\text { Only }\end{array}$ \\
\hline & & MAX & & & & & MAX & & & & & Reef MAX & & & \\
\hline MetroZoo Total & 1 & & 0 & 1 & 0 & 1 & & 0 & 1 & 0 & 1 & & 0 & 1 & 0 \\
\hline
\end{tabular}


Table H-9:

Shift Recreation-Weekday

\begin{tabular}{|c|c|c|c|c|c|c|c|c|c|c|c|}
\hline \multicolumn{12}{|c|}{ Weekday Service } \\
\hline & & & \multicolumn{3}{|c|}{ Shift 1} & \multicolumn{3}{|c|}{ Shift 2} & \multicolumn{3}{|c|}{ Shift 3} \\
\hline $\begin{array}{l}\text { Activity } \\
\text { Center }\end{array}$ & $\begin{array}{c}\text { Number } \\
\text { of } \\
\text { Routes }\end{array}$ & Routes & $\begin{array}{l}\text { AM/ } \\
\text { PM }\end{array}$ & $\begin{array}{l}\text { AM } \\
\text { Only }\end{array}$ & $\begin{array}{l}\text { PM } \\
\text { Only }\end{array}$ & $\begin{array}{l}\text { AM/ } \\
\text { PM }\end{array}$ & $\begin{array}{l}\text { AM } \\
\text { Only }\end{array}$ & $\begin{array}{l}\text { PM } \\
\text { Only }\end{array}$ & $\begin{array}{l}\text { AM/ } \\
\text { PM }\end{array}$ & $\begin{array}{l}\text { AM } \\
\text { Only }\end{array}$ & $\begin{array}{l}\text { PM } \\
\text { Only }\end{array}$ \\
\hline Pensacola Beach & $2^{1}$ & & & & & & & & & & \\
\hline & & Red & & & $\checkmark$ & $\checkmark$ & & & & $\checkmark$ & \\
\hline & & Blue & & & $\checkmark$ & $\checkmark$ & & & & $\checkmark$ & \\
\hline $\begin{array}{c}\text { Pensacola Beach } \\
\text { Total }\end{array}$ & 0 & & 0 & 0 & 0 & 0 & 0 & 0 & 0 & 0 & 0 \\
\hline & & & & & & & & & & & \\
\hline $\begin{array}{l}\text { Ft. Lauderdale } \\
\text { Beach }\end{array}$ & 4 & & & & & & & & & & \\
\hline & & 11 & $\checkmark$ & & & & $\checkmark$ & & $\checkmark$ & & \\
\hline & & 36 & $\checkmark$ & & & $\checkmark$ & & & $\checkmark$ & & \\
\hline & & 62 & $\checkmark$ & & & $\checkmark$ & & & & & $\checkmark$ \\
\hline & & 72 & $\checkmark$ & & & & $\checkmark$ & & $\checkmark$ & & \\
\hline $\begin{array}{l}\text { Ft. Lauderdale } \\
\text { Beach Total }\end{array}$ & 4 & & 4 & 0 & 0 & 2 & 2 & 0 & 3 & 0 & 1 \\
\hline Manatee Beach & 2 & & & & & & & & & & \\
\hline & & 3 & & & $\checkmark$ & & $\checkmark$ & & & & $\checkmark$ \\
\hline & & 5 & & & $\checkmark$ & & $\checkmark$ & & & & $\checkmark$ \\
\hline $\begin{array}{c}\text { Manatee Beach } \\
\text { Total } \\
\end{array}$ & 2 & & 0 & 0 & 2 & 0 & 2 & 0 & 0 & 0 & 2 \\
\hline & & & & & & & & & & & \\
\hline $\begin{array}{l}\text { Boca Raton } \\
\text { Hotel/Resort }\end{array}$ & 1 & & & & & & & & & & \\
\hline & & 92 & & & $\checkmark$ & & $\checkmark$ & & & & $\checkmark$ \\
\hline $\begin{array}{c}\text { Boca Raton } \\
\text { Hotel/Resort Total }\end{array}$ & 1 & & 0 & 0 & 1 & 0 & 1 & 0 & 0 & 0 & 1 \\
\hline & & & & & & & & & & & \\
\hline $\begin{array}{c}\text { Beaches (Brevard } \\
\text { County) }\end{array}$ & 3 & & & & & & & & & & \\
\hline & & 9 & & & $\checkmark$ & & $\checkmark$ & & & & $\checkmark$ \\
\hline & & 11 & $\checkmark$ & & & & & & & & \\
\hline & & 26 & & & $\checkmark$ & & $\checkmark$ & & & & \\
\hline $\begin{array}{c}\text { Beaches (Brevard } \\
\text { County) Total }\end{array}$ & 3 & & 1 & 0 & 2 & 0 & 2 & 0 & 0 & 0 & 1 \\
\hline
\end{tabular}


Table $\mathrm{H}-10$

Shift Recreation-Saturday/Sunday

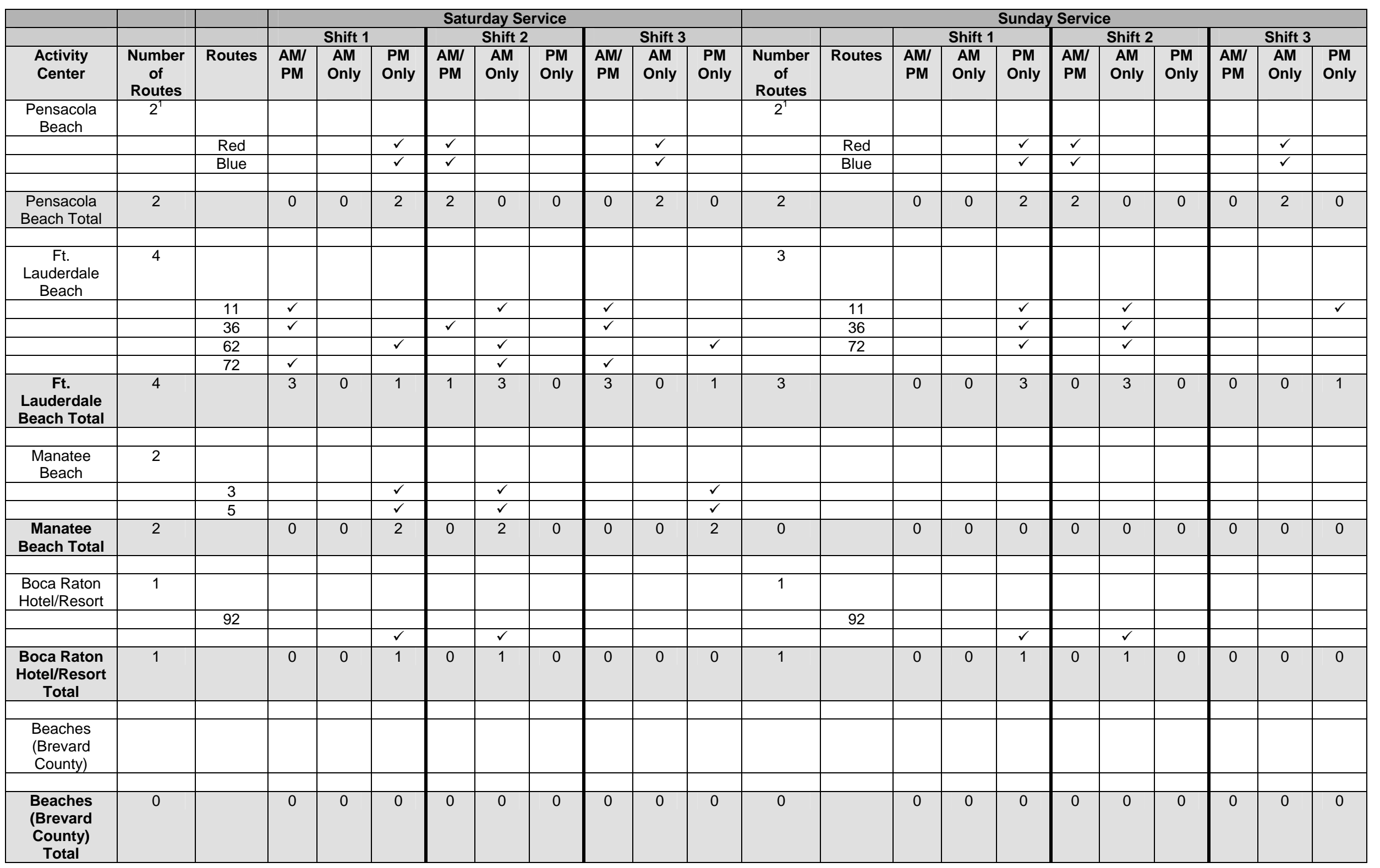


